\title{
Domestic Politics and the Bomb: The Influence of State Regime Type on Nuclear Deterrence
}

By

\author{
Mark Haichin
}

A thesis submitted to the Faculty of Graduate and Postdoctoral Affairs in partial fulfilment of the requirements for the degree of

\author{
Doctor of Philosophy \\ in \\ International Affairs
}

\author{
Norman Paterson School of International Affairs \\ Carleton University \\ Ottawa, Ontario
}

(C)2020

Mark Haichin 


\begin{abstract}
$\underline{\text { Abstract }}$
Why are some nuclear weapon states attacked more than others? Reviewing attacks against them shows that nuclear-armed democracies are attacked more than non-democratic ones, indicating that state regime type may play a role in nuclear deterrence credibility. This is largely ignored in the nuclear deterrence literature despite many conceptual similarities to conventional armed conflict, which has numerous theories on regime type influencing state conflict behaviour. In this dissertation, I seek to explain the disparity in attacks on nuclear weapon states with a novel theory that state political accountability mechanisms influence nuclear deterrence threat credibility. I hypothesize that democratic states are more sensitive to the costs of fulfilling their nuclear deterrence threats in low-intensity conflict scenarios due to popular accountability. Non-democratic nuclear weapon states can make more credible threats due to being accountable to an elite audience instead of the general population, allowing them to engage in cost-insensitive behaviour. To accomplish this, I use process tracing within a broader comparative case study framework to study crises affecting four nuclear weapon states during the 1945-2018 period. For each of these four states (Israel, India, Pakistan, and North Korea), I study the makeup of their government, including their domestic audiences, their nuclear deterrence threats, and command and control structures. I then compare pre- and post-nuclear deterrent acquisition crises targeting them and evaluate the rationales of decision-makers for both the defending and challenging states, particularly how the latter perceived the former's cost-sensitivity. The results indicate that, as anticipated, nuclear-armed democracies face greater difficulties in having their nuclear deterrence threats considered credible in low-intensity crises than their non-democratic counterparts. However, each case comes with notable caveats. Israel's nuclear opacity policy obscures whether government restraint is due to accountability or potential international reactions, while the Indian government often goes against popular sentiment in demonstrating restraint. While Pakistan and North Korea have both successfully deterred even low-intensity attacks against them due to the perception that they are sufficiently cost-insensitive to use nuclear weapons against any attack, the latter's aggression has led to it being considered sufficiently dangerous as to encourage potential pre-emptive strikes against it.
\end{abstract}




\section{$\underline{\text { Acknowledgements }}$}

This thesis would not have been possible without the support of numerous people.

I first need to thank my supervisor, David Carment, who for the past few years provided plenty of useful advice and honest feedback throughout the research and writing process. His knowledge of regime types and associated theories was critical in fine-tuning the theory and critical points in the case studies (and occasionally finding points that needed some elaboration or correction). Dr. Carment also deserves thanks for having taken me on as a research assistant and co-author on several projects throughout my $\mathrm{PhD}$ studies, as well as having taught the qualitative methodologies that served as the backbone of my research. It is safe to say that my experiences with him have made me a better research, and I am grateful for it.

I also need to thank my original supervisor, Jeremy 'Jez' Littlewood for guiding me in writing the original thesis proposal right up until his very last day at NPSIA. During that time, Dr. Littlewood's guidance was critical in helping me flesh out what was originally a rough idea into a viable theory and research design. While it was sad to see him leave NPSIA, I owe him thanks for his feedback and encouragement in the early steps of the thesis process, which also helped me get my first academic publication.

My advisors Elinor Sloan and Alex Wilner are both owed considerable thanks as well. Throughout the process of writing this thesis, they provided detailed and rapid feedback to my drafts (no mean feat, considering how long the chapters ended up being). Their extensive knowledge of deterrence theory and history helped keep me on the right track during the writing process, as well as pointing me towards sources that I likely would not have found otherwise.

My internal and external examiners, Dr. Mira Sucharov and Dr. James Fergusson, also deserve thanks for their constructive feedback during my thesis defence.

I'm also grateful to several others at NPSIA for their support throughout the process. Special thanks are owed in particular to David Long for his encouragement in the early stages of my PhD studies, as well as Stephen Saideman for having pointed out audience costs as a possible mechanism for my theory. And of course, the NPSIA administrative staff, particularly Patricia Lacroix and Coleen Kornelson, need to be thanked for helping me navigate the $\mathrm{PhD}$ program for the past $5+$ years.

Thanks are owed to NPSIA, Carleton University, and the Province of Ontario (Ontario Graduate Scholarship) for generously awarding funding that enabled me to concentrate full-time on my doctoral studies and to attend academic conferences during the past few years. 
I'm also grateful to Monika Thakur, who almost single-handedly convinced me to shift my career plans from law school to international relations during her Introduction to IR and International Security courses during my undergrad studies at Concordia University. Furthermore, she was the one who originally suggested that I apply to graduate programs in International Relations. It would not be an exaggeration for me to say that without her influence, my career path and life would have gone in a very different direction.

Naturally, there are many friends to thank for having supported me along the way. Sam MacIsaac and Kala Pendakur have been especially supportive since we first met in my second year in the program, with Sam having been willing to give informal feedback on my writing (even if it meant wading through some meandering prose far from his own field of expertise). Sarah Jansen, Lance Hadley, and Dani Belo have also been steadfast friends throughout my $\mathrm{PhD}$ experience, providing many laughs as we exchanged stories while all being clustered in the offices (and when the COVID-19 pandemic struck, online as well). Amber Warnat, Bryan Bereziuk, Michael Fejes, and Marshall Palmer also deserve thanks here as well.

Uri Marantz and Michael Shkolnik also need to be thanked for having set an example for myself and other NPSIA PhD students. Both of them have consistently provided friendly advice and support since the orientation session on my very first day at NPSIA.

Finally, my family have undoubtedly been the greatest source of support throughout my academic career. My parents Rick and Guittel supported my interests from an early age, even as they veered far from their own careers in medicine and dentistry, and always took the time and energy to help me out with schoolwork (and to occasionally provide a necessary reminder to step away from the ever-growing book pile). Their interest in current events, including the ever-present collection of Time magazines lying around the house and my mom's encouragement to apply to the IR program at LSE undoubtedly helped set my career path. Thank you both for having believed in me this whole time, even when I occasionally doubted what I was doing.

I'm also profoundly grateful to my siblings Michael and Kate for their support. Despite studying pharmacology and medicine at the same time, you two have been supportive of your anxious older brother. Your hard work in your own fields has inspired me to keep on pushing ahead whenever I was tempted to take it easy or (somewhat more often) whenever I felt stuck.

To my grandparents, Raphael, Georgette, and Martha, I can never thank you enough for supporting me, even if my research seemed somewhat esoteric to your own experiences. And to Shura, while I am sad that you aren't here to read this, I can only hope that you would have been proud, and I can never thank you enough for supporting my intellectual pursuits and that of everyone else in our family. 


\section{$\underline{\text { Table of Contents }}$}

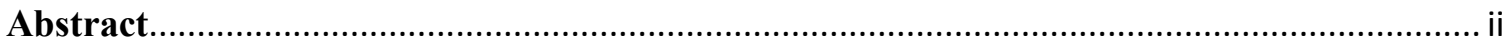

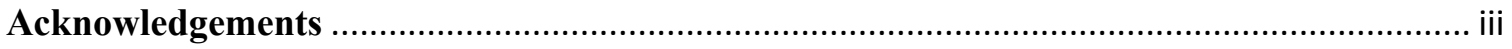

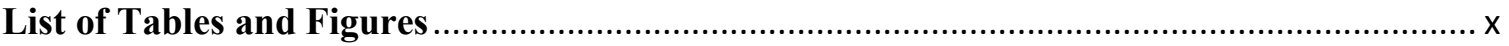

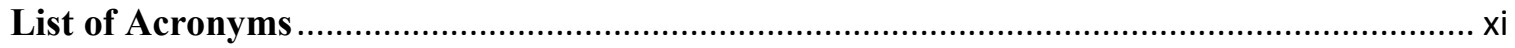

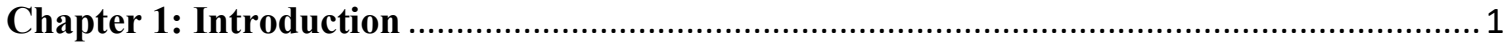

1.1: Are Some Nuclear Weapon States Better at Deterring Than Others? ........................ 1

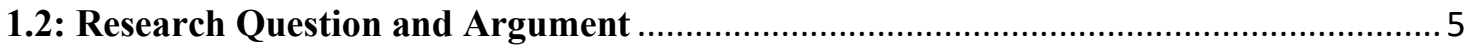

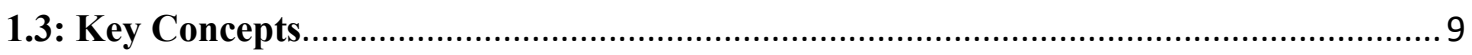

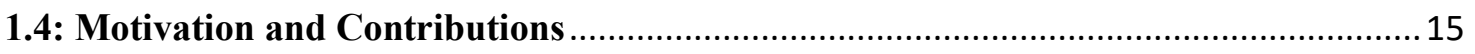

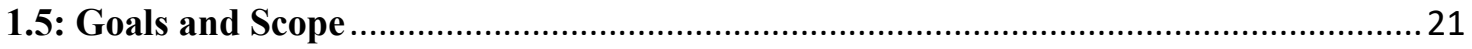

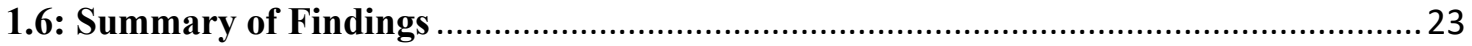

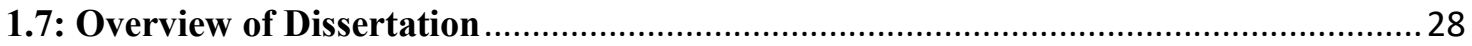

Chapter 2: Regime Type in Nuclear Deterrence and Conventional Conflict: A Literature

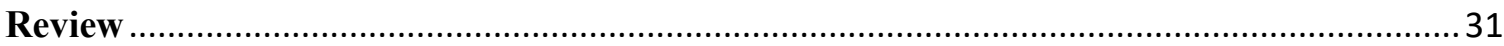

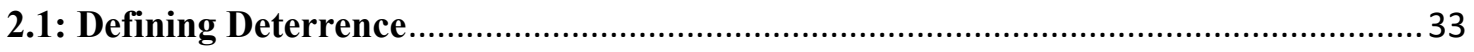

2.1.2: Differentiating Deterrence and Compellence .......................................................... 43

2.2: The Necessary Conditions for Nuclear Deterrence ................................................. 47

2.2.1: Deterrence Threat Credibility and the Signalling of Resolve .....................................53

2.2.2: The Costs of Using Nuclear Weapons …................................................................ 57

2.3: The Relationship between State Regime Type and Conventional Armed Conflict ....60

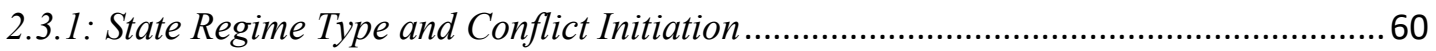

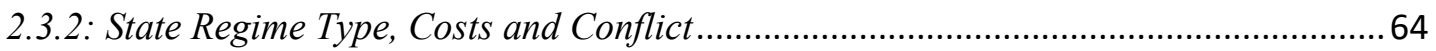

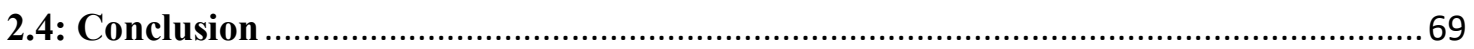

Chapter 3: Regime Cost Sensitivity and Nuclear Deterrence Credibility: A Theory ............71

3.1: Why Does Regime Type Matter for Nuclear Deterrence? ........................................ 75

3.1.1: Regime Type and Cost Sensitivity ............................................................................ 76

3.2: What Does Cost Sensitivity Mean for Nuclear Deterrence Credibility? .....................82

3.3: A Theory about State Regime Type and Nuclear Deterrence .................................... 89

3.3.1: The Influence of Reputation on Deterrence Credibility ..............................................95

3.3.2: Deterrence Credibility, Non-State Actors, and Asymmetric Conflict ..........................98

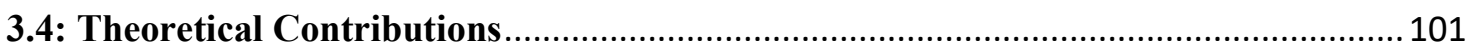

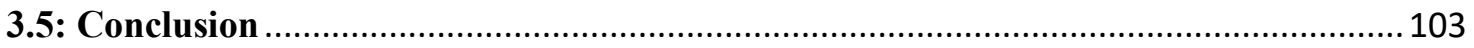




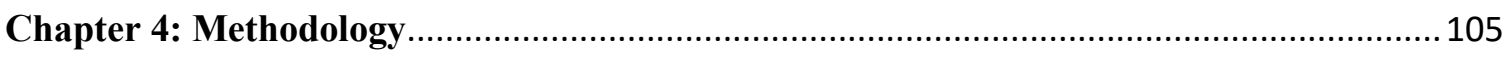

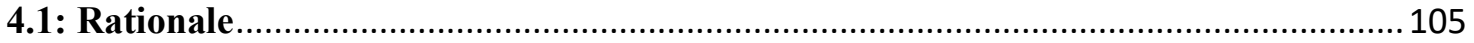

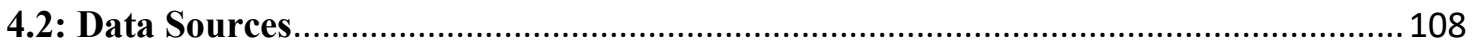

4.2.1: Primary \& Secondary Qualitative Sources ............................................................ 108

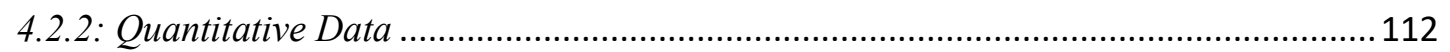

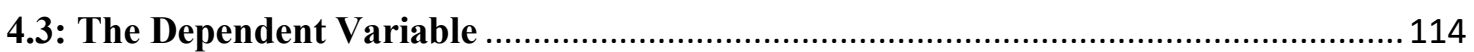

4.3.1: Crises and armed conflicts targeting the defending nuclear weapon state ................ 114

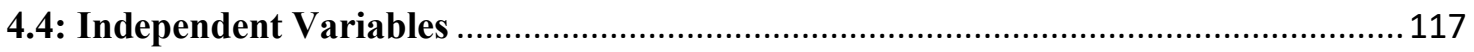

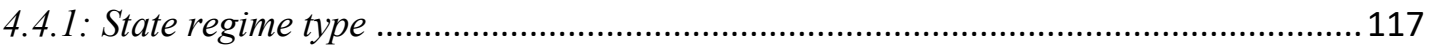

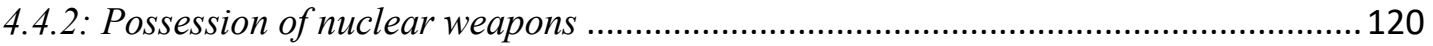

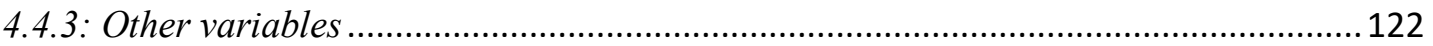

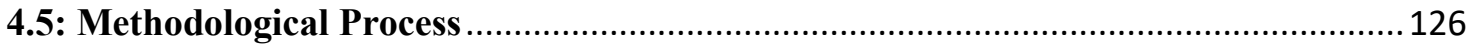

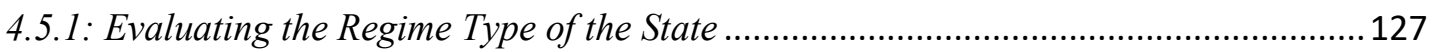

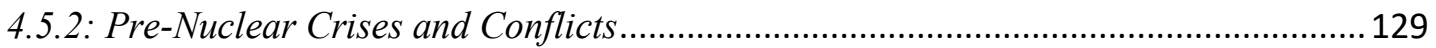

4.5.3: The Acquisition of Nuclear Weapons and Deterrence Threats ................................131

4.5.4: Post-Nuclear Crises and Conflicts (Or Lack Thereof): What Changed? ................... 133

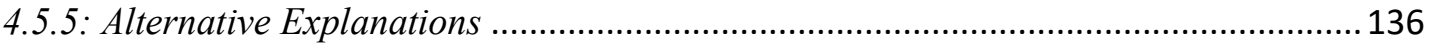

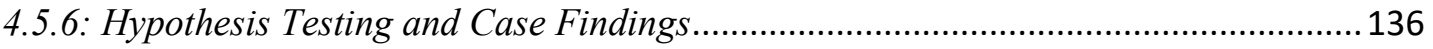

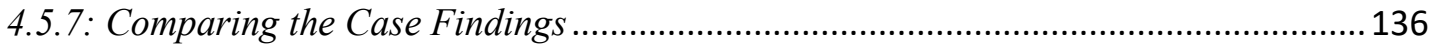

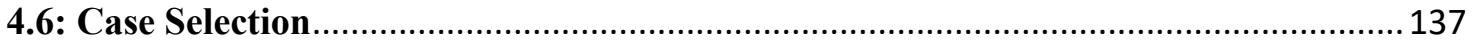

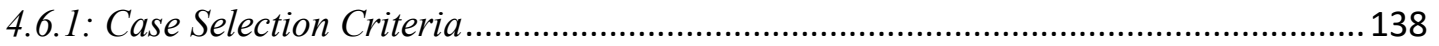

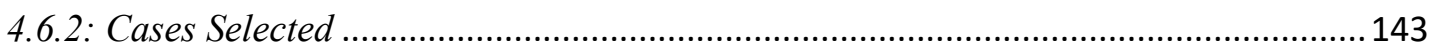

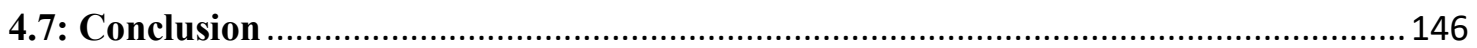

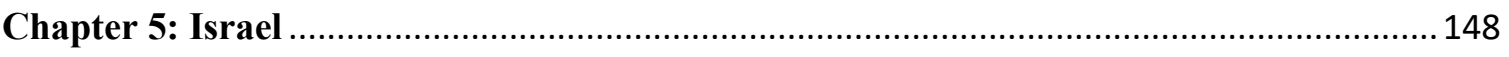

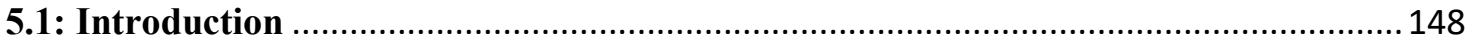

5.2: Democracy with National Security Exceptions: Evaluating Israeli Governance...... 150

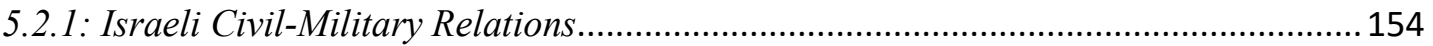

5.3: "We must bring about a decisive confrontation:'" Israeli Pre-Nuclear Crises and

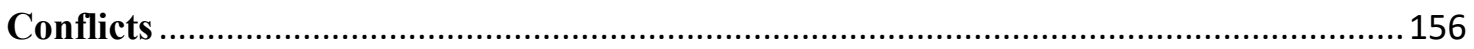

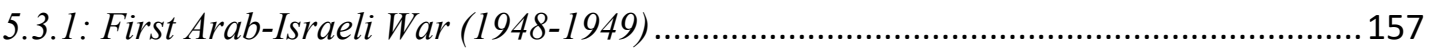

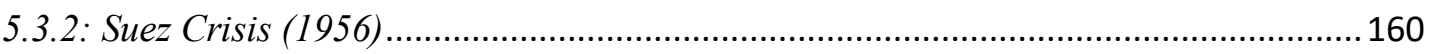

5.4: Preventing a Second Holocaust: Israeli Nuclear Weapons Development Motivations

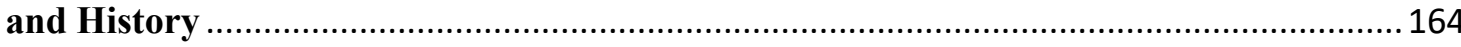

5.5: The Ambiguous Samson Option: Israeli Nuclear Deterrence and Opacity .............. 169 
5.5.2: Israeli Nuclear Command and Control and Deterrence Policy.....

5.6: "We should also prepare a nuclear option:" Israeli Post-Nuclear Crises and Conflicts

5.6.1: Six-Day War (1967) 179

5.6.2: War of Attrition (1967-1970) 185

5.6.3: Yom Kippur War (1973) 189

5.6.4: Gulf War (1991)...... 195

5.7: Alternative Explanations 198

5.8: Conclusion: Only Partially Deterred 201

Chapter 6: India 203

6.1: Introduction 203

6.2: Democracy and Strategic Elites: Evaluating Indian Governance.. 206

6.2.1: Civil-Military Relations. 209

6.3: "'Launching a bold offensive across the Punjab:"' Indian Pre-Nuclear Crises and Conflicts

6.3.1: Indo-Pakistani Wars .213

6.3.2: Sino-Indian War (1962). 222

6.3.3: Border Crises .225

6.4: From Smiling Buddha to Pokhran-II: Indian Nuclear Weapons Development Motivations and History.... .228

6.5: Minimum Deterrence and No-First-Use: Indian Nuclear Deterrence Threats and Command and Control. 232

6.6: "“Be prepared for escalation:"' Indian Post-Nuclear Crises and Conflicts 238

6.6.1: Kargil War (1999) 239

6.6.2: Incursions into Kashmir and Terror Crises. 242

6.7: Alternative Explanations ..... 250

6.8: Conclusion: Restrained Deterrence, but Not From Below .......................................2252

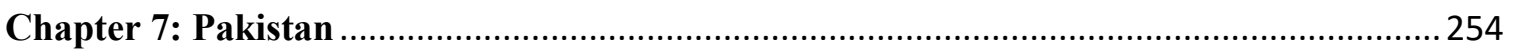

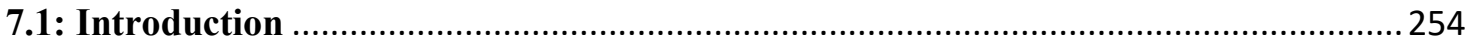

7.2: Shifting between Anocracy and Autocracy: Evaluating Pakistani Governance.......257

7.2.1: Military Dictatorship (1958-1971; 1977-1988; 1999-2008)....................................260

7.2.2: The Role of the Military. 263

7.3: Ready to Wage "'general and total war": Pakistani Pre-Nuclear Crises and Conflicts 267 
7.3.2: Operation Brasstacks (1986-1987)

7.4: "'Even if Pakistanis have to eat grass:'” Pakistani Nuclear Weapons Motivations and History. 278

7.5: Aiming Solely for India: Pakistani Nuclear Deterrence Threats and Institutions ...2 281

7.6: “'We shall use the bomb”": Pakistani Post-Nuclear Crises and Conflicts ................ 286

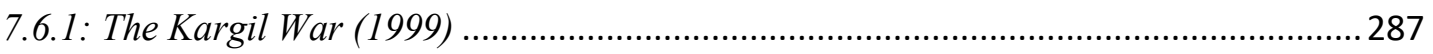

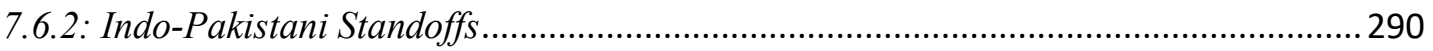

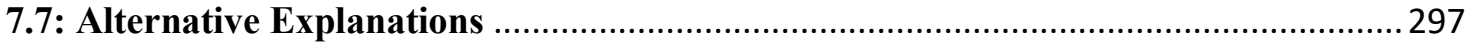

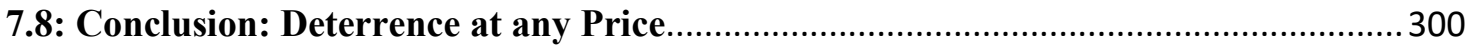

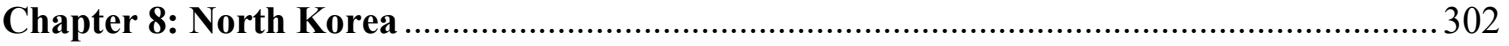

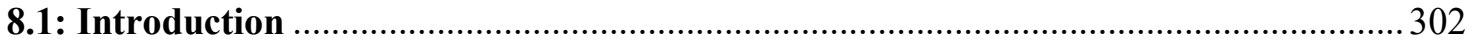

8.2: The Archetypal Authoritarian Regime: Evaluating North Korean Governance ..... 305

8.3: “We will turn Seoul into a sea of fire:" Key Pre-Nuclear Crises and Conflicts ..... 314

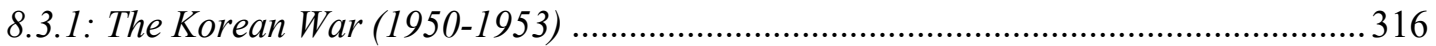

8.3.2: Provocative Actions: The Pueblo (1968) and axe murder incidents (1976).................. 320

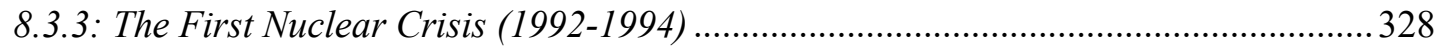

8.4: North Korean Nuclear Weapons: Motivations, Deterrence Threats, and Command

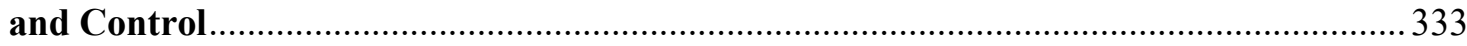

8.4.1: North Korea's Nuclear Doctrine and Command and Control ...................................335

8.5: "Fire and fury:"” North Korean Nuclear-era Crises ................................................. 338

8.5.1: The Second Nuclear Crisis (2006-present) .............................................................. 340

8.5.2: Clashes with South Korea: ROKS Cheonan (2010) and landmine incidents (2015) 344

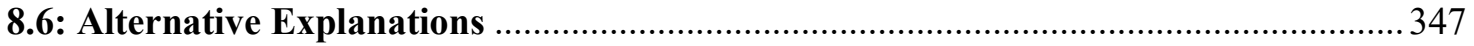

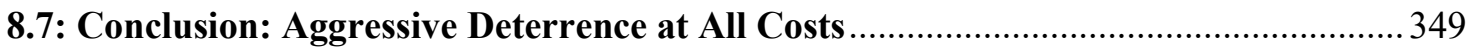

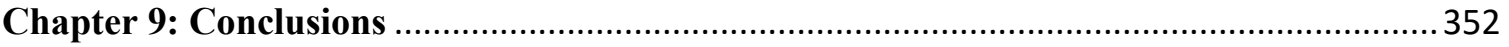

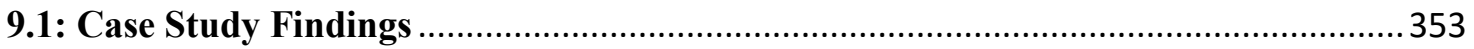

9.2: What Does This Mean for Regime Type and Nuclear Deterrence?.......................... 359

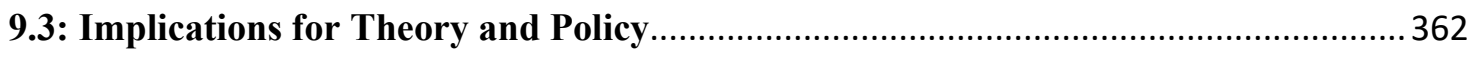

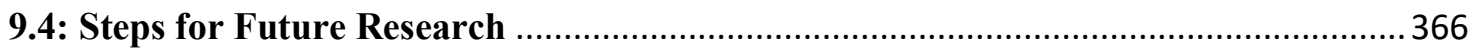

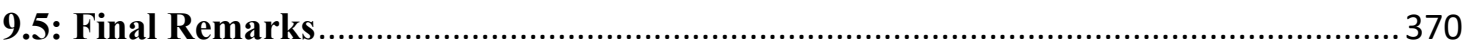

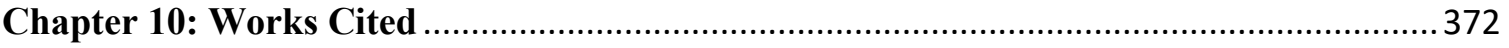

10.1: Popular and Scholarly Articles, Books, and Chapters ......................................... 372

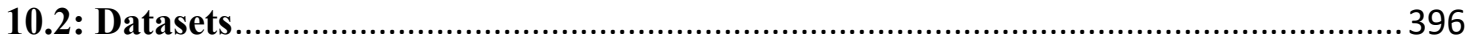


10.3: News Sources.

400

10.4: Government and International Organization Documents and Publications.

10.5: Additional Primary Sources 


\section{$\underline{\text { List of Tables and Figures }}$}

Table 1.1: Nuclear Weapon State MIDs Pre- and Post-Nuclearization, 1900-2010........3

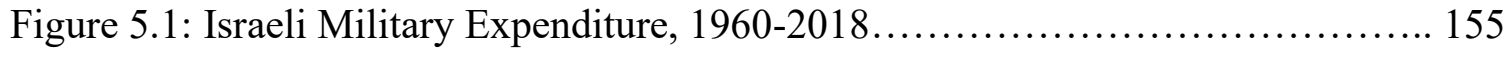

Figure 6.1: Indian and Pakistani Military Expenditure, 1956-2018................. 211

Figure 6.2: Indian, Pakistani, and Chinese Nuclear Arsenals, 1998-2018............ 235

Figure 7.1: Pakistan Polity Score, 1947-2018............................... 258

Figure 8.1: North Korea Polity Score, 1947-2018........................... 306 


\section{$\underline{\text { List of Acronyms }}$}

BJP - Bharatiya Janata Party (India)

$\mathrm{CCP}$ - Chinese Communist Party (China)

CGS - Chief of General Staff (Israel)

DAE - Department of Atomic Energy (India)

DCC - Development Control Committee (Pakistan)

DMZ - Korean Militarized Zone (North Korea - South Korea)

DPRK - Democratic People's Republic of Korea (North Korea)

DRDO - Defence Research \& Development Organisation (India)

ECC - Employment Control Committee (Pakistan)

GDP - Gross domestic product

GNP - Gross national product

IAEA - International Atomic Energy Agency

ICBM - Intercontinental ballistic missile

IsAEC - Israel Atomic Energy Commission (Israel)

IDF - Israeli Defense Forces (Israel)

InAEC - Indian Atomic Energy Commission (India)

ISI - Inter-Services Intelligence (Pakistan)

JCPOA - Joint Comprehensive Plan of Action

JCS - Joint Chiefs of Staff (United States)

JeM - Jaish-e-Mohammed (Pakistan)

JeI - Jamaat-e-Islami (Pakistan)

JSA - Joint Security Area (North Korea/South Korea)

KPA - Korean People's Army (North Korea)

KWP - Korean Workers' Party (North Korea)

LAC - Line of Actual Control (China-India)

LeT - Lashkar-e-Taiba 
LOC - Line of Control (India-Pakistan)

LWR - Light water reactor

MK - Member of the Knesset (Israel)

MID - Militarized interstate dispute

NCA - National Command Authority (NCA)

NDC - National Defence Commission (North Korea)

NPT - Treaty on the Non-Proliferation of Nuclear Weapons/Non-Proliferation Treaty

NSC - National Security Council (United States)

NSG - Nuclear Suppliers Group

NWS - Nuclear weapon state

PAF - Pakistan Armed Forces (PAF)

PLA - People's Liberation Army (China)

PML-N - Pakistan Muslim League (Nawaz)

PNE - Peaceful nuclear explosion

PPP - Pakistan Peoples' Party

PTI - Tekhreek-e-Insaf (Pakistan)

PVA - People's Volunteer Army (China)

ROK - Republic of Korea (South Korea)

SPD - Strategic Planning Division (Pakistan)

UAR - United Arab Republic

UNEF - United Nations Emergency Force

UNGA - United Nations General Assembly

UNSC - United Nations Security Council

USSR - Union of Soviet Socialist Republics 


\section{Chapter 1: Introduction}

\section{1: Are Some Nuclear Weapon States Better at Deterring Than Others?}

Nuclear weapons have played a major role in international politics since they were first used against the Japanese cities of Hiroshima and Nagasaki on August 6 and 9, 1945. Over the following 75 years, they have largely (though not universally viewed) as the ultimate deterrent against interstate warfare. ${ }^{1}$ In theory, even a small and conventionally weak state with a small nuclear arsenal could deter a stronger challenger from attacking it with the threat of suffering horrific losses in life and infrastructure in retaliation. States engaging in mutual nuclear deterrence, meanwhile, would be expected to keep warfare between themselves to a minimum, if not avoiding it entirely, due to the potential for mutually assured destruction (MAD) - a dynamic that defined the relationship between the United States and the Soviet Union for the duration of the Cold War. ${ }^{2}$ As of 2020, only 13 states have ever qualified as nuclear weapon states, with only nine remaining at present. $^{3}$ Nuclear deterrence theory would argue that all of these states should have experienced fewer armed attacks and crises relative to their pre-nuclear years, since the threat of nuclear retaliation would deter potential challengers from attacking them.

\footnotetext{
${ }^{1}$ For examples, see Bernard Brodie, "Implications for Military Policy," in The Absolute Weapon: Atomic Power and World Order, ed. Bernard Brodie (New York: Harcourt, Brace and Company, 1946), 70-107; Thomas C. Schelling, Arms and Influence (New Haven and London: Yale University Press, 1966); Lawrence Freedman, Deterrence (Cambridge: Polity Press, 2004).

${ }^{2}$ Andrew Brown and Lorna Arnold, "The Quirks of Nuclear Deterrence," International Relations 24, no. 3 (2010): 296.

${ }^{3}$ In order of initial test explosions, these states are the United States (1945), the Soviet Union/Russia (1949), the United Kingdom (1952), France (1960), China (1964), India (1974), Pakistan (1998), and North Korea (2006), with Israel believed to have possessed nuclear weapons by 1967. South Africa possessed a small arsenal in the 1980s and dismantled it by 1991, while Belarus, Kazakhstan, and Ukraine inherited portions of the Soviet Union's nuclear arsenal following its dissolution in 1991 and returned them to Russia between 1995 and 1996. See Kelsey Davenport and Kingston Reif, "Nuclear Weapons: Who Has What at a Glance," Arms Control Association, July 2019, https://www.armscontrol.org/factsheets/Nuclearweaponswhohaswhat.
} 
Puzzlingly, these benefits do not seem to be equal, as some nuclear weapon states are attacked more frequently than others. Table 1.1 shows that while many nuclear weapon states experience fewer militarized interstate disputes (MIDs), this change is not universal, nor are the effects consistent. India and Pakistan most notably have clashed in crises like the 1999 Kargil War despite both demonstrating nuclear capabilities in May 1998 and being de facto nuclear weapon states beforehand. ${ }^{4}$ This behaviour seemingly conforms to the stability-instability paradox's prediction of mutual nuclear deterrence encouraging lowintensity conflict, but falls short due to Pakistan attacking India much more than the reverse, with the February 2019 airstrike against Pakistan being highly unusual..$^{5}$ Israel has likewise been attacked by other states even after developing a nuclear deterrent, including the Six-Day War (1967) and the Yom Kippur War (1973), averaging four MIDs annually and an interstate war every nine years between 1948 and 2004. ${ }^{6}$ North Korea, by comparison, has had a hostile relationship with South Korea and the US since the 1950s and repeatedly engages in threats and provocations, but has largely avoided armed reprisal despite being conventionally weaker than both. ${ }^{7}$ Notably, deliberate interstate wars with a nuclear weapon state remain rare; challengers instead appear to largely limit themselves to low-intensity conflict with limited aims.

\footnotetext{
${ }^{4}$ Michael D. Cohen, "How Nuclear South Asia Is Like Cold War Europe: The Stability-Instability Paradox Revisited," Nonproliferation Review 20, no. 3 (2013): 433-451.

${ }^{5}$ S. Paul Kapur, "India and Pakistan's Unstable Peace: Why Nuclear South Asia Is Not Like Cold War Europe," International Security 30, no. 2 (2005): 136-142.

${ }^{6}$ Zeev Maoz, Defending the Holy Land: A Critical Analysis of Israel's Security and Foreign Policy (Ann Arbor: University of Michigan Press, 2008), 5.

${ }^{7}$ North Korea's nuclear arsenal as of 2020 is estimated at around 10-30 nuclear warheads, while the US possesses approximately 4,000. Van Jackson, On the Brink: Trump, Kim, and the Brink of Nuclear War (Cambridge: Cambridge University Press, 2018), 1-2, 59.
} 
Table 1.1: Nuclear Weapon State MIDs Pre- and Post-Nuclearization, 1900-2010

\begin{tabular}{|c|c|c|c|c|c|}
\hline $\begin{array}{l}\text { Nuclear } \\
\text { Weapon State }\end{array}$ & $\begin{array}{l}\text { Nuclearization } \\
\text { Year }\end{array}$ & $\begin{array}{l}\text { Pre- } \\
\text { nuclearization } \\
\text { MIDs (1900- ) }\end{array}$ & $\begin{array}{l}\text { Post- } \\
\text { nuclearization } \\
\text { MIDs (-2010) }\end{array}$ & $\begin{array}{l}\text { Total } \\
\text { MIDs }\end{array}$ & $\%$ change \\
\hline United States & 1945 & 100 & 357 & 457 & $257 \%$ \\
\hline $\begin{array}{l}\text { Soviet } \\
\text { Union/Russia }\end{array}$ & 1949 & 222 & 292 & 514 & $31.53 \%$ \\
\hline $\begin{array}{l}\text { United } \\
\text { Kingdom }\end{array}$ & 1952 & 171 & 115 & 286 & $-32.75 \%$ \\
\hline France & 1960 & 116 & 63 & 179 & $-45.69 \%$ \\
\hline China & 1964 & 267 & 166 & 433 & $-37.83 \%$ \\
\hline Israel & 1967 & 110 & 142 & 252 & $29.09 \%$ \\
\hline India & 1974 (PNE) & 58 & 64 & 122 & $10.34 \%$ \\
\hline India & $\begin{array}{l}1998 \text { (Pokhran- } \\
\text { II) }\end{array}$ & 92 & 30 & 122 & $-67.39 \%$ \\
\hline Pakistan & $\begin{array}{l}1986 \\
\text { (capability) }\end{array}$ & 54 & 53 & 107 & $-1.85 \%$ \\
\hline Pakistan & 1998 (Chagai-I) & 71 & 36 & 107 & $-49.3 \%$ \\
\hline North Korea & 2006 & 176 & 6 & 182 & $-96.59 \%$ \\
\hline
\end{tabular}

One possible explanation for these apparent differences is that a defending nuclear weapon state's nuclear deterrence effectiveness is influenced by its regime type. The aforementioned examples suggest that democratic nuclear weapon states are perceived by potential challengers as unlikely to use their nuclear weapons in response to armed attacks, and thus remain appealing targets. Autocracies appear to reap greater benefits from nuclear weapons, since potential challengers seem reluctant to attack them - even if, as with North

\footnotetext{
${ }^{8}$ MID dyad-year data used in this table is cited from Zeev Maoz et al., "The Dyadic Militarized Interstate Disputes (MIDs) Dataset Version 3.0: Logic, Characteristics, and Comparisons to Alternative Datasets," Journal of Conflict Resolution 63, no. 3 (2019): 811-35.
} 
Korea and Pakistan, the defender engages in provocations. The existing literature on nuclear deterrence, however, does not appear to engage with state regime type as a potential variable in depth. Qualitative studies of nuclear deterrence generally do not engage with regime type, with the few that do typically being case studies rather than efforts at theorybuilding. ${ }^{9}$ This gap is all the more notable when compared to the literature on nuclear proliferation and conventional armed conflict, both of which contain numerous studies and theories on state regime type's influence, most notably democratic peace theory. ${ }^{10}$ Scholars have begun to note the lack of research into the possible relationship, with a 2016 literature review of the nuclear deterrence literature questioning "what is the interaction between regime type... and nuclear status?" and noting the potential for variation among nuclear weapon states in how they use their nuclear arsenals for deterrence. ${ }^{11}$

This discrepancy between the nuclear deterrence literature and the trend in attacks against nuclear weapon states suggests that there is a gap in our understanding of deterrence. This gap has potentially significant policy implications given the damage nuclear weapons can cause and the role that nuclear deterrence plays in the defence strategies of states that possess them. The regime type of a defending nuclear weapon state

\footnotetext{
${ }^{9}$ Examples of case studies that study regime type and nuclear deterrence include Rajaram Panda, "North Korea's Nuclear Policy: Domestic Determinants, Strategy and Future," Journal of Comparative Asian Development 10, no. 2 (2011): 240-245; Scott A. Jones and James R. Holmes, "Regime Type, Nuclear Reversals, and Nuclear Strategy: The Ambiguous Case of Iran," in Strategy in the Second Nuclear Age: Power, Ambition, and the Ultimate Weapon, ed. Toshi Yoshihara and James R. Holmes (Baltimore: Georgetown University Press, 2012): 201-202.

${ }^{10}$ For examples of studies on conventional conflict and regime type, see Zeev Maoz and Bruce Russett, "Normative and Structural Causes of Democratic Peace, 1946-1986," American Political Science Review 87, no. 3 (1993): 624-638; Bruce Bueno de Mesquita and Alastair Smith, The Dictator's Handbook: Why Bad Behaviour Is Almost Always Good Politics (New York: PublicAffairs, 2011); and Jessica L. Weeks, "Strongmen and Straw Men: Authoritarian Regimes and the Initiation of International Conflict," American Political Science Review 106, no. 2 (2012): 326-47.

${ }^{11}$ Erik Gartzke and Matthew Kroenig, "Nukes with Numbers: Empirical Research on the Consequences of Nuclear Weapons for International Conflict,” Annual Review of Political Science 19 (2016): 408.
} 
playing a role in its ability to deter challengers would mean that there is a variable influencing its deterrence credibility functionally beyond its control. It suggests that democratic nuclear weapon states have an inherently greater risk of being attacked by challengers that consider them vulnerable and believe they can make some gains while

facing few to no consequences. Furthermore, such a conflict could potentially escalate if the defender's government fulfills its threats, leading to an otherwise avoidable nuclear conflict with potentially massive costs for both sides. Nuclear-armed non-democracies may also be emboldened into acting more aggressively towards adversaries in the belief that their nuclear arsenal will prevent retaliation. In short, a better understanding of nuclear deterrence and how regime type can influence it would allow for policy to counter the potential effects on conflict behaviour by both challengers and defenders.

\section{2: Research Question and Argument}

The above points lead to the following research question that this dissertation seeks to answer: "Does state regime type influence the ability of nuclear weapons to deter lowintensity conflict?" In answering this question, the dissertation advances a novel explanation for why some nuclear weapon states have appeared more successful in deterring low-intensity attacks by potential challengers than others. This theory draws on not only the existing literature on nuclear deterrence, but also studies of the relationship between conventional armed conflict and state regime type, to fill in conceptual gaps present in the former. It also builds upon concepts in the deterrence literature, such as audience costs theory and the stability-instability paradox, that seek to explain variation in nuclear deterrence effectiveness and suffer from notable shortcomings. 
I argue that a nuclear weapon state's regime type, particularly how accountable its government is and to whom, plays a significant role in the credibility of its nuclear deterrent and the likelihood of potential challengers launching low-intensity attacks against it. All governments are accountable to a domestic audience whose support is necessary to retain power. ${ }^{12}$ Where regime types vary is the makeup of this group, which can consist of voters or groups of elites, how constrained the government is by its need to satisfy them, and the presence of domestic institutions enabling supporters to punish the government. A larger support base is expected to make governments more sensitive to the costs of their policies and avoid actions that could negatively impact their citizens and their hold on power. ${ }^{13}$ This extends to fulfilling nuclear deterrence threats, as a state that uses nuclear weapons can be expected to suffer numerous negative consequences for it, such as the imposition of economic sanctions, a loss of international standing, and alliances forming against it. ${ }^{14}$ Governments that are perceived as cost-sensitive would be considered to lack the resolve to fulfill those deterrence threats out of fear of punishment. Potential challengers may then consider those threats non-credible and be encouraged to attack the defender in the belief that they will avoid nuclear retaliation.

The impact of regime type on nuclear deterrence threat credibility is expected to differ between high-intensity and low-intensity conflict, with its influence being most

\footnotetext{
${ }^{12}$ Bueno de Mesquita and Smith, The Dictator's Handbook, 5-6.

${ }^{13}$ Alexandre Debs and Henk E. Goemans, "Regime Type, the Fate of Leaders, and War," American Political Science Review 104, no. 3 (2010): 431; Benjamin E. Goldsmith, Dimitri Semenovich, Arcot Sowmya, and Gorana Grgic, "Political Competition and the Initiation of International Conflict: A New Perspective on the Institutional Foundations of Democratic Peace," World Politics 69, no. 3 (2017): 496. ${ }^{14}$ For more in-depth discussion of the anticipated costs of using nuclear weapons, see Nina Tannenwald, The Nuclear Taboo: The United States and the Non-Use of Nuclear Weapons Since 1945 (Cambridge: Cambridge University Press, 2007), 48-51; Todd S. Sechser and Matthew Fuhrmann, Nuclear Weapons and Coercive Diplomacy (New York: Cambridge University Press, 2017), 46-51.
} 
apparent for the latter. In cases of high-intensity conflict, such as interstate wars and other crises posing an existential threat to the state, all nuclear weapon states would be expected to be willing to use nuclear weapons against challengers. This is because the benefits of ensuring the continued survival of the state greatly outweigh any costs from using nuclear weapons, which may not be imposed at all if their use is considered necessary. ${ }^{15}$ Instances of low-intensity conflict between states, ranging from skirmishes and raids to limited wars, highlight the differences between regime types, as the costs of fulfilling nuclear deterrence threats would greatly outweigh whatever benefits could be gained instead of using conventional forces. ${ }^{16}$ Thus, low-intensity scenarios will have nuclear deterrence threats from cost-sensitive states perceived as less credible than those of relatively cost-insensitive ones.

The theory establishes a straightforward dichotomy in how democratic and nondemocratic nuclear weapon states will have their low-intensity conflict deterrence threats perceived and the willingness of challengers to attack them. Democratic governments will, due to being accountable to voters, be perceived as cost-sensitive and thus unwilling to use nuclear weapons against anything less than an existential threat due to the potential costs outweighing the benefits. This perceived non-credibility is expected to encourage challengers to attack democratic nuclear weapon states in the belief that they will only face limited conventional retaliation at worst. Non-democratic nuclear weapon state governments will be considered more willing to respond to low-intensity attacks with nuclear weapons due to being beholden to a small circle of elite supporters known in

\footnotetext{
${ }^{15}$ Bryan R. Early and Victor Asal, "Nuclear Weapons, Existential Threats, and the Stability-Instability Paradox," Nonproliferation Review 25, no. 3-4 (2018): 230-231.

${ }^{16}$ Sechser and Fuhrmann, Nuclear Weapons and Coercive Diplomacy, 50-51.
} 
selectorate theory as a "winning coalition. ${ }^{17 "}$ These elites allow governments to be relatively insensitive to the costs of their policies to their citizens, since they can retain power so long as their backers continue being rewarded. Thus, if leaders have an incentive to fulfill their nuclear deterrence threats, such as ensuring their continued rule by launching a pre-emptive strike against an adversary that they believe is seeking to overthrow them, their supporters are unlikely to restrain or punish them for doing so. ${ }^{18}$ This perceived costinsensitivity means that potential challengers are expected to view their nuclear deterrence threats as credible even for low-intensity conflict, and thus avoid attacking.

The credibility of a state's nuclear deterrence threats is expected to be further influenced by its reputation in past crises, particularly its willingness to act aggressively. The reputation of individual leaders and the state as a whole serve as sources of information for others to understand their past behaviour and infer their actions in similar scenarios in the future. ${ }^{19}$ A state whose leader has responded to territorial incursions with empty threats, for example, would be expected to do so again in the future. Similarly, a state known for launching unprovoked attacks against others will be seen as reckless and insensitive to fighting costs because its leaders demonstrate little regard for them. ${ }^{20}$ This has consequences for nuclear deterrence credibility, since demonstrated cost-insensitivity could translate to the necessary resolve to endure the costs of fulfilling nuclear deterrence

\footnotetext{
${ }^{17}$ Bueno de Mesquita and Smith, The Dictator's Handbook, 4-6.

${ }^{18}$ There is a greater chance of these supporters reacting negatively if such a pre-emptive attack is against another nuclear power and could result in mutual annihilation, but only if they believe that using nuclear weapons is unnecessarily dangerous in the given situation. As later chapters demonstrate, however, nondemocratic elites tend to view any kind of attack as a serious threat to their rule.

${ }^{19}$ Alexandra Guinsinger and Alistair Smith, "Honest Threats: The Interaction of Reputation and Political Institutions in International Crises," Journal of Conflict Resolution 46, no. 2 (2002): 177-178; Danielle L. Lupton, "Reexamining Reputation for Resolve: Leaders, States, and the Onset of International Crises," Journal of Global Security Studies 3, no. 2 (2018): 198-216.

${ }^{20}$ Lupton, "Reexamining Reputation for Resolve," 200.
} 
threats. ${ }^{21}$ Any state, regardless of their regime type, would be able to bolster their nuclear deterrence threats by developing such a reputation. Non-democracies in particular will have more opportunity to develop a reputation for aggression, and thus demonstrate their cost-insensitivity, because the autonomy of their executive from the population means that they can threaten and attack other states with little regard for popular support.

The remainder of this introductory chapter proceeds as follows. First, critical terms and concepts, such as nuclear deterrence, nuclear weapon states, and regime type are briefly defined. This is then followed by an overview of the existing nuclear deterrence literature to highlight the gap and what this study contributes to our understanding of the subject. Third, the main argument of the dissertation, as well as what it seeks to demonstrate and the scope of the research are discussed. Finally, the introduction concludes with a road map of the rest of the dissertation. This includes an overview of the process tracing and cross-case comparison methodology, the cases selection, and the conclusions reached.

\section{3: Key Concepts}

Given the nature of this dissertation, it is necessary to define certain key concepts to minimize ambiguity. Broadly speaking, deterrence refers to a defender attempting to convince a challenger to not perform a certain action by explicitly or implicitly threatening to impose costs that would leave the challenger worse off than if it did nothing. ${ }^{22}$ Nuclear deterrence in particular has the defender use threats of retaliation with nuclear weapons against the challenger or its allies to deter it. ${ }^{23}$ Deterrence threat credibility requires

\footnotetext{
${ }^{21}$ Todd S. Sechser, "Reputations and Signaling in Coercive Bargaining," Journal of Conflict Resolution 62, no. 2 (2018): 318-345.

${ }^{22}$ Freedman, Deterrence, 6-7.

${ }^{23}$ Bernard Brodie, "Implications for Military Policy," in The Absolute Weapon: Atomic Power and World Order, edited by Bernard Brodie (New York: Harcourt, Brace and Company, 1946), 71-75.
} 
defenders to demonstrate they possess the capability and resolve to carry them out (that is, both the ability and the will to do so); without these, challengers may conclude the defender is bluffing and choose to attack in spite of the threats. ${ }^{24}$ While conceptually simple, deterrence can be further complicated by instances where multiple defenders band together to deter a single challenger, one defender threatens multiple challengers, or a combination of both. ${ }^{25}$ The Cold War can be seen as an instance of the second, with NATO member states attempting to deter challenges by the Soviet Union. This particular form of deterrence, known as deterrence by punishment, differs from deterrence by denial, where challengers are deterred by the defender taking steps to prevent it from carrying out the specified action in the first place or from gaining from it. ${ }^{26}$

Given the focus on the practice of nuclear deterrence in this dissertation, the unit of analysis is nuclear weapon states, which broadly refers to any states that possess an independent nuclear weapon arsenal. The state in question must thus have completed both the development and assembly of at least one functional nuclear weapon. ${ }^{27}$ These are distinct from nuclear proliferators, which can be in the process of developing a nuclear weapon without ever actually succeeding and thus lack an actual nuclear deterrent, such as Iran. De facto nuclear weapon states also differ in having the capability to construct a nuclear weapon, potentially with relatively short notice, but lack an actual functional

\footnotetext{
${ }^{24}$ D. Marc Kilgour and Frank C. Zagare, "Credibility, Uncertainty, and Deterrence," American Journal of Political Science 35, no. 2 (1991): 306-307; Thérèse Delpech, Nuclear Deterrence in the 21 ${ }^{\text {st }}$ Century: Lessons from the Cold War for a New Era of Strategic Piracy (Santa Monica: RAND Corporation: 2012), 45.

${ }^{25}$ Hedley Bull, "Future Conditions of Strategic Deterrence," in "The Future of Strategic Deterrence: Part I Papers from the IISS Annual Conference," Special Issue, The Adelphi Papers 20, no. 160 (1980): 15.

${ }^{26}$ Michael J. Mazarr, "Understanding Deterrence," Perspectives (RAND Corporation: 2018), 2, https://www.rand.org/content/dam/rand/pubs/perspectives/PE200/PE295/RAND_PE295.pdf; Delpech, Nuclear Deterrence in the $21^{\text {st }}$ Century, 28.

${ }^{27}$ United Nations Office for Disarmament Affairs, "Treaty on the Non-Proliferation of Nuclear Weapons," July 1, 1968, https://www.un.org/disarmament/wmd/nuclear/npt/text/.
} 
device during a crisis, with Pakistan being an example of this during the $1980 \mathrm{~s} .{ }^{28}$ Finally, states hosting another's nuclear weapons in their territory would not be nuclear weapon states due to lacking launch authority; Japan, for example, hosted American nuclear weapons between 1951 and 1972, but would not be considered a nuclear weapon state for this reason. ${ }^{29}$ This establishes a fairly small universe of 9 cases, consisting of the US, USSR/Russia, UK, France, China, India, Israel, Pakistan, and North Korea. ${ }^{30}$

Nuclear weapon states can be further divided into superpowers and regional nuclear powers. Superpower nuclear weapon states refers to the US and Soviet Union (as well as Russia following the latter's 1991 dissolution), given the sheer size of their nuclear arsenals and their ability to project their power across vast distances. ${ }^{31}$ Significant analytical difficulties regarding nuclear deterrence occur as a result, as armed attacks against these states tend to target their allies, satellite states, and foreign military deployments rather than their home territory, making it difficult to discern when they are the target. Additionally, comparing nuclear superpowers to other states has fundamental issues due to their greater conventional strength and their arsenals being tens to hundreds of times larger, making it highly difficult to determine the actual effectiveness of their nuclear deterrents. ${ }^{32}$ Finally, it is unlikely that any new nuclear superpowers will emerge in the future, given the massive mobilization of resources that would be required and the deterrence capabilities of even a

\footnotetext{
${ }^{28}$ Kuldip Nayar, "We Have the A-Bomb, Says Pakistan's 'Dr Strangelove," The Observer, March 1, 1987.

${ }^{29}$ Robert S. Norris, William M. Arkin, and William Burr, "How Much Did Japan Know?" Bulletin of the Atomic Scientists 56, no. 1 (2000): 11-13, 78-79.

${ }^{30}$ This does not include South Africa, which unilaterally dismantled its arsenal by 1991, or Ukraine, Belarus, and Kazakhstan, which accidentally inherited Soviet nuclear weapons when the USSR dissolved in 1991 and returned them over the following few years. Hans M. Kristensen and Robert S. Norris, "Nuclear Arsenals of the World," Bulletin of the Atomic Scientists, 2018, https://thebulletin.org/nuclear-notebookmultimedia/.

${ }^{31}$ Vipin Narang, Nuclear Strategy in the Modern Era: Regional Powers and International Conflict (Princeton: Princeton University Press, 2014), 1-5.

${ }^{32}$ Narang, Nuclear Strategy in the Modern Era, 5.
} 
relatively small nuclear arsenal. ${ }^{33}$ This does not mean that no new superpowers will emerge at all, but rather that the model will continue to have limited applicability.

Regional nuclear powers differ significantly in both their nuclear capabilities and approaches to deterrence. The most straightforward definition advanced by Vipin Narang and others is that these are non-superpower states with nuclear arsenals. ${ }^{34}$ These states, which include France (1960), China (1964), Israel (1967), India (1974), Pakistan (1986), and North Korea (2006), differ significantly from their superpower counterparts due to more limited capabilities. In a quantitative sense, they all possess small arsenals, ranging from only a few dozen (North Korea) to several hundred (France and China) compared to the thousands or tens of thousands possessed by the superpowers. ${ }^{35}$ These correspondingly require regional nuclear powers to adopt different deterrence strategies than superpowers, such as focusing on deterring regional adversaries via ensuring the survivability of their nuclear forces. ${ }^{36}$ This dissertation focuses on regional powers to ensure applicability and policy relevance to future nuclear weapon states, which will likely be regional nuclear powers themselves due to the resource-intensive nature of nuclear weapons programs.

State regime type is integral to this dissertation as one of the independent variables studied. The term typically refers to the type of overarching structure of government that

\footnotetext{
33 The US Congressional Budget Office (CBO), for example, has projected that the total cost of modernizing and operating US nuclear forces for the 2019-2028 period would cost approximately US\$494 billion, with an estimated 3,800 active warheads and associated delivery systems as of 2019. US Congressional Budget Office, "Projected Costs of U.S. Nuclear Forces, 2019 to 2028" (Congressional Budget Office, January 24, 2019), https://www.cbo.gov/system/files/2019-01/54914-NuclearForces.pdf; Hans M. Kristensen and Matt Korda, "United States Nuclear Forces, 2020," Bulletin of the Atomic Scientists 76, no. 1 (2020): 46-60.

${ }^{34}$ Narang, Nuclear Strategy in the Modern Era, 2-3; Delpech, Nuclear Deterrence in the $21^{\text {st }}$ Century, 27; David Ochmanek and Lowell H Schwartz, The Challenge of Nuclear-Armed Regional Adversaries (Santa Monica, CA: RAND Corporation, 2008), 15-26, https://www.rand.org/pubs/monographs/MG671.html.

${ }^{35}$ Kristensen and Norris, "Nuclear Arsenals of the World."

${ }^{36}$ Narang, Nuclear Strategy in the Modern Era, 8.
} 
controls a state, which are differentiated according to key characteristics. ${ }^{37}$ While there are numerous regime type classification systems, this dissertation utilizes the Polity 5 Project's definitions. Democratic governments are characterized by institutions and procedures that allow meaningful expressions of citizen preference for government policy and leadership, institutions constraining executive power, and guaranteed civil liberties to all citizens. ${ }^{38}$ Many democracies are characterized by additional elements, such as the rule of law, checks and balances between branches of government, and freedom of the press. Autocracies instead restrict or suppress political competition and popular participation (overtly or covertly) in favour of political elites making leadership decisions and have few formal constraints on executive power. ${ }^{39}$ Some autocratic regimes like North Korea and Eritrea also exercise strict social and economic controls within their borders. Finally, anocracies, or hybrid regimes, are governments that demonstrate a mix of democratic and autocratic traits, such as a flawed democracy that holds elections that are not entirely free, with the specific mix of traits varying on a case-by-case basis. ${ }^{40}$

This study simplifies the division between state regime types somewhat into a dichotomy of democratic and non-democratic states. Democratic states are categorized as above - namely, any state whose citizens can express their choices in leadership both freely and in a way that meaningfully impacts governance, as well as possessing civil liberties and some form of constrain on executive power qualifies as such. Non-democracies

\footnotetext{
${ }^{37}$ Monty G Marshall and Ted Robert Gurr, Polity 5 Political Regime Characteristics and Transitions, 1800-2018: Dataset Users' Manual (Vienna: Center for Systemic Peace, 2020), 1-2, http://www.systemicpeace.org/inscr/p5manualv2018.pdf.

${ }^{38}$ Marshall and Gurr, Polity 5, 14.

${ }^{39}$ Marshall and Gurr, Polity 5, 15-16.

${ }^{40}$ James D. Fearon and David D. Laitin, "Ethnicity, Insurgency, and Civil War," American Political Science Review 97, no. 1 (2003): 81.
} 
encompass the various types of autocratic regimes, whether they are single-party states or outright personalist and military dictatorships. Anocracies falling between the two are classified on a case-by-case basis according to their institutional makeup. A state that holds regular, but rigged, elections would be considered non-democratic, while one holding free elections and suffering from corruption and a lack of government capacity could still be considered a flawed democracy.

Finally, it is important to note the distinctions between different intensities of armed conflict discussed in section 1.2, which can be categorized between high-intensity and lowintensity conflict. The two main considerations in distinguishing between the two are a) the challenger's aims and b) the means used to achieve them. ${ }^{41}$ High-intensity conflict refers to instances of armed conflict where the challenger's strategic aims are significant in scope, e.g. attempting to conquer large portions of the defender's territory, if not the entirety of the state, and thus tends to consist largely of major interstate wars. ${ }^{42}$ Correspondingly, the challenger will use sufficient military force to threaten the defender with significant damage to its economy and infrastructure and massive loss of life, and at worst threatening its existence as a political entity. Low-intensity conflict, in contrast, indicates more modest challenger aims, such as seizing a lightly defended border area or raiding the defender's territory, with the forces used being similarly limited. ${ }^{43}$ This can extend to limited war, where the challenger's aims are limited relative to a more general interstate war, but where the means used are more expansive than one-off attacks, e.g. sending a large force to

\footnotetext{
${ }^{41}$ Patricia Lynne Sullivan and Scott Sigmund Gartner, "Disaggregating Peace: Domestic Politics and Dispute Outcomes," International Interactions 32, no. 1 (2006): 10.

${ }^{42}$ Bryan R. Early and Victor Asal, "Nuclear weapons, existential threats, and the stability-instability paradox," Nonproliferation Review 25, nos. 3-4 (2018): 224.

${ }^{43}$ Glenn Palmer et al, "The MID4 dataset, 2002-2010: Procedures, coding rules and description," Conflict Management and Peace Science 32, no. 2 (2015): 222-242.
} 
capture a strip of territory. ${ }^{44}$ The focus on armed attacks in this dissertation means that other forms of conflict, such as cyberattacks, are not included under low-intensity conflict. However, more indirect means of armed conflict, such as state-sponsored terrorism, are included due to how the actions of the non-state actor are still ultimately attributable to a government that can be threatened and attacked with nuclear weapons.

There are two important details regarding conflict intensity. First, it can be understood as operating on a sliding scale, with specific cases shifting in intensity according to whether the challenger and/or defender escalate or de-escalate the situation. This means that armed conflict can start off as low-intensity, but can escalate to highintensity conflict when one or both sides responds more aggressively, or conversely can start off as high-intensity and become less intense over time. Secondly, while a challenger may intend to wage low-intensity conflict, the defender may instead perceive it as a much greater threat and fight accordingly. The 1973 Yom Kippur War was an example of this type of misperception: while the Egyptian-Syrian coalition sought to recapture lost territory in the Sinai and Golan Heights in 1973, Israeli officials like Defence Minister Moshe Dayan believed they faced an existential threat due to the size of the advancing forces, to the point that the use of nuclear weapons was considered. ${ }^{45}$

\section{4: Motivation and Contributions}

This dissertation is motivated primarily by the apparent relationship between the regime type of nuclear weapon states and the variation in which ones are attacked, along

\footnotetext{
${ }^{44}$ Thomas Schelling, The Strategy of Conflict (Cambridge: Harvard University Press, 1960), 187-194.

${ }^{45}$ Sechser and Fuhrmann, Nuclear Weapons and Coercive Diplomacy, 218; Avner Cohen and Arnan Azaryahu, "Interview with Arnan 'Sini' Azaryahu by Avner Cohen" (January 2008), 2, From the personal collection of Avner Cohen, History and Public Policy Program Digital Archive, https://digitalarchive.wilsoncenter.org/document/117848.
} 
with the lack of attention paid to regime type in the nuclear deterrence literature. Regime type has largely been ignored in the study of nuclear deterrence: those few studies that do study the relationship between the two are case studies of specific states, and do not engage in broader theory-building. ${ }^{46}$ One of the only areas to consider regime type is deterrence credibility, though even this appears to largely be restricted to audience cost theory. This gap is highly notable, given that regime type is often cited as a significant variable in studies of both nuclear weapons proliferation and conventional armed conflict. ${ }^{47}$ The lack of study regarding regime type and nuclear deterrence has even been explicitly remarked upon, with the possibility that regime type plays a role in conflict propensity differences being noted by Gartzke and Kroenig. ${ }^{48}$ Insofar as can be determined, there is no specific reason for regime type to not be studied in relation to nuclear deterrence, nor why the pattern of democratic nuclear weapon states being attacked more often has not been observed or discussed. This lack of study, when taken alongside the apparent variation in conflict involvement noted at the beginning of this chapter, suggests that there is a gap in the nuclear deterrence literature that needs to be addressed.

The absence of regime type in nuclear deterrence research is especially notable when compared to the numerous conventional conflict theories that focus on it, given the

\footnotetext{
${ }^{46}$ Some examples of case studies focusing on the relationship between state regime type and nuclear deterrence include Rajaram Panda, "North Korea's Nuclear Policy: Domestic Determinants, Strategy and Future," Journal of Comparative Asian Development 10, no. 2 (2011): 240-245; Scott A. Jones and James R. Holmes, "Regime Type, Nuclear Reversals, and Nuclear Strategy: The Ambiguous Case of Iran," in Strategy in the Second Nuclear Age: Power, Ambition, and the Ultimate Weapon, ed. Toshi Yoshihara and James R. Holmes (Baltimore: Georgetown University Press, 2012): 201-202.

${ }^{47}$ Some examples include Scott D. Sagan, "Why Do States Build Nuclear Weapons? Three Models in Search of a Bomb," International Security 21, no. 3 (1996): 54-86; Christopher Way and Jessica L. Weeks, "Making It Personal: Regime Type and Nuclear Proliferation," American Journal of Political Science 58, no. 2 (2014): 705-719; Zeev Maoz and Bruce Russett, "Normative and Structural Causes of Democratic Peace, 1946-1986," American Political Science Review 87, no. 3 (1993): 624-638.

${ }^{48}$ Erik Gartzke and Matthew Kroenig, "Nukes with Numbers: Empirical Research on the Consequences of Nuclear Weapons for International Conflict," Annual Review of Political Science 19 (2016): 408.
} 
conceptual similarities of the two subjects. Democratic peace theory argues that democracies are less likely to fight each other than against non-democracies due to inherent governance characteristics, particularly how institutions can hold elected officials accountable and allow their removal from power. ${ }^{49}$ Selectorate theory and others, meanwhile, argue that non-democracies are more willing to fight, even with low chances of victory, due to elite support allowing them to ignore popular opinion as long as elites are rewarded.$^{50}$ Many of these theories argue that democracies are highly sensitive to the costs of war due to popular accountability and assume they will avoid fighting when possible to avoid domestic punishment. ${ }^{51}$ Non-democracies, in contrast, are perceived as capable of fighting more because the relative lack of accountability beyond their supporters means they can be largely insensitive to those costs. ${ }^{52}$ Given that using nuclear weapons would incur costs, cost-sensitivity suggests these theories could be extended to nuclear deterrence - but no studies appear to have studied this connection or its significance.

Given this gap, this study makes two significant theoretical contributions to how we understand nuclear deterrence. The first of these is integrating state regime type as a potential determinant in nuclear deterrence. This would already be a significant innovation

\footnotetext{
${ }^{49}$ T. Clifton Morgan and Sally Howard Campbell, "Domestic Structure, Decisional Constraints, and War: So Why Kant Democracies Fight?," Journal of Conflict Resolution 35, no. 2 (1991): 189-192.

${ }^{50}$ Benjamin E. Goldsmith, Stephan K. Chalup, Michael J. Quinlan, "Regime Type and International Conflict: Towards a General Model," Journal of Peace Research 45, no. 6 (2008): 743-747.

${ }^{51}$ Empirically, this assumption has come under doubt due to instances of democratic governments going to war despite popular opinion or even being forced to fight due to popular demand. For further discussion of this, see Sebastian Rosato, "The Flawed Logic of Democratic Peace Theory," American Political Science Review 97, no. 4 (2003): 585-602; David J. Lorenzo, "Democratic Peace Theory, the Problems of Pluralism, and the Opposition to the Use of Military Force in the US," Democracy and Security 14, no. 4 (2018): 414-42.

${ }^{52}$ Bruce Bueno de Mesquita et al., "An Institutional Explanation of the Democratic Peace," American Political Science Review 93, no. 4 (1999): 791-807; Cigdem V. Sirin and Michael T. Koch, "Dictators and Death: Casualty Sensitivity of Autocracies in Militarized Interstate Disputes," International Studies Quarterly 59, no. 4 (2015): 802-14.
} 
in evaluating the effectiveness of nuclear deterrence, given the paucity of studies that address this variable at all, much less focusing on what role, if any, it plays in variations in the conflict propensity of nuclear weapon states. ${ }^{53}$ This dissertation aims to accomplish this by extending existing theories from the conventional conflict literature to nuclear deterrence while utilizing concepts shared between the two bodies of research, such as the presence of costs, thus grounding the resulting theory further in prior research.

Secondly, this study builds upon and rectifies issues present in existing theories of nuclear deterrence, particularly audience costs theory and the stability-instability paradox. Audience costs is one of the few theories in the nuclear deterrence literature that engages with regime type and its potential role in nuclear deterrence, specifically in how it can influence the credibility of threats. As originally articulated by James Fearon, audience costs suffers from notable shortcomings, notably how the argument that non-democratic threats are less credible than democratic ones assumes that the former lack accountability. ${ }^{54}$ This ignores that even non-democratic governments depend on elite domestic audiences that can punish them for actions that hurt their interests or for showing weakness, but will be more tolerant of costs that affect the disempowered general populace. ${ }^{55}$ Democratic governments, meanwhile, would expect to be punished for actions that lead to costs being unnecessarily imposed on their citizens. ${ }^{56}$ Additionally, audience costs tends to ignore the

\footnotetext{
${ }^{53}$ One of the few studies that attempts to study the role of regime type in nuclear deterrence (albeit with a very different theory and methodology) is Shoko Kohama and Kazuto Ohtsuki, "Political Institutions and Nuclear Deterrence" (60th International Studies Association Annual Convention, Toronto, March 27-30, 2019), http://web.isanet.org/Web/Conferences/Toronto\%202019-s/Archive/9ed874b6-e516-4f4e-bd0ef51198181128.pdf.

${ }^{54}$ James D. Fearon, "Domestic Political Audiences and the Escalation of International Disputes," American Political Science Review 88, no. 3 (1994): 581-582.

${ }^{55}$ Debs and Goemans, "Regime Type, the Fate of Leaders, and War," 431.

${ }^{56}$ Darren Filson and Suzanne Warner, "Bargaining and Fighting: The Impact of Regime Type on War Onset, Duration, and Outcomes," American Journal of Political Science 48, no. 2 (2004): 306.
} 
possible role of international audiences in favour of domestic audiences, dismissing the former as a long-term issue when international reactions such as economic sanctions would likely be taken into consideration by decision-makers. ${ }^{57}$ The theory advanced in this dissertation similarly operates on the basis of domestic regime type influencing deterrence credibility, but addresses the aforementioned shortcomings by integrating non-democratic accountability and international audiences.

The stability-instability paradox, meanwhile, provides an explanation for continued low-intensity conflict between nuclear weapon states, but can be extended by integrating regime type. The logic of the paradox is that mutual nuclear deterrence leads to reduced interstate war for fear of escalation to a nuclear exchange, but simultaneously encourages low-intensity conflict since it is seemingly non-credible for nuclear weapons to be used for such low-level fighting. ${ }^{58}$ While this explains why a nuclear weapon state would engage in low-intensity fighting with another - e.g. Pakistan attacking India - it fails to account for why a nuclear weapon state would avoid such fighting, such as how India has (largely) avoided attacking Pakistan since 1998. The paradox also fails to explain why a non-nuclear weapon state would be willing to attack despite a defender's nuclear deterrent, as in the 1973 Yom Kippur War, since the latter would not be restrained by possible nuclear war in fulfilling its threats.

Integrating state regime type into nuclear deterrence credibility serves to resolve these issues. The aforementioned India-Pakistan dyad, for example, could be explained

\footnotetext{
${ }^{57}$ Peter J. Partell and Glenn Palmer, "Audience Costs and Interstate Crises: An Empirical Assessment of Fearon's Model of Dispute Outcomes," International Studies Quarterly 43, no. 2 (1999): 390.

${ }^{58}$ Robert Jervis, The Illogic of American Nuclear Strategy (Ithaca: Cornell University Press, 1984), 148150 .
} 
with Pakistani leaders viewing India's deterrent as non-credible due to cost-sensitivity, while their Indian counterparts would refuse to attack due to perceiving Pakistan as sufficiently cost-insensitive to respond with nuclear weapons. Instances of nuclear democracies being attacked, meanwhile, can be explained by their being perceived by challengers as cost-sensitive to the point that they will avoid fulfilling their nuclear deterrence threats in low-intensity conflict regardless of whether the challenger has nuclear weapons or not, with T.V. Paul describing a similar outcome of self-imposed restraint due to reputational concerns as "self-deterrence." ${ }^{, 59}$ Regime type influencing the credibility of a state's nuclear deterrence threats thus not only provides a causal mechanism for the stability-instability paradox, but also allows for its extension to conflict situations involving a nuclear democracy and non-nuclear adversary.

The theory advanced in this dissertation has notable implications for policy. Perhaps foremost among these is that, if the theory is correct, democratic nuclear weapon states will be attacked more than their non-democratic counterparts because their apparent cost sensitivity leads challengers to view them as lacking the resolve to fulfill their deterrence threats. This means that democratic nuclear weapon states will need to take additional steps to demonstrate and signal resolve to potential challengers, such as taking actions to force themselves to fulfill nuclear deterrence threats in the appropriate circumstances. Additionally, establishing escalating conventional responses to lowintensity attacks and clearly communicating these to potential challengers would be necessary to bolster conventional deterrence, which would prove more credible than

\footnotetext{
${ }^{59}$ T.V. Paul, "Self-deterrence: Nuclear weapons and the enduring credibility challenge," International Journal 71, no. 1 (2016): 20-40.
} 
nuclear weapons. Non-democratic nuclear weapon states, meanwhile, would be too dangerous to attack in any way, as their governments would be more willing to use nuclear weapons to defend against any attacks. This means that attempting to use even shows of force to coerce these states has a high risk of escalating, making it necessary to use diplomatic and economic means against them.

\section{5: Goals and Scope}

The basic goal of this dissertation is to understand if and how the regime type of nuclear weapon states influences their ability to deter low-intensity attacks by developing a theory and testing it with case studies. The disparity in nuclear weapon state capabilities means that this cannot be perfectly applicable to all of them. The more modest conventional and nuclear capabilities of regional nuclear powers like India and North Korea means that the influence of regime type on their threat credibility and challenger behaviour is more apparent than with superpowers and their greater power projection capabilities. Focusing on regional nuclear powers will also lend the theory greater applicability to any future nuclear weapon states that emerge, whereas the superpower model has been derided as unrepresentative of the realities of nuclear deterrence since the end of the Cold War. ${ }^{60}$

The scope of the research focuses on a selection of four nuclear weapon states during the 1945-2018 period. All four of these states - India, Israel, Pakistan, and North Korea - were selected due to being regional nuclear powers and to ensure variation in regime types. The choice of years accounts for the introduction of nuclear weapons to the

\footnotetext{
${ }^{60}$ For some examples of discussions regarding the limited applicability of the superpower model of nuclear deterrence, see Frank P. Harvey, The Future's Back: Nuclear Rivalry, Deterrence Theory, and Crisis Stability after the Cold War (Montreal: McGill-Queen's University Press, 1997); Devin T. Hagerty, "Nuclear Deterrence in South Asia: The 1990 Indo-Pakistani Crisis," International Security 20, no. 3 (1995-96): 86; Brown and Arnold, "The Quirks of Nuclear Deterrence."
} 
international system in 1945, with 2018 being a cutoff point to ensure sufficient information is publicly available for analysis. While relevant incidents outside this timeframe are referenced (e.g. the February 2019 airstrike against Pakistan by India, the June 2020 India-China border clash, and the May 2020 Iranian cyberattacks on Israel), they are not subject to the same kind of in-depth analysis. Within the context of these states, the focus is on international crises targeting them before and after their acquisition of nuclear weapons to circumvent the issue of deterrence failure normally being a non-event, though the defender may be the one to initiate the crises. ${ }^{61}$ These are defined as instances where interstate interactions increase in hostility to the point of military action being more likely and where their relationship has destabilized as a result. ${ }^{62}$ My goal in following these conditions is to ensure that my analysis produces findings that would be applicable to as many current nuclear weapon states as possible, as well as any that emerge in the future.

At the same time, it is important to acknowledge the limitations that result from the case selection decisions. The small case selection, dictated by the small number of nuclear weapon states, runs the particular risk of selection bias affecting the results and making them unrepresentative of the greater trend among nuclear weapon states. ${ }^{63}$ This is somewhat mitigated, but not totally eliminated, by the use of process tracing to break down each case into multiple units of observation. ${ }^{64}$ Additionally, the use of both qualitative and

\footnotetext{
${ }^{61}$ Harvey, The Future's Back, 33.

${ }^{62}$ Michael Brecher and Jonathan Wilkenfeld, A Study of Crisis (Ann Arbor: University of Michigan Press, 1997), 4-5.

${ }^{63}$ Bruce Bueno de Mesquita, "Toward a Scientific Understanding of International Conflict: A Personal View," International Studies Quarterly 29, no. 2 (1985): 121-36.

${ }^{64}$ Process tracing is a method often used in historical case studies to evaluate explanations and determine causality by connecting phases in causal process leading the outcome of interest. David Collier and James Mahoney, "Insights and Pitfalls: Selection Bias in Qualitative Research," World Politics 49, no. 1 (1996): 70; Alexander L. George and Andrew Bennett, Case Studies and Theory Development in the Social Sciences (Cambridge: MIT Press, 2005), 176-177, 215.
} 
quantitative sources means that potential discrepancies between sources can be detected more easily, preventing the use of possibly flawed information. ${ }^{65}$

\section{6: Summary of Findings}

The findings of the four case studies in chapters $5,6,7$, and 8 appear to support the hypotheses that nuclear weapon state regime type influence nuclear deterrence threat credibility to challengers, albeit while highlighting unexpected issues in the theory. As expected, the two democracies studied appeared to have the credibility of their nuclear deterrence threats doubted by their challengers, with opposing leaders citing their apparent reluctance to suffer costs as a rationale for attacking despite the ostensible danger of nuclear retaliation. The non-democratic nuclear weapon states studied, meanwhile, had their nuclear deterrence threats against even low-level conflict and limited war viewed as credible by their challengers because they were seemingly cost-insensitive and willing to defend elite interests with any means, up to and including the use of nuclear weapons. They thus successfully deterred attacks even after initiating crises themselves, with Pakistan notably avoiding retaliation against its territory by India during the Kargil War in 1999 despite a similarly provocative attempt to seize territory in Kashmir in 1965 leading to an Indian invasion. With the exception of Pakistan, however, each case study has notable caveats that limit the apparent support for the hypotheses, which are discussed below.

Israel helps illustrate the greater challenges democracies face in signalling nuclear deterrence credibility during low-intensity crises, but its nuclear opacity policy both hinders the analysis and raises questions for the theory. Pre-nuclear crises such as the 1948

\footnotetext{
${ }^{65}$ Sidney Tarrow, "Bridging the Quantitative-Qualitative Divide in Political Science," The American Political Science Review 89, no. 2 (1995): 474.
} 
War of Independence and the 1956 Suez Crisis show that Israel had conventional superiority over adversaries such as Egypt and Syria. Despite these prior defeats and Israel's development of functional nuclear weapons by 1967, these states attacked despite their leaders being aware of Israel's nuclear program. Post-nuclear crises such as the 1967 Six-Day War and the 1973 Yom Kippur War were comparatively limited rather than deliberate existential threats to Israel. This, along with Israel's nuclear arsenal being meant exclusively for existential threats, indicates a deliberate effort to exploit a perceived aversion to costs by the leaders of challenger states, particularly Egypt's Gamal Nasser and Anwar Sadat. Israeli leaders opted against even nuclear test explosions as a warning during these crises to avoid being punished by the US and others in spite of Moshe Dayan and others believing Israel's existence was threatened, further indicating that nuclear weapons were a last resort.

Israel's longstanding policy of ambiguity around all nuclear affairs, including deterrence, presents issues in this regard due to its impact on the ability of Israeli voters to ostensibly hold the government to account. As discussed in further detail in chapter 5, various aspects of national security are already subject to secrecy, including via the use of a military censor for domestic journalism and academic publications. Nuclear issues in particular are further obscured from the public due to Clause 32 of the Basic Law delegating control directly to the prime minister and all discussions in the Knesset being referred to secret meetings of a subcommittee of the Defence and Foreign Affairs Committee. These measures, beyond presenting additional hurdles for study, also make it impossible for the Israeli public to hold elected officials accountable for nuclear deterrence policy, as they have little concrete information to work with. This makes it unclear whether 
Israeli nuclear restraint is due to concerns that the public will punish their leaders for using nuclear weapons in low-intensity conflict, as the theory argues, or whether officials are more concerned about the possible reaction from other states.

India similarly provides support for the hypothesis that challengers perceiving costsensitivity undermines democratic nuclear deterrence for low-intensity conflict, though elite dominance in foreign and defence policy goes against the expectation that possible electoral backlash plays a role. Notably, outright war between India and Pakistan has declined with the introduction of nuclear weapons to the region in 1998, with only one being fought in 1999 as opposed to three pre-nuclear wars. Pakistani support for militant groups within India, including directing terrorist attacks, and efforts to seize Kashmir via salami-slicing has not abated, however. Statements by Pakistani leaders before and after India's development of a nuclear deterrent indicate a consistent view of Indian leaders as afraid of suffering costs to the point of expecting them to treat the loss of territory to Pakistan as a fait accompli rather than fighting back. These views have been partially vindicated in post-nuclear crises due to Indian responses to aggression being limited to within their own territory due to political concerns over potential escalation. Contradicting the theory, however, this is seemingly not due to potential voter backlash, as Indian voters outside the foreign-policy-oriented strategic elite have largely favoured using force, including nuclear weapons, against even low-level provocations. Thus, while Indian leaders appear to be more sensitive to the costs of escalating conflict and international responses than public backlash, they are still perceived as overly cost-sensitive by challengers, encouraging low-intensity conflict as a result. 
Pakistan is perhaps the most straightforward of all the cases in demonstrating the influence of perceived cost-insensitivity on nuclear deterrence credibility for even lowintensity conflict. Prior to developing nuclear weapons, Pakistani attacks against India led to counter-attacks against Pakistani territory, with the 1965 and 1971 Indo-Pakistani Wars leading to Lahore being besieged and the loss of East Pakistan, respectively. Once Pakistan demonstrated its nuclear capabilities in May 1998, this shifted drastically, which is most apparent in how the 1999 Kargil War saw India avoid attacking Pakistani territory because of its nuclear arsenal despite the circumstances being nearly identical to the 1965 war. This was likely due to Pakistani officials warning during post-nuclear crises that they were willing to use nuclear weapons against even minor incursions by Indian forces. Statements indicating that Pakistani nuclear doctrine outlines using tactical nuclear weapons within the country's borders, despite the potential civilian casualties, serves to reinforce the image that the Pakistani government is willing to do anything to deter Indian attacks.

Indian leaders, for their part, appear to consider these threats credible. As previously mentioned, this has led to their ordering that any retaliation against Pakistani provocations be limited to within their own borders to avoid escalation to the nuclear level. A notable exception to this, albeit beyond the scope of this dissertation, is the February 2019 airstrike launched by Narendra Modi’s government, which may suggest a greater willingness by Indian leaders to test the credibility of these threats. All of this is due to the influence of the military in Pakistani governance and society, as it has championed an aggressive foreign policy against India to the point of organizing infiltrations without the knowledge of civilian leaders. Furthermore, Pakistani generals have done everything possible to ensure there are almost no checks on their ability to use nuclear weapons, 
including provisions to seize full launch authority and pre-delegating tactical nuclear weapons to battlefield commanders.

Finally, the credibility of North Korea's nuclear deterrent appears to have benefitted from the perceived cost-insensitivity of its leadership making it appear willing to use its nuclear arsenal in response to any attack, though it may also have created a security dilemma with the US that has almost provoked pre-emptive strikes. The state's authoritarian style of rule, which has been present since it gained independence in 1947 and has been enshrined in state ideology to the point of forming a cult of personality around the Kim family, is based on the support of military and party leaders to the exclusion of all other citizens. A consequence of the North Korean system and the weakness of its conventional forces relative to the US and South Korea is that Kim Jong Un, his predecessors, and his supporters have all equated any kind of attack as an existential threat to the state and, by extension, a death sentence for them.

These factors, when taken together, have led to successive American and South Korean governments taking North Korean threats to retaliate against any attack seriously throughout pre- and post-nuclear acquisition crises. The sheer cost in human lives and economic damage, particularly to South Korea, has repeatedly been cited to justify using shows of force or diplomacy in response to North Korean provocations rather than retaliatory attacks. Since North Korea's first nuclear test explosion in 2006, the US and South Korea have been reluctant to use even the former for fear of it being misinterpreted as an attack and triggering a nuclear war. This may be a double-edged sword, as North Korea's aggression and newfound ability to directly attack the US with nuclear weapons has potentially created a security dilemma between the two. Concern over credible North 
Korean nuclear threats may, in fact, have encouraged discussion of pre-emptive strikes in the Trump administration throughout 2017 and early 2018.

\section{7: Overview of Dissertation}

The remainder of the dissertation is structured as follows. Chapter 2 is a review of the scholarly literature on nuclear deterrence. This includes not only definitions of the practice, but also how it has been challenged since the end of the Cold War, particularly by the emergence of the concept of smaller regional nuclear powers, and the necessity for threat credibility and other conditions for deterrence to succeed. The review also includes discussions of related concepts such as possible costs of using nuclear weapons and the taboo against their use, both of which are notable in this area of the literature for referencing regime type. As shown in the chapter, this stands in marked contrast with the literature on conventional armed conflict, where study of the influence of regime type on various aspects of conflict behaviour is plentiful. The lack of similar discussion for nuclear deterrence, despite several conceptual commonalities, is indicative of a research gap.

Chapter 3 develops a theory based on these existing areas of study to explain how differences in state regime type can lead to variation in nuclear weapon states being attacked, along with corresponding hypotheses. This chapter includes explanations for why democratic governments would be more reluctant to fulfill nuclear deterrence threats outside of high-intensity conflict situations than non-democratic ones, and how this negatively impacts the credibility of those threats. It also includes a discussion regarding how a state's deterrent would benefit from a reputation for aggression due to the information it conveys regarding cost-sensitivity, along with the ineffectiveness of nuclear deterrence towards non-state actors. Finally, the chapter also includes a detailed 
comparison of the theory to Fearon's audience costs theory and the stability-instability paradox, including how it differs from the two and where it expands on them.

Chapter 4 subsequently advances a methodology for testing the theory. This consists of an embedded comparative case study using qualitative data, with quantitative data used in a supporting capacity for filling information gaps. This method involves conducting case studies for each of the 4 selected nuclear weapon states following the approach discussed in the next paragraph, followed by a final comparison of the findings for each case study ${ }^{66}$ Qualitative data is obtained from consulting secondary and primary qualitative sources (e.g. government memoranda, diplomatic cables, reports). Quantitative data, meanwhile, is obtained from various datasets. The designated unit of analysis for the study are nuclear weapon states, with the crises targeting the selected defending states before and after their acquisition of nuclear weapons serving as the observations.

Chapters 5 through 8 each consist of a case study from the 1945-2018 period, focusing on Israel, India, Pakistan, and North Korea, respectively. Each of these case study chapters includes an overview of the regime type of the state in question and any relevant shifts over time, particularly regarding accountability mechanisms and civil-military relations. Major crises targeting them prior to their acquisition of nuclear weapons are subsequently analyzed, focusing particularly on the rationales of decision-makers on both sides of the crisis and how their perceptions influenced their decisions. Each case study chapter also provides an overview of the defending state's nuclear weapons program, including the underlying motivations for pursuing nuclear weapons, its command and

\footnotetext{
${ }^{66}$ John W. Cresswell and Vicki L. Plano Clark, Designing and Conducting Mixed Methods Research: Second Edition (Los Angeles: SAGE Publications, 2011), 71.
} 
control structure, and the nature of its nuclear deterrence threats. Major crises targeting the case study states after their acquisition of nuclear weapons are then studied, including a comparison to how challengers acted in pre-nuclear crises, what role the defender's nuclear deterrent played, and how challengers perceived the resolve of the defender to actually fulfill its threats. Alternative explanations for these behaviours are studied, with each chapter concluding with hypothesis testing and a brief discussion of the findings.

Finally, chapter 9 contains concluding remarks regarding the research. This primarily consists of the aforementioned comparison of the case study findings from chapters 5-8 to determine what role regime type has played in nuclear deterrence credibility, if any. This involves comparing the results for the two democracies (Israel and India) to each other to determine similarities and differences between them, and then doing the same for the non-democracies (Pakistan and North Korea). These are then compared to the hypotheses advanced in chapter 3 regarding regime type's role (as well as the potential impact of an aggressive reputation on deterrence credibility) to determine whether they should be rejected or hold up. Potential caveats that could have influenced the findings are also discussed here. Finally, the chapter also includes a brief discussion of the implications for nuclear deterrence policies. 


\section{Chapter 2: Regime Type in Nuclear Deterrence and Conventional Conflict: A Literature Review}

Chapter 1 demonstrated that there appears to be variation in armed attacks targeting nuclear weapon states, with democracies seemingly being attacked more than nondemocracies. A review of the nuclear deterrence literature shows that this correlation has not been significantly studied, with more attention paid to other variables like the distance between states, the degree of economic interdependence between them, and their nuclear deterrence strategy. ${ }^{1}$ This gap is so notable that in a 2016 literature review, Erik Gartzke and Matthew Kroenig noted a distinct lack of research on the subject despite the possibility that regime type could influence conflict propensity towards nuclear weapon states. ${ }^{2}$ In this chapter, I find that while the study of nuclear deterrence has changed significantly since the Cold War, including drastic changes to models of nuclear weapon state behaviour, only a few scholars have tied regime type to nuclear deterrence. The few theories that have emerged - the variation in domestic audience costs between democracies and nondemocracies and its impact on threat credibility, the role of public opinion in creating a taboo against the use of nuclear weapons - suffer from their own shortcomings, however. Potential solutions to this can be found in the conventional conflict literature, where the role of regime type in conflict initiation and state behaviour is heavily studied.

The literature review proceeds as follows. The chapter begins with definitions of nuclear deterrence and how it has evolved in the literature, particularly with post-Cold War

\footnotetext{
${ }^{1}$ Robert Rauchhaus, "Evaluating the Nuclear Peace Hypothesis: A Quantitative Approach," Journal of Conflict Resolution 53, no. 2 (2009): 267-268; Vipin Narang, Nuclear Strategy in the Modern Era:

Regional Powers and International Conflict (Princeton: Princeton University Press, 2014), 4.

${ }^{2}$ Erik Gartzke and Matthew Kroenig, "Nukes with Numbers: Empirical Research on the Consequences of Nuclear Weapons for International Conflict," Annual Review of Political Science 19 (2016): 408.
} 
critiques, and highlights how it differs from compellence to establish the foundational concepts for this study. This first section highlights how the original nuclear deterrence model of two nuclear superpowers fails to capture the reality of smaller regional nuclear powers, as well as how the primary issue of nuclear compellence - the stakes being too low to make the use of nuclear weapons plausible - is also present in nuclear deterrence. The second section discusses necessary conditions for nuclear deterrence to succeed, particularly threat credibility, along with related concepts, such as the potential costs of using nuclear weapons and how they could influence the resolve to use them and the taboo against nuclear weapon use. Both domestic audience costs and the nuclear taboo are notable for being among the few subjects in the nuclear deterrence literature to argue that regime type can influence deterrence. However, each suffers from notable shortcomings, with audience costs oversimplifying non-democratic governments as more or less unaccountable and the nuclear taboo being derived primarily from US cases, making it unclear how applicable it is or is not to non-democratic states or smaller nuclear powers.

To highlight the shortcomings of the nuclear deterrence literature regarding regime type, the third section discusses how the conventional conflict literature engages with state regime type as a variable. This focuses on theories of conflict initiation, such as democratic peace theory and its underlying causal logic, as well as theories regarding how regime type influences the cost sensitivity of governments. Both, particularly the idea of cost sensitivity, are notable due to how they could potentially be extended to nuclear deterrence, given the concepts shared in both bodies of literature. Finally, the conclusion of this chapter highlights how, despite conceptual common ground between the literature on nuclear deterrence and conventional conflict, the former does not engage with regime type in the 
same way, leaving a research gap. At the same time, it also highlights how this research gap could be remedied by building upon the conventional conflict work cited to develop a theory of regime type and nuclear deterrence credibility.

\section{1: Defining Deterrence}

Deterrence, while often thought as exclusively tied to nuclear weapons, is a broad concept. At its core, deterrence occurs when a "defender" attempts to dissuade a "challenger" from carrying out a specified action. ${ }^{3}$ In most discussions of deterrence, this has the defender seeking to persuade the challenger to not attack a specific target, whether it is the defender itself (general or immediate deterrence) or allies that the defender has committed to protecting (extended deterrence). ${ }^{4}$ Defenders typically do this by explicitly or implicitly threatening to punish the challenger that it would be left worse off than if it had not attacked in the first place. ${ }^{5}$ Deterrence is thus a form of coercive diplomacy in that it is meant to protect the status quo from states seeking to revise it via the use of threats and punishments. ${ }^{6}$ Successful deterrence is also an expression of rational choice theory, since it is presumed that challengers have weighed the costs of attacking against the benefits and found the former were greater. ${ }^{7}$ Even deterrence failure, which is sometimes attributed to irrational decisions by leaders, can be the result of challengers making rational

\footnotetext{
3 John Stone, "Conventional Deterrence and the Challenge of Credibility," Contemporary Security Policy 33, no. 1 (2012): 109.

${ }^{4}$ Paul K. Huth, "Reputations and Deterrence: A Theoretical and Empirical Assessment," Security Studies 7, no. 1 (1997): 74.

${ }^{5}$ Ibid.

${ }^{6}$ Lawrence Freedman, Deterrence (Cambridge: Polity Press, 2004), 110.

${ }^{7}$ Thomas C. Schelling, The Strategy of Conflict (Cambridge: Harvard University, 1960); Christopher H. Achen and Duncan Snidal, "Rational Deterrence Theory and Comparative Case Studies," World Politics 41, no. 2 (1989): 143-169.
} 
assessments of these costs and benefits and concluding, whether accurately or through misperception, that the benefits of attacking are greater than the costs. ${ }^{8}$

While both focused on the defending state, general and immediate deterrence differ in several key respects. General deterrence has opposing sides maintain conventional or nuclear forces to deter each other, with a challenger avoiding going beyond contemplation of attacking due to the other side's threats. ${ }^{9}$ In practice, this means that general deterrence threats are directed towards any potential attacker and is all-encompassing. ${ }^{10}$ Immediate deterrence, in contrast, arises specifically in crisis situations where one side is seriously considering attacking the other, and thus focuses on specific targets. ${ }^{11}$ As a result, general deterrence can be maintained indefinitely due to not even requiring a specific enemy, whereas immediate deterrence occurs infrequently and for brief periods due to focusing on a specific challenger. ${ }^{12}$ Put simply, general deterrence is meant to prevent crises from occurring at all, while immediate deterrence aims to keep a crisis from escalating further into outright war between the states involved. ${ }^{13}$ This also means that immediate deterrence only becomes relevant when general deterrence threats have failed, making the two complementary to each other.

The distinction between general and immediate deterrence means that they also differ in how they are judged as having succeeded or failed. General deterrence is considered successful if a crisis never occurs specifically because of the defender's

\footnotetext{
${ }^{8}$ Achen and Snidal, "Rational Deterrence Theory and Comparative Case Studies," 148-149.

${ }^{9}$ Patrick Morgan, Deterrence Now (Cambridge: Cambridge University Press, 2003), 80; Vesna Danilovic, "Conceptual and Selection Bias Issues in Deterrence," Journal of Conflict Resolution 45, no. 1 (2001): 99.

${ }^{10}$ Morgan, Deterrence Now, 81.

${ }^{11}$ Morgan, Deterrence Now, 82; Freedman, Deterrence, 40.

${ }^{12}$ Morgan, Deterrence Now, 82.

${ }^{13}$ Stephen L. Quackenbush, "Deterrence Theory: Where Do We Stand?," Review of International Studies 37, no. 2 (2011): 752.
} 
deterrence threats and capabilities. ${ }^{14}$ This means that if a potential challenger opts against attacking despite possessing the capability due to another reason, or did not even contemplate doing so, the situation is simply the absence of conflict and not a case of successful general deterrence. ${ }^{15}$ Conversely, general deterrence is deemed to have failed if a challenger threatens to attack a defender or actually does so in spite of the latter's deterrence threats, meaning that it can be undermined by a challenger's probing of defences. ${ }^{16}$ In practice, determining the success or failure of general deterrence is difficult due to not just the potential reasoning for a challenger to not attack, but also because general deterrence threats may only restrict fighting instead of outright preventing it and do nothing to prevent challengers from planning attacks without carrying them out. ${ }^{17}$ As a result, the success and failure of general deterrence can be somewhat subjective.

The success or failure of immediate deterrence, by comparison, is somewhat more straightforward. Immediate deterrence in a crisis is considered successful if the defender's threats manage to convince the challenger to avoid escalating the situation further or even withdraw to the status quo or a similar state of affairs. ${ }^{18}$ As with general deterrence, the challenger performing these actions for reasons besides the deterrence threats or capabilities of the defender (e.g. domestic pressure) means that it is not a case of successful immediate deterrence. ${ }^{19}$ Immediate deterrence is deemed to have failed if the challenger

\footnotetext{
${ }^{14}$ Danilovic, "Conceptual Selection and Bias," 102.

${ }^{15}$ Alexander L. George and Richard Smoke, Deterrence in American Foreign Policy: Theory and Practice (New York: Columbia University Press, 1974), 516; Frank P. Harvey, The Future's Back: Nuclear Rivalry, Deterrence Theory, and Crisis Stability after the Cold War (Montreal: McGill-Queen's University Press, 1997), 25.

${ }^{16}$ Morgan, Deterrence Now, 83; Quackenbush, "Deterrence Theory," 754.

${ }^{17}$ Morgan, Deterrence Now, 84.

${ }^{18}$ George and Smoke, Deterrence in American Foreign Policy, 516.

${ }^{19}$ George and Smoke, Deterrence in American Foreign Policy, 516; Harvey, The Future's Back, 25.
} 
persists with its actions in spite of the defender's threats and capabilities, whether because it somehow failed to receive the threat, considered it non-credible, or decided that the costs were not high enough to back down. ${ }^{20}$ Immediate deterrence failure is much easier to detect than its general deterrence counterpart (or even immediate deterrence success) due to the subsequent behaviour of the states involved being directly observable. ${ }^{21}$

While originally associated with conventional warfare, deterrence has become closely tied to nuclear weapons. The concept can be traced back to Roman warfare, with the word being derived from the Latin terrere (to frighten). ${ }^{22}$ Soon after nuclear weapons were used in World War II, military strategist Bernard Brodie noted that their sheer destructive potential made physical defences useless due to their being meant to simply allow a target to absorb greater damage than it could otherwise. ${ }^{23}$ Brodie argued that this quality meant that the winner of a nuclear war would not necessarily be the one with the most nuclear weapons, but the one who destroyed their opponent's population centres first. ${ }^{24}$ States with nuclear weapons would therefore need to shift from winning wars to averting them by threatening to respond to nuclear attack with retaliation in kind, potentially inhibiting state aggression entirely in the process. ${ }^{25}$

\footnotetext{
${ }^{20}$ Paul Huth and Bruce Russett, "What Makes Deterrence Work? Cases from 1900 to 1980," World Politics 36, no. 4 (1984): 497.

${ }^{21}$ Richard Ned Lebow and Janice Gross Stein, "Rational Deterrence Theory: I Think, Therefore I Deter," World Politics 41, no. 2 (1989): 220-222.

${ }^{22}$ Freedman, Deterrence, 6-7; Andrew Brown and Lorna Arnold, "The Quirks of Nuclear Deterrence," International Relations 24, no. 3 (2010): 296.

${ }^{23}$ Bernard Brodie, "War in the Atomic Age," in The Absolute Weapon: Atomic Power and World Order, edited by Bernard Brodie (New York: Harcourt, Brace and Company, 1946), 28-29.

${ }^{24}$ Brodie, "War in the Atomic Age," 46-47.

${ }^{25}$ Bernard Brodie, "Implications for Military Policy," in The Absolute Weapon: Atomic Power and World Order, edited by Bernard Brodie (New York: Harcourt, Brace and Company, 1946), 71-75.
} 
Brodie later expanded his views of nuclear deterrence in Strategy in the Missile Age, with two points being particularly noteworthy. First, Brodie criticized the Eisenhower administration's massive retaliation policy, which promised nuclear weapon use even in limited conflicts or where no vital American interests were at stake, as being so disproportionate as to be non-credible to opponents. ${ }^{26}$ This point indicates, as others have since noted, that threats need to be credible to challengers, with disproportionate threats only leading challengers to consider them bluffs and attack anyways. Secondly, Brodie also remarked that US officials would need to consider both domestic and allied opposition to nuclear weapon use in their deterrence policies. ${ }^{27}$ This last point arguably serves as a basis for the nuclear taboo, which draws directly on this conception of popular opposition hindering the use of nuclear weapons. More broadly, it suggests potential avenues for study regarding how differences in government accountability could influence their ability to fulfill deterrence threats. While some of the nuclear deterrence literature has touched on this last concept and related issues, most prominently in the study of audience costs and how it differs in affecting threat credibility across regime types, there has been little effort to establish a typology on this basis.

The ideas raised by Brodie appear to have served as the basis of nuclear deterrence theory throughout the Cold War and US deterrence policy, with other scholars refining them by highlighting practical limitations. Donald Brennan, for example, wrote about the limitations of nuclear weapons in deterring non-nuclear attack, noting that it could lead to a conflict escalating and being less suitable to protecting an object of provocation than

\footnotetext{
${ }^{26}$ Bernard Brodie, Strategy in the Missile Age (Santa Monica: RAND Corporation, 1959), 248-273.

${ }^{27}$ Brodie, Strategy in the Missile Age, 324-325.
} 
conventional forces. ${ }^{28}$ Morton Halperin likewise argued that nuclear weapons would be of limited utility in certain contexts, especially limited conflicts, due to their potentially encouraging escalation to total war and generating uncertainty about the outcome. ${ }^{29}$ Thomas Schelling notably articulated several limitations of nuclear deterrence in his work. One example is the argument that successful deterrence requires a signal of the threat's sincerity to challengers, such as stationing American troops in Berlin to indicate the US commitment to defend it, with these signals requiring the defender to pay a cost, such as US troops dying in a Soviet invasion of Berlin, in order to lend further credibility. ${ }^{30}$ Schelling also notably proposed that brinksmanship, the practice of manipulating the risk of escalation in crises to make the outcome uncertain, is necessary to the success of nuclear deterrence to avoid challengers finding ways to make gains without causing escalation. ${ }^{31}$

On the surface, nuclear deterrence and its conventional counterpart appear to be largely similar to each other, with the main difference being that the former revolves around nuclear weapons and the latter being couched in more conventional armaments. After all, both are noted as requiring an intense inter-state conflict or rivalry, rational state actors, and the ability to prevent war with retaliatory threats that convince challengers to back down after calculating that the costs of attacking would outweigh the benefits. ${ }^{32}$ However, the literature indicates that there are more significant theoretical differences between the two, which stem from the simple fact that nuclear weapons are capable of causing greater damage than conventional weapons, as well as doing so very rapidly. This means that while

\footnotetext{
${ }^{28}$ Donald G. Brennan, "Setting and Goals of Arms Control," Daedalus 89, no. 4 (1960): 688-689.

${ }^{29}$ Morton H. Halperin, "Nuclear weapons and limited war," Journal of Conflict Resolution 5, no. 2 (1961): 151-156.

${ }^{30}$ Thomas C. Schelling, Arms and Influence (New Haven and London: Yale University Press, 1966), 44-52.

${ }^{31}$ Schelling, Arms and Influence, 99-110.

${ }^{32}$ Paul, "Self-deterrence," 24.
} 
what Brodie referred to as "passive defences" can potentially withstand significant conventional force, there is no real defence against nuclear attack. ${ }^{33}$ Generally speaking, these differences can be attributed to the certainty or uncertainty of deterrence outcomes and variation in deterrence credibility between the two.

One agreed-upon difference between conventional and nuclear deterrence theory is that the outcome of fulfilling conventional deterrence threats is much more uncertain than nuclear threats. This is due to how, even if one state in a conflict has numerically superior forces, it may not necessarily win. ${ }^{34}$ Its opponent could, for example, possess betterequipped or better-trained forces that could nullify the numerical advantage, or may use better strategies that allow it to out-maneuver it on the battlefield. ${ }^{35}$ It may even be that an otherwise conventionally superior state is seen as defeatable by an opponent because the former is seen as lacking the political will to suffer enough losses to achieve victory. ${ }^{36}$

The use of nuclear weapons, in contrast, has a much more certain outcome. Even a single one successfully striking a target will cause considerable damage that is almost impossible to defend against, which makes a positive outcome for the challenger highly unlikely. ${ }^{37}$ This also means that unlike conventional deterrence, possessing superior forces is unnecessary for nuclear deterrence, which only requires demonstrating a willingness to hurt the opponent. ${ }^{38}$ In fact, as Schelling noted early on, victory in warfare is not even

\footnotetext{
${ }^{33}$ Brodie, Strategy in the Missile Age, 180-181.

${ }^{34}$ James J. Wirtz, "How Does Nuclear Deterrence Differ from Conventional Deterrence?," Strategic Studies Quarterly 12, no. 4 (Winter 2018): 60-61.

${ }^{35}$ Wirtz, "How Does Nuclear Deterrence Differ from Conventional Deterrence?," 60-61.

${ }^{36}$ This view, for example, led Saddam Hussein to invade Kuwait in 1990 in the belief that the US was unwilling to suffer losses to drive Iraqi forces out. Wirtz, "How Does Nuclear Deterrence Differ from Conventional Deterrence?," 60-61.

${ }^{37}$ Schelling, Arms and Influence, 22; Wirtz, "How Does Nuclear Deterrence Differ from Conventional Deterrence?," 62-63.

${ }^{38}$ Brodie, Strategy in the Missile Age, 274-275.
} 
necessary for nuclear deterrence threats to be fulfilled and massive harm to be inflicted on the enemy's territory, since they can be directly launched at enemy forces and cities. ${ }^{39}$ In short, it is much more difficult for a potential challenger to believe it can achieve its goals with minimal losses when faced with nuclear deterrence than with conventional threats.

Secondly, conventional and nuclear deterrence threats differ in that the latter may lack credibility in given situations. The concept of deterrence credibility (discussed in greater detail in section 2.2.1) means that for deterrence to work, challengers need to believe that the defender will fulfill its threats. ${ }^{40}$ While nuclear deterrence is generally considered credible against existential threats to a state, it has been noted as being so disproportionate to lesser threats (i.e. small incursions) as far back as Brodie that it would be considered unbelievable to challengers. ${ }^{41}$ Conventional deterrence, conversely, is seen as being more credible for those types of threats due to being more flexible, since a limited conventional conflict is much more viable than a limited nuclear war. ${ }^{42}$ It also has the advantage of being successfully demonstrated, whereas nuclear deterrence threats have yet to be fulfilled, though nuclear threats can be more successful when a challenger believes it can withstand significant conventional punishment. ${ }^{43}$ Furthermore, nuclear weapon use is seen as having high costs attached (discussed in section 2.2.2), which may not be justifiable for a state to pay in situations with relatively low stakes. ${ }^{44}$ Put simply, conventional weapons have the advantage of being considered more usable in low-level conflict than

\footnotetext{
${ }^{39}$ Schelling, Arms and Influence, 22.

${ }^{40}$ Brodie, Strategy in the Missile Age, 273.

${ }^{41}$ Brodie, Strategy in the Missile Age, 273.

${ }^{42}$ Brodie, Strategy in the Missile Age, 273.

${ }^{43}$ Elinor Sloan, Modern Military Strategy: An Introduction (New York: Routledge, 2017), 62.

44 Todd S. Sechser and Matthew Fuhrmann, Nuclear Weapons and Coercive Diplomacy (New York: Cambridge University Press, 2017), 46-51.
} 
nuclear weapons, making deterrence threats that use the former more plausible than the latter. ${ }^{45}$ Rather than being mutually exclusive, however, the two can be seen as complementary due to their suitability in deterring different types of threats.

The Cold War conception of nuclear deterrence theory has since been challenged due to subsequent shifts in international politics and technology. It is often critiqued as only applying to the US and Russia, with new models focusing on how smaller nuclear powers will behave differently due to more limited capabilities. Hedley Bull noted that the focus on two superpowers fails to explain nuclear deterrence dynamics between three or more nuclear weapon states or when there is a significant capability gap. ${ }^{46}$ Vipin Narang and others have critiqued assumptions that all nuclear weapon states will act like the US and Russia, highlighting how states like India, Pakistan, and North Korea instead possess vastly smaller arsenals of several hundred warheads at most. ${ }^{47}$ The constraint of smaller nuclear arsenals forces these regional nuclear powers to use deterrence strategies focusing on limited use for territorial defence, rather than mutual annihilation. ${ }^{48}$ These states are considered more representative of post-Cold War nuclear deterrence, leading authors like Keith Payne to argue that traditional mutually assured destruction needs to be replaced by more flexible deterrence. ${ }^{49}$ These arguments directly refute those advanced by authors like Kenneth Waltz that the old model of nuclear deterrence is applicable regardless of the

\footnotetext{
${ }^{45}$ Sloan, Modern Military Strategy, 61-62.

${ }^{46}$ Hedley Bull, "Future Conditions of Strategic Deterrence," in "The Future of Strategic Deterrence: Part I Papers from the IISS Annual Conference," Special Issue, The Adelphi Papers 20, no. 160 (1980): 15.

${ }^{47}$ Vipin Narang, Nuclear Strategy in the Modern Era: Regional Powers and International Conflict (Princeton: Princeton University Press, 2014), 1-7.

${ }^{48}$ Ibid.

${ }^{49}$ Keith B. Payne, Deterrence in the Second Nuclear Age (Lexington: University Press of Kentucky, 1996), 17; Narang, Nuclear Strategy in the Modern Era, 5-7.
} 
historical context and the capabilities of the defending nuclear state in question. ${ }^{50}$ Any study of nuclear deterrence, including this dissertation, thus needs to consider how these regional nuclear powers differ in behaviour than the aforementioned superpowers.

The debates on the applicability of Cold War nuclear deterrence theory have also revolved around the role of technological changes since that time. Increasing cyberwarfare capabilities are a particular concern in this regard, with Stephen Cimbala noting that automated systems for controlling nuclear weapons could be vulnerable to false indicators or even being shut down. ${ }^{51}$ This could result, he argues, in a rush to use nuclear weapons in response to what is believed to be an enemy attack, and thus cause an unintentional nuclear war. ${ }^{52}$ Others, such as Keir Lieber and Daryl Press, point to advancing capabilities in products of the computer revolution and their increasing ability to locate nuclear forces as capable of undermining nuclear deterrence. ${ }^{53}$ These advancements make nuclear forces more vulnerable by letting other states locate and attack previously hidden nuclear weapon sites, which could prevent retaliatory second strikes and potentially render nuclear deterrence threats toothless in the process. ${ }^{54}$ These two examples, particularly the increasing emphasis on smaller nuclear powers, illustrates how the study of nuclear deterrence has changed considerably from mutual deterrence between superpowers, making it necessary for scholars to account for its increasing complexity.

\footnotetext{
${ }^{50}$ Kenneth N. Waltz, "More May be Better," in The Spread of Nuclear Weapons: An Enduring Debate, Third Edition, eds. Scott D. Sagan and Kenneth N. Waltz (New York: W.W. Norton \& Company, 2013), 12-16.

${ }^{51}$ Stephen J. Cimbala, Nuclear Weapons and Strategy: U.S. Nuclear Policy for the Twenty-First Century (Abingdon: Routledge, 2005), 17-19.

${ }_{53}^{52}$ Cimbala, Nuclear Weapons and Strategy, 19-20.

${ }^{53}$ Keir A. Lieber and Daryl G. Press, "The New Era of Counterforce: Technological Change and the Future of Nuclear Deterrence," International Security 41, no. 4 (2017): 9-10.

${ }^{54}$ Lieber and Press, "The New Era of Counterforce," 10.
} 
This dissertation primarily focuses on deterrence by punishment, though another variant instead focuses on preventing challengers from attacking at all. Deterrence by denial has defenders take the initiative by taking actions that make challengers less likely to succeed or prevent them from acting at all. ${ }^{55}$ The most straightforward example of this would be pre-emptively deploying forces to keep a challenger from fulfilling its goals and discourage it from attacking in the first place ${ }^{56}$ Cyberwarfare raises the possibility of a defender engaging in deterrence by denial by building up cyber defences to force challengers to invest more time and resources into attacks so that they either derive little benefit or do not attack at all. ${ }^{57}$ In the nuclear realm, deterrence by denial and by punishment can overlap, such as how early theorists argued that tactical nuclear weapons could simultaneously block a Soviet advance and discourage it in the first place with the ensuing damage.$^{58}$ Lieber and Press, meanwhile, note the rise in counterforce capabilities, as well as the increasing incentive to develop more sophisticated defence or even strike first in order to avoid losing a war. ${ }^{59}$ While nuclear deterrence in practice remains largely focused on punishment, the increasing use of electronic warfare and its possible use against nuclear arsenals could make denial more prominent.

\subsection{2: Differentiating Deterrence and Compellence}

Discussions of deterrence in the literature are often accompanied by compellence, which is also a form of coercive diplomacy, albeit with enough differences to make them

\footnotetext{
${ }^{55}$ Michael J. Mazarr, “Understanding Deterrence,” in Perspectives (RAND Corporation, 2018), 2 , https://www.rand.org/content/dam/rand/pubs/perspectives/PE200/PE295/RAND_PE295.pdf.

${ }^{56}$ Mazarr, "Understanding Deterrence," 2.

57 Joseph S. Nye, "Deterrence and Dissuasion in Cyberspace," International Security 41, no. 3 (2017): 56.

${ }^{58}$ Lawrence Freedman and Jeffrey Michaels, The Evolution of Nuclear Strategy: New, Updated and Completely Revised, Fourth edition (London: Palgrave Macmillan UK, 2019), 138.

${ }^{59}$ Lieber and Press, "The New Era of Counterforce," 12.
} 
distinct. While deterrence has the defender threaten potential challengers into not attacking, compellence instead has the sender coerce a target into performing certain actions with the threat of continuous punishment. ${ }^{60}$ Both are thus premised on a state influencing the actions of another with the threat of punishing non-compliance and leaving it worse off than if it acquiesced. ${ }^{61}$ Cases like the Cuban Missile Crisis have the two overlap, where one state's deterrence threats are seen as compellence by others due to differing perceptions of the status quo. ${ }^{62}$ Some authors have even argued that compellence and deterrence exist on a single continuum of sorts as a result, with instances of the two being distinguished on the basis of whether threats are made before or after the challenger/target is punished, the sender's demands, and their scope and intent. ${ }^{63}$ Stephen Cimbala, for example, has argued that compellence is a more active form of deterrence, at least when it is used after another state has carried out an undesirable action, rather than before. ${ }^{64}$

Despite the similarities, there are several key differences between deterrence and compellence. Schelling noted early on that deterrence requires the sender to cede the initiative by waiting for challengers to set off a tripwire to initiate retaliation, whereas compellence has the sender act first by threatening or punishing the target to force it to perform an action. ${ }^{65} \mathrm{He}$ also noted that deterrence can be maintained for potentially indefinite periods of time, while the punishment needed for compellence to work can only

\footnotetext{
${ }^{60}$ Payne, Deterrence in the Second Nuclear Age, 33-35.

${ }^{61}$ Gary Schaub Jr., "Deterrence, Compellence, and Prospect Theory," Political Psychology 25, no. 3 (2004): 389.

${ }^{62}$ Maria Sperandei, "Bridging Deterrence and Compellence: An Alternative Approach to the Study of Coercive Diplomacy," International Studies Review 8, no. 2 (2006): 259-261.

${ }^{63}$ Robert J. Art and Patrick M. Cronin, The United States and Coercive Diplomacy (Washington: United States Institute of Peace Press, 2003); Freedman, Deterrence, 111; Sechser and Fuhrmann, Nuclear

Weapons and Coercive Diplomacy, 24-27.

${ }^{64}$ Cimbala, Nuclear Weapons and Strategy, 10-11.

${ }^{65}$ Schelling, Arms and Influence, 69-71.
} 
be sustained for a limited period before the target refuses to comply. ${ }^{66}$ Authors like Lawrence Freedman and Todd Sechser have also noted that compellence is meant to alter the status quo between the states involved, as it has the sender force the target of the threat to perform actions to end or avert punishment. ${ }^{67}$ Deterrence, in contrast, is much more passive, as it is based on the sender of the threat convincing other states to not act, thus focusing on preserving the status quo. ${ }^{68}$ Deterrence is thus considered successful if potential challengers do not attack, making it difficult to distinguish from a non-event, whereas compellence requires the target to act in the desired manner. ${ }^{69}$

The similarities between deterrence and compellence have inevitably led to debates on the use of nuclear weapons for compellence, with a nuclear weapon state threatening a target into making concessions with its arsenal without needing to use force. As noted by Richard Betts, nuclear compellence could be more beneficial than conventional force due to the latter requiring force deployment to signal credibility and having costs associated with it. ${ }^{70}$ Authors like Kyle Beardsley and Victor Asal have further argued that nuclear weapon states do better in coercing non-nuclear weapon states due to nuclear weapons being able to impose heavy costs. ${ }^{71}$ This requires, however, that the issue in question is salient enough to the sender that the target believes nuclear weapons could be used, limiting its utility. ${ }^{72}$ Matthew Kroenig has likewise argued, utilizing a data set of nuclear crisis

\footnotetext{
${ }^{66}$ Schelling, Arms and Influence, 72.

${ }^{67}$ Freedman, Deterrence, 110; Todd Sechser, "Militarized Compellent Threats, 1918-2001," Conflict Management and Peace Science 28, no. 4 (2011): 380.

${ }^{68}$ Freedman, Deterrence, 110.

${ }^{69}$ Achen and Snidal, "Rational Deterrence Theory and Comparative Case Studies," 151-153.

${ }^{70}$ Richard K. Betts, Nuclear Blackmail and Nuclear Balance (Washington: The Brookings Institute, 1987), 8-9.

${ }^{71}$ Kyle Beardsley and Victor Asal, "Winning with the Bomb," Journal of Conflict Resolution 53, no. 2 (2009): 282.

72 Beardsley and Asal, "Winning with the Bomb," 283.
} 
dyads, that a nuclear weapon state will be emboldened by having a larger nuclear arsenal than its opponent, and thus be willing to take greater risks in such crises. ${ }^{73}$ The role of issue salience is of particular interest, since it ties in to the role of credibility in deterrence and the concept of audience costs (discussed in greater detail in section 2.2.1) - namely, that nuclear threats will lack credibility unless the government making them has some way of signalling the importance of the issue at stake.

This last point has led arguments that nuclear weapons are impractical for compellence. Sechser and Fuhrmann argue this extensively in Nuclear Weapons and Coercive Diplomacy by applying a mixed-methods approach to studying instances of explicit or implicit nuclear coercion, with archival research being used to determine causation in the few seemingly successful cases. ${ }^{74}$ Their conclusion is the vast majority of these situations have lacked sufficient issue salience for the targets to view the use of nuclear weapons as credible, leading to their refusing to comply with the sender's demands. ${ }^{75}$ In their view, this is due to the use of nuclear weapons for aggression rather than deterrence carrying the risk of heavy economic and political costs for the nuclear weapon state, such as international isolation and domestic backlash. ${ }^{76}$ Nuclear compellence would thus be rendered largely toothless, as the target would not believe that the sender would knowingly make itself worse off by fulfilling the threat for relatively little gain. ${ }^{77}$

\footnotetext{
${ }^{73}$ Matthew Kroenig, "Nuclear Superiority and the Balance of Resolve: Explaining Nuclear Crisis Outcomes," International Organization 67, no. 1 (2013): 141-171.

${ }^{74}$ Sechser and Fuhrmann, Nuclear Weapons and Coercive Diplomacy, 64-71.

${ }^{75}$ Sechser and Fuhrmann, Nuclear Weapons and Coercive Diplomacy, 12-16.

${ }^{76}$ Sechser and Fuhrmann, Nuclear Weapons and Coercive Diplomacy, 12, 48-50.

${ }^{77}$ Sechser and Fuhrmann, Nuclear Weapons and Coercive Diplomacy, 14.
} 
This in turn raises an interesting point, given the debate over whether deterrence and compellence are two sides of the same coin: if nuclear compellence is ineffective due to nuclear weapons being too costly to use in those circumstances, could the same be said for deterrence? This exact point has been raised by Nina Tannenwald regarding Sechser and Fuhrmann's work, noting that "the high costs and illegitimacy of a nuclear first strike undermine not only attempts at nuclear compellence but even deterrence against nonnuclear states." ${ }^{78}$ This suggests that, at least under certain circumstances, a nuclear deterrent's credibility could be undermined by challengers believing their attacks would not threaten the defender enough for nuclear weapons to justifiably be used. While this is implausible for major interstate wars, which a defender could consider an existential threat, it is a distinct possibility in low-intensity conflict. In those situations, the challenger's strategy and means would be deliberately limited to achieve small gains without significant escalation, also known as salami-slicing. ${ }^{79}$ The following section shows that the credibility of a nuclear deterrent and what influences it plays a significant role in its success or failure.

\section{2: The Necessary Conditions for Nuclear Deterrence}

The nuclear deterrence literature contains multiple debates on what conditions must be met for a state's nuclear forces to successfully deter challengers from attacking. As discussed in this section, many scholars argue that the content of the threat itself is key to ensuring successful deterrence, as the defender needs to make it clear to challengers that the former would benefit from actually fulfilling the threat to make it plausible. In contrast, a subset of authors, most notably Kenneth Waltz, have argued that the mere possession of

\footnotetext{
${ }^{78}$ Robert Trager et al., "Roundtable 11-15 on Nuclear Weapons and Coercive Diplomacy," H-Diplo | ISSF, April 6, 2020, https://issforum.org/roundtables/11-15-coercive.

${ }^{79}$ Schelling, Arms and Influence, 66-68.
} 
nuclear weapons by a defender will be sufficient to deter most challengers, with the specific threat changing little. Others have debated whether successful deterrence requires a response proportional to the challenger's initial attack or if the defender should threaten to inflict massive damage regardless of the actual harm inflicted by the challenger. Ultimately, these debates establish that credibility is key to successful deterrence.

One of the most discussed elements for nuclear deterrence to succeed, at least in theory, is for the threat to be rational for the defender to carry out. This was noted early on by Schelling, who wrote that a rational mindset emphasizing value-maximizing behaviour is key to strategy because it provides common ground between the defender and challenger in communicating the sincerity of the threat. ${ }^{80}$ Kilgour and Zagare have argued that for a deterrence threat to be considered rational, its fulfillment needs to at least be perceived as the optimal course for the defender under those circumstances by offering greater benefits and fewer costs than other available options. ${ }^{81}$ A rational threat is presumed to be more credible, and thus successful, since challengers will be more likely to believe that the defender will carry it out. A seemingly irrational threat would conversely encourage challengers to treat it as a bluff and attack, regardless of its actual sincerity. ${ }^{82}$ The assumption, therefore, is that decision-makers will be perfectly rational actors, and will know to take rational threats by others seriously.

This theoretical assumption of perfectly rational decision-makers falls short in explaining actual nuclear deterrence policies, with other scholars arguing that bounded

\footnotetext{
${ }^{80}$ Schelling, The Strategy of Conflict, 13-15.

${ }^{81}$ D. Marc Kilgour and Frank Zagare, "Credibility, Uncertainty, and Deterrence," American Journal of Political Science 35, no. 2 (1991): 307-308.

${ }^{82}$ Frank Sauer, Atomic Anxiety: Deterrence, Taboo, and the Non-Use of U.S. Nuclear Weapons (Houndmills: Palgrave Macmillan, 2015), 9-10, 21-22.
} 
rationality is more accurate or that rationality is insufficient for predicting strategic behaviour. Bounded rationality, originally proposed by Herbert Simon, differs by arguing that decision-makers act according to available (and possibly incomplete) information and interpret it through their own cultural and psychological lenses. ${ }^{83} \mathrm{~A}$ defender's threats may seem rational to them, but can appear irrational to challengers to the point of being considered a bluff and causing deterrence failure. Scholars such as Lebow and Stein instead argue that rational deterrence theory presents an inaccurate impression of actual policy, with leaders often calculating utility in very different ways from each other. ${ }^{84} \mathrm{~A}$ prominent example of this is the Cuban Missile Crisis, with the Kennedy administration's threats, meant to force the Soviet leadership to back down, instead encouraging Khrushchev to believe that action was necessary to improve the Soviet Union's strategic position. ${ }^{85}$ Contrary to traditional rational deterrence theory, this would instead indicate that decisionmakers interpret nuclear deterrence threat credibility differently according to their perceptions, including how they think their opponents will behave, and act accordingly.

Others have argued that the response detailed in the deterrence threat influences its chances of successfully convincing potential challengers to not attack. Originally, the preferred US approach was to promise massive retaliation against any attack to discourage any attacks against itself or its allies. ${ }^{86}$ Since then, authors like Brodie have argued that deterrence threats need to be flexible and proportional to the given situation due to universal threats of overwhelming force being unbelievable due to being grossly

\footnotetext{
${ }^{83}$ Payne, Deterrence in the Second Nuclear Age, 46-47; Herbert A. Simon, Models of Bounded Rationality (Cambridge: MIT Press, 1982), 291-294; Jeffrey D. Berejikian, “A Cognitive Theory of Deterrence," Journal of Peace Research 39, no. 2 (2002): 167.

${ }^{84}$ Lebow and Stein, "Rational Deterrence Theory," 208-24.

${ }^{85}$ Lebow and Stein, "Rational Deterrence Theory," 215.

${ }^{86}$ Brown and Arnold, "The Quirks of Nuclear Deterrence," 298.
} 
disproportionate to lower-level attacks. ${ }^{87}$ Robert Powell in particular has argued that promising a limited response, rather than all-out retaliation, can make deterrence more effective by leaving challengers with something to lose and discouraging further escalation. ${ }^{88}$ Schelling similarly argued that threatening limited war better serves deterrence due to giving the defender more flexibility, albeit while also introducing a degree of chance via brinksmanship so that subsequent escalation could appear uncontrollable and discourage attacks entirely. ${ }^{89}$ The general consensus is that nuclear deterrence will only work for defending issues or objects of such importance that threatening nuclear war is actually proportionate. Otherwise, a challenger can quickly assume, correctly or otherwise, that the defender is bluffing about using nuclear weapons, particularly if the challenger already perceives it as unwilling to fight.

A commonly advanced proposition, particularly among realists, is that merely possessing nuclear weapons is sufficient for successful deterrence. Kenneth Waltz notably argued that possessing nuclear weapons deters challengers due to their ability to cause more damage than conventional weapons and with greater certainty, even in the case of states with small nuclear arsenals, so long as they have a credible second-strike capability. ${ }^{90}$ While this would not completely prevent nuclear states from being attacked, Waltz believed that the risk of escalation would reduce the frequency and intensity of wars. ${ }^{91}$ Authors like Robert Jervis have advanced similar arguments that the capacity to destroy an

\footnotetext{
${ }^{87}$ Brodie, Strategy in the Missile Age, 273-278; Daniel G. Arce and Todd Sandler, "Deterrence: Credibility and Proportionality," Economics \& Politics 21, no. 3 (2009): 384-408

${ }^{88}$ Robert Powell, "Nuclear Deterrence and the Strategy of Limited Retaliation," American Political Science Review 83, no. 2 (1989): 505.

${ }^{89}$ Schelling, The Strategy of Conflict, 191-201.

${ }^{90}$ Waltz, "More May be Better," 8-9, 17-26.

${ }^{91}$ Waltz, "More May Be Better," 33-36.
} 
enemy's population is absolute and not subject to the relative size of each state's nuclear forces. ${ }^{92}$ This view is flawed due to embracing a "one-size-fits-all" approach to deterrence that fails to account for how smaller nuclear weapon states would need different deterrence strategies than those with enough weapons to completely destroy an enemy state. ${ }^{93}$ It also assumes that challengers always consider deterrence threats to be credible, ignoring that they may attack if they believe the defender is bluffing. ${ }^{94}$ Put simply, merely possessing nuclear weapons is not a sufficient condition for successful nuclear deterrence, as a defender needs to convince challengers of its willingness to use them.

A key concept in the nuclear deterrence literature is the stability-instability paradox. Glenn Snyder originally argued that the risk of escalation makes states in a mutual nuclear deterrence dyad reluctant to go to war with each other, creating strategic stability, but encourages low-intensity conventional violence in the belief that it will fall below the nuclear weapon use threshold, generating instability. ${ }^{95}$ Jervis has further argued that the latter occurs because challengers consider using nuclear weapons in low-intensity conflict non-credible. ${ }^{96}$ Nuclear war would thus be averted, but both states will use conventional force for salami-slicing while remaining below the nuclear threshold. ${ }^{97}$ This follows prospect theory, as larger incursions are easier to deter than smaller ones due to the high stakes for the defender making it more willing to respond with heavy punishment. ${ }^{98}$ Some

\footnotetext{
${ }^{92}$ Robert Jervis, “Why Nuclear Superiority Doesn't Matter," Political Science Quarterly 94, no. 4 (1979): 618.

${ }^{93}$ Narang, Nuclear Strategy in the Modern Era, 5-7.

${ }^{94}$ Sauer, Atomic Anxiety, 21-22.

${ }^{95}$ Glenn H. Snyder, "The Balance of Power and the Balance of Terror," in Balance of Power, ed. Paul Seabury (San Francisco: Chandler Publishing Co., 1965), 198-199, quoted in Christopher J. Watterson, "Competing Interpretations of the Stability-Instability Paradox: The Case of the Kargil War," Nonproliferation Review 24, no. 1-2 (2017): 88-89.

${ }^{96}$ Robert Jervis, The Illogic of American Nuclear Strategy (Ithaca: Cornell University Press, 1984), 29-31.

${ }^{97}$ Jervis, Illogic, 148-150; Schelling, The Strategy of Conflict, 66-68.

${ }^{98}$ Schaub, "Deterrence, Compellence, and Prospect Theory," 406.
} 
studies support the paradox's existence, citing an apparent decline in conflict intensity between nuclear weapon states while frequency remains consistent, whereas others argue that nuclear state dyads do not experience significant reductions in conflict frequency or intensity. ${ }^{99}$ Even case studies of the same states lead to differing conclusions, with Kapur and Cohen arguing against and for the paradox's role in the India-Pakistan conflict, respectively. ${ }^{100}$ Though evidence for the stability-instability paradox remains mixed, it notably advances a theory for why nuclear weapon states will fight each other: namely, a belief that using nuclear weapons in low-intensity conflict is outright unbelievable.

Even if the stability-instability paradox is supported, it suffers from being unable to explain why non-nuclear weapon states would attack a nuclear weapon state. The logic for why nuclear weapon states would limit themselves to low-intensity conflict - to reduce the risk of escalation to nuclear war - is sound. A non-nuclear weapon state would not have the same assurance when attacking a nuclear weapon state, which would not be constrained by the fear of mutual annihilation. If strictly adhering to the underlying logic of the paradox, such a scenario would require the non-nuclear challenger to be irrational. This can be reconciled, however, if the non-nuclear challenger considered the defender's deterrence threats to be non-credible, and that it would not fulfill its threats against limited

\footnotetext{
${ }^{99}$ For examples of studies supporting the existence of the stability-instability paradox, see Robert Rauchhaus, "Evaluating the Nuclear Peace Hypothesis: A Quantitative Approach," Journal of Conflict Resolution 53, no. 2 (2009): 269-271; Bryan R. Early and Victor Asal, "Nuclear weapons, existential threats, and the stability-instability paradox," Nonproliferation Review 25, nos. 3-4 (2018): 246-247. Studies that discount it are David Sobek, Dennis M. Foster, and Samuel B. Robison, "Conventional Wisdom? The Effect of Nuclear Proliferation on Armed Conflict, 1945-2001," International Studies Quarterly 56, no. 1 (2012): 160; Mark S. Bell and Nicholas L. Miller, "Questioning the Effect of Nuclear Weapons on Conflict," Journal of Conflict Resolution 59, no. 1 (2015): 86-87.

${ }^{100}$ S. Paul Kapur, "India and Pakistan's Unstable Peace: Why Nuclear South Asia Is Not Like Cold War Europe," International Security 30, no. 2 (2005): 127-152; Michael D. Cohen, "How Nuclear South Asia Is Like Cold War Europe: The Stability-Instability Paradox Revisited," Nonproliferation Review 20, no. 3 (2013): 433-451.
} 
force. The question that remains, however, is how would the challenger reach this conclusion (whether it is merely perceived or a matter of fact) to begin with? This dissertation argues that challengers, whether armed with nuclear weapons or not, may conclude that the defender will not use nuclear weapons because it is unwilling to suffer unnecessary costs for doing so, and may infer this information from how its form of government influences its behaviour.

\subsection{1: Deterrence Threat Credibility and the Signalling of Resolve}

One of the main points of consensus in the nuclear deterrence literature, which has continuously emerged in the previous sections, is that threats will only succeed in dissuading challengers if they are considered credible. This requires the defender to be able and willing to fulfill the threat and communicate this to challengers to avoid the perception that it is bluffing. Most notably, this is one of the few areas in the nuclear deterrence literature where regime type is given serious consideration. Specifically, this arises in discussions of the concept of audience costs, where the ability of domestic audiences to punish their government for bluffing in a crisis varies according to its regime type and influences the state's apparent resolve to fulfill its threats. As is made clear in this subsection, however, regime type is generally ignored beyond this, and the concept of audience costs itself suffers from notable shortcomings.

For a defender's deterrent to be credible, it must be able to convince challengers that it has the capability and resolve to fulfill its threats. Put simply, this means that the defender must show that it can carry out its threats under the specified conditions and that it is willing to do so. ${ }^{101}$ Brodie raised this point early on when critiquing massive retaliation,

${ }^{101}$ Kilgour and Zagare, "Credibility, Uncertainty, and Deterrence," 306-307. 
as such a disproportionate response to minor conflicts would be entirely non-credible compared to a more limited and proportionate response. ${ }^{102}$ How a defender can make its deterrent more credible is heavily debated: Stone argues that it stems from the defender's military capabilities, a demonstration of political will, and the ability to communicate the threat and punishment to challengers. ${ }^{103}$ Huth similarly considers credibility to be a function of relative military capabilities and perceived resolve. ${ }^{104}$ Others, such as Guinsinger and Smith, argue that the state's reputation from diplomacy can indicate resolve and increase threat credibility. ${ }^{105}$ The recurring element, however, is that threat credibility is heavily reliant on the defender's ability to communicate its sincerity to potential challengers; if it is unable to, or if the challenger somehow ignores or misinterprets these signals, it is likely the threats will be dismissed as simple bluffing.

The most effective way for states to communicate deterrence threat credibility, particularly resolve, is via costly signals. By taking actions that impose costs on themselves, such as mobilizing armed forces, states are able to demonstrate to challengers that their threats are sincere and not instances of bluffing. ${ }^{106}$ Schelling discussed this issue early on, suggesting that threat credibility could be established through means such as a trip wire, citing the placement of American troops in West Berlin as a way of forcing the US to intervene against a Soviet attack. ${ }^{107}$ Fearon's audience costs concept is itself a costly signal, as domestic audiences punishing governments for failing to fulfill threats in crises

\footnotetext{
102 Brodie, Strategy in the Missile Age, 273.

103 Stone, "Conventional Deterrence," 110.

${ }^{104}$ Huth, "Reputations and Deterrence," 74.

105 Alexandra Guinsinger and Alistair Smith, "Honest Threats: The Interaction of Reputation and Political Institutions in International Crises,” Journal of Conflict Resolution (2002): 176-177.

106 James D. Fearon, "Domestic Political Audiences and the Escalation of International Disputes," American Political Science Review 88, no. 3 (1994): 579.

107 Schelling, Arms and Influence, 44-47, 71.
} 
gives them an incentive to act. ${ }^{108}$ Guinsinger and Smith further argue that a reputation for using force is itself a costly signal due to informing challengers of the defender's past demonstrations of resolve in threat fulfillment and enduring conflict. ${ }^{109}$ Furthermore, states that have developed a reputation for resisting in the past are seen as having a strong incentive in continuing to fulfill deterrence threats instead of bluffing, as failing to do so would lead to future threats being perceived as bluffs as well. ${ }^{110}$

Audience costs and their role in signalling deterrence credibility is one of the few areas of the nuclear deterrence literature where state regime type can play a significant role. Fearon specifically noted in writing about audience costs that the ability for domestic audiences to punish their governments for bluffing varies among regime types due to differences in accountability. ${ }^{111}$ Democracies are considered capable of generating more costly signals, and thus making more credible threats, due to their citizens being able to punish bluffing. ${ }^{12}$ Autocracies, in contrast, are seen as sending lower-value signals because their comparative lack of accountability allows them to make empty threats with little fear of punishment. ${ }^{113}$ Schultz and Prins have further argued that a strong political opposition, generally associated with democracies, reinforces threat credibility by providing audiences with the ability to punish the government by replacing it. ${ }^{114}$

\footnotetext{
${ }^{108}$ Fearon, "Domestic Political Audiences," 579-582.

${ }^{109}$ Guinsinger and Smith, "Honest Threats," 176-177.

${ }^{110}$ Guinsinger and Smith, "Honest Threats," 176-177.

${ }^{111}$ Fearon, "Domestic Political Audiences," 581-582.

112 Fearon, "Domestic Political Audiences," 582.

${ }^{113}$ Fearon, "Domestic Political Audiences," 582.

${ }^{114}$ Kenneth A. Schultz, "Domestic Opposition and Signaling in International Crises," American Political Science Review 92, no. 4 (1998): 829-844; Brandon C. Prins, "Institutional Instability and the Credibility of Audience Costs: Political Participation and Interstate Crisis Bargaining, 1816-1992," Journal of Peace Research 40, no. 1 (2003): 72.
} 
Fearon's claim that autocracies lack accountability, and thus make less credible threats, has received some criticism in recent years. Brown and Marcum, for example, have noted that the smaller domestic audiences of autocratic regimes could more capably monitor and sanction leaders for failures than broad democratic ones. ${ }^{115}$ Weeks has also noted that while personalist governments are less reliant on audiences, military and singleparty regimes are comparatively accountable due to needing elite support. ${ }^{116}$ Despite these differences, audience costs establishes that the regime type of a defending state can play a role in nuclear deterrence, with variation in accountability mechanisms causing differences in the credibility of their threats and, by extension, the willingness of potential challengers to attack them.

Despite regime type's potential influence on nuclear deterrence credibility, it appears that audience costs is one of the only theories where it has been considered. Studies of nuclear deterrence rarely consider regime type beyond basic characteristics; the few that engage with it in depth tend to be case studies and do not engage in broader theorybuilding. ${ }^{117}$ As a result, there are few instances of the nuclear deterrence literature drawing any connection between nuclear deterrence and the regime type of the defending state, despite the potential role of the latter being an explicit point in discussion of audience

\footnotetext{
115 Jonathan N. Brown and Anthony S. Marcum, "Avoiding Audience Costs: Domestic Political Accountability and Concessions in Crisis Diplomacy," Security Studies 20, no. 2 (2011): 141-170.

116 Jessica L. Weeks, “Autocratic Audience Costs: Regime Type and Signaling Resolve," International Organization 62, no. 1 (2008): 36-46.

${ }^{117}$ For examples, see Rajaram Panda, "North Korea's Nuclear Policy: Domestic Determinants, Strategy and Future," Journal of Comparative Asian Development 10, no. 2 (2011): 240-245; Scott A. Jones and James R. Holmes, "Regime Type, Nuclear Reversals, and Nuclear Strategy: The Ambiguous Case of Iran," in Strategy in the Second Nuclear Age: Power, Ambition, and the Ultimate Weapon, ed. Toshi Yoshihara and James R. Holmes (Baltimore: Georgetown University Press, 2012): 201-202.
} 
costs. ${ }^{118}$ The consequence of this lack of attention is that there is a potentially significant literature gap in the study of nuclear deterrence, which is made all the more notable by the numerous challenges to its traditional conception in the post-Cold War period.

\subsection{2: The Costs of Using Nuclear Weapons}

One concept discussed in the nuclear deterrence literature is the idea that a state that uses nuclear weapons would incur costs for itself in the process. This area of study remains largely theoretical due to nuclear weapons only being used in wartime against Japan in August 1945, when they were newly introduced to public awareness, and there are thus no actual instances of a nuclear weapon state suffering costs. The literature on this subject therefore extrapolates from various sources to draw conclusions about potential costs, primarily historical cases of nuclear weapon use being considered and subsequently rejected, as the reasoning behind these decisions can yield insight into what consequences decision-makers expected. Popular sentiment regarding nuclear weapons, including the emergence of a taboo against the use of nuclear weapons, and the ways that states have responded to nuclear weapons proliferation and testing have also been used to determine what kinds of costs are incurred by the use of nuclear weapons.

The use of nuclear weapons also has the potential to harm allied relations or even leave the nuclear weapon state isolated. Brodie, for example, noted that the Eisenhower administration decided against using tactical nuclear weapons during the Korean War

\footnotetext{
${ }^{118}$ To my knowledge, one of the few studies that has devised a theory of how differences in regime type create variation in nuclear deterrence is Shoko Kohama and Kazuto Ohtsuki, "Political Institutions and Nuclear Deterrence" (60th International Studies Association Annual Convention, Toronto, March 27-30, 2019), http://web.isanet.org/Web/Conferences/Toronto\%202019-s/Archive/9ed874b6-e516-4f4e-bd0ef51198181128.pdf.
} 
(1950-1953) in part due to allied opposition over using nuclear weapons in wartime. ${ }^{119}$ Both Halperin and Betts likewise cited this decision to argue that using nuclear weapons within allied territory carried the risk of discouraging other states from accepting American military aid and potentially leaving it politically isolated. ${ }^{120}$ More recently, Sechser and Fuhrmann have argued that nuclear compellence would be non-credible due to nuclear weapon use leading to political isolation, states aligning against the aggressor, and potentially even provoking military retaliation against it. ${ }^{121}$ As they point out, while these punishments are expected to occur if nuclear weapons are used for coercion or against a low-intensity attack, defenders using them against an existential threat would likely face few, if any, such costs. ${ }^{122}$ This raises the important point that how states respond to nuclear weapon use will be dictated by circumstances, and in turn suggests that anticipated international responses could influence the defender's decision to use them.

The idea of a taboo or tradition of nuclear weapon non-use is also derived in part from the idea of nuclear weapons having costs attached to their use. The emergence of norms against using nuclear weapons is most prominently discussed in Nina Tannenwald's The Nuclear Taboo, which studies the increasing unpopularity of nuclear weapons via key cases where the US considered their use. ${ }^{123}$ Tannenwald argues that increasing public awareness of the effects of nuclear weapons from the late 1940s onwards turned US and international sentiment against their potential use, regardless of possible retaliation. ${ }^{124}$

\footnotetext{
119 Brodie, Strategy in the Missile Age, 319-320.

${ }^{120}$ Halperin, "Nuclear weapons and limited war," 159; Betts, Nuclear Blackmail, 34-35.

${ }^{121}$ Sechser and Fuhrmann, Nuclear Weapons and Coercive Diplomacy, 46-51.

122 Sechser and Fuhrmann, Nuclear Weapons and Coercive Diplomacy, 46.

${ }^{123}$ Nina Tannenwald, The Nuclear Taboo: The United States and the Non-Use of Nuclear Weapons Since 1945 (Cambridge: Cambridge University Press, 2007).

124 Tannenwald, The Nuclear Taboo, 17-24.
} 
These concerns contributed to the Eisenhower administration deciding not to use nuclear weapons during the Korean War, and with the subject not even being discussed by the 1991 Gulf War. ${ }^{125}$ Brodie previously referenced this concept in 1959 , noting the need to consider domestic popular sentiment, particularly "nonrational feelings" regarding the distinction between nuclear and non-nuclear weapons. ${ }^{126}$ T.V. Paul has further argued that the reputational cost for using nuclear weapons resulting from their continued non-use has led nuclear weapon states to self-deter. ${ }^{127}$ Much like audience costs, the taboo is one of the only subjects in nuclear deterrence to account for regime type, as Tannenwald argues that public accountability played a key role in restraining US nuclear weapon use and laid the foundations for the taboo as a whole. ${ }^{128}$

One issue with the nuclear taboo is its American-centric origins, making it uncertain whether it can be applied to nuclear weapon states with differing regime types and capabilities and creating a literature gap in the process. Tannenwald herself notes that while aspects of her findings would apply to other democratic nuclear weapon states, this may not be the case for non-democracies. ${ }^{129}$ While the taboo could explain how decision-makers in a nuclear democracy like India would account for domestic popular sentiment, the same may not apply to a non-democracy like China. The US also possesses significantly greater conventional and nuclear forces than almost any other state, providing it with a wider array of options for addressing crises than smaller nuclear powers. In short, the nuclear taboo potentially explains how regime type could cause variation in conflict propensity among

\footnotetext{
125 Tannenwald, The Nuclear Taboo, 17-24.

${ }^{126}$ Brodie, Strategy in the Missile Age, 323-324.

127 T.V. Paul, "Self-deterrence: nuclear weapons and the enduring credibility challenge," International Journal 71, no. 1 (2016): 28-36.

128 Tannenwald, The Nuclear Taboo, 366.

${ }^{129}$ Tannenwald, The Nuclear Taboo, 22-23.
} 
nuclear weapon states, as democracies would self-deter due to potential public backlash and render their threats potentially non-credible. That the explanation is solely derived from the US leaves its applicability to other nuclear weapon states, particularly those that are not democratic and/or have weaker conventional and nuclear forces, in doubt.

\section{3: The Relationship between State Regime Type and Conventional Armed Conflict}

Much of this chapter shows that the existing nuclear deterrence literature pays little attention to how regime type influences nuclear deterrence effectiveness or even if it plays a role at all. This notably contrasts with the study of conventional armed conflict, where there are numerous theories on how state regime type influences conflict initiation and how states fight. Most interestingly, some of these theories discuss how regime type influences the sensitivity of governments (or relative lack thereof) to the various costs of conflict. This raises a common point between conventional conflict and nuclear deterrence, given existing work on how nuclear weapon states may choose to avoid using nuclear weapons

due to the anticipated costs of doing so. The following subsections first discuss some of the theories on how regime type influences conflict initiation, such as democratic peace theory, followed by an overview of how regime type is expected to determine cost sensitivity. Taken together, these suggest a possible avenue for extending conventional conflict theories on the role of regime type to the nuclear deterrence literature via cost sensitivity, which is elaborated upon in more detail in chapter 3.

\subsection{1: State Regime Type and Conflict Initiation}

Perhaps the most prominent theory on how state regime type affects conflict initiation is democratic peace theory. The theory's core argument is that democratic governance has largely prevented war between democracies, with various attributes cited 
as possible causal mechanisms. ${ }^{130}$ The normative argument, derived from Immanuel Kant, is that norms of internal political behaviour, such as negotiated compromises and diplomacy, are extended to interstate interactions. ${ }^{131}$ The institutional argument credits the constraints of political institutions like elected legislatures for the lack of armed conflict between democratic states, with democracies being considered unique in requiring popular support to wage war due to checks and balances on the exercise of power. ${ }^{132}$ The logic is that governments that fight unpopular wars risk losing power due to the public being generally averse to suffering the costs of war unnecessarily. ${ }^{133}$ The risk of punishment is believed to have largely prevented war between democracies, since mutual public opposition would force negotiated resolution instead of fighting except as a last resort. ${ }^{134}$ War against non-democracies may be seen as more acceptable, particularly if they are perceived as a threat, but may still not be immediately desirable due to the ensuing costs. ${ }^{135}$ Democracies are thus expected to be relatively peaceful, at least towards each other.

Despite the apparent explanatory power of democratic peace theory, it has significant flaws. The most significant of these is the assumption that popular sentiment in democracies is generally against war, which is suspect given several cases where it has

\footnotetext{
${ }^{130}$ Zeev Maoz and Bruce Russett, "Normative and Structural Causes of Democratic Peace, 1946-1986," American Political Science Review 87, no. 3 (1993): 625-627.

${ }^{131}$ William J. Dixon, "Democracy and the Peaceful Settlement of International Conflict," American Political Science Review 88, no. 1 (1994): 15-18.

${ }^{132}$ T. Clifton Morgan and Sally Howard Campbell, "Domestic Structure, Decisional Constraints, and War: So Why Kant Democracies Fight?," Journal of Conflict Resolution 35, no. 2 (1991): 189-192; Scott Sigmund Gartner and Gary M. Segura, "War, Casualties, and Public Opinion," Journal of Conflict Resolution 42, no. 3 (1998): 278-300.

${ }^{133}$ Benjamin E. Goldsmith, Stephan K. Chalup, Michael J. Quinlan, "Regime Type and International Conflict: Towards a General Model," Journal of Peace Research 45, no. 6 (2008): 743-747.

${ }^{134}$ Morgan and Campbell, "So Why Kant Democracies Fight," 193.

${ }^{135}$ David Lektzian and Mark Souva, "A Comparative Theory Test of Democratic Peace Arguments, 19462000,” Journal of Peace Research 46, no. 1 (2009): 19-20.
} 
favoured fighting. ${ }^{136}$ David Lorenzo, for example, has noted that the US has gone to war on multiple occasions, such as the 2003 invasion of Iraq, since the fragmented nature of American domestic opposition hindered its ability to mobilize the public against war. ${ }^{137}$ Nationalist sentiment has also been noted as potentially steering public opinion towards favouring war, to the point that leaders may themselves be pushed into conflict against their own judgement. ${ }^{138}$ Democracies have also been known to engage in wars of conquest, contradicting the normative assumption that democracies will consistently extend their internal political norms to foreign relations. ${ }^{139}$ These flaws indicate that while democracies may be more pacific than other regime types due to internal characteristics, they are not entirely constrained from initiating armed conflicts.

In contrast to democracies, non-democratic regimes are perceived in the conflict literature as being more prone to initiating armed conflict, with Bruce Bueno de Mesquita's selectorate theory being one of the most widely cited. The theory argues that while democratic governments rely on large coalitions to retain power, non-democracies buy the continued support of relatively small groups of elites, known as "winning coalitions," with private rewards. ${ }^{140}$ So long as the government's policies do not negatively impact the winning coalition's rewards, it can expect to retain their support. ${ }^{141}$ Elite support means that non-democratic governments can implement policies that negatively impact their

\footnotetext{
${ }^{136}$ Sebastian Rosato, "The Flawed Logic of Democratic Peace Theory," American Political Science Review 97, no. 4 (2003): 594-596.

${ }^{137}$ David J. Lorenzo, "Democratic Peace Theory, the Problems of Pluralism, and the Opposition to the Use of Military Force in the US," Democracy and Security 14, no. 4 (2018): 431-437.

${ }^{138}$ Rosato, "Flawed Logic," 595.

${ }^{139}$ Hilde Ravlo, Nils Petter Gleditsch, and Han Dorussen, "Colonial War and the Democratic Peace," Journal of Conflict Resolution 47, no. 4 (2003): 521-524.

${ }^{140}$ Bruce Bueno de Mesquita, James D. Morrow, Randolph M. Siverson, and Alastair Smith, "An Institutional Explanation of the Democratic Peace," American Political Science Review 93, no. 4 (1999): 794.

${ }^{141}$ Bueno de Mesquita et al., "An Institutional Explanation," 794.
} 
citizens or even deliberately pass down costs to them so long as their supporters benefit from it. ${ }^{142}$ Waging war thus becomes more viable, since it can be used to gain wealth and resources to reward supporters regardless of the cost to the state's citizens. ${ }^{143}$ War is not entirely cost-free for non-democracies, as defeat can make them appear weak and encourage supporters to forcibly replace leaders with successors who can better defend their interests or even encourage an uprising. ${ }^{144}$ This behaviour is expected to vary among different non-democratic regimes, with personalist regimes having even fewer constraints than single-party or military governments due to relying on a small group of elites instead of a governing party or military junta. ${ }^{145}$

Dictatorial peace theory, meanwhile, argues that autocracies are hindered from going to war by internal constraints. As with democratic peace, this theory is based on empirical observations that personalist dictatorships rarely fight each other, nor do military dictatorships and single-party regimes. ${ }^{146}$ Single-party regimes and military dictatorships, like democracies, have some institutional constraints, with single-party regimes in particularly answering to a broader audience of party members, who do not necessarily benefit from war have some influence over the leadership. ${ }^{147}$ Personalist regimes lack these formal institutional constraints, but are at risk of being overthrown by the military in a

\footnotetext{
${ }^{142}$ Bruce Bueno de Mesquita and Alastair Smith, The Dictator's Handbook: Why Bad Behaviour Is Almost Always Good Politics (New York: PublicAffairs, 2011), 227-230; Goldsmith, Chalup, and Quinlan, "Regime Type and International Conflict," 746-748.

${ }^{143}$ Cigdem V. Sirin and Michael T. Koch, "Dictators and Death: Casualty Sensitivity of Autocracies in Militarized State Disputes," International Studies Quarterly 59, no. 4 (2015): 804-805.

${ }^{144}$ Alexandre Debs and Henk E. Goemans, "Regime Type, the Fate of Leaders, and War," American Political Science Review 104, no. 3 (2010): 430-445.

${ }^{145}$ Jessica L. Weeks, "Strongmen and Straw Men: Authoritarian Regimes and the Initiation of International Conflict," American Political Science Review 106, no. 2 (2012): 330-335.

${ }^{146}$ Mark Peceny, Caroline C. Beer, and Shannon Sanchez-Terry, "Dictatorial Peace?," American Political Science Review 96, no. 1 (2002): 16.

${ }^{147}$ Weeks, "Autocratic Audience Costs," 45-46.
} 
coup, leading them to deliberately weaken their armies by promoting loyal officers over competent ones. ${ }^{148}$ Other interpretations of the theory suggest that these regimes will dedicate much of their resources towards repressing their populations to secure their power, which can include stamping out internal dissent using their militaries. ${ }^{149}$ Both, however, suggest that autocratic regimes may be limited in their ability to wage war.

\subsection{2: State Regime Type, Costs and Conflict}

The idea of states involved in armed conflict suffering costs as a result is widely discussed in the literature. The concept of conflict costs has long existed and is considered to be a key facet of the institutional constraints explanation of democratic peace. ${ }^{150}$ States are expected to inevitably incur costs when participating in armed conflict, regardless of regime type. As elaborated further in this sub-section, these costs, such as casualties, economic harm, and potential political harm, are not necessarily influenced by state regime type. What is influenced by regime type differences is the sensitivity of a given government to costs due to variations in their governing institutions.

One of the primary costs that states endure in armed conflict are military and civilian casualties. Regardless of regime type, this is largely borne by citizens of the participating states, who both provide the soldiers who are killed or injured while fighting and are the primary audience for democracies. ${ }^{151}$ Civilians themselves can also become casualties by being caught up in fighting or suffering from food shortages and disease

\footnotetext{
148 Peceny, Beer, and Sanchez-Terry, "Dictatorial Peace?," 18.

149 Rosato, "Flawed Logic," 596-597.

${ }^{150}$ Bruce Bueno de Mesquita and Randolph M. Siverson, "War and the Survival of Political Leaders: A Comparative Study of Regime Types and Political Accountability," American Political Science Review 89, no. 4 (1995): 841-855.

${ }^{151}$ D. Scott Bennett and Allan C. Stam III, "The Declining Advantages of Democracy: A Combined Model of War Outcomes and Duration," Journal of Conflict Resolution 42, no. 3 (1998): 344; Bueno de Mesquita and Siverson, "War and the Survival of Political Leaders," 849.
} 
outbreaks when state infrastructure is damaged. ${ }^{152}$ Considerable research shows that even an initially enthusiastic public can become war-weary and turn against the government, with Gartner and Segura's study of the Korean and Vietnam Wars finding that increasing casualties were interpreted as a sign the war was going poorly. ${ }^{153}$ Authors such as Sarah Croco, Michael Tomz, and Jessica Weeks have similarly found that the human cost of war can negatively influence public opinion, which has potential repercussions for the continued tenure of leaders. ${ }^{154}$ Even casualties among the opponent's civilians can be viewed negatively if considered excessive or unnecessary, which played a large part in declining support for the Vietnam War. ${ }^{155}$

Armed conflict is also expected to inflict financial costs on the states involved. The most readily apparent form of this is increased taxation, as governments need to spend more on troops, equipment, and supplies relative to peacetime deployments. ${ }^{156}$ The mobilization of troops and materiel increases the need for this even further, as they may need to be transported considerable distances and would result in considerable costs. ${ }^{157}$ Governments may also attempt to increase their military spending during wartime by reallocating funding from non-military programs, such as social welfare and education,

\footnotetext{
${ }^{152}$ Benjamin A. Valentino, Paul K. Huth, and Sarah E. Croco, "Bear Any Burden? How Democracies Minimize the Costs of War," The Journal of Politics 72, no. 2 (2010): 530-531.

${ }^{153}$ Gartner and Segura, "War, Casualties, and Public Opinion," 295-299.

${ }^{154}$ Sarah E. Croco, "The Decider's Dilemma: Leader Culpability, War Outcomes, and Domestic Punishment," American Political Science Review 105, no. 3 (2011): 468, 473-475; Michael R. Tomz and Jessica L.P. Weeks, "Public Opinion and the Democratic Peace," American Political Science Review 107, no. 4 (2013), 849-865.

${ }^{155}$ Eric V. Larson and Bogdan Savych, Misfortunes of War: Press and Public Reactions to Civilian Deaths in Wartime (Santa Monica: RAND Corporation: 2006), xix-xxii; John E. Mueller, War, Presidents, and Public Opinion (New York: Wiley, 1973); Christopher Gelpi, Peter Feaver, and Jason Reifler, "Success Matters: Casualty Sensitivity and the War in Iraq," International Security 30, no. 3 (2005): 10-13.

${ }^{156}$ Jeff Carter, "The Political Cost of War Mobilization in Democracies and Dictatorships," Journal of Conflict Resolution 61, no. 8 (2017): 1771-1772.

${ }^{157}$ Ibid.
} 
which would negatively impact a significant part of the state's population. ${ }^{158}$ Additionally, quantitative studies have found that war can disrupt international trade for the states involved, potentially leaving their populations poorer during wartime than during the prewar period. ${ }^{159}$ As with the human costs of war, many of these economic costs are expected to be unpopular unless the benefits of fighting are presented to the public, though these have the potential to endure beyond the duration of the conflict.

States that initiate armed conflict or wage it in a way that violates international norms can harm its standing among other states, leading to the state becoming less secure or facing internal discontent. States that are considered to have started a conflict would be particularly prone to this due to violating international norms against aggression. ${ }^{160}$ This norm was codified into international law following the Second World War in Article 2(4) of the Charter of the United Nations, which prohibits member states from using force against another's territorial integrity or independence, leading aggressors to justify their actions on grounds such as pre-emptive self-defence. ${ }^{161}$ Aggressive behaviour can lead to a state being punished with economic and political sanctions that leave it economically crippled and isolated. ${ }^{162}$ In some cases, other states may even choose to align themselves against the aggressor in question in order to better defend themselves from it, leaving it

\footnotetext{
158 Jeff Carter and Glenn Palmer, "Keeping the Schools Open While the Troops are Away: Regime Type, Interstate War, and Government Spending," International Studies Quarterly 59, no. 1 (2015): 145-149.

${ }^{159}$ Charles H. Anderton and John R. Carter, "The Impact of War on Trade: An Interrupted Time Series Study," Journal of Peace Research 38, no. 4 (2001): 445-457; Reuven Glick and Alan M. Taylor, "Collateral Damage: Trade Disruption and the Economic Impact of War," Review of Economics and Statistics 92, no. 1 (2010): 102-127.

${ }^{160}$ Mark W. Zacher, "The Territorial Integrity Norm: International Boundaries and the Use of Force," International Organization 55, no. 2 (2001): 215-250.

${ }^{161}$ United Nations, Charter of the United Nations, 1945, Article 2(4); Tom Ruys, "The Meaning of 'Force' and the Boundaries of the Jus Ad Bellum: Are 'Minimal' Uses of Force Excluded from UN Charter Article 2(4)?" American Journal of International Law 108, no. 2 (2014): 159-210.

${ }^{162}$ David Lektzian and Mark Souva, "An Institutional Theory of Sanctions Onset and Success," Journal of Conflict Resolution 51, no. 6 (2007): 848-871.
} 
more vulnerable than it would be otherwise. ${ }^{163}$ These costs, particularly economic sanctions, can often prove unpopular with a state's general population due to their negative impact.

While state regime type is not expected to influence conflict costs directly, it is believed to affect a given state's sensitivity to those costs, with the institutional constraints and political accountability associated with particular regime types being considered a main factor. Democracies, in keeping with democratic peace theory, are believed to be highly sensitive to armed conflict costs due to their being borne by the voters they rely on, which could lead to their being removed in elections. ${ }^{164}$ The ability of voters to punish elected leaders for fighting unwanted or unwinnable wars, particularly if there is a credible domestic opposition, is expected to make them much more selective in starting wars. ${ }^{165}$ Bennett and Stam, for example, found that democracies will fight shorter wars to minimize their casualties due to the expected decline in public support as they mount. ${ }^{166}$ Filson and Warner, meanwhile, argue that the cost sensitivity of democratic governments will lead them to only fight wars they believe that they can win, or at least try to avoid those where victory is uncertain. ${ }^{167}$

Non-democratic governments, in contrast, are considered relatively insensitive to armed conflict costs due to elite support. Selectorate theory's argument that autocracies can ignore the costs of their policies because of elite support means they can pass down the

\footnotetext{
163 Jesse C. Johnson, "External Threat and Alliance Formation," International Studies Quarterly 61, no. 3 (2017): 736-745.

164 Debs and Goemans, "Regime Type, the Fate of Leaders, and War," 431.

165 Patricia Lynne Sullivan and Scott Sigmund Gartner, "Disaggregating Peace: Domestic Politics and Dispute Outcomes," International Interactions 32, no. 1 (2006): 1-4.

166 Bennett and Stam, "Declining Advantages," 344-366.

${ }^{167}$ Darren Filson and Suzanne Warner, "Bargaining and Fighting: The Impact of Regime Type on War Onset, Duration, and Outcomes," American Journal of Political Science 48, no. 2 (2004): 305-309.
} 
costs of fighting while rewarding their supporters with seized resources, wealth, and territory. ${ }^{168}$ Non-democratic regimes would not only be relatively insensitive to fighting costs, but may even be incentivized to do so by these benefits. Cost-insensitivity is expected to vary between sub-types due to winning coalition size differences, with the relatively large support bases of single-party regimes makes them more sensitive than personalist and military regimes that rely on small groups of political and military elites. ${ }^{169}$ Even nondemocratic governments will be somewhat sensitive to conflict costs, since threats to the benefits and status of their supporters can lead to their being overthrown. ${ }^{170}$ Overall, selectorate theory indicates that non-democracies have greater latitude in initiating conflict due to the structure of government allowing them to more easily ignore the negative ramifications beyond their circle of supporters.

The literature on conventional conflict costs parallels the anticipated costs of using nuclear weapons, suggesting there is merit in studying regime type as a potential cause of variation in nuclear deterrence as well. Both indicate that governments can face costs from a displeased domestic audience or from other states, with the main difference being in the treatment of state regime type as a source of variation. The conventional conflict literature indicates that democracies will be more reluctant than non-democracies to initiate conflict due to needing popular support to remain in power instead of paying off an elite coalition. The nuclear deterrence literature instead largely ignores regime type and cost sensitivity in the fulfillment of nuclear deterrence threats except for audience costs and the nuclear taboo,

\footnotetext{
${ }^{168}$ Mark Peceny and Christopher K. Butler, "The Conflict Behaviour of Authoritarian Regimes," International Politics 41, no. 4 (2004): 565-581; Dan Reiter and Allan C. Stam, "Democracy, War Initiation, and Victory," American Political Science Review 92, no. 2 (1998): 378-379.

169 Sirin and Koch, "Dictators and Death," 803-805.

${ }^{170}$ Debs and Goemans, "Regime Type, the Fate of Leaders, and War," 433-434.
} 
and even these are limited or US-centric. As a result, academic debate on the ramifications of nuclear weapon use is sorely lacking in discussion of whether state regime type is a source of variation, much less how it does so, despite the logic underlying nuclear weapon costs and those for conventional conflict ostensibly being the same.

\section{4: Conclusion}

A review of the nuclear deterrence literature shows that the field has changed considerably since the Cold War. The most prominent shift in the field is the recognition that the model focusing on two opposing superpowers with vast nuclear arsenals is not representative of the more numerous regional nuclear powers and their considerably smaller nuclear stockpiles. Despite the shifts in the nuclear deterrence literature, state regime type continues to be ignored as a possible variable, with some exceptions including the discussion surrounding audience costs and the nuclear taboo. This stands in marked contrast with the conventional conflict literature, where there is a large body of work debating how regime type influences various aspects of state conflict behaviour, including how it influences government sensitivity to costs and the subsequent willingness to engage in armed conflict. These two fields share common ground in recognizing the costs of armed conflict, with the nuclear deterrence literature having long acknowledged that states using nuclear weapons may suffer penalties domestically and internationally for doing so.

The continued non-presence of state regime type in the nuclear deterrence literature leaves a significant research gap. Put simply, this lack of study means that we do not know if state regime type plays any role in nuclear deterrence, much less how variations in a nuclear weapon state's regime type affects conflict propensity towards it. The discussion of the literature on deterrence and conventional armed conflict in this chapter, particularly 
relating to cost and regime type variation, show that there is sufficient conceptual common ground between the two subjects to import theories from the latter to the former. It is apparent, however, that scholars have not made the connection between the two.

This dissertation thus seeks to fill in the gap by advancing a novel theory of how a defending nuclear weapon state's regime type can affect the likelihood of its being attacked by challengers. The literature review presented in this chapter indicates that this is due to variation in the accountability mechanisms of a defending nuclear weapon state affecting the credibility of its nuclear deterrence threats. Chapter 3 utilizes the literature cited in this review to develop and explain a theory for this variation, based on differences in perceived cost-sensitivity and the impact on credibility, along with associated hypotheses. The chapter also draws upon additional research not cited in the literature review to further develop the finer points of the theory and to ensure the hypotheses are testable. Chapter 4 subsequently advances a methodology for studying this variation in a sample group of nuclear weapon states using process tracing and cross-case comparison. 


\section{Chapter 3: Regime Cost Sensitivity and Nuclear Deterrence Credibility: A Theory}

The preceding chapter showed that the nuclear deterrence literature has largely avoided engaging with state regime type, particularly how it may influence variation in the frequency of nuclear weapon states being targeted with armed attacks. While numerous authors have studied related issues, such as variations in conflict cost sensitivity, determinants of threat credibility, and how anticipated nuclear weapon costs influence the willingness to use them, these disparate elements have yet to be tied into a cohesive theory. These elements can be tied together with regime type and have been explored in this way in the conventional conflict literature, but not in relation to nuclear deterrence. The lack of research into this variable is problematic, given how related concepts like audience costs explicitly account for regime type as a source of variation in crisis outcomes. Furthermore, differences in the regime type of defending nuclear weapon states could, as discussed in chapter 1 , explain why democratic nuclear weapon states appear to be involved in more crises and instances of low-intensity conflict than their non-democratic counterparts. This variation between nuclear weapon states, along with the lack of study on the possible influence of state regime type, leads to the question "Does state regime type influence the ability of nuclear weapons to deter low-intensity conflict?"

To answer this question, this chapter advances a theory for how a nuclear weapon state's regime type can affect the willingness of other states to attack it by drawing on conventional conflict theories. The theory argues that varying government cost sensitivity, caused by differences in accountability, will affect the credibility of nuclear deterrence threats for low-intensity conflict, with greater accountability making threats less credible. 
Democratic governments are very cost-sensitive due to needing popular support to remain in office and thus being accountable to their citizens. This sensitivity can make their nuclear deterrence threats towards low-intensity attacks seem non-credible to challengers due to the costs of fulfilling them outweighing the benefits, encouraging low-intensity attacks. Non-democratic governments, in contrast, rely on the support of small elite coalitions rather than their general population, and are thus relatively insensitive to the costs of their policies to their citizens, instead prioritizing the interests of their supporters. Their insensitivity can make their nuclear deterrence threats seem credible to challengers, even for low-intensity attacks, as the lack of accountability to citizens means they can ignore the costs of fulfilling those threats.

Regardless of regime type, defending nuclear weapon states are expected to be less frequently targeted with interstate war and other forms of high-intensity conflict, as the benefits of fulfilling nuclear deterrence threats in that situation would outweigh the costs even for democratic defenders. Low- and high-intensity conflict can be distinguished according to the challenger's aims and the means it uses to achieve them. Low-intensity conflict typically has challengers seeking to achieve relatively limited goals and using similarly restrained means to do so, up to and including limited war. ${ }^{1}$ High-intensity conflict, by comparison, refers to instances of armed conflict of sufficient scope that the defender is at risk of suffering significant loss of life or even its destruction as a coherent political entity, primarily consisting of general interstate war. ${ }^{2}$

\footnotetext{
${ }^{1}$ Glenn Palmer et al, "The MID4 dataset, 2002-2010: Procedures, coding rules and description," Conflict Management and Peace Science 32, no. 2 (2015): 222-242; Donald G. Brennan, "Setting and Goals of Arms Control," Daedalus 89, no. 4 (1960): 687-688.

2 Bryan R. Early and Victor Asal, "Nuclear weapons, existential threats, and the stability-instability paradox," Nonproliferation Review 25, nos. 3-4 (2018): 224.
} 
The theory I propose in this chapter shares some common ground with previous studies of nuclear deterrence. Section 2.2.2 of the literature review shows that a state suffering costs for using nuclear weapons was discussed as early as 1961 by Morton Halperin and is an important component of theories advanced by scholars such as Nina Tannenwald, Todd Sechser, and Matthew Fuhrmann. ${ }^{3}$ Tannenwald's argument that these costs and the associated tradition or taboo of non-use could undermine nuclear deterrence credibility is particularly noteworthy, given past historical examples of leaders deciding to avoid using nuclear weapons due to the potential backlash. ${ }^{4}$ My theory differs in this regard by moving beyond the US-centric focus of much of the existing literature to study the influence of cost sensitivity in other nuclear weapon states. It also builds on Sechser and Fuhrmann's work on nuclear compellence, specifically how nuclear weapon use costs can make nuclear threats non-credible, by extending the logic to deterrence scenarios where the costs of their use for the defender outweighs the benefits. ${ }^{5}$ Most importantly, the theory seeks to explain the apparent variation in nuclear deterrence effectiveness via differing cost sensitivities between regime types instead of assuming a universal reluctance to fulfill deterrence threats among nuclear weapon states.

The theory also bridges a theoretical gap by borrowing existing theories on the role of regime type and cost sensitivity in conventional conflict. This is done by arguing that variations in cost sensitivity associated with political accountability carry over to nuclear

\footnotetext{
${ }^{3}$ See Morton Halperin, "Nuclear weapons and limited war," Journal of Conflict Resolution 5, no. 2 (1961), 146-166; Nina Tannenwald, The Nuclear Taboo: The United States and the Non-Use of Nuclear Weapons Since 1945 (Cambridge: Cambridge University Press, 2007); Todd S. Sechser and Matthew Fuhrmann, Nuclear Weapons and Coercive Diplomacy (New York: Cambridge University Press, 2017).

${ }^{4}$ Tannenwald, The Nuclear Taboo, 48-50.

${ }^{5}$ Sechser and Fuhrmann, Nuclear Weapons and Coercive Diplomacy, 46-51.
} 
deterrence. ${ }^{6}$ Like the stability-instability paradox, the theory also expects that challengers to democratic nuclear weapon states will engage in salami-slicing with low-intensity conflict to avoid the risk of nuclear escalation that accompanies high-intensity conflict. ${ }^{7}$ The theory builds on the paradox by offering a potential explanation for why challengers believe they can launch low-intensity attacks without nuclear retaliation - namely, that the defender's deterrence threats will seem non-credible if it is seen as too concerned about the potential costs outweighing the benefits to actually fulfill them. It also serves to extend the paradox somewhat, as the anticipated behaviour only requires a defending nuclear weapon state to be a democracy, while the challenger is expected to launch low-intensity attacks regardless of whether it possesses nuclear weapons of its own or not.

The chapter proceeds as follows. It first outlines the variation in cost sensitivity between regime types, what costs states could expect to incur from fulfilling nuclear deterrence threats, and how the cost-benefit calculation of using nuclear weapons would differ between low- and high-intensity conflict situations. It then shows how variation in government cost-sensitivity can affect how potential challengers perceive the credibility of the defending nuclear weapon state's nuclear deterrence threats towards low-intensity conflict. As part of the theory building in this chapter, I draw on both research cited in the

\footnotetext{
${ }^{6}$ Zeev Maoz and Bruce Russett, "Normative and Structural Causes of Democratic Peace, 1946-1986," American Political Science Review 87, no. 3 (1993): 625-627.

${ }^{7}$ Glenn H. Snyder, "The Balance of Power and the Balance of Terror," in Balance of Power, ed. Paul Seabury (San Francisco: Chandler Publishing Co., 1965), 198-199, quoted in Christopher J. Watterson, "Competing Interpretations of the Stability-Instability Paradox: The Case of the Kargil War," Nonproliferation Review 24, no. 1-2 (2017): 88-89; Robert Jervis, The Illogic of American Nuclear Strategy (Ithaca: Cornell University Press, 1984), 148-150.
} 
preceding chapter and additional sources and concepts to ensure that testable hypotheses can be derived from the theory and applied to the cases selected in chapter $4 .^{8}$

This is followed by an explanation of the model that stems from the theory, as well as the hypotheses. The potential role of reputation, particularly regarding aggression and how it can signal cost-insensitivity, is also discussed, as is the relationship between nuclear deterrence and non-state actors, both of which draw on additional literature beyond nuclear deterrence and conventional interstate conflict. The similarities and differences between the theory advanced in this dissertation and audience costs are subsequently discussed, along with how it builds upon the stability-instability paradox. The chapter concludes with a summary of the theory and a discussion of what advances it brings to the nuclear deterrence literature.

\section{1: Why Does Regime Type Matter for Nuclear Deterrence?}

Issues related to regime type have been discussed in the nuclear deterrence literature, such as conflict cost sensitivity and aversion varying by regime type, threat credibility, and the anticipated costs of nuclear weapon use influencing threat fulfillment, but these have yet to be tied together. The section of the theory outlined below is a first step at doing so. It first outlines the kinds of costs states face from armed conflict, as well as how their sensitivity will differ according to the accountability mechanisms inherent to their regime type. This is followed by an overview of the domestic and international costs states are anticipated to face as a result of using a nuclear weapon, along with why more politically accountable states will be seen as more reluctant to endure these costs in

\footnotetext{
${ }^{8}$ Alexander L. George and Andrew Bennett, Case Studies and Theory Development in the Social Sciences (Cambridge: MIT Press, 2005), 75.
} 
response to low-intensity conflicts. The corresponding impact on nuclear deterrence credibility according to regime type is then discussed. This section of the chapter is then concluded with a discussion of how a state reputation for aggression can further influence nuclear deterrence credibility, as well as what the theory means for nuclear deterrence threats against non-state actors.

\subsection{1: Regime Type and Cost Sensitivity}

The conventional conflict literature establishes that governments must contend with various costs of fighting, with their sensitivity to these costs varying according to the accountability mechanisms of different regime types. The military and civilian casualties of armed conflict are the most prominent, since the military personnel states need to fight and that will suffer death and injury come from their own citizens and, for democracies, are also voters that the government needs. ${ }^{9}$ Public opinion can thus turn against a government because of excessive casualties and a prolonged conflict. ${ }^{10}$ Civilians killed directly in fighting or from damaged national infrastructure are likewise a cost of war, and even unnecessary or excessive civilian casualties on the opponent's side could spark a backlash. ${ }^{11}$ Democratic leaders will seek to avoid being embroiled in wars with high casualties or a high risk of defeat, as the costs would be borne by their voters and could

\footnotetext{
${ }^{9}$ Sebastian Rosato, "The Flawed Logic of Democratic Peace Theory," American Political Science Review 97, no. 4 (2003): 587; David Lektzian and Mark Souva, "A Comparative Theory Test of Democratic Peace Arguments, 1946-2000," Journal of Peace Research 46, no. 1 (2009): 20-21.

${ }^{10}$ Scott Sigmund Gartner and Gary M. Segura, "War, Casualties, and Public Opinion," Journal of Conflict Resolution 42, no. 3 (1998): 278-279; Sarah E. Croco, "The Decider's Dilemma: Leader Culpability, War Outcomes, and Domestic Punishment," American Political Science Review 105, no. 3 (2011): 468.

${ }^{11}$ Benjamin A. Valentino, Paul K. Huth, and Sarah E. Croco, "Bear Any Burden? How Democracies Minimize the Costs of War," The Journal of Politics 72, no. 2 (2010): 530-531; Eric V. Larson and Bogdan Savych, Misfortunes of War: Press and Public Reactions to Civilian Deaths in Wartime (Santa Monica: RAND Corporation: 2006), xix-xxii; Christopher Gelpi, Peter Feaver, and Jason Reifler, "Success Matters: Casualty Sensitivity and the War in Iraq," International Security 30, no. 3 (2005): 10-13.
} 
lead to their being removed from office. ${ }^{12}$ Non-democratic will be more willing to fight, even with high casualties and a low chance of victory, since they have little incentive to prioritize the interests of their citizens over those elite supporters; backing down could even weaken them domestically, meaning that they may be better off fighting and losing. ${ }^{13}$

Armed conflict can also exert a heavy financial toll on the populations of the states involved. Governments can be forced to increase taxes on their citizens to finance increased spending on troops, equipment, and various other supplies. ${ }^{14}$ Even the mere act of mobilizing armed forces can be costly, as troops and materiel need to be transported to wherever the conflict is occurring. ${ }^{15}$ Additionally, governments can be forced to reallocate their spending from non-military programs towards defence spending during wartime. Much of this non-military spending is expected to be for social programs that benefit a large portion of the state's population, making such a move potentially unpopular unless the benefits for doing so, such as fighting an existential threat to the state, is presented to the public. ${ }^{16}$ These costs are expected to be even more burdensome for the population, and thus unpopular, if a conflict extends over a significant period of time.

Finally, states can harm their international standing by initiating armed conflict and be punished by other states for it. The long-standing norm against international aggression was codified into international law in the post-Second World War period in Article 2(4) of

\footnotetext{
${ }^{12}$ D. Scott Bennett and Allan C. Stam, "The Declining Advantages of Democracy: A Combined Model of War Outcomes and Duration," The Journal of Conflict Resolution 42, no. 3 (1998): 349-350.

${ }^{13}$ Bruce Bueno de Mesquita and Alastair Smith, The Dictator's Handbook: Why Bad Behaviour Is Almost Always Good Politics (New York: PublicAffairs, 2011), 227-230.

${ }^{14}$ Jeff Carter, "The Political Cost of War Mobilization in Democracies and Dictatorships," Journal of Conflict Resolution 61, no. 8 (2017): 1771-1772.

${ }^{15}$ Ibid.

${ }^{16}$ Jeff Carter and Glenn Palmer, "Keeping the Schools Open While the Troops are Away: Regime Type, Interstate War, and Government Spending," International Studies Quarterly 59, no. 1 (2015): 145-149.
} 
the Charter of the United Nations to prohibit using force against the territorial integrity and independence of others. ${ }^{17}$ This had led to aggressors in armed conflict claiming their actions were somehow justified, such as launching a pre-emptive attack against a state that was preparing to attack first or treating a minor incident as aggression against it. ${ }^{18} \mathrm{Harm}$ to a state's standing is likely to only occur if it uses force when there are alternative policy choices available, such as negotiating with the other state, or if its use of force is perceived as disproportionate to the issue being disputed. ${ }^{19}$ The potential consequences for defying this international norm can significantly impact the state, ranging from reduced diplomatic and trading relations, the imposition of economic sanctions, or even other states forming alliances against it. All of these impose their own costs on the population of the state in question and can affect the decision-making processes of its government in the same way as the other costs discussed here.

It is important to note that armed conflicts can vary in intensity according to the challenger's aims and the scope of the resulting violence. High-intensity conflict refers to when a challenger's objectives and use of force threaten significant harm to the defender or even its very existence, while low-intensity conflict involves more limited political and strategic aims by the challenger. ${ }^{20}$ The two categories can be considered to operate on a

\footnotetext{
${ }^{17}$ While reputation and standing are often used to refer to how a given actor is perceived, uses of the former in this dissertation specifically refer to the concept in deterrence studies that past state behaviour provide indications of resolve. Christine Gray, International Law and the Use of Force, Third Edition (Oxford: Oxford University Press, 2008), 30-66; United Nations, Charter of the United Nations, 1945, Article 2(4).

${ }^{18}$ Tom Ruys, "The Meaning of 'Force' and the Boundaries of the Jus Ad Bellum: Are 'Minimal' Uses of Force Excluded from UN Charter Article 2(4)?” American Journal of International Law 108, no. 2 (2014): 159-210.

${ }^{19}$ Paul K. Huth and Todd L. Allee, "Domestic Political Accountability and the Escalation and Settlement of International Disputes," Journal of Conflict Resolution 46, no. 6 (2002): 759.

${ }^{20}$ Vipin Narang, Nuclear Strategy in the Modern Era: Regional Powers and International Conflict (Princeton: Princeton University Press, 2014): 235.
} 
single continuum rather than a binary, as instances of low-intensity conflict can escalate to high-intensity according to the actions of the defender and/or challenger. An example of this would be the 1999 Kargil crisis, as it began as an instance of low-intensity conflict when Pakistani troops seized unoccupied Indian positions in Kashmir, then escalated to war when the Indian government responded by mobilizing multiple battalions and the Air Force in response. ${ }^{21}$ It is therefore important to account for not just the intensity of fighting at the peak of a crisis, but also how it was initiated.

Cost sensitivity variations appear to be attributable to differences among regime types in the institutions that determine political accountability. Democratic governments are considered especially sensitive to potential conflict costs because they need the support of a majority of voters or electoral districts to remain in office. ${ }^{22}$ Fighting can potentially alienate voters by forcing them to fight and pay for it, often at the expense of beneficial social programs, and suffer the most from economic sanctions. ${ }^{23}$ This can end poorly for the government, since voters can hold leaders accountable for dragging them into a costly war with little benefit, especially when another leader is perceived as a viable alternative. ${ }^{24}$ Accountability encourages democratic governments to avoid armed conflict and the possibility of being removed from office, except when leaders believe there is a high

\footnotetext{
${ }^{21}$ Sunil Rao, "The Kargil Incident: Historical Analysis," Indian Historical Review 43, no. 1 (2016): 102134.

${ }^{22}$ Bruce Bueno de Mesquita and Randolph M. Siverson, "War and the Survival of Political Leaders: A Comparative Study of Regime Types and Political Accountability," The American Political Science Review 89, no. 4 (1995): 843, 852-853.

${ }^{23}$ Alexandre Debs and Henk E. Goemans, "Regime Type, the Fate of Leaders, and War," American Political Science Review 104, no. 3 (2010): 431.

${ }^{24}$ Benjamin E. Goldsmith, Dimitri Semenovich, Arcot Sowmya, and Gorana Grgic, "Political Competition and the Initiation of International Conflict: A New Perspective on the Institutional Foundations of Democratic Peace," World Politics 69, no. 3 (2017): 496.
} 
chance of victory with relatively low costs or if fighting is the only choice in a crisis. ${ }^{25}$ Even initially popular wars can lead to public opinion turning against the government if it is long and too costly. ${ }^{26}$ Democratic governments are thus expected to be highly costsensitive because of their accountability, constraining their ability to fight.

Non-democracies vary in their cost sensitivity according to the size and makeup of their domestic audience, but as a whole are relatively cost-insensitive, as their lack of accountability to citizens gives them significant autonomy . Unlike democracies, most nondemocratic governments answer to a relatively small group of elites whose make-up varies by regime rather than their citizens. Governments in single-party states are the most constrained by relying on a relatively large number of party members, whereas military regimes rely on military officers and personalist regimes draw support from a core group of elite loyalists. ${ }^{27}$ All these governments obtain elite support by providing private rewards, rather than winning popular support with private benefits, and their policies are thus constrained only by how their supporters benefit. ${ }^{28}$ These winning coalitions are generally unaffected by the costs of armed conflict, as anything not already imposed on the general population tends to be passed down by the elites. ${ }^{29}$ Regime supporters may even benefit

\footnotetext{
${ }^{25}$ Darren Filson and Suzanne Warner, "Bargaining and Fighting: The Impact of Regime Type on War Onset, Duration, and Outcomes," American Journal of Political Science 48, no. 2 (2004): 306.

${ }^{26}$ Gartner and Segura, "War, Casualties, and Public Opinion," 278-300.

${ }^{27}$ Mark Peceny and Christopher K. Butler, "The Conflict Behavior of Authoritarian Regimes," International Politics 41, 4 (2004): 568-574.

${ }^{28}$ Bruce Bueno de Mesquita, James D. Morrow, Randolph M. Siverson, and Alastair Smith, "Policy Failure and Political Survival: The Contribution of Political Institutions," Journal of Conflict Resolution 43, no. 2 (1999): 153-154.

${ }^{29}$ Cigdem V. Sirin and Michael T. Koch, "Dictators and Death: Casualty Sensitivity of Autocracies in Militarized Interstate Disputes,” International Studies Quarterly 59, no. 4 (2015): 802-814.
} 
from fighting due to the government providing gains like captured resources, wealth, and territory to them as rewards in exchange for further support. ${ }^{30}$

These traits mean that non-democratic governments are relatively insensitive to the costs of war, but are still somewhat constrained by the need to please their supporters and the possibility of harsh consequences for failing to do so. Because non-democratic leaders focus on the elite at the expense of other citizens, they can initiate armed conflict with little regard to the costs suffered by the latter and may be incentivized to fight by the potential plunder they can distribute to supporters. ${ }^{31}$ However, while elite supporters are largely shielded from conflict costs, they can still have their benefits or status negatively impacted if the government allocates too many resources to fighting. ${ }^{32}$ This can spur government supporters to turn against it by overthrowing it in favour of a successor who can keep them rich, while the incumbent is imprisoned, exiled, or even killed. ${ }^{33}$ Additionally, nondemocratic regimes with larger domestic audiences, particularly single-party states, will be more constrained in their actions, as these larger audiences are more difficult to retain with just private benefits. ${ }^{34}$ Non-democratic governments are not wholly cost-insensitive due to their need to satisfy their supporters, and thus not totally autonomous, but on the whole are less constrained than democracies with regard to armed conflict.

\footnotetext{
${ }^{30}$ Dan Reiter and Allan C. Stam, "Democracy, War Initiation, and Victory," American Political Science Review 92, no. 2 (1998): 378-379.

${ }^{31}$ Bueno de Mesquita and Smith, The Dictator's Handbook, 228-230.

32 Bueno de Mesquita and Smith, The Dictator's Handbook, 241.

${ }^{33}$ Debs and Goemans, "Regime Type, the Fate of Leaders, and War," 433-434.

${ }^{34}$ Jessica L. Weeks, "Strongmen and Straw Men: Authoritarian Regimes and the Initiation of International Conflict," American Political Science Review 106, no. 2 (May 2012): 330-335.
} 


\section{2: What Does Cost Sensitivity Mean for Nuclear Deterrence Credibility?}

Threat credibility - that is, whether the defender can plausibly fulfill a coercive threat or not - is a key aspect of deterrence. Deterrence threats can only succeed if potential challengers believe that the defender is actually able to punish it for defying its demands. ${ }^{35}$ Chapter 2 highlighted that deterrence credibility is based on determinants such as the proportionality of the threatened response to the challenger's actions, the defender's reputation for previously fulfilling threats, and the salience of the defended object. ${ }^{36}$ Ultimately, these contribute to the basic requirements of a defender possessing the capability and resolve to fulfill threats, with the latter requiring it to demonstrate to challengers that it is willing to retaliate to convince them to not attack. ${ }^{37}$ Defenders that are seen as lacking the resolve to fulfill threats, even if only in specific circumstances, could have challengers be more willing to attack them in the belief that their threats are bluffs. To signal their resolve to fulfill conventional and nuclear deterrence threats, defenders can take actions that impose costs on themselves, known as costly signals, such as issuing public threats so that failing to fulfill them would lead to domestic audiences punishing them. ${ }^{38}$ Conversely, a perceived unwillingness by the defender to endure costs for its deterrence threats can indicate a lack of resolve to potential challengers, encouraging them to defy deterrence threats and attack.

\footnotetext{
35 Schelling, Arms and Influence, 4.

${ }^{36}$ Daniel G. Arce and Todd Sandler, "Deterrence: Credibility and Proportionality," Economics \& Politics 21, no. 3 (2009): 385; Alexandra Guinsinger and Alistair Smith, "Honest Threats: The Interaction of Reputation and Political Institutions in International Crises," Journal of Conflict Resolution 46, no. 2 (2002): 197-198.

37 Thérèse Delpech, Nuclear Deterrence in the $21^{\text {st }}$ Century: Lessons from the Cold War for a New Era of Strategic Piracy (Santa Monica: RAND Corporation: 2012), 45.

38 T.V. Paul, "Self-deterrence: Nuclear weapons and the enduring credibility challenge," International Journal 71, no. 1 (2016): 25.
} 
The section that follows demonstrates that a defender's cost sensitivity can influence how potential challengers perceive the credibility of its threats. This is due to the costs that a defender may suffer for using nuclear weapons in a conflict, such as economic sanctions, declining public support, or even alliances forming against it. Because a government can face penalties from its citizens and other states for fulfilling its threats, more cost-sensitive leaders may choose to avoid doing unless it is necessary. Costaccepting leaders, in contrast, would be more willing to fulfill those threats regardless of the potential penalties. Essentially, cost-sensitivity or a lack thereof will directly influence leader resolve to fulfill threats, and by extension how credible challengers consider those threats to be. This perception may not even translate to the defender's actual practices, particularly if the challenger's preconceptions already influence how they perceive the defender's leaders.

Though nuclear weapon use has only been threatened since 1945, there are several costs that a state that uses them first in conflict would suffer. These stem from the tradition of nuclear non-use, sometimes referred to as a "nuclear taboo," which emerged due to the perception of nuclear weapons as dangerous and repugnant compared to conventional weapons due to their sheer destructive power and effects such as radiation poisoning. ${ }^{39}$ This perception has spread through political discourse globally so that using nuclear weapons outside of extreme circumstances, whether offensively or defensively, is anathema to most states. As a result, any state that uses nuclear weapons against another in war is expected to face various costs, both from their domestic audiences and from other

\footnotetext{
${ }^{39}$ See Tannenwald, The Nuclear Taboo; T.V. Paul, "Nuclear Taboo and War Initiation in Regional Conflicts," Journal of Conflict Resolution 39, no. 4 (1995): 696-717.
} 
states. The costs, which are discussed below, are expected to be severe enough that they would likely outweigh whatever benefits a government would expect to derive from their use outside of circumstances where the existence of the state is at stake. The tradition of non-use can thus serve as a significant constraint on decision-makers in using their nuclear arsenals during crises since, as rational actors, they would be expected to avoid actions with greater costs than benefits.

A state that uses nuclear weapons first in conflict, regardless of whether it initiated the conflict, is expected to face significant international backlash for violating the tradition of non-use. This backlash is partially normative in that it would stem from nuclear weapons violating laws of armed conflict governing discrimination and proportionality due to the impact on civilians and how it would cause damage in excess of most conceivable military objectives. ${ }^{40}$ This very issue was previously raised by the International Court of Justice, which ruled in a 1996 advisory case that using nuclear weapons against anything but a purely military target in a way that would not cause massive civilian casualties in the process would fail to meet these criteria. ${ }^{41}$ There is also a rational choice element, as the harm to the state's foreign relations could make it isolated and vulnerable, leaving it worse off than it did not use them. ${ }^{42}$ Historically, both the United States and Soviet Union were concerned about possible international outcry regarding their arsenals and the ramifications to their alliances, leading the former to invest in propaganda campaigns to promote more favorable views of nuclear weapons. ${ }^{43}$ More concretely, international opinion played a

\footnotetext{
${ }^{40}$ Jeffrey G. Lewis and Scott D. Sagan, "The Nuclear Necessity Principle: Making U.S. Targeting Policy Conform with Ethics \& the Laws of War," Daedalus 145, no. 4 (2016): 62-63.

${ }^{41}$ Legality of the Threat or Use of Nuclear Weapons, Advisory Opinion (1996), ICJ Rep. 95.

${ }^{42}$ Tannenwald, The Nuclear Taboo, 48-49.

${ }^{43}$ Tannenwald, The Nuclear Taboo, 49.
} 
significant role in the Eisenhower administration deciding against using nuclear weapons in the Korean War, believing that it could cost valuable allied support. ${ }^{44}$

In addition to reduced international standing, a state that uses nuclear weapons first in a conflict is expected to suffer economic punishment by others via sanctions. Sanctions have often been used as a way of punishing states for perceived violations of international laws and norms, with the goal being to compel their governments to change their behaviour to avoid similar actions from occurring again. ${ }^{45}$ Sanctions are already used as a measure to punish states for attempting to proliferate nuclear weapons, and have played a key role in forcing states like Iran to freeze their programs in exchange for sanctions relief. ${ }^{46}$ This approach would likely be even more appealing as a way of punishing a state for actually using nuclear weapons, since sanctions would serve to punish the state in question without the risk of escalation that would accompany the use of military force against it. Such a move could have serious repercussions for a nuclear weapon state's economy if sanctions are especially severe, as it could be largely cut off from the global economy.

States using nuclear weapons when other options are available would encourage states to form alliances against it or even develop their own nuclear weapons to ensure their own security. These reactions would occur because the disproportionate use of nuclear weapons against a non-existential threat makes the state appear to be a threat to the international community ${ }^{47}$ The possibility of such an alliance forming, and the resulting

\footnotetext{
${ }^{44}$ National Security Archive, “"Memorandum of Discussion at a Special Meeting of the National Security Council on Tuesday, March 31, 1953,' 7 April 1953, Top Secret," National Security Archive, accessed December 10, 2018, 9-13, https://nsarchive2.gwu.edu//dc.html?doc=4316141-Document-03-Memorandumof-Discussion-at-a; Tannenwald, The Nuclear Taboo, 129-130.

${ }^{45}$ Jonathan Kirshner, "The Microfoundations of Economic Sanctions," Security Studies 6, no. 3 (1997): 34.

${ }^{46}$ Farhad Rezaei, "Sanctions and Nuclear Rollback: The Case of Iran," Middle East Policy 24, no. 4 (2017): 74-90.

${ }^{47}$ Sechser and Fuhrmann, Nuclear Weapons and Coercive Diplomacy, 49.
} 
threat to national security, incentivizes nuclear weapon state compliance with the norm. These concerns have historical precedent: the possibility of the US using nuclear weapons during the Korean War was so reviled by other United Nations member states, particularly non-aligned states like India, that there were concerns that Asian states would align themselves with the Soviet Union if they were used..$^{48}$ Furthermore, a nuclear weapon being used may spur neighbouring states into developing their own nuclear deterrent to defend themselves. China's nuclear test in October 1964, for example, played a significant role in Indian leaders starting their own nuclear weapons program after having already suffered a humiliating conventional defeat in the 1962 Sino-Indian War. ${ }^{49}$ As with alliance formation, this would further harm the nuclear weapon state's security, as it could end up in a mutual nuclear deterrence relationship that would increase the risk of nuclear weapons being used against it in turn.

Beyond these international-level costs, states are expected to face domestic repercussions for using nuclear weapons outside of high-salience situations due to the costs outweighing the benefits, serving as additional incentive for governments to avoid their use unless necessary. The most readily apparent such cost would be the loss of public support for the government, given the existence of a nuclear taboo and the accompanying popular revulsion towards nuclear weapons. ${ }^{50}$ Popular opposition towards nuclear weapons originated in the late 1940s with the publicization of the after-effects of the Hiroshima and Nagasaki bombings, spurring protest and the emergence of anti-nuclear weapon

\footnotetext{
48 Tannenwald, The Nuclear Taboo, 122-123.

${ }^{49}$ Vergese Koithara, Managing India's Nuclear Forces (Washington: Brookings Institution Press, 2012), 87.

${ }^{50}$ Peter Gizewski, "From Winning Weapon to Destroyer of Worlds: The Nuclear Taboo in International Politics,” International Journal 51, no. 3 (1996): 397-419.
} 
organizations. ${ }^{51}$ The emergence of popular opposition has, in at least some cases, contributed to decision-makers of nuclear weapon states considering how they could justify their use to the public and even deciding against their use as a result. The most notable instances of these occurred during the Korean War, when both the Truman and Eisenhower administrations concluded that nuclear weapons were effectively unusable due to American popular opposition. ${ }^{52}$ Thus, the possibility of domestic opposition to nuclear weapon use is a cost that is significant enough that it can constrain the decision-makers in a nuclear weapon state from ordering their use.

Public outcry against nuclear weapon use is expected primarily in situation where the costs of their use are considered to outweigh the benefits. This issue is discussed by Sechser and Fuhrmann regarding the use of nuclear weapons for compellence. As they remark in Nuclear Weapons and Coercive Diplomacy, citizens of a nuclear weapon state could potentially overlook the costs of their use in high-stakes situations, but not "over issues that the coercer has already learned to live without. ${ }^{~} 53$ Numerous deterrence scholars have noted that compellence and deterrence can be considered to be part of a single continuum of coercive diplomacy, which, along with the aforementioned costs that could influence nuclear deterrence decisions, suggests that this logic could be extended to nuclear deterrence as well. ${ }^{54}$ This point has already been raised in relation to Sechser and Fuhrmann's work by scholars like Tannenwald, who has noted incidents such as the 1973

\footnotetext{
${ }^{51}$ Tannenwald, The Nuclear Taboo, 155-189.

52 Tannenwald, The Nuclear Taboo, 150-152.

${ }^{53}$ Sechser and Fuhrmann, Nuclear Weapons and Coercive Diplomacy, 50-51.

${ }^{54}$ Robert J. Art and Patrick M. Cronin, The United States and Coercive Diplomacy (Washington: United States Institute of Peace Press, 2003); Freedman, Deterrence, 111.
} 
Yom Kippur War as potential evidence to suggest that deterrence against non-nuclear states would be undermined by the "high costs and illegitimacy of a nuclear first strike." 55

Specifically, a nuclear weapon state's public is expected to be more accepting of nuclear weapons being used in response to a significant threat, such as a large-scale invasion of their territory or a possible nuclear attack, than for retaliating against lowintensity conflict or even limited war. The acceptance in the former scenario can be explained as a consequence of the benefits of using nuclear weapons in that case - such as ensuring the continued survival of the state and averting massive loss of life - would outweigh the costs outlined in this section. ${ }^{56}$ Using nuclear weapons in response to a challenger's use of low-intensity conventional violence against the defending nuclear weapon state, on the other hand, would spark a backlash due to a conventional response being more proportional and less costly. Some experimental work, such as the 2013 study by Press, Sagan, and Valentino, indicates that public opinion regarding the use of nuclear weapons, at least among Americans, is dictated by their perceived utility in given contexts. ${ }^{57}$ Thus, while domestic public backlash can constrain nuclear weapon use, it is largely expected to occur in response to unnecessary use of nuclear weapons and not during existential crises.

\footnotetext{
${ }^{55}$ As explained further in chapter 5, however, this is further complicated by the Israeli perspective that the 1973 war (like the 1967 Six Day War) was an existential threat to the state. Robert Trager et al., "Roundtable 11-15 on Nuclear Weapons and Coercive Diplomacy," H-Diplo | ISSF, April 6, 2020, https://issforum.org/roundtables/11-15-coercive.

${ }^{56}$ Sechser and Fuhrmann, Nuclear Weapons and Coercive Diplomacy, 46-51.

${ }^{57}$ Daryl G. Press, Scott D. Sagan, and Benjamin A. Valentino, "Atomic Aversion: Experimental Evidence on Taboos, Traditions, and the Non-Use of Nuclear Weapons," American Political Science Review 107, no. 3 (2013): 188-206.
} 


\section{3: A Theory about State Regime Type and Nuclear Deterrence}

Given state regime type variations in cost sensitivity and the costs of using nuclear weapons, what would the anticipated costs of fulfilling nuclear deterrence threats mean for deterrence credibility? In the face of a significant or even existential threat to the defender, such as interstate war or the use of nuclear weapons by challengers, the credibility of its nuclear deterrence threats is unlikely to vary by regime type. In these scenarios, the relevant audience for the government - the voting public for democracies and elite supporters for non-democracies - is unlikely to oppose fulfilling nuclear deterrence threats against a challenger due to the aversion of massive loss of life, damage to infrastructure, and even the political cohesion of the state, significantly outweighing whatever costs would be directed from international audiences. Because cost sensitivity would become a minimal factor in this type of situation, the regime type of the defending state would have little to no impact on the credibility of its nuclear deterrence threats.

Given the above, I hypothesize that nuclear weapon states, regardless of their regime type, will not be targeted by potential challengers with major interstate war from the outset, with such events being the result of low-intensity conflict (up to and including more limited wars) escalating. A necessary condition for this is that the challenger(s) understand what kind of aggression would constitute an act of war to the defender instead of a form of lower-intensity conflict to tailor its actions to fall below the defender's communicated nuclear threshold. Similarly, the defender implicitly or explicitly signalling to challengers that it will use nuclear weapons against challengers under specific conditions and that it has the capability and resolve to do so is also a necessary condition for nuclear 
weapons to deter interstate war. ${ }^{58}$ Neither of these is, on its own, sufficient for nuclear deterrence to prevent interstate wars against the defender: without the defender sending clear threats to the challenger, for example, the latter would not know what actions would cross the nuclear threshold and trigger retaliation by the defender. This is expressed in hypothesis $\mathrm{H} 1$ below:

H1: Nuclear weapon states, regardless of regime type, will not be deliberately targeted by challengers in major interstate wars.

The differences in nuclear deterrence credibility, and by extension effectiveness, between state regime types are expected to be apparent with lower-intensity conflict. Unlike the aforementioned high-intensity conflicts, the benefits of fulfilling nuclear deterrence threats would be outweighed by the associated costs. The credibility of the defender's threats would thus need to be assessed, at least in part, on the perceived costsensitivity of the defender's government. This cost-sensitivity is based on the regime type of the state in question, what is the nature of the audience the government answers to, and how that audience holds it accountable for its policy decisions. In this regard, it bears similarities to Fearon's audience costs theory, as both argue that the accountability of a defending state's government to its domestic audience signals resolve (or a lack thereof) in fulfilling deterrence threats to challengers. ${ }^{59}$

Fearon's audience costs theory, however, runs into issues regarding its assumptions of how audiences react to their governments making threats and the accountability of nondemocratic governments, which my theory addresses. Audience costs theory argues that

\footnotetext{
${ }^{58}$ Delpech, Nuclear Deterrence in the 21st Century, 45, 57-60.

${ }^{59}$ James D. Fearon, "Domestic Political Audiences and the Escalation of International Disputes," American Political Science Review 88, no. 3 (1994): 579-582.
} 
democratic threats are more credible since non-democratic leaders can more freely bluff due to a lack of accountability, while the former risk being punished. ${ }^{60}$ This runs into two issues: first, selectorate theory shows that non-democratic governments are not only incentivized to fulfill threats to avoid being considered weak by supporters and punished, but are cost-insensitive enough to let their citizens bear the costs of fighting. ${ }^{61}$ Fearon's argument that domestic audiences will punish governments for backing down on their threats ignores that they would punish governments for the unnecessary costs of fulfilling those threats in low-stake crises, giving governments an incentive to not fulfill threats. ${ }^{62}$ These two issues indicate that Fearon's audience costs theory is incorrect, because it does not account for the cost-sensitivity of the governments, whether actual or merely perceived, and how it influences credibility.

My theory reaches a different conclusion due to considering the variation of costsensitivity and accountability across regime types. Rather than greater accountability signalling defender resolve, it instead indicates in low-intensity conflict situations that the government is constrained by the risk of being removed from office. Governments that answer to their citizens and are sensitive to the costs of their policies will have their nuclear deterrence threats for low-intensity conflict considered non-credible. The possibility of democratic governments being punished by voters for harming their interests thus leads to their being perceived as reluctant to fulfill deterrence threats in low-intensity conflict because they have more to lose from doing so. Domestic support for the government would likely decline significantly if nuclear weapons were used against minor provocations or to

\footnotetext{
${ }^{60}$ Fearon, "Domestic Political Audiences," 581-582.

${ }^{61}$ Weeks, "Strongmen and Straw Men;" Bueno de Mesquita and Smith, The Dictator's Handbook, 195, 226-228.

${ }^{62}$ Debs and Goemans, "Regime Type, the Fate of Leaders, and War," 431.
} 
defend minor interests, given the subsequent impact on the state's international standing and possible punishments like economic sanctions.

These preferences and the ability to hold a government accountable means that democratic nuclear weapon states will at least be perceived by challengers as unlikely to use nuclear weapons outside of existential crises, if not actually being reluctant to do so. Because voters can remove democratic governments from office in elections for policies that go against their preferences, particularly if there is a viable opposition, democratic decision-makers will be considered reluctant to use nuclear weapons in low-stakes situations in order to avoid losing power. Potential challengers, particularly those lacking their own nuclear weapons, would be reassured that they would only face a conventional response, encouraging more aggressive behaviour against the defender and its territory. ${ }^{63}$ These attacks would need to remain fairly limited to minimize the risk of escalation by the defender, however, resulting in their being limited to probing, small incursions, or limited war at most. Regardless, the resulting attack against the defender (or even threat to do so) qualifies as a failure of general deterrence. ${ }^{64}$ Whether the defender's immediate deterrence threats fail depends on whether the challenger responds to them by complying with the demands or if it chooses to continue its aggressive behaviour. ${ }^{65}$ This leads to hypothesis $\mathrm{H} 2(\mathrm{a})$ :

H2(a): If a nuclear weapon state is democratic, then it will continue to be targeted with lowintensity armed attacks and limited wars by state challengers.

\footnotetext{
${ }^{63}$ Frank Sauer, Atomic Anxiety: Deterrence, Taboo, and the Non-Use of U.S. Nuclear Weapons (Houndmills: Palgrave MacMillan, 2015), 33.

${ }^{64}$ Patrick Morgan, Deterrence Now (Cambridge: Cambridge University Press, 2003), 80-84.

${ }^{65}$ Morgan, Deterrence Now, 80-84.
} 
Non-democracies, in contrast, are expected to deter even low-intensity attacks and limited wars against them after acquiring nuclear weapons due to their relative costinsensitivity making nuclear deterrence threats credible for all levels of conflict. Unlike democracies, these governments retain power by buying the support of a winning coalition of elites with private rewards rather than the popular support of their citizens, and thus only answer to the former. This gives non-democratic leaders considerable autonomy: so long as they do not harm the interests of their supporters, they can remain relatively insensitive to how their policies impact their citizens, who have no real way to hold them accountable. This also means that they will be insensitive to how the international community's response to using nuclear weapons, such as condemnation and sanctions, would impact their citizens, and may even pass down their own costs.

Furthermore, these governments are often incentivized to use whatever force is necessary to defend themselves and their supporters. This is due to the latter group potentially considering bluffing as a sign that their interests will not be defended, and may opt to violently replace the current leadership with more suitable successors. ${ }^{66}$ This helps encourage non-democratic governments to consider even low-intensity attacks against their territory as potential threats to their continued rule. Similarly, having weaker conventional forces than the challenger encourages treating even minor attacks as serious threats, since a loss could demonstrate weakness and undermine the government's control of the state. Combined with their relative cost-insensitivity, this means that these governments would be willing to fulfill threats to use nuclear weapons in response to low-

${ }^{66}$ Weeks, "Strongmen and Straw Men," 329. 
intensity attacks, as their dependence on elites means they are only concerned about the costs they would potentially suffer as opposed to their other citizens.

These combined elements will lead potential challengers to treat non-democratic nuclear deterrence threats as credible, which is expected to discourage them from launching even low-intensity attacks due to the risk of nuclear retaliation. Being a nuclear nondemocracy is not a sufficient condition for deterrence. As with any case of nuclear deterrence, a necessary condition is that the defender threatens potential challengers with nuclear retaliation for being attacked and shows that it has the capability to do so (such as possessing the delivery vehicles to ensure the specified targets can be attacked). The defending non-democracy's perceived cost-insensitivity demonstrate resolve to potential challengers, as various actions demonstrating this (e.g. repression of citizens, corruption, interstate aggression) would act as indicators of its willingness to use nuclear weapons. The degree to which this influences challenger reluctance to attack the defending nondemocracy may vary among specific sub-types of non-democracy according to audience size differences and the subsequent degree of leader autonomy. Specifically, the smaller audiences of personalist and military regimes mean they will have significantly more autonomy than single-party governments. As a whole, however, this means that nondemocracies are unlikely to suffer general deterrence failures (beyond possible threats of attack by other states that lead nowhere), much less immediate deterrence failures. ${ }^{67}$ This leads to the following hypothesis:

${ }^{67}$ Morgan, Deterrence Now, 80-84. 
H2(b): If a nuclear weapon state is non-democratic, then it will no longer be targeted with lowintensity armed attacks and limited wars by state challengers.

The comparatively low stakes of low-intensity conflict, and even limited war, is expected to cause significant variation between nuclear weapon states in their ability to deter challengers based on their regime type. Nuclear democracies are expected to still deter challengers from initiating interstate wars against them, but their cost-sensitivity could encourage low-intensity attacks by challengers seeking to exploit a perceived high threshold for nuclear weapon use. Non-democracies can more credibly deter such attacks with their threats of nuclear weapon use due to their accountability to elites making them less constrained in their ability to carry out these threats. The primary exception to this may be in situations where a nuclear non-democracy is facing another nuclear weapon state due to nuclear retaliation potentially sparking mutual annihilation, though this depends on how the non-democracy's leaders view their chances of survival or the possibility they could inflict enough pain on the challenger to avoid further escalation. ${ }^{68}$ Non-democratic nuclear deterrence threats being more credible than those of democratic states would serve to explain the apparent disparity in conflict targeting nuclear weapon states in chapter 1 as the result of the latter being perceived as less likely to retaliate with nuclear weapons.

\subsection{1: The Influence of Reputation on Deterrence Credibility}

A significant indicator of state resolve to fulfill threats is its prior reputation, which can enhance or detract from the credibility of its nuclear deterrent; a reputation for

\footnotetext{
${ }^{68}$ While the former condition would seem illogical, it would not be without precedent, given how Cold War planning in both the US and Soviet Union involved some thoughts that part of the population could survive. See Lawrence Freedman and Jeffrey Michaels, The Evolution of Nuclear Strategy: New, Updated and Completely Revised, Fourth edition. (London: Palgrave Macmillan UK, 2019), 166.
} 
aggression in particular can signal cost-insensitivity and can further accentuate the variation among regime types described above. Reputation is typically defined as the expectations set by a state's or leader's historical record of behaviour in certain circumstances, has long played a role in establishing the credibility of deterrence threats. ${ }^{69}$ It is especially useful as a resource for states lacking complete information about how another will act in a given type of situation, as it allows them to make inferences on the basis of how it acted in similar scenarios in the past. ${ }^{70}$ In issues relating to interstate conflict, for example, a state's reputation can allow others to predict if it will respond to uses of force against it with a proportional attack or if it will retaliate in some other manner.

A state that develops a reputation for aggressive foreign policy can utilize this to further bolster the credibility of its nuclear deterrence threats. In this context, an aggressive reputation refers to a state being perceived as willing to engage in behaviour that negatively impacts the security of other states, such as repeated threats or uses of force, while demonstrating its insensitivity towards the potential or actual costs of these actions. ${ }^{71}$ Cost sensitivity is particularly important in relation to deterrence credibility: both the theory advanced in this dissertation and the broader literature posit that perceptions of a defender as willing to endure the costs of conflict is key to persuading challengers that its deterrence threats are genuine and not mere bluffing. A state that cultivates a reputation for being willing to endure these costs, either actively or unwittingly, would thus be able to further

\footnotetext{
${ }^{69}$ Alexandra Guinsinger and Alistair Smith, "Honest Threats: The Interaction of Reputation and Political Institutions in International Crises," Journal of Conflict Resolution 46, no. 2 (2002): 177-178.

${ }^{70}$ Mark J.C. Crescenzi, "Reputation and Interstate Conflict," American Journal of Political Science 51, no. 2 (2007): 388.

${ }^{71}$ Danielle L. Lupton, "Reexamining Reputation for Resolve: Leaders, States, and the Onset of International Crises,” Journal of Global Security Studies 3, no. 2 (2018): 200.
} 
enhance the credibility of its threats. ${ }^{72}$ A nuclear weapon state that is perceived by others as aggressive in waging conventional conflict will thus likely have that reputation extended to nuclear deterrence, making those threats more credible.

The expectation is that regime type will continue to lead to variation in the credibility of nuclear deterrence threats by states with aggressive reputations, with nondemocratic states being more successful at deterring challengers than their democratic counterparts. The reason for this difference is a matter of opportunity: the relative costinsensitivity of non-democratic states makes them more likely to engage in aggressive foreign policy, including armed conflict, than democracies, and thus can more frequently demonstrate their willingness to endure costs. This allows them to develop a reputation for aggression, letting other states (including potential challengers) to infer how these defenders would behave in nuclear deterrence scenarios from conventional conflict. It is important to note that democratic nuclear weapon states are just as capable of developing such a reputation. The expectation set by the theory for this dissertation is that their propensity for choosing to fight wars that are believed to have a low risk of defeat and relatively low costs, due to their greater accountability to their citizens, means that they will fight less frequently, and thus have fewer opportunities to demonstrate cost insensitivity. ${ }^{73}$ This leads to the following hypothesis:

\footnotetext{
${ }^{72}$ Todd S. Sechser, "Reputations and Signaling in Coercive Bargaining," Journal of Conflict Resolution 62, no. 2 (2018): 318-345.

${ }^{73}$ In practice, some democratic states, particularly the United States, have demonstrated a strong willingness to fight wars, including long and costly ones that end in stalemate or defeat. Even in these cases, however, decision-makers are motivated by the belief that victory is likely and relatively cheap, or even that fighting is the best of a series of poor choices. Bueno de Mesquita and Smith, The Dictator's Handbook, 227-230; Filson and Warner, "Bargaining and Fighting," 296-313.
} 
H3: If a nuclear weapon state has a reputation for aggression, then it will no longer be targeted with low-intensity armed attacks and limited wars by state challengers.

\subsection{2: Deterrence Credibility, Non-State Actors, and Asymmetric Conflict}

The issue of nuclear weapons and non-state actors, such as terrorist organizations, has repeatedly been discussed in the literature, and though this dissertation focuses on interstate conflict, it is necessary to explain how this particular issue is addressed. These discussions primarily center around concerns that terrorists will either acquire a nuclear weapon or be able to develop their own, with concerns that their operating according to different values than those anticipated by deterrence, along with a goal of deliberately causing large-scale death, would make them impossible to deter. ${ }^{74}$ The consensus, however, is that it is very unlikely for a non-state actor to acquire or develop a nuclear weapon on their own: designing and assembling a nuclear weapon is a highly technical and expensive process that is difficult to carry out without being noticed, while existing nuclear weapons would be difficult to steal given the security measures implemented by states. ${ }^{75}$ It is possible that a state sponsor could provide a non-state actor with a nuclear weapon, though the risk of the weapon being traced back to it, the subsequent retaliation it would face, and the loss of control over a nuclear weapon makes this a slim possibility. ${ }^{76}$

Non-state actors are unlikely to be deterred from attacking a nuclear weapon state due to its nuclear arsenal regardless of regime type, at least not directly. First, they generally do not pose enough of a threat to states to justify using nuclear weapons against

\footnotetext{
${ }^{74}$ Anna Bella Korbatov, Erika Suzuki, and Bethany L. Goldblum, "The fight against nuclear terrorism needs global cooperation - and the IAEA," Bulletin of the Atomic Scientists 71, no. 5 (2015): 68-69; Robert S. Litwak, "Recalibrating Deterrence to Prevent Nuclear Terrorism," The Washington Quarterly 40, no. 1 (2017): 55-57.

${ }^{75}$ Litwak, "Recalibrating Deterrence," 56.

${ }^{76}$ Leonard Weiss, “On Fear and Nuclear Terrorism," Bulletin of the Atomic Scientists 71, no. 2 (2015): 79.
} 
them: terrorist attacks tend to only cause the deaths of tens or hundreds of individuals, with cases like the September 11, 2001 attacks being far outside the norm. ${ }^{77}$ The theory's requirement that credible nuclear deterrence requires a threat to the defender that justifies the costs means that non-state actors are unlikely to qualify. Targeting is also an issue, since these actors often lack a proper territorial base that could be targeted with nuclear weapons, and are likely throughout one or more countries, meaning that a nuclear weapon would cause significant collateral damage. ${ }^{78}$ Following the hypotheses outlined in section 3.3, democratic nuclear weapon states, such as the US, would be perceived as unlikely to follow through with its nuclear deterrence threats against these actors due to the potential civilian casualties and international outcry that would result. ${ }^{79}$ There are other practical issues, such as how some non-state actors do not value deterrence targets like territory or a functioning economy in the same way that states would, instead prioritizing non-material objects such as success and legitimacy that could not be directly targeted with nuclear weapons. ${ }^{80}$ Simply put, non-state actors acting on their own are unlikely to be deterred by nuclear weapons; in fact, the use of fear by terrorists to alter the status quo can be said to make it incompatible with traditional deterrence, which uses fear for preserving the status quo. $^{81}$

\footnotetext{
${ }^{77}$ Paul, "Self-deterrence," 28.

${ }^{78}$ Christoper McIntosh and Ian Storey, "Between Acquisition and Use: Assessing the Likelihood of Nuclear Terrorism," International Studies Quarterly 62, no. 2 (2018): 295-296.

${ }^{79}$ Arce and Sandler, "Deterrence," 397.

${ }^{80}$ Alex S. Wilner, "Deterring the Undeterrable: Coercion, Denial, and Delegitimization in Counterterrorism," Journal of Strategic Studies 34, no. 1 (2011): 11-12.

${ }^{81}$ Andreas Wenger and Alex Wilner, "Deterring Terrorism: Moving Forward," in Deterring Terrorism: Theory and Practice, ed. Andreas Wenger and Alex Wilner (Stanford, CA: Stanford University Press, 2020), 305.
} 
Nuclear deterrence becomes relevant in relation to state-sponsored terrorism since the sponsor in question can be deterred. In these cases, the terrorist organization can be considered to be acting as an extension of the state sponsoring it, meaning that the organization's actions can be attributed to the sponsor. ${ }^{82}$ Examples of state-sponsored organizations include Hezbollah, which has strong ties to the Iranian and Syrian governments, and militant groups in Jammu and Kashmir like Lashkar-e-Taiba, which are backed by Pakistani intelligence services and directed to attack Indian targets. ${ }^{83}$ In such cases, a nuclear weapon state could make deterrence threats against the state sponsor to pressure it into directing the non-state actor to not attack it or end their relationship entirely, though this has been noted as closer to compellence due to being meant to change state behaviour regarding sponsorship of terrorism. ${ }^{84}$ The effectiveness of such an approach, however, would vary according to the degree of control that the state sponsor has over the non-state actor; if it has little to no control over the group's actions and only supplies it with training and equipment, deterrence threats against the state would be ineffective in actually affecting terrorism.

Within the context of the theory, state-sponsored acts of conventional terrorism would qualify as a form of low-intensity conflict and would thus merit study. In such attacks, the perpetrators would be considered an extension of the state sponsor in question (e.g. an attack by Hezbollah directed by Iran would be attributable to Iran) rather than wholly independent actors. Because of this, the state sponsor could be the recipient of

\footnotetext{
82 Jeffrey Knopf, "The Fourth Wave in Deterrence Research,” Contemporary Security Policy 31, no. 1 (2010): 10.

${ }^{83}$ Wilner, "Deterring the Undeterrable," 15; Ahsan I. Butt, "Do nuclear weapons affect the guns-butter trade-off? Evidence on nuclear substitution from Pakistan and beyond," Conflict, Security \& Development 15, no. 3 (2015): 238.

${ }^{84}$ Knopf, "The Fourth Wave in Deterrence Research," 11.
} 
deterrence threats sent by the defender warning against supporting or directing such attacks. Those that are not committed on behalf of a state, or at least where a state does not appear to exert significant control over the actions of a terrorist organization, would fall outside the scope of the theory, since nuclear deterrence threats would seem non-credible in such instances.

\section{4: Theoretical Contributions}

This theory draws on the audience costs concept, but differs in two key respects. Fearon's audience costs argument argues that states with broader domestic political audiences, specifically democracies, can make more credible threats than those with small audiences due to being more vulnerable to punishment for bluffing and thus having additional incentive to fulfill threats. ${ }^{85}$ While the theory I propose in this dissertation similarly argues that deterrence threat credibility will vary according to the defending state's regime type and the ability of citizens to punish the government's actions, it differs in regard to the causal mechanism and which regime type can make more credible threats. The ability for voters to punish democratic governments by removing them from office means that they will be perceived as less likely to fulfill deterrence threats for low-intensity conflict because the costs on supporters for doing so would be too high. In contrast, the inability of citizens to punish non-democratic governments, given that they draw support from elites, means that their deterrence threats are more credible, as their actual supporters are unlikely to bear the costs of fulfilling them and they have strong incentives to avoid showing weakness.

\footnotetext{
${ }^{85}$ Fearon, "Domestic Political Audiences," 581-582; Joshua D. Kertzer and Ryan Brutger, "Decomposing Audience Costs: Bringing the Audience Back into Audience Costs Theory," American Journal of Political Science 60, no. 1 (2016): 234-249.
} 
Secondly, this theory also differs from audience costs in accounting for the possible role of international audiences. Audience costs largely, if not sometimes exclusively, focuses on domestic audiences, sidelining how other states may react as a long-term issue. ${ }^{86}$ I argue that the anticipated reaction of international audiences to the defender fulfilling its deterrence threats needs to be accounted for when evaluating threat credibility. The costs that these audiences could impose on the defending state, such as economic sanctions, are likely to be taken into consideration by its decision-makers when deciding to fulfill deterrence threats or not, since these could potentially lead to their being removed from power. This is another area in which the defender's reactions would vary according to regime type - non-democratic governments, as previously discussed, may pass down whatever costs their supporters suffer to citizens who have no power over them, with sanctions being no exception to this.

The theory also explains and expands upon the stability-instability paradox. A major point of the paradox is that mutual nuclear deterrence encourages low-level conflict between states, creating strategic instability as a result. ${ }^{87}$ The theory provides an explanation for democratic defenders in a nuclear dyad being attacked as the result of potential punishment by domestic audiences undermining their nuclear deterrence credibility. Potential challengers will perceive an opportunity to make small incremental gains against this defender with limited attacks that would fall below the defender's nuclear weapon threshold, only provoking a conventional response at worst. ${ }^{88}$ The theory also

\footnotetext{
${ }^{86}$ Peter J. Partell and Glenn Palmer, "Audience Costs and Interstate Crises: An Empirical Assessment of Fearon's Model of Dispute Outcomes," International Studies Quarterly 43, no. 2 (1999): 390.

${ }^{87}$ Jervis, The Illogic of American Nuclear Strategy, 148-150.

${ }^{88}$ Bryan R. Early and Victor Asal, "Nuclear Weapons, Existential Threats, and the Stability-Instability Paradox," Nonproliferation Review 25, no. 3-4 (2018): 228-229.
} 
allows for the extension of the paradox's dynamics to dyads where one side is a democratic nuclear weapon state and the other does not possess any nuclear weapons of its own. In those instances, the non-nuclear weapon state could launch low-intensity attacks against the democratic nuclear weapon state, believing that the latter will effectively self-deter from using nuclear weapons over cost concerns. ${ }^{89}$ This effectively replicates the dynamic that proponents of the stability-instability paradox believe would occur in instances of mutual nuclear deterrence while only requiring one state in the dyad to possess nuclear weapons.

\section{5: Conclusion}

The theory proposed in this chapter explains how variations in a defending nuclear weapon state's regime type can affect whether challengers target it with low-intensity attacks. Ultimately, the government's cost-sensitivity to fulfilling nuclear deterrence threats in response to such attacks and whether its citizens can hold it accountable for those costs will affect how credible those threats appear to potential challengers. More costsensitive democracies will be seen as unwilling to fulfill those threats in low-intensity conflict to reduce the risk of being removed from office, encouraging challengers to attack. Cost-insensitive non-democracies, meanwhile, will be seen as willing and able to use nuclear weapons in response to even minor attacks due to their need to avoid showing weakness to their elite supporters, with challengers viewing their threats as credible and not attacking as a result.

This theoretical framework makes two significant advances in our understanding of nuclear deterrence. First, it provides a possible explanation for why some nuclear

${ }^{89}$ Paul, “Self-deterrence,” 28-36. 
weapon states appear to be more successful in deterring armed attacks by challengers than others. Because non-democracies can make more credible nuclear deterrence threats against even low-intensity attacks, challengers will be dissuaded from attacking them outright. The difficulties faced by democracies in this regard, meanwhile, means challengers may instead be encouraged to launch such attacks in the belief that they can make small gains while avoiding significant escalation. Secondly, it also provides a possible roadmap for democratic states to recognize where their nuclear deterrent may suffer a credibility problem and how to remedy it. By taking actions that signal resolve and establishing varying levels of conventional response to aggression by challengers, democratic nuclear weapon states can demonstrate that challengers will still face some form of punishment for aggression. 


\section{Chapter 4: Methodology}

\section{1: Rationale}

This chapter outlines a methodology for testing the theory and associated hypotheses discussed in Chapter 3. The study, which focuses on the 1945-2018 period, examines changes in how nuclear weapon states are targeted by challengers with attacks between their pre- and post-nuclear acquisition periods to determine the role of the defender's regime type in the credibility of its nuclear deterrence threats. Given the challenges of studying nuclear deterrence, this study uses an embedded comparative case study approach that utilizes process tracing and qualitative data, along with some quantitative data for filling in gaps as they arise. ${ }^{1}$ The unit of analysis in this study consists of nuclear weapon states, with crises targeting select defending states before and after their acquisition of nuclear weapons serving as the observations. ${ }^{2}$ This approach, in addition to ensuring cross-case comparison between nuclear weapon states to determine the role of regime type, also allows for within-case comparisons for individual states to determine the impact of nuclear weapons on deterring armed conflict. ${ }^{3}$

The methodology described in this chapter and the overall theory use an iterative inductive approach rather than a purely deductive or inductive one. The puzzle motivating this dissertation lies with a "hunch" - that variation in regime type could explain differences in nuclear deterrence effectiveness because it affects credibility - making the

\footnotetext{
${ }^{1}$ John W. Cresswell and Vicki L. Plano Clark, Designing and Conducting Mixed Methods Research: Second Edition (Los Angeles: SAGE Publications, 2011), 71.

${ }^{2}$ Charles C. Ragin, The Comparative Method: Moving Beyond Qualitative and Quantitative Strategies (Berkeley: University of California Press, 2014), 7-9.

${ }^{3}$ Alexander L. George and Andrew Bennett, Case Studies and Theory Development in the Social Sciences (Cambridge: MIT Press, 2005), 67.
} 
core of the dissertation inductive. ${ }^{4}$ The theory and the hypotheses derived from it, however, are derived from the existing literature on nuclear deterrence, conventional conflict, and regime type. Along with the methodology following a clearly outlined procedure, this brings the bulk of the dissertation in line with a deductive approach. ${ }^{5}$ In following such an approach, I ensure that the dissertation has logical rigour, follows a replicable procedure, and is informed by theory.

As has been stated in previous chapters, there are few prior studies that seek to determine if there is a relationship between state regime type and nuclear deterrence, much less what that relationship is. At most, there are some case studies focusing on particular states that do not engage in theory-building, while the rare cases that have proposed theories did not test them using historical cases, making their methodologies incompatible with the objectives of this dissertation. ${ }^{6}$ To this end, I instead follow the example of prior scholarly works that utilize qualitative data and approaches to examine variation in nuclear deterrence effectiveness between states, particularly Vipin Narang's Nuclear Strategy in the Modern Era and Todd Sechser and Matthew Fuhrmann's Nuclear Weapons and Coercive Diplomacy. ${ }^{7}$

Several obstacles associated with the study of nuclear deterrence make a qualitative approach particularly useful. While the small number of nuclear weapon states, and thus

\footnotetext{
${ }^{4}$ Uwe Flick, An Introduction to Qualitative Research, $4^{\text {th }}$ Edition (London: SAGE Publication, 2009), Kindle ebook, loc. 1725.

${ }^{5}$ Stephen D. Krasner, “Toward Understanding in International Relations," International Studies Quarterly 29, no. 2 (1985): 142-143.

${ }^{6}$ Shoko Kohama and Kazuto Ohtsuki, "Political Institutions and Nuclear Deterrence" (60th International Studies Association Annual Convention, Toronto, March 27, 2019), http://web.isanet.org/Web/Conferences/Toronto\%202019-s/Archive/9ed874b6-e516-4f4e-bd0ef51198181128.pdf.

${ }^{7}$ It should be noted that both of these works use qualitative approaches within a broader mixed-methods framework, though the application of qualitative methods serves as the focal point of their studies.
} 
cases, precludes a purely quantitative approach, it also reduces the number of independent variables to account for. ${ }^{8}$ In total, there have been a total of 13 states that have ever possessed nuclear weapons, including South Africa, which had dismantled its arsenal by 1991, and Ukraine, Belarus, and Kazakhstan, which unintentionally inherited nuclear weapons during the Soviet Union's collapse and quickly returned them to Russia. The only nuclear weapon states as of 2020 are the United States, Russia, the United Kingdom, France, China, Israel, India, Pakistan, and North Korea. ${ }^{9}$ A qualitative approach can avoid the small- $n$ issue while being better suited to capturing historical details than quantitative data and approaches. ${ }^{10}$ However, a wholly qualitative study can be hindered by issues such as a lack of documentary evidence, only indirect insight into the object of study, and a potential lack of external validity due to a focus on particular cases. ${ }^{11}$ Integrating quantitative data alongside quantitative data and approaches can allow for a more complete understanding of the issue being studied by filling in gaps.. ${ }^{12}$

The rest of the chapter proceeds as follows. It first discusses the various data sources consulted, including justifications and examples. This is followed by an overview of the dependent variable of interest - the frequency of armed conflict targeting the defending nuclear weapon state - and independent variables such as the regime type of the defender and challengers and their possession of nuclear weapons, including how they are

\footnotetext{
${ }^{8}$ Krasner, "Toward Understanding in International Relations," 140-142.

${ }^{9}$ Kelsey Davenport and Kingston Reif, "Nuclear Weapons: Who Has What at a Glance," Arms Control Association, last modified July 2019, accessed February 14, 2020, https://www.armscontrol.org/factsheets/Nuclearweaponswhohaswhat.

${ }^{10}$ Todd S. Sechser and Matthew Fuhrmann, Nuclear Weapons and Coercive Diplomacy (New York: Cambridge University Press, 2017), 64-65.

${ }^{11}$ Sechser and Fuhrmann, Nuclear Weapons and Coercive Diplomacy, 70-71.

${ }^{12}$ Sidney Tarrow, "Bridging the Quantitative-Qualitative Divide in Political Science," American Political Science Review 89, no. 2 (1995): 473-74.
} 
defined and measured. This is followed by a step-by-step explanation of the analytical process for each case study, beginning with an evaluation of their governance, details of the pre- and post-nuclear crises being studied, the decision-making of the states involved, and the defender's nuclear deterrence threats and command and control structure. The chapter then concludes with a discussion of the criteria used in the case selection process. This includes explanations for excluding the five nuclear weapon states recognized in the Non-Proliferation Treaty (NPT), along with unsuccessful nuclear proliferator states and former nuclear weapon states. The four cases ultimately chosen for the dissertation - India, Israel, Pakistan, and North Korea - are discussed here, including the advantages and potential downsides associated with their selection.

\section{2: Data Sources}

\subsection{1: Primary \& Secondary Qualitative Sources}

One of the main types of sources consulted for this study are primary qualitative sources. This encompasses numerous types of documents, including government memoranda and meeting minutes, letters and journals written by government officials, reports, diplomatic cables, military budgets, and transcripts of legislative debates. Many of these documents are found in digital and physical archives, such as the George Washington University National Security Archive and the Woodrow Wilson Center Digital Archive. Others, such as transcripts of legislative debates, are available from the relevant governments through their legislatures' websites. These records are useful for gaining insight into the thought processes of individuals involved in decision-making and policy 
formulation during crises and conflicts. ${ }^{13}$ This can be advantageous relative to secondary sources, which are typically written long after the events being studied and thus benefit from hindsight. ${ }^{14}$ The challenges in interviewing relevant individuals who may either be deceased or unwilling to discuss crises means that primary sources can serve as a substitute.

Some content analysis is applied to documents studied in this dissertation, with the inferred data used to determine what elements influenced government decision-making processes during the selected crises and conflicts; however, limited opportunities for its use means that it only supports the process tracing. Krippendorf defines content analysis as a research technique designed to make inferences from data according to its context in a replicable manner, making it well-suited for analyzing documents. ${ }^{15}$ This dissertation specifically uses semantical content analysis, wherein certain objects in the text are studied for how often they are referenced and how they are characterized, then classified according to their meanings. ${ }^{16}$ From there, it is possible to infer how the authors of the documents view those particular objects and how policy is influenced. Correlation between the documents themselves and their broader context is also key for making inferences; for example, understanding a government's procedures for a given situation and what is being mobilized during a crisis can allow inference of how decision-makers view the situation. ${ }^{17}$

For this dissertation, this approach entails searching for terms and phrases that serve as indicators of decision-maker perceptions of their adversaries and a given crisis, then

\footnotetext{
${ }^{13}$ Vernon K. Dibble, "Four Types of Inference from Documents to Events," History and Theory 3, no. 2 (1963): 203-205.

${ }^{14}$ Lawrence Freedman, "The Benefits of Hindsight: Historical Research and Political Accountability," Survival 59, no. 3 (2017): 95.

${ }^{15}$ Klaus Krippendorf, Content Analysis: An Introduction to Its Methodology (London: SAGE Publications, 1980), 21.

${ }^{16}$ Krippendorf, Content Analysis, 33.

${ }^{17}$ Dibble, "Four Types of Inference," 210-213.
} 
determining if and how those attitudes influenced policy. Government documents describing the government of an opposing state as "cowardly," for example, can indicate that decision-makers believe their counterparts lack the resolve to fulfill their threats, which may signal a willingness for challengers to attack defenders. Conversely, descriptions of those opponents as "reckless" can indicate that they are perceived as willing to act despite the potential costs and consequences of their behaviour. Warnings by a defending state's officials that either allude or explicitly state what type of force they are willing to use in a crisis, such as not hesitating "to use any weapon in our arsenal," can be useful indicators of resolve, particularly if they are high-ranking officials or military officers. ${ }^{18}$ Statements regarding a defender or challenger's deterrence threats, whether conventional or nuclear, similarly can serve as indicators as to how seriously they take their threats and how they intend to respond. Orders to the military during crisis situations are also highly useful in this regard - for example, deliberate restrictions on where the military can operate and the capabilities it can use during a crisis can indicate concerns over a defender retaliating with nuclear weapons, particularly if these align with the defender's deterrence threats.

Primary sources do have important limitations, with limited access to many relevant documents being significant enough as to limit the utility of content analysis. This is often due to their remaining classified and thus inaccessible to the public, while others may have significant portions redacted. ${ }^{19}$ This largely occurs with more recent crises; for example, the US Department of State has only declassified documents up until the early 1980s, with

\footnotetext{
${ }^{18}$ Celia W. Dugger, "Atmosphere Is Tense as India and Pakistan Agree to Talks," New York Times, June 1, 1999, https://www.nytimes.com/1999/06/01/world/atmosphere-is-tense-as-india-and-pakistan-agree-totalks.html.

${ }^{19}$ George and Bennett, Case Studies and Theory Development, 99-101.
} 
others remaining under review. ${ }^{20}$ Even declassified documents can suffer from reflecting knowledge from the time of their production; while beneficial in understanding the mindsets of decision-makers, this makes it difficult to develop an understanding of a crisis solely utilizing these sources. ${ }^{21}$ In other cases, particularly government memoranda, letters, and journals, individuals may alter their accounts, unintentionally or otherwise, to portray their actions in a better light than the reality of the situation would suggest. ${ }^{22}$ As a result, relying solely on primary sources can lead to inaccurate inferences due to, for example, misperceptions of an adversary's intentions during a crisis. The limited number of primary sources available, meanwhile, meant that the actual use of content analysis in this dissertation proved limited.

The above means that secondary qualitative sources ultimately serve as the main source of data for this dissertation, as well as serving to confirm the veracity of primary sources and fill in potential gaps. As with primary sources, this is a broad category that includes academic books and manuscripts, peer-reviewed journal articles, and various media reports (including contemporaneous ones). These possess several distinct advantages over primary sources, most notably in their greater accessibility relative to potentially classified documents and their use in conceptualizing and operationalizing dependent and independent variables. ${ }^{23}$ Secondary sources can bypass the first issue by integrating information from multiple such documents, including those removed from

\footnotetext{
${ }^{20}$ United States Department of State Office of the Historian, "Status of the Foreign Relations of the United States Series," accessed March 17, 2019, https://history.state.gov/historicaldocuments/status-of-the-series.

${ }^{21}$ Glenn A. Bowen, "Document Analysis as a Qualitative Research Method," Qualitative Research Journal 9, no. 2 (2009): 31-32.

${ }^{22}$ Lisa Harrison, Political Research: An Introduction (New York: Routledge, 2001), 124.

${ }^{23}$ Flick, An Introduction to Qualitative Research, loc. 5410.
} 
public access. ${ }^{24}$ Furthermore, these also address issues regarding potential bias and error in primary source documents, as their authors may have misinterpreted or excluded some information and thus present an incomplete image. ${ }^{25}$ As such, their inclusion is necessary to check potential biases in primary sources and to fill in information gaps.

Other types of secondary sources, particularly media publications such as newspaper articles, are also useful for these purposes. News articles from a crisis can strike a balance between primary and secondary sources by providing contemporaneous insight into events like the former, but doing so in a more objective manner than documentation written by individuals directly involved in a crisis. ${ }^{26}$ Additionally, news articles can also present a contemporary perspective into events from outside the governments, as many of the aforementioned primary sources present the views of individuals working within governments and have information that the public would likely not have had access to at the time. This second point does mean that news articles are restricted to a complementary role due to this project's focus on decision-making processes.

\subsection{2: Quantitative Data}

This dissertation also includes quantitative sources of data in a supporting capacity. Quantitative data are useful for providing insight into broader conflict trends that may not be apparent solely from qualitative sources, particularly in the frequency that armed conflict occurs in dyads. ${ }^{27}$ The International Crisis Behaviour Project and Correlates of War (COW) Project MID datasets, for example, can help illustrate the frequency of

\footnotetext{
${ }^{24}$ Bowen, "Document Analysis," 33.

${ }^{25}$ Flick, An Introduction to Qualitative Research, loc. 5400-5413.

${ }^{26}$ Bowen, "Document Analysis," 30, 35.

${ }^{27}$ Cresswell and Plano Clark, Mixed Methods Research, 62.
} 
interstate crisis and conflicts over time, rather than simply highlighting key cases. As such, they can provide further context regarding broader state behaviours, thus filling in gaps left by qualitative sources and strengthening the external validity of the findings. ${ }^{28}$

However, purely quantitative sources suffer from several limitations in the study of nuclear deterrence. To begin with, the small universe of available nuclear weapon states to study precludes using more advanced statistical analysis. ${ }^{29}$ As discussed by Vipin Narang, they are also of limited utility in studying finer details of historical cases, including crisis decision-making processes, and can potentially muddy the analysis by obscuring causality. ${ }^{30}$ This is not helped by many existing quantitative sources utilizing a dummy variable for nuclear weapon states that disregards differences in their arsenals. ${ }^{31}$ Frank Harvey has similarly noted that quantitative data on nuclear deterrence is further limited in being unable to distinguish between normal observations and those where deterrence is successful, as further information about decision-making is necessary in order for the latter to be meaningfully distinct from the former. ${ }^{32}$ Given these limitations, using quantitative data in a supporting capacity to qualitative sources utilizes their ability to illustrate broader trends to further strengthen the findings while mitigating the weaknesses of both types of data. These limitations also mean that quantitative methods would be of limited utility hence the exclusively qualitative methodology used here.

\footnotetext{
${ }^{28}$ Cresswell and Plano Clark, Mixed Methods Research, 62.

${ }^{29}$ Sechser and Fuhrmann, Nuclear Weapons and Coercive Diplomacy, 64-65.

${ }^{30}$ Vipin Narang, Nuclear Strategy in the Modern Era: Regional Powers and International Conflict (Princeton: Princeton University Press, 2014), 10-11.

${ }^{31}$ Narang, Nuclear Strategy in the Modern Era, 229.

${ }^{32}$ Frank P. Harvey, The Future's Back: Nuclear Rivalry, Deterrence Theory, and Crisis Stability after the Cold War (Montreal: McGill-Queen's University Press, 1997), 33.
} 


\section{3: The Dependent Variable}

\subsection{1: Crises and armed conflicts targeting the defending nuclear weapon state}

The dependent variable studied in this dissertation is the number of crises and armed conflicts targeting a defending nuclear weapon state. This variable encompasses both threats and actual uses of force by at least one state (the challenger) towards a given nuclear weapon state (the defender). ${ }^{33}$ The period studied ranges from 1945, when nuclear weapons were first used, to the end of 2018, ensuring that there is sufficient information and documentation available on the crises studied to reach a conclusion on the role of regime type. Relevant crises that occur beyond this period, such as during 2019 and 2020, are referenced, but not studied to the same degree as others. For the purposes of this project, Brecher and Wilkenfeld's definition of a crisis as a situation where at least two states engage in increasingly hostile interactions with each other to the point that they increase the risk of military hostilities, destabilize their relationship, and challenge the structure of an international system, is used. ${ }^{34}$ Threats, meanwhile, are defined as statements by officials of a state (either a defender or challenger) to a target explicitly or implicitly promising retaliation if the target performs a specified action, and with their severity measured according to the degree of harm promised and the sender's ability to do so. ${ }^{35}$

The focus of this research is on both threatened and actual uses of force, particularly instances of low-intensity and high-intensity armed conflict, or when a crisis does not escalate from threats to uses of force. Low-intensity conflict refers to comparatively minor

\footnotetext{
${ }^{33}$ Zeev Maoz et al, "The Dyadic Militarized Interstate Disputes (MIDs) Dataset Version 3.0: Logic, Characteristics, and Comparisons to Alternative Datasets," Journal of Conflict Resolution 63, no. 3 (2019): 812.

${ }^{34}$ Michael Brecher and Jonathan Wilkenfeld, A Study of Crisis (Ann Arbor: University of Michigan Press, 1997), 4-5.

${ }^{35}$ Donald G. Brennan, "Setting and Goals of Arms Control,” Daedalus 89, no. 4 (1960): 681-707.
} 
militarized interstate disputes (MIDs), such as border skirmishes and small raids, as their relatively limited aims and scope will typically not pose a significant threat to the defending state. ${ }^{36}$ This definition also extends to limited wars, since the challenger's aims are still limited (at least relative to general interstate war), even if the force used is much more expansive in scope. ${ }^{37}$ General interstate wars, on the other hand, are considered higherintensity conflict due to posing a much more significant threat, if not being existential in scope, by disrupting the defender's political and economic cohesion. ${ }^{38}$ Such a conflict could even threaten the physical infrastructure and population of the defending state if the challenger uses sufficient conventional force or nuclear weapons. ${ }^{39}$ Interstate war, in the context of this dissertation, follows the COW Project definition of a conflict between at least two states with organized armed forces and with at least 1,000 battle-related deaths within a period of twelve months. ${ }^{40}$

There are two important details to note regarding the assessment of this variable. First, an armed conflict that starts off as high- or low-intensity may not stay that way throughout its duration. The former can gradually wind down from a major interstate conflict to occasional skirmishes without leading to a cease-fire or peace agreement. Conversely, cases of low-intensity conflict can become a full-blown war if the belligerents escalate their actions. Secondly, this project's focus on interstate relations, as well as the

\footnotetext{
${ }^{36}$ Glenn Palmer et al, "The MID4 dataset, 2002-2010: Procedures, coding rules and description," Conflict Management and Peace Science 32, no. 2 (2015): 222-242.

${ }^{37}$ Donald G. Brennan, "Setting and Goals of Arms Control," Daedalus 89, no. 4 (1960): 687-688.

${ }^{38}$ Bryan R. Early and Victor Asal, "Nuclear weapons, existential threats, and the stability-instability paradox," Nonproliferation Review 25, nos. 3-4 (2018): 224.

${ }^{39}$ Early and Asal, "Nuclear weapons, existential threats," 224.

${ }^{40}$ Meredith Reid Sarkees, The COW Typology of War: Defining and Categorizing Wars (Version 4 of the Data), Correlates of War Project, last modified 2010, accessed October 29, 2017, 1, http://www.correlatesofwar.org/data-sets/COW-war/the-cow-typology-of-war-defining-and-categorizingwars/at_download/file.
} 
broader issues regarding non-state actors and nuclear deterrence outlined in 3.3.2, means that attacks by non-state actors are only considered if it can be established that they were acting at the behest of a state sponsor. For an attack by a non-state actor to be considered state-sponsored, it must either have been directed to launch an attack by a state government agency, if not the government itself, and/or have received some degree of material support or training from it. ${ }^{41}$ This level of support would also mean that an attack would be attributable to the state sponsor.

Data on this variable is drawn from multiple qualitative and quantitative sources. Datasets such as the International Crisis Behaviour (ICB) Project, the COW Project MID dataset, and the UCDP/PRIO Armed Conflict Dataset are especially useful instances of the latter due to highlighting when crises and conflicts occurred, their duration, and intensity. These datasets additionally contain information about the use of threats by challengers and, particularly in the case of the ICB Project, other changes and actions that can trigger crises, such as regional-level changes and economic embargoes. ${ }^{42}$ Consulting multiple datasets instead of just one is beneficial due to compensating for variations in measurements and data collection practices. ${ }^{43}$ For example, the COW Project data on MIDs is considered to be particularly detailed, but at the time of writing only goes up to $2010 .{ }^{44}$ The UCDP/PRIO data, meanwhile, goes up to 2017 , but only begins around 1975, thus excluding a significant portion of the post-WWII period. ${ }^{45}$

\footnotetext{
${ }^{41}$ Jeffrey Knopf, “The Fourth Wave in Deterrence Research,” Contemporary Security Policy 31, no. 1 (2010): 10.

${ }^{42}$ Michael Brecher et al, International Crisis Behavior Data Codebook, Version 12, p. 10, 2017, http://sites.duke.edu/icbdata/data-collections/.

${ }^{43}$ Tarrow, "Bridging the Quantitative-Qualitative Divide," 474.

${ }^{44}$ Palmer et al, "The MID4 Dataset," 222-242.

${ }^{45}$ Uppsala University Department of Peace and Conflict, "Uppsala Conflict Data Program," last modified 2019, accessed March 15, 2019, https:/ucdp.uu.se/\#/.
} 
As previously discussed, relying solely on quantitative data is problematic due to the challenges they face in determining causality and capturing finer historical details, making qualitative sources much more important. Qualitative sources not only contextualize what is found in datasets, but can shed additional light on the crises and conflicts being studied. This includes the circumstances that cause a crisis, such as what led a challenger to initially threaten or attack the defender, and especially what led to policy-makers believing that their actions did not cross the threshold for nuclear weapon to be used in retaliation. Qualitative sources can further help to explain the decision-making processes within the governments of the challengers and the defender during any subsequent conflicts that emerged from these crises, including what domestic and international considerations may have influenced their policies. Importantly, this includes decisions to not use otherwise advantageous strategies and weapons. Finally, qualitative sources can provide insight into how conflicts ended and the consequences for the parties involved, which is not apparent in quantitative datasets.

\section{4: Independent Variables}

\subsection{1: State regime type}

One of the most important independent variables considered in this study is the regime type of the defending nuclear weapon state. The dissertation utilizes the Polity 5 Project definition of regime type as the structure of institutionalized governing authority for a given state. ${ }^{46}$ These are broadly grouped within the categories of democracy, anocracy/semi-democracy, and autocracy. These are somewhat simplified for this project

\footnotetext{
${ }^{46}$ Monty G Marshall and Ted Robert Gurr, Polity 5 Political Regime Characteristics and Transitions, 1800-2018: Dataset Users' Manual (Vienna: Center for Systemic Peace, 2020), 1-2, http://www.systemicpeace.org/inscr/p5manualv2018.pdf.
} 
to democratic and non-democratic states, with semi-democracies being categorized into one of the two according to their specific institutional make-up. The classification of a state into either category is determined in accordance with how they are scored by three different democracy indices: the Polity Project, the Economist Intelligence Unit's Democracy Index, and Freedom House's Freedom in the World.$^{47}$ Additional secondary sources are also used to ensure proper evaluation of the defending state's government. While the focus is on their regime type during the crises and conflicts being studied, any notable shifts (e.g. democratization, democratic backsliding) are discussed as they arise.

A state is considered democratic if it demonstrates three main elements. These are the ability for citizens to express preferences about government policies and leaders that impact governance, formal constraints on the exercise of executive power, and guaranteed civil liberties for all citizens, noted in Polity 5 as the $x c o m p, x c o n s t$, and parreg variables. ${ }^{48}$ Democracies typically also demonstrate rule of law, checks and balances on the exercise of government power, and freedom of the press, among others. ${ }^{49}$ Almost all democracies are expected to possess at least some form of open political competition, ensuring governments are accountable to voters for their policies. They can differ in various ways, however, most notably in whether they possess a parliamentary system (e.g. Canada and the United Kingdom) or a presidential one (e.g. the United States), with the former giving the legislative branch greater power and the latter giving more power to the head of state. ${ }^{50}$ Semi-democracies, also known as hybrid regimes or anocracies, demonstrate some

\footnotetext{
${ }^{47}$ While Polity 5 is the preferred version, some incomplete coding means that it is sometimes necessary to refer to Polity IV data. The version used will be explicitly noted as the need arises.

${ }^{48}$ Marshall, Gurr, and Jaggers, Polity 5, 14-15.

${ }^{49}$ Marshall, Gurr, and Jaggers, Polity 5, 14.

${ }^{50}$ Marshall, Gurr, and Jaggers, Polity 5, 15.
} 
democratic traits, but combine them with characteristics of non-democratic regimes to varying degrees, resulting in combinations like elections that are not entirely free. ${ }^{51}$

Non-democracies, particularly autocracies, are instead defined by their restrictions on political competition and lack of constraint on the exercise of executive power. The state's chief executive is typically chosen by elites, and any elections open to citizens will be heavily rigged in favour of the preferred candidate(s) ${ }^{52}$ Unconstrained executive power allows the government to exercise significant control over domestic social and economic activity; in practice, this depends on both the governing elite's political ideology and the government's capacity to actually impose such restrictions. ${ }^{53}$ Autocracies can be further divided into three subtypes. Single-party regimes are distinguished in their being governed by a single political party that controls government policy, the selection of leaders, and the state security apparatus. ${ }^{54}$ Military dictatorships are typically ruled by a junta of military officers, with the armed forces themselves being used to consolidate rule of the state. ${ }^{55}$ Finally, personalist dictatorships are the archetypal autocracy, with a single individual controls policy and personnel decisions within the state and typically relies on the support of at least one group to retain power. ${ }^{56}$

In practice, some non-democratic regimes demonstrate traits associated with multiple categories. China is one such case due to its government exhibiting traits of both

\footnotetext{
${ }^{51}$ James D. Fearon and David D. Laitin, "Ethnicity, Insurgency, and Civil War," American Political Science Review 97, no. 1 (2003): 81.

${ }_{52}$ Marshall, Gurr, and Jaggers, Polity 5, 15-16.

${ }^{53}$ Marshall, Gurr, and Jaggers, Polity 5, 16.

${ }^{54}$ Barbara Geddes, Joseph Wright, and Erica Frantz, "Autocratic Breakdown and Regime Transition: A New Data Set," Perspectives on Politics 12, no. 2 (2014): 318.

${ }^{55}$ José Antonio Cheibub, Jennifer Gandhi, and James Raymond Vreeland, "Democracy and dictatorship revisited," Public Choice 143, nos. 1-2 (2010): 85-86.

${ }^{56}$ Geddes, Wright and Frantz, "Autocratic Breakdown,” 319.
} 
single-party and personalist rule throughout its history, as both the General Secretary of the Chinese Communist Party and the Party membership have wielded significant power over governance, with personalist traits being most prominent under Mao Zedong. ${ }^{57}$ This is attributable to these forms of governance being more of a continuum than discrete categories, varying according to the size and makeup of what Bueno de Mesquita and Smith refer to as the government's winning coalition. ${ }^{58}$ While single-party regimes will be more constrained than personalist governments due to having a larger winning coalition to satisfy, no government is completely autonomous, as even personalist leaders will require at least some support to avoid being overthrown.

\subsection{2: Possession of nuclear weapons}

Another key independent variable in the dissertation is whether the defending state possesses nuclear weapons or not, which helps divide the crises and conflicts targeting that state into pre- and post-nuclear periods. For the purposes of this project, this means that the state in question has an independent nuclear weapons capability - that is, it possesses at least one nuclear explosive device that can be used against another state in warfare. This also means that, beyond the nuclear device itself, the state also has the necessary infrastructure and technical capabilities to actually deliver it, such as bombers and/or ballistic missiles and launchers.

This definition, which is based in the theory's focus on nuclear weapon states, is necessary to limit the scope of the dissertation by excluding states lacking the ability to

\footnotetext{
${ }^{57}$ Jessica L. Weeks, “Autocratic Audience Costs: Regime Type and Signaling Resolve,” International Organization 62, no. 1 (2012): 331.

${ }^{58}$ Bruce Bueno de Mesquita and Alastair Smith, The Dictator's Handbook: Why Bad Behaviour Is Almost Always Good Politics (New York: PublicAffairs, 2011), 6.
} 
deter challengers with nuclear weapons. Most prominently, it omits states that have been unsuccessful in their nuclear proliferation efforts during the 1945-2018 period, such as Iran, Libya, and Iraq, as they lacked an actual nuclear arsenal and, by extension, nuclear deterrence. States hosting nuclear weapons on behalf of another within their territory are excluded due to lacking launch authority over them. Japan, for example, would not be considered a nuclear weapon state despite hosting US nuclear weapons between 1951 and 1972, as those were fully under American control. ${ }^{59}$ De facto nuclear weapon states, which are capable of building nuclear weapons but have not actually done so, introduce an additional analytical problem, since they combine the technical capabilities of nuclear weapon states with the lack of a nuclear arsenal that hinders unsuccessful proliferators. For analytical purposes, crises targeting such a state are considered to be in their "post-nuclear period" if, at that time, the state is established as having an assembled nuclear device.

The project's focus on comparing the effectiveness of nuclear deterrence means that all defending states chosen for study have eventually developed an independent nuclear deterrent. Challengers may possess their own nuclear arsenals - which is most readily apparent in India and Pakistan's later crises - but they are not required to do so for a crisis to be studied. The main source of information on nuclear weapons, included the estimated numbers of active warheads and delivery systems as well as major milestones in their development, is the Bulletin of the Atomic Scientists and its Nuclear Notebook reports on state arsenals. Additional country-specific primary and secondary sources are used to verify these figures, as well as understanding the motivations for the state to have

\footnotetext{
${ }^{59}$ Robert S. Norris, William M. Arkin, and William Burr, "How Much Did Japan Know?" Bulletin of the Atomic Scientists 56, no. 1 (2000): 11-13, 78-79.
} 
developed nuclear weapons and their command and control structures. These also have the additional benefit of providing insight into contemporaneous perspectives of nuclear arsenals during crises.

\subsection{3: Other variables}

Both the theory advanced in this dissertation and the existing literature on nuclear deterrence necessitate considering other independent variables in the analysis to account for and evaluate potential alternative explanations. Chief among these are whether a challenger possesses nuclear weapons of its own and what the defender's nuclear deterrence doctrine is. Accounting for the former is crucial, as it potentially indicates that a challenger is attacking because it believes the defender is restrained by fear of nuclear war instead of cost-sensitivity, as predicted by the stability-instability paradox. ${ }^{60}$ Conversely, it is possible for a nuclear-armed challenger to attack in the belief that the defender is so cost-sensitive that, as the theory anticipates, it will not fulfill nuclear deterrence threats for low-intensity attacks. Determining whether this is the case requires evaluating documents and statements by members of the challenger's government to infer motivations for attacking and perceptions of the defending government alongside secondary sources. The defender's nuclear doctrine, meanwhile, is key to understanding not only when it would threaten (explicitly or implicitly) to use nuclear weapons, but also provides insight into its resolve and how its approach to armed conflict is dictated by its domestic political structure. While straightforward for states with public nuclear doctrines,

${ }^{60}$ Robert Jervis, The Illogic of American Nuclear Strategy (Ithaca: Cornell University Press, 1984), 148150. 
those that have not publicized their nuclear use conditions require evaluating statements by officials and other documents, as well as correlation with behaviour in prior conflicts.

Similarly, the conventional military strength of both the defending nuclear weapon state and its challenger(s) needs to be accounted for. This is necessary to determine if challengers were deterred by changes in the defender's conventional strength rather than nuclear weapons and if the former is more credible than the latter due to relatively usability. ${ }^{61}$ Instances of challengers attacking with a relative conventional disadvantage, whether qualitative or quantitative, are especially noteworthy due to indicating a belief that the defender is restrained by cost sensitivity, though this would need to be supplemented with statements by the challenger. Conventional military capabilities of states are measured using sources such as the SIPRI Military Expenditure dataset, publicly released military budgets, and statements and estimates from primary and secondary sources. Additionally, challenger regime type needs to be considered, given that theories such as democratic peace argue that certain regime types are more or less likely to attack others. ${ }^{62}$

The focus on deterrence credibility in this dissertation also requires accounting for relevant independent variables. The defender's resolve to fulfill threats and how the challenger perceives it are due to their role in deterrence credibility ${ }^{63}$ As with other studies of resolve, this is measured by assessing public and private statements by officials in the

\footnotetext{
${ }^{61}$ John Stone, "Conventional Deterrence and the Challenge of Credibility," Contemporary Security Policy 33, no. 1 (2012): 110-112.

${ }^{62}$ Zeev Maoz and Bruce Russett, "Normative and Structural Causes of Democratic Peace, 1946-1986," American Political Science Review 87, no. 3 (1993): 625-627.

${ }^{63}$ Thérèse Delpech, Nuclear Deterrence in the 21 ${ }^{\text {st }}$ Century: Lessons from the Cold War for a New Era of Strategic Piracy (Santa Monica: RAND Corporation: 2012), 45.
} 
defending state and challenger perceptions when possible. ${ }^{64}$ For example, high-ranking officials of the challenging government describing adversaries as "weak" or "cowardly" indicates a perceived lack of resolve, whereas the defender's officials can signal its resolve by delineating specific responses to provocations. Reputation also influences credibility by informing how the defender acted in similar situations, with a past reputation for aggression in particular conveying a potential insensitivity to costs. ${ }^{65}$ Reputation's subjective nature, being based in how the defender is perceived, requires analyzing challenger statements and documents for indications of if and how it has assessed crises involving the defending state ${ }^{66}$ Indicators that the challenger perceives the defender as aggressive and accounts for this in a crisis, for example, would include references to prior threats or uses of force by it against the challenger or other states. ${ }^{67}$ When primary sources are insufficient or unavailable for study, relevant secondary sources are used instead.

The role of accountability and audience reactions in the theory means that audience costs also need to be accounted for. The nature of the concept, however, creates challenges in measuring it, given that it involves determining not only how domestic audiences have reacted in response to the government's actions during a crisis, but how the government believes those audiences will respond. ${ }^{68}$ Audience costs can be determined from several sources of data. One such source would be how decision-makers in the defending

\footnotetext{
${ }^{64}$ In theory, this would be done more formally with the aforementioned content analysis approach, but the limited number of primary sources meant that this was infeasible. Roseanne W. McManus, "Fighting Words: The Effectiveness of Statements of Resolve in International Conflict," Journal of Peace Research 51, no. 6 (2014): 729.

${ }^{65}$ Paul K. Huth, "Reputations and Deterrence: A Theoretical and Empirical Assessment," Security Studies

7, no. 1 (1997): 78-79.

${ }^{66}$ Huth, "Reputations and Deterrence," 80-81.

${ }^{67}$ Danielle L. Lupton, "Reexamining Reputation for Resolve: Leaders, States, and the Onset of International Crises," Journal of Global Security Studies 3, no. 2 (2018): 200.

${ }^{68}$ William G Nomikos and Nicholas Sambanis, "What Is the Mechanism Underlying Audience Costs? Incompetence, Belligerence, and Inconsistency," Journal of Peace Research 56, no. 4 (2019): 576-577.
} 
government believe their supporters will react to their actions in a crisis and how it influences their decisions. This can be determined from government documents and statements during the crises being studied along with secondary qualitative sources. Audience reactions, meanwhile, can be assessed from similar sources, as well as available polling data on public opinion, results from subsequent elections (in the case of democracies), and media sources.

Additional variables relating to the ties between a defending nuclear weapon state and others, including challengers, also require study due to their prominence in the existing nuclear deterrence literature. The diplomatic relations of the defending state could influence interstate conflict frequency, as improved relations with former adversaries would explain a reduction in crises and conflicts targeting the defender; conversely, deteriorating relations could explain their increasing. The defender's military alliances, along with that of challengers, can also serve to further bolster deterrence or embolden challengers into launching attacks, respectively. ${ }^{69}$ The economic ties of the defending state and its challengers are also studied, given that economic interdependence could discourage challengers from attacking it to avoid harming their own economies in the process. ${ }^{70}$ Finally, non-military punitive and exclusionary measures used against nuclear weapon states, such as sanctions, prohibitions on participation in international organizations, and public denunciations also need to be considered due to their potential as an alternative to sanctions. An example of this is India and Pakistan's continued exclusion from the Nuclear

\footnotetext{
${ }^{69}$ Robert Rauchhaus, "Evaluating the Nuclear Peace Hypothesis: A Quantitative Approach," Journal of Conflict Resolution 53, no. 2 (2009): 268.

${ }^{70}$ Rauchhaus, "Evaluating the Nuclear Peace Hypothesis," 268; Benjamin E. Goldsmith, Stephan K. Chalup, and Michael J. Quinlan, "Regime Type and International Conflict: Towards a General Model," Journal of Peace Research 45, no. 6 (2008): 754.
} 
Suppliers Group (NSG) due to their nuclear arsenals and refusal to sign the NPT despite otherwise meeting the membership criteria. ${ }^{71}$

\section{5: Methodological Process}

This dissertation utilizes an embedded comparative case study approach with process tracing that primarily uses qualitative data from primary and secondary sources (with limited content analysis), while quantitative data plays a supporting role. Following this approach involves collecting and analyzing both types of data within discrete case studies, then comparing the case findings to each other to test the hypotheses. ${ }^{72}$ The qualitative focus means that quantitative data is meant to fill in potential gaps and help ensure consistency. ${ }^{73}$ The dissertation's focus on individual state behaviour and the influence of domestic institutions means the level of analysis is at the state/domestic level. ${ }^{74}$ The units of observation for this dissertation are major crises and conflicts targeting a defending nuclear weapon state, both before and after it developed a nuclear deterrent. As stated previously, the study focuses on the 1945-2018 period, ensuring a balance in covering almost the entirety of the nuclear era and in having access to sufficient data to test hypotheses.

The steps in the dissertation consist of within-case process tracing using qualitative and quantitative data, followed by cross-case comparison. ${ }^{75}$ The process tracing itself has

\footnotetext{
${ }^{71}$ Mark Hibbs, "Eyes on the prize: India's pursuit of membership in the Nuclear Suppliers Group," Nonproliferation Review 24, nos. 3-4 (2017): 275-276.

${ }^{72}$ Creswell and Plano Clark, Mixed Methods Research, 71-72.

${ }^{73}$ Creswell and Plano Clark, Mixed Methods Research, 62; Bowen, "Document Analysis," 28.

${ }^{74}$ J. David Singer, "International Conflict: Three Levels of Analysis," World Politics 12, no. 3 (1960): 457458.

${ }^{75}$ As explain in chapter 1, process tracing is often used in historical case studies to evaluate explanations by examining the causal process leading to the outcome of interest and highlighting the role given variables play in it. This in turn allows for those cases to be used in theory-building. Alexander L. George and
} 
multiple steps. Each case chapter begins with an evaluation of the defending nuclear weapon state's regime type. This is followed by analysis of key crises and conflicts targeting it pre-nuclear weapon acquisition, with the variables discussed in section 4.4.3 studied to determine what impact they had, if any. The motivations for the defender to develop a nuclear deterrent, along with its command and control structure, deterrence threats, and regime type's influence are subsequently analyzed. Post-nuclear acquisition crises are studied in a similar manner as pre-nuclear ones, with a focus on a) how the defender's resolve was perceived by the challenger and b) what variables influenced these perceptions. The last step in the process tracing is studying possible alternative explanations for the changes in armed conflict that would potentially contradict the theory and their shortcomings. Once this is done, the hypotheses stated in chapter 3 are then tested against the findings to determine whether they should be rejected or can be confirmed. After applying this process to each of the states studied in this project in chapters 5-8, the findings are compared in chapter 9.

\subsection{1: Evaluating the Regime Type of the State}

The first step for each state studied is to determine its regime type and how it may have changed over time. This involves using data from the Polity Project, the Economist Intelligence Unit's Democracy Index, and Freedom House's Freedom in the World index, as well as qualitative sources. The datasets establish basic governance traits, such as the civil liberties and openness of political participation, relative to others, as well as how they

Andrew Bennett, Case Studies and Theory Development in the Social Sciences (Cambridge: MIT Press, 2005), 176-177, 215. 
may have shifted over time ${ }^{76}$ Drawing on the three indices instead of one serves to further ensure internal validity. ${ }^{77}$ The qualitative sources serve to parse out finer details about governance that are not available from these datasets, such as whether a democracy uses a presidential or parliamentary system, and their influence on decision-making. These sources can also elaborate on whether non-democratic regimes are hybrid regimes or autocracies, and if the latter, whether they are a military, single-party, or personalist regime or some mix of the three. These sources help provide insight into shifts in regime type over time, such as democratic backsliding.

This stage of the research focuses on institutions within the state that influence the accountability of government decision-makers to their audiences, as well as the command and control system for nuclear weapons. For democracies, this would primarily focus on formal institutions like state legislatures, which can serve as avenues for political opponents of the government to question officials on policy decisions and to publicly criticize them. ${ }^{78}$ Media sources, such as newspapers and cable news, also serve as accountability mechanisms in democracies by providing information to the general public and influencing their perception and support of government policy. ${ }^{79}$ These and other mechanisms mean that a democratic government, even one granted considerable authority

\footnotetext{
${ }^{76}$ Economist Intelligence Unit, Democracy Index 2017: Free speech under attack (London: Economist Intelligence Unit 2018), 5, accessed September 3, 2018, https://pages.eiu.com/rs/753-RIQ438/images/Democracy Index 2017.pdf; Marshall, Gurr, and Jaggers, Polity IV Project, 14-17.

${ }^{77}$ Bruce Bueno de Mesquita, "Toward A Scientific Understanding of International Conflict: A Personal View," International Studies Quarterly 29, no. 2 (1985): 132-134.

${ }^{78}$ Dan Reiter and Erik R. Tillman, "Public, Legislative, and Executive Constraints on the Democratic Initiation of Conflict," The Journal of Politics 64, no. 3 (2002): 810-826.

${ }^{79}$ Matthew A. Baum and Philip B.K. Potter, "The Relationships Between Mass Media, Public Opinion, and Foreign Policy: Toward a Theoretical Synthesis," Annual Review of Political Science 11 (2008): 39-65.
} 
in foreign policy and national security issues, can ultimately be held accountable for its actions by the public and, if necessary, punished.

Non-democratic states similarly possess accountability mechanisms, albeit informal ones. Some states, particularly semi-democratic and single-party regimes, possess legislative bodies that can wield authority over decision-makers in a similar manner as their democratic counterparts, albeit in a somewhat more limited manner. ${ }^{80}$ In many cases, however, the governments of non-democratic states will primarily be accountable directly to a group of elites, which will vary according to the regime in question. This typically includes military leaders, business leaders, and key bureaucrats. ${ }^{81}$ As discussed in Chapter 3 , these audiences will continue to support the regime in exchange for various continued benefits, and will punish it for policy failures that threaten this.

\subsection{2: Pre-Nuclear Crises and Conflicts}

Once the regime type of the defending nuclear weapon state has been established, the second step is to look at key crises and armed conflict targeting it prior to its acquisition of nuclear weapons. Doing so establishes the threat environment that it faced before possessing a nuclear deterrent, including which states the defender has been in conflict with. In addition, studying of pre-nuclear crises with nuclear ones for the same state establishes a meaningful basis for comparison, as the former can essentially serve as a control group for determining the influence of nuclear deterrence. In studying these crises, it is also necessary to touch on relevant facets of the states challenging the state being

\footnotetext{
${ }^{80}$ Mark Peceny, Caroline C. Beer, and Shannon Sanchez-Terry, "Dictatorial Peace?" American Political Science Review 96, no. 1 (2002): 17.

${ }^{81}$ Bruce Bueno de Mesquita and Randolph M. Siverson, "War and the Survival of Political Leaders: A Comparative of Regime Types and Political Accountability," American Political Science Review 89, no. 4 (1995): 843.
} 
studied, such as its own regime type, given how their own internal processes can influence their conflict behaviour. As mentioned in 4.4.1, these can be studied using secondary qualitative source and, to a much more limited extent, content analysis of relevant documents.

The most important factor to consider in this section is how these crises started and ended. While dates for when a given crisis took place can be found in a dataset, particularly the ICB, much of this information is challenging to capture in a purely quantitative manner and thus needs to be derived from qualitative sources. Secondary sources and government documents, for example, can serve to establish the specific chain of events that led to a crisis, as well as what occurred throughout. They can also explain what led to a given crisis or conflict ending or, in the case of especially enduring ones, why they have continued. These sources help identify who the main actors in the decision-making processes in the defending and challenging states were and what factors played into their behaviours. This includes why challengers chose to act in a way that initiated a crisis, as well as what led defenders to respond the way they did.

The focus in studying these decision-making processes is on the influence of factors related to regime type and cost sensitivity. The most prominent of these are the preferences of key domestic audiences regarding the prospect of armed conflict and how it would be fought. For example, do the citizens of a democracy support retaliating against attacks by another state, or would they be against it? How did they react to the prospect of continued fighting? This also requires determining the costs suffered by the defending state and its challengers in terms of lives, economic and territorial integrity, and international standing. These can be determined in part via analysis of government documents, but will be more 
reliant on relevant secondary sources, news articles, and datasets. By combining the two groups of sources, it is possible to assess government views of the crisis outcome while accounting for potential biases. This leads to a more accurate understanding of, for example, the losses suffered by the defending state, whose government may understate them to present a more favourable impression of its performance.

\subsection{3: The Acquisition of Nuclear Weapons and Deterrence Threats}

The third step for analyzing each nuclear weapon state in this dissertation is determining what drove it to acquire nuclear weapons in the first place and its deterrence strategy. Understanding the causes of the defender's decision to develop a nuclear deterrent highlights what is considered a significant external threat and government practices for national security issues. One example would be how Pakistan's development of nuclear weapons in response to Indian conventional superiority indicates that the latter was considered a major threat. ${ }^{82}$ Qualitative sources make it possible to determine the motivations for the state to have pursued a nuclear weapons program to the point of completion. These can be roughly categorized according to Sagan's three basic models of nuclear weapons increasing national security, advancing domestic political/bureaucratic interests, and serving as a normative symbol of state modernity and prominence. ${ }^{83}$ The first two are key, as the outcomes of pre-nuclear crises and conflicts could potentially push the defending state to develop nuclear weapons as a guarantee in similar situations, as could a need to satisfy the domestic audience demands. This section also discusses the reactions of other states to these proliferation efforts, including diplomatic and economic repercussions

\footnotetext{
${ }^{82}$ T.V. Paul, The Warrior State: Pakistan in the Contemporary World (Oxford: Oxford University Press, 2014), 52-53.

${ }^{83}$ Scott Sagan, "Why Do States Build Nuclear Weapons? Three Models in Search of a Bomb," International Security 21, no. 3 (1996/97): 55.
} 
such as downgraded relations and sanctions imposition. They could even extend to other states threatening or using force against the defending state in question.

The next step is determining what its deterrence policies were, and how they changed over time. Typically, this can be distinguished between a MAD stance, which focuses on totally destroying the other state, and a minimum deterrence, which involves maintaining fewer nuclear weapons and only aiming for certain strategic targets. ${ }^{84}$ The state may also have maintained, or continues to maintain, a policy of ambiguity regarding its possession of nuclear weapons and how it would use them, as Israel does. ${ }^{85}$ In other cases, the state may have a clearly established and publicly known nuclear doctrine, as the United States and India do ${ }^{86}$ The circumstances where the defending state may use nuclear weapons also need to be understood, such as whether it has pledged to not use nuclear weapons unless it is attacked with them first (also known as a no-first-use, or NFU, pledge). If the defending state maintains a minimum deterrence stance, it may also specify whether it will focus solely on military targets or if it will aim for other leadership targets.

The aforementioned aspects of the state's deterrence policies are analyzed alongside the potential effects of its regime type and audiences. For instance, a democracy would be expected to maintain a more public deterrence stance due to accountability mechanisms. Such a state is likely to also cater more to public opinion in devising these policies, which is hypothesized to lead to a more restrained deterrence posture due to democratic publics being expected to be more sensitive to costs. Non-democratic states,

\footnotetext{
${ }^{84}$ Stephen J. Cimbala, Nuclear Weapons and Strategy: U.S. Nuclear Policy for the Twenty-First Century (Abingdon: Routledge, 2005), 4.

${ }^{85}$ Zeev Maoz, “The Mixed Blessing of Israel's Nuclear Policy," International Security 28, no. 2 (2003): 44-77.

${ }^{86}$ Narang, Nuclear Strategy in the Modern Era, 99-101.
} 
meanwhile, would be expected to maintain an aggressive deterrence posture so long as it satisfies the demands of the relevant elite supporters that make up their audiences.

In each case, it is also necessary to study the command and control structure governing the state's use of nuclear weapons. A state's institutions and procedures for using nuclear weapons can provide considerable insight into various aspects of its regime type, including how it views the potential use of nuclear weapons. The hypothesis that democratic nuclear weapon states will seek to avoid using nuclear weapons when possible suggests that there will be considerable differences from non-democratic nuclear weapon states in this respect. Specifically, democratic nuclear weapon states are expected to have strict controls and procedures for their arsenals to minimize the risk of unauthorized use, whereas non-democratic states will have fewer controls to allow more rapid use in crisis situations. While some information regarding command and control is declassified and available in the public sphere, much of this is obtained from secondary sources.

\subsection{4: Post-Nuclear Crises and Conflicts (Or Lack Thereof): What Changed?}

The next step of the analysis after determining the defender's nuclear deterrence policies is studying post-nuclear acquisition crises. For analytical purposes, this means that any incidents that occurred prior to the completion of a nuclear weapon would be considered a pre-nuclear crisis, and thus serve as a control for studying each defender in the within-case comparison. ${ }^{87}$ As before, this involves looking at inciting events, the decisions made on both sides, and how the crises ended. In many ways, this section resembles the process discussed for 4.5.2. Similar sources are used, though there is a much

\footnotetext{
${ }^{87}$ However, any post-nuclear acquisition crises where the defender does not appear to even consider the use of nuclear weapons is still classified as a post-nuclear crisis, given that the division is based on when they occurred.
} 
greater emphasis on understanding the decisions made by officials in the defending and challenging state and the reasoning behind them.

In addition to these, however, it is also necessary to determine what has changed about crises following the defender's acquisition of a nuclear deterrent. Conflict datasets are of limited utility here beyond establishing when crises occurred and costs that the belligerents suffered that can be represented in quantitative format (e.g. casualties). The need to explore decision-making processes on both sides means that qualitative sources play a much larger role, particularly for understanding why challengers engaged in hostilities with a nuclear weapon state and whether they considered the deterrent credible, or why they chose to not escalate a crisis further. The mindset of decision-makers on the defending side also need to be understood, especially if they had any intension of fulfilling their nuclear deterrence threats or viewed doing so as off-limits. This step also covers how relevant audiences in the defending and challenging states viewed the risk of a nuclear crisis and how those factored into government decisions.

Each crisis requires evaluating several elements. Besides examining the crisis trigger(s), factors that influenced decisions on both sides such as anticipated costs need to be understood. This includes the possibility of the defender using nuclear weapons and whether the challenger expects the benefits to outweigh that risk. The reactions of international audiences, particularly the allies of the defender and challenger, are also considered due to their ability to impose additional costs via sanctions or to actively join a conflict. The defender's nuclear deterrence threats, if any, need to be studied, including if 
the defender is practicing general deterrence or making specific threats in response to the crisis (whether explicit or implicit). ${ }^{88}$

As discussed in the literature review, there are some differences in the conditions for deterrence success or failure according to whether general or immediate deterrence is being practiced. General deterrence is considered successful if the defender's deterrence threats convince potential challengers to not attack or even threaten to do so, while immediate deterrence will have succeeded if those threats cause a challenger to avoid escalating a crisis or even back down. ${ }^{89}$ These are contingent on the threats being considered credible due to the defender communicating sufficient capabilities and resolve to carry them out. ${ }^{90}$ This is distinct from cases where the challenger did not actually intend to attack the defender or chose to avoid doing so due to unrelated reasons such as domestic pressure, which makes it difficult to determine whether general deterrence succeeded or other factors led to the absence of conflict. ${ }^{91}$ General deterrence is considered to have failed if the challenger threatens to attack or actually does so, while immediate deterrence has failed if the challenger persists with its behaviour in a crisis despite the defender's threats. ${ }^{92}$ These failures can occur for a variety of reasons, including a failure to communicate the threats, misperceptions of capabilities and resolve undermining their credibility, or the challenger believing the costs are not high enough to justify backing down. ${ }^{93}$

\footnotetext{
${ }^{88}$ Vesna Danilovic, “Conceptual and Selection Bias Issues in Deterrence," Journal of Conflict Resolution 45, no. 1 (2001): 99-100.

${ }^{89}$ Danilovic, "Conceptual and Selection Bias," 99.

${ }^{90}$ Danilovic, "Conceptual and Selection Bias," 102.

${ }^{91}$ Harvey, The Future's Back, 25, 38.

92 Paul Huth and Bruce Russett, "What Makes Deterrence Work? Cases from 1900 to 1980," World Politics 36, no. 4 (1984): 497.

${ }^{93}$ Harvey, The Future's Back, 38; Huth and Russett, "What Makes Deterrence Work," 497.
} 


\subsection{5: Alternative Explanations}

In addition to the above, it is necessary to evaluate possible alternative explanations for the initiation and outcomes of the crises studied. This section draws upon the additional independent variables discussed earlier in this chapter to determine whether differences in accountability among defending nuclear weapon states played a major role in differences in conflict frequency. For example, a defending state that experiences fewer low-intensity armed attacks or limited wars against it after acquiring nuclear weapons could have also built up its conventional forces simultaneously. In such a situation, it would be necessary to determine if a nuclear deterrent is in fact the reason that the state has suffered fewer attacks, or if the potentially more credible threat of a conventional military response is a cause, particularly if the defending state has a stronger military than its challengers.

\subsection{6: Hypothesis Testing and Case Findings}

The final section for each chapter consists of a review of the findings regarding the changes in crisis and conflict behaviour once the defender developed a nuclear deterrent. Beyond providing an overview of the chapter, this section also includes a discussion of the hypotheses outlined in chapter 3.3 and whether the case findings correspond to their predictions or fall short. This includes a brief explanation of how they met expectations or, if the hypotheses proved incorrect, where the issues were. Any relevant crises that may have occurred outside the scope of the research (e.g. following 2018) are also referenced in this section, including what their significance regarding future trends may be.

\subsection{7: Comparing the Case Findings}

The final research step is comparing the findings from each case chapter in chapter 9. This involves comparing the differences between the states that emerged, such as shifts 
in the frequency of conflicts targeting them, and whether the hypotheses were ultimately correct in predicting that shifts in conflict behaviour after nuclear weapon acquisition are attributable to the defender's regime type and associated accountability mechanisms. Hypotheses that are falsified by the selected cases, however, are studied more in-depth here to determine what factors beyond regime type influenced deterrence effectiveness. The comparison of the case findings is also important for determining whether the differences in post-nuclear conflict behaviour between the states being studied are consistently due to differences in their regime type, or if other variables offer greater explanatory power. The use of multiple democratic and non-democratic states means that it is possible to highlight potential differences within types of government that could further influence challenger perceptions of cost sensitivity (e.g. differing approaches to command and control, national security policies). This allows for isolation of the impact of regime type on nuclear deterrence and testing the explanatory power of the theory against other causal factors.

\section{6: Case Selection}

As discussed in preceding sections, only a few nuclear weapon states have existed throughout the $20^{\text {th }}$ and $21^{\text {st }}$ centuries. Even when including South Africa, which unilaterally dismantled its weapons program, and Ukraine, Belarus, and Kazakhstan, which had unintentionally inherited the Soviet nuclear weapons within their territory and quickly returned them to Russia, there have only ever been 13 nuclear weapon states. ${ }^{94}$ As of 2020 , only nine of 206 states possess nuclear weapons: the United States, Russia, the United Kingdom, France, China, Israel, India, Pakistan, and North Korea. Even within this small group, not all nuclear weapon states are comparable to one another: for example, Israel,

\footnotetext{
${ }^{94}$ Davenport and Reif, "Nuclear Weapons."
} 
India, Pakistan, and North Korea are not recognized as nuclear weapon states within the NPT, whereas the other five are. ${ }^{95}$ This means that states within the former group are treated much differently than the others, such as being unable to do business with members of the NSG due to lacking International Atomic Energy Agency (IAEA) safeguards. ${ }^{96}$ Due to the differences arising between nuclear weapon states, it is necessary to select a subset that are comparable while maintaining some variance in regime type.

This section of the chapter first discusses the criteria for selecting the case states. As explained below, the nuclear weapon states that have disarmed themselves, as well as states that have pursued nuclear weapons without success thus far, will not be considered due to functionally being no different than any other non-nuclear weapon state, and thus intrinsically different than the nine mentioned above. Additionally, the sheer conventional and nuclear force disparity between the US and Russia and all other nuclear weapon states makes comparisons between them problematic. Other issues with the three remaining NPT nuclear weapon states (the UK, France, and China) pose challenges in comparing them to the others. This is then followed by an overview of the advantages and possible issues with studying Israel, India, Pakistan, and North Korea and how those issues are addressed.

\subsection{1: Case Selection Criteria}

The first case selection criterion is excluding states that either no longer possess nuclear weapons or have not managed to acquire any thus far. This criterion is due to such states, despite their pursuit of nuclear weapons, being the same as any other non-nuclear weapon state in lacking a nuclear deterrent. Their inclusion would thus require

\footnotetext{
${ }^{95}$ United Nations Office for Disarmament, "Treaty on the Non-Proliferation of Nuclear Weapons," July $1^{\text {st }}$, 1968, https://www.un.org/disarmament/wmd/nuclear/npt/text/.

${ }^{96}$ Hibbs, "Eyes on the prize," 282.
} 
fundamentally shifting the research objectives of this dissertation towards a comparison of nuclear weapon and non-nuclear weapon states. States that have engaged in nuclear proliferation without actually assembling a nuclear weapon, such as Iran, are not included in the dissertation. ${ }^{97}$ Likewise, states that have dismantled or otherwise relinquished the nuclear weapons in their possession, specifically South Africa, Ukraine, Belarus, and Kazakhstan, are excluded from the study. South Africa's nuclear arsenal did not appear to have played a large role in deterrence, given its small size and purpose being to coerce American support in wars with its neighbours. ${ }^{98}$ The former Soviet satellites, meanwhile, had unintentionally inherited their nuclear arsenals with the collapse of the Soviet Union in 1991, and all three moved quickly to negotiate their surrender to Russia in exchange for concessions. ${ }^{99}$

Secondly, the US and Russia are excluded due to their being sufficiently different from other nuclear weapon states that discerning the influence of regime type on their nuclear deterrent from other variables would be highly challenging. The most apparent of these is the sheer size of their nuclear forces relative to others. While most nuclear weapon states have arsenals of tens to hundreds of warheads, with the peak being France's 540 warheads in 1991, the US and Russia have retained thousands of warheads even after massive stockpile reductions. ${ }^{100}$ At their Cold War peaks, the US possessed 31,000 warheads by 1967 before focusing on fewer and more effective weapons, while the Soviet

\footnotetext{
${ }^{97}$ Richard Nephew, "How the Iran Deal Prevents a Covert Nuclear Weapons Program," Arms Control Today 45, no. 7 (2015): 8-15.

${ }^{98}$ Peter Liberman, "The Rise and Fall of the South African Bomb," International Security 26, no. 2 (2001): 56.

${ }^{99}$ Mariana Budjeryn, "The Power of the NPT: International Norms and Ukraine's Nuclear Disarmament," Nonproliferation Review 22, no. 2 (2015): 225-226.

${ }^{100}$ Hans M. Kristensen and Robert S. Norris, "Nuclear Arsenals of the World," Bulletin of the Atomic Scientists, accessed October 31, 2018, https://thebulletin.org/nuclear-notebook-multimedia/.
} 
Union had over 40,000 warheads by 1986 , and even now control approximately 8,300 of the 9,220 active warheads globally. ${ }^{101}$ By comparison, France and the UK, which have the third- and fourth-largest nuclear arsenals respectively, only possess 515 warheads combined. The sheer number of American and Russian nuclear weapons, alongside delivery systems like intercontinental ballistic missiles (ICBMs), means that they can effectively deter any attack by another state with its total destruction, regardless of distance.

Regime type's influence on the credibility of American and Russian nuclear deterrence threats is also further obscured by the size of their conventional military forces, which can serve as a much more credible deterrent. Annual US military expenditure has consistently remained above $\$ 300$ billion (in 2016 USD) since 1951, and in 2017 reached $\$ 610$ billion, a third of the estimated US\$1.74 trillion spent on militaries globally that year. ${ }^{102}$ Russia, meanwhile, has the fourth-highest military expenditures in the world, even after significant reductions from Soviet-era spending, spending US\$66.3 billion in $2017 .{ }^{103}$ Historically, the Soviet Union possessed the largest active army in the world during the Cold War period, with low estimates suggesting 2.8 million active personnel, and was still able to field 1.1 million troops in 1989 , when it was nearing collapse; by comparison, the entirety of NATO was only able to deploy 691,000 troops that same. ${ }^{104}$ The sheer size of US and Soviet/Russian conventional forces makes analyzing the effectiveness of their

\footnotetext{
${ }^{101}$ Ibid.

${ }^{102}$ Stockholm International Peace Research Institute, "SIPRI Military Expenditure Database, 2019," accessed February 20, 2019, https://www.sipri.org/databases/milex; Stephanie Blenckner and Alexandra Manolanche, "Global military spending remains high at \$1.7 trillion," Stockholm International Peace Research Institute, last modified May 2, 2018, https://www.sipri.org/media/press-release/2018/globalmilitary-spending-remains-high-17-trillion.

${ }^{103}$ SIPRI, "Military Expenditure, 2019."

${ }^{104}$ William E. Odom, The Collapse of the Soviet Military (New Haven: Yale University Press, 1998), 39; Scott Boston et al, Assessing the Conventional Force Imbalance in Europe: Implications for Countering Russian Local Superiority (Santa Monica: RAND Corporation, 2018), 3.
} 
nuclear deterrents even more difficult, as their conventional capabilities would be just as capable of deterring attacks, if not more so than nuclear weapons due to additional credibility.

The United Kingdom, France, and China also present potential issues that led to their being removed as possible cases. For the UK and France, this is due to their possessing extended nuclear deterrence commitments from the US that protected them prior to developing their arsenals, meaning they had the benefits of nuclear deterrence early on, as well as a lack of suitable crises to study. The UK in particular poses additional issues due to its nuclear deterrence strategy being operated largely in lockstep with the US, to the point of having its nuclear force targets assigned by the US during the Cold War. ${ }^{105}$ France, meanwhile, enjoyed extended nuclear deterrence commitments by the US and NATO during the 1950s, though the French nuclear program emerged from a desire to guarantee its own security and concerns that American commitments were insufficiently credible. ${ }^{106}$ In addition, virtually none of the crises involving these two states after 1945 - the period of interest - had their core territories threatened by state adversaries, leaving no cases that would be suitable for study in the theoretical framework. ${ }^{107}$ For the most part, these crises either were caused by non-state actors in their core territories or colonies or had them act as the challenger(s). For the former, nuclear threats would be non-credible given the presumption of cost-sensitivity, as they would essentially be threatening to use nuclear weapons against their own territory, whereas the latter scenario would shift from nuclear

\footnotetext{
${ }^{105}$ Narang, Nuclear Strategy in the Modern Era, 3-4.

106 Stéfanie Von Hlatky, “Revisiting France's nuclear exception after its 'return' to NATO," Journal of Translatlantic Studies 12, no. 4 (2014): 393.

${ }^{107}$ Michael Brecher and Jonathan Wilkenfeld, A Study of Crisis (Ann Arbor: University of Michigan Press, 1997); Michael Brecher et al., International Crisis Behavior Data Codebook, Version 12, 2017, http://sites.duke.edu/icbdata/data-collections/.
} 
deterrence to compellence, which is outside the scope of this dissertation. ${ }^{108}$ In rare situations where a state attacked their territory, such as Argentina in the Falklands War, there is no evidence that the use of nuclear weapons was even contemplated, or that the territory in question was sufficiently valued as to make it a viable option at all. ${ }^{109}$ Simply put, attempting to use the UK or France within the existing theoretical framework presents numerous serious issues that discounts them from study.

China would have been a case of interest, but has its own issues that make it difficult to use for comparative purposes. On the surface, China appears suitable, given its status as a single-party regime and as a regional nuclear power, possessing around 300 nuclear warheads at most. ${ }^{110}$ However, much like the US and USSR/Russia, China has the issues of dwarfing much of the world in conventional military strength: military spending has gradually increased over time to the point that China is now second only to the US, while the People's Liberation Army is the largest standing army in the world. ${ }^{111}$ Furthermore, its economic ties have expanded to the point that the Chinese government could choose to significantly harm a state through economic means alone. ${ }^{112}$ Both of these mean that China can credibly deter other states from targeting it through non-nuclear means, raising difficulties in determining the role of nuclear deterrence, as well as making it difficult to make meaningful comparisons to other states in this regard. While these make it something

\footnotetext{
108 Thomas C. Schelling, Arms and Influence (New Haven and London: Yale University Press, 1966), 6971; Lawrence Freedman, Deterrence (Cambridge: Polity Press, 2004), 110.

109 Todd S. Sechser and Matthew Fuhrmann, Nuclear Weapons and Coercive Diplomacy (New York: Cambridge University Press, 2017), 167-169.

${ }^{110}$ Hans M. Kristensen and Robert S. Norris, "Nuclear Arsenals of the World."

${ }^{111}$ International Institute for Strategic Studies, "Chapter Six: Asia," The Military Balance 118, no. 1 (2018): 225-235, https://doi.org/10.1080/04597222.2018.1416982; Stockholm International Peace Research Institute, "SIPRI Military Expenditure Database," SIPRI, 2019, https://sipri.org/databases/milex. 112 T. V. Paul and Erik Underwood, “Theorizing India-US-China Strategic Triangle,” India Review 18, no. 4 (2019): 353, https://doi.org/10.1080/14736489.2019.1662190.
} 
of a borderline case, the limited time and resources available led to it being excluded to ensure the dissertation could be completed in a timely manner. In short, the US, Russia, UK, France, and China raise several issues that make them less than ideal for the purposes of this study.

\subsection{2: Cases Selected}

Following the above criteria, the four nuclear weapon states studied in this dissertation are India, Israel, Pakistan, and North Korea. All four are considered regional nuclear powers due to possessing relatively small nuclear arsenals - Pakistan's being the largest with 140 warheads as of $2017 .{ }^{113}$ This means they are largely limited to armed conflict with states in their own region, avoiding the entanglement issues of the US and Russia. Additionally, none of the four have possessed extended nuclear deterrence commitments from other states prior to developing their own arsenals, ensuring it does not interfere with pre-nuclear crisis and conflict behaviour. ${ }^{114}$

Focusing on these four states has several advantages. First, all four gained independence around 1947-1948, enabling a consistent time frame for comparative purposes. It also ensures variation in regime type, allowing for comparison of differences within regime types. Indian and Israel are both democratic states, but differ in areas such as their parliamentary systems and civil-military relations. ${ }^{115}$ Pakistan has fluctuated between outright military dictatorship and a flawed military-influenced democracy, while

\footnotetext{
${ }^{113}$ Hans M. Kristensen and Robert S. Norris, "Nuclear Arsenals of the World."

114 Avner Cohen, The Worst-Kept Secret: Israel's Bargain with the Bomb (New York: Columbia University Press, 2010); Jonathan D. Pollack, No Exit: North Korea, Nuclear Weapons and International Security (Abingdon: Routledge, 2011); Saira Khan, Nuclear Weapons and Conflict Transformation: The case of India-Pakistan (Abingdon: Routledge, 2009).

${ }^{115}$ Center for Systemic Peace, "Polity IV Country Report 2010: Israel," Polity IV Project, 2010, http://www.systemicpeace.org/polity/Israel2010.pdf; Center for Systemic Peace, "Polity IV Country Report 2010: India," Polity IV Project, 2010, https://www.systemicpeace.org/polity/India2010.pdf.
} 
North Korea is the archetypical example of an autocratic state. ${ }^{116}$ India and Israel also vary in their nuclear policies: while India has had a public nuclear doctrine and civiliancontrolled command and control structure since 1998, Israel has maintained a strict policy of nuclear ambiguity. ${ }^{117}$ This is particularly useful for testing the framework advanced in Chapter 3, as these differing approaches could lead to potential differences in accountability among nuclear democracies.

Studying these particular states also makes the findings more applicable to any future nuclear weapon states, owing to their being outside the NPT and being regional nuclear powers. Israel, India, and Pakistan are noteworthy in being nuclear powers that never signed the treaty in order to avoid the accompanying scrutiny of national nuclear programs, while North Korea is unique for being the only state to withdraw from the NPT in 2003 after it was accused of developing nuclear weapons by the Bush administration. ${ }^{118}$ By focusing on these non-NPT nuclear weapon states, it is possible to control for changes in the international system by holding adherence to the non-proliferation regime constant. ${ }^{119}$ Furthermore, any new nuclear weapon states that emerge in the future would need to similarly defy the NPT, given that almost all states have signed it, and would likely share their regional nuclear power status due to the challenges in developing even a small nuclear deterrent. This second point is key: as noted by Narang, regional nuclear powers

\footnotetext{
${ }^{116}$ Sumit Ganguly and C. Christine Fair, "The structural origins of authoritarianism in Pakistan," Commonwealth \& Comparative Politics 51, no. 1 (2013): 122-123; Victor Cha, The Impossible State: North Korea, Past and Future (New York: HarperCollins, 2012), 91-96.

${ }_{117}$ Maoz, "Mixed Blessing," 44-77; Narang, Nuclear Strategy in the Modern Era, 99-101.

${ }^{118}$ Cha, Impossible State, 343.

${ }^{119}$ Etel Solingen, Nuclear Logics: Contrasting Paths in East Asia \& The Middle East (Princeton: Princeton University Press, 2007), 8-9.
} 
are fundamentally different from nuclear superpowers due to the gulf in resources in capabilities, making models of the latter largely incompatible. ${ }^{120}$

Some potential issues from the case selection should be noted, however. Chief among these is the potential for selection bias, which is always present to at least some degree in small- $n$ studies, but is virtually unavoidable in the study of nuclear weapon states due to the small range of choices. Attempting to address this by including proliferating states would be problematic due to how it would fundamentally change the nature of the research due to their being non-nuclear weapon states. Some of the issues relating to selection bias are addressed here: by choosing cases according to regime type and nuclear weapon status instead of changes in international conflict after developing nuclear weapons, this project avoids selecting on dependent variables. ${ }^{121}$ Furthermore, comparing the pre- and post-nuclear weapons acquisition conflicts and sanctions of these states allows the former to serve as a form of control group for within-case comparison.

The selected states also present their own individual challenges. Israeli nuclear ambiguity has led to strict censorship of nuclear affairs in domestic news and academic literature, along with relevant documents remaining classified, necessitating a greater reliance on secondary sources. ${ }^{122}$ India and Pakistan present challenges due to the significant overlap caused by their largely being in conflict with each other, as well as Pakistan's use of terrorist groups directed by the Inter-Services Intelligence (ISI), such as

\footnotetext{
${ }^{120}$ Narang, Nuclear Strategy in the Modern Era, 14

${ }^{121}$ Jack S. Levy, "Case Studies: Types, Designs, and Logics of Inference," Conflict Management and Peace Science 25, no. 1 (2008): 8.

122 Cohen, The Worst-Kept Secret, 101-119.
} 
Lashkar-e-Taiba and Jaish-e-Mohammed in attacking India. ${ }^{123}$ The former issue is addressed by studying India and Pakistan separately, with each chapter focusing on the decision-making, proliferation, and policy decisions, while acts of state-sponsored terror are, in keeping with the theory, treated as extensions of Pakistani policy. Finally, North Korea's insularity and relatively rapid advances in nuclear capabilities since 2006 create challenges in obtaining reliable information on its government and nuclear weapons program. These issues can largely be overcome with secondary sources and documentation from the archives of North Korea's allies, such as how information on its efforts to acquire nuclear weapons during the Cold War have been discerned from the diplomatic archives of fellow Soviet bloc states like Romania and Hungary. ${ }^{124}$ Ultimately, the North Korea chapter requires much more focus on challenger behaviour and inference of North Korean decision-making processes.

\section{7: Conclusion}

This chapter outlines the methodology used for studying the potential role of regime type in the credibility of a state's nuclear deterrent. The need for historical detail and the paucity of nuclear weapon states means that a comparative case study using process tracing and both qualitative and quantitative data, is the most suitable means of studying this issue. Each defending state is studied by determining what regime type it corresponds to and how challengers responded to it during pre-nuclear crises. After reviewing the motivations for developing its nuclear arsenal and its nuclear doctrine, post-nuclear crises are compared to previous ones to determine how challenger behaviour differed, whether the defender's

\footnotetext{
${ }^{123}$ Ahsan I. Butt, "Do nuclear weapons affect the guns-butter trade-off? Evidence on nuclear substitution from Pakistan and beyond," Conflict, Security \& Development 15, no. 3 (2015): 238.

${ }^{124}$ Wilson Center, "North Korean Nuclear History," Wilson Center Digital Archive, accessed April 25, 2019, https://digitalarchive.wilsoncenter.org/collection/113/north-korean-nuclear-history.
} 
nuclear deterrent played a role, and what influenced its perceived credibility to the challengers. Each case will then have alternative explanations reviewed before having the hypotheses from chapter 3 tested, with all case findings being compared in chapter 9 . This chapter also provided a detailed explanation of the case selection process, which necessitates the exclusion of unsuccessful proliferators, former nuclear weapon states, and the 5 NPT states. As a result, the four nuclear weapon states studied are India, Israel, Pakistan, and North Korea, which not only ensures that the findings for each will be comparable, but that they will also be applicable to any future nuclear weapon states that arise. 


\section{Chapter 5: Israel}

\section{1: Introduction}

Israel is an important case for studying how nuclear deterrence can be influenced by regime type. It is one of the few democracies in the Middle East and has been involved in numerous crises with neighbouring states throughout its history. It was also the first nonNPT state to develop nuclear weapons, having reportedly developed nuclear devices by 1967. ${ }^{1}$ Israel's involvement in both pre- and post-nuclear acquisition crises makes it useful for studying the influence of nuclear weapons on conflict. It is also unique in maintaining a nuclear ambiguity policy, known as amimut (“ambiguity" in Hebrew), using ambiguous statements and strict censorship. ${ }^{2}$ Combined with nuclear authority being held exclusively by the prime minister, Israeli officials lack almost any accountability on nuclear policy.

The chapter begins with an overview of Israeli governance, including how it has been influenced by national security concerns. This is followed by a study of pre-nuclear acquisition crises involving Israel, primarily focusing on the First Arab-Israeli War (19481949) and the Suez Crisis (1956). The motivations for Israel's nuclear weapons program are subsequently discussed. This is then followed by its suspected nuclear deterrence policy, the specifics of its nuclear opacity approach, and what information is known about Israel's command and control structure. Post-nuclear crises targeting Israel are subsequently analyzed, with a focus on the Six-Day War (1967), the War of Attrition

\footnotetext{
${ }^{1}$ Kelsey Davenport and Kingston Reif, "Nuclear Weapons: Who Has What at a Glance," Arms Control Association, June 2018, https://www.armscontrol.org/factsheets/Nuclearweaponswhohaswhat.

${ }^{2}$ On occasion, officials have made statements accidentally confirming this, most recently when Prime Minister Benjamin Netanyahu referred to Israel as a "nuclear power" during a January 2020 Cabinet meeting. Jeffrey Heller, "Netanyahu, in Apparent Stumble, Calls Israel 'Nuclear Power," Reuters, January 5, 2020, https://www.reuters.com/article/us-israel-netanyahu-nuclear-idUSKBN1Z40CS.
} 
(1967-1970), the Yom Kippur War (1973), and the Iraqi missile attack in the Gulf War (1991). This section of the chapter seeks to determine not only if Israel's challengers were aware of its nuclear weapons, but also whether they perceived it as overly cost-sensitive and how this would have affected their willingness to attack. Alternative explanations to the theory are also examined, specifically the possibility of challengers seeking to take advantage of a perceived conventional disparity and the stability-instability paradox.

Studying the crises targeting Israel appears to support H2(a)'s prediction that nuclear democracies face difficulties in credibly deterring low-intensity armed attacks and limited war, though nuclear ambiguity raises issues in this regard. Crises such as the SixDay and Yom Kippur Wars, among others, would initially suggest that Israel's nuclear arsenal has failed as a deterrent. Unlike the existential threat of the 1948 war, post-nuclear crises involved much more limited aims towards Israel. ${ }^{3}$ When considered alongside the attitudes of leaders such as Gamal Nasser, these appear to support the predictions of $\mathrm{H} 1$ and H2(a) in that Israel's nuclear deterrent has reduced armed conflict intensity, but has not deterred it entirely. The Six-Day War and Yom Kippur War in particular support the prediction that government cost-sensitivity plays a role due to Israeli officials being constrained by concerns over costs to their citizens. The use of state-sponsored terrorism and cyberattacks by Iran (specifically directing and supporting Hezbollah), while not

\footnotetext{
${ }^{3}$ Avraham Sela, "The 1973 Arab War Coalition: Aims, Coherence, and Gain-distribution," Israel Affairs 6, no. 1 (1999): 36-69; Martin Walker and David Fairhall, "Iraqi Missiles Strike Israel," The Guardian, January 18, 1991, https://www.theguardian.com/world/1991/jan/18/iraq.davidfairhall.
} 
discussed in this chapter, lends further credence to Israel's challengers not being deterred by its nuclear arsenal in launching lower-intensity attacks. ${ }^{4}$

This is complicated, however, by Israel's nuclear ambiguity, which introduces uncertainty regarding accountability and how aware Israel's challengers were of the risks of nuclear war. It is unclear whether Israeli nuclear threats were communicated in the SixDay and Yom Kippur Wars, and nuclear deterrence only seems to have been considered in the latter conflict. This may be due to Israel's nuclear deterrent being reserved for existential threats and not wars with limited aims. ${ }^{5}$ However, this ignores that some Israeli officials $\mathrm{did}$ consider these crises to be existential and only decided against nuclear test explosions as a show of force due to the potential costs. ${ }^{6}$ Furthermore, the measures upholding amimut mean that the Israeli public is unaware of when their deterrent would be used and who is accountable. Israel's approach to nuclear deterrence requires abrogating its democratic practices, but in the process may undermine its ability to deter challengers.

\section{2: Democracy with National Security Exceptions: Evaluating Israeli Governance}

Israel has long been reputed as the only democracy in the Middle East, and while this can be disputed, most measures indicate that it remains the region's most democratic state. The Polity 5 Project has given Israel high scores, as it remained at 9 or 10 on a 21point scale up until 1980, but it has since declined to a total score of 6 due to a decline in

\footnotetext{
${ }^{4}$ Ronen Bergman and David M. Halbfinger, "Israel Hack of Iran Port Is Latest Salvo in Exchange of Cyberattacks," New York Times, May 19, 2020, https://www.nytimes.com/2020/05/19/world/middleeast/israel-iran-cyberattacks.html.

${ }_{5}^{5}$ Seymour M. Hersh, The Samson Option: Israel's Nuclear Arsenal and American Foreign Policy (New York: Random House, 1991), 137.

${ }^{6}$ The belief among some Israeli political and military elites that Arab states want to eradicate all Jewish Israelis has been dubbed the Holocaust syndrome due to the repeated invocation of the Holocaust as a point of comparison. See Michael Brecher, Decisions in Crisis: Israel, 1967 and 1973 (Berkeley, University of California Press, 1980), 38-39, 94-95.
} 
its democ score and a slight increase of its autoc score from 0 to $1 .^{7}$ Freedom House, meanwhile, has consistently graded Israel as "free" in its annual Freedom in the World reports, albeit somewhat declining from an overall score of 80/100 in 2017 to $76 / 100$ in 2020. ${ }^{8}$ The Economist Intelligence Unit's Democracy Index has similar been critical, referring to Israel as a "flawed" democracy due to scoring between 7.3 and 7.85 overall out of a possible 10 between 2007 and $2018 .^{9}$ All three indices attribute these declines to heavy restrictions on Palestinians in occupied territories, unequal treatment of Arab Israelis and other minorities, and restrictive national security laws. Israel remains the most democratic Middle Eastern state due to all others being hybrid or purely authoritarian regimes. ${ }^{10}$

The fractious nature of Israel's legislature forces governments to be highly sensitive to voter preferences to remain in power. The Knesset is highly contested, with an estimated $33 \%$ of its 120 members (or MKs) being replaced in each election. ${ }^{11}$ The large number of parties with seats in the Knesset makes governing without a coalition impossible, with only one of the 35 governments formed since 1949 not being a coalition government. ${ }^{12}$ Prior to 1973, many of these coalitions included a variety of ideologies, resulting in their including left-wing, right-wing, centrist, and religious parties simultaneously, but have since become

\footnotetext{
${ }^{7}$ Center for Systemic Peace, "Polity 5 Annual Time-Series, 1946-2018," Center for Systemic Peace, April 23, 2020, http://www.systemicpeace.org/inscr/p5v2018.xls.

${ }^{8}$ Freedom House, "Freedom in the World," Freedom House, 2020, https://freedomhouse.org/sites/default/files/202002/2020 Country and Territory Ratings and Statuses FIW1973-2020.xlsx. "Freedom in the World 2017: Israel," Freedom House, 2017, https://freedomhouse.org/country/israel/freedom-world/2017; "Freedom in the World 2020: Israel," Freedom House, 2020, https://freedomhouse.org/country/israel/freedom-world/2020.

${ }^{9}$ Laza Kekic, The Economist Intelligence Unit's index of democracy (London: Economist Intelligence Unit, 2007), 3; Economist Intelligence Unit, Democracy Index 2018: Me too? Political participation, protest and democracy (London: Economist Intelligence Unit, 2019), 32.

${ }^{10}$ Economist Intelligence Unit, Democracy Index 2018, 32.

${ }^{11}$ Naomi Chazan, "The Knesset," Israel Affairs 11, no. 2 (2005): 395.

${ }^{12}$ As of 2020, there is a total of 12 parties sitting in the Knesset. "All Governments of Israel," The Knesset, 2020, accessed July 14, 2020, https://main.knesset.gov.il:443/EN/mk/government/Pages/governments.aspx.
} 
more homogenous due to including parties with broadly similar views. ${ }^{13}$ These coalition governments typically include a power-sharing agreement between the leaders of the governing parties to alternate the position of prime minister between themselves. ${ }^{14}$

Israel's political system includes numerous guaranteed freedoms and checks and balances on government power. While Israel lacks a written constitution, it instead uses Basic Laws passed by the Knesset to fulfill a similar function. ${ }^{15}$ These laws being passed by the Knesset means that they can be easily overridden with any other legislation, with only some specifying amendment conditions. ${ }^{16}$ Israeli courts, particularly the Supreme Court, have often struck down such laws, resulting in their reinterpretation or being subject to requests for clarification and correction. ${ }^{17}$ These freedoms have not applied to Arab Israelis to the same extent, as while they enjoy the same legal protections as other citizens, they face systemic discrimination and are often ruled against by the government. ${ }^{18}$

The most notable shortcomings in Israeli democracy have emerged out of a desire to ensure national security, with Israeli law giving the government considerable latitude in this regard. In particular, Clause 32 of the Basic Law, known as the "residual power clause," authorizes the government to "perform... all actions which are not legally

\footnotetext{
${ }^{13}$ Gabriel Sheffer, "From crisis to change: The Israeli political elites and the 1973 war," Israel Affairs 6, no. 1 (1999): 154-155.

${ }^{14}$ Jacob Magid, “After 508-Day Crisis, Israel's New Government Finally Sworn in by Knesset," The Times of Israel, May 17, 2020, https://www.timesofisrael.com/ending-political-crisis-new-government-sworn-inby-knesset/.

15 "Basic Law: The Government (2001)," The Knesset, 2001, https://knesset.gov.il/laws/special/eng/basic14 eng.htm.

${ }^{16}$ Nir Kedar, "The Rule of Law in Israel," Israel Studies 23, no. 3 (2018): 168-169.

${ }^{17}$ Chazan, "The Knesset," 402-403.

${ }^{18}$ Kedar, "The Rule of Law," 168-170; Economist Intelligence Unit, Democracy Index 2016: Revenge of the "Deplorables," (London: Economist Intelligence Unit, 2017), 44, http://www.eiu.com/Handlers/WhitepaperHandler.ashx.
} 
incumbent on another authority," provided they do not violate existing laws. ${ }^{19}$ Israeli national security agencies not governed by the General Security Service Law, such as the Mossad, thus answer directly to the prime minister without Knesset oversight, allowing for covert operations and assassinations. ${ }^{20}$ Israel is also one of the only Western democracies to still have a military censor, known as the Censora, which is under AMAN's authority and reviews domestic publications for any content that could harm national security. ${ }^{21}$ Any news articles, books, or even social media posts deemed to have harmful content can be subject to edits, redactions, or even a publication ban, with 271 articles being banned and 2,087 being redacted out of 11,035 submitted for review in 2017 alone. $^{22}$

The elements referred to in this sub-section thus establish that Israel possesses a highly democratic and accountable government in many respects, but has broad latitude regarding national security. The residual power clause and the Censora allow Israeli leaders to not only order actions that potentially contravene Israeli law with little to no accountability, but also ensure that the Israeli public is kept in the dark about various relevant policies and decisions, barring unauthorized leaks. As is explained later in this chapter, these two elements both play key roles in Israeli nuclear policy, particularly in enabling continued nuclear ambiguity and a lack of accountability. In the process, it introduces a complication to the theory's prediction regarding the role of accountability in

\footnotetext{
19 "Basic Law: The Government (2001)."

${ }^{20}$ Ronan Bergman, Rise and Kill First: The Secret History of Israel's Targeted Assassinations (New York: Random House, 2018), 643.

${ }^{21}$ AMAN, or the Israeli Military Intelligence Directorate, is the primary military intelligence agency in Israel. Aluf Benn, "Censoring the Past," Bulletin of the Atomic Scientists 57, no. 4 (2001): 17-19.

${ }^{22}$ Anna Ahronheim, "IDF Military Censor Banned Nearly 300 Articles Last Year," The Jerusalem Post, July 12, 2018, https://www.jpost.com/International/IDF-Military-Censor-banned-nearly-300-articles-lastyear-562318.
} 
making governments wary of using nuclear weapons in low-intensity conflict by reducing the accountability of Israeli officials.

\subsection{1: Israeli Civil-Military Relations}

Given Israel's history of conflict with neighbouring states, the use of compulsory military service and the subsequently fraught security situation, it is unsurprising that the Israeli Defense Forces (IDF) and intelligence agencies hold considerable sway in both Israel's government and broader society. The IDF is widely respected by the Israeli public for its role in national security, to the point of being one of the country's most trusted institutions: polls between 2000 to 2010 indicating that $79-90 \%$ of the Jewish Israeli population supports it. ${ }^{23}$ Numerous IDF officers, such as Ariel Sharon, Benjamin Netanyahu, and former Chiefs of the General Staff (CGS) Yitzhak Rabin (1964-1968), Ehud Barak (1991-1995), and Benny Gantz (2011-2015) have used this popularity to establish civilian political careers and even become prime ministers. ${ }^{24}$ Despite this, the IDF has not been overly dominant in civilian politics, instead being deferential to the point that civilian officials are perceived as imposing their will on the military. ${ }^{25}$ It does mean, however, that most Israeli politicians have prioritized defence spending, which Figure 5.1 shows has increased over time. Israeli politicians have also proven willing to engage in large-scale military operations, such as the Second Lebanon War (2006) and Operation Protective Edge (2014), despite the apparent costs associated with them.

\footnotetext{
${ }^{23}$ Roni Tiargan-Orr and Meytal Eran-Jona, “The Israeli Public's Perception of the IDF: Stability and Change," Armed Forces \& Society 42, no. 2 (2016): 329.

${ }^{24}$ Stuart A. Cohen, "Changing Civil-Military Relations in Israel: Towards an Over-Subordinate IDF?," Israel Affairs 12, no. 4 (2006): 787.

${ }^{25}$ Cohen, "Changing Civil-Military Relations in Israel," 771.
} 
Figure 5.1: Israeli Military Expenditure, 1960-2018

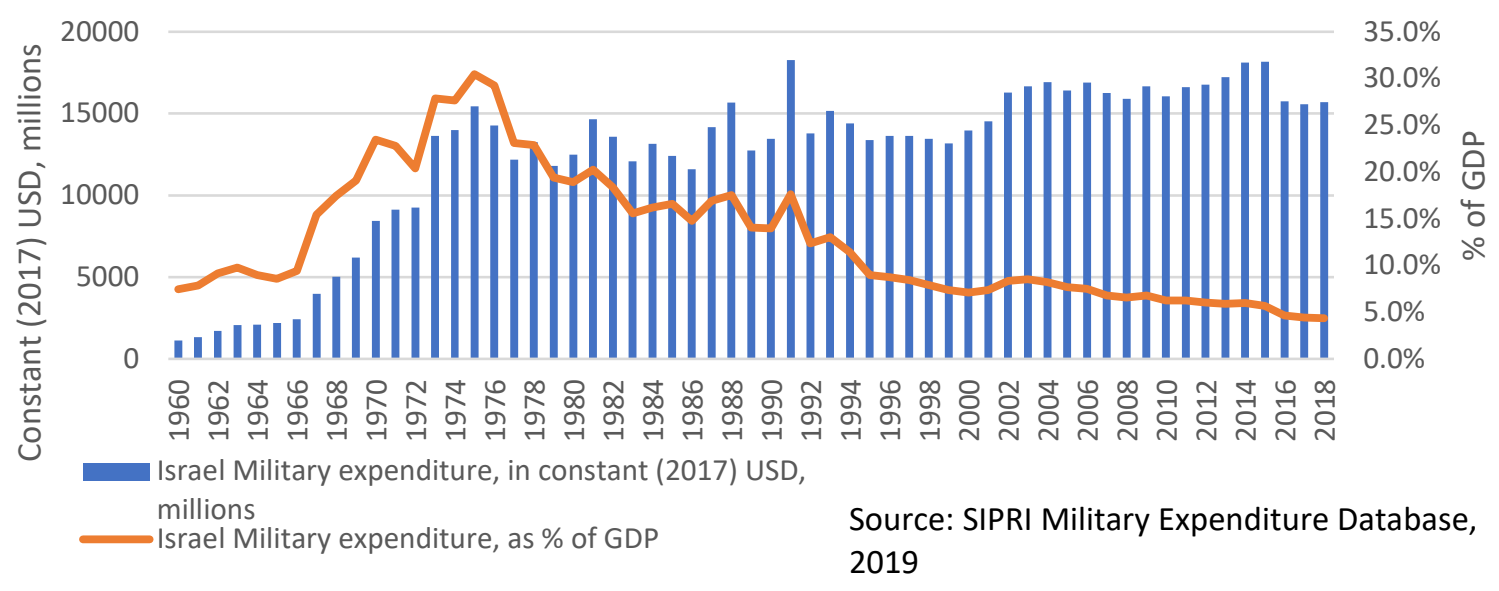

Military influence on Israeli politics was originally much greater in Israel's early years before gradually waning. Former CGS Moshe Dayan (1953-1958) is a prominent example for his willingness to speak out on non-military issues and even lobbying for a leadership change in the then-governing Labour Party. ${ }^{26}$ Between the 1960s and 1980s, the IDF's monopoly on strategic intelligence through the military intelligence agency AMAN gave it considerable influence over civilian policy. ${ }^{27}$ This period also saw the IDF's independence gradually reduced when the 1974 Agranat Commission recommended formally defining civil-military relations, leading to the 1976 Basic Law: The Army. ${ }^{28}$ The IDF only became completely subordinate to civilian authorities during Netanyahu's first premiership in 1996-1999 due to efforts to reduce military influence. ${ }^{29}$ Military and national security chiefs have sometimes disputed government decisions, most notably when CGS Gabi Ashkenazi and Mossad chief Meir Dagan strongly protested possible

\footnotetext{
${ }^{26}$ Motti Golani, "Shall We Go to War? And If We Do, When? The Genesis of the Internal Debate in Israel on the Road to the Sinai War," Israel Affairs 6, no. 3-4 (2000): 23.

${ }^{27}$ Cohen, "Changing Civil-Military Relations in Israel," 773-774.

${ }^{28}$ Amir Bar-Or, "Political-Military Relations in Israel, 1996-2003," Israel Affairs 12, no. 3 (2006): 365.

${ }^{29}$ Bar-Or, "Political-Military Relations in Israel," 366-367.
} 
attacks on Iranian nuclear facilities in 2010 , but this is considered a rarity. ${ }^{30}$ At present, the Israeli military and security apparatus generally complies with civilian authorities.

Taken together, these traits suggest that the Israeli public, while necessary to retain power, is less influential in national security decisions. The highly contentious nature of Israeli politics forces parties to form governing coalitions to maintain sufficient popular support, which would indicate high government accountability among MKs and the public. However, this does not seem to extend to national security due to the aforementioned laws and practices that have formed over time, which allows the government to create policy with little to no oversight and outright prevent public accountability via censorship. Instead, governments have focused on maintaining elite support, particularly during crises such as the Six-Day and Yom Kippur Wars, when decisions were almost entirely made by these groups without any public scrutiny. ${ }^{31}$ This does not mean that Israeli governments are wholly unaccountable in this regard: as discussed in 5.6.3, Golda Meir's government was pressured to resign in April 1974 by a no-confidence vote spurred by its perceived failure to prepare for the Yom Kippur War in the previous year.

\section{3: "We must bring about a decisive confrontation:'" Israeli Pre-Nuclear Crises and Conflicts}

Israel is notable for having been plunged into a crisis immediately after declaring independence, and has been repeatedly targeted by neighbouring states and various nonstate actors for attacks throughout its history. This has made it one of the most conflictprone states in the post-Second World War period: between 1948 and 2004, it fought in 6

\footnotetext{
${ }^{30}$ Clive Jones, “Israel's Security Nexus as Strategic Restraint: The Case of Iran 2009-2013,” Journal of Strategic Studies 41, no. 1-2 (2018): 160-80.

${ }^{31}$ Brecher, Decisions in Crisis, 354-358.
} 
interstate wars, the First and Second Intifadas (considered to be intrastate conflicts), and was involved in 144 dyadic MIDs of varying severity. ${ }^{32}$ This means, as stated earlier, that Israel is particularly useful for determining whether nuclear weapons have a mitigating effect on wars and lower-intensity attacks, since it provides a basis for comparison between before and after it possessed nuclear weapons.

This section focuses on the First Arab-Israeli War (1948-1949) and the Suez Crisis (1956). As with the other crises studied, these were selected using the International Crisis Behaviour (ICB) dataset and secondary sources. ${ }^{33}$ The former is one of the few crises that posed an existential threat to Israel and was its most costly conflict in terms of lives lost. The crisis also served as the basis for subsequent Arab-Israeli hostility and motivated the Israeli nuclear weapons program. The Suez Crisis is similarly important: while Israel invaded the area around the Canal, it was originally triggered by Gamal Nasser's closure of the Straits of Tiran which, due to their importance to Israeli trade and Nasser's support for cross-border raids, led to it being considered an act of war. While the 1948 War resulted from perceived Israeli weakness, rather than a lack of resolve, the low-intensity attacks that contributed to the Suez Crisis were based on the assumption of limited Israeli retaliation.

\subsection{1: First Arab-Israeli War (1948-1949)}

The First Arab-Israeli War, or the Israeli War of Independence, is notable in being one of the only crises where Israel faced an existential threat. The breakpoint of the crisis was Israel's declaring independence on May 14, 1948, with the triggering entities being

\footnotetext{
${ }^{32}$ Zeev Maoz, Defending the Holy Land: A Critical Analysis of Israel's Security and Foreign Policy, 2nd edition (Ann Arbor: University of Michigan Press, 2008), 5.

${ }^{33}$ Michael Brecher et al., International Crisis Behavior Data Codebook, Version 12, 2017, http://sites.duke.edu/icbdata/data-collections/.
} 
the governments of Syria, Iraq, Lebanon, Egypt, and Transjordan, which had threatened to invade in such an event and did so on May $15 .{ }^{34}$ The invasion was justified as necessary to stymie regional unrest caused by the influx of 250,000-300,000 refugees into neighbouring states by Jewish-Palestinian fighting since November 29, $1947 .{ }^{35}$ Public opinion in Arab states was also a factor, as war was favoured to the point that recalcitrant leaders risked assassination, along with the personal leanings of leaders like Egypt's King Farouk. ${ }^{36}$ The interim Israeli government led by David Ben-Gurion considered the invasion to be an existential threat, as Arab propaganda and targeting of civilians leading them to believe they faced a potential genocide, and declared a state of emergency on May $19^{\text {th }} .37$

The power discrepancy between Israel's Haganah paramilitary and Arab coalition forces is popularly seen as favoring the latter, though in reality both sides became evenly matched over the course of the war. By May 1948, Israel had a total population of 650,000 , but only 29,677 of its 80,000 poorly-equipped conscripts were on active duty, though by December this grew to 108,300 troops equipped with Czechoslovakian arms. ${ }^{38}$ Arab coalition forces were expected to number around 120,000 troops: instead, they initially numbered 23,500 (largely Egyptian and Transjordanian) and only reached 68,000 by November, albeit while retaining a qualitative advantage. ${ }^{39}$ This is attributable to the

\footnotetext{
${ }^{34}$ Maoz, Defending the Holy Land, 3.

${ }^{35}$ Benny Morris, The Birth of the Palestinian Refugee Problem Revisited (New York: Cambridge University Press, 2004), 262-263; Abdul Rahman Hassan Azzam, "Press Release S/745: Cablegram Dated 15 May 1948 Addressed to the Secretary-General by the Secretary-General of the League of Arab States" (United Nations Department of Public Information, May 15, 1948), https://unispal.un.org/DPA/DPR/unispal.nsf/0/A717E30BD2F6E5EC8525761E0072E9B3.

36 Thomas Mayer, "Egypt's 1948 Invasion of Palestine," Middle Eastern Studies 22, no. 1 (1986): 28-32.

${ }^{37}$ Moshe Naor, "Israel's 1948 War of Independence as a Total War," Journal of Contemporary History 43, no. 2 (2008): 244-245.

${ }^{38}$ Ahron Bregman, Israel's Wars: A History Since 1947, Third Edition (Abingdon: Routledge, 2010), 2426; Solingen, Nuclear Logics, 192.

${ }^{39}$ Maoz, Defending the Holy Land, 4; Bregman, Israel's Wars, 25.
} 
coalition only forming two weeks before the invasion, competition among members for prestige, and a general sense of overconfidence, exemplified by Arab League General Secretary Abdul Rahman Azzam's dismissal of the number of Israeli troops as "irrelevant." ${ }^{, 40}$ The existing evidence regarding coalition motivations to attack Israel in 1948 suggest that it was not due to perceiving it as vulnerable because it was a democracy, but instead because it was a nascent state.

The crisis ultimately ended in Israel's favor. Over the following nine months, the Haganah fought against Arab forces in former British Mandate territory and Egypt's Sinai Peninsula, with numerous attempted truces and a UN-mediated armistice. ${ }^{41}$ Crisis involvement for coalition members ended at different times, with Egypt being the last following its defeat at Eilat on March 10, 1949. ${ }^{42}$ Armistice agreements were signed by July 20, terminating the crisis, and the agreed-upon borders were upheld until the 1967 SixDay War. ${ }^{43}$ The crisis was the costliest war Israel has fought to date, with 5,862 being killed - roughly $1 \%$ of the state's Jewish population - while the Arab coalition had an estimated 3,700 killed. ${ }^{44}$ The refugee crisis caused by the mass displacement of 700,000 Palestinians further generated dissatisfaction with the crisis outcome among the coalition leaders, particularly the Egyptian government. ${ }^{45}$ Cross-border raids against Israel by refugees began shortly after the war, and the reprisal policy implemented by Israel against

\footnotetext{
${ }^{40}$ Sela, "The 1973 Arab War Coalition,” 38; Alec Kirkbride, From the Wings: Amman Memoirs 1947-1951 (London: Routledge, 1976), 24.

${ }^{41}$ The most notable such effort was made by UN mediator Count Folke Bernadotte, who was assassinated in September 1948 by the Israeli terrorist group Lehi. Maoz, Defending the Holy Land, 4; Bregman, Israel's Wars, 29-30.

${ }^{42}$ Naor, "Israel's 1948 War of Independence as a Total War."

${ }^{43}$ Michael Brecher and Jonathan Wilkenfeld, A Study of Crisis (Ann Arbor: University of Michigan Press, 1997), 270.

${ }^{44}$ Bregman, Israel's Wars, 35.

${ }^{45}$ Moshe Ma'oz, "From Conflict to Peace? Israel's Relations with Syria and the Palestinians," Middle East Journal 53, no. 3 (1999): 393-416; Naor, "Israel's 1948 War of Independence as a Total War," 256.
} 
Arab villages and military installations spurred Egypt to begin supporting the raids by 1953. ${ }^{46}$ The lingering tensions caused by the outcome of the 1948-1949 war and the subsequent raids on Israel meant that another Arab-Israel crisis would be likely to occur.

\subsection{2: Suez Crisis (1956)}

The Suez Crisis is key to understanding future Israeli perceptions and behaviours due to reinforcing the view that Israel could not rely on other states for support. The immediate trigger of the crisis was the Suez Canal's nationalization by Egyptian President Gamal Nasser on July 26, $1956 .{ }^{47}$ The earlier breakpoints for Israel, however, were the 1950 closure of the Straits of Tiran and Nasser's clandestine support for cross-border raids by guerillas in the West Bank and Gaza Strip since $1953 .{ }^{48}$ Though the closure was not enforced until 1953, their importance to Israeli trade meant it was considered an act of war, with Abba Eban warning in September 1955 that they would be reopened " "by whatever methods"” necessary. ${ }^{49}$ The guerilla attacks against Israel further worsened Arab-Israeli relations due to the costs: between 1949 and 1956, there were 11,650 infiltrations, with an estimated 530 to 967 Israeli settlers and soldiers killed and an estimated 750,000-1,000,000 Israeli pounds in annual economic damages. ${ }^{50}$ Israel launched numerous reprisal raids,

\footnotetext{
${ }^{46}$ Maoz, Defending the Holy Land, 234-239.

${ }^{47}$ Bregman, Israel's Wars, 50-51.

${ }^{48}$ Maoz, Defending the Holy Land, 49-51; Brecher and Wilkenfeld, A Study of Crisis, 275.

${ }^{49}$ Eitan Barak, "Between Reality and Secrecy: Israel's Freedom of Navigation through the Straits of Tiran, 1956-1967," Middle East Journal 61, no. 4 (2007): 661-662; "Israel Protests in U.N.," New York Times, September 29, 1955, https://timesmachine.nytimes.com/timesmachine/1955/09/29/83375249.html?pageNumber=3.

${ }^{50}$ Benny Morris, Israel's Border Wars, 1949-1956: Arab Infiltration, Israeli Retaliation, and the Countdown to the Suez War (Oxford: Oxford University Press, 1993), 97-102; Thomas Rid, "Deterrence beyond the State: The Israeli Experience," Contemporary Security Policy 33, no. 1 (2012): 132.
} 
which Ben-Gurion and Dayan considered necessary due to considering Arab hostility as "fundamental and enduring." 51

Nasser's nationalization of the Suez Canal caused these tensions to boil over. Since he took power in 1954, Nasser was viewed by Ben-Gurion as "Israel's most dangerous enemy" due to his efforts to unite the Arab states. ${ }^{52}$ Ben-Gurion was personally ambivalent about fighting Egypt due to the potential backlash, but was pressured by hawks like Dayan, who stated in October 1955 that to guarantee Israel's security, “"we must bring about a decisive confrontation with Egypt." ${ }^{25}$ Domestic political opponents, such as Herut party leader Menachem Begin, also called for preventive war against Egypt. ${ }^{54}$ The opportunity for this arose when the French and British governments, whose own interests were threatened by Nasser's nationalization of the Suez, approached the Israeli government. The three states secretly signed the Protocol of Sèvres on October 24, which committed Israel to attack Egypt and occupy the Canal on October 29, followed by the British and French, with the goal of destabilizing Nasser's rule and overthrowing him. ${ }^{55}$

The fighting in the crisis proved to be relatively brief, but ultimately helped to isolate Israel further and foment further tensions with Egypt. The Israeli attack on Egypt, which targeted the Sinai and Gaza Strip, was launched on October 29 after being approved by Cabinet: within 100 hours, Field Marshall Abdul Hakim Amer ordered the withdrawal of Egypt's forces, allowing the IDF to occupy the Sinai and British and French forces to

${ }^{51}$ Cohen, Israel and the Bomb, 42.

${ }^{52}$ Cohen, Israel and the Bomb, 42, 48.

${ }_{53}$ Maoz, Defending the Holy Land, 58-63, 66.

${ }^{54}$ G. L., "Suez and Its Consequences: The Israel View," The World Today 13, no. 4 (1957), 155.

${ }^{55}$ Avi Shlaim, "The Protocol of Sevres, 1956: Anatomy of a War Plot," International Affairs 73, no. 3 (1997): 509-30. 
seize the Suez on November $4 .{ }^{56}$ International backlash proved severe, as the Soviet Union threatened military action against Israel and the Eisenhower administration contemplated economic sanctions ${ }^{57}$ The United Nations deployed the United Nations Emergency Force (UNEF) on November 7 to ensure an end to hostilities. While Ben-Gurion's government refused to sign a cease-fire agreement, UNEF's presence and American pressure led to the IDF withdrawing to the 1949 armistice lines by March 1957, terminating the crisis.

The Suez Crisis ultimately laid the groundwork for later Israeli-Egyptian crises, most notably the Six-Day War. Egypt's rapid defeat in the conflict, largely due to officers being promoted for loyalty over competence, remained a sore point for Nasser and his supporters. ${ }^{58}$ This spurred efforts to regain military superiority, including the short-lived United Arab Republic (UAR) with Syria during 1958-1961 and a massive rearmament effort that included the purchase of Soviet jets. While Israel avoided serious losses, it did not maintain territorial gains and continued to be attacked. ${ }^{59}$ The crisis did benefit Israel by demonstrating its military advantage over Egypt and ensuring the Straits of Tiran were re-opened, with the Israeli government warning that closing them again would be a casus belli.$^{60}$ Furthermore, the crisis strengthened French-Israeli ties to the point of being able to

\footnotetext{
${ }^{56}$ Michael B. Oren, Six Days of War: June 1967 and the Making of the Modern Middle East (New York: RosettaBooks, 2004), 11.

${ }^{57}$ Maoz, Defending the Holy Land, 72

${ }^{58}$ Moshe Gat, "Nasser and the Six Day War, 5 June 1967: A Premeditated Strategy or An Inexorable Drift to War?," Israel Affairs 11, no. 4 (2005): 626-628.

${ }^{59}$ Leonard Weiss, "The Lavon Affair: How a False-Flag Operation Led to War and the Israeli Bomb," Bulletin of the Atomic Scientists 69, no. 4 (2013):

${ }^{60}$ Golda Meir, "26 Statement to the General Assembly by Foreign Minister Meir - 1 March 1957" (Israel Ministry of Foreign Affairs, March 1, 1957), https://mfa.gov.il $/ \mathrm{mfa} /$ foreignpolicy/mfadocuments/yearbook $1 /$ pages $/ 26 \% 20$ statement $\% 20$ to $\% 20$ the $\% 20$ ge neral $\% 20$ assembly $\% 20$ by $\% 20$ foreign $\% 20$ mi.aspx.
} 
purchase a nuclear reactor and uranium which served as the basis of Israeli nuclear efforts. $^{61}$

The role of regime type in Israel's two major pre-nuclear crises appears minimal, largely influencing the government's crisis behaviour rather than that of its challengers. The existential threat of the 1948 war makes perceptions of Israel's regime type moot, in keeping with the theory's expectations for democratic behaviour. The perceived nature of the threat to Israel means that, regardless of its government and cost-sensitivity, it would have been expected to use all of its resources in such a situation. Importantly, regime type also did not influence the decision by the coalition members to declare war on Israel, as they were motivated by the need for prestige and quelling domestic unrest, neither of which was influenced by the form of Israel's government. ${ }^{62}$

The Suez Crisis, meanwhile, was partially fuelled by domestic audience considerations, albeit driven more by elite concerns than the fear of punishment by voters. The decision to invade Egypt was driven by not only the threat posed by the closure of the Suez, but Ben-Gurion being pressured into preventive war by political opponents like Begin and officials such as Dayan. ${ }^{63}$ In this regard, however, it was largely dictated by the concerns of Israeli political and military elites regarding the inevitability of another war, rather than being restrained in their actions by fear of domestic audiences punishing costly policies as the theory anticipated. ${ }^{64}$ Nasser's decision to support raids against Israel appears to have had nothing to do with it being considered more vulnerable as a democracy, but

\footnotetext{
${ }^{61}$ Weiss, "The Lavon Affair: How a False-Flag Operation Led to War and the Israeli Bomb," 64-65.

${ }^{62}$ Mayer, "Egypt's 1948 Invasion of Palestine," 28-32.

${ }^{63}$ Golani, "Shall We Go to War? And If We Do, When?"

${ }^{64} \mathrm{Maoz}$, Defending the Holy Land, 48-49, 60-61.
} 
instead out of a desire to garner regional prestige.${ }^{65}$ Israel's regime type thus seems to have factored into pre-nuclear crises largely due to how it dictated the domestic political situation, rather than encouraging aggression against it.

The pre-nuclear crises experienced by Israel served to not only demonstrate the credibility of its conventional threats, but also cultivate a reputation for aggressiveness in its foreign policy. Within 15 years of Israel being founded, it had already been involved in two wars with neighboring states, one of which it had instigated itself, and had launched numerous raids in retaliation for infiltration attacks. In doing so, it demonstrated a willingness to endure serious losses and rebukes by the international community to preserve its security, which may be attributable to many early immigrants, and by extension military recruits, being Holocaust survivors. ${ }^{66}$ This type of behaviour would normally be expected to lead to a reduction of armed attacks against Israel since it would increase the credibility of conventional and non-conventional deterrence threats. The numerous crises during the 1960s and 1970s analyzed in section 5.5 indicate that this was not the case.

\section{4: Preventing a Second Holocaust: Israeli Nuclear Weapons Development}

\section{Motivations and History}

Israel's nuclear weapons program is best known for deliberate ambiguity around its very existence. As a result, much of the history surrounding its nuclear development efforts, and the motivations behind them in the first place, have had to be inferred by historians via unofficial sources. This evidence indicates the program was motivated by perceived existential threats to Israel, culminating in usable devices being assembled by

\footnotetext{
${ }^{65}$ Cohen, Israel and the Bomb, $42-49$.

${ }^{66}$ Maoz, Defending the Holy Land, 56.
} 
May 1967. This section first studies the perceived need to deter Arab states from attacking and the lack of allied security guarantees, particularly from the US. Finally, the secrecy surrounding the process that resulted from Ben-Gurion, his allies, and their successors, being concerned about potential international backlash is discussed.

Hostility by Arab states towards Israel, particularly the 1948 war, was a primary factor in Ben-Gurion and others believing that Israel faced an existential threat that could not be defended against through purely conventional means. The existential threat of the 1948 invasion and persistent anti-Israel rhetoric from Arab governments contributed to Ben-Gurion's view that Israel was at risk of a second Holocaust. ${ }^{67}$ Ben-Gurion himself drew an explicit link from this to the need for deterrence, writing to John F. Kennedy in 1962 that "“What was done to six million of our brethren"” could occur to Israel if the IDF was defeated. ${ }^{68}$ The potential for a unified Arab coalition with a massive population and resource base became a constant concern for Ben-Gurion, who informed Kennedy in a 1961 meeting that there was a 15:1 population gap in Egypt's favour. ${ }^{69}$ Ben-Gurion and hawks like Dayan believed that the IDF, no matter well-armed or trained, would not be enough given such a gap. Their suspicions regarding the intentions of Nasser and other leaders who maintained a hostile stance towards Israel contributed to Ben-Gurion's sense of insecurity, leading him to reject negotiations in favour of reprisals against raids. ${ }^{70}$

\footnotetext{
${ }^{67}$ Brecher, Decisions in Crisis, 38. Cohen, Israel and the Bomb, 10.

${ }^{68}$ David Ben-Gurion, “308. Letter from Prime Minister Ben Gurion to President Kennedy" (United States Department of State, June 24, 1962), Foreign Relations of the United States, 1961-1963, Volume XVII, Near East, 1961-1962, United States Department of State - Office of the Historian, https://history.state.gov/historicaldocuments/frus1961-63v17/d308.

${ }^{69}$ Etel Solingen, Nuclear Logics: Contrasting Paths in East Asia \& The Middle East (Princeton: Princeton University Press, 2007), 188; Avraham Harman, "Ambassador Harman's Record of the Meeting of President Kennedy and Prime Minister Ben-Gurion," May 30, 1961, 2, National Security Archive, https://nsarchive.gwu.edu/dc.html?doc=2806695-Document-9C-Ambassador-Harman-s-Record-of-the.

${ }^{70}$ Cohen, Israel and the Bomb, 48.
} 
The Israeli government's, and particularly Ben-Gurion's, sense of insecurity was further exacerbated by a lack of security guarantees from other states. Even informal military relations were rejected by the US, UK, and Soviet Union due to their desiring stronger ties with Arab states. ${ }^{71}$ US/Soviet condemnation of Israel during the Suez Crisis further reinforced this sense of isolation. The American view was that Israel already possessed regional military superiority without its support and that the UAR would not pose a threat due Egyptian and Syrian infighting. ${ }^{72}$ While this changed as the special relationship emerged with Johnson, Israel did not receive extended deterrence guarantees to avoid driving Arab states to the Soviets. ${ }^{73}$ The Soviets similarly sought to improve ties with Arab states, with a 1955 arms deal for US\$55 million with Egypt paving the way to the provision of military aid until $1989 .{ }^{74}$ Finally, though the Sèvres Protocol did lead to French arms sales and nuclear support, relations began to strain in 1962 due to Charles de Gaulle's efforts to secure better ties with Arab states, while improved relations with the UK appear to have been temporary. ${ }^{75}$ To Israeli leaders, their country was not only surrounded by adversaries, but was only able to count on allies for military hardware and not more concrete support for deterrence purposes - a serious issue given the view in Israeli strategic culture that even a single loss could be disastrous for the state. ${ }^{76}$

These two issues drove Ben-Gurion and his political allies to consider nuclear weapons as necessary for Israeli security. A secret deal was struck with France in 1957 for

\footnotetext{
${ }^{71}$ Sharad Joshi, "Israel's Nuclear Policy: A Cost-benefit Analysis," Strategic Analysis 23, no. 12 (2000): 2090.

${ }^{72}$ Cohen, Israel and the Bomb, 119-120.

${ }^{73}$ Solingen, Nuclear Logics, 191.

${ }^{74}$ Solingen, Nuclear Logics, 192.

${ }^{75}$ Joshi, "Israel's Nuclear Policy," 2090; Maoz, Defending the Holy Land, 77, 312.

${ }^{76}$ Dima Adamsky, "From Israel with Deterrence: Strategic Culture, Intra-War Coercion and Brute Force," Security Studies 26, no. 1 (2017): 165.
} 
a nuclear reactor and plutonium reprocessing facility in the Negev Desert, which became known as Dimona, as well as uranium. ${ }^{77}$ Secrecy was necessary to avoid US nonproliferation pressure and potential domestic criticism due to the existing burden of IDF modernization on taxpayers. ${ }^{78}$ The nuclear program's estimated cost of US\$80-300 million would have been opposed by the Israeli public and dovish Cabinet members like Finance Minister Levi Eshkol and Education Minister Abba Eban. ${ }^{79}$ CGS Tzvi Tzur and hawks like Foreign Affairs Minister Golda Meir, meanwhile, would have opposed it as taking resources from the IDF's US\$11 million/year modernization program. ${ }^{80}$

Ben-Gurion and his allies Dayan and Deputy Defence Minister Shimon Peres, believing that public knowledge would end the weapons program, worked to minimize awareness of it. The IDF was prevented from even knowing about it through the use of private fundraising instead of defence spending, with Peres estimating that they were able to raise US\$40 million, or "half the price of a reactor." ${ }^{81}$ All nuclear activities were placed under the exclusive control of Lakam, then the IsAEC, which also served to establish Israeli nuclear decisions as entirely civilian matters. ${ }^{82}$ Perhaps most significantly, virtually the entire Cabinet was kept unaware of the reactor by avoiding it in meetings, though members of Ben-Gurion's Mapai party like Meir and Eshkol were eventually informed and avoided

\footnotetext{
${ }^{77}$ Solingen, Nuclear Logics, 187; Zeev Maoz, “The Mixed Blessing of Israel's Nuclear Policy,” International Security 28, no. 2 (2003): 45-46.

78 Solingen, Nuclear Logics, 198.

${ }^{79}$ Nuclear weapons cost estimate is in 1960 US dollars. Cohen, Israel and the Bomb, 64-67.

${ }^{80}$ IDF modernization was roughly $33 \%$ of Israeli defence spending. Cohen, Israel and the Bomb, 64-67.

${ }^{81}$ Benjamin Pinkus, "Atomic Power to Israel's Rescue: French-Israeli Nuclear Cooperation, 1949-1957," Israel Studies 7, no. 1 (March 1, 2002): 130.

${ }^{82}$ Lakam ("Bureau of Scientific Relations") is an intelligence agency focused on collecting scientific intelligence. The IAEC, meanwhile, is referred to as IsAEC in this dissertation to avoid confusion with the similarly-named Indian Atomic Energy Commission (written as InAEC). Solingen, Nuclear Logics, 200.
} 
challenging the decision due to his personal clout in national politics. ${ }^{83}$ These efforts at concealment appear to be the basis for what later became Israel's nuclear ambiguity policy.

These nuclear efforts became public by 1961 due to American pressure, albeit without impacting weapons development. The Eisenhower administration became aware of the reactor by December 1960, forcing Ben-Gurion to publicly claim in December 1961 that Dimona was solely for non-military research ${ }^{84}$ However, it is likely that a final decision to develop nuclear weapons was already made by this time with Cabinet consensus. ${ }^{85}$ What is certain is that it had advanced too much to stop when Ben-Gurion was forced to resign in 1963 over the Lavon Affair: despite the misgivings of Eshkol, who became prime minister, pressure from other ministers, bureaucrats from the RAFAEL R\&D laboratories, and Ben-Gurion himself ensured that it continued. ${ }^{86}$ The exact time when Israel possessed a functional weapon remains unknown. Statements from thenAMLACH head Brigadier General Yitzhak Ya'akov and Dimona radiation safety officer Elie Geisler indicate that, at the latest, a few crude devices were assembled by May $1967 .{ }^{87}$

\footnotetext{
${ }^{83}$ Cohen, Israel and the Bomb, 71-72, 138; Solingen, Nuclear Logics, 198.

${ }^{84}$ Cohen, Israel and the Bomb, 86-89; Maoz, "Mixed Blessing," 46.

${ }^{85}$ Edwin S. Cochran, "Israel's Nuclear History," Israel Affairs 6, no. 3-4 (March 1, 2000): 137.

${ }^{86}$ The Lavon Affair stemmed from a failed 1954 covert operation by Israeli agents in Egypt to plant bombs in American- and British-controlled areas to discredit Communists and the Muslim Brotherhood, which was ordered by Ben-Gurion and subsequently blamed on Defence Minister Pinhas Lavon when it was publicly exposed. Lavon was subsequently exonerated by a Cabinet committee in December 1960. See Cohen, Israel and the Bomb, 137-141; Solingen, Nuclear Logics, 201.

${ }^{87}$ AMLACH ("Weapons Means department" in English) is a body within the IDF General Staff responsible for liaising between the IDF and civilian R\&D agencies, such as RAFAEL. See Yitzhak Ya'akov, Interview with Yitzhak "Ya'tza" Ya'akov by Avner Cohen, 1999, History and Public Policy Program Digital Archive, https://digitalarchive.wilsoncenter.org/document/145093; Elie Geisler, "The Israeli Nuclear Drama of May 1967: A Personal Testimony," The Nonproliferation Review 25, no. 5-6 (2018): $399-404$.
} 


\section{5: The Ambiguous Samson Option: Israeli Nuclear Deterrence and Opacity}

The most distinctive characteristic of Israel's approach to nuclear deterrence is its continued ambiguity through amimut. While it is not the only nuclear weapon state to have done so, it is unique in its longevity and the measures involved. ${ }^{88}$ Nuclear ambiguity has required extensive censorship and nuclear policy's centralization within the Prime Minister's Office. This means that Israeli voters lack knowledge of their state's deterrence strategy and thus cannot hold their government accountable for it. Available information indicates that Israel's nuclear arsenal, estimated as 80-200 warheads that can be delivered by aircraft and land- and sea-based missiles is meant solely for existential threats, specifically if the IDF is completely defeated or in response to an unconventional attack. ${ }^{89}$ This strategy corresponds to the theory's prediction that democracies will tailor their nuclear deterrent solely towards existential threats to the state.

\subsection{1: Israeli Nuclear Opacity}

Israel's democratic practices have a considerable blind spot due to nuclear ambiguity being based on measures that contradict democratic norms. Sometimes referred to as amimut (Hebrew for "opacity"), this largely unique policy has been critical to the Israeli government's stringent refusal to confirm or deny that it possesses nuclear weapons. The practice, which emerged from efforts to conceal nuclear weapons development, is meant to ensure that Israel can retain the benefits of possessing a nuclear deterrent while avoiding domestic opposition and an international backlash to its proliferation of nuclear

\footnotetext{
${ }^{88}$ India, Pakistan, and South Africa also practiced nuclear ambiguity, though all have since abandoned this by openly testing or dismantling their arsenals. Mitsuru Kitano, "Opaque nuclear proliferation revisited: determinants, dynamism, and policy implications," Nonproliferation Review 23, nos. 3-4 (2016): 459-479. ${ }^{89}$ Hans M. Kristensen and Robert S. Norris, "Israeli Nuclear Weapons, 2014," Bulletin of the Atomic Scientists 70, no. 6 (2014): 97-115, https://doi.org/10.1177/0096340214555409.
} 
weapons, including an end to American aid. The reality, however, is that maintaining this ambiguity has required the Israeli government to make it impossible to publicly discuss nuclear weapons or legislate related activities.

The core of amimut is censoring any discussion of Israeli nuclear activities, particularly in news and academic publications. The Censora prohibits any mention of nuclear weapons in domestic media unless it is attributed to foreign sources.$^{90}$ Originally, even indirect references were banned, leading to Haaretz being unable to even report on Arab perceptions of a possible Israeli nuclear arsenal in $1967 .{ }^{91}$ Academic research is similarly restricted, with Avner Cohen having been detained and interrogated in 2001 for citing declassified American and Israeli documents in Israel and the Bomb. ${ }^{92}$ Leaks are harshly punished, with former nuclear technician Mordecai Vanunu being sentenced to 18 years in prison for treason after leaking information on Israel's nuclear arsenal to the Sunday Times in $1986 .{ }^{93}$ Information about Israeli nuclear policy, including its deterrent strategy, is unavailable to the public. This makes it extremely difficult, if not outright impossible, for any public debate about nuclear weapons to occur, allowing the Israeli government to devise policy without risking punishment from its voting audience.

Amimut has also led to a near-total lack of public oversight over any nuclear issues in Israel. The lack of legislation on Israeli nuclear affairs or IsAEC's responsibilities mean that, under Clause 32, the prime minister is responsible for these issues and, unlike other

\footnotetext{
${ }^{90}$ Avner Cohen, The Worst-Kept Secret: Israel's Bargain with the Bomb (New York: Columbia University Press, 2010), 112.

${ }^{91}$ Yoel Cohen, "Nuclear Ambiguity and the Media: The Israeli Case," Israel Affairs 12, no. 3 (2006): 531.

${ }^{92}$ Benn, "Censoring the Past," 17-19.

93 "Revealed: The Secrets of Israel's Nuclear Arsenal," The Sunday Times, October 5, 1986, The Sunday

Times Digital Archive, accessed October 19, 2018, https://link-gale-

com.proxy.library.carleton.ca/apps/doc/FP1802397806/GDCS? $\mathrm{u}=$ ocul_carleton\&sid=GDCS\&xid=88a5905

7; Hersh, The Samson Option, 307-310.
} 
democracies does not have his/her power legally defined or subject to oversight. ${ }^{94}$ Reportedly, domestic nuclear issues are almost never discussed by Cabinet, being reserved for meetings between the prime minister, the defence minister, and the CGS.${ }^{95}$ Virtually all nuclear activities are classified to the point that only the existence of the Dimona and Soreq research centres has been acknowledged, with the last official statement being in $1961 .{ }^{96}$ These policies are the result of Ben-Gurion's successors emulating his practice of nuclear secrecy, even within Cabinet. ${ }^{97}$ This concentration of power has arguably succeeded in maintaining Israel's nuclear ambiguity, but also means that government officials cannot be held accountable for nuclear issues. The lack of internal discussion also means that policy is unlikely to be critically evaluated, with a high risk of groupthink.

Under ambiguity, Israeli nuclear weapons are taboo even in the Knesset. Attempts to discuss the issue have consistently been referred to the Defence and Foreign Affairs Committee, which has jurisdiction due to its national security focus. ${ }^{98}$ In practice, the Committee's policy of only meeting behind closed doors and delegating nuclear issues to a sub-committee indicates this is to avoid a record of nuclear policy. Some exceptions have occurred, such as MK Issam Makhoul's attempt to force a nuclear weapons debate in February 2000 by threatening a Supreme Court appeal and a failed Knesset bill to force Israel to sign the NPT in July $2018 .{ }^{99}$ For the most part, these procedures ensure few MKs

\footnotetext{
${ }^{94}$ Avner Cohen, "Nuclear Legislation for Israel," Strategic Assessment 12, no. 1 (2009): 10-11, 14.

${ }^{95}$ Edwin S. Cochran, "Deliberate Ambiguity: An Analysis of Israel's Nuclear Strategy," Journal of Strategic Studies 19, no. 3 (September 1, 1996): 332.

${ }^{96}$ Cohen, The Worst-Kept Secret, xxvii, 155.

${ }^{97}$ Cohen, Israel and the Bomb, 3.

${ }^{98}$ Cohen, "Israeli Case," 533-534.

99 “Knesset Openly Debates Nukes for First Time," Jewish Telegraphic Agency, February 2, 2000, http://www.jta.org/2000/02/02/default/knesset-openly-debates-nukes-for-first-time; Gil Hoffman, "Knesset Rejects International Nuclear Oversight," The Jerusalem Post, July 4, 2018, https://www.jpost.com/IsraelNews/Knesset-votes-against-nuclear-monitoring-for-Israel-561520.
} 
are aware of nuclear deterrence policy and discourages leaking by ensuring that the source can easily be traced. As with the minimal Cabinet discussion of nuclear policy, this is incongruous with Israeli democracy due to preventing legislative oversight of nuclear policy, and by extension keeping voters from holding the government accountable.

Nuclear ambiguity is primarily to avoid punishment by the US for nuclear proliferation. Israel's dependence on American foreign aid early in its history would have been jeopardized by its nuclear program due to the non-proliferation agendas of the Kennedy and Johnson administrations. ${ }^{100}$ Kennedy in particular pressured Ben-Gurion into allowing inspections in May 1961 to ensure Dimona was only used for peaceful research, which continued throughout the decade. ${ }^{101}$ While no evidence of a weapons program was found, the lack of reference to a reprocessing plant being built at the time suggests that Israeli officials deceived the inspectors. ${ }^{102}$ The Nixon administration, particularly National Security Advisor Henry Kissinger, was more concerned that an Israeli program would spur Arab withdrawal from the NPT or even spark a Middle East nuclear arms race. ${ }^{103}$ Efforts to pressure Israel with the suspension of arms sales were fruitless, as Ambassador Yitzhak Rabin argued that producing and possessing nuclear weapons did not qualify as

\footnotetext{
${ }^{100}$ Central Intelligence Agency, "National Intelligence Estimate, NIE 35-61, 'The Outlook for Israel”" (October 5, 1961), CIA declassification release. Obtained by William Burr, History and Public Policy Program Digital Archive, https://digitalarchive.wilsoncenter.org/document/123846; Joshi, "Israel's nuclear policy," 2095; William Burr, "Israeli Nuclear Capabilities in Mid-1967: What Washington Knew (and Didn't Know)," The Nonproliferation Review 25, no. 5-6 (2018): 379.

${ }^{101}$ Joshi, "Israel's nuclear policy," 2095; William Burr, "Israeli Nuclear Capabilities in Mid-1967: What Washington Knew (and Didn't Know),” The Nonproliferation Review 25, no. 5-6 (2018): 379.

${ }^{102}$ Interview with Tzvi Tzur at the Rabin Memorial Center, Tel Aviv, interview by Boaz Lev Tov, August 16, 2001, Rabin Memorial Center, obtained by Adam Raz, History and Public Policy Program Digital Archive, https://digitalarchive.wilsoncenter.org/document/134926.

${ }^{103}$ Henry A. Kissinger, "Memorandum from Henry Kissinger to President Nixon, 'Israeli Nuclear Program,' n.d., with Enclosures Dated 19 July 1969, Top Secret, Excised Copy" (Richard Nixon Presidential Library, July 19, 1969), 4-6, National Security Archive, https://nsarchive2.gwu.edu/nukevault/ebb485/docs/Doc\%2010\%207-19-69\%20circa.pdf.
} 
"introduction," but that "there must be public acknowledgment." 104 This presented the US with the dilemma of risking alienating Israel or failing to prevent nuclear proliferation.

Nixon and Golda Meir ultimately reached a compromise in 1969 to allow Israel to retain nuclear weapons without losing aid, which is considered the beginning of ambiguity as official policy. During a September 26 meeting, Meir's reported emphasis on Israel's need for a nuclear deterrent led Nixon to agree to ignore it, as well as ending inspections and pressure to sign the NPT, so long as it remained secret. ${ }^{105}$ The US could thus continue providing aid to Israel even after the 1976 Arms Control Export Act prohibited providing military and economic aid to nuclear proliferators. ${ }^{106}$ The resulting legal fiction makes it difficult to sanction Israel through the United Nations since, even if there was evidence, the US could veto them as a permanent Security Council member. Continued Israeli nuclear ambiguity also has the benefit of reducing public pressure in Middle Eastern states like Egypt to develop nuclear weapons due to the lack of immediate incentive, reducing the risk of an arms race. ${ }^{107}$ Ambiguity allows Israel to benefit from nuclear deterrence while avoiding many associated problems, albeit with some compromises to democracy.

\subsection{2: Israeli Nuclear Command and Control and Deterrence Policy}

Israel's nuclear ambiguity means that little concrete information is available regarding its nuclear command and control and conditions for use. What evidence there is

\footnotetext{
104 John P. Walsh, "NSSM 40: Israeli Nuclear Weapons Program" (United States Department of State, May 30, 1969), 2, National Security Archive, https://nsarchive2.gwu.edu/nukevault/ebb485/docs/Doc\%206\%205-30-69\%20NSSM\%2040\%20report.pdf; Paul Warnke, "Memorandum of Conversation: Negotiations with Israel - F-4 and Advanced Weapons" (United States Department of Defense, November 12, 1968), 3, National Security Archive, https://nsarchive2.gwu.edu/NSAEBB/NSAEBB189/IN-03c.pdf.

${ }^{105}$ Ofer Israeli, "Israel's Nuclear Amimut Policy and Its Consequences," Israel Affairs 21, no. 4 (2015): 545 .

${ }^{106}$ Israeli, "Israel's Nuclear Amimut," 547.

${ }^{107}$ Joshi, "Israel's nuclear policy,” 2107.
} 
indicates that Israel's nuclear command and control structure centres around a few officials and is primarily civilian-controlled, though military leaders need to agree to the use of nuclear weapons. Israel's nuclear arsenal, which can be delivered using aircraft, land-based missiles, or from submarines, is meant exclusively as a final resort against existential threats to the state, and is referred to by Seymour Hersh and others as "the Samson Option." 108

Israel's approach to nuclear ambiguity, particularly the focus on the prime minister, provides some insight into its nuclear command and control. This would be consistent with how Clause 32 of the Basic Law requires all nuclear decisions to fall under the purview of the Prime Minister's Office due to a lack of legislation stating otherwise. ${ }^{109}$ The IsAEC serves as the core of nuclear bureaucracy, but the prime minister always serves as its chair and appoints its chief, board members, and the directors of the Soreq and Dimona reactors. ${ }^{110}$ This does not translate to the prime minister having exclusive control over weapons, as the defence minister, CGS, and head of the Israeli Air Force (IAF) need to agree on launch decisions due to the warheads requiring multiple keys to access. ${ }^{111}$ Cabinet involvement in this process is unclear, given its existing lack of involvement in nuclear issues. While it would be expected to have some say over the use of nuclear weapons, given the potential response by voters, the existing practice of nuclear decisions being made without their involvement suggests that there is no legal obligation to include them.

\footnotetext{
${ }^{108}$ The name is a reference to the Biblical story of Samson, who killed himself and the Philistines who captured him by tearing down the building he was chained to.

${ }^{109}$ Cohen, The Worst-Kept Secret, 181-182.

${ }^{110}$ Cohen, The Worst-Kept Secret, 93.

${ }^{111}$ Hersh, The Samson Option, 215-218.
} 
This command and control structure has both benefits and notable downsides. It can be inferred from the need for consensus among the prime minister and key officials that no one individual can order the use of nuclear weapons. This requirement also adds accountability, as the PM and defence minister being elected officials means that they are accountable to Israeli voters, including for the decision to use nuclear weapons. The small number of decision-makers involved, however, has been noted as creating a risk of groupthink regarding nuclear weapon use, since the decision does not require consulting outside experts (and amimut would in fact discourage doing so). ${ }^{12}$ Finally, actual government accountability remains limited, since most Cabinet ministers do not appear to have any formal influence on the decision to use nuclear weapons.

Despite Israel's nuclear ambiguity, the consensus is that its arsenal is meant only to be used against existential threats to the state. This policy was reportedly devised in 1966 by Levi Eshkol's government, with Eshkol referring to it as the "Samson option." 113 This strategy outlines four possible scenarios where Israel faces total destruction and all conventional options have failed, necessitating nuclear weapons to inflict massive losses on the challengers. This includes Arab military forces penetrating the post-1949 borders, the destruction of the Israeli Air Force, the use of "massive and devastating" air attacks against cities, and chemical, biological, or nuclear attacks against Israeli territory. ${ }^{114}$ The threat of nuclear retaliation has been deliberately alluded to through public statements and leaks, but never to the point of explicitly confirming the existence of Israel's nuclear

\footnotetext{
112 Israeli, "Israel's nuclear amimut," 548-549.

113 Cohen, Israel and the Bomb, 236.

${ }^{114}$ Cohen, Israel and the Bomb, 237.
} 
arsenal. ${ }^{115}$ These insinuations serve as a more indirect form of nuclear deterrence threat than the norm, creating some space for misinterpretation in the process.

The relatively stringent conditions for use mean that Israel is only suspected of having put its nuclear forces on alert three times in its history: during the 1967 Six-Day War, the 1973 Yom Kippur War, and the 1991 Gulf War. ${ }^{116}$ Israel's nuclear forces consist of a nuclear triad of land-based ballistic missiles, military aircraft capable of carrying nuclear gravity bombs, and submarine-launched missiles. ${ }^{117}$ These ensure that Israel both retains an assured second-strike capability and the ability to strike anywhere in the Middle East. The last resort nature of Israel's nuclear deterrent, as well as its civilian-run command and control structure, means that it is kept at arm's length from the IDF rather than being integrated into military doctrine. ${ }^{118}$ This policy appears to at least partially stem from concerns that using nuclear weapons will lead to the international community sanctioning Israel or attempting to confiscate its arsenal. ${ }^{119}$ All of this indicates that, if what is known is accurate, Israel's nuclear deterrent is highly constrained, with its use or even deployment being unlikely outside of an existential crisis or what Israeli leaders consider to be one.

This nuclear ambiguity means that Israel's nuclear deterrence practices do not conform to the theory's expectations regarding the behaviour of a nuclear democracy. The use of its nuclear deterrent as a last resort against existential threats instead of warding off even low-intensity attacks, or even limited war, matches expected nuclear democracy

\footnotetext{
115 That said, there are occasions where Israeli officials have mistakenly made statements that came close to dispelling ambiguity, the most recent being PM Benjamin Netanyahu's reference to Israel being a "nuclear power" before correcting himself. Heller, "Netanyahu, in Apparent Stumble."

${ }^{116}$ Israeli, "Israel's nuclear amimut," 544.

${ }^{117}$ Kristensen and Norris, "Israeli Nuclear Weapons, 2014."

${ }^{118}$ Vipin Narang, Nuclear Strategy in the Modern Era: Regional Powers and International Conflict (Princeton: Princeton University Press, 2014), 184-185.

${ }^{119}$ Narang, Nuclear Strategy in the Modern Era, 180-181.
} 
behaviour. The cost-benefit analysis regarding potential ramifications of use also fits since democratic cost-sensitivity is expected to act as a source of restraint in using nuclear weapons. The theory anticipates cost-sensitivity being due to government accountability to voters; nuclear ambiguity is problematic in this regard, as it is unclear how Israeli voters can hold officials accountable for nuclear decisions without access to relevant information. Instead, the cost-sensitivity demonstrated by Israeli decision-makers appears to be motivated primarily by fears of punishment by the international community that could leave Israel vulnerable to challengers, which only partially conforms to theoretical expectations. While the Israeli approach to nuclear deterrence conforms to theoretical expectations, whether the underlying motivations do remains an open question.

\section{6: “'We should also prepare a nuclear option:”" Israeli Post-Nuclear Crises and}

\section{Conflicts}

Israel's nuclear deterrent would, on the surface, appear to have helped deter interstate war, but not lower-intensity attacks. The Six-Day and Yom Kippur Wars saw Arab states mobilize to attack Israel, which would seemingly make them instances of deterrence failure. These crises and the War of Attrition saw Israel's challengers pursue limited political and strategic aims, putting them under Israel's nuclear threshold. The 1967 and 1973 wars additionally had Israeli leaders consider test explosions as a show of force before rejecting them due to the possibility of conventional victory, cementing their use as a last resort. Similarly, the 1991 Iraqi missile attacks appear to be a failure of deterrence, but the use of conventional warheads over chemical ones may be attributable to veiled nuclear threats. These would suggest that nuclear democracies like Israel will continue 
experiencing low-intensity armed attacks due to their sensitivity to the costs of using nuclear weapons in those situations undermining deterrence credibility to challengers.

Israel's policy of nuclear ambiguity, however, makes it unclear to what extent nuclear deterrence influenced the conflict behaviour of other states towards it. The nature of this policy means that there is no indication of whether any nuclear deterrence threats were made to Egypt and other challengers, meaning that they may have attacked without realizing the risk of nuclear war. Furthermore, it is unclear that Nasser and other leaders were even aware that Israel possessed nuclear weapons by the 1967 war. The sole case where there is reasonable certainty that a nuclear deterrence threat was issued would be the 1991 Gulf War missile attacks. As a result, the actual role of Israel's nuclear deterrent in the calculations of its adversaries from 1967 onwards, and thus whether their use would have been considered credible, remains largely uncertain.

The criteria outlined in chapters 3 and 4 mean that multiple crises are excluded from this chapter. Both the 1982 and 2006 Lebanon Wars are excluded due to being fought against non-state actors (the PLO in 1982 and Hezbollah in 2006), albeit with Iranian support, and was largely fought outside Israel (barring the use of thousands of rockets against Israeli cities). ${ }^{120}$ As discussed in chapter 3.3.2, nuclear deterrence would be largely irrelevant in such conflicts due to the threat of non-state actors being insufficient to justify the costs of using nuclear weapons. ${ }^{121}$ Additionally, the 1982 war was caused by Israel attacking first, and unlike the Suez Crisis and Six-Day War, was not triggered by another state's actions. These factors, when taken together, make these wars less relevant than the

\footnotetext{
${ }^{120}$ Bregman, Israel's Wars, 159-162, 252; Maoz, Defending the Holy Land, 621.

121 T.V. Paul, "Self-deterrence: Nuclear weapons and the enduring credibility challenge," International Journal 71, no. 1 (2016): 28.
} 
other crises studied in this chapter, particularly given time constraints. The First and Second Intifadas and military operations in Gaza such as Cast Lead and Protective Edge are similarly excluded due to the other major actor being Hamas, a non-state actor. Furthermore, their occurring entirely within Israel and its occupied territories poses two issues. First, Israel threatening to use nuclear weapons against terrorists within its own territory would be non-credible due to being a wholly disproportionate response to their actions and requiring it to inflict massive damage against itself. Secondly, actually following through would, according to the theory's prediction, result in massive backlash from the Israeli public towards its government. These mean that nuclear deterrence is essentially irrelevant towards those domestic crises.

\subsection{1: Six-Day War (1967)}

The Six-Day War, which took place between June 5 and 11, 1967, was fought between Israel and a coalition consisting of Egypt, Syria, Jordan, and Iraq. The crisis was rooted in Nasser seeking to maintain Egyptian prestige after the Suez Crisis and the UAR's collapse in 1961, as well as threatening preventive war against Israel if it developed nuclear weapons after the 1960 public acknowledgement of Dimona. ${ }^{122}$ Nur al-Din al'Atassi's Ba'ath government in Syria also favoured a "“war of liberation' against Israel” and repeatedly clashed with the IDF, with 6 Syrian fighters being shot down over Damascus in April 1967. ${ }^{123}$ Israeli officials like then-CGS Yitzhak Rabin did not anticipate war due to Egypt being heavily involved in the Yemeni Civil War and Syria and Jordan not attacking

\footnotetext{
${ }^{122}$ Bregman, Israel's Wars, 64; Avner Cohen, "Nuclear Dimensions of the 1967 Middle East War: An Israeli Perspective," The Nonproliferation Review 25, no. 5-6 (2018): 364.

123 Joseph Mann, "Syria, Precipitator of the Six Day War," Middle Eastern Studies 49, no. 4 (2013): 54762; "Syrian Chief of State Calls for 'liberation War' Against Israel," Jewish Telegraphic Agency, November 4, 1966.
} 
without its support; at worst, Egypt was expected to attack Dimona with airstrikes. ${ }^{124} \mathrm{~A}$ Soviet report provided to Egypt in April 1967 that (incorrectly) claimed the IDF would mobilize ten brigades to the Syrian border changed this calculus, as Nasser was subjected to pressure from the Egyptian public and rivals such as Jordan's King Hussein to honor the Egypt-Syria defence agreement. ${ }^{125}$

Nasser's subsequent decision to mobilize his forces, as well as Syria, Iraq, and Jordan following suit, triggered a crisis for Israel. By May 14, Nasser pressured UN Secretary-General U Thant into withdrawing UNEF from the Sinai, and deployed 100,000 troops there by the end of the month. ${ }^{126}$ Defence pacts signed with Jordan and Iraq on May 30 and June 4 meant that the coalition's forces totalled 226,000 soldiers by early June, compared to Israel's $100,000{ }^{127}$ This mass mobilization, already of concern to Israeli officials, was accompanied by Nasser closing the Straits of Tiran to Israeli shipping on May 22 and Egyptian surveillance flights over Dimona on May 17 and 26. ${ }^{128}$ During a May 26 Cabinet meeting, officials like AMAN head Aharon Yariv believed that "with the forces he [Nasser] has, he can attack... it's the most unlikely scenario, but he can do it." "129 The flights over Dimona raised additional concerns that it might be bombed, with IAF fighters being authorized to pursue flights into Egypt if necessary. ${ }^{130}$ By the end of May, the consensus among Israel's leadership was that they were facing another war.

\footnotetext{
124 Gat, "Nasser and the Six Day War," 608-610; Cohen, "Nuclear Dimensions," 365.

125 Maoz, Defending the Holy Land, 80; Bregman, Israel's Wars, 67.

${ }^{126}$ Gat, "Nasser and the Six Day War," 608; Maoz, Defending the Holy Land, 81-86.

127 Bregman, Israel's Wars, 67-73.

${ }^{128}$ Gat, "Nasser and the Six Day War," 622, 626.

${ }^{129}$ Israeli Foreign Affairs and Defense Committee, "Protocol number 62 of the Israeli Foreign Affairs and Defense Committee, Friday, May 26, 1967 at 4 pm, in The Kirya, Tel Aviv" (May 26, 1967), 5-7, Israel State Archives. Obtained by Adam Raz, History and Public Policy Program Digital Archive, https://digitalarchive.wilsoncenter.org/document/145002.

${ }^{130}$ Cohen, "Nuclear dimensions," 367.
} 
The scale of the threat being faced proved more divisive. Optimists like Rabin believed that IDF armor at the borders meant that "we can stand an Egyptian military attack," whereas others viewed it as an existential crisis, with Shimon Peres stating that "the nation is in its worst state today, worse than in 1956 and worse than in 1948." ${ }^{\prime 131}$ Eshkol himself was against pre-emptive strikes, but was undermined by a badly-delivered May 28 radio address that led to widespread criticism of his apparent competence. ${ }^{132}$ This forced the creation of a national unity government with the RAFI and GAHAL parties on June 1, with Begin becoming a minister without portfolio and Dayan taking Eshkol's defence portfolio. ${ }^{133}$ The Israeli public appears to have been more pessimistic, with a June $4^{\text {th }}$ poll indicating that $78 \%$ of respondents "expected a war in which centers of population would be bombed." ${ }^{134}$ By that point, pressure had been building for Eshkol to authorize an attack from Cabinet, the public, and the IDF General Staff, with some generals reportedly ready to defy his authority in the belief that acting second would mean Israel's defeat. ${ }^{135}$ The main obstacle was fear of US punishment for attacking first, or at least that acting without American support would be risky, with Ben-Gurion arguing that "it was very dangerous to initiate a war where Israel would have to fight alone." 136 By June 4, the Johnson

\footnotetext{
${ }^{131}$ Foreign Affairs and Defense Committee, "Protocol number 62," 7-9.

132 The infamous "stuttering address" has since been attributed to Eshkol reading from a speech draft that had been changed without his knowledge, rather than a lack of preparation. ${ }^{132}$ Oded Heilbronner, "The Morale of the Israeli Public on the Eve of the Six-Day War as Seen in Public Opinion Polls," Israel Studies 24, no. 1 (2018): 152, 168.

${ }^{133}$ Brecher, Decisions in Crisis, 157-158.

${ }^{134}$ Heilbronner, "The Morale of the Israeli Public," 161.

${ }^{135}$ Maoz, Defending the Holy Land, 87-88; Oren, Six Days of War, 132-133.

${ }^{136}$ This latter view has been dubbed the Ben-Gurion complex due to its being primarily associated with Ben-Gurion, who was hesitant for Israel to act without some form of great power support. See Brecher, Decisions in Crisis, 37-38, 167.
} 
administration hinted approval to Israel to attack, stating that sanctions would not be imposed and the Soviet Union would be kept from intervening. ${ }^{137}$

The internal pressures and subtle American approval led to Israel launching preemptive strikes against the Arab forces on June 5, and by June 11 had forced them to withdraw and signed a cease-fire, which terminated the crisis. Airstrikes essentially destroyed the entirety of the coalition air forces with virtually no Israeli losses, with Egypt in particular losing 300 of its 450 aircraft, while IDF ground forces pushed back the Egyptian and Syrian forces. ${ }^{138}$ A ceasefire was signed on June 11, terminating the war in Israel's favor with its occupation of the Gaza Strip, the Sinai, the West Bank, and the Golan Heights with only around 800 deaths against numerically superior forces, while the Arab coalition lost most of their air forces and up to 20,000 soldiers. ${ }^{139}$ As a result, Israel was the only state satisfied with the outcome, with tensions being elevated by Arab coalition members, particularly Egypt seeking to regain their territory over the following years.

The nuclear aspect of the Six-Day War appears to have been minimal, as Israel's nuclear weapons neither provoked nor deterred its challengers. Despite Nasser's claim that Israeli nuclear weapons would be a casus belli, he stated that Egyptian information indicated that Dimona "is not being used"” for nuclear weapons in 1964, reiterating this view in 1966, 1967, and even in $1969 .{ }^{140}$ Records of a May 13 meeting between Nasser and senior officials where they decided to deploy troops to the Sinai also made no reference

\footnotetext{
${ }^{137}$ Maoz, Defending the Holy Land, 82.

${ }^{138}$ Kenneth M. Pollack, “Air Power in the Six-Day War,” Journal of Strategic Studies 28, no. 3 (2005): 474-475; Bregman, Israel's Wars, 84-88; Maoz, Defending the Holy Land, 82, 109-110.

${ }^{139}$ Egypt in particular is estimated to have lost 10-15,000 troops in the Six-Day War. Oren, Six Days of War, 305.

${ }^{140}$ Robert Stephens and Patrick Seale, "Nasser: We Want to Be Friends with Britain," The Observer, July 5, 1964; Hassan Elbahtimy, "Missing the Mark: Dimona and Egypt's Slide into the 1967 Arab-Israeli War," The Nonproliferation Review 25, no. 5-6 (2018): 388-389.
} 
to nuclear weapons, focusing on Israeli-Syrian tensions instead. ${ }^{141}$ While the May 1967 surveillance flights over Dimona could indicate interest from Nasser or officials within his government, it is unclear if there was any intent to attack it. ${ }^{142}$ That Nasser did not justify mobilizing against Israel for its nuclear weapons program, given his prior threats and desire for regional prestige, lends credence to his being unaware of its advanced state.

Other evidence further indicates that Arab heads of state were unconcerned or unaware of Israel's nuclear arsenal in 1967. To begin with, Egypt appears to have been the only Arab state to be concerned about a potential Israeli nuclear arsenal, as little to no attention was paid to the issue during multiple Arab Summit Conferences prior to $1967 .{ }^{143}$ Furthermore, it does not appear that Israel signalled its possession of nuclear weapons: while Shimon Peres is known to have suggested that Israel "reveal to the United States that it had a nuclear capability,"' there is no indication that Egypt and its allies would have been informed. ${ }^{144}$ This is noteworthy due to Peres himself being among those who believed there was an existential threat, suggesting that the deterrent was either never communicated to the challengers or done so discreetly that there is no public record of it. Given the limited available evidence, it appears that Nasser and his peers mobilized against Israel due to the perceived threat to Syria instead of a preventive war, since there is nothing to indicate they were aware that Israel had nuclear weapons by May 1967.

Available documentation indicates that Israel had a few nuclear devices by the SixDay War and that their use was considered by officials before being rejected. Multiple

\footnotetext{
${ }^{141}$ Elbahtimy, "Missing the Mark," 389-391.

142 Cohen, "Nuclear dimensions," 365-368.

143 Ariel E. Levite and Emily B. Landau, “Arab Perceptions of Israel's Nuclear Posture, 1960-1967,” Israel Studies 1, no. 1 (1996): 43.

${ }^{144}$ Cohen, Israel and the Bomb, 275.
} 
sources indicate that at least a few such devices had been assembled by May 1967, with radiation safety officer Elie Geisler claiming he guarded a radioactive "metallic halfsphere" resembling a nuclear bomb core. ${ }^{145}$ These were apparently intended to be used, as Shimon Peres wrote that he "proposed 'a certain idea"" that would avert war, which has been interpreted as a show of force with a test explosion in the Sinai. ${ }^{146}$ AMLACH head Yitzhak Ya'akov later claimed that Rabin authorized him to conduct such a test across the border in late May 1967, lending credence to Peres' claim. ${ }^{147}$ Concrete steps were taken in this direction, with an IDF unit training to place a device on a mountain in Sinai and remotely detonating it. ${ }^{148}$ Peres' proposal was rejected by Dayan and reportedly was not even given serious consideration by Eshkol due to his personal opposition to Israel's nuclear arsenal. ${ }^{149}$ Instead, the Israeli response remained wholly conventional in nature.

The test explosion option appears to have been rejected due to Israel's conventional victory and the possible costs of carrying out the plan. The plan was motivated by fears of conventional Israeli forces being insufficient for the looming crisis. The rapid resolution of the crisis in Israel's favour instead proved its conventional superiority and made a show of force unnecessary. Beyond this, a test explosion could have been highly detrimental for Israel, as detonating a nuclear device in Sinai would likely spread fallout into Israel and cause a health crisis. ${ }^{150}$ Detonating a nuclear device in Egypt would likely have worsened the crisis by provoking direct Soviet involvement despite American efforts, given its

\footnotetext{
${ }^{145}$ See Cohen, Israel and the Bomb, 273-275; Cohen, The Worst-Kept Secret, 73; Burr, "Israeli nuclear capabilities in mid-1967," 383; Geisler, "A personal testimony," 399-404.

${ }^{146}$ Cohen, "Nuclear dimension," 360; Ya'akov, "Interview with Ya'akov."

${ }^{147}$ Ya'akov, "Interview with Ya'akov," 3-8.

${ }_{148}$ Or Rabinowitz, Bargaining on Nuclear Tests: Washington and Its Cold War Deals (Oxford: Oxford University Press, 2014), 85.

${ }^{149}$ Rabinowitz, Bargaining on Nuclear Tests, 85.

${ }^{150}$ Gat, "Nasser and the Six Day War," 628.
} 
ongoing support for Egypt, possibly causing a nuclear crisis. ${ }^{151}$ It would almost certainly have harmed foreign relations, particularly with the US given the Johnson administration's non-proliferation policies, potentially costing Israel a vital source of military aid and leaving it isolated. ${ }^{152}$ A nuclear show of force was thus not only unnecessary, but would have involved numerous costs that Israeli leaders were unwilling to pay.

These motivations for rejecting a test explosion largely conform to the theory's expectation of democratic governments being too sensitive to the costs of nuclear weapon use outside of existential crises. Where the Six-Day War decision-making process runs into issues, however, is the ambiguity surrounding Israel's nuclear arsenal and how it impacted accountability. The available evidence makes no indication that political considerations factored into possible responses, particularly since the unity government meant that opposition leaders such as Menachem Begin were fully informed and involved in this process. ${ }^{153}$ Furthermore, the secrecy surrounding Israel's nuclear program at the time means that the public had no way of holding their leaders accountable for using or not using nuclear weapons in the war. Instead, decisions appear to have been driven entirely by the perspectives of the Israeli political and military leadership and what they considered to be best for the state. Thus, while the Israeli government's behaviour during the crisis conforms to the theory's expectations, whether the motivations do so remains in question at best.

\subsection{2: War of Attrition (1967-1970)}

The often-overlooked War of Attrition is often considered a continuation of the SixDay War, as it began shortly after that crisis concluded and was caused by Egyptian

${ }^{151}$ Gat, "Nasser and the Six Day War," 628.

${ }^{152}$ Burr, "Israeli Nuclear Capabilities in Mid-1967."

${ }^{153}$ Israeli Foreign Affairs and Defense Committee, "Protocol number 62." 
dissatisfaction with its outcome, particularly the loss of the Sinai Peninsula. When it began is disputed due to Egypt only formally breaching the 1967 cease-fire in March 1969, but began fighting with Israel for the Suez Canal and Sinai in June 1967. ${ }^{154}$ The breakpoint for the crisis was Egypt closing the Suez Canal to Israel in retaliation for its occupation of the Sinai, triggering years of low-intensity conflict that culminated in a cease-fire on August 7, 1970. ${ }^{155}$ The crisis is notable compared to the Six-Day War and the subsequent Yom Kippur War in that there is no evidence that Israel contemplated the use of nuclear weapons despite the ongoing losses. This is likely due to Israel's nuclear deterrence strategy being focused on existential threats: as the War of Attrition largely consisted of raids and artillery barrages between the two countries, it failed to meet the necessary threshold, and thus could not deter Egypt.

The breakpoint of the War of Attrition was Egypt's loss to Israel in the Six-Day War, motivating Nasser to persist in an anti-Israel policy. Beyond losing large swathes of territory and up to 15,000 soldiers, the Six-Day War harmed Nasser's standing among his own citizens and fellow Arab heads of state. ${ }^{156}$ Retaking the Sinai became Nasser's top priority, instructing Minister of War Muhammad Fawzi to devise a plan while refusing to negotiate or even recognize Israel, even as Eshkol was willing to return it in exchange for formal peace. ${ }^{157}$ The crisis was triggered when Nasser closed the Suez Canal to Israel on July 1 in response to the IDF preventing the establishment of an Egyptian post, provoking clashes with Israel akin to the 1956 crisis. ${ }^{158}$ Both states engaged in commando raids and

\footnotetext{
${ }^{154}$ Maoz, Defending the Holy Land, 114.

${ }^{155}$ Maoz, Defending the Holy Land, 114-115.

${ }^{156}$ Maoz, Defending the Holy Land, 113; David Rodman, "Arms and Influence: The American-Israeli Relationship and the 1969-1970 War of Attrition," Israel Affairs 25, no. 1 (2019): 27-28.

${ }^{157}$ Sela, "The 1973 Arab War coalition," 41-43.

${ }^{158}$ Ibid.
} 
artillery exchanges, with Nasser's apparent reasoning being to cause unacceptable harm to the IDF so that Israel would be pressured into withdrawing from the Sinai without his making concessions, while Israel retaliated against Egyptian forces and infrastructure. ${ }^{159}$ The Israeli view, informed by AMAN intelligence estimates, was that escalating the crisis by attacking deeper into Egypt carried some risk of provoking further Soviet support for Egypt, though actual intervention was considered unlikely. ${ }^{160}$

By 1969, Nasser formally renounced the June 1967 cease-fire, causing the War of Attrition to escalate. While there was strong support for peace among both the public and leaders like Finance Minister Pinhas Sapir, this fell apart with Levi Eshkol's death in February 1969 and his being succeeded by Golda Meir. ${ }^{161}$ Meir instead began a bombing campaign against Egypt in January 1970 despite concerns from IDF planners, Eban, and Dayan that IAF planes would be shot down and that there would be Soviet intervention. ${ }^{162}$ This latter point was ignored by Meir, who was advised by both Rabin and AMAN in fall 1969 that the Soviets would not risk provoking a direct confrontation with the US. ${ }^{163}$ The concerns proved justified, as Nasser demanded during a January 22 visit to Moscow that the Soviets provide military advisors and air defence systems, threatening to pivot to the US otherwise. ${ }^{164}$ The presence of Soviet forces, which resulted in an air battle with the IAF on April 18, led to Israel ending its bombing campaign, as Meir and other officials like

\footnotetext{
${ }^{159}$ Rodman, "Arms and Influence," 28.

${ }^{160}$ Dima Adamsky and Uri Bar-Joseph, “"The Russians Are Not Coming': Israel's Intelligence Failure and Soviet Military Intervention in the 'War of Attrition,"' Intelligence and National Security 21, no. 1 (2006): 3-4.

${ }^{161}$ Maoz, Defending the Holy Land, 121-122.

${ }_{162}$ Maoz, Defending the Holy Land, 122-124; Adamsky and Bar-Joseph, “'The Russians Are Not Coming," "5-6.

${ }^{163}$ Adamsky and Bar-Joseph, "The Russians Are Not Coming,"” 6-7.

${ }^{164}$ Notably, this was the first time that Soviet combat units were deployed outside of the Warsaw Pact since 1945. Adamsky and Bar-Joseph, “"The Russians Are Not Coming,"” 1-25.
} 
Dayan sought to avoid further Soviet involvement. ${ }^{165}$ This allowed Egypt to retake the initiative, and by August 1970 it had gained air superiority around the Suez Canal.

The War of Attrition was terminated in September 1970 through a ceasefire agreement between Israel and Egypt. It was at this point that Nasser's government proposed a ceasefire, which Meir's government accepted on August 7, though a number of ministers from the right-wing GAHAL party protested this move by leaving the national unity government. ${ }^{166}$ The ceasefire briefly fell apart later that month due to Egypt moving its anti-aircraft batteries closer to the Suez: while more hawkish officials like Dayan called for retaliatory airstrikes, Meir's government chose to continue adhering to it, allowing the crisis to ultimately be resolved. Nasser's main motivation for the conflict - regaining the Sinai - remained unaddressed. ${ }^{167}$ This meant that future fighting was almost certain.

The low-intensity nature of the War of Attrition largely supports the theory's prediction of nuclear democracies facing difficulties in deterring limited conflict, though Israeli nuclear ambiguity leaves some questions unanswered. Nasser's sole aim in this crisis was to retake the Sinai Peninsula. The means used by Egyptian forces from 1967 to the 1970 cease-fire matched this, since instead of full mobilization, it was largely limited to raids and artillery fire until the spring of 1970 . This was likely motivated primarily by Israel's demonstrated conventional superiority, with small-scale attacks being unlikely to trigger the same level of retaliation that full mobilization would. It does not appear likely that Israel's nuclear arsenal played a role in this crisis: as discussed in section 5.6.1, Nasser

\footnotetext{
165 Rodman, "Arms and Influence," 30.

166 Maoz, Defending the Holy Land, 130.

${ }^{167}$ Hemda Ben-Yehuda and Shmuel Sandler, The Arab-Israeli Conflict Transformed: Fifty Years of Interstate and Ethnic Crises (Albany: State University of New York Press, 2002), 71.
} 
continued to express a belief that Israel did not possess nuclear weapons into $1969 .{ }^{168}$ As with the Six-Day War, there is no indication that the Israeli government informed Egypt of its nuclear weapons, or that such information deterred Nasser's low-intensity campaign.

Israeli actions during the War of Attrition additionally conform to the expectation that democracies will be sensitive to costs during conflict. For much of the crisis, fighting remained limited to the Suez and the Sinai, with Israel only penetrating further into Egypt after Golda Meir became prime minister. This restraint is attributable to the more dovish outlook of Eshkol's government, a desire to keep IDF casualties to a minimum, and the aforementioned fear of Soviet intervention. ${ }^{169}$ Expanding the scope of the conflict would have made it costlier for Israel, particularly since it was heavily reliant on its air superiority over Egypt to maintain deterrence. The lack of a direct threat to Israel in the crisis also meant that there was considerable support from the Israeli public and within the government to reach a political settlement with Egypt, with public criticism emerging as the war escalated. ${ }^{170}$ The crisis overall suggests that Nasser sought to exploit Israeli costsensitivity and its difficulty in deterring low-intensity conflict to regain the Sinai.

\subsection{3: Yom Kippur War (1973)}

The Yom Kippur War is notable as both the last interstate war fought in Israeli territory and the closest Israel came to defeat in conventional war. As with the War of Attrition, the crisis was caused by the desire to recover lost territory, with Egypt's Anwar Sadat and Syria's Hafez al-Assad seeking to regain the Sinai and the Golan Heights,

\footnotetext{
${ }^{168}$ Elbahtimy, "Missing the Mark," 388-389.

${ }^{169}$ Yair Evron, Israel's Nuclear Dilemma (London: Routledge, 1994), 52; Rodman, “Arms and Influence," 28-29.

${ }^{170}$ Maoz, Defending the Holy Land, 137-138.
} 
respectively, leading them to ally and wage a limited war against Israel. ${ }^{171}$ Sadat was also motivated by domestic politics, as he faced pressure from members of the elite, the upper echelons of the military, and student riots to end his inaction against Israel. ${ }^{172}$ Following a false alarm in April 1973, when the Israel government believed an Egyptian invasion was about to occur, Israeli intelligence came to the conclusion that neither state would invade due to lacking the necessary air superiority. ${ }^{173}$ This advice led many in the government, including Meir, to doubt that war would occur, even as Egyptian and Syrian forces were built up around the border throughout September. ${ }^{174}$

The breakpoint of the crisis was on October 6, when the Egyptian and Syrian armies began advancing from the Suez Canal and the Golan Heights, respectively. This initial attack benefitted from taking place on the Jewish holiday of Yom Kippur, ensuring that Israeli resistance was minimal at first. ${ }^{175}$ The Israeli response was further delayed by concerns among leaders in the governing Labor Party that it was another false alarm whose wasted mobilization costs would haunt the government in the upcoming elections, particularly since they faced strong opposition from Begin's Likud coalition. ${ }^{176}$ Disputes between Dayan and CGS David Elazar regarding how many of the IDF reserves needed to be deployed further slowed down the Israeli response. ${ }^{177}$ In short, Israel was caught completely unprepared, realizing earlier fears from the Six-Day War.

\footnotetext{
${ }^{171}$ Sadat had succeeded Nasser as president following the latter's death on September 28, 1970. Uri BarJoseph, The Watchman Fell Asleep: The Surprise of Yom Kippur and Its Sources (Albany: State University of New York Press, 2005), 11-13, 46-47; Sela, "The 1973 Arab War Coalition," 57.

172 Sela, "The 1973 Arab War Coalition," 44.

173 Bar-Joseph, The Watchman Fell Asleep, 4.

174 Brecher, Decisions in Crisis, 59.

175 Yom Kippur is considered the most important holiday in Judaism, to the point that even most secular Israeli Jews were attending synagogue that day. See Bar-Joseph, The Watchman Fell Asleep, 18.

176 Brecher, Decisions in Crisis, 70.

177 Sheffer, "From Crisis to Change: The Israeli Political Elites and the 1973 War," 165-167.
} 
The Yom Kippur War remains the closest Israel has been to military defeat, though it eventually repelled the invasion. The Syrian advance on the Golan Heights in particular left the IDF near defeat due to air defence systems keeping the IAF from bombing targets. ${ }^{178}$ Despite the limited aims of the Egyptian and Syrian armies, the lopsided nature of the fighting led Israeli leaders to believe they were facing an existential crisis, with Dayan stating that " "this is now a war for the land of Israel." "179 The crisis turned in Israel's favor when the Egyptian and Syrian forces overextended themselves, putting them beyond their air defences and leaving them vulnerable to the IAF. ${ }^{180}$ US materiel airlifts to Israel in response to Soviet support of Egypt and Syria from October 12 onwards also contributed to the shift in the war. ${ }^{181}$ By October 20, the IDF broke through to the Egyptian side of the Suez Canal, and within 2 days were within $101 \mathrm{~km}$ of Cairo and $40 \mathrm{~km}$ of Damascus. ${ }^{182}$ After the crisis briefly escalated with the threat of Soviet intervention, a cease-fire was signed and peace agreements were signed with Egypt and Syria on January 18 and May 31, 1974, respectively. ${ }^{183}$ As of the time of writing, this was the last time an interstate war was fought within Israeli territory.

The Yom Kippur War proved to be costly for all the participants, and caused the end of Meir's government. Despite Israel's victory, it still lost nearly 3,000 soldiers, suffered roughly US\$7 billion in economic damage, and lost territory near the Suez Canal

\footnotetext{
${ }^{178}$ Sela, "The 1973 Arab War Coalition," 58.

${ }^{179}$ Todd S. Sechser and Matthew Fuhrmann, Nuclear Weapons and Coercive Diplomacy (New York: Cambridge University Press, 2017), 218.

${ }^{180}$ Bregman, Israel's Wars, 138-139.

${ }^{181}$ There is speculation that the airlift was spurred by Israel arming nuclear-capable Jericho missiles, but US archival evidence has led to this theory being dismissed. See Elbridge Colby et al., "The Israeli Nuclear Alert" of 1973: Deterrence and Signaling in Crisis" (Fort Belvoir, VA: Defense Technical Information Center, April 1, 2013), 26-27, 31-34.

${ }^{182}$ Bregman, Israel's Wars, 142.

${ }^{183}$ Susan Hattis Rolef, "The Domestic Fallout of the Yom Kippur War," Israel Affairs 6, no. 1 (1999): 186
} 
and in the Golan Heights, while the Arab coalition is estimated to have lost 15,600 troops, mostly Egyptian. ${ }^{184}$ Politically, the war was a disaster for Meir and her Cabinet, who were blamed for not acting quickly despite obvious indications of an attack. While she managed to win the delayed December 1973 elections, the Agranat Commission's report in March 1974 blamed the IDF and numerous officers for failing to act quickly, while Meir's responsibility was left ambiguous. ${ }^{185}$ Meir, along with her Cabinet, resigned a month later rather than face of a no-confidence vote that she was almost certain to lose, leaving Yitzhak Rabin to succeed her as PM until Labour was voted out in $1977 .{ }^{186}$ Sadat, meanwhile, was forced to pivot away from pressuring Israel towards negotiations, though Egypt's initial success in the war allowed it to maintain prominence among other Arab states. ${ }^{187}$

Unlike the Six-Day War, the Egyptian and Syrian leadership were almost certainly aware that Israel possessed nuclear weapons by 1973, but their relatively limited aims seemingly led them to conclude that it would remain conventional. In a 1977 meeting with Israeli Defence Minister Ezer Weizmann, Sadat stated that he did not intend to go beyond the Sinai due to "“what Israel had,"” alluding to its nuclear deterrent. ${ }^{188}$ Assad is believed to have likewise known about Israel's nuclear arsenal, but the Syrian advance beyond the Golan Heights into Israeli territory suggests that it was not taken seriously. ${ }^{189}$ Both leaders anticipated high casualties despite their limited aims, as Sadat expected 50,000 Egyptian dead while Assad "instructed hospitals and graveyards" to expect a large number of

\footnotetext{
184 Bregman, Israel's Wars, 142.

185 Rolef, “The Domestic Fallout," 181-182.

186 Rolef, "The Domestic Fallout," 182.

187 Sela, "The 1973 Arab War Coalition," 64.

188 Colby et al., "The Israeli Nuclear Alert" of 1973," 10-11.

189 Sechser and Fuhrmann, Nuclear Weapons and Coercive Diplomacy, 221-222.
} 
bodies. ${ }^{190}$ This suggests that while significant resistance was expected, Sadat's awareness of Israel's deterrent led him to limit the conflict's scope so that it would remain conventional. The Egyptian military strategy, and possibly Syria's, was thus meant to avoid crossing Israel's nuclear threshold.

Like the Six-Day War, some Israeli leaders sought to use a nuclear test explosion as a show of force, which was again rejected. Dayan reportedly met with Meir and other Cabinet officials on October 7 to discuss the Syrian advance in the Golan Heights, then proposed "“that we should also prepare a nuclear option for demonstration," which only required Meir's authorization to carry out. ${ }^{191}$ Minister without Portfolio Yisrael Galili and Deputy Prime Minister Yigal Allon responded that "“we will fight with conventional weapons without involving any other means, directly or indirectly,"' with Meir explicitly rejecting Dayan's plan. ${ }^{192}$ Their belief that conventional forces would be enough contrasted that of Dayan and other Cabinet members who believed that "this is the end of the Third Temple" due to Israel's lack of strategic depth. ${ }^{193}$ While Sadat and Assad were correct in believing that limited war would fall below Israel's nuclear threshold, the issue is that it was not clear to Israel's leaders that they were not facing an existential crisis.

Further restraints on Israel's nuclear weapons also need to be considered, particularly the impact on Israelis. As with Peres' rejected proposal in the 1967 crisis, a nuclear test explosion would likely deposit large quantities of fallout in Israel. The crisis

\footnotetext{
${ }^{190}$ Maoz, Defending the Holy Land, 153.

${ }^{191}$ Avner Cohen and Arnan Azaryahu, "Interview with Arnan 'Sini' Azaryahu by Avner Cohen" (January 2008), 2, From the personal collection of Avner Cohen, History and Public Policy Program Digital Archive, https://digitalarchive.wilsoncenter.org/document/117848.

192 Azaryahu, "Interview with Azaryahu," 3.

${ }^{193}$ Narang, Nuclear Strategy in the Modern Era, 187
} 
would likely have escalated further as a result, since it could have spurred direct Soviet involvement in the fighting against Israel. ${ }^{194}$ Such an act would likely have drawn widespread international condemnation and would have breached Nixon and Meir's 1969 agreement to keep Israel's nuclear weapons secret, jeopardizing US aid in the process. ${ }^{195}$ These would all in turn have had significant political ramifications in Israel due to the elections scheduled for the end of October, meaning that Meir's government was constrained in how it could proceed in a war that could still be conventionally won.

Both the actions of Israel and its challengers during the Yom Kippur War support that nuclear democracies will encounter difficulties deterring what their challengers believe to be limited conflict. In this case, the Egyptian-Syrian attacks were meant to be relatively limited and to accomplish specific goals, rather than posing a threat to Israel's existence, with Sadat deliberately acting below Israel's nuclear threshold. This also avoids the uncertainty introduced by nuclear ambiguity in the Six-Day War, as Sadat was fully aware of Israel's nuclear deterrent. The Israeli government, for its part, avoided a nuclear show of force due to the potential costs, with leaders demonstrating concern over the possible reactions of voters to various decisions in the upcoming elections. This indicates that the theory's prediction of democratic nuclear weapon states being constrained by potential costs to their public in non-existential crises, though it remains unclear to what extent this perceived cost-sensitivity factored into Sadat and Assad's strategic calculations.

\footnotetext{
${ }^{194}$ Sechser and Fuhrmann, Nuclear Weapons and Coercive Diplomacy, 222-223.

${ }^{195}$ Colby et al., "The Israeli Nuclear Alert" of 1973," 44-45.
} 


\subsection{4: Gulf War (1991)}

The Gulf War crisis differs from the others in that Israel was not actively participating in the war, but was instead attacked with Iraqi missiles. The crisis breakpoint for Israel occurred on September 24, 1990, when Iraqi president Saddam Hussein threatened to attack other states in the region if he was sanctioned for invading Kuwait. ${ }^{196}$ Israeli-Iraqi relations were already poor, since Iraq had participated in previous wars against Israel and had been the subject of numerous Israeli efforts to sabotage its nuclear weapons program, culminating in the 1981 airstrike against the Osirak nuclear reactor. ${ }^{197}$ At the time, Saddam's threat was interpreted as involving the use of chemical warheads, as his conventional forces were dedicated to occupying Kuwait and defending Iraq, but had a sizable chemical weapon arsenal. ${ }^{198}$ Iraq did, however, possess a sizable arsenal of chemical weapons, including nerve agents like VX and sarin, as well as SCUD missiles that could be used to strike at Israel directly. ${ }^{199}$

During the crisis, threats by Israeli officials barely veiled their allusions to using nuclear weapons in response to Iraqi missiles, nearly ignoring ambiguity entirely. Prime Minister Yitzhak Shamir notably warned during an October 1990 CNN interview that "Somebody threatening you with the most terrible weapons in the world has to think about certain responses to the use of such weapons." ${ }^{200}$ CGS Dan Shomron was more explicit in

\footnotetext{
${ }^{196}$ John F. Burns, "Confrontation in the Gulf; Iraqis Threaten to Attack Saudis and Israelis If Nation Is 'Strangled' by Embargo," New York Times, September 24, 1990, https://www.nytimes.com/1990/09/24/world/confrontation-gulf-iraqis-threaten-attack-saudis-israelis-ifnation-strangled.html.

${ }^{197}$ Joshi, “Israel's Nuclear Policy,” 2099-2100.

${ }^{198}$ At the time, Iraq's armed forces consisted of approximately 1 million personnel vs Israel's 141,000. International Institute for Strategic Studies, "The Middle East and North Africa," The Military Balance 90, no. 1 (1990): 105-106.

${ }^{199}$ Hal Brands and David Palkki, "Saddam, Israel, and the Bomb: Nuclear Alarmism Justified?," International Security 36, no. 1 (2011): 159.

${ }^{200}$ Cohen, "Vanunu," 425.
} 
warning that "'Israel would not be the first to use nuclear weapons in the Middle East"” on December 29. ${ }^{201}$ Both Shamir and Shomron's statements were clearly meant to warn Saddam that using chemical weapons against Israel would lead to nuclear retaliation, which is one of the conditions outlined in the $1960 \mathrm{~s} .{ }^{202}$ Even the US contributed, with thenSecretary of Defence Richard Cheney stating in a CNN interview on February 2, 1991 that Israel would respond to a chemical weapon attack with "“unconventional weapons.",203 That these remain the least ambiguous nuclear threats by Israeli officials emphasizes the threat they perceived from Iraq's chemical weapons. It has even been reported that nuclear weapons were prepared for possible use for the third time in Israel's history, indicating that these were not bluffs, though ambiguity makes this impossible to confirm. ${ }^{204}$

These threats did not stop Iraq from attacking Israel, though they may have reduced the danger posed by Iraqi missiles. Over the course of the Gulf War, 38-39 SCUD missiles were fired at Israeli cities, including the major cities of Tel Aviv and Haifa, though they all used conventional warheads rather than chemical weapons. ${ }^{205}$ Israel's direct involvement in the crisis came to an end after January $22^{\text {nd }}$, when the final missile attack occurred, though the Gulf War itself would not be resolved until Iraq agreed to a ceasefire on February $28^{\text {th }}$. Israel suffered considerable damage to property and infrastructure from the missiles, as well as around 74 deaths, though only 2 were directly killed in the attacks. ${ }^{206}$

\footnotetext{
${ }^{201}$ Avner Golov, "Deterrence in the Gulf War," The Nonproliferation Review 20, no. 3 (2013): 454.

202 Cohen, Israel and the Bomb, 237.

203 Golov, "Deterrence in the Gulf War," 454-455.

${ }^{204}$ Israeli, "Israel's nuclear amimut," 544.

205 Maoz, Defending the Holy Land, 316-317.

${ }^{206}$ Steve Fetter, George N Lewis, and Lisbeth Gronlund, "Why Were Casualties so Low?," Nature 361, no. 6410 (January 28, 1993): 293-96.
} 
The main question from this crisis is whether the implied Israeli nuclear threats deterred Saddam from using chemical warheads, with evidence suggesting that they did, albeit with little effect on conventional weapon use. While Saddam used chemical weapons throughout the Iran-Iraq War, he notably avoided doing so in 1990-91 despite the greater threat posed by the US and Israel, both of which signalled a willingness to use nuclear weapons in response to chemical attacks. ${ }^{207}$ Israeli threats appear to have been sincere, given their unusual openness, reduced Israeli censorship, and reports that nuclear weapons were put on alert during the crisis. ${ }^{208}$ Furthermore, Saddam was willing to use chemical weapons for deterrence, having informed visiting US senators in April 1990 of his orders to " take everything that can carry a binary [chemical weapon] to Israel and send this to their territory" "if nuclear weapons were used against Iraq. ${ }^{209}$

Israel's threats appear to have been considered credible given Saddam's previous willingness to use chemical weapons against adversaries. At the same time, the use of conventional missiles against Israel would suggest a belief that they would fall below the nuclear threshold, as the threats made by Israeli officials only referenced unconventional weapons. Furthermore, Saddam's objective appears to have primarily been to deter Israel from actively fighting Iraq with the imposition of (relatively low) costs, given the specific focus on attacking cities. ${ }^{210}$ These actions suggest that Saddam and his subordinates perceived Israel as cost-sensitive and tailored their missile attacks to simultaneously take advantage of this while falling below its nuclear threshold. This was an overly optimistic

\footnotetext{
${ }^{207}$ Golov, "Deterrence in the Gulf War," 463.

${ }^{208}$ Cohen, "Israeli Case," 535.

${ }^{209}$ Cited in Amatzia Baram, "An Analysis of Iraqi WMD Strategy," Nonproliferation Review 8, no. 2 (2001), 31.

${ }^{210}$ Maoz, Defending the Holy Land, 317-319.
} 
view, however, as Israeli retaliation for the missile attacks was only averted by American pressure to not participate in the war (ostensibly to maintain relations with allied Arab states). ${ }^{211}$ It is possible, however, that the Iraqi leadership launched the missile attacks with the deliberate intent to provoke such a response from Israel to disrupt US alliances, though this would require Israel to not retaliate with nuclear weapons..$^{212}$

These events and motivations conform to the expectation that nuclear democracies can still be the target of low-intensity attacks due to perceived cost-sensitivity, but at the same time can remain credible for higher-intensity attacks. The Iraqi use of conventional weapons would, at first glance, suggest that Israel's perceived cost-sensitivity made its nuclear deterrent non-credible despite public threats by Israeli officials. However, these threats appear to have pressured Iraq into avoiding chemical weapon use, despite having been willing to use them in the Iran-Iraq War and as an unconventional deterrent. Israeli threats appear to have been considered credible for chemical weapon use due to their being referenced in public statements, whereas conventional missile attacks were seen as falling below the nuclear threshold and thus potentially safe to use against Israel.

\section{7: Alternative Explanations}

One alternative explanation for continued attacks against Israel despite its nuclear deterrent is that neighboring states have sought to take advantage of a perceived conventional military disparity. This is largely based in Israel possessing a smaller military than its challengers: during the Yom Kippur War in 1973, for example, Israel possessed

\footnotetext{
${ }^{211}$ Amos Harel, Aluf Benn, and Ha'Ha'aretz Service, “Israel to U.S.: We Won't Practice Restraint of Gulf War," Ha'aretz, October 8, 2002, https://www.haaretz.com/1.5025851.

${ }^{212}$ Harel, Benn, and Ha'Ha'aretz Service, "Israel to U.S."
} 
94,500 troops, while Egypt and Syria combined could have fielded $390,000 .{ }^{213}$ This explanation has two notable flaws. First, it ignores Israel's qualitative advantage, particularly the IAF and its key role in the 1967 and 1973 crises. Secondly, it fails to account for the limited use of force against Israel in post-1967 crises: if it was simply a matter of taking advantage of superior numbers, Egypt and Syria would not have limited their goals during the Yom Kippur War. Democratic nuclear deterrence being non-credible for limited conflict provides a more comprehensive explanation, in that Israel's nuclear deterrent was considered unlikely to be used in limited conflict over territory due to the associated costs, whereas perceived existential threats would justify their use.

Similar reasoning also applies to the possibility of a security dilemma encouraging low-intensity attacks and limited war against Israel. While it corresponds to the reasoning behind the formation of an Arab coalition in the Six-Day War (to prevent suspected Israeli mobilization against Syria), it falls short for every other post-nuclear crisis studied, as they were primarily fought over territory. If a security dilemma between Israel and neighbouring Arab states was the cause for the latter launching low-intensity attacks and limited war, these crises would have stemmed from Arab governments reacting to a perceived threat from Israel. ${ }^{214}$ As shown throughout this chapter, this has largely proven not to be the case.

The stability-instability paradox can also explain this dynamic, but falls short due to its requirement for mutual nuclear deterrence. The logic of the paradox is that mutual nuclear deterrence causes war and other forms of high-intensity conflict to decline due to

\footnotetext{
${ }^{213}$ When including reservists, Israeli forces would number 275,000 though these are generally not deployed at once due to the economic impact. International Institute for Strategic Studies, "The Middle East and the Mediterranean," The Military Balance 73, no. 1 (1973): 30-38.

${ }^{214}$ Jack S. Levy and William R. Thompson, Causes of War (Chichester: Wiley-Blackwell, 2010), 30.
} 
fear of nuclear war, while low-intensity conflict increases due to the belief that incremental gains can be made via salami-slicing while remaining below the nuclear threshold. ${ }^{215}$ This dynamic is apparent between Israel and its neighbours post-1967, but runs into issues due to Israel being the only nuclear power involved in these crises. As of 2020, no other Middle Eastern states have successfully produced nuclear weapons. The theory advanced in this dissertation predicts a similar dynamic as the paradox, but sidesteps the need for mutual nuclear deterrence by arguing that the same outcome can occur with a nuclear weapon state that is considered unwilling to use nuclear weapons for low-intensity conflict. This appears to be the case with Israel's post-nuclear crises, barring the Six-Day War, but the ambiguity surrounding its nuclear arsenal and decisions makes this uncertain.

Israel's alliances, meanwhile, appear to have done relatively little to deter other states from attacking it. Given the challenges it faced in obtaining security guarantees discussed in 5.4, its primary ally during the post-nuclear acquisition crises has been the US. However, this support has largely taken the form of funding and military equipment to Israel rather than direct commitments to defend it from attack. As a result, Israeli-US ties appear to have played little role in the Six-Day War and War of Attrition, and was limited to the provision of materiel to Israel in the Yom Kippur War. Its most direct role in any of the post-nuclear crises studied was the Bush administration's backing of Israeli threats during the Gulf War, which proved to be of limited effectiveness. While the lack of US involvement in the War of Attrition and Yom Kippur War can be explained by Soviet

${ }^{215}$ Robert Jervis, The Illogic of American Nuclear Strategy (Ithaca: Cornell University Press, 1984), 148150 . 
involvement and a desire to avoid escalating the crises, this indicates that Israel's alliances did little to deter limited conflicts.

\section{8: Conclusion: Only Partially Deterred}

Israeli crises seemingly support $\mathrm{H} 2$ (a)'s prediction that nuclear democracies will face low-intensity attacks due to difficulties in credibly threatening nuclear retaliation, but there are notable issues due to nuclear ambiguity. Despite demonstrating conventional superiority in pre-1967 crises, Israel remained unable to deter challengers from attacking in the following years despite possessing nuclear weapons. This can be attributed in part to later crises not being meant as existential threats to Israel, unlike the 1948 war, since they were meant to accomplish more limited goals. The Israeli government's nuclear arsenal being meant solely for existential crises and rejection of plans to use it during the Six-Day and Yom Kippur Wars conforms to H2(a). Specifically, these decisions demonstrate that Israeli leaders were sensitive to the potential costs of conducting a nuclear test explosion (particularly the fallout, the risk of escalation, and possible international isolation) to the point of avoiding their use so long as their conventional forces proved sufficient for dealing with the current crisis. Similarly, the War of Attrition and the 1991 Gulf War crisis indicate that Israel's challengers considered its nuclear deterrent credible for potential existential threats (whether an invasion or chemical weapon attacks), but that they would not risk those costs for more limited attacks. This meant that Sadat, Assad, and Saddam were respectively able to exploit this gap to accomplish limited objectives while remaining below Israel's nuclear threshold.

As is discussed throughout this chapter, however, studying Israeli nuclear deterrence is made more challenging by its unique ambiguity policy, which also has 
ramifications for its deterrent strategy. Methodologically, it introduces uncertainty around Israel's nuclear decisions and the nature of its arsenal, requiring a heavy reliance on documents no longer accessible to the public and the testimony of retired officials. It is not clear if and how nuclear deterrence threats were communicated to challengers. This is most readily apparent in the Six-Day War and War of Attrition, as Nasser appeared unaware that Israel even had nuclear weapons, much less when it would use them.

Meanwhile, evidence from the crises studied in this chapter give little indication that decisions, barring mobilization in the Yom Kippur War, were based on concerns of electoral backlash from Israeli citizens, instead focusing on the international repercussions of using nuclear weapons. This can be explained by nuclear ambiguity being engineered so that the Israeli public knows nothing of the state's nuclear policies, and thus cannot hold the government accountable. It does, however, contradict the anticipated reason for democratic governments being cost-sensitive - domestic audiences punishing the government for unnecessary costs - and instead points to an elite-driven nuclear decisionmaking process. This is similar to what can be discerned from India's decision-making process for nuclear weapons in chapter 6 , as both nuclear democracies appear to have political and military elites exhibit restraint regardless of voter preference. However, the apparent cost-sensitivity makes Israel distinct from the two non-democracies, Pakistan and North Korea, as their leaders appear to be largely insensitive to the possible costs of using nuclear weapons to their citizens, giving them greater nuclear deterrence credibility. 


\section{Chapter 6: India}

\section{1: Introduction}

As a democratic nuclear weapon state, India is an important case for understanding how state regime type and government cost-sensitivity influence nuclear deterrence credibility. Like Israel, India has a long history of conflict: over the period studied in this dissertation (1945-2018), it has fought four wars with Pakistan, including after independence in 1947 and in 1999 after both revealed their nuclear weapons, and one with China in 1962. ${ }^{1}$ This does not include numerous skirmishes, state-sponsored terrorist attacks, and border standoffs between India and Pakistan over control of Jammu and Kashmir, including Indian airstrikes against a Pakistani terrorist camp in February $2019 .^{2}$ India first demonstrated the ability to develop nuclear weapons with a peaceful nuclear explosion in 1974, and while it only confirmed possession of nuclear weapons with the May 1998 Pokhran-II tests, it is suspected to have possessed functional devices as early as 1989. ${ }^{3}$ In keeping with the country’s democratic practices and military oversight, nuclear decisions, are almost wholly civilian-dominated, making political considerations key.

This chapter begins with an overview of Indian governance practices. This includes a focus on Indian civil-military relations and the role of "strategic elites" in foreign policy decisions. Key pre-nuclear crises and conflicts targeting India are subsequently analyzed,

\footnotetext{
${ }^{1}$ The 1999 Kargil War is particularly noteworthy as one of the only wars fought between two nuclear weapon states. Vipin Narang, Nuclear Strategy in the Modern Era: Regional Powers and International Conflict (Princeton: Princeton University Press, 2014), 250.

2 S. Paul Kapur, “India and Pakistan's Unstable Peace: Why Nuclear South Asia Is Not Like Cold War Europe," International Security 30, no. 2 (2005): 127-152; Suhasini Haidar and Dinakar Peri, "India Bombs Jaish Camp in Pakistan's Balakot," The Hindu, February 26, 2019, https://www.thehindu.com/news/national/air-strikes-hit-balakot-in-pakistan-initial-assessment-100-hitsources/article26373318.ece.

${ }^{3}$ Narang, Nuclear Strategy in the Modern Era, 95-98.
} 
with a focus on the three Indo-Pakistani Wars (1947-1949; 1965; 1971), the Sino-Indian War (1962), and the Brasstacks crisis (1986-1987). Section 6.3 of the chapter covers Indian motivations to develop a nuclear deterrent and the program's history, including the 1974 Smiling Buddha test and public confirmation of its nuclear status in 1998. India's command and control structure and its nuclear deterrence strategy, which is meant solely as a secondstrike option, are then examined. Post-nuclear crises targeting India are subsequently studied, specifically focusing on the Kargil War (1999), the 2001-2002 border standoff, and the response to the November 2008 attack on Mumbai. This section of the chapter studies how challenger perceptions of Indian cost-sensitivity influenced their willingness to attack and the credibility of Indian nuclear deterrence threats. Possible alternative explanations for challengers attacking India - namely security dilemmas, challenger assumptions of allied intervention, and the stability-instability paradox - are then reviewed.

As with Israel, the theory's prediction that nuclear-armed democracies will continue to be attacked due to their nuclear deterrence threats being rendered non-credible by perceived cost-sensitivity appears to be partially correct for India, though some aspects of the crises bring parts of the theory into question. Historical evidence shows that Indian leaders have repeatedly shown concern over the potential costs of using nuclear weapons, particularly for foreign relations and the domestic economy, restraining them in the process. The few opinion polls that assess how the Indian public views nuclear weapon use, however, indicate support for their use in various situations regardless of casualties and other costs. ${ }^{4}$ This contradicts the theory's anticipated reason for democratic

\footnotetext{
${ }^{4}$ David Cortright and Amitabh Mattoo, "Indian Public Opinion and Nuclear Weapons Policy," in India and the Bomb: Public Opinion and Nuclear Options, ed. David Cortright and Amitabh Mattoo, (Notre Dame:
} 
governments to avoid fulfilling nuclear deterrence threats in low-intensity conflict: that the potential costs of nuclear weapon use would be so politically unpopular that leaders would avoid it to ensure their political survival. In India's case, it instead appears that government officials and the strategic elite within and outside government act as restraints for nuclear weapon use, focusing on broader costs over electoral consequences. This may be attributable to the nuclear weapons program originating in part as a way of developing Indian national prestige. ${ }^{5}$ This indicates that, contra theoretical expectations, elite behaviour is ultimately more important for nuclear decision-making even in democracies.

Despite this, the perception of Indian officials as overly cost-sensitive appears to have had an impact on challenger behaviour, particularly Pakistan. Low-intensity attacks and state-sponsored terrorism have continued since 1998 despite India's nuclear arsenal, while the Kargil War is attributable to miscalculations of Indian resolve. Pakistani generals have demonstrated a belief that they can attack without fear of reprisal due to India lacking the will to endure combat losses despite possessing a larger military. This was apparent in the 1965, 1971, and 1999 wars, where Pakistan's initial attacks were spurred by a false belief that India would sue for peace instead of fighting. India's nuclear deterrent has done little to discourage these attacks due to being meant exclusively for retaliating against nuclear attacks, not low-intensity attacks and incursions. Pakistan's use of such tactics is encouraged by their falling under India's nuclear threshold, and thus potentially leading to

\footnotetext{
University of Notre Dame Press, 1996), 10; Benjamin A. Valentino and Scott D. Sagan, "Atomic Attraction," The Indian Express, June 3, 2016, https://indianexpress.com/article/opinion/columns/barackobama-hiroshima-speech-india-nuclear-weapon-terrorism-atomic-attraction-2831348/; Aditi Malhotra, "Assessing Indian Nuclear Attitudes: A Visiting Fellow Working Paper" (Washington, DC: Stimson Centre, 2016), https://www.stimson.org/sites/default/files/fileattachments/Assessing\%20Indian\%20Nuclear\%20Attitudes\%20-\%20Final.pdf.

${ }_{5}^{5}$ Scott D. Sagan, "Why Do States Build Nuclear Weapons? Three Models in Search of a Bomb," International Security 21, no. 3 (1996): 67-68.
} 
incremental gains with lower risks than higher-intensity ones. The predictions for democratic behaviour are thus partially incorrect, as Indian leaders are not constrained from using nuclear weapons in low-intensity conflict by fears of domestic punishment. India's democratic status appears to still play a role by feeding a perception of cost-aversion and deterrence non-credibility, encouraging challengers to launch low-intensity attacks.

\section{2: Democracy and Strategic Elites: Evaluating Indian Governance}

India is, by most measures, a highly democratic state. While the Polity 5 project initially gave India a democracy score of 5/10 between 1952 and 1966, it has remained at 8 or 9 out of a possible 10 , while its autocracy score has remained at $0 / 10$ for the entire period studied. ${ }^{6}$ The only notable change occurred during 1975-1976, when Indira Gandhi declared a state of emergency, but even this period is scored as $7 / 10$. Freedom House similarly has consistently rated India as "Free" since 1972, with the exceptions of the 19751976 state of emergency and 1991-1997 due to widespread corruption and religious violence. ${ }^{7}$ The Democracy Index, in contrast, is somewhat less sanguine, having consistently scored India as a flawed democracy over the past decade. ${ }^{8}$ This is attributed to a number of reasons, including the use of coercive tactics by Prime Minister Narendra Modi's Bharatiya Janata Party (BJP) to retain power, increasing violence by Hindu

\footnotetext{
${ }^{6}$ The initial democracy score is a notable change from Polity IV, where it was scored as 9/10. An explanation for this is not present in the Polity Project's update notes. Center for Systemic Peace, "Polity IV Project Annual Time Series, 1800-2018," Center for Systemic Peace, July 27, 2019, http://www.systemicpeace.org/polityproject.html; Center for Systemic Peace, "Polity 5 Annual TimeSeries, 1946-2018," Center for Systemic Peace, April 23, 2020, http://www.systemicpeace.org/inscr/p5v2018.xls.

${ }^{7}$ Freedom House, "Freedom in the World," Freedom House, 2020, https://freedomhouse.org/sites/default/files/202002/2020 Country and Territory Ratings and Statuses FIW1973-2020.xlsx; Charles Graybow et al., Freedom in the World 1997-1998, ed. Adrian Karatnycky and Roger Kaplan (New York: Freedom House, 1998), 278-282.

${ }^{8}$ Economist Intelligence Unit, Democracy Index 2018: Me too? Political participation, protest and democracy (London: Economist Intelligence Unit, 2019), 37.
} 
vigilantes against minority groups and political dissenters, and increasing support for centralized rule. ${ }^{9}$

Since becoming independent in 1947, India's government has been structured similarly to other Commonwealth states. It possesses both a central federal government and devolved state governments with differing powers, though the former is heavily involved in state-level issues as well. ${ }^{10}$ The Indian legislative branch is a bicameral parliament made up of the popularly-elected Lok Sabha (House of the People) and the Rajya Sabha (Council of States), whose members are either elected by state-level legislatures or appointed by the Indian president. ${ }^{11}$ The president serves as the head of state, but is constitutionally bound to follow the advice of the prime minister, who acts as the head of government and is responsible for most policy decisions. While the president is the Commander-in-Chief of the armed forces, the prime minister directs nuclear and strategic policy with the Cabinet Committee on Political Affairs and the National Security Council, while the Lok Sabha remains more or less uninvolved. ${ }^{12}$ Practically speaking, this means that Indian conventional and nuclear strategy is determined by the prime minister, Cabinet, and political appointees.

As a democracy, Indian governments rely on citizen support, though the national security and foreign policy literature indicates a particular emphasis on the "strategic elite"

\footnotetext{
${ }^{9}$ Economist Intelligence Unit, Democracy Index 2015: Democracy in an Age of Anxiety (London: Economist Intelligence Unit, 2016), 26, http://www.eiu.com/Handlers/WhitepaperHandler.ashx?fi=EIUDemocracy-Index-2015.pdf\&mode=wp\&campaignid=DemocracyIndex2015; Economist Intelligence Unit, Democracy Index 2017: Free Speech under Attack (London: Economist Intelligence Unit, 2018), 27, https://pages.eiu.com/rs/753-RIQ-438/images/Democracy_Index_2017.pdf; Economist Intelligence Unit, Democracy Index 2018, 37.

${ }^{10}$ Stephen Philip Cohen, India: Emerging Power (Washington, D.C: Brookings Institution Press, 2001), 110 .

${ }^{11}$ Mahendra Prasad Singh, “The Decline of the Indian Parliament," India Review 14, no. 3 (2015): 352.

${ }^{12}$ Karsten Frey, India's Nuclear Bomb and National Security (Abingdon: Routledge, 2006), 48.
} 
or "strategic core." This group is made up of the wealthy, elected politicians, journalists, and analysts and bureaucrats, particularly specialists in foreign affairs and national security. ${ }^{13}$ Since the 1970 s, the strategic elite has primarily been divided between hawks and experts promoting diplomacy to keep India secure, whereas the consensus under Nehru focused on Indian non-alignment. ${ }^{14}$ The strategic elite's prominence is the result of the broader Indian public being generally uninterested in foreign policy, with the exception of Pakistan; even China has received little interest until recently. ${ }^{15}$ This disinterest allows the strategic elite to dominate discussion and decision-making in foreign and defence policy due to it being of little interest in elections. ${ }^{16}$ While this means that public opinion is deemphasized in foreign policy, governments are still accountable to voters in practice.

India's largely democratic tendencies have been disrupted by a period of authoritarian rule through emergency powers and an increasing shift towards Hindu nationalism in recent years. The former occurred when Prime Minister Indira Gandhi pressured then-President Fakhruddin Ali Ahmed to declare a state of emergency on June 25, 1975, allowing her to rule by decree, suspend civil liberties, and imprison political opponents until it ended in January $1977 .{ }^{17}$ On a smaller scale, there have also been over 100 instances of the Indian federal government using emergency powers to pressure its state-level counterparts. ${ }^{18}$ Indian politics have gradually shifted away from secularism

\footnotetext{
${ }^{13}$ Vipin Narang and Paul Staniland, "Institutions and Worldviews in Indian Foreign Security Policy," India Review 11, no. 2 (2012): 80.

${ }^{14}$ Cohen, India: Emerging Power, 37-40, 58-65.

${ }^{15}$ Malhotra, "Assessing Indian Nuclear Attitudes," 2-3.

${ }^{16}$ Narang and Staniland, "Institutions and Worldviews," 80.

17 Thorsten Wojczewski, "Populism, Hindu Nationalism, and Foreign Policy in India: The Politics of Representing "the People," International Studies Review (2019), 8; Singh, "The Decline of the Indian Parliament," 369.

${ }^{18}$ Anoop Sadanandan, "Bridling Central Tyranny in India: How Regional Parties Restrain the Federal Government," Asian Survey 52, no. 2 (2012): 247-69.
} 
since the late 1980s as governments increasingly appeal to the Hindu majority to secure more votes. ${ }^{19}$ This has accelerated under Narendra Modi's government, which has been criticized for implementing discriminatory policies against ethnic and religious minorities, such as a December 2019 law that prevents Muslim refugees from applying for citizenship. ${ }^{20}$ Despite these issues, however, Indian governance remains largely democratic.

\subsection{1: Civil-Military Relations}

India is notable for civilian authorities holding complete control over the military since independence, in contrast with military-dominated Pakistan. In practice, Ministry of Defence bureaucrats, not elected officials, tend to formulate security policy. ${ }^{21}$ Nehru and his successors minimized the role of military officials in decision-making to prevent them from using their influence from political gain, including making the president commanderin-chief in 1950 to ensure civilian supremacy. ${ }^{22}$ The downside is that important decisions tend to be made with little regard for their potential strategic impact. This behaviour peaked in the 1962 Sino-Indian War, when Nehru and Minister of Defence V.K. Menon micromanaged strategy to the point that Indian officers were unable to make independent decisions. ${ }^{23}$ Recent years have seen efforts to involve the armed forces in strategic decisions, with the Strategic Policy Group created in 1999 to ensure the three service chiefs

\footnotetext{
${ }^{19}$ Kanchan Chandra, "The Roots of Hindu Nationalism's Triumph in India," Foreign Affairs, September 13, 2019, https://www.foreignaffairs.com/articles/india/2019-09-11/roots-hindu-nationalisms-triumphindia.

${ }^{20}$ Suparna Chaudhry, “Analysis” India's New Law May Leave Millions of Muslims without Citizenship," Washington Post, December 13, 2019, https://www.washingtonpost.com/politics/2019/12/13/indias-newlaw-may-leave-millions-muslims-without-citizenship/.

${ }^{21}$ Walter C. Ladwig III, “A Cold Start for Hot Wars? The Indian Army's New Limited War Doctrine," International Security 32, no. 3 (Winter 2007): 170.

${ }^{22}$ Frey, India's Nuclear Bomb, 31.

${ }^{23}$ Narang, Nuclear Strategy in the Modern Era, 113.
} 
are involved in policy formulation. ${ }^{24}$ Modi's government created the position of Chief of Defence Staff in January 2020, though it lacks actual command authority over the service branches and is superseded by the Minister of Defence. ${ }^{25}$

Despite these changes, political leaders continue to determine strategic policy, with the bureaucracy wielding more influence in the process than the military officials tasked with carrying it out. This has been attributed, as discussed earlier, to a lack of interest or awareness among most of the public regarding foreign policy issues, leading to elected officials being passive about the subject due to the lack of electoral benefits. The result is that the Lok Sabha and Rajya Sabha provide little to no input into foreign policy, with the executive branch deciding the direction primarily according to elite views. ${ }^{26}$ This is not to say that the public has no input into these issues, as opposition parties can frame these issues in a way that influences electoral outcomes (e.g. as a matter of national security). ${ }^{27}$ It does mean, however, that governments typically formulate these policies with little regard for public views - including nuclear deterrence.

\footnotetext{
${ }^{24}$ Frey, India's Nuclear Bomb, 31.

${ }^{25}$ Anonymous, "A Major Modern General," The Economist, January 18, 2020, 54-55, https://www.economist.com/asia/2020/01/18/indias-armed-forces-get-their-biggest-shake-up-in-decades. ${ }^{26}$ Devesh Kapur, "Public Opinion and Indian Foreign Policy," India Review 8, no. 3 (2009): 287-290.

${ }^{27}$ Kapur, "Public Opinion and Indian Foreign Policy," 290.
} 
Figure 6.1: Indian and Pakistani Military Expenditure, 19562018

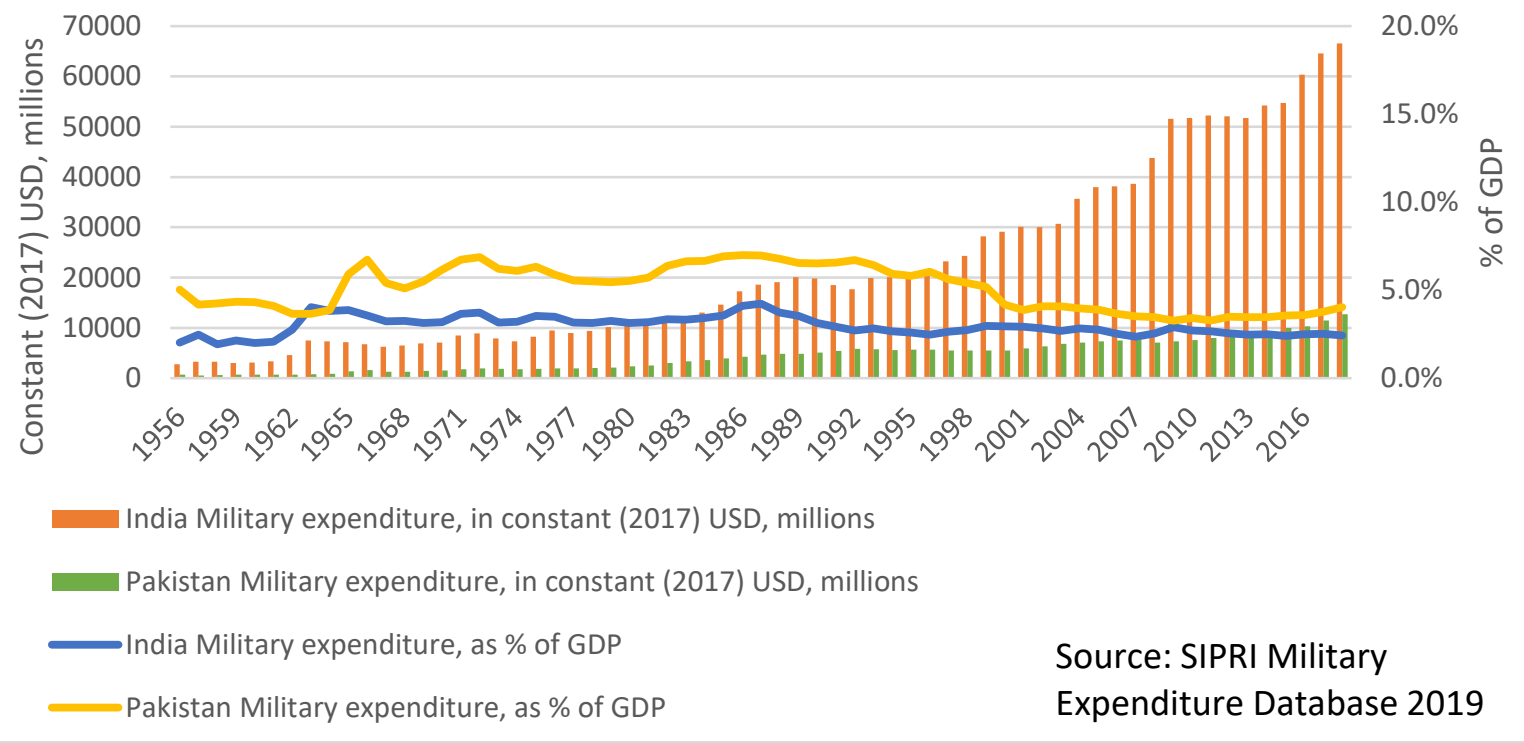

The Indian government has invested heavily in its armed forces, but is unlikely to be able to fight a sustained conventional conflict. India has gradually become one of the largest defence spenders in the world since independence, with defence spending increasing by $6.3 \%$ on average between 1997 and $2015 .{ }^{28}$ This means that the 2019 defence budget is around 4.3 trillion rupees (approximately US $\$ 49.68$ billion), putting India behind only the US, China, and Saudi Arabia and, as shown in Figure 6.1, quintupling Pakistan's US\$9.6 billion. ${ }^{29}$ However, given the scale of India's armed forces $(1,150,900$ personnel as of 2015), this is only sufficient for basic operational capabilities. ${ }^{30}$ At present, it is believed that India's armed forces could only fight a war for three weeks before running out of ammunition, while its armored vehicles are so outdated that only a third of the army

\footnotetext{
${ }^{28}$ Walter C. Ladwig III, "Indian Military Modernization and Conventional Deterrence in South Asia," Journal of Strategic Studies 38, no. 5 (2015): 730.

${ }^{29}$ Dinakar Peri, "Budget 2019: Defence Allocation Disappoints Military," The Hindu, July 7, 2019, https://www.thehindu.com/news/national/defence-allocation-disappoints-military/article28313288.ece. ${ }^{30}$ Ladwig, "A Cold Start," 755.
} 
can move within its own borders. ${ }^{31}$ These issues became apparent in the February 2019 airstrike, as the Pakistani Air Force shot down 2 Indian fighters in response. ${ }^{32}$ Increasing tensions with China, including the June 2020 clash that saw 20 Indian soldiers and an unknown number of Chinese troops killed, have also highlighted the issues India faces at present. ${ }^{33}$ Thus, while India spends heavily on defence on paper, actual funding allocations suggest that it is a low priority for civilian leaders and bureaucrats.

\section{3: "'Launching a bold offensive across the Punjab:" Indian Pre-Nuclear Crises and Conflicts}

Prior to possessing nuclear weapons, India was involved in numerous crises, including wars. These have largely been over territory, with Indo-Pakistani tensions largely fuelled by disputed control of Jammu and Kashmir, while the Sino-Indian War (1962) was the result of a border demarcation dispute with China. These conflicts were at least partially caused by challengers believing the Indian government lacked the resolve to defend its territory or that their actions would not merit an armed response. All three Indo-Pakistani Wars $(1947-1949 ; 1965 ; 1971)$ had Pakistani leaders believing their Indian counterparts were too cost-sensitive to fight, with the 1965 and 1971 wars having started due to false optimism that Indian leaders would not respond to incursions and pre-emptive strikes because of this. The Brasstacks crisis, meanwhile, saw Pakistani leaders feel emboldened

\footnotetext{
${ }^{31}$ Ladwig, "Indian Military Modernization," 751; Shashank Joshi, "India's Military Instrument: A Doctrine Stillborn," Journal of Strategic Studies 36, no. 4 (2013): 528

${ }^{32}$ Maria Abi-Habib, "After India Loses Dogfight to Pakistan, Questions Arise About Its 'Vintage' Military," The New York Times, March 3, 2019, https://www.nytimes.com/2019/03/03/world/asia/indiamilitary-united-states-china.html.

${ }^{33}$ Michael Safi, Hannah Ellis-Petersen, and Helen Davidson, "Soldiers Fell to Their Deaths as India and China's Troops Fought with Rocks," The Guardian, June 17, 2020, https://www.theguardian.com/world/2020/jun/17/shock-and-anger-in-india-after-worst-attack-on-chinaborder-in-decades.
} 
by their de facto nuclear capability (and unintimidated by India's own) that they responded to India's military exercises by supporting a Sikh insurgency. The Sino-Indian War is exceptional in this regard due to being motivated by a sense of insecurity regarding Indian behaviour over disputed territory rather than a perceived lack of resolve.

\subsection{1: Indo-Pakistani Wars}

The First Indo-Pakistani War (1947-1949) was caused by a territorial demarcation dispute between India and Pakistan over control of the state of Jammu and Kashmir. The state remained independent during the 1947 Partition, with both attempting to claim it due to having a Muslim-majority population and a Hindu maharaja. ${ }^{34}$ The crisis was triggered by an October 22 invasion of tribesmen backed by Prime Minister Liaquat Ali Khan to take control of Kashmir and secure Pakistan's border. ${ }^{35}$ Maharaja Hari Singh requested military support from India, which was provided on October 26 in exchange for Kashmir acceding to India, and by February 1948 Indian forces had driven the invaders out of Srinagar and begun a counter-offensive. ${ }^{36}$ This served as a crisis breakpoint for Pakistan, with GovernorGeneral Muhammad Ali Jinnah ordering the military to fight India alongside the irregular forces. ${ }^{37}$ The crisis was terminated by a UN-mediated ceasefire on January 1, 1949 that established a military control line through Kashmir. ${ }^{38}$ While Nehru's government was satisfied, having referred the conflict to the UN in the first place, Pakistan was dissatisfied

\footnotetext{
${ }^{34}$ Barbara D. Metcalf and Thomas R. Metcalf, A Concise History of Modern India, Third Edition, (New York: Cambridge University Press, 2012), 224.

${ }^{35}$ Chandrasekhar Dasgupta, War and Diplomacy in Kashmir, 1947-48 (Thousand Oaks: SAGE Publications, 2014), 38-41; Michael Brecher and Jonathan Wilkenfeld, A Study of Crisis (Ann Arbor: University of Michigan Press, 1997), 166-167.

${ }^{36}$ Saira Khan, Nuclear Weapons and Conflict Transformation: The Case of India-Pakistan (New York: Routledge, 2009), 63; Metcalf and Metcalf, A Concise History, 224.

${ }^{37}$ Khan, Nuclear Weapons and Conflict Transformation, 63; Brecher and Wilkenfeld, A Study of Crisis, 167.

${ }^{38}$ T.V. Paul, The Warrior State: Pakistan in the Contemporary World (Oxford: Oxford University Press, 2014), 43.
} 
with only retaining one-third of Kashmir. ${ }^{39}$ As a result, tensions remained between the two over control of Kashmir, though another major crisis did not occur until $1965 .^{40}$

While the 1947-1948 war was spurred by a territorial demarcation dispute, a key aspect of the conflict was that Pakistani leaders did not anticipate India would defend Kashmir, much less get it to accede. Jinnah was reportedly enraged by Kashmir joining India, claiming that it "was based on 'fraud and violence,", and was only prevented from ordering an invasion by Field Marshal Auchinleck's threat to remove all British military officers from Pakistan. ${ }^{41}$ This, along with the Pakistani army's limited capabilities at the time, meant support for the tribesmen largely consisted of officers “"conveniently” on leave from the army" until May 1948, when regular forces were deployed to counter potential Indian intervention in Pakistan itself. ${ }^{42}$ Some have argued that Nehru's delay in sending troops to defend Kashmir was due to a sense of discomfort among Indian leaders in using military force. ${ }^{43}$ This is only partially true, as India's military chiefs and Governor-General Lord Mountbatten sought to convince Nehru that intervening in Kashmir without accession would be impermissible and highly risky, and even they ultimately conceded. ${ }^{44}$ Regardless, it is clear that the Pakistani government at least perceived an apparent Indian reluctance to defend Jammu and Kashmir and provided support to the tribes there on that basis.

\footnotetext{
${ }^{39}$ Paul, The Warrior State, 43.

${ }^{40}$ A military standoff occurred briefly in June 1951, leading to concerns that war would recur, but these were short-lived. See Julian Schofield, "Militarized Decision-Making for War in Pakistan: 1947-1971," Armed Forces \& Society 27, no. 1 (2000): 138-139.

${ }^{41}$ Both India and Pakistan relied on British officers assisting with the transition for their first few years, with Pakistan depending on them to the point that even lower-level officers were considered “irreplaceable." See Dasgupta, War and Diplomacy, 50-51; Victoria Schofield, Kashmir in Conflict: India, Pakistan and the Unfinished War (London: I.B. Tauris, 2000), 61.

${ }^{42}$ Schofield, Kashmir in Conflict, 65.

${ }^{43}$ Rudra Chaudhuri, "Indian 'Strategic Restraint' Revisited: The Case of the 1965 India-Pakistan War," India Review 17, no. 1 (2018): 56-57.

${ }^{44}$ Dasgupta, War and Diplomacy, 201-202.
} 
The Second Indo-Pakistani War (1965) similarly stemmed from the Kashmir dispute, but is a more clear-cut case of Pakistani leaders wrongly believing that India lacked the resolve to fight. This misperception was reinforced by the response to Pakistani forces attacking Indian positions in the Rann of Kutch between April $8^{\text {th }}$ and $26^{\text {th }}, 1965$ after having claimed the area in $1948 .{ }^{45}$ Indian forces performed poorly due to being outnumbered and outgunned, and were ordered to abandon their positions ${ }^{46}$ Rather than send reinforcements, Prime Minister Lal Bahadur Shastri let an international commission decide the issue in May 1965 in a British-mediated conference, with a cease-fire being signed on July $1 .{ }^{47}$ Shastri and other civilian leaders opted for a cease-fire due to considering the Rann of Kutch unimportant and, along with Army Chief of Staff Jayanto Chaudhuri, wished to avoid overly high losses over it. ${ }^{48}$ Domestic opponents protested that Shastri's decision was a "virtual surrender of our [India's] national interest." ${ }^{49}$ Shastri publicly warned in April 1965 that if Pakistan " persists in its aggressive activities our army will defend the country." ${ }^{50}$ The Indian position was not that it was completely unwilling to endure costs, but that the Rann of Kutch was not worth fighting a war.

Pakistani leaders interpreted these actions very differently, believing that their Indian counterparts were unwilling to suffer losses defending their territory. While Pakistan already believed that India's loss in the 1962 Sino-Indian War sapped its resolve

\footnotetext{
${ }^{45}$ Rudra Chaudhuri, “'Just Another Border Incident': The Rann of Kutch and the 1965 India-Pakistan War," Journal of Strategic Studies 42, no. 5 (2019): 654; Brecher and Wilkenfeld, A Study of Crisis, 170. ${ }^{46}$ Chaudhuri, "Rann of Kutch," 664.

${ }^{47}$ Sumit Ganguly, Conflict Unending: India-Pakistan Tensions Since 1947 (New York: Columbia University Press, 2001), 41; Chaudhuri, "Rann of Kutch," 668.

${ }^{48}$ Ganguly, Conflict Unending, 41.

49 "Sovereignty surrendered," Times of India, July 1, 1965. Quoted in Chaudhuri, "Rann of Kutch," 668.

${ }^{50}$ Ganguly, Conflict Unending, 38-39.
} 
to fight, the push for diplomacy in the Rann of Kutch incident seemingly confirmed this. ${ }^{51}$ President Ayub Khan, who ran Pakistan as a military dictator since a 1958 coup, publicly boasted on June 20 that the crisis had left India "“squealing like they did after their conflict with China," with other generals believing that India as a whole was demoralized. ${ }^{52}$ Shastri's warning against Pakistani aggression led Khan to publicly decry it on May $1^{\text {st }}$ as "'reckless and provocative"” and warn that it meant "“a general and total war"” that Pakistan would not shy away from. ${ }^{53}$ Khan's belief that Shastri was bluffing was shared by officials such as Foreign Minister Zulfikar Ali Bhutto and Foreign Secretary Aziz Ahmed, who believed that ongoing unrest and rioting in Kashmir would make it easy to seize, particularly if the Indian government lacked the will to fight. ${ }^{54}$ In short, Indian officials being unwilling to start a war over unimportant tracts of land was (incorrectly) perceived by Pakistan's leadership as their lacking the resolve to spend lives to defend land.

This sentiment was clearly not motivated by Pakistani military superiority; in fact, there were concerns that India was becoming too strong. By mid-1965, the Indian army totalled 869,000 personnel, with two divisions stationed within Kashmir and another eight along the border, while Pakistan's army only had a total of $208,000 .{ }^{55}$ Furthermore, Pakistan's generals were concerned by India's increasing military spending after 1962, which went from US\$4.5 billion to US\$7.1 billion between 1962 and 1965, while

${ }^{51}$ Ganguly, Conflict Unending, 41.

${ }^{52}$ Chaudhuri, "Rann of Kutch," 668.

${ }^{53}$ Ganguly, Conflict Unending, 39.

${ }^{54}$ Chaudhuri, "Indian 'Strategic Restraint,"” 60-61.

${ }^{55}$ International Institute for Strategic Studies, "Central Treaty Organization," The Military Balance 65, no. 1 (1965): 28; International Institute for Strategic Studies, "Part III: Non-aligned Countries," The Military Balance 65, no. 1 (1965): 34. 
Pakistan's military budget remained at US $\$ 1.4$ billion. ${ }^{56}$ This meant that Pakistan's leadership held two seemingly contradictory views that encouraged seizing Kashmir as quickly as possible. India's military buildup meant that the window of opportunity to annex Kashmir was rapidly closing, since Pakistan would be unable to win a conventional war. At the same time, what Khan and others perceived as Shastri and other Indian political and military leaders being overly cost-sensitive meant that Kashmir could potentially be taken without a fight with a sufficient display of force.

These two views led to the formulation of a plan to first foment a large-scale Kashmir uprising and then send a larger invasion. The first phase, Operation Gibraltar, quickly failed, when the 5,000 Pakistani soldiers who infiltrated Kashmir on August 9, 1965, were reported to Indian police, triggering a crisis for India. ${ }^{57}$ Shastri faced pressure to take action from military advisors and the public, including an August 16 demonstration by over 100,000 protestors in New Delhi, leading to the Indian Army being sent to Kashmir on August 25. ${ }^{58}$ In turn, Khan ordered that Operation Grand Slam proceed, with Pakistani forces crossing the 1949 ceasefire line on September $1 .{ }^{59}$ Khan's reasoning, according to an August 29 memo, was to “"weaken India's resolve and bring her to a conference table without provoking a general war." ${ }^{60}$ Put simply, Khan and subordinates such as General Muhammad Musa and Major-General Akhtar Malik, believed that India would avoid

\footnotetext{
${ }^{56}$ Dollar amounts are in constant 2017 USD. See Stockholm International Peace Research Institute, "SIPRI Military Expenditure Database 2019,” 2019, accessed February 20, 2019, https://www.sipri.org/databases/milex.

${ }^{57}$ Khan, Nuclear Weapons and Conflict Transformation, 67; Brecher and Wilkenfeld, A Study of Crisis, 171.

${ }^{58}$ Schofield, Kashmir in Conflict, 109.

${ }^{59}$ Sumit Ganguly and S. Paul Kapur, India, Pakistan, and the Bomb: Debating Nuclear Stability in South Asia (New York: Columbia University Press, 2010), 12-13.

${ }^{60}$ Schofield, Kashmir in Conflict, 109.
} 
responding to even an invasion of Kashmir due to a lack of resolve even in the face of evidence proving otherwise, which has persisted long after the 1965 war ended.

Contrary to these expectations, Shastri's government escalated the crisis instead of backing down, with the ensuing war ending in a Pakistani defeat. This involved sending Indian troops over the international border and invading Pakistan on September 6; within a week, Lahore, then the capital of West Pakistan, was under siege. ${ }^{61}$ The crisis was terminated shortly thereafter with another UN-brokered ceasefire on September 23, followed by the Tashkent Agreement on January 10, $1966 .{ }^{62}$ In total, approximately 3,000 Indian soldiers and 3,800 Pakistani troops were killed. ${ }^{63}$ The Indian government was largely satisfied with the outcome, as the agreement required the withdrawal of armed forces to their previous positions. ${ }^{64}$ The Pakistani government, however, was not, having failed to seize Kashmir, harming relations with Western allies over its aggression, and being required to abandon the use of force in its disputes with India by Tashkent. ${ }^{65}$ Khan's position as President was eroded by the failed invasion and accusations of rigging the 1965 election, culminating in a 1969 coup by General Yahya Khan, while Bhutto was fired in 1966 and became a prominent opposition leader after founding the PPP in 1967.

The Third Indo-Pakistani War (1971) differs in being caused by a civil war in East Pakistan instead of the Kashmir dispute, but false optimism by Yahya Khan and other Pakistani leaders regarding the Indian government's perceived lack of resolve to fight a

\footnotetext{
${ }^{61}$ Chaudhuri, "Rann of Kutch," 674.

62 Chaudhuri, "Indian 'Strategic Restraint,", 67.

${ }^{63}$ Bhashyam Kasturi, "Chapter 10: The State of War with Pakistan," in A Military History of India and South Asia: From the East India Company to the Nuclear Era (Bloomington: Indiana University Press, 2007), 145.

${ }^{64}$ Frey, India's Nuclear Bomb, 16.

${ }^{65}$ Ganguly, Conflict Unending, 47.
} 
war played a role. The civil war in question was caused by Yahya Khan and Bhutto refusing to recognize election results that favored East Pakistani leaders, leading the former to send troops into East Pakistan in February 1971 to suppress nationalist sentiment. ${ }^{66}$ This escalated on March $25^{\text {th }}$ when West Pakistani soldiers began attacking Dacca, with as many as 2 million being killed and another 9-10 million refugees fleeing to India, which could not support them due to an economic downturn. ${ }^{67}$ Pro-intervention sentiment spread quickly among officials and the public after a March 31 talk by civil servant $\mathrm{K}$. Subrahmanyam arguing that it would be less costly than integrating the refugees. ${ }^{68}$

Despite this sentiment, India did not immediately intervene, at least directly. When members of Indira Gandhi's cabinet began demanding intervention, they were informed in an April 28 meeting by Army Chief General Sam Manekshaw that the Indian army suffered from serious enough issues that attempting to do so would result in "“ $100 \%$ defeat.",69 Instead, the government began training and supporting Bengali militant groups, known as the Mukti Bahini, which attacked the Pakistani army in a form of indirect warfare. ${ }^{70}$ This did not prevent Pakistani forces from massing at the border with India, ostensibly to deter any intervention or support for the Mukti Bahini, leading to clashes with the Indian army as early as November $22 .{ }^{71}$

The increasing tensions led Yahya Khan to order pre-emptive airstrikes on December 3. While intended to coerce India into ending support for the Mukti Bahini, it

\footnotetext{
${ }^{66}$ Sonia Cordera, "India's Response to the 1971 East Pakistan Crisis: Hidden and Open Reasons for Intervention," Journal of Genocide Research 17, no. 1 (2015): 45-62.

${ }^{67}$ Kasturi, "The State of War," 146.

${ }^{68}$ Ganguly, Conflict Unending, 63-64.

${ }^{69}$ Srinath Raghavan, "Soldiers, Statesmen, and India's Security Policy," India Review 11, no. 2 (2012): $122-123$.

${ }^{70}$ Kasturi, "The State of War," 146.

${ }^{71}$ Kasturi, "The State of War," 139-140.
} 
instead triggered a crisis and provoked an Indian invasion of East Pakistan. ${ }^{72}$ The subsequent war was terminated by December 16, with Indian forces not only driving Pakistani forces out of East Pakistan, but capturing 93,000 soldiers as well. ${ }^{73}$ Bhutto was forced to negotiate the Simla Accord with Gandhi on July 2, 1972 to secure the release of the prisoners in exchange for both countries recognizing the ceasefire line through Kashmir as a permanent Line of Control (LoC) that could not be unilaterally altered through force or otherwise. ${ }^{74}$ While this was a satisfactory outcome for India, with approval for Indira Gandhi rising, Yahya Khan was forced to resign due to the humiliation of the loss, which led to Pakistan being dismembered and left vulnerable by East Pakistan's independence. ${ }^{75}$

The intent behind the airstrikes appears to have been to both seize an offensive advantage in an increasingly inevitable war and force India into backing down. By nullifying India's airpower while it was on the ground in the same way Israel struck first in the Six-Day War, Yahya Khan and his fellow generals believed that it would then be possible to pressure the Indian government into avoiding war. ${ }^{76}$ At least part of this can be blamed on Yahya Khan's military advisors, as he was heavily reliant on military support and thus vulnerable to pressure from generals to strike first. ${ }^{77}$ As with previous IndoPakistani conflicts, the airstrike was not the result of a power disparity favoring Pakistan: by 1971, India's armed forces had grown to 980,000 personnel, while Pakistan's remained

\footnotetext{
${ }^{72}$ Khan, Nuclear Weapons and Conflict Transformation, 96.

${ }^{73}$ Ganguly, Conflict Unending, 70.

${ }^{74}$ Indira Gandhi and Zulfikar Ali Bhutto, "Agreement between the Government of India and the Government of the Islamic Republic of Pakistan on Bilateral Relations (Simla Agreement)" (Ministry of External Affairs, Government of India, July 2, 1972), https://www.mea.gov.in/bilateraldocuments.htm?dtl/5541/Simla+Agreement.

${ }^{75}$ Cordera, "India's Decision," 55.

${ }^{76}$ Ahmad Faruqui, "Failure in Command: Lessons from Pakistan's Indian Wars, 1947_1999," Defense Analysis 17, no. 1 (2001): 35-36.

${ }^{77}$ Schofield, "Militarized Decision-Making," 141-142.
} 
around 365,000 total. ${ }^{78}$ However, Yahya Khan's government had the advantage of proPakistani sentiment in both the Nixon administration and the Chinese government after assisting in Sino-American rapprochement. This, along with a visit to Beijing in October, seems to have emboldened Yahya Khan to believe that China would intervene against an Indian attack, ignoring that Indo-Soviet ties made this unlikely. ${ }^{79}$ This suggests that their thinking remained similar to that of Ayub Khan and Bhutto in the 1965 crisis: that the Indian government lacked the will to fight to defend its territory, and would make concessions when faced with costs.

The three pre-nuclear Indo-Pakistani wars are all partially attributable to Pakistan's leaders seeking to take advantage of a perceived Indian lack of resolve and unwillingness to endure armed conflict costs despite a military capability gap. Evidence from the 1947 war suggests that Pakistan's leaders did not anticipate India defending Jammu and Kashmir, forcing the mobilization of regular Pakistani forces. ${ }^{80}$ The 1965 war most readily demonstrates this line of thinking, as Ayub Khan, Bhutto, and Ahmed (wrongly) concluded after the Rann of Kutch incident that the Indian government and its citizens were unwilling to pay the necessary costs to defend their territory, and planned to invade Kashmir on that basis despite the overwhelming power disparity. ${ }^{81}$ Finally, the 1971 crisis was the result of Yahya Khan and other Pakistani leaders seeking to use a pre-emptive strike to force India into backing down, believing that Gandhi's government would give in even after limited airstrikes. ${ }^{82}$ Regime type only seems to have been applicable during the Second Indo-

\footnotetext{
${ }^{78}$ International Institute for Strategic Studies, "Asia and Australasia," The Military Balance 71, no. 1 (1971): 46, 50.

${ }^{79}$ Ganguly, Conflict Unending, 67.

${ }^{80}$ Dasgupta, War and Diplomacy, 50-51.

${ }^{81}$ Chaudhuri, "Indian 'Strategic Restraint,"” 60-61.

${ }^{82}$ Faruqui, "Failure in Command," 35-36.
} 
Pakistani War, given the sentiment that the Indian public would not tolerate costs. All three cases, however, had Pakistan's leaders demonstrate the expected viewpoint that the defender was too cost-sensitive and thus vulnerable, albeit due to false optimism.

Notably, while none of these crises posed an existential threat to India, there was considerable Indian domestic support for military action. The 1947 and 1965 wars were meant solely to seize control of then-independent Jammu and Kashmir, with no indication that Pakistani leaders had any greater designs against India. The 1971 pre-emptive strike, meanwhile, was meant to keep India from interfering in Pakistan's domestic affairs. In all three instances, however, there was considerable support for Indian military action among the general public and in government circles, with the 1971 war notably preceded by calls for military intervention 6 months before Pakistan had even mobilized to the border. ${ }^{83}$ Much of the restraint seems to have come from Indian prime ministers and their close supporters, who largely followed Nehru in mistrusting the military and embracing a (relatively) pacifist agenda. This means that while Indian leaders have demonstrated costsensitivity for armed conflict, as is expected in the theory and much of the prior literature, the actual mechanism is not what was expected. Rather than democratic leaders demonstrating cost-sensitivity to avoid being punished by voters who want to avoid fighting, they instead appear to have acted with restraint despite citizen preference.

\subsection{2: Sino-Indian War (1962)}

The Sino-Indian War, which took place between October $20^{\text {th }}$ and November $21^{\text {st }}$, 1962, is notable as one of the few crises in Indian history tied to a state besides Pakistan

${ }^{83}$ Raghavan, “Soldiers, Statesmen," 122-123. 
and the only war that it has lost. The crisis was rooted in disputes between India and China over the demarcation of their shared border since the latter occupied Tibet in 1951, but escalated when Prime Minister Zhou Enlai declared the McMahon Line to be illegitimate in $1959 .{ }^{84}$ Negotiations in 1960 between Zhou and Nehru had the former further insist that Tibet and India's northern Aksai Chin region were historically Chinese territories, with Nehru pushing back with the Chinese government's acceptance of maps indicating otherwise as legitimate in the previous year. ${ }^{85}$ Chinese officials also believed that the Indian government was supporting a rebellion that broke out in Tibet in March 1959 to make it a buffer state, provoking multiple clashes between them. ${ }^{86}$ Tensions escalated further when Nehru's Forward Policy was implemented in November 1961, which established military posts in disputed areas to deter Chinese incursions ${ }^{87}$ Instead, Chinese officials viewed it as a deliberately provocative policy to seize disputed territories. ${ }^{88}$

\footnotetext{
${ }^{84}$ The McMahon Line, established in the 1914 Simla Agreement by the British, divides Tibet and northeast India. F. K. Kaul and Hanfu Zhang, "Meeting Minutes between Chinese Vice Foreign Minister Zhang Hanfu and Indian Commissioner T.N. Kaul" (November 27, 1951), PRC FMA 105-00082-03, 10-14, History and Public Policy Program Digital Archive, https://digitalarchive.wilsoncenter.org/document/114750; Zhou Enlai, "Letter from Prime Minister of China to the Prime Minister of India, 23 January 1959" (January 23, 1959), Ministry of External Affairs, Government of India, Notes, Memoranda and Letters Exchanged and Agreements Signed between the Governments of India and China 1954-1959: White Paper I (New Delhi: External Publicity Division, Ministry of External Affairs, 1959), 52-54, History and Public Policy Program Digital Archive, https://digitalarchive.wilsoncenter.org/document/175951.

${ }^{85}$ Zhou Enlai and Jawaharlal Nehru, "Record of Talks between P.M. [Jawaharlal Nehru] and Premier Chou En Lai [Zhou Enlai] Held on 22nd April, 1960 from 10 A.M. to 1.10 P.M." (April 22, 1960), Nehru Memorial Museum and Library, P.N. Haksar Papers (I-II Installment), Subject File \#24, 40-53., History and Public Policy Program Digital Archive, https://digitalarchive.wilsoncenter.org/document/175916; Zhou Enlai and Jawaharlal Nehru, "Record of Talks between P.M. [Jawaharlal Nehru] and Premier Chou En Lai [Zhou Enlai] Held on 24th April, 1960, from 10.30 a.m. to 1.45 p.m." (April 24, 1960), Nehru Memorial Museum and Library, P.N. Haksar Papers (I-II Installment), Subject File \#24, 69-85, History and Public Policy Program Digital Archive, https://digitalarchive.wilsoncenter.org/document/121124.

${ }^{86}$ Srinath Raghavan, "Chapter 11: A Bad Knock: The War with China, 1962," in A Military History of India and South Asia: From the East India Company to the Nuclear Era, ed. Daniel P. Marston and Chandar S Sundaram (Bloomington: Indiana University Press, 2007), 159-160.

${ }^{87}$ Raghavan, “A Bad Knock," 161.

${ }^{88}$ John W. Garver, "China's Decision for War with India in 1962," in New Directions in the Study of China's Foreign Policy, ed. Alastair Iain Johnson and Robert S. Ross (Stanford: Stanford University Press, 2006), 112.
} 
The Forward Policy served as the trigger for the Sino-Indian War in late 1962, which was resolved in China's favour due to its military advantage. People's Liberation Army (PLA) soldiers originally crossed the border into Aksai Chin and along the McMahon line on October 20, targeting India's forward posts in the northeast regions. ${ }^{89}$ The war ended with a unilateral Chinese ceasefire and withdrawal across the McMahon Line on November 21, by which time 4,885 Indian troops were killed, another 3,968 were captured, and only 722 Chinese troops killed.${ }^{90}$ India's defeat has been attributed to both its forces being outnumbered 5:1 and Nehru and Menon overruling military officers in favour of directly micromanaging strategy. ${ }^{91}$ The disastrous outcome of the crisis for India led Menon and army chief General Pran Nath Thapar to resign, while the Indian government was forced to avoid even engaging with China until after Nehru's death in 1964 to ensure even the appearance of a compromise would not lead to popular backlash. ${ }^{92}$ This was the only war fought between China and India, though there have been sporadic incidents of violence between their troops since then, most notably with a skirmish in Galwan Valley in June 2020 that saw at least 20 Indian soldiers and potentially 50 Chinese soldiers killed. ${ }^{93}$

Unlike the three pre-nuclear Indo-Pakistani wars, the Sino-Indian War was not encouraged by perceived Indian cost-sensitivity or lack of resolve, but was the result of a security dilemma caused by the Forward Policy. The perception that Nehru was trying to

\footnotetext{
${ }^{89}$ Stephen P. Westcott, "Mao, Nehru and the Sino-Indian Border Dispute: A Poliheuristic Analysis," India Quarterly 75, no. 2 (2019): 162.

${ }_{90}$ Westcott, "Mao, Nehru and the Sino-Indian Border Dispute," 162.

${ }^{91}$ Narang, Nuclear Strategy in the Modern Era, 113; Jiye Kim, "China's Wars and Strategies: Looking Back at the Korean War and the Sino-Indian War," Strategic Analysis 42, no. 2 (2018): 119-33.

${ }_{92}$ Westcott, "Mao, Nehru," 162; Raghavan, "A Bad Knock," 172.

${ }^{93}$ Safi, Ellis-Petersen, and Davidson, "Soldiers Fell to Their Deaths as India and China's Troops Fought with Rocks."
} 
seize historical Chinese territory was only worsened by the Forward Policy stationing Indian troops within that very territory. ${ }^{94}$ This, along with a July 1962 statement by Menon describing the territory as Indian, led Zhou and Foreign Minister Chen Yi to conclude that “"Nehru wants a war with us" "and that the "“forward policy is a knife." "95 While moderates in the Chinese Communist Party (CCP) like Deng Xiaoping pushed for negotiations, Mao believed that force was necessary to deter perceived Indian expansionism, and declared in October that they needed to "teach them a lesson"" and "knock Nehru to the negotiating table" in a limited war. ${ }^{96}$ There is no indication that the CCP leadership believed that Nehru or other Indian leaders were overly cost-sensitive and lacking resolve because of regime type or otherwise. The perception instead appears to have been that their Indian counterparts were aggressive and posed a threat to China that required using force.

\subsection{3: Border Crises}

Modern Indian history has, in addition to wars, been marked by border skirmishes and standoffs with Pakistan. According to the Correlates of War Dyadic Militarized Interstate Disputes dataset, there have been 31 dyad-years with MIDs where Pakistan has targeted India with actions short of war, such as border clashes and raids, between 1947 and 2010. ${ }^{97}$ Additionally, there has also been indirect conflict since the late 1980s via the use of Kashmiri separatist groups and mujahideen crossing over the LoC from Pakistan's side of the border. Some of the most prominent non-state groups involved in this violence, such as Jaish-e-Mohammed (JeM) and Lashkar-e-Taiba (LeT), have received material

\footnotetext{
${ }^{94}$ Garver, "China's Decision," 94-95.

${ }^{95}$ Garver, "China's Decision," 111-112.

${ }^{96}$ Garver, "China's Decision," 115-119; Westcott, "Mao, Nehru," 166-167.

${ }^{97}$ Zeev Maoz et al., "The Dyadic Militarized Interstate Disputes (MIDs) Dataset Version 3.0: Logic, Characteristics, and Comparisons to Alternative Datasets," Journal of Conflict Resolution 63, no. 3 (2019): $811-35$.
} 
support or explicit directions from elements of the Pakistani government as a form of indirect warfare to undermine Indian control of Kashmir with a level of plausible deniability ${ }^{98}$ The Pakistani government is also known to have provided support for the Sikh insurgency within India during this period, with President Zia ul-Haq having approved this in order to further undermine India. ${ }^{99}$ On some occasions, this has led to border standoffs between the Indian and Pakistani militaries and an elevated risk of war.

The most notable pre-nuclear Indo-Pakistani standoff was the Brasstacks crisis (1986-1987). The crisis was triggered by an Indian military exercise, Operation Brasstacks, that took place near the border in Punjab in December 1986 and involved approximately 600,000 military personnel. The exercise was meant by Prime Minister Rajiv Gandhi and Army Chief of Staff Krishnaswamy Sundarji to intimidate Pakistan into ending support for the Sikh insurgency, but the sheer scale and proximity to the border instead led the Pakistani government to believe it was cover for an invasion. ${ }^{100}$ The decision to use Brasstacks to intimidate Pakistan appears to have been motivated by political concerns, as Gandhi's Congress Party was losing ground to Hindu nationalist parties like the BJP due to the perception of being soft on terror. ${ }^{101}$ In response, Pakistan expanded its own military exercises and, once completed in December 1986, left its forces deployed near the IndoPakistani border. ${ }^{102}$ When the Indian government discovered this in January 1987,

\footnotetext{
${ }^{98}$ Bruce Riedel, Avoiding Armageddon: America, India, and Pakistan to the Brink and Back (Washington, DC: Brookings Institution Press, 2013), 93-94.

${ }^{99}$ Ganguly, Conflict Unending, 85.

${ }^{100}$ Narang, Nuclear Strategy in the Modern Era, 63; Khan, Nuclear Weapons and Conflict Transformation, 101.

${ }^{101}$ Praveen Swami, "Failed Threats and Flawed Fences: India's Military Responses to Pakistan's Proxy War," India Review 3, no. 2 (2004): 155.

${ }^{102}$ Gaurav Kampani, "New Delhi's Long Nuclear Journey: How Secrecy and Institutional Roadblocks Delayed India's Weaponization," International Security 38, no. 4 (2014): 91.
} 
additional troops were deployed to the border in Punjab and Kashmir in response. ${ }^{103}$ The result was a massive stand-off between India and Pakistan.

While the crisis was relatively short-lived - having ended by mid-February - it nearly resulted in a war. By January 23, Indian Minister of State for External Affairs Natwar Singh warned Pakistan that "appropriate steps" would be taken if Pakistani troops were not withdrawn from the border, with his Pakistani counterpart expressing similar sentiments around the same time. ${ }^{104}$ Pakistani threats escalated further: sometime in January, Minister of State for Foreign Affairs Zain Noorani reportedly informed the Indian ambassador on behalf of Zia that if India breached Pakistan's sovereignty, they were "capable of inflicting unacceptable damage"” beyond its northern region to even Bombay, alluding to their nuclear program. ${ }^{105}$ Chief nuclear scientist A.Q. Khan made a more blatant nuclear threat in a January 28 interview with The Observer that "we shall use the bomb if our existence is threatened." 106 Notably, there is no evidence that Pakistan had actual nuclear weapons during the Brasstacks crisis, only being a de facto nuclear weapon state. It is almost certain that these threats were made with Zia's approval, as he later stated in an interview that "Pakistan has the capability of building the bomb... whenever it wishes." "107 The crisis was terminated by February 19 through US- and Soviet-mediated talks that had India and Pakistan agree to withdraw their troops by the end of the month. ${ }^{108}$

\footnotetext{
${ }^{103}$ Brecher and Wilkenfeld, A Study of Crisis, 174-175; Kampani, "New Delhi’s Long Nuclear Journey," 91.

104 Ganguly, Conflict Unending, 87.

${ }^{105}$ Kargil Review Committee, From Surprise to Reckoning: The Kargil Committee Report (New Delhi: SAGE Publications, December 15, 1999), 191.

${ }^{106}$ Kuldip Nayar, “We Have the A-Bomb, Says Pakistan's 'Dr Strangelove,” The Observer, March 1, 1987.

107 William R. Doerner, "Pakistan Knocking at the Nuclear Door," Time Magazine, March 30, 1987, http://content.time.com/time/magazine/article/0,9171,963894,00.html.

${ }^{108}$ Brecher and Wilkenfeld, A Study of Crisis, 175.
} 
The Brasstacks crisis once again had Pakistan's leaders try to exploit the perceived cost-sensitivity of Indian politicians and reluctance to engage in an unnecessary war, albeit more successfully than previous attempts. Similar to Operation Gibraltar in 1965, Pakistani leaders had attempted to weaken India by fomenting rebellion, but while that crisis provoked a counter-invasion, implicit nuclear threats were sufficient in 1987 to push Gandhi to mediation. ${ }^{109}$ The two main differences are the lack of an actual invasion and the nuclear threats and associated risk of general war, whose costs would greatly outweigh the Punjab rebellion. Sundarji himself later admitted that the threats meant that Indian options "“no longer includes launching a bold offensive across the Punjab border" and made Indian politicians hesitant to use conventional force. ${ }^{110}$ This shows the Pakistani assessment that India's leadership would back down in the face of threats was partially correct, in that attacking was no longer an option due to costs. As with other pre-nuclear crises, India's regime type does not seem to have factored into Pakistan's decision-making, but likely influenced Gandhi to take a more aggressive stance to regain popular support.

\section{4: From Smiling Buddha to Pokhran-II: Indian Nuclear Weapons Development Motivations and History}

India's nuclear arsenal can be construed as being solely to deter Pakistan, given the numerous crises between them. However, the decision to pivot towards the development of nuclear weapons in the 1960s was instead motivated by the threat of Chinese conventional and nuclear superiority, as well as a lack of reliable extended deterrence. International outcry to India's peaceful nuclear explosion in 1974 temporarily led to further

\footnotetext{
${ }^{109}$ Ganguly and Kapur, India, Pakistan, 12-13; Khan, Nuclear Weapons and Conflict Transformation, 101103.

${ }^{110}$ Swami, "Failed Threats and Flawed Fences," 155-156.
} 
weaponization efforts being shut down; however, Pakistan's efforts to develop its own nuclear deterrent against India spurred the Indian government to resume its efforts to develop an overt weapons capability.

India's pursuit of nuclear weapons can be traced back to hostilities with China. The 1962 Sino-Indian War proved to be a humiliating defeat, as the Indian military was completely unprepared to fight China and was at risk of losing significant parts of Assam when the PLA unilaterally withdrew. ${ }^{111}$ The defeat spurred significant increases in Indian military spending to deter Chinese aggression. The Chinese nuclear test explosion on October 16, 1964, rendered these efforts moot, since China could then use the threat of nuclear weapons to intimidate or coerce India. ${ }^{12}$ Pakistani belligerence was not a major consideration, since it had yet to win a conventional war with India and, at the time, was believed to lack the necessary scientific expertise and infrastructure for nuclear weapons development. ${ }^{113}$ Efforts to obtain extended deterrence from a nuclear power failed: the US Joint Chiefs of Staff were against any measures supporting India that would harm US relations with Pakistan, while British PM Harold Wilson rebuffed Shastri's request during a 1964 visit to London. ${ }^{114}$ India was thus forced to seek its own nuclear deterrent due to being outmatched by China and unable to obtain security guarantees from other states.

Shastri's subsequent approval of a secret nuclear research program culminated in a peaceful nuclear explosion (PNE) in 1974. Shastri's PNE decision, made in December

\footnotetext{
${ }^{111}$ P.K. Chakravorty, "Sino-Indian War of 1962,” Indian Historical Review 44, no. 2 (2017): 309-310.

112 Andrew B. Kennedy, "India's Nuclear Odyssey: Implicit Umbrellas, Diplomatic Disappointments, and the Bomb," International Security 36, no. 2 (Fall 2011): 125.

${ }^{113}$ Vergese Koithara, Managing India's Nuclear Forces (Washington, DC: Brookings Institution Press, 2012), 18.

${ }^{114}$ Kargil Review Committee, The Kargil Committee Report, 201.
} 
1965, was in response to pressure from his own Congress Party; in public, he appeared to be going against popular demands for nuclear weapons, and persistently refused to authorize testing. ${ }^{115}$ This only occurred under Indira Gandhi to take advantage of popular demand for nuclear weapons to bolster her waning support. ${ }^{116}$ The Pokhran-I test, or "Smiling Buddha," was conducted on May 18, 1974, but was labelled a PNE due to the device's unsuitability as a weapon and as a way to provide some nuclear ambiguity. ${ }^{117}$ The test was hugely successful in boosting Gandhi's domestic popularity, with June 1974 polls indicating that $91 \%$ of the literate adult population knew of it and $90 \%$ of those expressed approval. ${ }^{118}$ It also drew significant international condemnation, with the US and Canada suspending nuclear cooperation agreements and the Nuclear Suppliers Group (NSG) being created to monitor nuclear technologies and materials to prevent future covert weapons programs. ${ }^{119}$ While relatively limited, this backlash led Gandhi's government to halt further nuclear developments.

Indian nuclear weapon development largely stalled after 1974, resuming once it became clear that Pakistan had its own program and culminated in new tests in May 1998. The international backlash to Pokhran-I, concerns over the economic costs of nuclear weapon development, and the moral misgivings of officials put the program on hold. ${ }^{120}$ This policy changed under Rajiv Gandhi's government during the 1980s when it became clear that Pakistan was enriching uranium while receiving Chinese aid in designing nuclear

\footnotetext{
${ }^{115}$ Rajesh M. Basrur, "Nuclear Weapons and Indian Strategic Culture," Journal of Peace Research 38, no. 2 (2001): 186.

${ }^{116}$ Ganguly and Kapur, India, Pakistan, 18; Malhotra, "Assessing Indian Nuclear Attitudes," 13.

${ }^{117}$ Kennedy, "India's Nuclear Odyssey," 125.

${ }^{118}$ Sagan, "Why Do States Build Nuclear Weapons?," 67-68.

${ }^{119}$ Koithara, Managing, 88-89; Khan, Nuclear Weapons and Conflict Transformation, 77.

${ }^{120}$ Kennedy, "India's Nuclear Odyssey," 126.
} 
weapons. ${ }^{121}$ An exact date for nuclear weapons development resuming is unclear, though Gandhi is believed to have ordered it in 1988-1989 after reports of further Pakistani efforts, indicating that India was a de facto nuclear weapon state by the end of the decade. ${ }^{122}$ This continued even after Atal Bihari Vajyaee and the BJP took office in 1998, as the party had repeatedly promised to develop an Indian nuclear deterrent. ${ }^{123}$ In fact, Vajpayee had already sought to carry out open nuclear testing when he had formed a government in 1996, only being prevented from doing so when it collapsed after 13 days. ${ }^{124}$ Perhaps unsurprisingly, the Pokhran II tests were carried out over May 11-13, almost immediately after Vajpayee's coalition government took power. ${ }^{125}$

As with the 1974 test, Pokhran-II was domestically popular. While the Congress Party was critical of the nuclear program being made overt, opinion polls suggested $91 \%$ of respondents approved of the tests and another $63 \%$ improved their opinion of the government because of them. ${ }^{126}$ This popular sentiment notably continued even after sanctions were imposed by the US and 15 other countries, though these were completely lifted by 2001 and had little immediate impact due to India receiving relatively little foreign aid. ${ }^{127}$ The continued support of the Indian public for the development of nuclear weapons, even after sanctions, highlights its greater cost-insensitivity relative to the government on national security issues. This also ties into the trend of Indian voters being more open to

\footnotetext{
${ }^{121}$ Koithara, Managing, 19.

${ }^{122}$ Ganguly and Kapur, India, Pakistan, 19; Koithara, Managing, 95.

${ }^{123}$ Achin Vanaik and Jamia Millia Islamia, "Making India Strong: The BJP-led Government's Foreign Policy Perspectives," South Asia: Journal of South Asian Studies 25, no. 3 (2002): 323.

${ }^{124}$ Vanaik and Islamia, "Making India Strong," 323; David Cortright and Amitabh Mattoo, "Indian Public Opinion and Nuclear Weapons Policy," in India and the Bomb: Public Opinion and Nuclear Options, ed. David Cortright and Amitabh Mattoo, (Notre Dame: University of Notre Dame Press, 1996), 10.

${ }^{125}$ Basrur, "Indian Strategic Culture," 188-189.

${ }^{126}$ Malhotra, "Assessing Indian Nuclear Attitudes," 14-15.

${ }^{127}$ Daniel Morrow and Michael Carriere, "The Economic Impacts of the 1998 Sanctions on India and Pakistan," The Nonproliferation Review 6, no. 4 (1999): 1-16.
} 
using force than their leaders and the strategic elite, which is both readily apparent in postnuclear crises and goes against the theory's expectation that their cost-sensitivity would restrain the government in low-intensity conflict.

\section{5: Minimum Deterrence and No-First-Use: Indian Nuclear Deterrence Threats and Command and Control}

India's approach to nuclear command and control is largely similar to most defence issues, with civilian leaders and bureaucrats dominating decision-making while sidelining their military counterparts. At first, this meant that while India was a de facto nuclear weapon state since the 1980s, it originally lacked formal institutions for controlling nuclear weapons, or even a doctrine for their potential use, until Prime Minister V.P. Singh had officials study possible responses to a Pakistani nuclear attack in $1990 .{ }^{128}$ However, India's National Security Advisory Board only began drafting a nuclear doctrine in December 1998, more than half a year after the Pokhran-II tests. ${ }^{129}$ The actual draft nuclear doctrine was only announced to the public on August 17, 1999, a month after India had fought the Kargil War with Pakistan, and was only officially adopted by the Indian Cabinet in January 2003. ${ }^{130}$ Until then, the only publicly known aspect of India's nuclear deterrence policy was the announcement of a no-first-use policy in Parliament after the Pokhran-II test in May 1998. ${ }^{131}$ The slow pace in determining how nuclear weapons would be handled suggests that they were not considered a high priority, at least by civilian officials.

\footnotetext{
${ }^{128}$ Koithara, Managing, 100.

${ }^{129}$ Reshmi Kazi, “India's Nuclear Doctrine: A Study of Its Tenets,” Indian Foreign Affairs Journal 9, no. 1 (2014): 46.

${ }^{130}$ Kazi, "India's Nuclear Doctrine," 146.

${ }^{131}$ Mario E. Carranza, "Deterrence or Taboo? Explaining the Non-Use of Nuclear Weapons during the Indo-Pakistani Post-Tests Nuclear Crises," Contemporary Security Policy 39, no. 3 (2018): 446.
} 
The finalized 2003 doctrine established that India's nuclear arsenal is wholly civilian-controlled. According to the document, the core of Indian command and control is the Nuclear Command Authority (NCA), which consists of a Political Council chaired by the prime minister and an Executive Council chaired by the national security advisor. ${ }^{132}$ The latter is an exclusively advisory body, while the Political Council holds the power to order nuclear weapon use. Other organizations associated with managing nuclear forces include the Defence Research \& Development Organisation (DRDO), the Department of Atomic Energy (DAE), and the three branches of the armed forces. ${ }^{133}$ This structure means that any legitimate nuclear launch decision requires the prime minister's approval.

Notably, the military's role in the command and control process appears to be deliberately minimized. Under this structure, the armed forces only control the delivery vehicles for nuclear weapons, such as missiles. The actual warheads and fissile cores, meanwhile, are kept by the DAE and DRDO, which are both civilian organizations. ${ }^{134}$ This appears to stem from not only a desire to ensure nuclear weapons remain a last resort, but also as a way of minimizing the risk of unauthorized use, since the cores would only be released with the permission of the Prime Minister's office. ${ }^{135}$ This system thus ensures that the military can at most provide advice regarding the use of nuclear weapons, but the ultimate decision to launch remains entirely with civilian authorities. This bears some

\footnotetext{
${ }^{132}$ Ministry of External Affairs, "The Cabinet Committee on Security Reviews Operationalization of India's Nuclear Doctrine," Government of India, January 3, 2003, https://www.mea.gov.in/pressreleases.htm?dtl/20131/The+Cabinet + Committee+on+Security+Reviews + perationalization + of + Indias + Nuc lear+Doctrine.

${ }^{133}$ Koithara, Managing, 2.

${ }^{134}$ Koithara, Managing, 104.

${ }^{135}$ Narang, Nuclear Strategy in the Modern Era, 107-108.
} 
similarity to Israel, albeit with even more emphasis on civilian control, and stands in stark contrast to the military-dominated approaches of Pakistan and North Korea.

India's nuclear deterrence policy largely emphasizes its defensive intent, albeit with some ambiguity. No-first-use has been integral, with the 2003 doctrine establishing nuclear weapons would only be used in response to "a nuclear attack on Indian territory or on Indian forces anywhere," and not against non-nuclear weapon states. ${ }^{136}$ The Indian government also reserves using nuclear weapons in retaliation for the use of biological or chemical weapons against Indian territory or its forces. ${ }^{137}$ The doctrine's intent appears to be to simultaneously deter China and Pakistan while assuring them of India's defensive intentions to discourage pre-emptive attacks. ${ }^{138}$ However, the doctrine's ambiguous wording means that theoretically any use of nuclear weapons against Indian forces, even a low-yield tactical weapon, would justify a nuclear response. ${ }^{139}$ This makes the policy's scope expansive to the point of non-credibility in this respect, since it would mean a potential nuclear war and all the associated domestic and international costs. ${ }^{140}$

\footnotetext{
${ }^{136}$ Ministry of External Affairs, "India's Nuclear Doctrine."

${ }^{137}$ Koithara, Managing, 84.

${ }^{138}$ Kazi, "India's Nuclear Doctrine," 50.

139 Jaganath Sankaran, "Pakistan's Battlefield Nuclear Policy: A Risky Solution to an Exaggerated Threat," International Security 39, no. 3 (2014): 120.

${ }^{140}$ Karthika Sasikumar, "After Nuclear Midnight: The Impact of a Nuclear War on India and Pakistan," Bulletin of the Atomic Scientists 73, no. 4 (2017): 226-32.
} 
Figure 6.2: Indian, Pakistani, and Chinese nuclear arsenals, 1998-2018

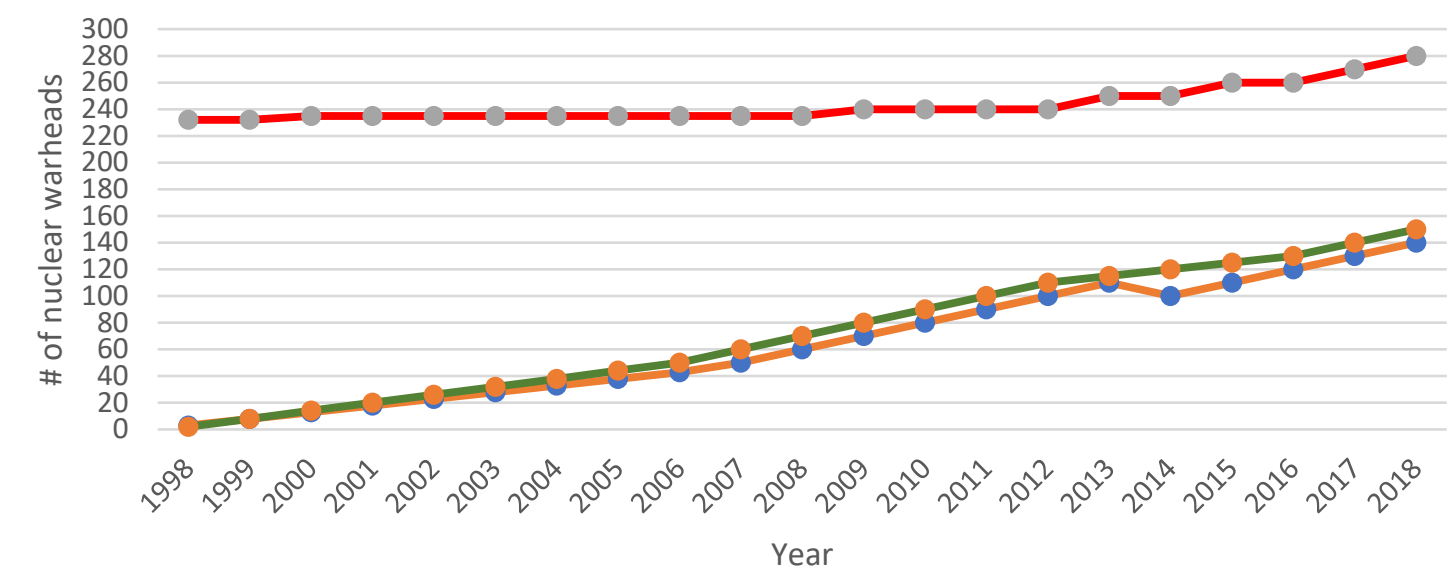

-\# of Indian nuclear weapons $\quad-$ \# of Pakistani nuclear weapons

Source: Bulletin of the Atomic Scientists, Nuclear Notebook, -\# of Chinese nuclear weapons 2018

The Indian government has also focused on maintaining a minimum nuclear deterrent. This is seemingly contradicted by the 2003 doctrine's promise to respond to a first strike with "massive" and "unacceptable damage," which would require a large arsenal. ${ }^{141}$ In reality, India's nuclear arsenal is small compared even to other regional nuclear powers, having only grown from an estimated three warheads to 140 between 1998 and 2018. ${ }^{142}$ Figure 6.2 shows that this places India's nuclear forces on par with Pakistan's estimated 150 warheads, but far behind the estimated 280 possessed by China. Compared to the other two states studied in this dissertation, India's arsenal is potentially outstripped

\footnotetext{
${ }^{141}$ Ministry of External Affairs, "The Cabinet Committee on Security Reviews Operationalization of India's Nuclear Doctrine."

${ }^{142}$ Hans M. Kristensen and Robert S. Norris, "Nuclear Arsenals of the World," Bulletin of the Atomic Scientists (blog), 2018, https://thebulletin.org/nuclear-notebook-multimedia/.
} 
by Israel's - which is estimated at being between 80 and 200 warheads - and is much larger than North Korea's arsenal of 20-30 warheads. ${ }^{143}$

This minimum deterrent serves multiple purposes. For one, it avoids provoking an arms race between India and its neighbours, which would not only be costly for all parties, but would also create a sense of insecurity by making stockpile increases appear to be preparation for a first strike. A relatively small arsenal, in contrast, serves to emphasize the defensive nature of the Indian nuclear arsenal. Minimum deterrence also means that India's deterrence strategy is focused on hitting strategic targets within states that attack with nuclear weapons instead of attempting to cause maximum casualties and infrastructure damage. When considered alongside the no-first-use policy, the Indian government has signalled that it possesses (at least in theory) a high threshold for using nuclear weapons. The minimum deterrent approach thus serves to not only reduce spending on nuclear weapons, but also provides a confidence-building measure.

India's approach to nuclear deterrence ends up conforming to the expectations of the theory advanced in this dissertation by encouraging low-intensity attacks and limited war, as they fell below its perceived nuclear threshold due to not posing an existential threat. Post-nuclear acquisition attacks against India have all involved relatively limited aims in seeking to seize disputed territory, with Pakistan's attempts at fomenting and supporting insurgencies being motivated by a belief that India would use limited force, if any, in response. This is because India's nuclear arsenal is meant to deter the use of nuclear

\footnotetext{
${ }^{143}$ These figures do not include fissile material estimates for North Korea, which are believed to be sufficient for an additional 30-60 warheads. Kelsey Davenport and Kingston Reif, "Nuclear Weapons: Who Has What at a Glance," Arms Control Association, July 2019, https://www.armscontrol.org/factsheets/Nuclearweaponswhohaswhat.
} 
and other conventional weapons against it, and the lack of applicability in such lowintensity conflict means that other states could attack India with little concern of a nuclear response. Even if India's government went against its stated doctrine in threatening nuclear weapon use in response to low-intensity attacks and limited wars, those threats may be seen as non-credible due to the costs that would be incurred, largely from the international community.

It is important to note here that the Indian case goes against theoretical expectations in a very significant way, in that the Indian public appears to accept or outright favour using nuclear weapons in various situations, including low-intensity conflict. A major part of democracies being more averse to low-intensity nuclear weapon use is the ability of citizens to punish governments for actions that are considered repugnant and have their benefits outweighed by their costs. ${ }^{144}$ The few polls on Indian attitudes towards nuclear weapons suggest that the public would tolerate or even favour their use in low-intensity conflict. A 1996 survey of Indian elites found that only 44\% of respondents opposed ever using nuclear weapons, while $30 \%$ of those in favour believed they should be used if Pakistan was about to take over Kashmir. ${ }^{145}$ A 2015 poll, meanwhile, found that 53\% favored using nuclear weapons to stop terrorists near Lahore from building their own device even if it killed 50,000 civilians and was no more effective than a conventional attack, since it would "“send a strong message."”146 These sentiments appear to be reflective of broader support for the Indian military, with a 2013 Lowy Institute survey showing 95\% of Indian respondents consider it vital for achieving foreign policy goals, while $79 \%$

\footnotetext{
${ }^{144}$ See Nina Tannenwald, The Nuclear Taboo: The United States and the Non-Use of Nuclear Weapons Since 1945, (Cambridge: Cambridge University Press, 2007).

${ }^{145}$ Cortright and Mattoo, "Indian Public Opinion," 15-16.

146 Valentino and Sagan, "Atomic Attraction."
} 
thought the same of its nuclear arsenal. ${ }^{147}$ These apparently indicate that the Indian public is not restraining the government from using nuclear weapons, but rather that officials and strategic elites are the main source of restraint, which is borne out by the post-nuclear crises studied in the next section.

\section{6: "'Be prepared for escalation:" Indian Post-Nuclear Crises and Conflicts}

Contrary to expectations, armed attacks against India have not abated after revealing its nuclear capabilities in 1998. Instead, it has continued to be challenged by Pakistan despite mutual nuclear deterrence and India's conventional advantage. The strategy used by Pakistan has shifted since the pre-nuclear period towards covert troop infiltrations and state-backed militancy in Kashmir. This seems to have been encouraged by the 1999 Kargil War, which validated Pakistani officers' belief that India's leaders would restrict their response to the presence of Pakistani troops to conventional force and avoid using nuclear weapons. This trend has continued throughout other post-1998 crises, including the 2001-2002 border standoff and the response to the 2008 Mumbai attack, with Pakistan's leaders continuing to believe that their Indian counterparts would not use nuclear weapons. This appears to largely stem from the pre-nuclear crisis view that Indian leaders lacked the resolve and cost-insensitivity to retaliate against Pakistani attacks. India's nuclear doctrine focusing solely on retaliation against nuclear attacks creates a high threshold for use, encouraging low-level infiltration and state-sponsored terrorism by Pakistan due to falling below it and only meriting a conventional response at worst.

\footnotetext{
${ }^{147}$ Rory Medcalf, “India Poll 2013,” Lowy Institute, May 20, 2013, https://www.lowyinstitute.org/publications/india-poll-2013.
} 


\subsection{1: Kargil War (1999)}

The 1999 Kargil War, also known as the Kargil Crisis, is unique for being the only war fought directly by two nuclear weapon states. The trigger for India was the May 1999 discovery that 1,500-2,400 disguised Pakistani troops had taken over unoccupied Indian military posts on the Siachen Glacier in Kargil during the preceding winter. ${ }^{148}$ Vajpayee's government responded with Operation Vijay on May 7, deploying mountain brigades, artillery, and the IAF to retake the glacier and prevent further incursions over the following two months. ${ }^{149}$ At least some leaders expected further escalation, with Army Chief General V.P. Malik warning commanders on June 18 to " "be prepared for escalation... along the LoC or the international border" " or even a wider war. ${ }^{150}$ The crisis was terminated by July 26 due to the Clinton administration pressuring Prime Minister Nawaz Sharif to agree to a cease-fire and the Indian military forcing out lingering troops. ${ }^{151}$ India proved largely satisfied with the outcome, having retaken the glacier with minimal losses, though a review

committee was established to study how Pakistani forces avoided detection. ${ }^{152}$ Pakistan was dissatisfied, having been internationally condemned for using force, experienced public outrage for the humiliating loss, and generals were displeased for being blamed. ${ }^{153}$ This not only led to increased Indo-Pakistani tensions, but Sharif being overthrown in an October coup by Chief of Army Staff Pervez Musharraf.

\footnotetext{
${ }^{148}$ Kargil Review Committee, "Kargil Committee Report 1999," 96-97.

${ }^{149}$ Sunil Rao, "The Kargil Incident: Historical Analysis," Indian Historical Review 43, no. 1 (2016): 118.

${ }^{150}$ Riedel, Avoiding Armageddon, 131.

${ }^{151}$ John H. Gill, "Provocation, War and Restraint under the Nuclear Shadow: The Kargil Conflict 1999," Journal of Strategic Studies 42, no. 5 (2019): 717-718.

${ }_{152}$ P.R. Chari, Pervaiz Iqbal Cheema, and Stephen P. Cohen, Four Crises and a Peace Process: American Engagement in South Asia (Washington, DC: Brookings Institution Press, 2007), 139, 145-147.

${ }^{153}$ Kasturi, "The State of War," 150-152.
} 
The Kargil War was consistent with pre-nuclear crises in that Pakistani leaders approved the attack while believing that India would avoid using force, at least against Pakistan itself. Musharraf and other generals approved the incursion to strengthen Pakistan's defences, believing that the Indian military would be deterred from recapturing them due to the difficult terrain. ${ }^{154}$ Notably, they would have had limited insight into Indian nuclear strategy, as the only official statement was the 1998 no-first-use pledge. ${ }^{155}$ As with 1965, Pakistan's military leaders continued to believe that the Indian response would be minimal, in spite of India's armed forces having over 1.1 million active personnel and 774 combat aircraft while Pakistan had only 587,000 personnel and half as many aircraft. ${ }^{156}$ Instead, they again believed that Indian politicians and officers were too timid and preoccupied with Kashmir to do anything more than accept the loss as a fait accompli. ${ }^{157}$ Furthermore, former prime minister Benazir Bhutto claimed that Pakistan's nuclear arsenal “"[gave] the military confidence that India cannot wage a conventional war"” against them. ${ }^{158}$ This all suggests that Pakistani generals considered India's deterrent to be noncredible and that limited force would be met with a constrained response.

Evidence indicates that the Pakistani view was only partially correct, given differing views among Indian leaders. Vajpayee stated after the crisis that going into Pakistan was never off the table and that "We never thought atomic weapons would be

\footnotetext{
${ }^{154}$ Rao, "The Kargil Incident," 115.

${ }^{155}$ Kazi, "India's Nuclear Doctrine," 46.

${ }^{156}$ International Institute for Strategic Studies, “Central and South Asia," The Military Balance 99, no. 1 (1999): 161-163, 166-167.

${ }^{157}$ Gill, "Provocation, War," 706-707; Feroz Khan, Eating Grass: The Making of the Pakistani Bomb (Redwood City: Stanford University Press, 2012), 312.

${ }^{158}$ S. Paul Kapur, "Ten Years of Instability in a Nuclear South Asia," International Security 33, no. 2 (2008): 75-76.
} 
used." 159 This view was not shared by Malik, who wrote to commanders that "“nuclear weapons... will not be used in war-fighting," nor is it consistent with orders to avoid striking targets in Pakistan. ${ }^{160}$ It also contradicts reports that Vajpayee was concerned about escalation, having explicitly referred to Pakistan's arsenal when Malik warned of the risks of expanding the war. ${ }^{161}$ This lends credence to Indian leaders being self-restraining, given that the BJP was increasingly unpopular and was facing elections in September, and thus faced popular pressure for an aggressive response. ${ }^{162}$ This concern appears to have been driven by not only concerns over escalation, but world opinion as well, with Malik having claimed that Indian officials wanted to "“get international support" by demonstrating restraint in the conflict, with high commissioner to Pakistan G. Parthasarathy concurring. ${ }^{163}$

Indian restraint during the Kargil War was thus a balance between responding to the incursions to avoid a popular backlash while avoiding the potential domestic and international costs of escalating the conflict. There are, however, indications that Indian leaders believed that Pakistan was preparing nuclear weapons for possible use in the later stages of the Kargil crisis, and put their own nuclear forces on alert in response. ${ }^{164}$ While this has yet to be confirmed, Pakistan's nuclear doctrine (discussed in chapter 7) would indicate that arming nuclear weapons in response to the possibility of Indian forces crossing the LoC was plausible. This would suggest that while the Indian government wished to

\footnotetext{
${ }^{159}$ Kapur, "Ten Years of Instability in a Nuclear South Asia," 79.

${ }^{160}$ Quoted in Carranza, "Deterrence or Taboo?" 448; Chari, Cheema, and Cohen, Four Crises, 139-140.

${ }^{161}$ Narang, Nuclear Strategy in the Modern Era, 272.

162 Chari, Cheema, and Cohen, Four Crises, 141-142.

${ }^{163}$ Kapur, "Ten Years of Instability in a Nuclear South Asia," 77-78.

${ }^{164}$ Narang, Nuclear Strategy in the Modern Era, 270-271.
} 
keep the conflict limited due to the scope of the incursions and the costs of escalation, it was prepared to retaliate further if necessary.

The Kargil War demonstrates how democratic nuclear deterrence threats can fail to deter low-intensity attacks, much less limited war, due to their perceived cost-sensitivity leading other states to consider them non-credible. It is clear that Pakistani military leaders were not deterred by Indian nuclear or conventional forces, believing that India was so lacking in resolve and cost-sensitive that it would avoid retaliating against Pakistan or even simply abandon its lost positions. This view seemingly extended to nuclear deterrence, with India's arsenal being ignored despite the conditions for their use being largely unknown. These beliefs were at least somewhat correct: while India used force to retake Kargil, it avoided retaliating against Pakistan itself despite having done so in similar circumstances in 1965 and 1971. That Indian nuclear weapons were only put on alert after Pakistan had reportedly done so would further indicate that they would only be used second. This restraint was spurred by not only the potential costs of escalating the war, but concerns over losing international support. Altogether, this signifies that, as predicted, Pakistani leaders considered Indian nuclear deterrence to be non-credible in the Kargil War while anticipating limited conventional resistance at worst.

\subsection{2: Incursions into Kashmir and Terror Crises}

India and Pakistan's struggle for control of Jammu and Kashmir has not been limited to wars. Over the decades, Pakistan has sought to exploit separatist unrest and rebellion in Kashmir, most notably with Operation Gibraltar in 1965. Violence increased considerably by 1989 due to the Indian government's refusing to grant Kashmir selfdetermination and numerous human rights abuses by police and military in the region, with 
an estimated 43,000 killed between 1990 and 2011. ${ }^{165}$ This has been encouraged by the Pakistani military and the Inter-Services Intelligence (ISI), which has actively supported groups such as JeM and LeT to encourage separatism in Jammu and Kashmir with the goal of integrating them into Pakistan. ${ }^{166}$ This support has taken the form of providing equipment, funding, and training, as well as planning attacks. ${ }^{167}$ These groups serve as extensions of the Pakistani government in carrying out its policies; as discussed in chapter 3 , this makes nuclear deterrence more relevant than it would be for other non-state actors.

Two especially notable incidents of cross-border terrorism triggered major crises during 2001-2002 and 2008 and sparked concerns over a possible Indo-Pakistani war. The two crises were caused by Indian officials believing that the ISI had directed the militants and provided them with the necessary training and equipment to carry out the attacks. The Indian response to each differed: while the 2001 attacks caused a lengthy Indo-Pakistani border standoff as a form of compellence, the 2008 Mumbai attacks did not lead to such a show of force. On both occasions, the Indian government restrained itself from launching retaliatory strikes to avoid triggering Pakistani nuclear retaliation. These two crises show that, as predicted by the theory, Pakistani leaders considered Indian nuclear deterrence as irrelevant to such attacks, and believed that there would be no conventional response due to domestic politics and a fear of international backlash for escalating. This was only partially correct: while India did ultimately back down, it did so despite considerable political pressure to retaliate, with limited conventional strikes being considered in 2002 .

\footnotetext{
${ }^{165}$ Amnesty International, “'Denied': Failures in Accountability for Human Rights Violations by Security Force Personnel in Jammu and Kashmir" (London: Amnesty International, 2015), 8, https://www.amnesty.org/download/Documents/ASA2018742015ENGLISH.PDF.

${ }_{166}$ Riedel, Avoiding Armageddon, 14-16.

${ }^{167}$ Riedel, Avoiding Armageddon, 2-7.
} 
The 2001-2002 crisis was triggered by a terrorist attack on the Indian Parliament. Five men, who were later confirmed to be members of LeT and JeM, opened fire on the Parliament building on December 13 before being killed by police, with at least 12 people, including themselves, being killed. ${ }^{168}$ The attack was deemed a serious threat to national security due to Parliament having been in session, with Vajpayee declaring it to be an attack on India itself, drawing international support. ${ }^{169}$ Indian officials attributed the attack to Pakistan and demanded action be taken against LeT and JeM, with Musharraf denying government involvement and claiming a lack of evidence to avoid acting against them. ${ }^{170}$ By December $18^{\text {th }}$, Indian and US pressure led to Musharraf's government relenting and arresting fifty militants, but refusing to extradite suspects to India. ${ }^{171}$ Facing pressure from the Parliamentary opposition, Vajpayee's government mobilized roughly 800,000 troops to the international border and the LoC over three weeks, with Musharraf sending 300,000 Pakistani troops in response. ${ }^{172}$ This caused a massive military standoff at the border.

The standoff, known in India as Operation Parakram, caused concern about potential escalation to war between India and Pakistan, but ended with Indian forces unilaterally withdrawing to their traditional positions in October 2002. India's mobilization appears to have originally been political in nature, as plans to launch strikes across the border were cancelled and a commander was removed for deploying troops to battlefield

\footnotetext{
${ }^{168}$ Chari, Cheema, and Cohen, Four Crises, 149.

${ }^{169}$ Chari, Cheema, and Cohen, Four Crises, 151.

170 Sumit Ganguly and Michael R. Kraig, "The 2001-2002 Indo-Pakistani Crisis: Exposing the Limits of Coercive Diplomacy," Security Studies 14, no. 2 (2005): 289-290; Chari, Cheema, and Cohen, Four Crises, 149.

${ }^{171}$ Ganguly and Kraig, "The 2001-2002 Indo-Pakistani Crisis,” 299.

172 Ganguly and Kraig, "The 2001-2002 Indo-Pakistani Crisis," 299; Narang, Nuclear Strategy in the Modern Era, 274.
} 
positions without authorization. ${ }^{173}$ The Bush administration was sufficiently concerned, however, as to pressure Musharraf into banning LeT and JeM. ${ }^{174}$ The situation worsened with a May 14 terrorist attack on an Indian training camp that killed 32 people, which spurred Vajpayee and General Sundarajan Padmanabhan to begin planning retaliatory attacks for June, with one plan potentially splitting Pakistan in two. ${ }^{175}$ This ultimately never occurred due to the government not giving the order to cross the border or the $\mathrm{LoC}$, at least partially because the US pressured Musharraf into promising in June to permanently end militant infiltrations. ${ }^{176}$ Instead, both states continued to face off against each other until Indian forces were ordered to return to their normal deployments in October, which terminated the crisis.

The unilateral Indian withdrawal is attributable to several causes, primarily the ongoing costs of the deployment, the toll it took on domestic support, and the potential for nuclear war. Operation Parakram not only cost an estimated US\$2 billion for mobilization, but also led to travel advisories that harmed tourism and left the possibility of economic sanctions open. ${ }^{177}$ Launching strikes was potentially dangerous, given Pakistani nuclear signals such as the testing and deployment of nuclear-capable ballistic missiles in late May. ${ }^{178}$ Furthermore, former ISI Director General Javed Ashraf Qazi warned that if Pakistan was conventionally defeated, “"we will destroy them [India] by using the nuclear option," while Musharraf warned Vajpayee that they would be used if Indian troops even

\footnotetext{
${ }^{173}$ Chari, Cheema, and Cohen, Four Crises, 154.

${ }^{174}$ Ladwig, "A Cold Start for Hot Wars? The Indian Army's New Limited War Doctrine," 161-162.

${ }^{175}$ Ganguly and Kapur, India, Pakistan, 55; Narang, Nuclear Strategy in the Modern Era, 275.

${ }^{176}$ Kapur, "Ten Years of Instability in a Nuclear South Asia," 82.

177 Riedel, Avoiding Armageddon, 151.

${ }^{178}$ Narang, Nuclear Strategy in the Modern Era, 275.
} 
crossed the border. ${ }^{179}$ While Indian leaders publicly signalled they would retaliate in kind, with Minister of Defence George Fernandes warning on June 3 that "'India can survive a nuclear attack, but Pakistan cannot,"” it appears that Vajpayee, National Security Advisor Brajesh Mishra, and others wished to avoid nuclear war. ${ }^{180}$ The standoff was unsustainable for India, which was losing money and support and risked a nuclear war if it attacked.

The 2001-2002 border standoff and the Parliament attack illustrated how Indian nuclear deterrence was considered non-credible for lower-intensity conflict. The Parliament attack and other preceding incidents occurred despite Indian policy having shifted towards limited conventional retaliation against Pakistan for cross-border attacks. ${ }^{181}$ The limited Indian response to Kargil likely contributed, as Indian forces avoided crossing into Pakistan and nuclear weapons were only armed in response to Pakistan doing so. The high nuclear threshold in the 1999 draft doctrine would have further undermined nuclear credibility against such low-intensity attacks. Furthermore, Pakistani strategists likely viewed Indian mobilization as tied to upcoming state-level elections due to the BJP's increasing unpopularity, especially after the spring 2002 Gujarat riots. ${ }^{182}$ Vajpayee's government quashing plans to attack prior to May 14 and the contradiction between nuclear policy and government warnings would have only reinforced the impression that the standoff was purely political. The nuclear threats in late May suggest

\footnotetext{
${ }^{179}$ Narang, Nuclear Strategy in the Modern Era, 275; Mainichi Japan, "Interview: Ex-Pakistani Pres. Musharraf Mulled Using Nukes against India after 2001 Attack," Mainichi Daily News, July 26, 2017, https://mainichi.jp/english/articles/20170726/p2a/00m/0na/018000c.

${ }^{180}$ Michael Richardson, "Q\&A / George Fernandes: India and Pakistan Are Not 'imprudent' on Nuclear Option," The New York Times, June 3, 2002, https://www.nytimes.com/2002/06/03/news/qa-georgefernandes-india-and-pakistan-are-not-imprudent-on-nuclear.html; Narang, Nuclear Strategy in the Modern Era, 278.

${ }^{181}$ Kapur, "India and Pakistan's Unstable Peace," 148.

${ }^{182}$ Chari, Cheema, and Cohen, Four Crises, 156-158.
} 
that Musharraf had not entirely dismissed the possibility of India crossing the border. However, these domestic political factors and Vajpayee's apparent unwillingness to allow any actual retaliation suggests that Indian nuclear deterrence was a non-issue in this crisis.

The 2008 Mumbai crisis began similarly to 2001-2002, but proceeded very differently due to Indian cost-sensitivity preventing any show of force. As before, the crisis breakpoint was a major terror attack against India, with members of LeT carrying out shootings and bombings throughout Mumbai between November $26^{\text {th }}$ and $29^{\text {th }}$, killing around 163 people. The sole surviving attacker not only attributed the attacks to LeT, but claimed that the ISI had directed and supplied them. ${ }^{183}$ As before, the Pakistani government, now led by Asif al-Zardari, condemned the attacks but denied Pakistani involvement. ${ }^{184}$ Unlike in 2002, Prime Minister Manmohan Singh and the governing Congress party decided against mobilizing after studying possible retaliation with airstrikes or commando raids. ${ }^{185}$ Instead, Singh opted for diplomatic outreach to Pakistan, even when Pakistani forces went on alert in response to potential Indian mobilization. The crisis was ultimately terminated by the end of December, with Singh subsequently offering to reopen talks with Pakistan during the Summit of the Non-Aligned Movement in July 2009. ${ }^{186}$

As before, India's nuclear deterrent appears to have been non-credible against lowintensity attacks, while India was deterred from attacking targets in Pakistan in retaliation. The irrelevance of nuclear weapons to a terrorist attack, even before accounting for India's

\footnotetext{
${ }^{183}$ Riedel, Avoiding Armageddon, 5-7.

184 Jane Perlez and Salman Masood, "Pakistan Denies Any Role in Mumbai Attacks," The New York Times, November 29, 2008, https://www.nytimes.com/2008/11/30/world/asia/30pstan.html.

185 Pranab Dhal Samanta, "26/11: How India Debated a War with Pakistan That November," Indian

Express, November 26, 2010, http://archive.indianexpress.com/news/2611-how-india-debated-a-war-withpakistan-that-november/716240/0.

${ }^{186}$ Riedel, Avoiding Armageddon, 22-23.
} 
high nuclear threshold, means that the ISI elements responsible would have had little concern of serious retaliation. Furthermore, Pakistan continued to threaten using nuclear weapons in response to any conventional attack on its territory, leading the Army Chief to state in a November 29 meeting that "any strike would definitely lead to a military conflict." ${ }^{187}$ However, when Singh asked "if there was a chance Pakistan could misjudge a conventional strike by India and trigger a nuclear response," the consensus was that there was no certainty of it being recognized as a limited strike. ${ }^{188}$ Even launching airstrikes solely targeting LeT camps could have been interpreted as an act of war by Pakistan, potentially starting a nuclear war. ${ }^{189}$ Military options were further restricted by Singh making it clear "that he did not favour another Operation Parakram." ${ }^{190}$ In short, the situation was such that the attackers had little fear of a conventional or nuclear response, as India would not be able to retaliate without triggering a costly and possibly nuclear war.

What is particularly notable about the 2008 crisis is the Indian government's refusal to retaliate despite strong political pressure favouring it. The Indian public largely favoured responding with force, while the government's failure to prevent the massacres led to it being considered neglectful and incompetent. ${ }^{191}$ There was also considerable pressure to attack from Parliament, particularly the BJP, which suggested during the campaign period for the scheduled May 2009 elections that the Congress party's peaceful response would encourage further terrorism and that Singh was "weak and naïve" for using diplomacy. ${ }^{192}$

\footnotetext{
187 Samanta, "26/11."

188 Samanta, "26/11."

${ }^{189}$ Narang, Nuclear Strategy in the Modern Era, 279.

190 Samanta, "26/11."

${ }^{191}$ Raju Gopalakrishnan, "India Directs Anger at Politicians after Mumbai Attacks," Reuters, November 30, 2008, https://in.reuters.com/article/idINIndia-36786620081130.

192 Riedel, Avoiding Armageddon, 22-23.
} 
Yet despite this pressure, Singh's government continued to exercise restraint in its response, believing that costly military action with the risk of escalation would be against the national interest. ${ }^{193}$ This is indicative, as with previous crises, that the theory in this dissertation is limited by assuming that voters in a nuclear democracy will oppose actions that could lead to nuclear weapon use and not considering that the government and foreign policy elites will act as the primary restraint on their use.

These two crises, as well as broader support for cross-border attacks by elements of the Pakistani government, indicate that the theory is only partially correct regarding the inability of democratic states to use their nuclear arsenals to deter low-intensity conflict. It is clear from the triggering events for the 2001-2002 and 2008 crises that India's nuclear deterrent failed to deter Pakistan from supporting terrorism in India. This followed from the Kargil War, which showed that the Indian government would act against low-intensity within India, but restricted itself from crossing the Indo-Pakistani border due to the potential costs that could result. Yet during these two crises, there was considerable public support for the Indian government to punish Pakistan with retaliatory attacks, with Indian political leaders only being stopped by their concern over the risk of escalation and the potential response of the international community. This would suggest that while the theory proposed in this dissertation is correct in anticipating that democratic nuclear weapon states will have their deterrence threats viewed as incredible due to their cost-sensitive nature, it is not necessarily the case that these costs will be imposed by the voting public.

\footnotetext{
${ }^{193}$ Vipin Narang and Paul Staniland, "Democratic Accountability and Foreign Security Policy: Theory and Evidence from India," Security Studies 27, no. 3 (2018): 432.
} 


\section{7: Alternative Explanations}

One alternative explanation for India being the target of low-intensity and limited conflict is that it has generated security dilemmas with neighbouring states. Some crises seemingly resulted from such dilemmas: Chinese leaders believed in 1962 that the Forward Policy was meant to seize disputed territory, while Pakistani actions in 1965 and 1971 were partially motivated by concerns over the stronger Indian military. This further suggests that Pakistani support of Kashmiri militants is meant to gradually erode Indian control while avoiding a possible nuclear war. This explanation would be consistent with Chinese policy, since the 1962 war appears to have been wholly motivated by these concerns, and there have only been relatively minor border skirmishes between them since. ${ }^{194}$ It falls short for Pakistan, which dismissed Indian deterrence as bluffing both before and after nuclear weapons were introduced to the region despite India possessing the necessary capabilities. ${ }^{195}$ It also fails to explain why Pakistani governments have continued to support infiltration efforts and militant groups despite previous efforts resulting in humiliating defeats. This can be explained by Pakistani leaders believing their own nuclear arsenal is sufficient to deter India from retaliating in turn due to the ramifications of a nuclear war.

Another alternative explanation for the Pakistani government challenging India is an assumption that its allies, the US and China, would intervene in its favour. This belief has been present in pre- and post-nuclear crises due to Pakistan and China sharing a strong opposition to India and the US having provided military aid to Pakistan for decades. ${ }^{196}$ This was especially salient during the Kargil War, when Pakistan expected Chinese intervention

\footnotetext{
${ }^{194}$ Chietigj Bajpaee, “China-India: Regional Dimensions of the Bilateral Relationship,” Strategic Studies Quarterly 9, no. 4 (2015): 108-45.

195 Narang and Staniland, "Democratic Accountability."

${ }^{196}$ Ladwig, "Indian Military Modernization," 734; Cordera, "India’s Response,” 49.
} 
and was ultimately disappointed. ${ }^{197}$ This would help to explain Pakistani belligerence via a belief that the threat of allied retaliation would constrain escalation in an India-Pakistan conflict. The issue with this explanation, however, is that it does not account for the losses it has faced at lower levels of conflict with India, before those alliances would be relevant.

The final alternative explanation examined is the stability-instability paradox. The India-Pakistan dyad has been used as a practical example of the paradox, albeit a disputed one. ${ }^{198}$ India-Pakistan seemingly fits the expectation of mutual nuclear deterrence discouraging war while encouraging low-intensity violence between states, but crises from 1999 onwards have shown that the required stability is not present, nor are the two states equally deterred by nuclear war. The decision by Musharraf and other officers to send troops to infiltrate Kashmir in 1999 relied, at least in part, on India refusing to take significant action against Pakistan in return due to the fear of nuclear weapons being used against it. ${ }^{199}$ Pakistani support for the Kashmir insurgency, meanwhile, has remained largely unreciprocated by the Indian government, indicating that low-intensity conflict has, contrary to the paradox, remained one-sided. ${ }^{200}$ This would suggest that the paradox is not wholly applicable in India's case, since it assumes that both nuclear weapon states in a dyad will exploit the fear of nuclear war to engage in low-intensity conflict.

\footnotetext{
197 Riedel, Avoiding Armageddon, 132.

${ }^{198}$ For more on this debate, see S. Paul Kapur, “India and Pakistan's Unstable Peace: Why Nuclear South Asia Is Not Like Cold War Europe," International Security 30, no. 2 (2005): 127-152; Christopher J.

Watterson, "Competing Interpretations of the Stability-Instability Paradox: The Case of the Kargil War," Nonproliferation Review 24, no. 1-2 (2017): 83-99.

${ }^{199}$ Narang, Nuclear Strategy in the Modern Era, 272.

${ }^{200}$ Kapur, "India and Pakistan's Unstable Peace."
} 


\section{8: Conclusion: Restrained Deterrence, but Not From Below}

The crises studied in this chapter lend credence to H2(a)'s prediction that that India's nuclear arsenal is ineffective in deterring low-intensity armed conflict and limited wars. However, public sentiment towards nuclear weapon use was the opposite of what the theory anticipated, and appears to have played a much smaller role relative to elite preferences, suggesting that while the hypothesis was correct, the mechanism for it was not as predicted. While wars targeting India have largely abated with the introduction of nuclear weapons, Pakistani support for militant groups has not abated, nor have efforts to seize Jammu and Kashmir via salami-slicing. Security dilemmas and a belief that the US and China would step in to limit harm to Pakistan go some way in explaining this, but not entirely. Post-1998 crises show that while the Indian military was ready to respond to Pakistani aggression with retaliatory strikes or even crossing the border, they have generally been overruled by political leaders expressing concern about the potential ramifications, including international condemnation and escalation to war. Pakistani leaders, meanwhile, have consistently expressed false optimism that their provocations would meet little to no resistance due to Indian leaders being unwilling to suffer losses and thus lacking resolve. This seemingly supports the theory that defender regime type influences nuclear deterrence credibility; specifically, H2(a)'s prediction that democracies face challenges in deterring low-intensity conflict and limited war due to their perceived cost-sensitivity making the use of nuclear weapons non-credible.

Despite the findings, the chapter shows that this explanation faces shortcomings, most notably in how the Indian public views armed conflict and nuclear weapon use. Contrary to what the theory anticipated, popular sentiment in India does not oppose using 
force or nuclear weapons outside of existential crises, and in fact favours them even in lowlevel scenarios. The evidence from the three post-1998 crises studied in this chapter shows that India has avoided using force against Pakistani territory not because of public pressure, but rather because Indian political and military elites have recognized the potential dangers. This suggests that Indian governments have resisted using force in crises or imposed limitations less out of concern over how the public would react and more to prevent escalation to general war and avoid international punishment. This is somewhat similar to what was established with Israel in the previous chapter, albeit due to general public disinterest in foreign issues rather than deliberate obfuscation in some areas. Furthermore, the government still remains accountable to a greater extent than Israel, and very much unlike Pakistan and North Korea. Nevertheless, this chapter demonstrates that even the perception that the Indian government is unwilling to endure the costs of conflict is sufficient to encourage continued armed attacks against it. 


\section{Chapter 7: Pakistan}

\section{1: Introduction}

Pakistan is unique among the states studied in this dissertation for fluctuating between military dictatorship and flawed democracy since independence in 1947. Even in nominally democratic periods, Pakistan's civilian leaders are subject to heavy military influence due to generals threatening to remove uncooperative officials or even launch coups supported by military-aligned bureaucrats and wealthy landowners. ${ }^{1}$ Pakistan's foreign relations are primarily defined by hostilities with India: during the studied 19472018 period, it initiated four wars and supported several terrorist attacks targeting India, as well as developing nuclear weapons to deter perceived Indian aggression. ${ }^{2}$ Pakistan's leadership being functionally unaccountable to citizens and prioritizing the interests of elite supporters means that it differs significantly from Israel and India and has more in common with North Korea. While Israeli and Indian decision-makers have been constrained in crises by how their citizens would be affected, Pakistani decisions have largely focused on the interests of civilian and military elites.

This chapter studies whether the Pakistani government's apparent conflict costinsensitivity and its relative lack of accountability makes its nuclear deterrence threats more credible. It begins by evaluating Pakistan's regime type, how it has shifted over time, and the military's role in governance to determine what domestic audiences the government responds to. Major crises from Pakistan's pre-nuclear period (1947-1998) are

\footnotetext{
${ }^{1}$ Kunal Mukherjee, "Why Has Democracy Been Less Successful in Pakistan Than in India?," Asian Affairs 41, no. 1 (2010): 72.

2 Samina Ahmed, "Pakistan's Nuclear Weapons Program: Turning Points and Nuclear Choices," International Security 23, no. 4 (1999): 178-204.
} 
then studied, with a particular focus on the three Indo-Pakistani Wars (1947-1949; 1965, 1971) and subsequent border crises, as well as the decisions made by Pakistani and Indian leaders. The rationale for Pakistan's nuclear deterrent, particularly the humiliating losses to India in 1965 and 1971, India's 1974 nuclear test, and the gap in their conventional capabilities, is subsequently examined, along with Pakistan's nuclear doctrine and command and control structure. Post-nuclear crises (1998-2018) are then studied, focusing on the 1999 Kargil War, the 2001-2002 border standoff, and the 2008 Mumbai crisis and how Pakistan's nuclear deterrent factored into Indian and Pakistani decisions. Finally, potential alternative explanations for why India has not attacked Pakistan since the latter's development of nuclear weapons are studied, such as its ties with the US and China.

The findings of this chapter support hypothesis H2(b), which argued that nondemocracies like Pakistan will suffer few, if any, low-intensity armed attacks or limited wars due to nuclear deterrence credibility being bolstered by the government's lack of accountability making it appear insensitive to the costs of fulfilling them. The shift in Pakistani deterrence pre- and post-1998 is stark: while the 1965 and 1971 Indo-Pakistani Wars saw India respond by counter-invading Pakistan, post-1998 aggression was not met with a similar response. This was already apparent when Pakistan was only a de facto nuclear weapon state during the 1986-87 Brasstacks crisis, with the standoff between India and Pakistan ending peacefully following warnings that Pakistan was willing to use nuclear weapons. ${ }^{3}$ Evidence from post-1998 crises makes it clear that Indian leaders considered Pakistani nuclear threats credible, believing that any attack against Pakistani territory could trigger a nuclear war. This is most apparent with the 2001-2002 border standoff, when Atal

\footnotetext{
${ }^{3}$ Kuldip Nayar, "We Have the A-Bomb, Says Pakistan's 'Dr Strangelove," The Observer, March 1, 1987.
} 
Bihari Vajpayee's government refrained from attacking after multiple warnings of nuclear retaliation, including by Pakistani President Pervez Musharraf. ${ }^{4}$ Notably, Pakistan's alliances with the US and China appear to have little impact given their reluctance to directly support it in crises.

Pakistan's nuclear deterrence threats are credible to India, despite their extreme nature, due to Pakistani military dominance, a history of cost-insensitive behaviour, a conventional military balance favoring India, and explicit Pakistani warnings of nuclear first use. Altogether, these make it appear that Pakistani generals are willing to use nuclear weapons against Indian incursions regardless of civilian decisions, the impact on their citizens, or even the actual threat posed by India. India's conventional advantage and a widespread belief that it seeks to destroy Pakistan means that any Indian attack is considered a potential existential threat, making nuclear weapon use appear even more credible. Indian civilian and military leaders have thus become reluctant to respond to Pakistani provocations beyond shows of force for fear of unintentionally provoking nuclear war. The February 2019 airstrikes by Narendra Modi's government against a terrorist training camp in Pakistan, while beyond this dissertation's scope, suggest that Indian leaders are increasingly willing to test these threats, but so far remains a unique incident. ${ }^{5}$ As the chapter shows, this lends credence to H2(b)'s claim of non-democracies more credibly threatening nuclear retaliation and, by extension, the theory that state regime type influences nuclear deterrence credibility.

\footnotetext{
${ }^{4}$ Vipin Narang, Nuclear Strategy in the Modern Era: Regional Powers and International Conflict (Princeton: Princeton University Press, 2014), 275.

${ }^{5}$ Suhasini Haidar and Dinakar Peri, "India Bombs Jaish Camp in Pakistan's Balakot," The Hindu, February 26, 2019, https://www.thehindu.com/news/national/air-strikes-hit-balakot-in-pakistan-initial-assessment100-hit-sources/article26373318.ece.
} 


\section{2: Shifting between Anocracy and Autocracy: Evaluating Pakistani Governance}

Pakistan stands out among the nuclear weapon states studied in this dissertation due to the relative instability of its government throughout its history. Since gaining independence in 1947, it has shifted between being a flawed democracy, an anocracy, and an outright military dictatorship. The only two constants during its history have been the existence of civilian government institutions, whose actual importance varies, and the Pakistan Armed Forces (PAF) openly or covertly exercising control of governance. Pakistan's government has thus shifted between appealing to voters and suppressing them, but consistently satisfies the demands of military leaders, bureaucrats, and wealth landowners.

Evaluations by democracy indices further underscore the volatility of Pakistani governance. The Polity 5 Project's overall score for Pakistan has shifted between -7 and +8 on a 21-point scale throughout its history, as shown in Figure 7.1, capturing both military rule and episodes of democratic governance. ${ }^{6}$ The Economist Intelligence Unit's Democracy Index is more critical, typically ranking Pakistan around $104^{\text {th }}$ to $112^{\text {th }}$ of the 167 states evaluated and explicitly categorizing it as a hybrid regime. ${ }^{7}$ Freedom House's Freedom in the World index reaches a similar conclusion, noting Pakistan as "Partly Free" due to its multiparty system being marred by the military's influence, extralegal uses of

\footnotetext{
${ }^{6}$ Center for Systemic Peace, "Polity 5 Annual Time-Series, 1946-2018," Center for Systemic Peace, April 23, 2020, http://www.systemicpeace.org/inscr/p5v2018.xls.

${ }^{7}$ Economist Intelligence Unit, Democracy Index 2013: Democracy in Limbo (London: Economist Intelligence Unit, 2014), 6, http://www.eiu.com/Handlers/WhitepaperHandler.ashx?fi=Democracy Index 2013 WEB2.pdf\&mode=wp\&campaignid=Democracy0814; Economist Intelligence Unit, Democracy Index 2018: Me Too? Political Participation, Protest and Democracy (London: Economist Intelligence Unit, 2019), 39, http://www.eiu.com/public/thankyou_download.aspx?activity=download\&campaignid=Democracy2018.
} 
forces, and restricted civil liberties. ${ }^{8}$ The overall consensus is that while Pakistan is not sufficiently repressive to meet the criteria for authoritarianism, military dominance and limited freedoms prevent it from being considered fully democratic.

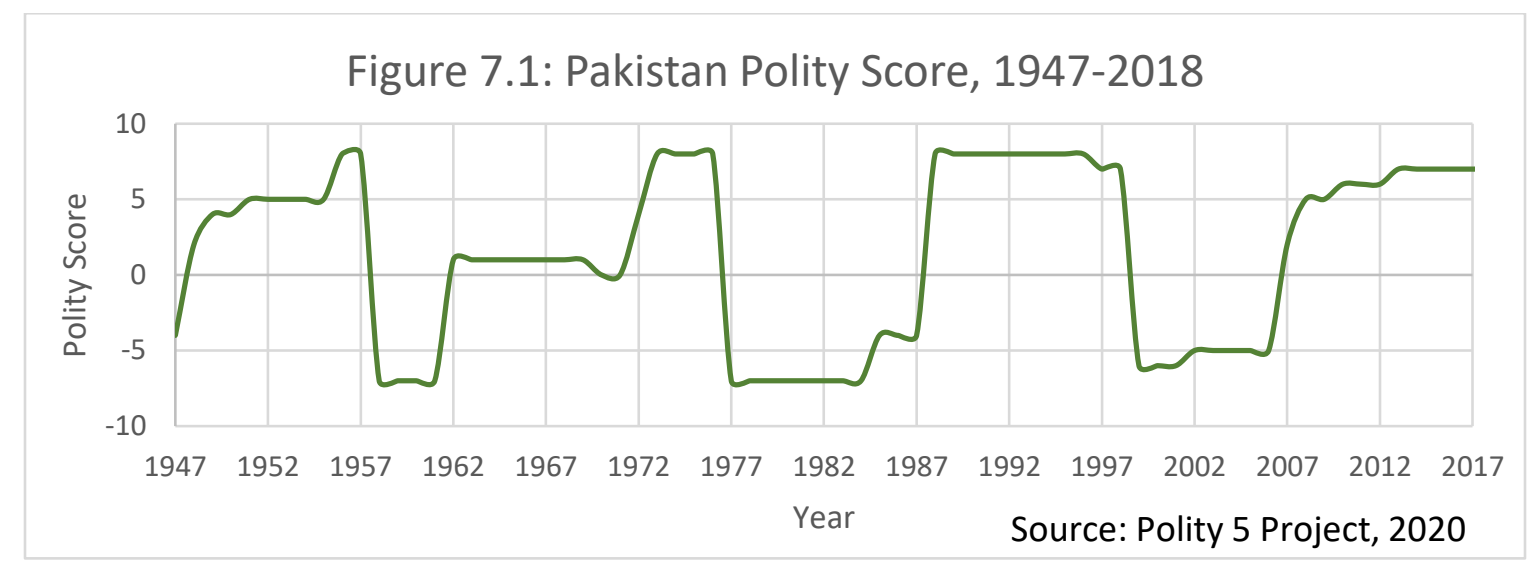

Pakistan is nominally a democracy with a presidential bicameral system, though actual democratic practices are limited. The 1947 Pakistani constitution gave the governorgeneral various emergency powers, including unilaterally firing the Cabinet, calling new elections, and removing regional governments, which have persisted through constitutional revisions and a shift to a presidential system. ${ }^{9}$ The continued influence of the PAF leadership means that few elected governments have served a full term or even transitioned to an elected successor. ${ }^{10}$ This is most apparent in the 1988-1999 period: while ostensibly democratic, four general elections were held over the decade due to military leaders forcing

\footnotetext{
${ }^{8}$ Freedom House, "Freedom in the World 2018: Pakistan," Freedom House, January 5, 2018, https://freedomhouse.org/report/freedom-world/2018/pakistan.

${ }^{9}$ Aqil Shah, "Constraining Consolidation: Military Politics and Democracy in Pakistan (2007-2013)," Democratization 21, no. 6 (2014): 1010.

${ }^{10}$ This bears some similarity to the Indian constitution, which also allows for the use of emergency powers, though as discussed in chapter 6, these have been used much less extensively than in Pakistan apart from the 1975-1977 Emergency. Ajay Darshan Behera, "Pakistan General Elections 2018: Clear Signs of a Guided Democracy," International Studies 55, no. 3 (2018): 238-239.
} 
the president to dismiss the government. ${ }^{11}$ This democratic period ended with Nawaz Sharif being overthrown and exiled in an October 1999 coup by Chief of Staff Pervez Musharraf, who subsequently declared himself president and ruled until 2008. The first successful electoral transition only occurred in 2013, when Asif Ali Zardari's Pakistan Peoples' Party (PPP) was succeeded by Nawaz Sharif’s Pakistan Muslim League (PML-N), followed by Imran Khan's Pakistan Tehreek-e-Insaf (PTI) in 2018. ${ }^{12}$

Pakistan governance has been further undermined by the brevity of governments and other issues encouraging widespread corruption. Frequent government turnover incentivizes politicians to use their positions for rent-seeking before inevitably being removed from office, while opposition members are encouraged to use extra-constitutional means, including military support, to force early elections to seize power. ${ }^{13}$ Landowners wield considerable political influence due to their importance in farming and real estate, allowing them to lobby against and block various reforms in order to avoid paying taxes and encourage further rent-seeking. ${ }^{14}$ This is a consequence of the preservation of the preindependence feudal system by landlords who joined the Muslim League early on to preserve their power. ${ }^{15}$ Finally, Pakistan's bureaucracy is highly corrupt, with civil servants often working alongside landowners and the military to stymie reforms and avoid enforcing

\footnotetext{
${ }^{11}$ Michael Hoffman, "Military Extrication and Temporary Democracy: The Case of Pakistan," Democratization 18, no. 1 (2011): 89; Katharine Adeney, "How to Understand Pakistan's Hybrid Regime: The Importance of a Multidimensional Continuum," Democratization 24, no. 1 (2017): 121.

${ }^{12}$ Behera, "Pakistan General Elections 2018," 238-239.

${ }^{13}$ C. Christine Fair, "Why the Pakistan Army Is Here to Stay: Prospects for Civilian Governance," International Affairs 87, no. 3 (2011): 576.

${ }^{14}$ Ian Talbot, Pakistan: A New History (London: Hurst \& Company, 2012), 32.

${ }^{15}$ Stephen Philip Cohen, The Idea of Pakistan (New York: Brookings Institution Press, 2004), 56.
} 
laws in order to enrich themselves. ${ }^{16}$ Endemic corruption means that Pakistani democracy remains highly flawed, with most officials being focused on short-term gains.

\subsection{1: Military Dictatorship (1958-1971; 1977-1988; 1999-2008)}

The PAF has consistently dominated Pakistani governance, but on three occasions went so far as to rule directly via military dictatorship. The first of these (1958-1971) saw General Mohammed Ayub Khan seize power in a coup and establish a Basic Democracy system that ensured he would win $95 \%$ of the popular vote while maintaining martial law. ${ }^{17}$ He also suppressed potential opposition by banning political parties until 1962 and using the Public Offices Order to ban specific individuals from serving in office. ${ }^{18}$ Popular protests and Pakistan's loss in the 1965 Indo-Pakistani War led to Ayub Khan being overthrown in a 1969 coup by Commander-in-Chief Muhammed Yahya Khan, who allowed Pakistan's first elections since independence in 1970 while maintaining martial law. ${ }^{19}$ The East Pakistan-based Awami League's victory over Zulfikar Ali Bhutto's PPP led to Operation Searchlight in March 1971, which killed thousands and ultimately provoked the Third Indo-Pakistani War in December. ${ }^{20}$ The resulting loss and dismemberment of Pakistan forced Yahya Khan to step down, with Bhutto becoming president on December 20 and ending martial law by April 1972.

The second military dictatorship (1977-1988) was the result of Chief of Army Staff Mohammed Zia-ul-Haq launching another coup. Bhutto was arrested on July 5 after

\footnotetext{
${ }^{16}$ Cohen, The Idea of Pakistan, 258.

${ }^{17}$ Kunal Mukherjee, “Ayub Khan's Basic Democracy and Political Continuity in Contemporary Pakistan," India Quarterly 72, no. 3 (2016): 272.

18 Talbot, A New History, 77.

${ }^{19}$ Mukherjee, "Why Has Democracy Been Less Successful," 73.

${ }^{20}$ T.V. Paul, The Warrior State: Pakistan in the Contemporary World (Oxford: Oxford University Press, 2014), 51; Julian Schofield, "Militarized Decision-Making for War in Pakistan: 1947-1971," Armed Forces \& Society 27, no. 1 (2000): 141-142.
} 
opponents called for his removal, and was executed in April 1979 for having a political opponent killed. ${ }^{21}$ After declaring himself president, Zia restructured the government into a semi-presidential system with executive powers such as unilaterally appointing military service chiefs and dismissing the prime minister and other officials. ${ }^{22}$ Political parties were prohibited to prevent an opposition from forming, which was further aided by Zia allying with Islamist groups like Jamaat-e-Islami (JEI) to develop political legitimacy and mandating that newspapers obtain approval from censors to publish. ${ }^{23}$ State corporations and government offices were dominated by military officers who were actively encouraged to engage in rent-seeking. ${ }^{24}$ Zia's rule only ended with his sudden death in an August 1988 plane crash, with his successor Ghulam Ishaq Khan giving somewhat freer reign to the PPP government and Prime Minister Benazir Bhutto.

The most recent period of military rule (1999-2008) was the result of Musharraf ousting Sharif in a coup. Musharraf, who had clashed with Sharif after directing the Kargil War, exiled his predecessor in October 1999 and declared himself president. ${ }^{25}$ The 2002 elections were notably rigged in Musharraf's favor with polling station irregularities, officials being required to hold degrees or madrassah-issued certifications, and a two-term limit on the office of prime minister to prevent Sharif and Bhutto from running. ${ }^{26}$ Musharraf subsequently had the National Accountability Bureau investigate political opponents and implemented sedition laws to restrict freedom of association and ban

\footnotetext{
${ }^{21}$ Paul, The Warrior State, 54.

22 Vali Nasr, "Military Rule, Islamism and Democracy in Pakistan," The Middle East Journal 58, no. 2 (2004): 196; Shah, "Constraining Consolidation," 1012.

${ }^{23}$ Vali Nasr, "Military Rule, Islamism and Democracy in Pakistan," The Middle East Journal 58, no. 2 (2004): 196.

${ }^{24}$ Talbot, A New History, 135-136.

${ }^{25}$ Adeney, "How to Understand Pakistan,"119.

${ }^{26}$ Nasr, "Military Rule," 202; Shah, "Constraining Consolidation," 1013.
} 
political rallies. ${ }^{27}$ The Inter-Services Intelligence (ISI) also monitored journalists, with those covering politically sensitive issues being at risk of being assaulted, tortured, or killed. ${ }^{28}$ Musharraf's rule was ultimately ended by his efforts to arrest Supreme Court Justices after a November 2007 ruling that he was ineligible as a presidential candidate, sparking mass protests. ${ }^{29}$ Facing impeachment and having lost military support due to pressure from junior officers and the US, Musharraf resigned and fled Pakistan on August 18. ${ }^{30}$ Military influence over government has since declined somewhat, but remains significant, if less overt than previously.

Though Pakistani military governments have been repressive, democratic governments have used similar tactics to stay in office. Zulfikar Ali Bhutto's government was initially popular in December 1971, but used increasingly authoritarian tactics to retain power, including maintaining press censorship, banning the National Awami Party, cracking down on protestors, and allegedly rigging the 1977 general election. ${ }^{31}$ Both Benazir Bhutto and Nawaz Sharif used political appointments to benefit themselves and their supporters, such as appointing party loyalists to the judiciary to ensure favorable legal rulings. ${ }^{32}$ More recently, Imran Khan's government has been accused of working so closely with the military that it has been described as "a pseudodemocratic façade," having apparently taken cues from the PAF leadership in implementing domestic and foreign policy. ${ }^{33}$ This last point, however, is hardly a new one: as the following subsection makes

\footnotetext{
27 Talbot, A New History, 181.

${ }^{28}$ Ganguly and Fair, "Structural Origins," 135-136.

${ }^{29}$ Shah, "Constraining Consolidation," 1014-1015.

${ }^{30}$ Shah, "Constraining Consolidation," 1015.

${ }^{31}$ Talbot, A New History, 103; Riedel, Avoiding Armageddon, 83.

32 Talbot, $A$ New History, 145.

${ }^{33}$ Aqil Shah, "Pakistan: Voting Under Military Tutelage," Journal of Democracy 30, no. 1 (2019): 141.
} 
clear, the Pakistani military wields significant power in government even when it is not officially leading the state.

\subsection{2: The Role of the Military}

The periods of military rule and the PAF's continued influence over civilian governance highlights that it is the single most powerful institution in Pakistan. This dates back to the 1947 Partition, as the British Indian Army battalions that served as the basis for the PAF were the only established administrative units in the area, and began actively interfering in politics as early as a failed 1951 coup against Prime Minister Liaquat Ali Khan. ${ }^{34}$ Military influence only grew from there: in August 1953, Prime Minister Mohammad Ali Bogra stated that " "he would much rather starve the country than allow any weakening of its defense," and by $1957,60 \%$ of the budget was spent on defence. ${ }^{35}$ Subsequent governments have maintained high defence spending and deference to the military: those that have attempted to interfere with military affairs, such as Benazir Bhutto, have been forced out of office or worse. ${ }^{36}$ Independent estimates by the Stockholm Institute of Peace Research (SIPRI) indicate that military spending increased from US\$209 million in 1960 to approximately US\$12.7 billion in 2018, consistently remaining between 3-7\% of Pakistani GDP, though Indian defence spending has remained greater despite being a smaller proportion of GDP. ${ }^{37}$ In essence, Pakistan's military elite has been able to direct

\footnotetext{
${ }^{34}$ Mukherjee, "Why Has Democracy Been Less Successful," 70; Zillur R. Khan, "Civil-Military Relations and Nuclearization of India and Pakistan," World Affairs 166, no. 1 (2003): 26.

${ }^{35}$ Paul, The Warrior State, 46; Shah, "Constraining Consolidation," 1010.

${ }^{36}$ H-A. Rizvi, "Civil-Military Relations in Contemporary Pakistan," Survival 40, no. 2 (1998): 102.

${ }^{37}$ Dollar amounts are in constant 2017 USD. See Stockholm International Peace Research Institute, "SIPRI Military Expenditure Database 2019,” 2019, accessed February 20, 2019, https://www.sipri.org/databases/milex.
} 
the country's politics to benefit their interests and their supporters with the threat of punishing detractors.

Outside of direct military rule, the PAF has largely embraced disguised rule to protect its interests and those of its supporters. While Pakistan is nominally a civiliangoverned state, it is still directed by the military, albeit indirectly. ${ }^{38}$ This mostly involves pressuring civilian officials to avoid encroaching in its policy fiefdoms, such as defence and relations with India. ${ }^{39}$ Some steps to assert some civilian control, such as creating a Parliamentary Committee on National Security in 2013, have been taken by legislators, but still rely on military consent. ${ }^{40}$ This influence is further extended by many retired officers running military-owned corporations, entering the civil service, or receiving ambassadorial appointments, which also ensures their loyalty with the promise of a reward. ${ }^{41}$ The Pakistani military also works to control public discussion of defence issues, with openly critical journalists risking ostracism or even being charged with treason, which occurred to Dawn assistant editor Cyril Almeida 2018 for his criticism of the handling of the 2008 Mumbai crisis. ${ }^{42}$ Academics who contradict state and military policy in their work are unlikely to be published, and are often overlooked in favor of former military officers. ${ }^{43} \mathrm{In}$ essence, the PAF wields considerable influence even when not overtly ruling Pakistan.

Pakistan's military has further established control over domestic security and other policy areas via the ISI. The ISI is often described as "a state within a state" due to acting

\footnotetext{
${ }^{38}$ Paul Staniland, Adnan Naseemullah, and Ahsan Butt, "Pakistan's Military Elite," Journal of Strategic Studies (2018), 1-30.

${ }^{39}$ Adeney, "How to Understand Pakistan," 127-128.

${ }^{40}$ Shah, "Constraining Consolidation," 1020.

${ }^{41}$ Staniland, Naseemullah, and Butt, "Pakistan's Military Elite," 1-2.

${ }^{42}$ Sannia Abdullah, "Nuclear Ethics? Why Pakistan Has Not Used Nuclear Weapons ... Yet," The

Washington Quarterly 41, no. 4 (2018): 165.

${ }^{43}$ Abdullah, "Nuclear Ethics," 165.
} 
independently from civilian authority in favor of the military and its own objectives. ${ }^{44}$ Though the ISI nominally answers to the prime minister, it is a military agency in all but name, traditionally being directed by a lieutenant-general and staffed by active-duty officers. ${ }^{45}$ The ISI's independence is most readily apparent in its directing and supporting militant groups like JEI and Lashkar-e-Taiba (LET) to indirectly combat India in Kashmir, even when ordered not to. ${ }^{46}$ It also interferes in domestic politics, such as working with PML allies in the 1988 election to prevent a PPP majority government and ensure Sharif succeeded Bhutto after her dismissal in $1990 .{ }^{47}$ The ISI is also alleged to have pressured judges into giving specific verdicts in cases, including the 2017 corruption case that led to Sharif's lifetime ban from Pakistani politics. ${ }^{48}$ The ISI thus serves as an additional tool for military leaders to exercise control over Pakistan's government and society.

The Pakistani military's influence over governance has gradually become more covert. This is partially due to the 2010 passage of the $18^{\text {th }}$ Amendment to Pakistan's Constitution, which prevents the president from unilaterally dissolving Parliament or firing the prime minister. ${ }^{49}$ This removed one of the main tools for Pakistani generals to remove prime ministers, as Chief of Army Staff Mirza Aslam Beg pushed Ishaq Khan to dismiss Bhutto in 1990 and Sharif in $1992 .{ }^{50}$ Musharraf's 2008 resignation was followed by Chief of Army Staff Ashfaq Parvez Kayani limiting military involvement in politics by banning officers from contacting politicians, removing them from civil service positions, and

\footnotetext{
${ }^{44}$ Staniland, Naseemullah, and Butt, "Pakistan's Military Elite," 25.

${ }^{45}$ Shah, "Constraining Consolidation," 1021.

${ }^{46}$ Riedel, Avoiding Armageddon, 109; Cohen, The Idea of Pakistan, 100.

${ }^{47}$ Hoffman, "Military Extrication and Temporary Democracy," 79.

${ }^{48}$ Behera, "Pakistan General Election 2018," 241.

${ }^{49}$ Adeney, "How to Understand Pakistan," 129.

${ }^{50}$ Rizvi, "Civil-military relations," 102-103, 106.
} 
ordering the ISI to cease domestic political interference. ${ }^{51}$ This did not mean military influence ended: Kayani himself stated in 2008 that "military interventions are sometimes necessary to maintain Pakistan's stability," and generals often clashed with Sharif before pressing the Supreme Court to remove him from office in $2017 .{ }^{52}$ The ISI is also believed to have interfered in the July 2018 election to ensure Imran Khan's Tehreek-e-Insaf party won due to Khan's past statements supporting military intervention. ${ }^{53}$ Thus, any reduction of military influence over Pakistan's government appears to be superficial at most.

Despite the Pakistani military's efforts to subvert civilian rule towards its own purposes, it retains considerable public support. As with the military's influence as a whole, this can be traced back to its role in protecting and settling refugees from India during Partition. ${ }^{54}$ The perceived existential threat of India, which is commonly viewed as refusing to recognize Pakistan and seeking its annexation, has helped the military's image as the defender of the state, and it has become associated with vital services like education, health care, and infrastructure. ${ }^{55}$ Civilian authorities, in contrast, are considered to be comparatively corrupt and ineffective, which has been used to justify military intervention. ${ }^{56}$ An April 2009 survey, for example, indicates that only $20 \%$ of respondents thought the military should not be able to control Pakistan at all, while $60 \%$ favoured the chief of army staff directing the military over the president or prime minister. ${ }^{57}$ A May 2011 Gallup survey, meanwhile, indicated that $78 \%$ of Pakistanis have confidence in the

\footnotetext{
${ }^{51}$ Shah, "Constraining Consolidation," 1016.

52 Shah, "Constraining Consolidation," 1017; Behera, "Pakistan General Elections 2018," 239.

${ }^{53}$ Behera, "Pakistan General Elections 2018," 239, 246; Shah, "Voting Under Military Tutelage," 128.

${ }^{54}$ Hoffman, "Military Extrication and Temporary Democracy," 83.

${ }^{55}$ Fair, "Why the Pakistan Army Is Here to Stay," 573; Paul, The Warrior State, 86.

${ }^{56}$ Cohen, The Idea of Pakistan, 128.

${ }^{57}$ Fair, "Why the Pakistan Army Is Here to Stay," 575.
} 
military, placing it far above the judicial system, police, and national government. ${ }^{58}$ This suggests that despite some dissatisfaction, the Pakistani public continues to favour the military as a ruling institution over elected civilian leaders.

\section{3: Ready to Wage "“general and total war": Pakistani Pre-Nuclear Crises and}

\section{Conflicts}

Pakistan has been involved in several pre-nuclear crises, primarily revolving arounds its clashes with India for control of Jammu and Kashmir. The most prominent crises are the three Indo-Pakistani Wars $(1947-1949 ; 1965 ; 1971)$ and the Brasstacks border standoff (1986-1987). Though Pakistan initiated these crises, all three IndoPakistani Wars saw India launch counter-offensives into Pakistan-controlled Kashmir or within Pakistan's borders. Evidence indicates that India's willingness to attack Pakistan was enabled by its greater conventional strength in the 1965 and 1971 wars and Indian leaders considering it necessary to resolve these crises. The Brasstacks crisis, in contrast, saw both sides engage in diplomacy and ultimately agree to disengage by February 1987, with India's reluctance to escalate the situation being attributable to a fear of instigating a war and the possibility that Pakistan possessed nuclear weapons. These crises thus demonstrate that pre-nuclear Pakistan was unable to deter Indian attacks, with the Indian government's own cost sensitivity being the main source of restraint.

\subsection{1: Indo-Pakistani Wars}

The first Indo-Pakistani War (1947-1949) was caused by Indian and Pakistani disputes over which had greater claim to the then-independent state of Jammu and

\footnotetext{
${ }^{58}$ Nicole Naurath and Julie Ray, "Pakistanis Still Rate Military Tops Among National Institutions," Gallup, July 29, 2011, https://news.gallup.com/poll/148709/Pakistanis-Rate-Military-Tops-Among-NationalInstitutions.aspx.
} 
Kashmir. The crisis was only triggered by Pakistani Prime Minister Liaquat Ali Khan choosing to support a tribal rebellion on October 22, 1947, spurring Maharaja Hari Singh to have the state join India in exchange for military support by October $26 .{ }^{59}$ The conflict escalated further in February 1948 after Indian forces launched a counter-offensive into tribal-controlled west Kashmir after defending the state capital of Srinagar. ${ }^{60}$ Pakistani leaders, particularly Governor-General Muhammad Ali Jinnah, and military officers who originally opposed the war then moved to directly support the irregulars, culminating in an attack on the Indian city of Poonch on March $17 .{ }^{61}$ Fighting continued throughout 1948 and only ended when Pakistan accepted a UN-brokered and India-supported ceasefire on December 31, establishing a cease-fire line between Pakistan-controlled Azad Kashmir and the state of Jammu and Kashmir. ${ }^{62}$ Pakistan's leaders and their successors were displeased by the outcome, with future crises arising from their desire to control the entire state and the need to counter the apparent threat India posed.

Pakistan avoided being directly attacked during the First Indo-Pakistani War, though this is attributable more to Prime Minister Jawaharlal Nehru's concerns about the cost to India than Pakistan's capabilities. Following Partition, India possessed most of the region's British military infrastructure, including bases and factories, whereas Pakistani armed forces were "barely in existence" by May $1948 .{ }^{63}$ Despite this conventional advantage, communications between American diplomats and officials like Commander-

\footnotetext{
${ }^{59}$ Sumit Ganguly and S. Paul Kapur, India, Pakistan, and the Bomb: Debating Nuclear Stability in South Asia (New York: Columbia University Press, 2010), 12.

${ }^{60}$ Michael Brecher and Jonathan Wilkenfeld, A Study of Crisis (Ann Arbor: University of Michigan Press, 1997), 167.

${ }^{61}$ Brecher and Wilkenfeld, A Study of Crisis, 167; Schofield, "Militarized Decision-Making," 136-137.

${ }^{62}$ Paul, The Warrior State, 43.

${ }^{63}$ Paul, The Warrior State, 42; Victoria Schofield, Kashmir in Conflict: India, Pakistan and the Unfinished War (London: I.B. Tauris, 2000), 65.
} 
in-Chief General Roy Bucher indicate there were no preparations to go on the offensive. ${ }^{64}$ Nehru's government was instead kept from attacking Azad Kashmir by a lack of political will, as officials believed it required expanding the scope of the conflict to force Jinnah and Ali Khan to stop supporting insurgents. ${ }^{65}$ This would have been extraordinarily costly for India, which was still consolidating authority over state-level governments and would have had difficulty in sustaining a war with Pakistan since, as Deputy Prime Minister Sardar Patel wrote, "'our military resources are strained to the utmost." "66 Nehru thus pushed for the UN ceasefire as early as January 1948 to avert further fighting. ${ }^{67}$ Pakistani deterrence in 1948 was mixed: while it avoided direct attack, it was due more to Indian domestic concerns than Pakistan's own military strength and credibility.

The Second Indo-Pakistani War (1965) further demonstrated Pakistan's inability to deter India from attacking it directly. The crisis was caused by Pakistani leaders interpreting their Indian counterparts' lackluster efforts in defending the Rann of Kutch in May 1965 as a sign that they would be unwilling to endure costs to retain Kashmir. ${ }^{68}$ Indian Prime Minister Lal Bahadur Shastri warned in April 1965 that “"our army will defend the country" against Pakistani aggression, with Ayub Khan retorting on May 1 that Shastri was “"reckless and provocative"” and that Pakistan was ready to fight “"a general and total war." ${ }^{69}$ Ayub Khan's government subsequently launched Operation Gibraltar on August

\footnotetext{
${ }^{64}$ Office of the Historian, "207. Telegram: The Chargé in India (Donovan) to the Secretary of State," January 2, 1948, Foreign Relations of the United States, 1948, The Near East, South Asia, and Africa, Volume V, Part 1, United States Department of State, https://history.state.gov/historicaldocuments/frus1948v05p1/d207.

${ }^{65}$ Sumit Ganguly, Conflict Unending: India-Pakistan Tensions Since 1947 (New York: Columbia University Press, 2001), 18-19.

${ }^{66}$ Schofield, Kashmir in Conflict, 66.

${ }^{67}$ Ganguly, Conflict Unending, 18-19

${ }^{68}$ Rudra Chaudhuri, “'Just Another Border Incident': The Rann of Kutch and the 1965 India-Pakistan War," Journal of Strategic Studies 42, no. 5 (2019): 654.

${ }^{69}$ Ganguly, Conflict Unending, 39.
} 
9, but the 5,000 disguised soldiers sent to foment a Kashmiri uprising were quickly turned over to the police, spurring Shastri to deploy the Indian Army. ${ }^{70}$ As explained in chapter 6, Ayub Khan chose to persist with the follow-up invasion of Kashmir, Operation Grand Slam, on September 1 despite Gibraltar's failure. ${ }^{71}$ This was apparently done in the belief that, as with the Rann of Kutch incident, Shastri's government would be too cost-averse to resist.

Instead, Shastri's government not only acted to defend Kashmir, but even launched a counter-offensive into Pakistan. The Indian military launched a two-pronged attack, sending troops to the Punjabi city of Sialkot on September 6 and besieging Lahore, then the capital of West Pakistan, by September 13. ${ }^{72}$ Accounts indicate that Ayub Khan and other leaders responsible for planning the war, such as then-Foreign Secretary Zulfikar Ali Bhutto, did not expect Indian forces to cross the border. ${ }^{73}$ One of the main driving factors behind Operations Gibraltar and Grand Slam was the belief among Pakistani civilian and military leaders that India's loss in the Sino-Indian War had left its government unwilling to endure losses to defend territory. ${ }^{74}$ Instead, Shastri's government proved itself willing to escalate to force Pakistan to back down, believing that striking Pakistan directly would end the war quickly and deter future attacks. ${ }^{75}$ The siege of Lahore forced Ayub Khan to withdraw troops from Kashmir and agree to a UN ceasefire by September 23, with the status quo being restored by the Tashkent Agreement on January 10, $1966 .^{76}$ The

\footnotetext{
${ }^{70}$ Khan, Nuclear Weapons and Conflict Transformation, 67.

${ }^{71}$ Paul, The Warrior State, 48-49.

${ }^{72}$ Ganguly, Conflict Unending, 44.

${ }^{73}$ Ganguly, Conflict Unending, 48.

${ }^{74}$ Schofield, "Militarized Decision-Making," 140.

${ }^{75}$ Schofield, "Militarized Decision-Making," 140.

${ }^{76}$ Paul, The Warrior State, 48-49.
} 
humiliation of the loss led to Ayub Khan being overthrown by his own Army Chief, Yahya Khan, in March 1969.

What led Shastri and his government to order Indian forces to cross the international border in 1965? Government meetings in early September indicate that while they were sensitive to costs, a counter-invasion was deemed necessary. A September 3 Cabinet meeting had Shastri outline the government's objectives: "To defeat the Pakistani attempt to seize Kashmir by force," "destroy the offensive power of Pakistan's armed force," and "to occupy minimum Pakistani territory necessary." 77 Other meetings between Shastri, his Chief Ministers, and Parliament further indicate that they reluctantly viewed an offensive as necessary, since Punjab and other border states "'could not be defended if the Indian army was on the defensive." ${ }^{178}$ The counter-offensive's limited nature is apparent from Shastri agreeing to a UN cease-fire resolution on September 21, only a week after attacking Lahore, instead of attempting to seize more territory. ${ }^{79}$ This notably occurred despite heavy opposition from Minister of Defence Y.B. Chavan and Army Chief of Staff J.N. Chaudhuri, who pushed for a broader war with Pakistan ${ }^{80}$ It thus seems that Shastri, along with much of the Indian government, believed that attacking Pakistan to end the war would be less costly than staying on the defensive, provided that the attack remain limited.

India's willingness to counter-invade Pakistan was likely encouraged by their military advantage. The Indian loss in the 1962 Sino-Indian War spurred a massive military buildup, and by 1965, its armed forces had expanded to 869,000 personnel compared to

\footnotetext{
${ }^{77}$ Rudra Chaudhuri, "Indian 'Strategic Restraint' Revisited: The Case of the 1965 India-Pakistan War," India Review 17, no. 1 (2018): 63.

${ }^{78}$ Chaudhuri, "Indian 'Strategic Restraint,"” 64.

${ }^{79}$ Ganguly, Conflict Unending, 45.

${ }^{80}$ Ganguly, Conflict Unending, 45-46.
} 
Pakistan's 208,000, as well as possessing more advanced equipment and ten divisions along the border for rapid offensives. ${ }^{81}$ Even though Pakistan received considerable aid from the US and China, including an estimated US\$700 million in American military equipment, it was not enough to close the quantitative gap with India. ${ }^{82}$ Given the situation by September 1965, Ayub Khan's earlier claim that Pakistan was ready to fight a general war against India was false: his only options against the Indian counter-offensive would have been to withdraw his forces to defend West Pakistan, escalate the war further, or concede to India. Given the conventional disparity, however, the Pakistani military would have been hard-pressed to achieve either of the first two options.

The Third Indo-Pakistani War (1971) is unique in revolving around Pakistani efforts to maintain control of East Pakistan, rather than Kashmir, but still showed Pakistan's inability to deter direct attacks. The crisis saw Yahya Khan and Bhutto, who were dissatisfied with the Awami League's 1970 election victory, send troops to East Pakistan in February 1971 in response, killing up to 2 million people while another 9-10 million fled to India. ${ }^{83}$ Indira Gandhi's government indirectly intervened by training and supplying Mukti Bahini militants to relieve the burden of refugees in an economic downturn and to weaken Pakistan. ${ }^{84}$ Direct intervention was initially deemed too risky, with Army Chief General Sam Manekshaw warning in an April 28 Cabinet meeting that several issues, including a lack of air bases near the border, meant that he would "guarantee

\footnotetext{
${ }^{81}$ International Institute for Strategic Studies, "Central Treaty Organization," The Military Balance 65, no. 1 (1965): 28; International Institute for Strategic Studies, "Part III: Non-aligned Countries," The Military Balance 65, no. 1 (1965): 34.

${ }^{82}$ Saira Khan, Nuclear Weapons and Conflict Transformation: The Case of India-Pakistan (New York: Routledge, 2009), 80.

${ }^{83}$ Brecher and Wilkenfeld, A Study of Crisis, 173; Kasturi, "The State of War," 146.

${ }^{84}$ Kasturi, "The State of War," 146; Ganguly, Conflict Unending, 51-52, 61.
} 
you $100 \%$ defeat" if troops were sent. ${ }^{85}$ Chinese intervention was also a concern after warnings from the US to Gandhi, but was alleviated by the Indo-Soviet Friendship Treaty in August $1971 .{ }^{86}$ India's lack of direct intervention is thus attributable to domestic concerns and Pakistan's allies, rather than Pakistan's own deterrence capabilities.

Indian support for guerillas escalated the crisis, pushing Pakistan to launch a preventive attack in December and triggering a war. Pakistan responded to the Mukti Bahini by deploying troops to the border, who clashed with Indian forces as early as November $22 .{ }^{87}$ Pressured by politically valuable military officers, Yahya Khan ordered a pre-emptive airstrike against Indian air bases for December 3 in the belief that costsensitive Indian leaders would avoid retaliating and end support for the Mukti Bahini ${ }^{88}$ As in 1965, this ignored that Pakistan only had 365,000 personnel compared to India's $980,000 .{ }^{89}$ Pakistani predictions were again overly optimistic, as the strikes led Gandhi to order an immediate invasion of East Pakistan, triggering the Bangladesh War. ${ }^{90}$ By December 16, Indian troops had not only forced Pakistani forces out of what became Bangladesh, but captured 93,000 soldiers. ${ }^{91}$ Pakistan's humiliation was magnified when Bhutto (who succeeded Yahya Khan as president) was forced to recognize the 1949 ceasefire line as a permanent Line of Control and renounce changing it with force in the

\footnotetext{
${ }^{85}$ Srinath Raghavan, “Soldiers, Statesmen, and India's Security Policy," India Review 11, no. 2 (2012): 122-123.

${ }^{86}$ Ganguly, Conflict Unending, 65; Riedel, Avoiding Armageddon, 76-77.

${ }^{87}$ Paul, The Warrior State, 51.

${ }^{88}$ Schofield, "Militarized Decision-Making," 141-142; Ahmad Faruqui, "Failure in Command: Lessons from Pakistan's Indian Wars, 1947-1999," Defense Analysis 17, no. 1 (2001): 35-36.

${ }^{89}$ International Institute for Strategic Studies, "Asia and Australasia," The Military Balance 71, no. 1 (1971): 46, 50.

${ }^{90}$ Khan, Nuclear Weapons and Conflict Transformation, 96.

${ }^{91}$ Paul, The Warrior State, 51.
} 
1972 Simla Agreement to retrieve the prisoners. ${ }^{92}$ These events played a significant role in Pakistan's nuclear weapons program, which was meant to prevent another such defeat.

It is apparent that Pakistani leaders were unable to deter India from directly attacking it in pre-nuclear crises, with Indian officials instead being constrained by political concerns over the costs of war. The 1947-1949 Indo-Pakistani War is unique in that Pakistan itself was not actually attacked, with Nehru's government having no intention of doing so. Records indicate that Nehru pressed for a cease-fire in recognition that continued fighting would be politically costly for the nascent state, despite retaining a considerable military advantage over Pakistan. That Pakistan did not attack India itself initially seems to have played a part in this restraint - something that sets it apart from later crises.

Nehru's successors shared his restraint in crises, but were not deterred from directly attacking Pakistan in response to serious provocations. The 1965 Indo-Pakistani War demonstrated that Shastri's government was willing to directly attack Pakistan in response to an invasion instead of minor skirmishes like the Rann of Kutch, with Ayub Khan's threats of a general war having little effect due to India's 4:1 military advantage. While Shastri was initially reluctant to attack, stating that his government only sought to defend border states and deter further Pakistani aggression, this was due more to a desire to avoid sacrificing troops for minor tracts of territory than Pakistan's capabilities. ${ }^{93}$ Indira Gandhi's government was likewise reluctant to fight Pakistan directly in 1971 due to the apparent risks and domestic concerns, but Yahya Khan's preventive attack provoked a forceful

\footnotetext{
92 Indira Gandhi and Zulfikar Ali Bhutto, "Agreement between the Government of India and the Government of the Islamic Republic of Pakistan on Bilateral Relations (Simla Agreement)" (Ministry of External Affairs, Government of India, July 2, 1972), https:/www.mea.gov.in/bilateraldocuments.htm?dtl/5541/Simla+Agreement.

${ }^{93}$ Chaudhuri, "Indian 'Strategic Restraint,'” 63-64.
} 
response to deter further aggression. All three cases would suggest that Indian leaders viewed Pakistan as willing to retaliate against India, but considered force to be necessary to limit escalation after being attacked first.

\subsection{2: Operation Brasstacks (1986-1987)}

The most significant pre-1998 crisis involving Pakistan was the Operation Brasstacks border standoff, which took place between December 1986 and February 1987. This was initially caused by India's Brasstacks military exercise in late 1986, which was meant by PM Rajiv Gandhi and Army Chief of Staff Krishnaswamy Sundarji to intimidate Pakistan into ending its support of a Sikh insurgency. ${ }^{94}$ Instead, Pakistani leaders concluded that it was a cover for war preparations, and responded by leaving its own forces deployed near the border after completing their own military exercises in December $1986 .{ }^{95}$ This led to a massive stand-off in January 1987, with demands from both sides to withdraw troops, such as Indian Minister of State for External Affairs Natwar Singh warning "appropriate steps" would be taken, indicating a risk of escalation to war. ${ }^{96}$ Both states reached an agreement to withdraw troops to their normal positions, peacefully doing so by February 19 and terminating the crisis.

The Brasstacks crisis differs from the others in that Pakistan had reportedly become a de facto nuclear weapon state by early 1987 , bolstering deterrence. This stems from chief nuclear scientist A.Q. Khan's threat in a January 28 interview with the Observer that "“we

\footnotetext{
${ }^{94}$ Narang, Nuclear Strategy in the Modern Era, 63; Cohen, The Idea of Pakistan, 109.

${ }^{95}$ Gaurav Kampani, "New Delhi’s Long Nuclear Journey: How Secrecy and Institutional Roadblocks Delayed India's Weaponization," International Security 38, no. 4 (2014): 91; Narang, Nuclear Strategy in the Modern Era, 63.

${ }^{96}$ P.R. Chari, Pervaiz Iqbal Cheema, and Stephen P. Cohen, Four Crises and a Peace Process: American Engagement in South Asia (Washington, DC: Brookings Institution Press, 2007), 54-55; Ganguly, Conflict Unending, 87.
} 
shall use the bomb if our existence is threatened." ${ }^{\prime 97}$ While the interview was only published after the crisis, Indian officials are believed to have been aware of it earlier. ${ }^{98}$ The threat was likely made at the direction of Zia and other military elites, given their excluding civilian authorities like Prime Minister Muhammad Khan Junejo and Ambassador Humayun Khan from decisions ${ }^{99}$ Furthermore, Zia's government would have been shielded from domestic repercussions due to being supported by the military and landed elite, with the former being particularly concerned about Indian intentions. ${ }^{100}$ This meant that they would have been able to issue threats to India with little concern for domestic consequences, since their primary audience viewed India as a potentially existential threat.

What is notable is that the Pakistani government did not actually possess nuclear weapons at the time. As noted by Vipin Narang, Pakistan only seems to have been capable of signalling that it had "an ambiguous capacity to assemble a weapon if necessary" at most. ${ }^{101}$ Zia's remarks in a post-crisis interview with Time that “"Pakistan has the capability of building the bomb... whenever it wishes"' appear to confirm that Pakistan was only a de facto nuclear weapon state at the time, having the capability to assemble nuclear weapons but not actually having done so. ${ }^{102}$ While Brasstacks was not in itself a nuclear crisis, Zia's claim suggests that Pakistan could have quickly assembled and deployed nuclear devices for possible use against India.

\footnotetext{
${ }^{97}$ Nayar, "We Have the A-Bomb."

${ }^{98}$ Narang, Nuclear Strategy in the Modern Era, 264.

${ }^{99}$ Chari, Cheema, and Cohen, Four Crises, 61-62.

100 Talbot, A New History, 115-116.

${ }^{101}$ Narang, Nuclear Strategy in the Modern Era, 264.

102 William R. Doerner, "Pakistan Knocking at the Nuclear Door," Time Magazine, March 30, 1987, http://content.time.com/time/magazine/article/0,9171,963894,00.html.
} 
The Brasstacks crisis differs from previous Indo-Pakistani crises due to India being successfully deterred from attacking, seemingly due in part to the nuclear threat, despite Indian officers wishing to attack regardless. The conventional disparity between them remained sizable: by December 1986, the Indian Army had 1,100,000 personnel and Pakistan's armed forces had a total of 480,600 personnel, suggesting that Pakistan's conventional strength was not a sufficient deterrent. ${ }^{103}$ As noted by Vipin Narang and others, Indian officers like Sundarji favored the exercises as a cover for a preventive strike against Pakistani nuclear facilities, with Lt. General P.N. Hoon later writing that Brasstacks “"was a plan to build up a situation for a fourth war with Pakistan."”104 However, Sundarji also remarked that the nuclear threat sufficiently intimidated Indian politicians that " the menu of Indian responses to Pakistani provocation... no longer includes launching a bold offensive across the Punjab." ${ }^{105}$ The threat would likely have been credible to Indian decision-makers, given that an actual Indian invasion from Brasstacks' location in the Rajasthani desert could split Pakistan in two. ${ }^{106}$ Combined with the aforementioned prominence of Pakistani generals in decision-making during the crisis and its past aggression, the Pakistani nuclear threat appears to have convinced Indian politicians that an actual offensive would encourage the acceleration of Pakistan's nuclear efforts.

\footnotetext{
${ }^{103}$ International Institute for Strategic Studies, “Asia and Australasia," The Military Balance 87, no. 1 (1987): 156, 168.

${ }^{104}$ Narang, Nuclear Strategy in the Modern Era, 261-262.

105 Praveen Swami, "Failed Threats and Flawed Fences: India's Military Responses to Pakistan's Proxy War," India Review 3, no. 2 (2004): 155-156.

${ }^{106}$ Narang, Nuclear Strategy in the Modern Era, 262.
} 


\section{4: "'Even if Pakistanis have to eat grass:"' Pakistani Nuclear Weapons}

\section{Motivations and History}

Pakistan's nuclear weapons program is almost inextricably tied with India's own nuclear ambitions, having emerged in response to Indian conventional superiority. This was not always the case, with the Pakistan Atomic Energy Commission originally being established in 1957 for civilian energy purposes. ${ }^{107}$ Pakistan's loss in the 1965 IndoPakistani War appears to have encouraged initial interest in nuclear weapons due to the increasing gap between the Pakistani and Indian militaries. ${ }^{108}$ Then-Minister of Foreign Affairs Zulfikar Ali Bhutto famously stated that if India acquired nuclear weapons, Pakistan would do so as well "“even if Pakistanis have to eat grass." 109 This attitude, combined with suspicions of Indian intentions, meant that Pakistan followed its example in declining to sign the Treaty on the Non-Proliferation of Nuclear Weapons (NPT) in 1968. ${ }^{110}$ An actual weapons program, however, had not emerged at that point.

Pakistan's pursuit of nuclear weapons was solidified by its continued inability to win a conventional war with India and fears of an Indian nuclear arsenal. The crushing defeat suffered by Pakistan in the 1971 war, particularly the loss of East Pakistan, made it clear that India militarily outmatched it. Neither the US or China were willing to provide an outright security guarantee to Pakistan despite supplying large quantities of military equipment, with the US in particular being seen by Bhutto as unreliable. ${ }^{111}$ One of his first decisions as president was establishing a nuclear weapons program in January 1972 to

\footnotetext{
107 Ganguly and Kapur, India, Pakistan, 18.

${ }^{108}$ Ganguly and Kapur, India, Pakistan, 18.

109 Ahmed, "Pakistan's Nuclear Weapons Program," 183.

${ }^{110}$ Ahmed, "Pakistan's Nuclear Weapons Program," 183.

111 Ganguly, Conflict Unending, 106.
} 
ensure a "'great equalizer" for inevitable future wars with India. ${ }^{112}$ The Indian peaceful nuclear explosion (PNE) in May 1974 made this seem even more necessary to deter India from its perceived goal of destroying Pakistan. ${ }^{113}$ By 1976, a covert weapons program was established at the Kahuta Research Laboratories under A.Q. Khan's direction. ${ }^{114}$ Pakistan's military leadership ultimately supported the nuclear weapons program, as it continued after Bhutto's ouster by Zia in July 1977, likely due to the Indo-Pakistani capabilities gap.

The US unsuccessfully attempted to halt Pakistani nuclear development. The Carter administration passed the Symington and Glenn Amendments to the Arms Export Control Act in 1976 and 1977, prohibiting US economic and military aid to non-NPT compliant states and requiring sanctions, which were imposed on Pakistan in September 1977 and April 1979 to no avail. ${ }^{115}$ These sanctions were waived by the Reagan administration in 1980 to provide Zia with military and economic aid against Soviet forces in Afghanistan despite Pakistan's continued proliferation efforts, but ended in 1990 under the George H.W. Bush administration and left Sharif increasingly reliant on military support. ${ }^{116}$ The weapons program was completely controlled by military leaders like Army Chief of Staff Mirza Aslam Beg and bureaucrats, to the point that Prime Minister Benazir Bhutto only learned about it while visiting the US in $1989 .{ }^{117}$ The program remained secret to not only prevent India from attacking facilities, but because China was covertly supplying weapon designs and nuclear materials and A.Q. Khan had established a global network to illicitly

\footnotetext{
${ }_{112}$ Paul, The Warrior State, 52-53.

${ }^{113}$ Paul K. Kerr and Mary Beth D. Nikitin, "Pakistan's Nuclear Weapons," Congressional Research Service Report (Washington, DC: United States Congressional Research Service, August 1, 2016), 2, https://fas.org/sgp/crs/nuke/RL34248.pdf.

${ }^{114}$ Ganguly, Conflict Unending, 106.

${ }^{115}$ Ahmed, "Pakistan's Nuclear Weapons Program," 184-186.

${ }^{116}$ Riedel, Avoiding Armageddon, 98; 111-112.

${ }^{117}$ Ahmed, "Pakistan's Nuclear Weapons Program," 188-189.
} 
acquire equipment while circumventing export controls. ${ }^{118}$ This structure meant that unaccountable military officers made almost all nuclear weapons development decisions, while Pakistani civilian leaders and the public were at best aware that a program existed.

Pakistan was thus able to maintain nuclear ambiguity from the late 1980 s, when it was a de facto nuclear weapon state, to May 1998, when it revealed its capabilities with the Chagai-I and Chagai-II nuclear tests. Pakistan's de facto status became apparent during the Brasstacks crisis due to Khan and Zia's public threats towards India, and Indian intelligence claimed that Pakistan had three functional devices by $1988 .^{119}$ It was only officially disclosed in February 1992, when Foreign Secretary Shahryar Khan stated in an interview with the Washington Post that "his country now has the components and knowhow to assemble at least one nuclear device." ${ }^{20}$ Confirmation that Pakistan actually had nuclear weapons, however, only came with the nuclear tests conducted on May 28 and 30, 1998, in response to India's Pokhran-II tests earlier that month. The Chagai tests further demonstrate PAF influence over government, as Sharif was pressured by military officers and hawkish ministers into authorizing them despite his personal opposition, later informing President Clinton that the decision " was out of my hands." 121 The militarydriven nature of the decision means that audiences costs do not appear to have been

\footnotetext{
${ }^{118}$ Khan's network was subsequently tied to the provision of nuclear technology to several states interested in developing their own nuclear arsenal, particularly Libya, Iran, and North Korea. Abdullah, "Nuclear Ethics?," 158; Kerr and Nikitin, "Pakistan's Nuclear Weapons," 3.

${ }^{119}$ Kargil Review Committee, From Surprise to Reckoning: The Kargil Committee Report (New Delhi: SAGE Publications, December 15, 1999), 190; Nayar, "We Have the A-Bomb."

${ }^{120}$ Steve Coll, "U.S. Nuclear Diplomacy in South Asia Faces Obstacles," Washington Post, February 8, 1992, https://www.washingtonpost.com/archive/politics/1992/02/08/us-nuclear-diplomacy-in-south-asiafaces-obstacles/a75cff43-ccb7-412d-9d98-60b1abb070e6/; Samina Ahmed and David Cortright, "1: Pakistani Public Opinion and Nuclear Weapons Policy," in Pakistan and the Bomb: Public Opinion and Nuclear Options (Notre Dame: University of Notre Dame Press, 1998), 3-27.

${ }^{121}$ Ahmed, "Pakistan's Nuclear Weapons Program," 193-195.
} 
considered, though public opinion was favorable after the tests. ${ }^{122}$ This sudden shift to an openly nuclear Indian subcontinent set the stage for several crises, including an accidental war less than a year later.

\section{5: Aiming Solely for India: Pakistani Nuclear Deterrence Threats and Institutions}

Pakistan is a rare instance of a nuclear weapon state without an officially stated nuclear doctrine. Public statements by Pakistani military and civilian officials, strategic decisions, and past behaviour all indicate that nuclear weapons are considered vital in deterring perceived Indian aggression, particularly by the military. This unofficial doctrine has Pakistan threaten to respond to any direct attack against its territory with nuclear weapons, including the use of lower-yield tactical nuclear weapons in a first strike against small-scale Indian incursions. Pakistan's nuclear command and control organization, the National Command Authority (NCA), enables this due to the nominal division of launch authority between civilian and military leaders easily being circumvented by the latter to unilaterally launch and deploy nuclear weapons. Furthermore, the military forcing the predelegation of tactical nuclear weapons to battlefield commanders for a rapid response, which is unique among nuclear weapon states, lends additional credibility to Pakistan's ability to respond to Indian aggression. ${ }^{123}$

Pakistan's nuclear doctrine has not been officially disclosed; unofficially, it is willing to use nuclear weapons in response even to purely conventional attacks by India.

\footnotetext{
${ }^{122}$ Ahmed, "Pakistan's Nuclear Weapons Program," 195.

${ }^{123}$ While Pakistan's nuclear weapon numbers are not officially disclosed, 2018 estimates indicate that it likely possesses approximately 42 warheads with a yield of 5-12 kilotons out of a total stockpile of 140-150 warheads, which would meet the criteria for tactical nuclear weapons. See Hans M. Kristensen, Robert S. Norris, and Julia Diamond, "Pakistani Nuclear Forces, 2018," Bulletin of the Atomic Scientists 74, no. 5 (2018): 349 .
} 
The clearest public articulation of Pakistan's nuclear policy was then-Strategic Planning Division (SPD) head Lieutenant-General Khalid Kidwai's 2002 statement that “'Pakistani nuclear weapons would be used only if the very existence of Pakistan as a state is at stake"” and that they were "“aimed solely at India." ${ }^{124}$ Kidwai further specified nuclear use conditions as being if India conquered large parts of Pakistani territory, destroyed a significant part of its land or air forces, engaged in "economic strangling of Pakistan," or deliberately encouraged political instability within Pakistan. ${ }^{125}$ Figure 6.2 in chapter 6 further supports the focus being on India, with the growth of Pakistan's nuclear arsenal (from 2 warheads in 1998 to an estimated 150 by 2018) staying in lockstep with India's own nuclear stockpile as part of an arms race between the two. ${ }^{126}$ Pakistan has also refused to pledge no first use to preserve the ability to launch pre-emptive attacks, with President Asif Ali Zardari's November 2008 statement that "'Pakistan will not be the first country ever to use (nuclear weapons)"' leading to sharp military rebukes and a retraction. ${ }^{127}$

Taken together, these indicate that Pakistan has a low threshold of use for its nuclear arsenal, which appears to be wholly focused on deterring India. Statements such as Kidwai's remarks indicate that while the use conditions are lacking in specifics, they can be taken to mean that nuclear weapons would be used in response to almost any attack against Pakistan by India. These remarks, if representative of the Pakistani government's doctrine, also indicate that nuclear weapons could be used even in response to India

\footnotetext{
${ }^{124}$ Paolo Cotta-Ramusino and Maurizio Martinelli, "Nuclear Safety, Nuclear Stability and Nuclear Strategy in Pakistan: A Concise Report of a Visit by Landau Network - Centro Volta, (January 14, 2002)," Pugwash Conferences on Science and World Affairs, January 14, 2002, https://pugwash.org/2002/01/14/report-onnuclear-safety-nuclear-stability-and-nuclear-strategy-in-pakistan/.

${ }^{125}$ Cotta-Ramusino and Martinelli, "Nuclear Safety."

${ }^{126}$ Hans M. Kristensen and Robert S. Norris, "Nuclear Arsenals of the World," Bulletin of the Atomic Scientists (blog), 2018, https://thebulletin.org/nuclear-notebook-multimedia/.

${ }^{127}$ Abdullah, "Nuclear Ethics," 164.
} 
imposing economic sanctions, though the likelihood of nuclear war breaking out as a result suggests that this is unlikely in practice. The emphasis on maintaining a first use policy means that, unlike India, Pakistan would not reserve the use of nuclear weapons solely in response to unconventional attacks, but would be willing to use them against even uses of conventional force. The result is that Pakistan's deterrence policy is intended to discourage any attacks or sanctions by India.

Pakistan's nuclear weapons are ostensibly under joint civilian and military control, but in practice, the military can co-opt the decision process. The body charged with command and control is the National Command Authority (NCA), which was informally created in February 2000 to alleviate concerns over unauthorized use before being established in law by the 2010 National Command Authority Act. ${ }^{128}$ The NCA is divided into three sub-committees, with the Prime Minister chairing the NCA itself and the Employment Control Committee (ECC), which approves the use of nuclear weapons. ${ }^{129}$ This decision requires unanimous approval by the ten ECC members, which are evenly divided between civilian officials and military officers in order to ensure joint approval. ${ }^{130}$ The NCA also includes the Development Control Committee (DCC), which administers associated organizations, while the SPD is charged with ensuring reliable command and control and possesses disassembled nuclear warheads during peacetime. ${ }^{131}$ This structure

\footnotetext{
${ }^{128}$ Timothy D. Hoyt, "Pakistani Nuclear Doctrine and The Dangers of Strategic Myopia," Asian Survey 41, no. 6 (2001): 964; Kerr and Nikitin, "Pakistan's Nuclear Weapons."

${ }^{129}$ Hoyt, "Pakistani Nuclear Doctrine," 965.

${ }^{130}$ Sébastien Miraglia, "Deadly or Impotent? Nuclear Command and Control in Pakistan," Journal of Strategic Studies 36, no. 6 (2013): 846.

${ }^{131}$ Kerr and Nikitin, "Pakistan's Nuclear Weapons," 14; Rizwan Zeb, "Pakistan's Nuclear Weapons: How Safe Is Safe Enough? Transparency versus Opacity,” Defense \& Security Analysis 30, no. 3 (2014): 236.
} 
seemingly indicates at least some shared nuclear launch authority between civilian and military leaders.

The reality, however, is that this power-sharing arrangement is largely nominal, as the military can wrest full control away from civilian NCA members whenever it wishes. A provision in the NCA Act allows the chairman of the Joint Chiefs of Staff Committee to take over as NCA Chairman if the prime minister "is incapacitated or indisposed," giving the military a majority vote on launch decisions. ${ }^{132}$ Even before the Act, Benazir Bhutto and Sharif were often excluded from nuclear decisions, including the reported decision to ready nuclear weapons for use in the 1999 Kargil War. ${ }^{133}$ More recently, PAF generals have shown themselves willing to use their authority within the NCA to pressure Zardari to relinquish his position as chairman to the prime minister following the aforementioned no-first-use comments. ${ }^{134}$ Former military officers such as Kidwai and Brigadier Feroz Hassan Khan have also argued that civilian command and control should be supplanted during a crisis. ${ }^{135}$ Given the military's existing propensity for subverting civilian authority, this would likely be the case if civilian officials impeded nuclear weapon use in a crisis.

Pakistani nuclear command and control is further undermined by tactical nuclear weapons being pre-delegated to battlefield commanders, illustrating an insensitivity to the costs of their use. This policy serves the dual purposes of providing "full spectrum deterrence" against India and enabling pre-emptive strikes, with the apparent intent of

\footnotetext{
132 Miraglia, "Deadly or Impotent," 855-856.

${ }^{133}$ Miraglia, "Deadly or Impotent," 850-851.

134 Abdullah, "Nuclear Ethics," 164.

${ }^{135}$ Miraglia, "Deadly or Impotent," 855.
} 
deterring even Indian incursions while avoiding further escalation. ${ }^{136}$ Pre-delegation to commanders increases deterrence credibility by ensuring a rapid response, but at the cost of greatly increasing the risk of accidental or unauthorized use. ${ }^{137}$ This aspect of Pakistan's nuclear doctrine is notably cost-insensitive to the likely international backlash and the impact on their own civilians: using tactical nuclear weapons near Lahore, for example, could kill anywhere between 50,000 and 300,000 Pakistanis. ${ }^{138}$ Though this policy demonstrates the Pakistani military's willingness to deter India at any cost, it also carries a significant risk of unintentional escalation.

Pakistan's nuclear doctrine, while extreme, is made credible by the widespread belief that any Indian attack could pose an existential threat to the state. A common thread in pre-nuclear crises is the view within Pakistan, even among generals and civilian leaders, that India seeks to destroy and annex the state. ${ }^{139}$ This has only been reinforced by India's demonstrated conventional advantage in prior crises, leading to the belief that any attack poses a major threat to Pakistan, with the belief that the 1986 Brasstacks exercise was meant to bisect Pakistan being an example. ${ }^{140}$ This means that nuclear deterrence is considered vital to Pakistan's continued survival, and threatening it against even seemingly minor incursions serves to deter all Indian aggression. The cost-insensitivity of the Pakistani military leadership plays a major role in this, since it and its support base can

\footnotetext{
${ }^{136}$ Arka Biswas, "Pakistan's Tactical Nukes: Relevance and Options for India," The Washington Quarterly 40, no. 3 (2017): 170-173; Kerr and Nikitin, "Pakistan's Nuclear Weapons," 12.

${ }^{137}$ Miraglia, "Deadly or Impotent," 856-857.

138 Jaganath Sankaran, "Pakistan's Battlefield Nuclear Policy: A Risky Solution to an Exaggerated Threat," International Security 39, no. 3 (2014): 141.

${ }^{139}$ Fair, "Why the Pakistan Army Is Here to Stay," 573.

${ }^{140}$ That this belief is so widespread while contradicting the other long-held belief that Indian leaders are too cost-sensitive to defend territory remains unexplained. Narang, Nuclear Strategy in the Modern Era, 262.
} 
make such extreme threats with little regard for the costs or punishment by voters, particularly since the military is more trusted than any elected body.

\section{6: "We shall use the bomb": Pakistani Post-Nuclear Crises and Conflicts}

Whereas India has continued to be targeted with direct and indirect attacks after demonstrating its nuclear weapons capability, Pakistan's May 1998 nuclear tests and doctrine appear to have bolstered deterrence against armed attacks of various intensities. Despite remaining conventionally weaker, Pakistan has largely avoided military reprisals for its attacks against India, with the February 2019 airstrike being an exception. The role of its nuclear deterrent is most apparent with the 1999 Kargil War: while Pakistan's probing of Kargil was reminiscent of the 1965 Indo-Pakistani War, India restrained itself to driving out Pakistani troops from its territory instead of invading Pakistan. The 2001-2002 border standoff and the 2008 Mumbai attacks similarly saw India avoid escalating the crises.

This section shows that Indian governments have, until recently, been reluctant to launch counter-offensives against Pakistan due to viewing its threats of nuclear retaliation against any attack as credible. It focuses on three post-nuclear crises involving Pakistan: the 1999 Kargil War, the 2001-2002 border standoff, and the 2008 Mumbai attack. Pakistan's nuclear deterrence credibility is attributable to PAF dominance over most aspects of government, including nuclear command and control, a history of aggression towards India conveying cost-insensitivity, and the perception that India poses an existential threat to Pakistan. Evidence that nuclear weapons were prepared for use in crises indicates that these are genuine threats rather than bluffs. As mentioned previously, the credibility of these threats may be waning, as the February 2019 Indian airstrike, while outside the period of study, suggests Indian leaders are increasingly willing to attack. 


\subsection{1: The Kargil War (1999)}

The Kargil War was a turning point in Pakistan's ability to deter Indian counterattacks, as its nuclear threats played a significant role in the deliberations of Indian leaders. As explained in chapter 6, the crisis was triggered by the May 1999 discovery that Indian military posts on Kargil's Siachen Glacier had been occupied by 1,500-2,400 Pakistani troops. ${ }^{141}$ The occupation, approved by then-Chief of Staff Musharraf, was spurred by a belief among Pakistani officers that the Indian Army was too weak and timid to assault fortified mountain positions and that nuclear weapons made retaliation against Pakistan itself unlikely, with Musharraf asserting " "there is a zero chance of war." ${ }^{142}$ The former proved incorrect, as Vajpayee's government launched Operation Vijay on May 7 to retake the captured mountain positions through a combination of infantry, artillery, and airpower. ${ }^{143}$ The fighting continued for two months before Bill Clinton pressured Sharif into withdrawing troops and signing a cease-fire during a July 4 meeting, with the crisis terminated by July $26 .{ }^{144}$ While India was satisfied, Pakistan suffered international condemnation for its aggression, including from its American and Chinese allies, and public outrage for the loss. ${ }^{145}$ The loss also contributed to Musharraf's October coup and the establishment of a military government.

Though Indian leaders were willing to retake the lost positions, Musharraf and other Pakistani leaders were correct that nuclear weapons would deter attacks against Pakistan

\footnotetext{
${ }^{141}$ Sunil Rao, "The Kargil Incident: Historical Analysis," Indian Historical Review 43, no. 1 (2016): 118.

${ }^{142}$ John H. Gill, "Provocation, War and Restraint under the Nuclear Shadow: The Kargil Conflict 1999," Journal of Strategic Studies 42, no. 5 (2019): 706; Priyanjali Malik, India's Nuclear Debate:

Exceptionalism and the Bomb (New Delhi: Routledge, 2010), 254.

${ }^{143}$ Ganguly, Conflict Unending, 117.

${ }^{144}$ Gill, "Provocation, War and Restraint under the Nuclear Shadow," 717-718.

${ }^{145}$ Kasturi, "The State of War," 150-152.
} 
itself. Indian leaders were prepared for conventional war within India, with Army Chief General V.P. Malik warning commanders to prepare for escalation near the LoC or international border. ${ }^{146}$ The government also issued directives to avoid combat beyond India's borders, including ordering the Air Force to avoid crossing the $\mathrm{LoC}$ or the international border, despite this drawing out the conflict and costing more Indian lives. ${ }^{147}$ The Kargil War thus stands apart from the 1965 and 1971 wars, which saw Shastri and Indira Gandhi (reluctantly) order counter-offensives against Pakistan in response to India being attacked. The 1999 crisis, meanwhile, had the Indian government actively limit the conflict within its borders despite a considerable conventional advantage - with 1.1 million active armed forces personnel to Pakistan's 587,000 - and the favor of the international community, as even Pakistan's allies were condemning the Kargil incursion. ${ }^{148}$

Indian restraint is attributable to Pakistani officials alluding to their nuclear arsenal in statements. Foreign Secretary Shamshad Ahmad, for example, warned on May 30 that Pakistan "wwould not hesitate to use any weapon in our arsenal to defend our territorial integrity." ${ }^{\prime 149}$ Musharraf was even more explicit, repeatedly warning that if Indian troops “"took even a step across the international border or the LoC... it will not remain a conventional war."'150 The Indian government took these threats seriously, having reportedly mobilized nuclear delivery vehicles and preparing to attach nuclear warheads

\footnotetext{
${ }^{146}$ Riedel, Avoiding Armageddon, 131.

${ }^{147}$ Chari, Cheema, and Cohen, Four Crises, 139.

${ }^{148}$ International Institute for Strategic Studies, "Central and South Asia," The Military Balance 99, no. 1 (1999): 161-163, 166-167; Gill, "Provocation, War and Restraint under the Nuclear Shadow," 715-716. ${ }^{149}$ Celia W. Dugger, "Atmosphere Is Tense as India and Pakistan Agree to Talks," The New York Times, June 1, 1999, https://www.nytimes.com/1999/06/01/world/atmosphere-is-tense-as-india-and-pakistanagree-to-talks.html.

${ }^{150}$ Narang, Nuclear Strategy in the Modern Era, 268.
} 
on short notice. ${ }^{151}$ Whether Vajpayee himself believed them remains unclear, as some generals reported that he was against expanding the conflict due to Pakistan's nuclear arsenal, suggesting he did. ${ }^{152}$ Vajpayee himself later claimed that “We never thought atomic weapons would be used, even if we had decided to cross the LOC." "153 Other officials have stated otherwise, with both Foreign Minister Jaswant Singh and Malik concluding that Pakistan was "operationalizing its nuclear missiles"” based on unusual missile force movement. ${ }^{154}$ Overall, it seems that Pakistan's nuclear threats during the Kargil crisis were credible to Indian leaders.

The risk of escalation to nuclear war was further increased by Pakistani civilian leaders being kept uninvolved and possibly unaware of the Kargil operation and its nuclear dimensions. The July 4 meeting notably had Clinton inform Sharif that CIA satellite imagery showed Pakistani forces apparently deploying nuclear weapons, reportedly surprising him. ${ }^{155}$ Sharif's knowledge of the operation as a whole remains in doubt, though the Indian Foreign Ministry stated in late May that it "“was obviously undertaken with the full complicity and support of the Pakistan government." ${ }^{\prime 156}$ Sharif has maintained that he was initially kept unaware of the operation, which Musharraf has denied. ${ }^{157}$ Past PAF behaviour led some Indian officials, such as National Security Advisor Brajesh Mishra, to express concern that lower-level commanders could use nuclear weapons without the

\footnotetext{
${ }^{151}$ Mario E. Carranza, "Deterrence or Taboo? Explaining the Non-Use of Nuclear Weapons during the Indo-Pakistani Post-Tests Nuclear Crises," Contemporary Security Policy 39, no. 3 (2018): 448.

${ }^{152}$ Narang, Nuclear Strategy in the Modern Era, 272.

${ }^{153}$ Carranza, "Deterrence or Taboo?," 448.

${ }^{154}$ Riedel, Avoiding Armageddon, 133.

${ }^{155}$ Riedel, Avoiding Armageddon, 133-134.

${ }^{156}$ Chari, Cheema, and Cohen, Four Crises, 143.

157 Gill, "Provocation, War and Restraint under the Nuclear Shadow," 707.
} 
authorization of military or civilian superiors. ${ }^{158}$ Given military's dominance of Pakistani politics, Musharraf and his fellow generals almost certainly had full authority over the Kargil operation regardless of Sharif's knowledge, would have been able to take steps that he would not have agreed to, including the potential use of nuclear weapons.

The Kargil War shows how the military's control of Pakistan made nuclear deterrence credible in an otherwise low-stakes crisis. The trigger event of Pakistani troops infiltrating Kashmir and India's conventional response bore marked similarities to the 1965 Indo-Pakistani War. While that conflict saw India directly attack Pakistan in response, the Kargil War instead had the Indian government deliberately limit itself despite a sizable military advantage and Pakistan lacking any international support. The introduction of nuclear weapons into the rivalry and the threats to use them if Indian troops crossed the border explains this reticence despite the low stakes of the crisis. From what can be confirmed, the Pakistani military operated with no civilian oversight whatsoever, and Indian leaders believed that Musharraf and his subordinates were willing to follow through on their nuclear threats. This crisis shows that while Pakistan's nuclear deterrent was insufficient to force a fait accompli in seizing Indian territory, its military leadership and past behaviour made it credible enough to prevent more serious retaliation.

\subsection{2: Indo-Pakistani Standoffs}

The credibility of Pakistan's nuclear deterrent to Indian leaders became even more apparent in post-Kargil crises. Several crises were caused by Pakistan's government supporting and directing non-state militant groups to attack Indian civilians as part of a

${ }^{158}$ Narang, Nuclear Strategy in the Modern Era, 272-273. 
broader pattern of supporting militants in Jammu and Kashmir since 1989, with approximately 43,000 people being killed during the $1990-2011$ period. ${ }^{159}$ This has largely been done through the ISI providing equipment, funding and training to select militant groups and even directly targeting and planning attacks, making this a form of statesponsored terrorism. ${ }^{160}$ Pakistani military leaders have directed this strategy to gradually seize Jammu and Kashmir while circumventing India's conventional advantage, while their nuclear deterrent discourages Indian retaliation against Pakistan. Two particular crises stemming from such attacks - the 2001-2002 border standoff and the 2008 Mumbai attack - demonstrate the success of this approach, as the Indian government has deliberately restrained itself to avoid nuclear war.

The crisis that had the greatest risk of uncontrollable escalation was the 2001-2002 Indo-Pakistani border standoff. The crisis was triggered by members of Lashkar-e-Taiba (LeT) and Jaish-e-Mohammed (JeM) attacking the Indian Parliament on December 13, 2001, which surviving attackers claimed was directed by the ISI. ${ }^{161}$ This was denied by the Pakistani government, with military spokesman Major-General Rashid Qureshi warning that "“India will pay heavily if they engage in any misadventure,"” and refused to extradite suspects to India. ${ }^{162}$ This, along with parliamentary pressure, led to Vajpayee mobilizing approximately 800,000 Indian troops to the international border and the LOC by early

\footnotetext{
${ }^{159}$ Amnesty International, “'Denied': Failures in Accountability for Human Rights Violations by Security Force Personnel in Jammu and Kashmir" (London: Amnesty International, 2015), 8, https://www.amnesty.org/download/Documents/ASA2018742015ENGLISH.PDF

160 Riedel, Avoiding Armageddon, 2-7.

${ }^{161}$ Chari, Cheema, and Cohen, Four Crises, 149.

162 "Pakistan Forces Put on High Alert: Storming of Parliament," Dawn, December 15, 2001, http://beta.dawn.com/news/10821/pakistan-forces-put-on-high-alert-storming-of-parliament; Sumit Ganguly and Michael R. Kraig, "The 2001-2002 Indo-Pakistani Crisis: Exposing the Limits of Coercive Diplomacy,” Security Studies 14, no. 2 (2005): 299.
} 
January 2002 and Musharraf responding by deploying 300,000 Pakistani troops. ${ }^{163}$ The resulting standoff, known as Operation Parakram in India, lasted until October 2002, at which point Indian forces withdrew to their normal deployments.

A major factor in the standoff lasting so long was the Indian government refusing to escalate further for fear of Pakistan using nuclear weapons. Indian forces were ordered early on to avoid crossing into Azad Kashmir or Pakistan, which, combined with the BJP's increasing unpopularity by spring 2002 , led to the entire deployment being seen as a political stunt to maintain popular support. ${ }^{164}$ This meant scrapping planned commando operations and removing at least one officer who defied orders from command. ${ }^{165}$ India's stance shifted following the May 14 attack in Kaluchak, with Vajpayee and General Sundarajan Padmanabhan planning a retaliatory strike against Pakistan, which was only prevented by Musharraf announcing an end to Pakistani support for terrorist attacks. ${ }^{166}$ By time India demobilized in October, the deployment had cost India an estimated US\$2 billion with nothing to show for it. ${ }^{167}$ Indian troops were thus unilaterally demobilized from their border positions, with the Indian government having been humiliated as a result.

It is important to note that some Indian civilian and military leaders believed it was possible to attack Pakistan without crossing its nuclear threshold, but were apparently deterred by Pakistani leaders alluding to nuclear weapon use. At one point, Vajpayee apparently told the Indian service chiefs to prepare for war with Pakistan, apparently in the

\footnotetext{
163 Ganguly and Kraig, "The 2001-2002 Indo-Pakistani Crisis,” 299.

${ }^{164}$ Chari, Cheema, and Cohen, Four Crises, 156-158.

${ }^{165}$ Chari, Cheema, and Cohen, Four Crises, 154.

166 Todd S. Sechser and Matthew Fuhrmann, Nuclear Weapons and Coercive Diplomacy (New York: Cambridge University Press, 2017), 156; Ganguly and Kapur, India, Pakistan, 55.

${ }^{167}$ Chari, Cheema, and Cohen, Four Crises, 160-162.
} 
belief that a limited war could be fought without escalating to nuclear weapon use. ${ }^{168}$ Following the May 14 attack, Vajpayee and General Sundarajan Padmanabhan began planning a retaliatory conventional strike against Pakistan that would have seized the Sindh and Punjab provinces and cut the country in two. ${ }^{169}$ Other possible scenarios for attacking Pakistan in retaliation, including repeating the 1965 siege of Lahore and launching special forces raids, were also considered. ${ }^{170}$ Finally, officials also warned that a Pakistani nuclear attack would be met in kind by India, with Minister of Defence George Fernandes stating in June 2002 that if Musharraf used nuclear weapons, "'he should realize that India can survive a nuclear attack, but Pakistan cannot." "171 Initially, it seems as though Indian leaders thought that Pakistan would not risk nuclear war over even a limited strike.

This belief proved short-lived, as the Pakistani government quickly took steps to credibly warn that a conventional Indian attack would lead to nuclear retaliation. On May 25 and 28, three nuclear-capable ballistic missiles were test-fired alongside a statement that India should “"apply brakes on its most ambitious plan ever."”172 Both countries deployed short-range nuclear-capable missiles to the border, and Brigadier General Feroz Hassan Khan's statement that Pakistani “"dispersal and mating plans were actually tested" during this period means that they may have been nuclear-armed. ${ }^{173}$ Perhaps most significantly, former ISI Director General Javed Ashraf Qazi warned in an interview that "“If Pakistan is being destroyed through conventional means, we will destroy them by using the nuclear

\footnotetext{
${ }^{168}$ Chari, Cheema, and Cohen, Four Crises, 156.

${ }^{169}$ Narang, Nuclear Strategy in the Modern Era, 275.

${ }^{170}$ Chari, Cheema, and Cohen, Four Crises, 154-155.

${ }^{171}$ Sechser and Fuhrmann, Nuclear Weapons and Coercive Diplomacy, 158.

172 Narang, Nuclear Strategy in the Modern Era, 275.

${ }^{173}$ Narang, Nuclear Strategy in the Modern Era, 275.
} 
option," with other officials echoing this. ${ }^{174}$ Musharraf's claim in a 2017 Mainichi Shimbun interview that he considered using nuclear weapons against India during the standoff suggests that these were not mere bluffing. ${ }^{175}$ Pakistan's military government would have lent these threats additional credibility, given its demonstrated willingness to use force, the prior deployment of tactical nuclear weapons in 1999, and the lacking checks and balances on their use. Even then, the policy of giving launch authority to battlefield commanders would have increased the risk of a nuclear war occurring in response to an Indian attack regardless of whether their use was authorized by Islamabad.

One of the other major crises affecting Pakistan during the post-1998 period was the November 2008 attack on Mumbai. The crisis trigger was the aforementioned attack on Mumbai by members of LeT during November $26^{\text {th }}$ to $29^{\text {th }}$, which killed around 163 people and was attributed by the sole surviving attacker to the ISI's orders. ${ }^{176}$ By this time, Pakistan had shifted from a military dictatorship under Musharraf to a (loosely) democratic state, with President Asif al-Zardari condemning the attacks while denying Pakistani involvement. ${ }^{177}$ Despite the heavy casualties, India's response was very limited, with Prime Minister Manmohan Singh stating on November 29 that "he did not favour another Operation Parakram" and explicitly ruled against mobilizing troops. ${ }^{178}$ Limited strikes against Pakistan were also ruled out, with Army Vice-Chief M.L. Naidu stating that while

\footnotetext{
${ }^{174}$ Narang, Nuclear Strategy in the Modern Era, 275.

${ }^{175}$ Mainichi Japan, "Interview: Ex-Pakistani Pres. Musharraf Mulled Using Nukes against India after 2001 Attack," Mainichi Daily News, July 26, 2017, https://mainichi.jp/english/articles/20170726/p2a/00m/0na/018000c.

${ }^{176}$ Riedel, Avoiding Armageddon, 5-7.

177 Jane Perlez and Salman Masood, "Pakistan Denies Any Role in Mumbai Attacks," The New York Times, November 29, 2008, https://www.nytimes.com/2008/11/30/world/asia/30pstan.html.

${ }^{178}$ Pranab Dhal Samanta, "26/11: How India Debated a War with Pakistan That November," Indian Express, November 26, 2010, http://archive.indianexpress.com/news/2611-how-india-debated-a-war-withpakistan-that-november/716240/0.
} 
possible, they would be "'highly risky" and "would definitely lead to an escalated military conflict." ${ }^{\prime 179}$ Singh and his government instead opted for diplomatic outreach to Pakistan, despite facing considerable domestic pressure to punish Pakistan by the Bharatiya Janata Party (BJP) and elections in May 2009. ${ }^{180}$ By the end of December 2008, the crisis was resolved without further use of force, with Singh offering to reopen diplomatic relations with Pakistan in the upcoming Summit of the Non-Aligned Movement.

As with the earlier 2001-2002 crisis, evidence from 2008 indicates that the Indian government was deterred from retaliating by Pakistan's nuclear posture and its credibility. India continued to possess a conventional advantage, with armed forces totalling approximately 1.2 million personnel versus Pakistan's $617,000 .{ }^{181}$ Singh also faced considerable pressure to retaliate, as the BJP sought to capitalize on widespread dissatisfaction to make gains in the upcoming May 2009 elections. ${ }^{182}$ Even members of the government, such as Foreign Secretary Shivshankar Menon, favoured “'immediate visible retaliation of some sort." ${ }^{\prime 183}$ Though no explicit Pakistani threats were issued in 2008, its nuclear deterrence doctrine remained unchanged. This meant that any attack against Pakistan - even limited airstrikes - could trigger a disproportionate nuclear response, particularly since Zardari lacked control over the PAF to the point of being forced to resign as NCA Chairman a few days after the attack. ${ }^{184}$ The NCA's structure also means that generals on the ECC could choose to use nuclear weapons regardless of what civilian

\footnotetext{
179 Samanta, "26/11."

${ }^{180}$ Riedel, Avoiding Armageddon, 22.

${ }^{181}$ International Institute for Strategic Studies, "Chapter Seven: Central and South Asia Caribbean and Latin America," The Military Balance 109, no. 1 (2009): 345-350, 353-355.

182 Riedel, Avoiding Armageddon, 22-23.

${ }^{183}$ Vipin Narang and Paul Staniland, "Democratic Accountability and Foreign Security Policy: Theory and Evidence from India,” Security Studies 27, no. 3 (2018): 432.

${ }^{184}$ Abdullah, "Nuclear Ethics," 164.
} 
leaders decided. Singh and other Cabinet officials were aware of this risk, having raised the concern that "Pakistan could misjudge a conventional strike by India and trigger a nuclear response" when discussing possible responses to the attack. ${ }^{185}$ In short, it was believed that any attack against Pakistan in response could trigger a nuclear response, and the lack of civilian control in government meant that such sudden escalation was credible.

These two crises and the Kargil War support the hypothesis that non-democratic nuclear weapon states can more credibly deter armed attacks. All three instances mirrored past Indo-Pakistani crises in being the result of Pakistani provocations by military leaders or the ISI seemingly acting independently. Yet in all three instances, Indian responses proved limited to combat within their own borders at most, with the 2008 attack notably being met with diplomatic outreach despite calls for retaliatory strikes. This stands in sharp contrast with the pre-nuclear crises discussed in this chapter: similar provocations by Pakistan in 1965 and 1971 led to India directly attacking Pakistani territory in response, and the 1986-87 Brasstacks crisis almost led to war. This change is not attributable to India losing its conventional advantage against Pakistan - if anything, the gap has only grown wider over time. Rather, it is the result of Pakistan developing a nuclear deterrent that Indian leaders have believed to be credible.

All three post-nuclear acquisition crises studied share a common theme of Indian leaders considering Pakistani threats to use nuclear weapons in response to any attack to be credible, which corresponds to the theory's expectations for a non-democratic nuclear deterrent. These threats are made plausible largely due to the influence the PAF leadership

${ }^{185}$ Samanta, "26/11." 
wields over Pakistani governance even when it is not directly ruling the country, as well as its drawing support primarily from bureaucrats and wealthy elites rather than voting citizens. This enables Pakistan's generals to order the use of nuclear weapons despite control ostensibly being shared with civilian authorities with little regard for being held accountable by most Pakistanis. Furthermore, there would be a strong incentive for use in a crisis, given the conventional disadvantage and a widespread belief that India seeks to destroy Pakistan, meaning that any Indian attack could be construed as a potential existential threat. In short, Pakistan can credibly threaten to use nuclear weapons even in low-intensity crises due to the military and its elite supporters believing that any Indian attack could cause regime collapse and not being constrained by the need for popular support in devising a deterrent strategy. This perceived existential outlook also explains the apparent lack of concern towards India's own nuclear deterrent, since it would be assumed that any attack would already be a worst-case scenario for Pakistan.

\section{7: Alternative Explanations}

One potential alternative explanation for the lack of attacks against Pakistan is that it is protected by its alliances with the United States and China. China is one of Pakistan's most important allies and largest arms suppliers as well as being equally hostile towards India and expressing a willingness to intercede on Pakistan's behalf during crises. ${ }^{186}$ It also played a key role in Pakistan's nuclear weapons program, having illicitly provided technology and weapons designs. ${ }^{187}$ The US, meanwhile, became close to Pakistan due to Zulfikar Ali Bhutto's role in opening Sino-American relations and Zia acting as an

\footnotetext{
${ }^{186}$ Cohen, The Idea of Pakistan, 144; Talbot, A New History, 107.

${ }^{187}$ Kerr and Nikitin, "Pakistan's Nuclear Weapons," 3.
} 
intermediary for supplying anti-Soviet fighters in Afghanistan during the Soviet occupation. ${ }^{188}$ Since then, the US-Pakistan relationship has largely revolved around the War on Terror and Pakistan's support for regional US operations, though it has been strained by Pakistan's tolerance for Islamic militants within its own borders. ${ }^{189}$ Given this, potential Chinese and American retaliation via economic, political, or military means could have deterred India from attacking Pakistan during crises.

This explanation does not withstand closer scrutiny, however, as the threat of retaliation by Pakistan's allies was seemingly ignored in crises. Implicit and explicit warnings of Chinese intervention were present in pre-nuclear crises, but seemingly did nothing to deter India, particularly in the Second and Third Indo-Pakistani Wars. During the 1965 crisis, both Ayub Khan and Bhutto interpreted negative remarks about India by Marshal Ch'en Yi that year as a sign of Chinese support during a war despite no references to military assistance. ${ }^{190}$ China's most significant response was a September 17 ultimatum warning India to dismantle fortifications near Tibet or face " grave consequences"” that was fulfilled three days later. ${ }^{191}$ Likewise, Pakistan received little material support from its allies in 1971, though Kissinger is known to have warned Indian ambassador L.K. Jha that China would intervene on Pakistan's behalf and that India would not receive corresponding American support. ${ }^{192}$ Instead, the US and China largely restricted themselves to condemning India's actions at the UN, with the most extreme response being the

\footnotetext{
${ }^{188}$ Paul, The Warrior State, 56-57; Riedel, Avoiding Armageddon, 75.

${ }^{189}$ Paul, The Warrior State, 61-65.

${ }^{190}$ Ganguly, Conflict Unending, 42.

${ }^{191}$ Ganguly, Conflict Unending, 46.

${ }^{192}$ Ganguly, Conflict Unending, 65.
} 
deployment of the USS Enterprise to the Bay of Bengal to intimidate India. ${ }^{193}$ Indian offensives during pre-nuclear crises thus seem to have largely ignored Pakistan's alliances.

Such warnings were not issued during the studied post-nuclear crises by Pakistan's allies; in fact, Pakistan's aggression and threats led to its allies publicly condemning it. During the Kargil War, Pakistani leaders apparently believed that they would draw international support for their position on the Kashmir dispute and encourage an Indian non-response, but were instead widely condemned. ${ }^{194}$ US officials attempted to pressure Pakistan into ending hostilities throughout June 1999, culminating in Clinton warning that Sharif was "'messing with nuclear war"” and demanding that Pakistani forces withdraw from Indian territory. ${ }^{195}$ The 2001-2002 crisis, meanwhile, demonstrated little evidence of any Chinese involvement at all, much less defending Pakistan, while the Bush administration sided with India in pressuring Musharraf despite needing his support in the nascent War on Terror. ${ }^{196}$ US-Pakistani relations have only continued to sour over time due to improving US-India ties, rendering its role in deterrence moot.

Other potential explanations similarly fail to hold up. For one, Pakistan has never held a conventional military advantage against India, with the latter having 2-3 times as many troops and vehicles as Pakistan, as well as higher overall military expenditure. ${ }^{197}$ In fact, relying solely on conventional forces for deterrence proved to be an utter failure in all pre-nuclear acquisition crises save for Brasstacks, when nuclear threats were issued. As discussed in chapter 6 , the stability-instability paradox also falls short in that it fails to

\footnotetext{
193 Riedel, Avoiding Armageddon, 76-77.

${ }^{194}$ Kasturi, "The State of War," 150-152.

195 Sechser and Fuhrmann, Nuclear Weapons and Coercive Diplomacy, 149.

${ }^{196}$ Chari, Cheema, and Cohen, Four Crises, 172, 178.

197 Stockholm International Peace Research Institute, "SIPRI Military Expenditure Database 2019."
} 
explain why Pakistani leaders consider Indian nuclear deterrence non-credible for lowintensity conflict while the reverse is not the case for their Indian counterparts. Finally, while a security dilemma appears to be present (seen in the nuclear arms racing between India and Pakistan), it does not appear to have encouraged either side to attack. Instead, the comparatively few Indian attacks against Pakistan have been in response to incursions and other provocations.

\section{8: Conclusion: Deterrence at any Price}

History makes it clear that Pakistan's nuclear deterrent has largely been successful in deterring both low- and high-intensity attacks. In the three post-1998 crises studied in this chapter, evidence shows that Pakistan's nuclear arsenal has played a sizable role in the Indian government's refusal to expand hostilities beyond its own borders. This has been especially influenced by Pakistani civilian and military leaders threatening to respond to even minor incursions with nuclear weapons, to say nothing of larger-scale invasions reminiscent of the 1965 and 1971 wars. These threats are made credible largely by the military's predominant role in governing Pakistan directly or indirectly, given its

consistently aggressive stance towards the perceived existential threat of India. In particular, it means that Pakistani military leaders can force the government to use nuclear weapons in response to any Indian attack and grant launch authority to battlefield commanders. In essence, Pakistan's regime type allows it to maintain a hair trigger for its nuclear deterrent and makes its threats more plausible by removing almost all checks on its use, discouraging virtually any attacks against the state up to this point.

These traits and the shift in conflict behaviour towards Pakistan supports the theory that a nuclear weapon state's regime type influences the credibility of its nuclear deterrence 
threats, and thus the likelihood of their being attacked. Specifically, it supports hypothesis H2(b)'s claim that non-democratic states will not be targeted with low-intensity armed attacks or limited wars after developing a nuclear deterrent. This sets Pakistan apart from India and Israel, both nuclear democracies that have continued to be the target of lowintensity armed attacks despite possessing nuclear weapons. While their elites are accountable to voters, Pakistan's government relies on the continued support of the military, which has proved willing to replace uncooperative leaders, as well as its own supporters in the bureaucracy and elite. This gives it much greater leeway in fulfilling its nuclear deterrence threats, since the military's lack of accountability to Pakistani citizens makes it relatively insensitive to the costs of its policies. As discussed in the following chapter, this makes it more like North Korea, which has a government accountable only to elite supporters and thus is insensitive to the potential costs of its nuclear deterrence policies to its own citizens. 


\section{Chapter 8: North Korea}

\section{1: Introduction}

The final country studied in this dissertation is the Democratic People's Republic of Korea (DPRK), more commonly known as North Korea. Since gaining independence in 1948, and despite its small size and relative poverty, North Korea has become infamous for its highly authoritarian government, its hostility towards South Korea, the US, and Japan, and its possession of nuclear weapons. ${ }^{1}$ These traits have led to it being involved in numerous crises despite it being significantly weaker than South Korea and the US, though the only war to have actually occurred is the Korean War (1950-1953). This is especially noteworthy, given that several of these crises, particularly the two nuclear crises (19921994; 2006-present), had the US consider launching pre-emptive strikes against North Korea before relenting. However, this can be explained by how the North Korean government and its elite supporters prioritize their own interests and continued survival regardless of cost, even the well-being of the rest of the population, and have demonstrated this in both domestic and foreign policy. ${ }^{2}$

The chapter studies how North Korea's government, particularly its lack of accountability beyond elites and its near-total insensitivity to costs imposed on its populace, has made its nuclear deterrent credible even against low-intensity attacks by

\footnotetext{
${ }^{1}$ Accurate figures are difficult to come by due to North Korea's isolationist stance, but the population is estimated to be around 24-25 million people, while GDP per capita is estimated at around US\$1700. Choonsik Yoo, "North Korea's Economy Tanks as Sanctions, Drought Bite: South Korea," Reuters, July 26, 2019, https://www.reuters.com/article/us-northkorea-economy-gdp-idUSKCN1UL08G.

${ }^{2}$ In this sense, North Korean audiences (the political and military elite) depart from traditional models of audience costs by focusing on crisis outcomes (their continued survival and prosperity) rather than whether the leadership is consistent or overly belligerent in its threats. See William G Nomikos and Nicholas Sambanis, "What Is the Mechanism Underlying Audience Costs? Incompetence, Belligerence, and Inconsistency," Journal of Peace Research 56, no. 4 (2019): 575-88.
} 
studying crises during the 1948-2018 period. It begins with an evaluation of North Korea's regime type, including how the Kim family maintains its power by rewarding supporters and crushing dissent. This is followed by a study of pre-nuclear crises, including the Korean War (1950-1953), several subsequent major crises between it and the US, and the first nuclear crisis (1992-1994). What information has been extrapolated about North Korea's nuclear doctrine and command and control structure is discussed, including the central role of current Supreme Leader Kim Jong Un. Post-nuclear acquisition crises are then studied, including the ongoing nuclear crisis stemming from its 2006 test explosion, the 2010 sinking of the ROKS Cheonan, and the 2015 landmine incident. The evaluation of these crises focuses on whether decision-makers accounted for North Korea's nuclear deterrence threats and how it ultimately affected their calculations. Alternative explanations, such as the possible role of North Korea's alliances with the Soviet Union and China in deterrence, are also examined.

The chapter's main finding is that North Korea's nuclear deterrent has been bolstered by its status as a cost-insensitive authoritarian regime, to the point that successive US and South Korean governments considered its retaliatory threats credible; however, its aggression over the years may have created a security dilemma. North Korean ideology, which emphasizes absolute loyalty to the Supreme Leader and total self-sufficiency to withstand foreign hostility, justifies imposing massive costs on its populace for almost any policy with no regard for popular sentiment. This is readily apparent in the ruling Kim family's numerous infiltration efforts and attacks against South Korea, as well as their economic mismanagement leading to hundreds of thousands starving to death in the 
1990s. ${ }^{3}$ Despite being left a poor and isolated state, the Kim family remains in power by buying the support of a winning coalition of elites in the in the Korean Workers' Party (KWP) and Korean People's Army (KPA), while the remaining population is marginalized, closely adhering to selectorate theory. ${ }^{4}$ This makes North Korea vastly different from the two democracies studied in this program, as India and Israel are forced to balance their deterrence threats with the need to minimize the costs to their citizens in order for governments to remain in office. Pakistan, meanwhile, is much closer to North Korea in having decisions dictated by military leaders and civilian elites, albeit to a lesser extent.

These characteristics have translated to a demonstration of resolve for North Korea that makes even its most extreme threats appear credible, albeit at the expense of potentially encouraging pre-emptive attacks against it. The Kim family's central role, the repressive means used to maintain its power and that of its supporters, and the subsequent costs to its citizens act as a signal that the government will do anything to stay in power. The KPA's relative weakness and elite fears that losing power would be fatal have led to extreme paranoia that any attack is a potential existential threat. While these discouraged attacks against North Korea before 2006, its nuclear arsenal now means that even a show of force risks inadvertently triggering a nuclear war. This appears to support hypothesis H2(b)'s claim that non-democratic states will not be targeted with low-intensity attacks or limited war after developing a nuclear deterrent. However, North Korea's nuclear arsenal and aggressiveness has unintentionally created a security dilemma with the US and South Korea. The credibility of its nuclear deterrence threats, combined with its perceived

\footnotetext{
${ }^{3}$ Stephan Haggard and Marcus Noland, Hard Target: Sanctions, Inducements, and the Case of North Korea (Redwood City: Stanford University Press, 2017), 2.

${ }^{4}$ Bruce Bueno de Mesquita and Alastair Smith, The Dictator's Handbook: Why Bad Behaviour Is Almost Always Good Politics (New York: PublicAffairs, 2011), 6, 17-18.
} 
aggression and newfound ability to directly strike the US, could encourage the US to launch pre-emptive strikes against North Korea. In effect, North Korea's nuclear arsenal may prove to be a double-edged sword for the so-called hermit kingdom.

\section{2: The Archetypal Authoritarian Regime: Evaluating North Korean Governance}

North Korea is generally considered one of the most repressive states in the world. Critics often compare it to the Soviet Union under Stalin or George Orwell's Nineteen Eighty-Four, citing the absence of any freedoms, harsh punishments for political dissent, and the absolute control the Kims and their supporters wield over every aspect of society. ${ }^{5}$ North Korea's political system is expressly designed to keep the Kims, the KWP, and KPA in power by buying elite support with wealth and privileges. Most of the population is strictly policed for any dissent, and is deemed so irrelevant to maintaining power that the cost of failed policies on them are largely ignored. North Korea's government is a nearperfect example of Bruce Bueno de Mesquita and Alistair Smith's selectorate theory, since the government's provision of private rewards to a small elite audience allows it to implement policy with no regard for the broader population. ${ }^{6}$

Numerous studies have found that North Korea demonstrates virtually every trait associated with authoritarianism, leading to being ranked at the very bottom of democracy indices. The Polity 5 Project, as seen in Figure 8.1, has given North Korea a democracy score of 0/10 every year since 1948, while its autocracy score has steadily increased from

\footnotetext{
${ }^{5}$ Michael Hirsh, "How Kim Jong Il Became the Most Successful Dictator in Modern History," The Atlantic, December 19, 2011, https://www.theatlantic.com/international/archive/2011/12/how-kim-jong-ilbecame-the-most-successful-dictator-in-modern-history/250194/.

${ }^{6}$ Bueno de Mesquita and Smith, The Dictator's Handbook, 6, 17-18
} 


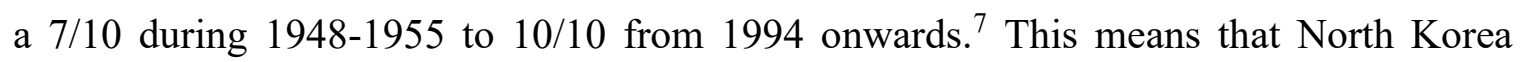
possesses an overall score of -10 on its 21-point scale, comparable only to Saudi Arabia, Qatar, and Bahrain in the post-1945 period. The Economist Intelligence Unit's Democracy Index, meanwhile, has consistently ranked North Korea as the worst of 167 states since 2006, noting it as totally lacking in electoral processes, civil liberties, and pluralism, with general political participation being functionally impossible. ${ }^{8}$ Freedom House similarly ranks North Korea as "Not Free," describing it as a "dynastic totalitarian dictatorship."" The overall image painted by these and other democracy indices indicates that North Korea is perhaps the most extreme example of an authoritarian regime in the international system today.

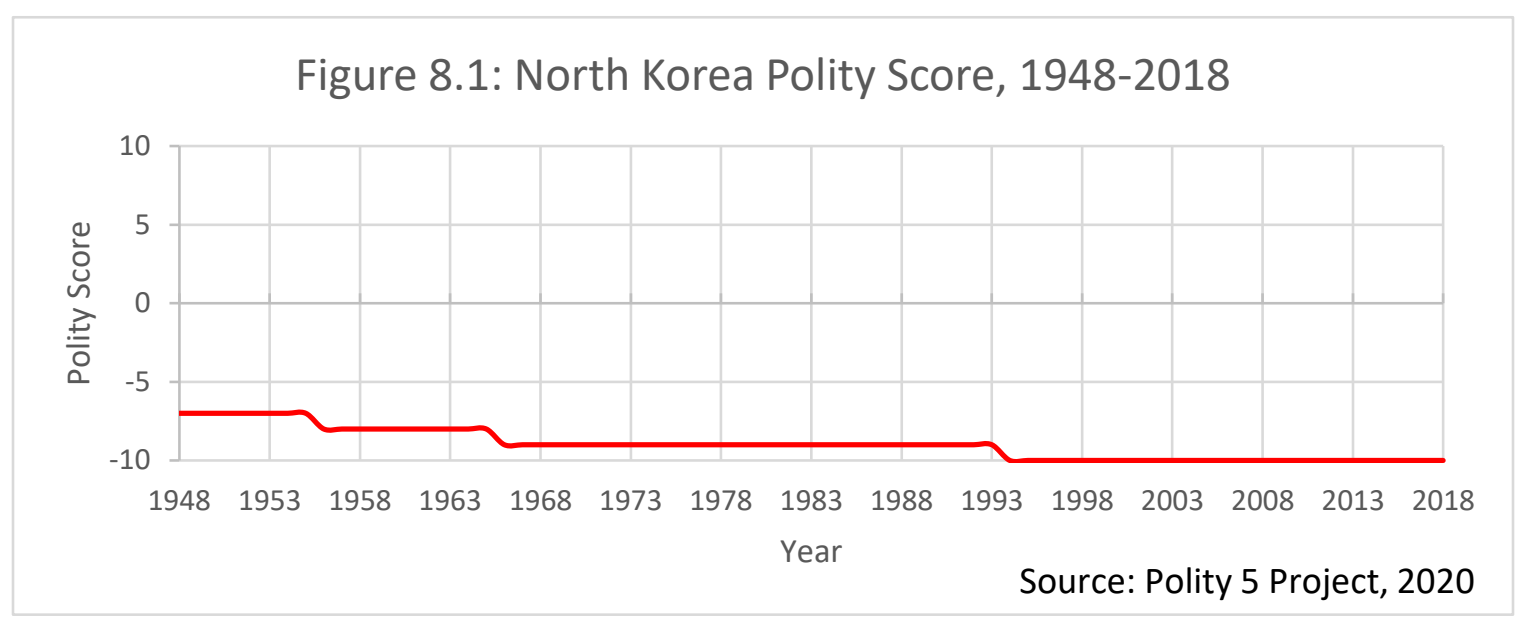

North Korea was originally established as a socialist state under KWP rule, but the emergence of a Kim dynasty and the party's subordinate position makes it a hereditary monarchy in all but name. The KWP is the only legal political party in North Korea, with

\footnotetext{
${ }^{7}$ Center for Systemic Peace, "Polity 5 Annual Time-Series, 1946-2018," Center for Systemic Peace, April 23, 2020, http://www.systemicpeace.org/inscr/p5v2018.xls.

${ }^{8}$ Economist Intelligence Unit, Democracy Index 2018: Me too? Political participation, protest and democracy (London: Economist Intelligence Unit, 2019), 40.

9 "Freedom in the World 2020: North Korea," Freedom House, 2020, https://freedomhouse.org/country/north-korea/freedom-world/2020.
} 
a membership of around three million, or roughly $16 \%$ of the country's population. ${ }^{10}$ The KWP's charter states that government decisions are made by the Central Committeeappointed Politburo, though it has been a rubber stamp since Kim Il Sung consolidated his power in the 1950s. ${ }^{11}$ Instead, nominally subordinate bodies such as the Presidium and National Defence Commission (NDC) are considered the state's true decision-makers. ${ }^{12}$ Kim Jong Il's reign saw him expand the NDC's authority from national security and defence to all political affairs, making it North Korea's most powerful institution and elevating his position as NDC chairman to being second only to his father's title of Eternal President. ${ }^{13}$ This lasted until his son Kim Jong Un ordered the NDC's dissolution and replacement with the State Affairs Commission in 2016, which directs all policy relating to state sovereignty. ${ }^{14}$

Despite shifts in North Korea's ruling ideology, it consistently extolls isolationism, a strong military, and unquestioning fealty to the Kims and the KWP. Juche, which was unofficially practiced since 1955, emphasized the need for national self-reliance and isolation due to foreign hostility and demanded total obedience to the KWP and the Supreme Leader. ${ }^{15}$ The Korean War and the international community's perceived hostility have justified this and a strong military, with propaganda and strict limits on travel and

\footnotetext{
${ }^{10}$ Ken Gause, "Chapter 2: The Role and Influence of the Party Apparatus," in Kyung-ae Park and Scott Snyder, eds., North Korea in Transition: Politics, Economy, and Society (Plymouth: Rowman and Littlefield, 2013), 21.

${ }^{11}$ Gause, "The Role and Influence," 23-24.

12 Gause, "The Role and Influence," 23-24.

13 Jongseok Woo, "Structural Impediments, Domestic Politics, and Nuclear Diplomacy in Post-Kim Il-Sung North Korea," Pacific Focus 30, no. 1 (2015): 70

${ }^{14}$ Anna Fifield, The Great Successor: The Divinely Perfect Destiny of Brilliant Comrade Kim Jong Un (New York: PublicAffairs, 2019), 190.

${ }^{15}$ Victor Cha, The Impossible State: North Korea, Past and Future (New York: HarperCollins Publishers Inc, 2012), 37-38, Kindle edition; Rajaram Panda, "North Korea's Nuclear Policy: Domestic Determinants, Strategy and Future," Journal of Comparative Asian Development 10, no. 2 (2011): 228.
} 
foreign contacts reinforcing these views. ${ }^{16}$ Juche was formally replaced by songun ("military first") after 1992 constitutional revisions elevated the KPA and expanded the NDC's authority.$^{17}$ Songun continued to emphasize state self-reliance and the KPA's importance, with a February 1997 editorial in the government-controlled Rodong Sinmun stating that "Without the army, there exists no people, no state, and no party." 18 Songun was itself replaced by byungin ("parallel development") in 2013, which equally emphasized nuclear weapons and the economy while making the KWP and KPA equal. ${ }^{19}$ Byungjin appears to have itself been replaced by a new variant of juche that wholly emphasizes the economy, as Kim Jong Un stated that the former was "over" in a 2018 KWP meeting. ${ }^{20}$ Despite the changes, North Korean ruling ideology has consistently advocated national isolation and unquestioning loyalty for survival to justify repression.

North Korean governance conforms very closely to selectorate theory, with the Kim family bribing a winning coalition of elites with various privileges and material benefits for their support while ignoring the ancillary general population. Kim Il Sung's inner circle originally consisted of fellow anti-Japanese guerillas appointed to key positions to reward their loyalty and counter rival KWP factions present until the 1970s. ${ }^{21}$ Kim Jong Il instead relied on anywhere between 200 and 5,000 military officers, party officials, bureaucrats, and family members like his sister Kim Kyong Hui and her husband, NDC vice-chairman

\footnotetext{
${ }^{16}$ Vaclav David, A. M. Puzanov, and Kohousek, "Report on Political Development in the DPRK," April 18, 1961, State Central Archive in Prague, translated by Adolf Kotlik, History and Public Policy Program Digital Archive, https://digitalarchive.wilsoncenter.org/document/116752.

${ }^{17}$ Sung Chull Kim, North Korea under Kim Jong Il: From Consolidation to Systematic Dissonance (Albany: State University of New York Press, 2006), 81-82; Woo, "Structural Impediments," 70.

${ }^{18} \mathrm{Kim}$, North Korea under Kim Jong Il, 91-92.

${ }^{19}$ Haggard and Noland, Hard Target, 7.

${ }^{20}$ Fifield, The Great Successor, 260.

${ }^{21}$ Etel Solingen, Nuclear Logics: Contrasting Paths in East Asia \& The Middle East (Princeton: Princeton University Press, 2007), 129.
} 
Jang Song Thaek. ${ }^{22}$ KPA support was particularly important due to its supporting Kim Jong Il's ascension after he used his position as general secretary to promote loyal officers; the KWP, meanwhile, was deemed useless due to its economic policies failing in the 1990s. ${ }^{23}$ High-ranking KPA officers were rewarded with greater influence over governance through songun and the NDC's expanded role, in addition to enriching themselves with their control of defence-related economic sectors. ${ }^{24}$

Kim Jong Un's support base has shifted considerably. It now largely centres on younger elites to ensure long-term support, including wealthy donju ("masters of money") and individuals critical to nuclear weapons development. ${ }^{25}$ Many of Kim Jong Il's supporters have been purged in turn: Vice Marshal Ri Yong Ho vanished in 2012, while General Hyon Yong Chol was executed with anti-aircraft guns in 2016 for supposedly falling asleep while Kim Jong Un was speaking. ${ }^{26}$ Most infamously, Kim's uncle Jang Song Thaek was expelled from the KWP, stripped of his titles, and executed in December 2013 for his ties to China and demands for economic reform. ${ }^{27}$ These purges have been extensive, with an estimated 100 of the top 200 government officials having been replaced by $2018 .{ }^{28}$ The mass purges are likely due to Kim Jong Un taking power relatively quickly

\footnotetext{
${ }^{22}$ Daniel Byman and Jennifer Lind, "Pyongyang's Survival Strategy: Tools of Authoritarian Control in North Korea," International Security 35, no. 1 (2010): 60.

${ }^{23}$ Gause, "The Role and Influence," 25.

${ }^{24}$ Terence Roehrig, "Chapter 3: The Role and Influence of the Military," in North Korea in Transition: Politics, Economy, and Society, ed. Kyung-Ae Park and Scott Snyder (Lanham: Rowman and Littlefield, 2013), 55-61; Solingen, Nuclear Logics, 126.

${ }^{25}$ Fifield, The Great Successor, 147, 157.

${ }^{26}$ Fifield, The Great Successor, 131.

${ }^{27}$ Hanhee Lee, "Analyzing the Political Survival Prospects of Kim Jong-Un's North Korean Regime through the Framework of Selectorate Theory," Japanese Journal of Political Science 19, no. 3 (September 2018): 480-481.

${ }^{28}$ Emma Chanlett-Avery et al., "North Korea: U.S. Relations, Nuclear Diplomacy, and Internal Situation," Congressional Research Service Report (Washington, DC: United States Congressional Research Service, July 27, 2018), 4, https://crsreports.congress.gov/product/pdf/R/R41259.
} 
compared to the decades his father spent cultivating support. ${ }^{29}$ While Kim Jong Un appears to have solidified his rule, he is still largely dependent on elite support for his government.

The Kim family has taken numerous steps to stamp out political dissent, such as the songbun caste system. This system divides North Koreans into core, hostile, and wavering castes. ${ }^{30}$ Core members, who constitute around $15 \%$ of the population and are descended from the anti-Japanese resistance and pre-independence lower class, enjoy various privileges such as the right to live in Pyongyang and receiving better education, homes, and food than other citizens. ${ }^{31}$ These are contingent on absolute fealty to the regime, and any sign of dissent can lead to demotion to wavering or hostile status. Roughly $40 \%$ of North Koreans are in the hostile caste, which is made up of the descendants of Japanese collaborators, businessmen, defectors, and criminals, and have virtually no rights. ${ }^{32}$ Finally, the wavering caste serves as a peasant class, and is better treated than the hostiles without enjoying the privileges of the core. ${ }^{33}$ Songbun reduces the impact of food and resource shortages by allocating more to the core while leaving the wavering and hostile castes to starve. ${ }^{34}$ The system also discourages uprisings, as core members fear losing their privileges and the lower castes lack the resources.

North Korea's government also has near-total control over political activity, information, and movement. These policies emerged relatively early on, with allied Soviet diplomats noting government efforts to curtail foreign contacts in $1961 .^{35}$ This has

\footnotetext{
${ }^{29}$ Lee, "Political Survival Prospects," 476-477.

${ }^{30}$ Cha, The Impossible State, 185.

${ }^{31}$ Fifield, The Great Successor, 121.

${ }^{32}$ Cha, The Impossible State, 185; Fifield, The Great Successor, 121.

${ }^{33}$ Byman and Lind, "Pyongyang's Survival Strategy," 62.

${ }^{34}$ Byman and Lind, "Pyongyang's Survival Strategy," 62.

${ }^{35}$ David, Puzanov, and Kohousek, "Report on Political Development in the DPRK."
} 
expanded to outright prohibitions on unsanctioned foreign travel, with efforts to emigrate to China being punishable with five years of labour. ${ }^{36}$ The KWP's status as the only legal party and its control over all civil organizations, which it creates, operates, and monitors, makes independent civil society impossible. ${ }^{37}$ All domestic media is state-run, and possessing any foreign media, including something as innocuous as South Korean soap operas, is punishable with imprisonment. ${ }^{38}$ Journalists have reported that all North Korean homes have radios regularly playing propaganda that cannot be turned off or switched to other stations. ${ }^{39}$ Only core members with explicit permission have Internet access to select websites, and cell phones can only make calls within North Korea. ${ }^{40}$ Even freedom of movement is non-existent due to the presence of military checkpoints on the main roads of every city and town. ${ }^{41}$ In short, it is almost impossible for North Koreans to legally access non-government sanctioned information. This has ramifications for audience costs, since any citizen with information contradicting the government would be unable to act on it without being harshly punished, and leader accountability is thus greatly reduced.

The government's legitimacy largely relies on the Kim family's cult of personality. This cult was established around the Korean War and grew enough by 1955 that Soviet and

\footnotetext{
${ }^{36}$ Bureau of Democracy, Human Rights, and Labour, "Country Reports on Human Rights Practices for 2011: Korea, Democratic People's Republic Of,” Bureau of Democracy, Human Rights and Labor Country Reports on Human Rights Practices for 2011 (Washington, DC: United States Department of State, 2011), 13-14, https://2009-2017.state.gov/documents/organization/186491.pdf.

${ }^{37}$ Byman and Lind, "Pyongyang's Survival Strategy," 49.

${ }^{38}$ Victor Cha and Nicholas Anderson, "Chapter 5: North Korea after Kim Jong Il," in North Korea in Transition: Politics, Economy, and Society, ed. Kyung-Ae Park and Scott Snyder (Lanham: Rowman and Littlefield, 2013), 100.

${ }^{39}$ Fifield, The Great Successor, 113.

${ }^{40}$ Fifield, The Great Successor, 114.

${ }^{41}$ Bureau of Democracy, Human Rights, and Labour, "Country Report 2011," 12-13.
} 
Chinese officials expressed their concerns to Kim Il Sung. ${ }^{42}$ The cult's growth was encouraged via purges of Kim Il Sung's political opponents, particularly those opposing isolationism, as well as co-opting Confucian traditions of filial piety to make him the metaphorical father of the state. ${ }^{43}$ Once Kim Il Sung died in 1994, a constitutional revision posthumously deified him as Eternal President, with Kim Jong Il following suit as Eternal General Secretary after his death in $2012 .{ }^{44}$ Portraits of the three Kims are required in all public squares, houses, and offices, with an estimated 34,000 monuments to Kim Il Sung alone throughout the country. ${ }^{45}$ Criticizing the Kims or defacing or simply failing to maintain their images is considered a criminal offence. ${ }^{46}$ This cult of personality makes open criticism of the government impossible while reinforcing the need for total obedience.

Any actual dissent in North Korea is severely punished. As discussed previously, most forms of dissent are punished by hard labour or outright execution. The most infamous punishment is being sentenced to special prison camps known as the kwanliso for crimes such as trying to leave the country without authorization, possessing foreign media, or improper care of a portrait of the Supreme Leader. ${ }^{47}$ The families of dissenters are also at risk due to a family responsibility principle allowing up to three generations to be imprisoned. ${ }^{48}$ Kwanliso conditions are notoriously poor due to prisoners being subject

\footnotetext{
${ }^{42}$ Fifield, The Great Successor, 21; Anastas Ivanovich Mikoyan and Il Sung Kim, "Telegram from A. Mikoyan to the CPSU Central Committee" (September 23, 1956), GARF, Fond 5446, Opis 98c, Delo 718, Listy 3-6, translated by Gary Goldberg, History and Public Policy Program Digital Archive, https://digitalarchive.wilsoncenter.org/document/120189.

${ }^{43}$ Miroslav Holub, "Report from East German Ambassador to North Korea, 'Some Aspects of the Political Line of the Korean Workers' Party after the January Events" (February 15, 1968), Archives of the Ministry of Foreign Affairs. Translated for NKIDP by Vojtech Mastny, History and Public Policy Program Digital Archive, https://digitalarchive.wilsoncenter.org/document/113196; Cha, The Impossible State, 40.

${ }^{44}$ Gause, "The Role and Influence," 26.

${ }^{45}$ Paul French, North Korea: State of Paranoia, (London: Zed Books, 2014), 99-100.

${ }^{46}$ French, State of Paranoia, 99.

${ }^{47}$ Haggard and Noland, Hard Target, 42.

${ }^{48}$ Chanlett-Avery et al., "North Korea," 18-19.
} 
to starvation diets, 18 hours of manual labour daily, beatings, and torture, with so few being released that it is effectively a death sentence. ${ }^{49}$ This further deters any form of dissent, with even minor protests risking imprisonment and death for entire families.

The North Korean government's focus on retaining power above all else means that it prefers letting citizens starve or die en masse over potentially losing control by opening its borders. The most notable example is the 1994-1997 Arduous March (gonaneui haenggun), when economic mismanagement, the end of Soviet food imports, and droughts and floods led to an estimated $600,000-1,000,000$ people starving to death and many more fleeing the country. ${ }^{50}$ Food shortages were so severe that even rank-and-file KPA soldiers, normally a priority in food distribution, suffered from malnourishment. ${ }^{51}$ Kim Jong Il's government reluctantly accepted international aid, but demanded that aid organizations allow the government to distribute food, and also spent over US\$1 billion expanding his father's tomb in the Kumsusan Palace of the Sun. ${ }^{52}$ This refusal to cede any control likely stems from Kim Il Sung and Kim Jong Il observing how Eastern European counterparts like Romania's Nicolae Ceausescu were subsequently overthrown and executed. ${ }^{53}$ Continued elite support and the perceived dangers of liberalization have likely convinced North Korean leaders that allowing large numbers of their own citizens to die is preferable to risking regime survival, even during crises.

\footnotetext{
${ }^{49}$ According to journalist Anna Fifield, there are no reports of any prisoners being released from any kwanliso in 2011. See Fifield, The Great Successor, 125-127.

${ }^{50}$ Woo, "Structural Impediments," 66-67; Haggard and Noland, Hard Target, 2.

${ }^{51}$ French, State of Paranoia, 326.

${ }^{52}$ Haggard and Noland, Hard Target, 115-116; Byman and Lind, "Pyongyang's Survival Strategy," 52.

${ }^{53}$ Haggard and Noland, Hard Target, 7.
} 
These measures have stifled most, but not all, expressions of protest against the North Korean government. Notably, currency reforms in November 2009 requiring citizens to exchange their currency for new dominations so the government could reassert economic control sparked a wave of protests due to wiping out the savings of many households. ${ }^{54}$ Various acts of protest ensued, including graffiti criticizing Kim Jong Il, police being attacked, and the public burning of old won - all punishable with imprisonment or death. ${ }^{55}$ The government gave in to popular demand by increasing the exchange limit, executing Planning and Finance head Pak Nam Gi as a scapegoat, and Kim Jong Il publicly apologizing. ${ }^{56}$ Officially, 12 people were executed for protesting, though the actual number may be as high as $52 .{ }^{57}$ There have been some other instances of popular protest, including sporadic clashes with the KPA throughout the 1980s and student protests at Kim Il Sung University in 1990, these appear to be exceptional. ${ }^{58}$ Overall, however, North Korea's tools of repression have been successful in stamping out internal dissent.

\section{3: “'We will turn Seoul into a sea of fire:"” Key Pre-Nuclear Crises and Conflicts}

North Korean history has been defined by hostilities with South Korea and its allies, particularly the US, and the resulting crises. The Correlates of War Project's Militarized Interstate Dispute (MID) dataset lists 45 MIDs between 1948 and 2006, 33 of which led to North Korean forces being put on alert or clashing with South Korean and American

\footnotetext{
${ }^{54}$ Marcus Noland, "North Korea's Failed Currency Reform," Peterson Institute for International Economics, March 2, 2016, https://www.piie.com/commentary/op-eds/north-koreas-failed-currencyreform; Panda, "North Korea's Nuclear Policy," 238.

${ }^{55}$ Justin McCurry, "Senior Communist Falls Victim to North Korea's Currency Disaster," The Guardian, February 3, 2010, https://www.theguardian.com/world/2010/feb/03/north-korea-won-currency-revaluation.

${ }^{56}$ Andray Abrahamian, “North Korea’s Bounded Rationality,” Survival 61, no. 1 (2019): 146.

${ }^{57}$ Cha, The Impossible State, 158.

${ }^{58}$ Cha and Anderson, "North Korea after Kim Jong Il," 110.
} 
forces. ${ }^{59}$ This section focuses on four key crises involving North Korea prior to its October 2006 nuclear test. The Korean War (1950-1953) notably shaped North Korean relations with South Korea and the US and encouraged deterrence through aggression. Relatively minor incidents such as the 1968 capture of the USS Pueblo and the 1976 axe murder incident escalated into serious crises where the US contemplated using force and, for the latter, conducted a massive show of force with Operation Paul Bunyan. The last major prenuclear crisis was the first nuclear crisis (1992-1994), which saw various states attempt to halt North Korean nuclear weapons development and had the Clinton administration consider pre-emptive strikes before opting for diplomacy.

In three of these crises, North Korean authoritarianism and aggression successfully signalled deterrence threat credibility to American and South Korean officials, with the potential costs discouraging retaliation for its provocations. The Korean War is an exception, as the Eisenhower administration was deterred from using nuclear weapons by the possibility of nuclear war with the Soviet Union and concerns over domestic and international opinion. The other crises studied had the US and South Korea constrained by North Korean threats to attack South Korea with its 13,000-piece artillery force and massive military. ${ }^{60}$ These threats were made credible by past aggression, Kim Il Sung and Kim Jong Il's fear of being overthrown, and a disregard for human costs demonstrated by their domestic policies. These traits led US officials to respond to the 1968 and 1976 incidents with shows of force, as anything else risked provoking war. Finally, the Clinton

\footnotetext{
${ }^{59}$ In practice, some MIDs represent multiple incidents; for example, \#4018 represents a series of 42 incidents between January and April 1993 where North Korean forces fired at Chinese border guards. Glenn Palmer et al., "Updating the Militarized Interstate Dispute Data: A Response to Gibler, Miller, and Little," International Studies Quarterly 64, no. 2 (2020): 469-75.

${ }^{60}$ Cha, The Impossible State, 219-220.
} 
administration opted for negotiations during the first nuclear crisis due to pre-emptive airstrikes potentially leading massive American and South Korean casualties in retaliatory attacks.

\subsection{1: The Korean War (1950-1953)}

The roots of the Korean War lie in the original division of Korea along the $38^{\text {th }}$ parallel in 1945. The failure of the US-Soviet Joint Commission to establish a unified state led to North and South Korea holding their own elections in May and August 1948 that led to Kim Il Sung's Soviet-backed government and Syngman Rhee's UN-recognized ROK government. ${ }^{61}$ Both sought to forcibly unify the peninsula, though while Rhee's democratic-in-name-only government was stymied by North Korea-backed rebels from 1948 onwards, Kim Il Sung believed that a KPA invasion would encourage South Korean peasants to rebel and join his side. ${ }^{62}$ Kim was eventually granted permission to invade by Joseph Stalin in April 1950 along with economic and military aid on the condition that that Mao Zedong provide direct military support to the KPA if necessary. ${ }^{63}$ By mid-1950, the North Korean military had 201,000 well-equipped and well-trained troops, in contrast to South Korea's 103,827 troops, a token American force of 200-300 soldiers, and additional American forces stationed in Japan. ${ }^{64}$

\footnotetext{
${ }^{61}$ United Nations General Assembly, "United Nations General Assembly Resolution 195(III): The Problem of the Independence of Korea" (December 12, 1948), United Nations Documents, https://undocs.org/en/A/RES/195(III).

${ }^{62}$ Van Jackson, On the Brink: Trump, Kim, and the Brink of Nuclear War (Cambridge: Cambridge University Press, 2018), 15.

${ }^{63}$ Jonathan D. Pollack, No Exit: North Korea, Nuclear Weapons, and International Security (London: International Institute for Strategic Studies, 2011), 31-32.

${ }^{64}$ Il-Song Park, "Chapter 18: Republic of Korea Army," in The Ashgate Research Companion to the Korean War, ed. James Irving Matray and Donald W. Jr. Boose, eBook (Farnham: Routledge, 2014), 245.
} 
The Korean War was triggered by the KPA invading South Korea on June 25, 1950.

North Korea and other Soviet allies claimed without evidence that it was responding to a failed South Korean invasion. ${ }^{65}$ The military disparity meant that Seoul was captured in three days and the peninsula was largely occupied by August, with South Korean and American forces retreating to Busan. ${ }^{66}$ The UN Security Council passed Resolution 83 on June 27, calling for North Korea's withdrawal and recommending that member states assist South Korea "as may be necessary to repel the armed attack," allowing a US-led 16-state coalition to intervene as a "police action." ${ }^{" 67}$ The UN coalition forces landed in Incheon on September 15 and recaptured Seoul by September 25, though a massive bombing campaign of North Korean cities had begun around June 29 ${ }^{68}$ Supreme Allied Commander Douglas MacArthur escalated the conflict by attempting to invade North Korea despite warnings from China over the potential threat of a contiguous US-aligned Korea. ${ }^{69}$ By October, China sent troops to aid North Korea as a People's Volunteer Army (PVA) which, along with the KPA, received support from the Soviet Union. ${ }^{70}$ This led to both sides being caught in a stalemate until an armistice was signed on July 27,1953 . The conflict proved

\footnotetext{
${ }^{65}$ Terenti Shtykov, "Report of the DPRK Ministry of Internal Affairs" (June 25, 1950), translated by Gary Goldberg, History and Public Policy Program Digital Archive, https://digitalarchive.wilsoncenter.org/document/114909; Fifield, The Great Successor, 20.

${ }^{66}$ Pollack, No Exit, 32.

${ }^{67}$ United Nations Security Council, "Resolution 83: Complaint of Aggression upon the Republic of Korea," S/1511 § (1950), http://unscr.com/en/resolutions/83; Jackson, On the Brink, 16.

${ }^{68}$ According to US estimates, the bombing campaign involved the use of 635,00 tons of explosives, greater than the 503,000 used in the Pacific during the Second World War. See Fifield, The Great Successor, 20; Jackson, On the Brink, 16-17.

${ }^{69}$ Cha, The Impossible State, 317.

${ }^{70}$ Pollack, No Exit, 32-33; Georgii Maksimilianovich Malenkov et al., "Record of a Conversation between Stalin, Kim Il Sung, Pak Heon-yeong, Zhou Enlai, and Peng Dehuai" (September 4, 1952), translated by Gary Goldberg, History and Public Policy Program Digital Archive, https://digitalarchive.wilsoncenter.org/document/114936.
} 
costly for North Korea, as an estimated 1.3-2 million North Koreans, or up to $20 \%$ of the pre-war population, was killed in the fighting and bombing. ${ }^{71}$

This stalemate led to two instances where US leaders considered and rejected using nuclear weapons. The first had US military planners propose allowing the use of nuclear weapons as early as July 1950, though the Joint Chiefs of Staff (JCS) initially rejected this due to the small stockpile and lack of viable targets in North Korea. ${ }^{72}$ The proposal was revived by the stalemate, and while President Truman gave it serious consideration, including deploying nuclear weapons and bombers to Okinawa in 1951, it was ultimately abandoned. ${ }^{73}$ This was caused by strong opposition from major allies like France and the United Kingdom, Third World states that opposed nuclear weapons, and administration officials like Secretary of State Dean Acheson who were concerned about escalation. ${ }^{74}$ The fact that using nuclear weapons against China would likely cause it to deploy even more troops to Korea also played a role in deliberately limiting the war. ${ }^{75}$ Despite this, MacArthur requested 34 atomic bombs and a list of targets in Korea and China, and continued to demand them after he was rebuffed. ${ }^{76}$ Once he began publicly claiming that nuclear weapons should be under military control, Truman was forced to fire him in April

\footnotetext{
${ }^{71}$ Fifield, The Great Successor, 20.

${ }^{72}$ Nina Tannenwald, The Nuclear Taboo: The United States and the Non-Use of Nuclear Weapons Since 1945 (Cambridge: Cambridge University Press, 2007), 119.

${ }^{73}$ Tannenwald, The Nuclear Taboo, 121-122; Todd S. Sechser and Matthew Fuhrmann, Nuclear Weapons and Coercive Diplomacy (New York: Cambridge University Press, 2017), 179.

${ }^{74}$ Tannenwald, The Nuclear Taboo, 121-123; Harold Callender, "Paris Is Opposed to Atom Bomb Use," New York Times, December 1, 1950, http://timesmachine.nytimes.com/timesmachine/1950/12/01/91120174.html.

${ }^{75}$ Thérèse Delpech, Nuclear Deterrence in the 21st Century: Lessons from the Cold War for a New Era of Strategic Piracy (Santa Monica: RAND Corporation, 2012), 71.

${ }^{76}$ Tannenwald, The Nuclear Taboo, 123.
} 
1951 for insubordination. ${ }^{77}$ From that point on, the use of nuclear weapons in the war does not appear to have been discussed for the remainder of Truman's term.

Nuclear weapon use was against discussed when Dwight Eisenhower became president, with the idea again being rejected despite his own preferences. Eisenhower suggested using tactical nuclear weapons less than a month after his inauguration in the belief that it would break the stalemate, though the JCS advised against it due to the risk of alienating allies and escalating the war. ${ }^{78}$ The issue was discussed at length during a National Security Council (NSC) meeting on March 31, 1953, when Eisenhower noted that while there were few worthwhile targets, "he felt it would be worth the cost if... we could achieve a substantial victory over the Communist forces." ${ }^{" 79}$ The consultants present, along with Secretary of State John Foster Dulles, appear to have generally agreed with this. ${ }^{80}$ Eisenhower admitted, however, that the risk of a nuclear war with the Soviet Union would likely alienate allies, a point echoed by Dulles' admission “that in the present state of world opinion we could not use an A-bomb." ${ }^{\prime 1}$ Other NSC meetings that spring show that Eisenhower continued to personally favor using nuclear weapons, though this was avoided by China signing the armistice in July ${ }^{82}$ At no point in these discussions do North Korea's own military capabilities appear to have been discussed as a possible consideration.

\footnotetext{
${ }^{77}$ Delpech, Nuclear Deterrence in the $21^{\text {st }}$ Century, 71-72.

${ }^{78}$ Tannenwald, The Nuclear Taboo, 143-144.

${ }^{79}$ S. Everett Gleason, "Memorandum of Discussion at a Special Meeting of the National Security Council on Tuesday, March 31, 1953," March 31, 1953, George Washington University National Security Archive, https://nsarchive2. gwu.edu//dc.html?doc=4316141-Document-03-Memorandum-of-Discussion-at-a.

${ }^{80}$ Gleason, "NSC Memorandum 03/31/1953," 13.

${ }^{81}$ Gleason, "NSC Memorandum 03/31/1953," 13.

${ }^{82}$ Tannenwald, The Nuclear Taboo, 146-148; S. Everett Gleason, "515. Memorandum of Discussion at the 144th Meeting of the National Security Council, Wednesday, May 13, 1953" (United States Department of State, May 13, 1953), 1014, https://history.state.gov/historicaldocuments/frus1952-54v15p1/d515.
} 
These two instances make it clear that North Korean capabilities did not factor into the US decision to not use nuclear weapons, with restraint instead being encouraged by potential Soviet and Chinese escalation and concerns over domestic and international opinion. Neither the Truman nor Eisenhower administrations appear to have given much consideration towards North Korean retaliation, likely due to already trying to overthrow its government. If anything, the perceived lack of viable targets for nuclear weapons in North Korea appears to have benefitted it. There was instead much greater concern over North Korea's allies, particularly the possibility of entering into a nuclear war with the Soviet. This contributed to concerns over international opinion, given the potential ramifications for US allies participating in the war. Additionally, the nuclear taboo was a source of additional restraint, given the outcry from UN states and Dulles' remarks regarding world opinion.

\subsection{2: Provocative Actions: The Pueblo (1968) and axe murder incidents (1976)}

While the 1953 armistice ended the Korean War, North Korean aggression towards South Korea continued. Post-war relations between the two have largely been defined by numerous infiltration attempts, border clashes, and terrorist attacks, with North Korea estimated to have launched 292 such provocations between 1958 and April $2020 .{ }^{83}$ These acts of aggression, almost always directed towards South Korea or American forces, are typically accompanied with threats to retaliate against any attack against North Korea with the KPA and its 13,000-piece artillery force against South Korea ${ }^{84}$ These threats are intended to deter the US and South Korea from using force in response to North Korean

\footnotetext{
${ }^{83}$ CSIS Beyond Parallel, "Database: North Korean Provocations," Center for Strategic and International Studies, April 16, 2020, https://beyondparallel.csis.org/database-north-korean-provocations/.

${ }^{84}$ Cha, The Impossible State, 219-220.
} 
provocations, which are themselves intended (at least in part) to demonstrate the government's resolve to using force against perceived dangers, regardless of cost.

This section of the chapter focuses on two such incidents that became crises. The first is North Korea's capture of the USS Pueblo on January 23, 1968, with its crew held captive for 11 months before being released on December $23 .{ }^{85}$ The second is the axe murder incident, when North Korean soldiers killed two US Army officers in the Joint Security Area (JSA) of the Korean DMZ on August 17, 1976 ${ }^{86}$ Both instances had US leaders use shows of force against North Korea - the deployment of the USS Enterprise in 1968 and Operation Paul Bunyan in 1976 - after considering more aggressive responses, such as raids and airstrikes. Documentary evidence shows that US officials discussed these possible responses and even commissioned analyses, but chose to avoid further escalation. South Korean leaders opposed US escalation, with officials critiquing the response to the Pueblo incident and President Park Chung-hee only reluctantly providing support for Operation Paul Bunyan. North Korean threats were considered credible by the US and South Korea, despite their extreme nature, due to its aggressive stance and authoritarian nature convincing them it would fulfill them regardless of the costs.

The Pueblo incident demonstrated the extent of North Korean resolve as well as the constraints on possible US responses. The crisis breakpoint occurred when the USS Pueblo, a US Navy intelligence-gathering ship observing North Korea from international waters, was captured on January 23, 1968, along with 82 of its crew. ${ }^{87}$ The North Korean

\footnotetext{
${ }^{85}$ Michael Brecher and Jonathan Wilkenfeld, A Study of Crisis (Ann Arbor: University of Michigan Press, 1997), 218-219.

${ }^{86}$ Brecher and Wilkenfeld, A Study of Crisis, 219-220.

${ }^{87}$ Cha, The Impossible State, 54.
} 
government claimed that the Pueblo had been 12 nautical miles from its shores when it was captured, and thus within its territorial waters, though various reports indicate that it had been anywhere between 16 and 25 nautical miles away. ${ }^{88}$ The actual purpose was likely a combination of deflecting international attention from the failed Blue House Raid on January 21, pressuring the Soviets for material support, and weakening the US presence in Vietnam. ${ }^{89}$ American officials debated what could be done to retrieve the Pueblo and its crew, and diverted the Enterprise and a task force from Vietnam as a show of force on January $25 .{ }^{90}$ The failure of this attempt forced the US to negotiate, with the crew being returned on December 23 in exchange for a signed apology for spying on North Korea. ${ }^{91}$ The release of the crew terminated the crisis.

Evidence from the Pueblo crisis shows that US officials considered several other options, but ruled them out as ineffective or too dangerous. Minutes from a January 24 meeting highlight the constraints the Johnson administration faced, with National Security Advisor Walt Rostow noting that major action would be politically embarrassing due to

\footnotetext{
${ }^{88}$ N. Popa and Jae-bong Kim, "Telegram from Pyongyang to Bucharest, TOP SECRET, No: 75.015, Flash" (January 24, 1968), Political Affairs Fond, Telegrams from Pyongyang, Archive of the Romanian Ministry of Foreign Affairs, obtained and translated for NKIDP by Eliza Gheorghe, History and Public Policy Program Digital Archive, https://digitalarchive.wilsoncenter.org/document/113942; Jae-bong Kim and Jarck, "Memorandum of the Foreign Ministry of the DPRK for the Ambassadors and Acting Ambassadors of all Socialist Countries accredited to the DPRK" (January 24, 1968), MfAA C 1023/73, translated for NKIDP by Karen Riechert, History and Public Policy Program Digital Archive, https://digitalarchive.wilsoncenter.org/document/113715.

${ }^{89}$ On January 21, 1968, North Korean commandos infiltrated the Blue House (South Korea's presidential residence) in a failed attempt to assassinate South Korean President Park Chung-hee. Sergey Radchenko, "The Soviet Union and the North Korean Seizure of the USS Pueblo: Evidence from Russian Archives," Cold War International History Project Working Paper \#47 (Washington, DC: Woodrow Wilson International Center for Scholars, July 7, 2011), 11-16, https://www.wilsoncenter.org/sites/default/files/CWIHP_WP 47.pdf.

${ }^{90}$ Brecher and Wilkenfeld, A Study in Crisis, 218.

${ }^{91}$ Cha, The Impossible State, 54.
} 
1968 being an election year. ${ }^{92}$ As prior research has shown, taking such action and failing would have made the administration appear incompetent, jeopardizing the chances of a Democratic victory in November. ${ }^{93}$ Numerous approaches were highlighted during the meeting, including diplomacy, reinforcing local US forces, and even military actions such as raids. ${ }^{94}$ Concerns over escalation were raised, with advisor Clark Clifford questioning "whether the loss of a US ship with its crew was worth a major military confrontation with North Korea." 95 An Index of Possible Actions echoed these, predicting that a show of force would be ineffective in getting the Pueblo's crew released "unless Pyongyang were convinced that the US meant to take punitive action" - unlikely, given US commitments in South Vietnam and concerns over political repercussions. ${ }^{96}$ Raids were deemed highly risky, as they "could provoke Pyongyang into a similar action" and at worst "result in a wider war" due to violating the armistice. ${ }^{97}$ There were also concerns that the Soviets and China had supported capturing the Pueblo and would aid North Korea in a war. ${ }^{98}$ That the US did not escalate beyond the Enterprise's redeployment suggests that the possibility of North Korea escalating further was deemed credible.

The South Korean government was even more reluctant to provoke North Korea due to the latter's military advantage and credible threats. Immediately after the Enterprise's arrival, US Forces Korea Commander Charles Bonesteel was confronted by

\footnotetext{
${ }^{92}$ United States Department of State, Office of the Historian, "January 24, 1968: Summary Minutes of Pueblo Group," in Foreign Relations of the United States, 1964-1968, Volume XXIX, Part 1, Korea, vol. 29, Foreign Relations of the United States (Washington, DC: United States Department of State, 2018), 470, https://history.state.gov/historicaldocuments/frus1964-68v29p1/d217.

${ }^{93}$ William G Nomikos and Nicholas Sambanis, "What Is the Mechanism Underlying Audience Costs? Incompetence, Belligerence, and Inconsistency," Journal of Peace Research 56, no. 4 (2019): 577.

${ }^{94}$ Office of the Historian, "Summary Minutes of Pueblo Group."

${ }^{95}$ Office of the Historian, "Summary Minutes of Pueblo Group," 475.

96 "Index of Possible Actions," 19.

97 "Index of Possible Actions," 28-29, 31.

${ }^{98}$ Office of the Historian, "Summary Minutes of Pueblo Group."
} 
an "irate" Minister of National Defence Kim Sung-eun for acting without consulting his government. ${ }^{99} \mathrm{Kim}$ also noted that it could potentially provoke further North Korean raids and even war, particularly in the aftermath of the Blue House raid and the resulting South Korean casualties. ${ }^{100}$ Any conflict with North Korea would have been costly, since the KPA made up for its smaller forces $(384,000$ personnel to South Korea's 620,000$)$ with better training and equipment, and even US military support for South Korea would make it difficult to win. ${ }^{101}$ The unprovoked nature of the raid, the military imbalance, and the negative reaction by Park's government to the Enterprise's presence all indicate that South Korean officials considered North Korean retaliation to be credible.

Though actual evidence from North Korea is not available, evidence from its allies indicate that Kim Il Sung was ready to fight over the Pueblo due to assuming he had Soviet support. East German diplomats in Pyongyang reported that North Korea began preparing for war after the Pueblo's capture, with expectations that the Soviets and China would defend it with nuclear weapons. ${ }^{102}$ A letter from Kim in late January lends further credence to this due to references to the 1961 Soviet-North Korean Treaty of Friendship in requesting “"military and other aid and support"” to fight American aggression despite a

\footnotetext{
${ }^{99}$ Charles H. Bonesteel, "Telegram From the Commander in Chief, United Nations Command, and Commander of United States, Korea (Bonesteel) to the Commander in Chief, Pacific (Sharp)" (January 23, 1968), Department of State, History and Public Policy Program Digital Archive, https://digitalarchive.wilsoncenter.org/document/113368.

${ }^{100}$ Bonesteel, “Telegram from Bonesteel;” Yongho Kim, North Korean Foreign Policy: Security Dilemma and Succession (Lanham: Lexington Books, 2011), 102.

${ }^{101}$ International Institute for Strategic Studies, "Other Communist Countries," The Military Balance 68, no. 1 (1968): 13; International Institute for Strategic Studies, "American Bilateral Treaty Powers," The Military Balance 68, no. 1 (1968): 38-39.

102 J. Herrmann, "Informational Report by Ambassador Herrmann" (February 1, 1968), MfAA C 1023/73, translated by Karen Riechert, History and Public Policy Program Digital Archive, https://digitalarchive.wilsoncenter.org/document/113741.
} 
lack of prior consultation. ${ }^{103}$ Other Soviet bloc states believed that Kim was trying to provoke a war by capturing the Pueblo. ${ }^{104}$ Soviet General Secretary Leonid Brezhnev opposed this, informing Minister of Defence Kim Ch'ang-bong in late February that the treaty "'has a defensive character" and publicly criticizing North Korean policy as overly militant. ${ }^{105}$ This would suggest North Korea would have retaliated against any US action, though whether it would have received Soviet backing is unclear.

The 1976 axe murder incident similarly had the US and South Korea constrained from using force due to North Korean retaliation being considered credible, albeit to a lesser extent than in 1968. The crisis was triggered on August 17, 1976, when American soldiers sent to cut down trees between checkpoints in the DMZ were attacked by a North Korean patrol and two Americans were killed. ${ }^{106}$ While Kim Jong Il claimed that the soldiers were defending themselves, the UN Security Council concluded that it was a premeditated attack meant as a deliberate provocation. ${ }^{107}$ The Ford administration responded with Operation Paul Bunyan, going to DEFCON 3 and sending 813 troops (including 50 South Korean special forces soldiers) to cut down the tree on August $21^{\text {st }}$,

\footnotetext{
${ }^{103}$ Leonid Il'ich Brezhnev, “Excerpt from Leonid Brezhnev's Speech at the April (1968) CC CPSU Plenum, 'On the Current Problems of the International Situation and on the Struggle of the CPSU for the Unity of the International Communist Movement"' (April 9, 1968), Russian State Archive of Recent History (RGANI), obtained and translated by Sergey Radchenko, History and Public Policy Program Digital Archive, https://digitalarchive.wilsoncenter.org/document/110507.

${ }^{104}$ N. Popa, "Telegram from Pyongyang to Bucharest, TOP SECRET, No. 76.017, Flash,” January 25, 1968, Political Affairs Fond, Telegrams from Pyongyang, Archive of the Romanian Ministry of Foreign Affairs, obtained and translated by Eliza Gheorghe, History and Public Policy Program Digital Archive, https://digitalarchive.wilsoncenter.org/document/113944.

${ }^{105}$ Brezhnev, "Brezhnev's April 1968 Plenum Speech."

${ }^{106}$ Brecher and Wilkenfeld, A Study of Crisis, 220.

${ }^{107}$ Ion Datcu and William Tapley Bennett, "Telegram from New York to Bucharest, SECRET, Urgent, No. 060.387," August 20, 1976, Archives of the Romanian Ministry of Foreign Affairs, Matter 220 - Relations with the Democratic People's Republic of Korea, 1976, History and Public Policy Program Digital Archive, Woodrow Wilson International Center for Scholars, accessed October 10, 2018, https://digitalarchive.wilsoncenter.org/document/114115.
} 
with gunships, nuclear-armed B-52 bombers, and the USS Midway deployed as support. ${ }^{108}$ Despite Kim Il Sung having ordered the KPA to prepare for war, no violence actually occurred, and Kim publicly expressed regret for the deaths the following day. ${ }^{109}$ The crisis is considered to have been terminated at this point, with Kim Il Sung's public apology indicating that it was a humiliating outcome for North Korea.

Much like the Pueblo incident, the axe murder had US officials opt for a limited response to North Korean provocations to avoid starting a war, though not as limited as in 1968. Special Action Group meetings on August 18 and 19 show that there was a rapid consensus to have troops return to cut down the tree, though further measures were debated. ${ }^{110}$ Secretary of State Henry Kissinger argued "that they [North Korea]... must pay the price," and favored bombing North Korea. ${ }^{111}$ Others suggested a joint exercise with South Korea to cut the tree down due to how "the media and the US people" would react to conflict in an election year, indicating concerns over public opinion. ${ }^{112}$ These were echoed in a letter to National Security Advisor Brent Scowcroft noting that officials were aware "that there are severe risks and there could be casualties," and that the show of force could "lead to a major fight."113 Ford himself favored a limited military response, with

\footnotetext{
${ }^{108}$ The DEFCON alert system ranges from 1 to 5, with 5 being a normal state of readiness for US armed forces and 1 indicating that a nuclear war is about to start. Richard A. Mobley, "Revisiting the Korean Tree-Trimming Incident," Joint Force Quarterly 35 (2004), 111.

${ }^{109}$ Brecher and Wilkenfeld, A Study of Crisis, 220.

${ }^{110}$ Office of the Historian, "282. Minutes of Washington Special Actions Group Meeting, Washington, August 18, 1976, 3:47-4:43 p.m." (United States Department of State, August 18, 1976), Foreign Relations of the United States, 1969-1976, Volume E-12, Documents on East and Southeast Asia, 1973-1976, United States Department of State - Office of the Historian, https:/history.state.gov/historicaldocuments/frus1969-76ve12/d282.

${ }^{111}$ Office of the Historian, "SAG Meeting 08/18/1976," 5.

112 Office of the Historian, "SAG Meeting 08/18/1976," 5.

${ }^{113}$ William Hyland, "Letter from William Hyland to Brent Scowcroft," in After Detente: The Korean Peninsula, 1973-1976, ed. James Person (Wilson Center, 1976), 696, https://www.wilsoncenter.org/sites/default/files/2011_COHC_BB_Part_6_1976.pdf.
} 
Kissinger noting "that is what the President wants," albeit "in such a way as to avoid confrontation." ${ }^{114}$ More extreme actions to demonstrate resolve were clearly considered but deemed too provocative, making it clear that possible North Korean retaliation was a serious concern.

Park Chung-hee's government likewise was reluctant to provoke North Korea, and while it did ultimately cooperate with the US, North Korea was seemingly preparing to escalate. Originally, Park insisted that the US avoid a military response to the incident, and while he appeared to have changed his mind when meeting with US Forces Korea Commander Richard Stilwell, he insisted on responding to North Korea "without use of arms." 115 This meant that the South Korean forces deployed in Operation Paul Bunyan were, at Park's insistence, unarmed black belts. Park apparently sought to avoid escalating the crisis, particularly given North Korean warnings that DEFCON 3 was a pretext for war and the deployment of the KPA and paramilitary forces to wartime positions. ${ }^{16}$ The lack of North Korean retaliation to the tree cutting has been attributed by at least one highranking defector to Kim Il Sung believing that American nuclear weapons made victory against South Korea impossible even with a conventional advantage. ${ }^{117}$ The evidence indicates that North Korean belligerence led American and South Korean officials to

\footnotetext{
${ }^{114}$ Office of the Historian, "285. Minutes of Washington Special Actions Group Meeting, Washington, August 19, 1976, 8:12-9:15 a.m." (United States Department of State, August 19, 1976), 1-3, Foreign Relations of the United States, 1969-1976, Volume E-12, Documents on East and Southeast Asia, 19731976, United States Department of State - Office of the Historian, https://history.state.gov/historicaldocuments/frus1969-76ve12/d285.

115 Office of the Historian, "286. Minutes of Washington Special Actions Group Meeting, Washington, August 25, 1976, 10:30 a.m." (United States Department of State, August 25, 1976), Foreign Relations of the United States, 1969-1976, Volume E-12, Documents on East and Southeast Asia, 1973-1976, United States Department of State - Office of the Historian, https://history.state.gov/historicaldocuments/frus196976ve12/d286; Mobley, "Revisiting the Korean Tree-Trimming Incident," 111.

${ }^{116}$ Mobley, "Revisiting the Korean Tree-Trimming Incident," 111.

117 Jackson, On the Brink, 24.
} 
believe that Kim Il Sung would wage war over a minor incident regardless of the costs to his own country.

These two crises demonstrate that potential North Korean retaliation against South Korea was credible enough to the US and South Korea that using force carried significant risk. American responses to North Korean provocations in both crises were explicitly constrained by the possibility of starting a war, limiting them to shows of force. The conventional disparity between them and the US nuclear arsenal makes this notable, but can be explained by North Korea's leaders believing that even minor attacks are potential existential threats. A relative lack of constraint on Kim Il Sung's power and demonstrated cost-insensitivity during the Korean War would make threats to escalate against any attack seem even more credible, especially given his propensity for ordering the KPA to a war footing. These threats were of even greater concern to South Korea, which would have suffered the brunt of attacks and still relied on US support. North Korean threats succeeded thanks to Kim Il Sung's largely unfettered domestic authority and North Korean provocations demonstrating its resolve to fulfill threats.

\subsection{3: The First Nuclear Crisis (1992-1994)}

The final major pre-nuclear crisis discussed is the first North Korean nuclear crisis (1992-1994). Its roots lie in Kim Il Sung's concerns about North Korea being attacked with nuclear weapons, which section 8.3.1 shows to have been justified. ${ }^{118}$ Later events like the 1962 Cuban Missile Crisis led him to conclude that nuclear-armed allies were unreliable, with Khrushchev's removal of missiles from Cuba interpreted as a readiness to abandon

\footnotetext{
${ }^{118}$ French, State of Paranoia, 332.
} 
allies. ${ }^{119}$ The presence of American tactical nuclear weapons in South Korea and statements such as Secretary of State James Schlesinger's warning that massive firepower would be used to defend South Korea likely only made Kim and his domestic supporters more insecure. ${ }^{120}$ The military and economic balance shifting in South Korea's favour from the early 1970s onwards also meant that North Korea could no longer rely on conventional superiority to defend itself. ${ }^{121}$ In short, Kim Il Sung and his supporters likely viewed themselves as under constant threat by a nuclear-armed superpower and unable to rely on their allies to defend them, making a domestic nuclear arsenal appear necessary.

North Korea's nuclear proliferation efforts can be traced to the 1950s, though actual progress took much of the Cold War and considerable foreign aid. Some reports indicate that Kim Il Sung ordered a nuclear weapons program almost as soon as the Korean War ended, and successfully requested Soviet support for peaceful atomic research in $1958 .{ }^{122}$ China was only approached for aid after its successful October 1964 test explosion, with North Korea being rebuffed. ${ }^{123}$ Soviet support led to the construction of the Yongbyon nuclear complex, which served as the base for North Korean nuclear research after becoming operational in $1967 .{ }^{124}$ Both the Soviet Union and China attempted to dissuade North Korea from developing nuclear weapons, being alarmed by officials like Foreign

\footnotetext{
${ }^{119}$ Fifield, The Great Successor, 232.

120 "Schlesinger Vows Defense of Korea," New York Times, September 2, 1975, https://www.nytimes.com/1975/09/02/archives/schlesinger-vows-defense-of-korea.html.

${ }^{121}$ Youngwon Cho, "Method to the Madness of Chairman Kim: The Instrumental Rationality of North Korea's Pursuit of Nuclear Weapons.," International Journal 69, no. 1 (2014): 12-13.

${ }^{122}$ Andrei Andreevich Gromyko and Sin-pal Ri, "From the Journal of Gromyko, Record of a Conversation with Ambassador Ri Sin-Pal of the Democratic People's Republic of Korea" (April 28, 1958), 1-2, AVPRF fond 0102, opis 14, delo 4, translated for NKIDP by Gary Goldberg, History and Public Policy Program Digital Archive, https://digitalarchive.wilsoncenter.org/document/116019; French, State of Paranoia, 332.

${ }^{123}$ Solingen, Nuclear Logics, 118.

${ }^{124}$ Cha, The Impossible State, 249.
} 
Minister Pak Song Ch'ol expressing dissatisfaction with the NPT. ${ }^{125}$ Ultimately, the Soviets forced Kim Il Sung to sign the NPT and allow inspections in exchange for further aid in 1985, though North Korea continued to reject International Atomic Energy Agency (IAEA) inspections before signing a safeguards agreement in $1992 .^{126}$

The crisis was triggered by the discovery that North Korea was potentially developing nuclear weapons. When finally permitted to inspect Yongbyon, IAEA inspectors found discrepancies in reported plutonium reprocessing, potentially indicating a weapons program, but North Korea responded to further inspection requests by announcing its withdrawal from the NPT in March 1993. ${ }^{127}$ The US and others attempted to persuade Pyongyang to allow inspections over the following year with little success, with North Korea instead preparing to defend itself. ${ }^{128}$ Tensions increased due to a January 1994 CIA report that estimated North Korea had enough plutonium for two nuclear weapons. ${ }^{129}$ Despite officials in Pyongyang threatening in March to "'turn Seoul into a sea of fire"" with their artillery if attacked, the Clinton administration studied launching airstrikes to halt the program. ${ }^{130}$ The administration ultimately decided to allow former president Jimmy Carter to meet with Kim Il Sung in order to open negotiations. ${ }^{131}$ This allowed the US to negotiate an Agreed Framework with Kim Jong Il after his father's death

\footnotetext{
${ }^{125}$ Balazs Szalontai and Sergey Radchenko, "North Korea's Efforts to Acquire Nuclear Technology and Nuclear Weapons: Evidence from Russian and Hungarian Archives," Cold War International History Project Working Paper \#53 (Washington, DC: Woodrow Wilson International Center for Scholars, 2011), 32, https://www.wilsoncenter.org/sites/default/files/WP53 web_final.pdf.

${ }^{126}$ Solingen, Nuclear Logics, 122-123.

127 Solingen, Nuclear Logics, 122-123.

${ }^{128}$ Solingen, Nuclear Logics, 123.

${ }^{129}$ Cha, The Impossible State, 285.

${ }^{130}$ Emma Chanlett-Avery and Sharon Squassoni, "North Korea’s Nuclear Test: Motivations, Implications, and U.S. Options," Congressional Research Service Report (Washington, DC: United States Congressional Research Service, October 24, 2006), 17, https://fas.org/sgp/crs/nuke/RL33709.pdf; Jackson, On The Brink, 28.

131 Pollack, No Exit, 114.
} 
in July, with North Korea agreeing to freeze its weapons program in exchange for light water reactors (LWR), heavy oil shipments, and American guarantees to not attack. ${ }^{132}$ The agreement terminated this nuclear crisis, albeit only temporarily.

The first nuclear crisis is perhaps the clearest example of North Korean threats credibly deterring the US and South Korea from attacking. The airstrike proposal led to Clinton being informed that it could trigger a second Korean War, likely killing or wounding 52,000 American military personnel and approximately 500,000 South Korean soldiers, as well as "an untold number" of civilian casualties. ${ }^{133}$ US Forces Korea Commander Gary Luck further informed Clinton in a June 15 meeting that South Korea would suffer an estimated one million civilian casualties and US\$1 trillion in economic damage, while the US would suffer US $\$ 100$ billion in costs from fighting. ${ }^{134}$ This was sufficient to convince Clinton and Secretary of Defense William Perry, who favored deploying reinforcements to Korea, to reject the airstrikes due to the figures being "too much for the Clinton administration to stomach." ${ }^{" 135}$ South Korean President Kim Youngsam opposed any attack from the start, explicitly noting “"North Korean artillery would have been rolling out within three minutes"” against Seoul. ${ }^{136}$ This certainty is notable when considering that the KPA, despite having 1.13 million personnel compared to South Korea's 633,000 , would likely lose a conventional war due to qualitative inferiority and

\footnotetext{
${ }^{132}$ Panda, "North Korea's Nuclear Policy: Domestic Determinants, Strategy and Future," 229.

${ }^{133}$ Panda, "North Korea's Nuclear Policy: Domestic Determinants, Strategy and Future," 229.

${ }^{134}$ Cha, The Impossible State, 285.

135 Jonathan Watts, "How Clinton Came Close to Bombing," The Guardian, December 5, 2002, https://www.theguardian.com/world/2002/dec/05/northkorea.

${ }^{136}$ Choe Sang-Hun, "Korean Crisis Is Different This Time," New York Times, August 3, 2009, https://www.nytimes.com/2009/08/04/world/asia/04iht-letter.html.
} 
the Arduous March. ${ }^{137}$ As Kim Young-sam later explained, Kim Il Sung was then seen as willing to launch such an attack due to the precedent set by the Korean War and later provocations. $^{138}$

The events of the 1992-1994 crisis clearly demonstrated that North Korea's costaccepting behaviour deterred US and South Korean armed attacks even before it possessed nuclear weapons. The crisis provides no evidence that either government believed that Kim Il Sung and his followers were bluffing, and instead treated the threats as highly credible, particularly by the South Korean government. The Clinton administration's decision to not launch airstrikes or even send additional troops to South Korea suggests that they viewed the North Korean government as cost-insensitive and willing to carry out its threats. The South Korean government already believed North Korea would attack, despite its military inferiority making it a highly damaging but ultimately suicidal endeavour, with the potential costs in life and economic damage to Seoul alone making further escalation too risky. North Korea's military inferiority, both to South Korea and the US, would have further reinforced the perception that it would be willing to fulfill these threats. As explained earlier in this chapter, this is due to how the country's inability to win a war meant that any attack against it would pose an existential threat, since it could signal regime collapse and the deaths of Kim Il Sung and his supporters, and they would thus have little reason to avoid attacking South Korea in that scenario.

\footnotetext{
${ }^{137}$ International Institute for Strategic Studies, "East Asia and Australasia," The Military Balance 94, no. 1 (1994): 178-180.

${ }^{138}$ Choe, "Korean Crisis."
} 


\section{4: North Korean Nuclear Weapons: Motivations, Deterrence Threats, and Command and Control}

The preceding section shows that North Korea's nuclear ambitions are not a recent development. Given the state's extreme poverty and the estimated 1/3 of its GDP allocated to its armed forces, it is odd that it would spend even more on nuclear weapons, particularly as the proliferation efforts of wealthier states have met with failure and serious consequences. ${ }^{139}$ This section shows that North Korea's nuclear deterrent stems from a desire to deter perceived American aggression due to being badly outmatched: most North Korean troops are poorly trained and fed, and much of their weapons and equipment consist of Cold War surplus. In short, the development of a nuclear deterrent has proven itself beneficial to North Korea by allowing it to deter potential attacks at lower cost than before.

North Korea's leaders have viewed themselves and the state as besieged by the rest of the world since the Korean War, particularly by the US and South Korea due to its own provocations against them over decades. Along with juche emphasizing national selfreliance, this has led to the KPA's prominence and a large defence budget to ensure North Korea's survival. Exact figures are unavailable, but the defence budget is estimated to have reached $30 \%$ of GDP by 1966 , and has likely remained between $25-30 \%$ of GNI since then. ${ }^{140}$ Given existing estimates of North Korean GNI, this would indicate that by 2006 , North Korea was spending US\$7.83 billion on defence. ${ }^{141}$ This has led to the KPA being one of the largest standing armies in the world: by 2006, it had a total of 1.1 million personnel, with additional paramilitary forces including another 3.5 million personnel,

\footnotetext{
${ }^{139}$ Fifield, The Great Successor, 232.

${ }^{140}$ Cha, The Impossible State, 189; Fifield, The Great Successor, 232.

${ }^{141}$ Cho, "Method to the Madness," 12-13.
} 
compared to South Korea's 687,000 in the same year. ${ }^{142}$ Approximately $70 \%$ of the KPA is deployed within 100 miles of the DMZ and, along with the 13,000 artillery pieces located along the border, ensures that North Korea can rapidly attack South Korea, including the capital of Seoul. ${ }^{143}$ On the face of it, this would suggest that North Korea would be capable of handily winning a conventional war with South Korea and ostensibly deterring any perceived aggression in the process.

The reality, however, is that North Korea would be unable to win a conventional war with South Korea or the US despite prioritizing defence, leading to nuclear weapons being considered necessary for deterrence. South Korea's stronger economy after an economic boom in the 1970s means that it has been able to spend far more on defence than North Korea. ${ }^{144}$ As of 2018, for example, the South Korean defence budget was US\$39.2 billion (approximately $2.36 \%$ of GDP), which is greater than North Korea's estimated GDP of US\$30 billion for that year. ${ }^{145}$ Furthermore, despite the personnel disparity, South Korean soldiers are better-fed and trained than their North Korean counterparts, who are malnourished to the point of raiding Chinese villages for food. ${ }^{146}$ Much of North Korea's military equipment also consists of obsolete Cold War surplus, despite recent efforts to purchase hardware from Russia and India on credit. ${ }^{147}$ Nuclear weapons are comparatively cheap, with the program's total costs until March 2012 being placed around US\$3.1

\footnotetext{
${ }^{142}$ International Institute for Strategic Studies, "East Asia and Australasia," The Military Balance 106, no. 1 (2006): 276-280.

${ }^{143}$ Cha, The Impossible State, 219-220.

${ }^{144}$ Cho, "Method to the Madness," 11.

${ }^{145}$ International Institute for Strategic Studies, "Chapter Six: Asia," The Military Balance 118, no. 1 (2018): 219-314; Bank of Korea, "Gross Domestic Product Estimates for North Korea in 2018," July 26, 2019, https://www.bok.or.kr/eng/bbs/E0000634/view.do?nttId=10053001\&menuNo=400069.

${ }^{146}$ French, North Korea, 326.

${ }^{147}$ French, North Korea, 327.
} 
billion. ${ }^{148}$ Given the damage that even a single nuclear warhead can do, North Korea thus gets a large return from its relatively small arsenal of an estimated 10-20 warheads. ${ }^{149}$ All of this means that North Korea has a strong incentive to pursue a nuclear deterrent, since possessing even a few warheads does more to guarantee the government's survival than its conventional forces.

\subsection{1: North Korea's Nuclear Doctrine and Command and Control}

North Korea's nuclear doctrine is, much like Pakistan's, largely opaque, due to both its general isolationism and an apparent desire to maintain some ambiguity for nuclear weapon use conditions. Previous North Korean threats, legal documents, and existing information on the structure of its government indicates that its nuclear deterrent is intended solely to deter attacks, but what Kim Jong Un views as a threat to the state (and to his government and personal well-being) is very broad. This means that North Korea's threshold for using nuclear weapons may be so low that low-intensity attacks, such as preemptive strikes, could trigger a nuclear war due to being misperceived as the beginning of a war to destroy the state. What can be gleaned about North Korea's command and control indicates that launch authority largely, if not entirely, revolves around Kim Jong Un, though it is unclear how it is structured beyond this. Taken together, North Korean nuclear deterrence, much like its government, is wholly dedicated to the continued survival of the Kims and their supporters against external threats by making an attack incredibly costly.

By all indications, North Korea's nuclear weapons are meant solely to deter the US and South Korea, though this definition and its relative capabilities are vague enough that

\footnotetext{
148 Cho, "Method to the Madness," 21-22.

${ }^{149}$ Hans M. Kristensen and Robert S. Norris, "North Korean Nuclear Capabilities, 2018," Bulletin of the Atomic Scientists 74, no. 1 (2018): 41-51.
} 
Kim Jong Un and his supporters would consider launching pre-emptive attacks to be an extension of deterrence. Though the North Korean government has not released an official nuclear doctrine, its potential intentions can be gleaned from the April 2013 Law on Consolidation Position of Nuclear Weapon State. This law states that North Korea will only use nuclear weapons "to repel invasion or attack from a hostile nuclear weapons state" and any non-nuclear allies it may have. ${ }^{150}$ Additionally, Kim Jong Un himself stated at the $7^{\text {th }}$ KWP Congress in May 2016 that North Korea's nuclear weapons will only be used if “"its sovereignty is encroached upon by any hostile force with nuclear weapons." "151

While outwardly straightforward, these statements are highly ambiguous, particularly in how North Korean leaders define "defensive purposes." Given the KPA's weakness relative to South Korea and the US, North Korea is unlikely to win a conventional war. ${ }^{152}$ Other dictators who were executed after being deposed, such as Nicolae Ceausescu, Saddam Hussein, and Muammar Gaddhafi, has almost certainly convinced Kim Jong Un, much like his predecessors, that regime collapse is a death sentence for himself, his family, and his supporters. ${ }^{153}$ These would give him more than enough reason to treat any perceived aggression as if it is a potential existential threat. The wording of both Kim Jong Un's statement and the 2013 law suggest that North Korea will use nuclear weapons whenever a nuclear weapon state attacks it, even with purely conventional forces. ${ }^{154}$ This

\footnotetext{
${ }^{150}$ KCNA, "Law on Consolidating Position of Nuclear Weapons State Adopted," KCNA Watch (blog), April 1, 2013, https://kcnawatch.org/newstream/1451896124-739013370/law-on-consolidating-position-ofnuclear-weapons-state-adopted/.

${ }^{151}$ KCNA, "Kim Jong Un Makes Report on Work of WPK Central Committee at Its 7th Congress," KCNA Watch, May 7, 2016, https://kcnawatch.org/newstream/1546587644-964527319/kim-jong-un-makesreport-on-work-of-wpk-central-committee-at-its-7th-congress/.

${ }^{152}$ French, State of Paranoia, 324.

${ }^{153}$ Fifield, The Great Successor, 78.

${ }^{154}$ KCNA, "Law on Consolidating Position of Nuclear Weapons State Adopted;" KCNA, "7 7 th $C o n g r e s s . "$
} 
means that North Korea could escalate to a nuclear war merely because its challenger has nuclear weapons. Finally, previous North Korean provocations indicate a belief that they are necessary to demonstrate the necessary resolve to deter any possible aggression. ${ }^{155}$ These all indicate that North Korea is willing to respond to any attack by a nuclear weapon state or its ally with its own nuclear arsenal on the basis that it might be an existential threat, and because not doing so would show weakness.

North Korean command and control appears to differ from other states in not having distinct agencies handle nuclear weapons, but instead keeping them under direct KPA control and giving Kim Jong Un complete launch authority. The 2013 law explicitly states that nuclear weapons "can be used only by a final order of the Supreme Commander of the Korean People's Army," meaning that Kim Jong Un, as the Supreme Commander, has complete authority over North Korea's nuclear weapons. ${ }^{156}$ Given the centralization of authority in North Korea, this is unsurprising, since sharing launch authority would potentially undermine Kim's own power. It also adheres to what is known about the KPA, which has a highly rigid command and control structure that discourages any independent action by officers, to the point that war plans are apparently designed with no flexibility. ${ }^{157}$ While this would likely limit the possibility of unauthorized nuclear weapon use, it suggests that there are no contingency plans if Kim Jong Un could not give the order.

Kim Jong Un's central role in nuclear command and control raises important questions about who has launch authority if he dies, is incapacitated, or is simply unable to communicate with subordinates? One possibility is that North Korea's nuclear arsenal

\footnotetext{
155 Jackson, On the Brink, 37.

${ }^{156}$ KCNA, "Law on Consolidating Position of Nuclear Weapons State Adopted."

${ }^{157}$ Chanlett-Avery et al., "North Korea," 17-18.
} 
operates on a fail-deadly basis so that if its leadership is killed in a decapitation strike, the KPA would default to launching them at pre-designated targets. ${ }^{158}$ This is plausible, given the concerns of North Korea's leaders regarding their wartime prospects, but raises the possibility of accidental nuclear war from a communications blackout. It is also unclear how nuclear launch control is exercised when Kim Jong Un is abroad and may not be able to respond quickly in a crisis. Questions also arise as to what happens if Kim Jong Un is incapacitated or suddenly dies, which is highly probably given his apparent poor health due to his obesity and heavy smoking. ${ }^{159}$ This briefly became a concern in April 2020, when Kim Jong Un's lack of public appearances fuelled speculation that he was seriously ill or had secretly died. ${ }^{160}$ This last scenario is problematic: given the unclear line of succession in North Korea, it would introduce a risk of internal conflict within North Korea, in turn potentially leading to the unintentional use of nuclear weapons.

\section{5: “"Fire and fury:" North Korean Nuclear-era Crises}

The perception that North Korea is willing to use force regardless of cost has persisted into the nuclear era, with nuclear weapons making the potential costs for challengers greater than ever before. Since North Korea's first test explosion on October 9, 2006, US and South Korean governments have continued to be reluctant to retaliate against its provocations. In some ways, their possible responses are even more constrained than in the past, as a show of force like Operation Paul Bunyan now risks being misperceived by North Korea's leaders as an imminent attack and sparking a nuclear war.

\footnotetext{
${ }^{158}$ Vipin Narang and Ankit Panda, "Command and Control in North Korea: What a Nuclear Launch Might Look Like," War on the Rocks, September 15, 2017, https://warontherocks.com/2017/09/command-andcontrol-in-north-korea-what-a-nuclear-launch-might-look-like/.

${ }^{159}$ Fifield, The Great Successor, 255.

${ }^{160}$ Alex Ward, “The Rumors of Kim Jong Un's 'Grave' Illness, Explained,” Vox, April 23, 2020, https://www.vox.com/2020/4/23/21232665/north-korea-kim-jong-un-coronavirus-sick.
} 
This would seemingly suggest that North Korea's nuclear arsenal has successfully deterred other states from attacking it in any way. In practice, however, it has also proven to be a double-edged sword, as the North Korean government's aggression and its perceived willingness to retaliate for any provocation likely contributed to the Trump administration's interest in launching a pre-emptive attack in 2017.

This section of the chapter shows how US and South Korean governments have, with the possible exception of the Trump administration, been reluctant to retaliate against North Korean provocations with force due to considering its threats highly credible. The primary focus is on the second nuclear crisis, which began with the October 2006 nuclear test explosion and has persisted to the present, with the August 2017-June 2018 period being of particular interest. Two other crises between North and South Korea are also studied, specifically the 2010 sinking of the ROKS Cheonan and the 2015 landmine incident. As in the pre-nuclear period, North Korea's deterrence credibility is the result of its authoritarian government giving an incentive to threaten to cause as much damage to South Korea as possible to ward off existential threats, while provocations establish its resolve to fulfill them by demonstrating cost insensitivity.

This chapter does not discuss some provocations by North Korea and foreign reactions to them, specifically the use of cyber-attacks, due to not fitting within the theoretical framework advanced in this dissertation. The most notable such incident is the November 2014 cyber-attack against Sony Pictures Entertainment by a hacker group believed to have been directed by the North Korean government. ${ }^{161}$ In response, the Obama

\footnotetext{
${ }^{161}$ The main reason for the cyber-attack was Sony releasing The Interview, a comedy that largely revolved around mocking the North Korean government and Kim Jong Un in particular (including purportedly
} 
administration temporarily shut down North Korea's internet with a distributed denial-ofservice attack and imposed sanctions in January 2015. ${ }^{162}$ Other instances of North Korean cyberattacks include the 2017 WannaCry malware attack and various attacks aimed at extortion and other purposes. ${ }^{163}$ These are not studied in-depth in this dissertation, however, since the theoretical basis for the model lies in the possibility of armed attacks provoking nuclear retaliation. These cyberattacks, however, did not provoke armed attacks against North Korea in response, with escalation to nuclear war being somewhat implausible as a result. It does, however, open possible avenues for future research, which are discussed in greater detail in Chapter 9.

\subsection{1: The Second Nuclear Crisis (2006-present)}

The second North Korean nuclear crisis is one of the longest-lasting ones in the peninsula's modern history, having begun in October 2006 and continuing to the present. It can be traced back to the first nuclear crisis, as Kim Jong Il's government believed the US failed to uphold the 1994 Agreed Framework by failing to provide fuel as promised, leading to the Yongbyon reactor restarting in October 2002 and IAEA inspectors being expelled in December. ${ }^{164}$ This was encouraged by George W. Bush's attitude towards North Korea, having described it as part of an "axis of evil" in the January 2002 State of

the Union and refusing to negotiate. ${ }^{165}$ The North Korean government announced its

embarrassing claims that he enjoys Katy Perry and a scene where he is killed in a helicopter). See Jackson, On the Brink, 75.

162 Jackson, On the Brink, 76.

163 "Cyber-attack: US and UK blame North Korea for WannaCry," BBC News, December 19, 2017, https://www.bbc.com/news/world-us-canada-42407488; David E. Sanger and Nicole Perlroth, "U.S. Accuses North Korea of Cyberattacks, a Sign That Deterrence Is Failing," New York Times, April 15, 2020, https://www.nytimes.com/2020/04/15/world/asia/north-korea-cyber.html.

164 “North Korea's Nuclear Program, 2003," Bulletin of the Atomic Scientists 59, no. 2 (2003): 75.

${ }^{165}$ George W. Bush, "Text of President Bush's 2002 State of the Union Address," Washington Post, January 29, 2002, https://www.washingtonpost.com/wp-srv/onpolitics/transcripts/sou012902.htm. 
withdrawal from the NPT on January 10, 2003, claiming that "the IAEA is used as a tool for executing the U.S. hostile policy towards the DPRK." ${ }^{166}$ This spurred the Six-Party Talks between North Korea, the US, China, Russia, Japan, and South Korea by August 2003, with negotiations leading to North Korea promising in September 2005 to dismantle its nuclear program and rejoin the NPT. ${ }^{167}$ The talks broke down, however, when the US refused to provide the promised LWRs or US $\$ 25$ million from frozen accounts. ${ }^{168}$

The crisis breakpoint was North Korea conducting a nuclear test explosion on October 9, 2006, with additional test explosions under both Kim Jong Il and Kim Jong Un worsening it. The UN Security Council responded by passing Resolution 1718 to pressure North Korea into returning to the Six-Party Talks, with the resulting sanctions being considered "an act of war." 169 China also condemned the test, with the Foreign Ministry referring to it as hanran ("brazen"), normally reserved for adversaries. ${ }^{170} \mathrm{~A}$ second test took place on May 25, 2009 in response to pressure for IAEA verification, beginning a pattern of the UN, Obama administration, and various US allies imposing sanctions in response, which was repeated in February 2013, January 2016, and September 2016. ${ }^{171}$ Beginning with the third test, the Obama administration and Lee Myung-bak's government in South Korea began a policy of strategic patience, making sanctions relief contingent on North Korean disarmament. ${ }^{172}$ This approach differed greatly from earlier US responses to

\footnotetext{
${ }^{166}$ KCNA, "Statement of DPRK Government on Its Withdrawal from NPT," KCNA Watch, January 11, 2003, https://kcnawatch.org/newstream/1452003631-225477096/statement-of-dprk-government-on-itswithdrawal-from-npt/.

${ }^{167}$ Cha, The Impossible State, 260.

${ }^{168}$ Cha, The Impossible State, 264.

${ }^{169}$ Chanlett-Avery and Squassoni, "North Korea's Nuclear Test," 3.

${ }^{170}$ Cha, The Impossible State, 329-330.

${ }^{171}$ Panda, "North Korea's Nuclear Policy," 235; Haggard and Noland, Hard Target, 62-63.

172 Haggard and Noland, Hard Target, 201.
} 
presumed nuclear proliferation in Iraq and Libya, which involved threatening or using force, likely due to North Korea having demonstrated sufficient resolve for its threats to be credible and actually having the ability to produce nuclear weapons.

North Korea's perceived willingness to use nuclear weapons proved counterproductive with the Trump administration, with tensions growing through 2017 to the point that there were fears of war. These began with North Korea successfully testing the Hwasong-14 intercontinental ballistic missile (ICBM) on July 4, 2017, which theoretically could hit the US mainland with a nuclear weapon. ${ }^{173}$ President Trump responded on August 8 that further North Korean belligerence would "“be met with fire and fury... the likes of which the world has never seen before," which could be interpreted as a threat to use nuclear weapons. ${ }^{174}$ North Korea in turn warned that month and in October that " "The KPA strategic force is now carefully examining the operational plan for making an enveloping fire at the areas around Guam,"” where US military bases are located. ${ }^{175}$ The situation escalated further with a thermonuclear weapon test on September 3 and a warning by Foreign Minister Ri Yong Ho on the $23^{\text {rd }}$ that Trump mocking Kim Jong Un at the UN made “"our rockets' visit to the entire US mainland inevitable." 176 Trump's November 7 warning to South Korea's National Assembly that "'This is a very different

\footnotetext{
${ }^{173}$ Kristensen and Norris, "North Korean Nuclear Capabilities, 2018," 47-48.

${ }^{174}$ John Wagner and Jenna Johnson, "Trump Vows North Korea Will Be Met with 'Fire and Fury' If Threats Continue," The Washington Post, August 8, 2017, https://www.washingtonpost.com/news/postpolitics/wp/2017/08/08/trump-vows-north-korea-will-be-met-with-fire-and-fury-if-threatscontinue/?utm term $=.388742580061$.

175 Jackson, On the Brink, 139; Will Ripley, "North Korea Revives Guam Threat Ahead of US-South Korea Drills," CNN, October 15, 2017, https://www.cnn.com/2017/10/13/asia/north-korea-guamthreat/index.html.

${ }^{176}$ Carol Morello, "North Korea's Top Diplomat Says Strike against U.S. Mainland Is 'Inevitable,"” Washington Post, September 23, 2017, https://www.washingtonpost.com/world/national-security/northkoreas-top-diplomat-says-strike-against-us-mainland-is-inevitable/2017/09/23/c3bcb108-dd8f-4761-b55f92044348f179 story.html.
} 
administration" and would be less restrained than its predecessors reportedly inspired panic among North Korean officials. ${ }^{177}$ These remarks led to elites questioning foreigners to understand Trump's intentions and even attempting to contact his son-in-law Jared Kushner, as they lacked any real contact with the US government. ${ }^{178}$

Tensions grew to the point that reports began emerging in December 2017 that administration officials were pushing for preventive strikes on North Korean nuclear facilities, as the perceived cost-insensitivity and aggression that enhanced its deterrent now encouraged attacks against it instead. Various officials denied that such an attack was being planned, though this was contradicted by earlier statements. Then-National Security Advisor H.R. McMaster had previously stated that "all options are on the table," noting how Kim Jong Un "demonstrated his brutality" and was "a threat to all people in the region," which previously enhanced deterrence credibility, but had by then made North Korea seem too dangerous. ${ }^{179}$ These rumours were criticized by South Korean President Moon Jae-in, who already opposed an attack in August and said his government would “"do everything it can to prevent war from breaking out." "180 North Korean officials appear to have taken these threats seriously, asking foreign diplomats in Pyongyang about the possible repercussions of launching a missile near Guam as a warning. ${ }^{181}$

The irony of the situation is that a pre-emptive attack, while meant to avert war by demonstrating American resolve, would likely have triggered one instead. The paranoia

\footnotetext{
177 Jackson, On the Brink, 154-156.

178 Jackson, On the Brink, 156.

${ }^{179}$ ABC News, “"This Week' Transcript: High Alert, North Korea,” ABC News, April 16, 2017, https://abcnews.go.com/Politics/week-transcript-high-alert-north-korea/story?id=46819310.

${ }^{180}$ Choe Sang-Hun, "South Korea's Leader Bluntly Warns U.S. Against Striking North," New York Times, August 15, 2017, https://www.nytimes.com/2017/08/15/world/asia/south-korea-moon-jae-in-trump.html.

${ }^{181}$ Fifield, The Great Successor, 240.
} 
demonstrated by Kim and his supporters would have led them to interpret such an attack as a potential opening salvo in a war to overthrow them and thus meriting a maximum response. Failing to do so, in their minds, would lead to their being deposed and likely killed; even if it was a single attack, not fulfilling their threats would show weakness and encourage further strikes against North Korea. The situation was only defused due to Moon's diplomatic efforts during early 2018, beginning with a meeting with Kim's sister Kim Yo Jong during the Winter Olympics in February, allowing him to serve as an intermediary between Trump and Kim. ${ }^{182}$ This opening of diplomatic relations allowed the crisis to be terminated on June 12 with a summit between Trump and Kim in Singapore.

\subsection{2: Clashes with South Korea: ROKS Cheonan (2010) and landmine incidents (2015)}

Beyond the nuclear crisis, North Korea and South Korea have continued to clash with each other, largely because of North Korean aggression. While generally lowintensity, some provocations have escalated into full-blown crises with a risk of war. Despite this, South Korean governments have largely avoided military retaliation against the North in favor of diplomatic and economic responses. This restraint is attributable to South Korean concerns over war with North Korea since, like the pre-nuclear period, its threats of massive retaliation are considered credible, with the addition of nuclear weapons only magnifying the potential damage. The two particular incidents studied are the sinking of the ROKS Cheonan in March 2010 and the August 2015 landmine incident, though there have been various other provocations of lesser intensity, including the aforementioned various cyberattacks. ${ }^{183}$ Both were caused by North Korean actions - firing a torpedo at

\footnotetext{
${ }^{182}$ Fifield, The Great Successor, 242.

${ }^{183}$ Michael Brecher et al., International Crisis Behavior Data Codebook, Version 12, 2017, http://sites.duke.edu/icbdata/data-collections/.
} 
the Cheonan and planting landmines in South Korea's side of the DMZ - with the former leading to sanctions from South Korea and the latter escalating to a brief exchange of artillery fire. In both cases, South Korean leaders acted to avoid possible war, as North Korea began preparing for greater hostilities during both crises.

The sinking of the Cheonan in 2010 triggered a crisis over North and South Korean territorial waters, and while South Korea avoided force due to potential escalation, it did use economic means to retaliate against North Korea. The incident occurred in March 26, 2010, when the Cheonan was sunk by an explosion, with 46 of the 104 crew being killed, and was considered "one of the bloodiest incidents since the end of the Korean War."184 An international panel of experts concluded in September that the Cheonan had been struck by a North Korean submarine, likely in response to a perceived violation of disputed territorial waters, though North Korea, with Chinese support, denied responsibility. ${ }^{185}$ Despite warning in April that those responsible would "pay the consequences," President Lee Myung-bak did not use force in response, with an emergency meeting held shortly after the sinking largely consisting of diplomats. ${ }^{186}$ Instead, his government implemented the May 24 Measures, barring North Korean ships from South Korean waters, prohibiting virtually all cross-border trade and humanitarian aid to North Korea, and resuming psychological warfare with propaganda loudspeakers at the border. ${ }^{187}$ These measures were

\footnotetext{
${ }^{184}$ Park In-kook, "Letter Dated 4 June 2010 from the Permanent Representative of the Republic of Korea to the United Nations Addressed to the President of the Security Council" (United Nations Security Council, June 4, 2010), https://www.securitycouncilreport.org/atf/cf/\%7B65BFCF9B-6D27-4E9C-8CD3CF6E4FF96FF9\%7D/DPRK\%20S\%202010\%20281\%20SKorea\%20Letter\%20and\%20Cheonan\%20Repor t.pdf; Fifield, The Great Successor, 75.

${ }^{185}$ Cha, The Impossible State, 334.

186 "Seoul to Bolster Security Apparatus," The Korea Herald, April 27, 2010, http://www.koreaherald.com/view.php?ud=20100427000670.

187 "President Vows to Take Self-Defense Measures," The Korea Herald, May 24, 2010, http://www.koreaherald.com/view.php?ud=20100524000371; Kim So Yeol, "Psychological Warfare Will Resume," Daily NK, May 24, 2010, https://www.dailynk.com/english/psychological-warfare-will-resume/.
} 
likely adopted over a more aggressive posture, despite multiple naval clashes over the previous year, due to Kim Jong Il reportedly ordering the KPA to prepare for combat the previous week and issuing further threats as the measures were announced. ${ }^{188}$ By the end of July, the Cheonan crisis had been terminated, as the rhetoric and tensions had gradually gone down to their normal levels.

The 2015 landmine incident was more serious due to escalating to the point of both states exchanging artillery fire and North Korea preparing for war before talks were held. The crisis was triggered when two South Korean soldiers were injured by landmines on their side of the DMZ on August 4, 2015, with a joint US-South Korean investigation subsequently discovering that North Korea had deliberately planted the mines. ${ }^{189}$ President Park Geun-hye's government declared on August 10 that it would pursue “"a severe retaliation," and resumed anti-North Korean propaganda broadcasts over border loudspeakers. ${ }^{190}$ In response, North Korea demanded the loudspeakers be removed, in keeping with a 2004 agreement for both sides to end the broadcasts, and began broadcasting its own propaganda. ${ }^{191}$ The situation escalated further on August 20, when North Korean artillery shells struck South Korean territory in an apparent attempt to destroy a loudspeaker, which provoked South Korea to respond with its own barrage. By the next day, Kim Jong Un had convened the Central Military Commission and ordered the KPA to prepare for a "“quasi-state of war,"” while Park ordered South Korea's military to prepare

\footnotetext{
188 Jonathan Thatcher, "North Korea Threatens Fight with South," Reuters, May 25, 2010, https://www.reuters.com/article/us-korea-north-idUSTRE64N0F520100525.

${ }^{189}$ Choe, Sang-hun, "South Korea Accuses the North After Land Mines Maim Two Soldiers in DMZ," New York Times, August 10, 2015, https://www.nytimes.com/2015/08/11/world/asia/north-korea-placed-minesthat-maimed-2-south-korean-soldiers-at-dmz-seoul-says.html.

${ }^{190}$ Choe, "South Korea Accuses the North After Land Mines Maim Two Soldiers in DMZ."

${ }^{191}$ Franz-Stefan Gady, "North Korea Is Mobilizing for War," The Diplomat, August 21, 2015, https://thediplomat.com/2015/08/north-korea-is-mobilizing-for-war/.
} 
for a potential North Korean attack. ${ }^{192}$ The crisis only de-escalated following emergency talks at Panmunjom that saw Park's government remove the loudspeakers in exchange for North Korea expressing regrets for the incident. ${ }^{193}$

These crises show that despite possessing a conventional advantage, South Korean governments remain very reluctant to respond to North Korean provocations with force due to the potential costs of its reprisals. In both instances, North Korea attacked South Korean soldiers, with the Cheonan crisis being considered one of the worst post-Korean War provocations. ${ }^{194}$ However, even when South Korean governments responded with relatively restrained measures, such as limiting trade and broadcasting propaganda over the border, North Korea's reactions have been comparatively extreme. In both crises, Pyongyang not only threatened war in response to South Korea's actions, but took concrete steps to do so during the 2015 crisis. Past crises made it apparent that South Korean officials have taken North Korean threats to inflict massive damage as credible, and nothing in the nuclear era has changed to make them more implausible. Given the extreme threats to South Korean responses in these crises, any actual use of force carried a significant risk of starting a war.

\section{6: Alternative Explanations}

One variable that could serve as an alternate explanation for the American and South Korean aversion to retaliating against North Korea, rather than concluding its regime type makes it cost-insensitive, is its alliance with China and, to a lesser extent, the Soviet

\footnotetext{
${ }^{192}$ Gady, "North Korea is Mobilizing for War."

${ }^{193}$ Choe Sang-hun, "Koreas Agree on Deal to Defuse Tensions," New York Times, August 24, 2015, http://www.nytimes.com/2015/08/25/world/asia/south-korea-vows-not-to-back-down-in-military-standoffwith-north.html.

${ }^{194}$ Fifield, The Great Successor, 75.
} 
Union. These ties date back to North Korean independence, as its initial elections were supported by the Soviet Union and it received both Chinese and Soviet support in the Korean War. ${ }^{195}$ The relationship had an unambiguous deterrent effect in the war, as both Truman and Eisenhower avoided using tactical nuclear weapons due to the risk of nuclear war with the Soviets. ${ }^{196}$ This also factored in the Pueblo crisis due to US officials suspecting that the ship was captured with Soviet permission and that they would support North Korea in a war (as did North Korea). ${ }^{197}$ The Soviet Union's collapse and cooling Russian-North Korean relations led to China becoming North Korea's main ally due to their shared border affecting its own national security, and has essentially propped up North Korea's economy since the 1990s. ${ }^{198}$ These would suggest that the US and South Korea have been deterred not by the credibility of North Korea's threats to attack South Korea, but instead by the possibility of war with the Soviets or China.

In reality, North Korea's alliances have rarely played a major role in decisions to show restraint against it, and the actual reliability of its allies is in doubt. It is certain that both the Soviet Union and China would have intervened even more directly in the Korean War if it had escalated further, and both subsequently signed friendship treaties with North Korea to commit themselves to defending it. ${ }^{199}$ Since then, North Korea's allies have been repeatedly displeased with its actions due to its aggressive behaviour dragging them into unwanted conflict. The Pueblo crisis highlighted this with Brezhnev's criticism of Kim Il Sung as overly aggressive and warning that " that [the treaty] has a defensive character"”

\footnotetext{
${ }^{195}$ Pollack, No Exit, 31-32.

${ }^{196}$ Gleason, "NSC Memorandum 03/31/1953," 13.

197 "Index of Possible Actions," 18-19; Brezhnev, "Brezhnev's April 1968 Plenum Speech."

198 Jackson, On the Brink, 6-7.

${ }^{199}$ Kim, North Korean Foreign Policy, 82-85.
} 
and was not meant to be abused for North Korean provocations. ${ }^{200}$ China has been more supportive, but not unconditionally. The October 2006 test explosion, for example, was publicly condemned by the Chinese government as "brazen" due to being perceived as an act of supreme disrespect for China by Kim Jong Il. ${ }^{201}$

Relations have been more mixed under Kim Jong Un. When he first became Supreme Leader, he was perceived by Chinese leaders as overly reckless and possibly outright hostile after executing officials for close ties to China. ${ }^{202}$ While these ties have improved following Kim's visit to China in March 2018, it is unclear how committed Xi Jinping is to defending North Korea in a possible war. ${ }^{203}$ These alliances also proved to be a secondary concern during North Korea's pre-nuclear crises. US officials expressed greater concern over North Korea's reactions in the Pueblo crisis than those of its allies, while officials in the Ford administration did not discuss them at all when responding to the 1976 axe murders. ${ }^{204}$ While North Korea's alliances with the Soviet Union and China likely had some impact on how states responded to its provocations, its own perceived resolve to retaliate was just as significant, if not more so.

\section{7: Conclusion: Aggressive Deterrence at All Costs}

North Korea has succeeded in deterring low- and high-intensity attacks, though its possession of nuclear weapons and perceived aggression may have undermined deterrence by making it appear overly threatening. The three pre-nuclear crises after the Korean War

\footnotetext{
200 Brezhnev, "Brezhnev’s April 1968 Plenum Speech."

${ }^{201}$ Cha, The Impossible State, 329-330.

202 Jackson, On the Brink, 123.

203 Jackson, On the Brink, 188.

204 Office of the Historian, "Summary Minutes of Pueblo Group;" Office of the Historian, "SAG Meeting 08/18/1976."
} 
show that despite greatly outmatching North Korea, US officials were reluctant to take any action beyond shows of force. The regime's authoritarian nature allows it to implement policies, including aggression towards South Korea, without regard for cost and thus demonstrate the necessary resolve for its threats of massive retaliation. Documentary evidence shows that US officials considered using force in response to North Korean provocations or to stop its nuclear program, but the potential costs of it attacking South Korea prevented this. The development of a North Korean nuclear arsenal has both increased the costs of its threats and put the US itself within reach. The possibility of North Korea's leaders using nuclear weapons in response to even a low-intensity attack is considered highly credible. This is thanks to a pervasive sense of paranoia that leads to any attack being a potential existential threat, stemming from a desire to avoid regime change at any cost, and the state's command and control structure being centered entirely around Kim Jong Un. This is complicated, however, by the state's nuclear arsenal interacting with its aggressive posture and the credibility of its threats to create a security dilemma with the US, potentially encouraging attacks against it in the process.

The findings of the chapter appear to support the theory that state regime type will influence the credibility of a nuclear deterrent and the willingness of states to attack, though it indicates that the perceived cost-insensitivity of nuclear non-democracies may create a security dilemma. Put simply, North Korea's cost-insensitivity allows it to demonstrate resolve, which has long been established in theory as necessary for nuclear deterrence threats to be considered credible. ${ }^{205}$ The crises involving North Korea support H2(b)'s

\footnotetext{
${ }^{205}$ D. Marc Kilgour and Frank C. Zagare, "Credibility, Uncertainty, and Deterrence," American Journal of
} Political Science 35, no. 2 (1991): 306-307. 
prediction that non-democratic states will be targeted with fewer low-intensity armed attacks after developing a nuclear deterrent and $\mathrm{H} 3$ anticipating that aggressive nondemocratic states will experience even fewer such attacks. This creates a sharp contrast between North Korea and the other states studied in this dissertation. The two democracies, India and Israel, have continued to be targeted with low-intensity attacks by other states even after developing a nuclear deterrent, with their accountability to voters making them sensitive to the costs of using their arsenals outside of select circumstances and thus limiting their credibility. Pakistan, a fellow non-democracy, bears similarities in its government's relative lack of accountability and conventional inferiority to its opponents making its deterrence threats more credible, but it is much more unstable than North Korea and has a significant risk of unauthorized nuclear weapons use. 


\section{Chapter 9: Conclusions}

This chapter presents the core findings of the four case studies and their implications regarding the effect of state regime type on nuclear deterrence credibility, which appears to be one of the first attempts in the field of nuclear deterrence to study this issue beyond individual case studies. Using process tracing within an embedded comparative case study approach, I studied key pre- and post-nuclear acquisition crises and armed conflicts targeting Israel, India, Pakistan, and North Korea between 1945 and 2018. In chapter 3, I hypothesized that democratic nuclear weapon states would continue being targeted with low-intensity attacks and limited wars due to their accountability to voters making them sensitive to the costs of using nuclear weapons in response to such attacks, undermining the credibility of nuclear deterrence threats in the process (H2(a)). Conversely, non-democratic nuclear weapon states would suffer fewer, if any, such attacks due to their reliance on elite supporters making them insensitive to the costs of fulfilling those threats, making them more credible (H2(b)). I also hypothesized that a reputation for aggression would further bolster nuclear deterrence credibility, as it would signal greater cost-insensitivity to potential challengers, though this was expected to primarily benefit non-democracies due to their existing cost-sensitivity encouraging aggression $(\mathrm{H} 3)$.

The findings for each chapter suggest that there is support for the hypotheses, though issues are present. Both democratic nuclear weapon states studied in this dissertation - Israel and India - appear to have had their resolve underestimated by challengers in armed conflicts before and after their development of nuclear weapons, leading to their continuing to be attacked as anticipated in H2(a). Likewise, Pakistan and North Korea avoided being attacked after acquiring nuclear weapons because, as 
anticipated for $\mathrm{H} 2(\mathrm{~b})$, they were perceived as so insensitive to the costs of using nuclear weapons that challengers were unwilling to risk even low-intensity responses to provocations. This was particularly notable in Pakistan's case, given how its provocations in 1965 and 1971 led to India invading on both occasions. For the latter two, a reputation for aggression appears to have played a significant role in enhancing threat credibility, indicating that $\mathrm{H} 3$ is likewise correct. Notable caveats are present for each of the cases, with the exception of Pakistan, and are addressed later in this chapter. Overall, the results suggest that while state regime type is not sufficient to explain variation in deterrence threat credibility, given the other variables involved, it appears to be necessary.

The rest of the chapter first presents summaries of the findings of the four case study chapters. This is followed by a broader comparison of the findings for regime type and nuclear deterrence as a whole, including a final verdict on whether the hypotheses can be accepted or rejected. The potential implications of the findings for theory and policy, including what they mean for strategies relating to nuclear weapon states and what steps governments could take, are also discussed. The chapter concludes with some potential steps for future research in studying the relationship between state regime type and nuclear deterrence.

\section{1: Case Study Findings}

The Israeli case appeared to support that nuclear-armed democracies face difficulties in signalling nuclear deterrence credibility in low-intensity conflict and limited war, though its nuclear opacity policy (amimut) led to significant issues by limiting the availability of information, as well as introducing theoretical issues regarding the role of electoral fears in crisis decision-making. Between gaining independence in 1948 and 
successfully developing nuclear devices sometime in 1966, Israel was repeatedly attacked (both directly and through non-state actor proxies) by challengers such as Egypt and Syria despite demonstrating a conventional advantage over them. This did not change significantly after Israel developed a nuclear deterrent, since it was attacked in the 1967 Six Day War, the 1967-70 War of Attrition, the 1973 Yom Kippur War, and by Iraq during the 1991 Gulf War.

What becomes apparent is that while the 1948 War of Independence was an existential crisis for Israel, the post-nuclear acquisition conflicts were much more limited. Despite the sizable military force deployed against Israel in 1967 and 1973, for instance, the intent of leaders such as Egypt's Gamal Nasser and Anwar Sadat, as well as Syria's Hafez al-Assad, was to recapture lost territory and not to destroy Israel. These leaders would have been acting under the presumption that they had not met Israel's nuclear threshold, particularly since all available evidence indicates that the Israeli government's nuclear deterrence strategy is meant solely for existential threats to the state. That Israeli leaders like Levi Eshkol and Golda Meir resisted internal pressure for even test explosions as warnings due to the potential ramifications, such as (literal) fallout, sanctions, and Soviet involvement, supports that democratic cost-sensitivity will discourage nuclear weapon use outside of low-intensity conflict.

Israel's amimut policy does raise two key issues for the theory regarding accountability and the ability to signal potential challengers. As explained in chapter 5, Israel is notable for the various government measures for ensuring national security secrecy, including, uniquely among Western democracies, a military censor tasked with overseeing domestic news and academic publications. Israeli nuclear affairs are no 
exception to this, as even information about peaceful nuclear energy is restricted, while the only information regarding Israeli nuclear weapons that has been publicly confirmed by the government was a 1960 acknowledgement that it was building the Dimona nuclear reactor. ${ }^{1}$ Since then, government officials have at most alluded to possessing nuclear weapons, with any debate being restricted to secret Knesset subcommittee meetings and whistleblowers being prosecuted.

This means that the Israeli public has little to no way to hold the government to account for decisions relating to the state's nuclear deterrent because they have no access to information about whether it exists or not, much less how it would be used. At the same time, amimut also brings into question how aware Israel's challengers were of its nuclear deterrent. Evidence from the Six-Day War in particular suggests that Nasser and his allies, while aware that Israel was working to develop nuclear weapons, were not aware that they had successfully done so or had considered using them in the conflict. ${ }^{2}$ This appears to have changed by 1973, given Sadat's later remarks that Egyptian forces would go no further than the Sinai due to "what Israel had."'3 Amimut thus introduces a degree of uncertainty into a seemingly straightforward case.

India similarly appears to confirm that perceived cost-sensitivity stemming from popular accountability undermines nuclear deterrence threat credibility for low-intensity conflict, though it also has theoretical issues regarding the role of public sentiment on

\footnotetext{
${ }^{1}$ Avner Cohen, The Worst-Kept Secret: Israel's Bargain with the Bomb, (New York: Columbia University Press, 2010), xxvii, 155.

${ }^{2}$ Hassan Elbahtimy, "Missing the Mark: Dimona and Egypt's Slide into the 1967 Arab-Israeli War," The Nonproliferation Review 25, no. 5-6 (2018): 388-389.

${ }^{3}$ Elbridge Colby et al., "The Israeli Nuclear Alert" of 1973: Deterrence and Signaling in Crisis" (Fort

Belvoir, VA: Defense Technical Information Center, April 1, 2013), 10-11.
} 
decision-making processes. Despite the introduction of nuclear weapons with the 1974 peaceful nuclear explosion and the 1998 Pokhran-II tests, India has continued to be the target of low-intensity attacks, particularly by Pakistan. Crises occurring before and after India's development of a nuclear arsenal indicate that a persistent belief among Pakistani leaders, particularly within the military, that Indian officials are unwilling to bear the costs of defending their territory has motivated Pakistani incursions despite evidence indicating otherwise. ${ }^{4}$ Furthermore, India's nuclear doctrine explicitly states that there will be no nuclear first strikes, making it clear that only existential threats to the state are sufficient to meet the threshold for nuclear weapon use. Crisis discussions by Indian political leaders have shown them to be sufficiently concerned about the potential costs of escalation, including voter backlash and international condemnation, that they have deliberately restricted their uses of force.

Like Israel, however, the exact role of government accountability to its citizens remains questionable, albeit due to public sentiment rather than national security policy. The motivating logic of the theory - that domestic audiences will punish governments for the costs of nuclear weapon use - is not supported by Indian public opinion, which instead appears to favour their use against Pakistan even in relatively low-intensity situations. The evidence reviewed for post-nuclear crises targeting India suggests that the government has deliberately restricted the scope of its use of force due to the concerns of what is known as the strategic elite and the international consequences, not because the public forced it to. The perception that the Indian government is restrained by a need for public support and

\footnotetext{
${ }^{4}$ For more on the attitude of Pakistani military leaders regarding Indian cost sensitivity, see chapter 6.
} 
thus concerned over costs is present, however, and its role in encouraging continued lowintensity attacks against India still adheres to the expectations of the theory.

Pakistan is, as previously mentioned, the most straightforward of the cases, as it is readily apparent that the apparent cost-insensitivity of its government, particularly military leaders, plays a significant role in the success of its deterrence threats. Prior to developing nuclear weapons, Pakistan's attacks on India trigged armed responses, with the 1965 and 1971 Indo-Pakistani Wars being particularly noteworthy for provoking outright invasions. Since 1998, however, Pakistan has largely avoided reprisals: despite the circumstances that triggered the 1999 Kargil War being similar to 1965 , Indian retaliation was limited entirely to within its own borders. The reticence of Indian leaders to respond with force seems to have been fuelled, at least in part, by their Pakistani counterparts warning that even lowintensity attacks by India could escalate to the use of tactical nuclear weapons. ${ }^{5}$ In multiple post-nuclear acquisition crises, the risk of Pakistani escalation has been cited by Indian politicians as justification to not go beyond shows of force, indicating that they find Pakistan's nuclear threats sufficiently credible to be deterred.

These extreme threats have been made credible by the military's dominance of Pakistani government throughout the country's history and its apparent disregard for the costs the country would suffer from their fulfillment. At various points, military leaders have either pressured weak civilian governments to implement their desired policies or taken direct control of Pakistan as a military dictatorship. This means that the military has been able to not only institute aggressive policies against India due to considering it an

\footnotetext{
${ }^{5}$ Vipin Narang, Nuclear Strategy in the Modern Era: Regional Powers and International Conflict (Princeton: Princeton University Press, 2014), 275.
} 
existential threat, but to do so with little regard for public accountability. Most notably, Pakistani generals have been able to not only maintain a policy of using nuclear weapons in response to any Indian attack, but also delegate nuclear launch authority to battlefield commanders, essentially removing any checks on their use as a result despite the potential for a high civilian death toll.

North Korean nuclear deterrence credibility similarly appears to have benefitted from the perceived cost-insensitivity of its government, as it has avoided being attacked despite its provocative actions, though pre-nuclear crises and the emergence of a security dilemma raise questions regarding how much it has benefitted from nuclear deterrence. Crises from before the first North Korean test explosion in 2006, and those that have followed since, make it readily apparent that both US and South Korean officials consider North Korea's leadership to be sufficiently cost-insensitive that it will respond to any lowintensity attack with war. North Korea is unique among the states studied in this dissertation in that it was capable of deterring challengers from attacking it even before it possessed nuclear weapons based on external perceptions of the government's behaviour. Documentary evidence shows American and South Korean leaders repeatedly opted against using force in response to North Korean provocations such as the Pueblo incident or to stop its nuclear program due to the anticipated costs. The perceived willingness of Kim Jong Un and his supporters to respond to low-intensity attacks with nuclear weapons stems from a combination of the government wholly revolving around him and the weakness of North Korean conventional forces. These encourage a paranoid belief that any low-intensity attack could be a potential existential threat to the state (and the personal 
well-being of Kim and his supporters), which is accompanied with a complete absence of restraints on nuclear weapon use.

These findings are complicated somewhat by the pre-nuclear reluctance to attack North Korea and how its nuclear arsenal appears to have created a security dilemma. US and South Korean reluctance to use force against North Korea prior to 2006 makes it unclear just how much of a role nuclear weapons have played in deterring attacks. Furthermore, the demonstrated aggression of North Korea's leadership towards these two states appears to have interacted with its nuclear arsenal in a way that potentially undermines deterrence. By repeatedly threatening to attack the US with nuclear weapons, North Korea has potentially encouraged American leaders to plan pre-emptive strikes against its nuclear forces to ensure its security, despite the potential costs. Why such strikes did not occur as a result of the 2017-2018 tensions between the US and North Korea remains unclear as of the time of writing, though it may very well be possible that the risks associated with them contributed to a decision to use diplomatic means instead.

\section{2: What Does This Mean for Regime Type and Nuclear Deterrence?}

The case findings indicate that overall, there is support for $\mathrm{H} 2$ (a)'s prediction that democratic nuclear weapon states will continue to be targeted with low-intensity attacks and limited wars, though there are notable issues regarding the expected role of electoral backlash in decision-making processes. Both India and Israel, despite possessing nuclear weapons, have been unable to prevent challengers from targeting them with low-intensity attacks, whether directly with military forces or indirectly with state-sponsored terrorism. These crises occurred because challengers believed their actions would fall below the defender's nuclear threshold or that it would simply be too concerned about potential costs 
to retaliate in any meaningful way. The documents and secondary sources studied in this dissertation make it clear that throughout these crises, Israeli and Indian officials expressed concerns regarding the potential costs of using nuclear weapons, whether it was how the after-effects would harm their citizens, the risk of escalation, or how other states would respond. It is telling that, in the face of an apparent existential crisis for Israel in 1973, Golda Meir refused to entertain even a demonstrative test explosion because the IDF could still fight. ${ }^{6}$ India, meanwhile, has yet to face an existential crisis since revealing the bomb in 1998, though its leaders have consistently demonstrated cost sensitivity in their decisionmaking during subsequent crises.

Both the Israel and India cases faced issues that lead to their not perfectly adhering to the logic of the hypothesis while still ultimately supporting it. The presumption of the theory was that democratic governments would perceive themselves as constrained from using nuclear weapons outside of major wars or existential crises due to potential electoral backlash. This does not appear to have been the case for Israel during the crises that were studied, with concerns being largely directed towards potential international costs that would be incurred as a result. Any electoral backlash about possible nuclear ruminations in these crises would have been averted by amimut keeping public knowledge to a minimum, which also had the effect of limiting available information about these decisions for study. Indian elites, meanwhile, appear to have been willing to outright defy public opinion in favour of maintaining restraint, given apparent favourability towards responding to Pakistani provocations with conventional or even nuclear forces. These both suggest that

\footnotetext{
${ }^{6}$ Avner Cohen and Arnan Azaryahu, "Interview with Arnan 'Sini' Azaryahu by Avner Cohen" (January 2008), 2-3, From the personal collection of Avner Cohen, History and Public Policy Program Digital Archive, https://digitalarchive.wilsoncenter.org/document/117848.
} 
while the predicted outcomes were correct, public backlash does not play as significant a role in democratic nuclear decision-making as originally anticipated.

Support for non-democratic nuclear weapon states successfully deterring both lowand high-intensity conflict, expressed in H2(b), is also present in the two cases studied, though North Korea raises questions as to whether a security dilemma can arise and undermine these benefits. Pakistani and North Korean decision-makers closely adhere to selectorate theory's expectations by relying on elite supporters (particularly military officers, bureaucrats, and wealthy individuals) to remain in power while being unaccountable to citizens outside these groups. This form of governance is reflected in both their aggressive postures towards neighbouring states (India and South Korea, respectively) and their threats to use nuclear weapons in response to even low-intensity attacks, both indicating insensitivity to the costs to their citizens. This cost insensitivity has been effective in making these threats credible to other states, regardless of their seemingly extreme nature. Pakistan and North Korea's challengers have been unwilling to use force against them due to the belief that these threats would be fulfilled, even in response to provocations. These threats are made even more credible by the fact that during some crises, such as the 1999 Kargil War and the 2015 landmine incident, Pakistan and North Korea did begin deploying tactical nuclear weapons and mobilizing for war, respectively, before diplomatic measures were taken. US threats towards North Korea throughout 2017 and early 2018 , up to reportedly planning pre-emptive strikes, raise the unanticipated issue of a non-democratic nuclear weapon state creating a security dilemma and thereby undermining deterrence in the process. 
Lastly, these two states also confirm that a reputation for aggressive behaviour will bolster a state's nuclear deterrent, supporting H3. Chapters 7 and 8 showed that Pakistan and North Korea's history of aggression played a major role in making India, the US, and South Korea wary of the costs of retaliating against them. Both non-democracies had, prior to developing nuclear weapons, engaged in provocations (e.g. the 1965 war for Pakistan; the Korean War and 1968 Pueblo incident for North Korea) with seemingly little regard for potential costs. These and other incidents were referenced by other leaders in discussing how to respond to later provocations and, along with the other information they possessed, used to assess the likelihood that force would lead to undesirable escalation. This continued once these states acquired nuclear weapons, with their potential challengers inferring from their past aggression that they would be willing to use them to defend their territory even against low-intensity attacks, despite the cost. The perception that these states were aggressive, and thus cost-insensitive, thus served as a source of information for challengers to infer from to assess if deterrence threats would be fulfilled, as the hypothesis anticipated.

\section{3: Implications for Theory and Policy}

The findings of this dissertation have notable implications for nuclear deterrence theory. Most readily apparent is that it lends further support to the post-Cold War conception of nuclear deterrence, acknowledging that nuclear weapon states will differ from each other in terms of capabilities and behaviours rather than being like units. ${ }^{7}$ This means that it is inaccurate to follow a one-size-fits-all approach to deterrence theory, since differing characteristics - as this theory predicts regime type does - means that decisionmakers can be expected to make different decisions than each other while still adhering to

\footnotetext{
${ }^{7}$ Narang, Nuclear Strategy in the Modern Era, 1-7.
} 
what would be considered rational behaviour. Furthermore, the case studies present strong evidence against the claims made by Waltz and others that simply possessing nuclear weapons is enough to deter challengers, regardless of context or capabilities. ${ }^{8}$ Instead, states must articulate specific threats regarding the conditions for their use and ensure they are credible.

Secondly, my theory follows a logic similar to audience costs theory, but improves upon it by drawing upon theories of behavioural variation across regime types, resulting in two key differences. As discussed in chapter 3, the theory continues to argue that deterrence credibility will vary across regime types according to whether domestic audiences hold governments accountable. Where audience costs argues that democratic audiences punish bluffing by governments, encouraging threat fulfillment, I instead argue that audiences will punish leaders for policies that impose unnecessary costs on them. ${ }^{9}$ Nuclear weapon use costs like sanctions and alliances against the state means that democratic audiences would instead be expected to punish leaders for using nuclear weapons in low-intensity conflict due to the costs outweighing the benefits. Furthermore, Fearon's original argument that non-democratic governments are largely unaccountable is only true in relation to the nonelite portions of their populations, as their reliance on elite supporters means that they are still accountable to them. ${ }^{10}$ So long as they continue defending the interests of those supporters, however, they are likely to continue ruling.

\footnotetext{
${ }^{8}$ Kenneth N. Waltz, "More May be Better," in The Spread of Nuclear Weapons: An Enduring Debate, Third Edition, eds. Scott D. Sagan and Kenneth N. Waltz (New York: W.W. Norton \& Company, 2013), 12-16.

${ }^{9}$ James D. Fearon, "Domestic Political Audiences and the Escalation of International Disputes," American Political Science Review 88, no. 3 (1994): 581-582.

${ }^{10}$ Fearon, "Domestic Political Audiences," 582.
} 
Finally, my theory also builds upon the stability-instability paradox by providing a potential explanation for how mutual nuclear deterrence can result in one state attacking and the other avoiding fighting, as well as how the dynamics can occur even when only a defender possesses nuclear weapons. Because a democracy's nuclear deterrent is expected to be viewed as non-credible for low-intensity attacks by potential challengers, the expectation is that they will be attacked more frequently to make gains against them while remaining beneath their nuclear threshold. Conversely, a nuclear non-democracy's challengers are expected to avoid launching such low-intensity attacks against them because they are considered so cost-insensitive as to use nuclear weapons in response. The inclusion of cost-sensitivity variation across regime types also means that the paradox's dynamics can occur when a nuclear-armed democracy is attacked by non-nuclear challengers. Because the democracy would be perceived as too cost-sensitive to use nuclear weapons in low-intensity conflict - essentially self-deterring - even non-nuclear challengers are expected to use low-intensity attacks more frequently, but not deliberately engaging in interstate war. This means that increased strategic stability and tactical instability can occur so long as the nuclear weapon state is a democracy.

The theory and conclusions for each of the cases have notable implications for policy relating to nuclear deterrence as well. The findings for the two democracies make it clear that possessing a nuclear deterrent only benefits them vis-à-vis high-intensity conflicts. More limited, low-intensity attacks that fall below a democratic defender's nuclear threshold, or at least are perceived as such by the challenger, are expected to continue unabated because they are believed to be too cost-sensitive to respond except with conventional force, if at all. In essence, democracies suffer an inherent disadvantage in 
nuclear deterrence because the feature that defines them - their accountability to their citizens - can be perceived as creating an inherent lack of resolve to fulfill their threats. Thus, democratic states seeking to bolster deterrence should do so by sending costly signals to potential challengers to demonstrate resolve. This could be accomplished by articulating potential conventional responses tailored to specific types of provocations and deploying conventional forces accordingly. Doing so would also have the benefit of establishing a clear escalation ladder and responses to low-intensity attacks by challengers.

Non-democracies, meanwhile, raise very different issues. The Pakistan and North Korea cases highlight that non-democracies are hardly perceived as lacking the resolve to use nuclear weapons, and if anything, are willing to do so against even minor attacks without regard for the costs to their citizens. This not only means that low-intensity attacks against them carry a significant degree of risk for the challenger, but that a non-democracy could misperceive their actions as an attack and cause a crisis. Minimizing the latter risk requires the use of diplomatic outreach and confidence-building measures with the nondemocracy to reduce the risk of misperceptions and accidental nuclear war. The benefits that non-democracies enjoy from possessing nuclear weapons and their willingness to use them mean that pre-emptive strikes to destroy their arsenals are highly unwise. At best, the non-democracy's nuclear arsenal could be destroyed, but tensions between it and the challenger would increase, and it is likely that there would be a major conventional response to such an attack. At worst, the pre-emptive strike would fail to destroy the nondemocracy's nuclear arsenal, and would provoke it to retaliate with those weapons and start a nuclear conflict. Thus, states may be forced to accept living with a nuclear-armed non-democracy as the least terrible option available to them. 
Finally, this highlights the need to focus on preventing the emergence of future nuclear non-democracies. This is an increasingly relevant issue in recent years, given that the most recent nuclear weapon state (North Korea) and the two most likely states to develop their own weapons (Iran and Saudi Arabia) are all non-democracies known for their willingness to encourage regional conflict. Armed attacks against their nuclear facilities could lead to mixed results, either successfully slowing down their programs that they never reach the end goal of producing a deliverable nuclear device (as the 1981 Israeli airstrike on Iraq's Osirak reactor did) or encouraging the acceleration of their program by providing additional justification for its existence. Regardless of the direct impact on the non-democracy's nuclear program, tensions would almost certainly increase, and could in turn lead to a less-than-desirable conventional conflict. The best approach in this case is the use of economic pressure and negotiated agreements for the non-democracy in question to agree to freeze its program before reaching the point of assembling a functional nuclear device. This approach was largely successful in convincing the Iranian government to sign the Joint Comprehensive Plan of Action (JCPOA) and freeze its nuclear program in 2015 before the Trump administration's withdrawal from the agreement in May $2018 .{ }^{11}$

\section{4: Steps for Future Research}

My dissertation is thus far the only scholarly attempt to both advance a theory regarding the role of state regime type in nuclear deterrence and to test it with case studies. However, as has been stated throughout the dissertation, there have also been additional questions raised, particularly in regard to domestic factors for nuclear democracies.

\footnotetext{
${ }^{11}$ Zachary Laub and Kali Robinson, "What Is the Status of the Iran Nuclear Agreement?," Council on Foreign Relations, January 7, 2020, https://www.cfr.org/backgrounder/what-status-iran-nuclear-agreement.
} 
Limited time and resources also mean that only a few nuclear weapon states could be studied, meaning that further testing regarding the theory's applicability to other states remains open. This leaves multiple potential avenues for scholarly work within this subject area, both in terms of further establishing the theory's external validity and in introducing further refinements.

The most straightforward means of testing the theory's generalizability would be to test it against other nuclear weapon states in order to determine if it accurately predicts changes in conflict propensity towards them on the basis of regime type. While China and France were excluded, for example, the theory could potentially be applied to them, given their similar status as regional nuclear powers. ${ }^{12}$ The main challenge in this regard would be disentangling crises involving colonial holdings or only indirectly affecting the defender from those where it risked low-intensity attacks or was actually targeted by challengers. Applying the theory to France would also have an additional benefit in varying the regional politics surrounding the defending state, which would help in assessing the influence of that variable. The UK is also a potential candidate for further study, though the colonial holdings issue and the unique influence the US has had over its nuclear deterrence policies could introduce additional complications. As discussed in chapter 4, these ties are so close that the US has been able to determine potential targeting decisions for the UK nuclear arsenal. ${ }^{13}$ Testing the theory against additional nuclear weapon states, in short, could further enhance its external validity, or potentially indicate that its applicability is only limited to a small number of states.

\footnotetext{
${ }^{12}$ See chapter 4 for further discussion of which states qualify as regional nuclear powers.

${ }^{13}$ Narang, Nuclear Strategy in the Modern Era, 3-4.
} 
Future research may even be able to test the theory with the superpowers as cases. As stated in chapter 4, it would be difficult to properly compare the US and the Soviet Union/Russia against the various regional nuclear powers due to the sheer disparity in conventional and nuclear power. It may be more feasible, however, to compare them against each other, since their sharing superpower status would help ensure a basis for comparison between the two. It is alternatively possible to conduct studies applying the theory to a single one of the two states, or perhaps even a specific time period. Though this would require forgoing the comparative element present in this dissertation, single-case studies would potentially benefit from greater detail, as well as helping to highlight additional independent variables of interest to further refine the theory. ${ }^{14}$

Secondly, one unanticipated issue that arose over the course of this dissertation also merits closer study: the role of public sentiment regarding the use of nuclear weapons. India made this readily apparent: as what few polls have been conducted on public perceptions of nuclear weapon use indicate that a significant portion of the population would accept it even in response to relatively minor threats. ${ }^{15}$ This attitude contradicts one of the core assumptions underlying the theory: that the population of a state, which would bear much of the costs of nuclear weapons being used in low-intensity conflict, would act as a source of restraint on the government using them unless necessary. Instead, the Indian case suggests the reverse, where the government acts as the primary restraint on the use of force, largely due to the influence of strategic elites. This raises further questions about how

\footnotetext{
${ }^{14}$ Alexander L. George and Andrew Bennett, Case Studies and Theory Development in the Social Sciences (Cambridge: MIT Press, 2005), 80-81.

${ }^{15}$ Benjamin A. Valentino and Scott D. Sagan, “Atomic Attraction," The Indian Express, June 3, 2016, https:/indianexpress.com/article/opinion/columns/barack-obama-hiroshima-speech-india-nuclear-weaponterrorism-atomic-attraction-2831348/.
} 
popular opinion is considered in democracies when developing nuclear deterrence postures and strategies, if at all.

Third, future studies of this topic could be further expanded to account for the possible role of cyberwarfare. The definition of low-intensity conflict in this dissertation focused primarily on the use of force of arms (whether directly through state military forces or indirectly through state-sponsored terrorism). While this is representative of provocative actions for much of the nuclear era, increasing electronic capabilities and their potential to cause significant damage to infrastructure and military capabilities raise new questions as to what kind of damage to a defender could be sufficient to provoke a nuclear response. These even extend to the nuclear realm, as cyberwarfare is increasingly seen as being capable of interfering with nuclear launch systems, including second-strike capabilities, and thus potentially undermining deterrence. ${ }^{16}$

Future researchers could thus build upon the definition of low-intensity conflict used in this dissertation to include various forms of electronic warfare between states. This element is already apparent in the cases studied. North Korea, for example, has used hacking for a variety of objectives, ranging from retaliating against perceived slights against Kim Jong Un to theft of foreign funds or extortion. ${ }^{17}$ Furthermore, there has been retaliation in kind for at least some of these provocations: the 2014 Sony Entertainment hack saw the US respond by temporarily shutting down North Korea's Internet. Israel, meanwhile, has been engaged in an escalating cyber campaign with Iran that has recently

\footnotetext{
${ }^{16}$ Keir A. Lieber and Daryl G. Press, "The New Era of Counterforce: Technological Change and the Future of Nuclear Deterrence," International Security 41, no. 4 (2017): 9-10.

${ }^{17}$ David E. Sanger and Nicole Perlroth, "U.S. Accuses North Korea of Cyberattacks, a Sign That Deterrence Is Failing," The New York Times, April 15, 2020, https://www.nytimes.com/2020/04/15/world/asia/north-korea-cyber.html.
} 
led to mutual efforts to damage important infrastructure. ${ }^{18}$ This can even be expanded to nuclear weapon states beyond the sample studied in this dissertation, such as increasing cyberattacks and espionage between China and other states. ${ }^{19}$ Expanding the definition to include low-intensity conflict could thus aid in further refining the theory and ensure its continued applicability to future nuclear weapon states.

\section{5: Final Remarks}

In conclusion, this dissertation shows that that the regime type of a defending nuclear weapon state plays an important role in the credibility of its nuclear deterrent to potential challengers. Though the nuclear deterrence literature itself largely ignores regime type, extending concepts from the study of conventional conflict made it possible to devise a novel theory that the accountability and perceived cost-sensitivity of a defender's government can bolster or undermine the credibility of its nuclear deterrent for lowintensity armed conflict in the eyes of potential challengers. This theory, when tested against pre- and post-nuclear acquisition crises, showed that a belief that the defender was overly cost-sensitive or willing to endure them played a significant part in the challenger's decision to use low-intensity attacks against it, albeit with caveats discussed above. In the process, this study not only builds upon existing theories of deterrence credibility, but also provides new ideas for policy-makers in how to bolster a democracy's nuclear deterrent or approaching nuclear-armed non-democracies.

\footnotetext{
${ }^{18}$ Ronen Bergman and David M. Halbfinger, "Israel Hack of Iran Port Is Latest Salvo in Exchange of Cyberattacks," The New York Times, May 19, 2020, https://www.nytimes.com/2020/05/19/world/middleeast/israel-iran-cyberattacks.html.

${ }^{19}$ Eiji Furukawa, “'Hacker Armies' Linked to China and Russia Ramp up Cyberattacks," Nikkei Asian Review, July 18, 2020, https://asia.nikkei.com/Politics/International-relations/Hacker-armies-linked-toChina-and-Russia-ramp-up-cyberattacks.
} 


\section{Chapter 10: Works Cited}

\section{1: Popular and Scholarly Articles, Books, and Chapters}

Abdullah, Sannia. "Nuclear Ethics? Why Pakistan Has Not Used Nuclear Weapons ... Yet." The Washington Quarterly 41, no. 4 (2018): 157-73. https://doi.org/10.1080/0163660X.2018.1558681.

Abrahamian, Andray. "North Korea's Bounded Rationality." Survival 61, no. 1 (2019): 141-60. https://doi.org/10.1080/00396338.2019.1568048.

Achen, Christopher H., and Duncan Snidal. "Rational Deterrence Theory and Comparative Case Studies." World Politics 41, no. 2 (1989): 143-169. https://dx.doi.org/10.2307/2010405.

Adamsky, Dima. "From Israel with Deterrence: Strategic Culture, Intra-War Coercion and Brute Force." Security Studies 26, no. 1 (2017): 157-84. https://doi.org/10.1080/09636412.2017.1243923.

Adamsky, Dima, and Uri Bar-Joseph. “'The Russians Are Not Coming': Israel's Intelligence Failure and Soviet Military Intervention in the 'War of Attrition." Intelligence and National Security 21, no. 1 (2006): 1-25. https://doi.org/10.1080/02684520600568238.

Adeney, Katharine. "How to Understand Pakistan's Hybrid Regime: The Importance of a Multidimensional Continuum." Democratization 24, no. 1 (2017): 119-37. https://doi.org/10.1080/13510347.2015.1110574.

Ahmed, Samina. "Pakistan's Nuclear Weapons Program: Turning Points and Nuclear Choices." International Security 23, no. 4 (1999): 178-204. https://doi.org/10.1162/isec.23.4.178.

Amnesty International. “'Denied': Failures in Accountability for Human Rights Violations by Security Force Personnel in Jammu and Kashmir." London: Amnesty International, 2015. https://www.amnesty.org/download/Documents/ASA2018742015ENGLISH.PDF

Anderton, Charles H., and John R. Carter. "The Impact of War on Trade: An Interrupted Times-Series Study." Journal of Peace Research 38, no. 4 (2001): 445-57. https://doi.org/10.1177/0022343301038004003.

Arce, Daniel G., and Todd Sandler. "Deterrence: Credibility and Proportionality." Economics \& Politics 21, no. 3 (2009): 384-408. http://dx.doi.org/10.1111/j.1468-0343.2009.00352.x.

Bar-Joseph, Uri. The Watchman Fell Asleep: The Surprise of Yom Kippur and Its Sources. Albany: State University of New York Press, 2005. 
Bar-Or, Amir. "Political-Military Relations in Israel, 1996-2003." Israel Affairs 12, no. 3 (2006): 365-76. https://doi.org/10.1080/13537120600744578.

Barak, Eitan. "Between Reality and Secrecy: Israel's Freedom of Navigation through the Straits of Tiran, 1956-1967." Middle East Journal 61, no. 4 (2007): 657-79. https://doi.org/10.3751/61.4.15.

Baram, Amatzia. "An Analysis of Iraqi WMD Strategy." Nonproliferation Review 8, no. 2 (2001): 25-39. https://doi.org/10.1080/10736700108436848.

Basrur, Rajesh M. "Nuclear Weapons and Indian Strategic Culture." Journal of Peace Research 38, no. 2 (2001): 181-98. https://doi.org/10.1177/0022343301038002004.

Baum, Matthew A., and Philip B.K. Potter. "The Relationships Between Mass Media, Public Opinion, and Foreign Policy: Toward a Theoretical Synthesis." Annual Review of Political Science 11, no. 1 (2008): 39-65. https://doi.org/10.1146/annurev.polisci.11.060406.214132.

Beardsley, Kyle, and Victor Asal. "Winning with the Bomb." Journal of Conflict Resolution 53, no. 2 (2009): 278-301. http://dx.doi.org/10.1177/0022002708330386.

Behera, Ajay Darshan. "Pakistan General Elections 2018: Clear Signs of a Guided Democracy." International Studies 55, no. 3 (2018): 238-52. https://doi.org/10.1177/0020881718803433.

Bell, Mark S., and Nicholas L. Miller. "Questioning the Effect of Nuclear Weapons on Conflict." Journal of Conflict Resolution 59, no. 1 (2015): 74-92. http://dx.doi.org/10.1177/0022002713499718.

Ben-Yehuda, Hemda, and Shmuel Sandler. The Arab-Israeli Conflict Transformed: Fifty Years of Interstate and Ethnic Crises. Albany: State University of New York Press, 2002.

Benn, Aluf. "Censoring the Past." Bulletin of the Atomic Scientists 57, no. 4 (2001): 17 19. https://doi.org/10.1080/00963402.2001.11460468.

Bennett, D. Scott, and Allan C. Stam. "The Declining Advantages of Democracy: A Combined Model of War Outcomes and Duration." The Journal of Conflict Resolution 42, no. 3 (1998): 344-66. https://doi.org/10.1177/0022002798042003007.

Berejikian, Jeffrey D. "A Cognitive Theory of Deterrence." Journal of Peace Research 39, no. 2 (March 1, 2002): 165-83. https://doi.org/10.1177/0022343302039002002.

Bergman, Ronan. Rise and Kill First: The Secret History of Israel's Targeted Assassinations. New York: Random House, 2018. 
Betts, Richard K. Nuclear Blackmail and Nuclear Balance. Washington, DC: The Brookings Institution, 1987.

Biswas, Arka. "Pakistan's Tactical Nukes: Relevance and Options for India." The Washington Quarterly 40, no. 3 (2017): 169-86. https://doi.org/10.1080/0163660X.2017.1370355.

Boston, Scott, Michael Johnson, Nathan Beauchamp-Mustafaga, and Yvonne K. Crane. Assessing the Conventional Force Imbalance in Europe: Implications for Countering Russian Local Superiority. Santa Monica: RAND Corporation, 2018. https://www.rand.org/pubs/research_reports/RR2402.htm1.

Bowen, Glenn A. "Document Analysis as a Qualitative Research Method." Qualitative Research Journal 9, no. 2 (2009): 27-40. https://doi.org/10.3316/QRJ0902027.

Brands, Hal, and David Palkki. "Saddam, Israel, and the Bomb: Nuclear Alarmism Justified?" International Security 36, no. 1 (2011): 133-66. https://doi.org/10.1162/ISEC_a 00047.

Brecher, Michael. Decisions in Crisis: Israel, 1967 and 1973. Berkeley: University of California Press, 1980.

Brecher, Michael, and Jonathan Wilkenfeld. A Study of Crisis. Ann Arbor: University of Michigan Press, 1997.

Bregman, Ahron. Israel's Wars: A History Since 1947. Third Edition. Abingdon: Routledge, 2010.

Brennan, Donald G. "Setting and Goals of Arms Control." Daedalus 89, no. 4 (1960): 681-707. http://jstor.org/stable/20026611.

Brodie, Bernard. "Implications for Military Policy." In The Absolute Weapon: Atomic Power and World Order, edited by Bernard Brodie, 70-107. New York: Harcourt, Brace and Company, 1946.

. "War in the Atomic Age." In The Absolute Weapon: Atomic Power and World Order, edited by Bernard Brodie, 21-69. New York: Harcourt, Brace and Company, 1946.

- Strategy in the Missile Age. R-335. Santa Monica, CA: RAND Corporation, 1959.

Brown, Andrew, and Lorna Arnold. "The Quirks of Nuclear Deterrence." International Relations 24, no. 3 (2010): 293-312. https://doi.org/10.1177/0047117810377278.

Brown, Jonathan N., and Anthony S. Marcum. "Avoiding Audience Costs: Domestic Political Accountability and Concessions in Crisis Diplomacy." Security Studies 20, no. 2 (2011): 141-70. https://doi.org/10.1080/09636412.2011.572671. 
Budjeryn, Mariana. "The Power of the NPT: International Norms and Ukraine's Nuclear Disarmament." Nonproliferation Review 22, no. 2 (2015): 203-237. http://dx.doi.org/10.1080/10736700.2015.1119968.

Bueno de Mesquita, Bruce. "Toward a Scientific Understanding of International Conflict: A Personal View." International Studies Quarterly 29, no. 2 (June 1985): 121-36. https://doi.org/10.2307/2600500.

Bueno de Mesquita, Bruce, James D. Morrow, Randolph M. Siverson, and Alastair Smith. "An Institutional Explanation of the Democratic Peace." American Political Science Review 93, no. 4 (1999): 791-807. http://dx.doi.org/10.2307/2586113.

_. "Policy Failure and Political Survival: The Contribution of Political Institutions." The Journal of Conflict Resolution 43, no. 2 (1999): 147-61. https://doi.org/10.1177/0022002799043002002.

Bueno de Mesquita, Bruce, and Randolph M. Siverson. "War and the Survival of Political Leaders: A Comparative Study of Regime Types and Political Accountability." The American Political Science Review 89, no. 4 (1995): 84155. https://doi.org/10.2307/2082512.

Bueno de Mesquita, Bruce, and Alastair Smith. The Dictator's Handbook: Why Bad Behaviour Is Almost Always Good Politics. New York: PublicAffairs, 2011.

Bull, Hedley. "Future Conditions of Strategic Deterrence." Special Issue, The Adelphi Papers, The Future of Strategic Deterrence: Part I Papers from the IISS Annual Conference, 20, no. 160 (1980): 13-23. http://dx.doi.org/10.1080/05679328008457364.

Burr, William. "Israeli Nuclear Capabilities in Mid-1967: What Washington Knew (and Didn't Know)." The Nonproliferation Review 25, no. 5-6 (2018): 377-84. https://doi.org/10.1080/10736700.2018.1548096.

Butt, Ahsan I. "Do Nuclear Weapons Affect the Guns-Butter Trade-off? Evidence on Nuclear Substitution from Pakistan and Beyond." Conflict, Security \& Development 15, no. 3 (2015): 229-57. https://doi.org/10.1080/14678802.2015.1055120.

Byman, Daniel, and Jennifer Lind. "Pyongyang's Survival Strategy: Tools of Authoritarian Control in North Korea." International Security 35, no. 1 (2010): 44-74. https://doi.org/10.1162/ISEC a 00002.

Carranza, Mario E. "Deterrence or Taboo? Explaining the Non-Use of Nuclear Weapons during the Indo-Pakistani Post-Tests Nuclear Crises." Contemporary Security Policy 39, no. 3 (2018): 441-63. https://doi.org/10.1080/13523260.2017.1418725. 
Carter, Jeff. "The Political Cost of War Mobilization in Democracies and Dictatorships." Journal of Conflict Resolution 61, no. 8 (2017): 1768-94. https://doi.org/10.1177/0022002715620469.

Carter, Jeff, and Glenn Palmer. "Keeping the Schools Open While the Troops Are Away: Regime Type, Interstate War, and Government Spending." International Studies Quarterly 59, no. 1 (2015): 145-157. https://doi.org/10.1111/isqu.12160.

Cha, Victor. The Impossible State: North Korea, Past and Future. New York: HarperCollins Publishers Inc, 2012. Kindle ebook.

Chakravorty, P.K. “Sino-Indian War of 1962." Indian Historical Review 44, no. 2 (2017): 285-312. https://doi.org/10.1177/0376983617726649.

Chandra, Kanchan. "The Roots of Hindu Nationalism's Triumph in India." Foreign Affairs, September 13, 2019. https://www.foreignaffairs.com/articles/india/201909-11/roots-hindu-nationalisms-triumph-india.

Chari, P.R., Pervaiz Iqbal Cheema, and Stephen P. Cohen. Four Crises and a Peace Process: American Engagement in South Asia. Washington, DC: Brookings Institution Press, 2007.

Chaudhuri, Rudra. "Indian 'Strategic Restraint' Revisited: The Case of the 1965 IndiaPakistan War." India Review 17, no. 1 (2018): 55-75. https://doi.org/10.1080/14736489.2018.1415277.

_. "Just Another Border Incident': The Rann of Kutch and the 1965 IndiaPakistan War." Journal of Strategic Studies 42, no. 5 (2019): 654-76. https://doi.org/10.1080/01402390.2019.1571996.

Chazan, Naomi. “The Knesset.” Israel Affairs 11, no. 2 (2005): 392-416. https://doi.org/10.1080/1353712042000326524.

Cheibub, José Antonio, Jennifer Gandhi, and James Raymond Vreeland. "Democracy and Dictatorship Revisited." Public Choice 143, no. 1/2 (2010): 67-101. https://doi.org/10.1007/s11127-009-9491-2.

Cheng, Ta-Chen. "The Evolution of China's Strategic Nuclear Weapons." Defense \& Security Analysis 22, no. 3 (2006): 241-260. http://dx.doi.org/10.1080/14751790600933863.

Cho, Youngwon. "Method to the Madness of Chairman Kim: The Instrumental Rationality of North Korea's Pursuit of Nuclear Weapons." International Journal 69, no. 1 (2014): 5-25. http://dx.doi.org/10.1177/0020702013518489.

Cimbala, Stephen J. Nuclear Weapons and Strategy: U.S. Nuclear Policy for the TwentyFirst Century. Abingdon: Routledge, 2005. 
Cochran, Edwin S. "Deliberate Ambiguity: An Analysis of Israel's Nuclear Strategy." Journal of Strategic Studies 19, no. 3 (1996): 321-42. https://doi.org/10.1080/01402399608437642.

—_. "Israel's Nuclear History." Israel Affairs 6, no. 3-4 (2000): 129-56. https://doi.org/10.1080/13537120008719576.

Cohen, Avner. Israel and the Bomb. New York: Columbia University Press, 1998.

. "Nuclear Dimensions of the 1967 Middle East War: An Israeli Perspective." The Nonproliferation Review 25, no. 5-6 (2018): 359-75. https://doi.org/10.1080/10736700.2018.1605042.

__. "Nuclear Legislation for Israel." Strategic Assessment 12, no. 1 (June 2009): 7 18. Accessed January 8, 2019. http://www.inss.org.il/wpcontent/uploads/2013/07/1-1.pdf.

- The Worst-Kept Secret: Israel's Bargain with the Bomb. New York: Columbia University Press, 2010.

Cohen, Michael D. "How Nuclear South Asia Is Like Cold War Europe: The StabilityInstability Paradox Revisited.” Nonproliferation Review 20, no. 3 (2013): $433-$ 451. http://dx.doi.org/10.1080/10736700.2013.857126.

Cohen, Stephen Philip. India: Emerging Power. Washington, D.C: Brookings Institution Press, 2001.

—. The Idea of Pakistan. New York: Brookings Institution Press, 2004.

Cohen, Stuart A. "Changing Civil-Military Relations in Israel: Towards an OverSubordinate IDF?" Israel Affairs 12, no. 4 (2006): 769-88. https://doi.org/10.1080/13533310600890091.

Cohen, Yoel. "Nuclear Ambiguity and the Media: The Israeli Case." Israel Affairs 12, no. 3 (2006): 529-45. https://doi.org/10.1080/13537120600745146.

Colby, Elbridge, Avner Cohen, William McCants, Bradley Morris, and William Rosenau. "The Israeli Nuclear Alert" of 1973: Deterrence and Signaling in Crisis." Fort Belvoir, VA: Defense Technical Information Center, April 1, 2013. https://doi.org/10.21236/ADA579830.

Collier, David, and James Mahoney. "Insights and Pitfalls: Selection Bias in Qualitative Research.” World Politics 49, no. 1 (1996): 56-91. https://doi.org/10.1353/wp.1996.0023.

Cordera, Sonia. "India's Response to the 1971 East Pakistan Crisis: Hidden and Open Reasons for Intervention." Journal of Genocide Research 17, no. 1 (2015): 45-62. https://doi.org/10.1080/14623528.2015.991207. 
Cortright, David, and Amitabh Mattoo. "Indian Public Opinion and Nuclear Weapons Policy." In India and the Bomb: Public Opinion and Nuclear Options, edited by David Cortright and Amitabh Mattoo, 3-22. Notre Dame: University of Notre Dame Press, 1996.

Cotta-Ramusino, Paolo, and Maurizio Martinelli. "Nuclear Safety, Nuclear Stability and Nuclear Strategy in Pakistan: A Concise Report of a Visit by Landau Network Centro Volta, (January 14, 2002)." Pugwash Conferences on Science and World Affairs, January 14, 2002. https://pugwash.org/2002/01/14/report-on-nuclearsafety-nuclear-stability-and-nuclear-strategy-in-pakistan/.

Crescenzi, Mark J. C. "Reputation and Interstate Conflict." American Journal of Political Science 51, no. 2 (2007): 382-396. https://doi.org/10.1111/j.15405907.2007.00257.x.

Creswell, John W., and Vicki L. Plano Clark. Designing and Conducting Mixed Methods Research. 2nd ed. Los Angeles: SAGE Publications, 2011.

Croco, Sarah E. "The Decider's Dilemma: Leader Culpability, War Outcomes, and Domestic Punishment." American Political Science Review 105, no. 3 (2011): 457-77. https://doi.org/10.1017/S0003055411000219.

Danilovic, Vesna. "Conceptual and Selection Bias Issues in Deterrence." Journal of Conflict Resolution 45, no. 1 (2001): 97-125. https://dx.doi.org/10.1177/0022002701045001005.

Dasgupta, Chandrasekhar. War and Diplomacy in Kashmir, 1947-48. Thousand Oaks: SAGE Publications, 2014.

Davenport, Kelsey, and Kingston Reif. "Nuclear Weapons: Who Has What at a Glance." Arms Control Association, July 2019. https://www.armscontrol.org/factsheets/Nuclearweaponswhohaswhat.

Debs, Alexandre, and Henk E. Goemans. "Regime Type, the Fate of Leaders, and War." American Political Science Review 104, no. 3 (2010): 430-45. https://doi.org/10.1017/S0003055410000195.

Delpech, Thérèse. Nuclear Deterrence in the 21st Century: Lessons from the Cold War for a New Era of Strategic Piracy. Santa Monica, CA: RAND Corporation, 2012.

Dibble, Vernon K. "Four Types of Inference from Documents to Events." History and Theory 3, no. 2 (1963): 203-221. http://dx.doi.org/10.2307/2504279.

Dixon, William J. "Democracy and the Peaceful Settlement of International Conflict." American Political Science Review 88, no. 1 (1994): 14-32. http://dx.doi.org/10.2307/2944879. 
Do, Jein. "Loss Aversion and Risk Taking in North Korea's Militant Strategy, 19671968." Asian Perspective 40, no. 3 (2016): 523-46. https://doi.org/10.1353/apr.2016.0023.

Early, Bryan R., and Victor Asal. "Nuclear Weapons, Existential Threats, and the Stability-Instability Paradox." The Nonproliferation Review 25, no. 3-4 (2018): 223-47. https://doi.org/10.1080/10736700.2018.1518757.

Elbahtimy, Hassan. "Missing the Mark: Dimona and Egypt's Slide into the 1967 ArabIsraeli War." The Nonproliferation Review 25, no. 5-6 (2018): 385-97. https://doi.org/10.1080/10736700.2018.1559482.

Evron, Yair. Israel's Nuclear Dilemma. London: Routledge, 1994.

Fair, C. Christine. "Why the Pakistan Army Is Here to Stay: Prospects for Civilian Governance." International Affairs 87, no. 3 (2011): 571-88. https://doi.org/10.1111/j.1468-2346.2011.00991.x.

Faruqui, Ahmad. "Failure in Command: Lessons from Pakistan's Indian Wars, 19471999." Defense Analysis 17, no. 1 (2001): 31-40. https://doi.org/10.1080/07430170120041785.

Fearon, James D. "Domestic Political Audiences and the Escalation of International Disputes." American Political Science Review 88, no. 3 (September 1994): $577-$ 592. http://dx.doi.org/10.2307/2944796.

Fearon, James D., and David D. Laitin. "Ethnicity, Insurgency, and Civil War." American Political Science Review 97, no. 1 (February 2003): 75-90. http://dx.doi.org/10.1017/S0003055403000534.

Fetter, Steve, George N Lewis, and Lisbeth Gronlund. "Why Were Casualties so Low?" Nature 361, no. 6410 (January 28, 1993): 293-96. https://doi.org/10.1038/361293a0.

Fifield, Anna. The Great Successor: The Divinely Perfect Destiny of Brilliant Comrade Kim Jong Un. First edition. New York: PublicAffairs, 2019.

Filson, Darren, and Suzanne Warner. "Bargaining and Fighting: The Impact of Regime Type on War Onset, Duration, and Outcomes." American Journal of Political Science 48, no. 2 (2004): 296-313. https://doi.org/10.1111/j.00925853.2004.00071.x.

Flick, Uwe. An Introduction to Qualitative Research. 4th ed. London: SAGE, 2009. Kindle ebook.

Freedman, Lawrence. "The Benefits of Hindsight: Historical Research and Political Accountability." Survival 59, no. 3 (2017): 93-110. https://doi.org/10.1080/00396338.2017.1325602. 
—. Deterrence. Cambridge: Polity Press, 2004.

Freedman, Lawrence, and Jeffrey Michaels. The Evolution of Nuclear Strategy: New, Updated and Completely Revised. Fourth edition. London: Palgrave Macmillan UK, 2019. https://doi.org/10.1057/978-1-137-57350-6.

French, Paul. North Korea: State of Paranoia. Kindle edition. London: Zed Books, 2014.

Frey, Karsten. India's Nuclear Bomb and National Security. First. Routledge Advances in South Asian Studies 4. Abingdon: Routledge, 2006.

Ganguly, Sumit. Conflict Unending: India-Pakistan Tensions Since 1947. New York: Columbia University Press, 2001. . "Why the India-Pakistan Crisis Isn't Likely to Turn Nuclear." Foreign Affairs, April 17, 2019. https://www.foreignaffairs.com/articles/india/2019-03-05/whyindia-pakistan-crisis-isnt-likely-turn-nuclear.

Ganguly, Sumit, and C. Christine Fair. "The Structural Origins of Authoritarianism in Pakistan." Commonwealth \& Comparative Politics 51, no. 1 (2013): 122-42. https://doi.org/10.1080/14662043.2013.750064.

Ganguly, Sumit, and S. Paul Kapur. India, Pakistan, and the Bomb: Debating Nuclear Stability in South Asia. First. Contemporary Asia in the World. New York: Columbia University Press, 2010.

Ganguly, Sumit, and Michael R. Kraig. "The 2001-2002 Indo-Pakistani Crisis: Exposing the Limits of Coercive Diplomacy." Security Studies 14, no. 2 (2005): 290-324. https://doi.org/10.1080/09636410500232958.

Gartner, Scott Sigmund, and Gary M. Segura. "War, Casualties, and Public Opinion." Journal of Conflict Resolution 42, no. 3 (1998): 278-300. https://doi.org/10.1177/0022002798042003004.

Gartzke, Erik, and Matthew Kroenig. "Nukes with Numbers: Empirical Research on the Consequences of Nuclear Weapons for International Conflict." Annual Review of Political Science 19 (May 2016): 397-412. http://dx.doi.org/10.1146/annurevpolisci-110113-122130.

Garver, John W. "China's Decision for War with India in 1962." In New Directions in the Study of China's Foreign Policy, edited by Alastair Iain Johnson and Robert S. Ross, 86-130. Stanford: Stanford University Press, 2006.

Gat, Moshe. "Nasser and the Six Day War, 5 June 1967: A Premeditated Strategy or An Inexorable Drift to War?" Israel Affairs 11, no. 4 (2005): 608-35. https://doi.org/10.1080/13537120500233714. 
Gause, Ken. "Chapter 2: The Role and Influence of the Party Apparatus." In North Korea in Transition: Politics, Economy, and Society, edited by Kyung-Ae Park and Scott Snyder, 19-45. Plymouth: Rowman and Littlefield, 2013.

Geddes, Barbara, Joseph Wright, and Erica Frantz. "Autocratic Breakdown and Regime Transitions: A New Data Set." Perspectives on Politics 12, no. 2 (2014): 313-31. https://doi.org/10.1017/S1537592714000851.

Gelpi, Christopher, Peter D. Feaver, and Jason Reifler. "Success Matters: Casualty Sensitivity and the War in Iraq." International Security 30, no. 3 (2005): 7-46. http://dx.doi.org/10.1162/isec.2005.30.3.7.

George, Alexander L., and Andrew Bennett. Case Studies and Theory Development in the Social Sciences. Cambridge: MIT Press, 2005.

George, Alexander L., and Richard Smoke. Deterrence in American Foreign Policy: Theory and Practice. New York: Columbia University Press, 1974.

Gill, John H. "Provocation, War and Restraint under the Nuclear Shadow: The Kargil Conflict 1999." Journal of Strategic Studies 42, no. 5 (2019): 701-26. https://doi.org/10.1080/01402390.2019.1570144.

Gizewski, Peter. "From Winning Weapon to Destroyer of Worlds: The Nuclear Taboo in International Politics." International Journal 51, no. 3 (1996): 397-419. https://doi.org/10.1177/002070209605100301.

G. L. "Suez and Its Consequences: The Israel View." The World Today 13, no. 4 (1957): $152-61$.

Glick, Reuven, and Alan M. Taylor. "Collateral Damage: Trade Disruption and the Economic Impact of War." The Review of Economics and Statistics 92, no. 1 (2010): 102-27.

Gobarev, Viktor M. "Soviet Policy toward China: Developing Nuclear Weapons 19491969." Journal of Slavic Military Studies 12, no. 4 (1999): 1-53. https://doi.org/10.1080/13518049908430415.

Golani, Motti. "Shall We Go to War? And If We Do, When? The Genesis of the Internal Debate in Israel on the Road to the Sinai War." Israel Affairs 6, no. 3-4 (March 1, 2000): 22-42. https://doi.org/10.1080/13537120008719570.

Goldsmith, Benjamin E., Stephan K. Chalup, and Michael J. Quinlan. "Regime Type and International Conflict: Towards a General Model." Journal of Peace Research 45, no. 6 (2008): 743-63. https://doi.org/10.1177/0022343308096154.

Gray, Christine D. International Law and the Use of Force. Third Edition. Oxford: Oxford University Press, 2008. 
Guinsinger, Alexandra, and Alistair Smith. "Honest Threats: The Interaction of Reputation and Political Institutions in International Crises." Journal of Conflict Resolution 46, no. 2 (April 2002): 175-200. https://dx.doi.org/10.1177/0022002702046002001.

Hagerty, Devin T. "Nuclear Deterrence in South Asia: The 1990 Indo-Pakistani Crisis." International Security 20, no. 3 (Winter 1995-96): 79-114. https://doi.org/10.2307/2539140.

Haggard, Stephan, and Marcus Noland. Hard Target: Sanctions, Inducements, and the Case of North Korea. Redwood City: Stanford University Press, 2017.

Halperin, Morton H. "Nuclear Weapons and Limited War." Journal of Conflict Resolution 5, no. 2 (1961): 146-166. http://dx.doi.org/10.1177/002200276100500203.

Harrison, Lisa. Political Research: An Introduction. New York: Routledge, 2001.

Harvey, Frank P. The Future's Back: Nuclear Rivalry, Deterrence Theory, and Crisis Stability after the Cold War. Montreal: McGill-Queen's University Press, 1997.

Heilbronner, Oded. "The Morale of the Israeli Public on the Eve of the Six-Day War as Seen in Public Opinion Polls." Israel Studies 24, no. 1 (2018): 151-73. https://doi.org/10.2979/israelstudies.24.1.07.

Hersh, Seymour M. The Samson Option: Israel's Nuclear Arsenal and American Foreign Policy. New York: Random House, 1991.

Hibbs, Mark. "Eyes on the Prize: India's Pursuit of Membership in the Nuclear Suppliers Group." The Nonproliferation Review 24, no. 3-4 (2017): 275-96. https://doi.org/10.1080/10736700.2018.1436253.

Hoffman, Michael. "Military Extrication and Temporary Democracy: The Case of Pakistan." Democratization 18, no. 1 (2011): 75-99. https://doi.org/10.1080/13510347.2011.532617.

Hoyt, Timothy D. "Pakistani Nuclear Doctrine and The Dangers of Strategic Myopia." Asian Survey 41, no. 6 (2001): 956-77. https://doi.org/10.1525/as.2001.41.6.956.

Huth, Paul K. "Reputations and Deterrence: A Theoretical and Empirical Assessment." Security Studies 7, no. 1 (1997): 72-99. http://dx.doi.org/10.1080/09636419708429334.

Huth, Paul K., and Todd L. Allee. "Domestic Political Accountability and the Escalation and Settlement of International Disputes." The Journal of Conflict Resolution 46, no. 6 (2002): 754-90. https://doi.org/10.1177/002200202237928. 
Huth, Paul, and Bruce Russett. "What Makes Deterrence Work? Cases from 1900 to 1980." World Politics 36, no. 4 (1984): 496-526.

https://doi.org/10.2307/2010184.

Israeli, Ofer. "Israel's Nuclear Amimut Policy and Its Consequences." Israel Affairs 21, no. 4 (2015): 541-58. https://doi.org/10.1080/13537121.2015.1076185.

Jackson, Van. On the Brink: Trump, Kim, and the Brink of Nuclear War. Kindle edition. Cambridge: Cambridge University Press, 2018.

Jervis, Robert. The Illogic of American Nuclear Strategy. Ithaca: Cornell University Press, 1984.

—. "Why Nuclear Superiority Doesn't Matter." Political Science Quarterly 94, no. 4 (1979): 617-33. https://doi.org/10.2307/2149629.

Johnson, Jesse C. "External Threat and Alliance Formation." International Studies Quarterly 61, no. 3 (2017): 736-45. https://doi.org/10.1093/isq/sqw054.

Jones, Clive. "Israel's Security Nexus as Strategic Restraint: The Case of Iran 20092013.” Journal of Strategic Studies 41, no. 1-2 (2018): 160-80. https://doi.org/10.1080/01402390.2015.1104668.

Jones, Scott A., and James R. Holmes. "Regime Type, Nuclear Reversals, and Nuclear Strategy: The Ambiguous Case of Iran." In Strategy in the Second Nuclear Age: Power, Ambition, and the Ultimate Weapon, edited by Toshi Yoshihara and James R. Holmes, 201-224. Baltimore: Georgetown University Press, 2012.

Joshi, Sharad. “Israel's Nuclear Policy: A Cost-benefit Analysis.” Strategic Analysis 23, no. 12 (2000): 2089-2110. https://doi.org/10.1080/09700160008455182.

Joshi, Shashank. "India's Military Instrument: A Doctrine Stillborn.” Journal of Strategic Studies 36, no. 4 (2013): 512-40. https://doi.org/10.1080/01402390.2013.766598.

Kampani, Gaurav. "New Delhi's Long Nuclear Journey: How Secrecy and Institutional Roadblocks Delayed India's Weaponization.” International Security 38, no. 4 (2014): 79-114. https://doi.org/10.1162/ISEC_a 00158.

Kapur, Devesh. "Public Opinion and Indian Foreign Policy." India Review 8, no. 3 (2009): 286-305. https://doi.org/10.1080/14736480903116818.

Kapur, S. Paul. “India and Pakistan's Unstable Peace: Why Nuclear South Asia Is Not Like Cold War Europe.” International Security 30, no. 2 (2005): 127-152. http://dx.doi.org/10.1162/016228805775124570.

—. "Ten Years of Instability in a Nuclear South Asia." International Security 33, no. 2 (Fall 2008): 71-94. https://doi.org/10.1162/isec.2008.33.2.71. 
Kasturi, Bhashyam. "Chapter 10: The State of War with Pakistan." In A Military History of India and South Asia: From the East India Company to the Nuclear Era, 13956. Bloomington: Indiana University Press, 2007.

Kazi, Reshmi. "India's Nuclear Doctrine: A Study of Its Tenets." Indian Foreign Affairs Journal 9, no. 1 (March 2014): 46-55.

Kedar, Nir. "The Rule of Law in Israel." Israel Studies 23, no. 3 (2018): 164-71. https://doi.org/10.2979/israelstudies.23.3.20.

Kennedy, Andrew B. "India's Nuclear Odyssey: Implicit Umbrellas, Diplomatic Disappointments, and the Bomb." International Security 36, no. 2 (Fall 2011): 120-53. https://doi.org/10.1162/ISEC_a 00058.

Kertzer, Joshua D., and Ryan Brutger. "Decomposing Audience Costs: Bringing the Audience Back into Audience Costs Theory." American Journal of Political Science 60, no. 1 (January 2016): 234-249. http://dx.doi.org/10.1111/ajps.12201.

Khan, Feroz. Eating Grass: The Making of the Pakistani Bomb. Redwood City: Stanford University Press, 2012.

Khan, Saira. Nuclear Weapons and Conflict Transformation: The Case of India-Pakistan. First. Asian Security Studies. New York: Routledge, 2009.

Khan, Zillur R. "Civil-Military Relations and Nuclearization of India and Pakistan." World Affairs 166, no. 1 (2003): 24-36. http://dx.doi.org/10.2307/20672675.

Kilgour, D. Marc, and Frank C. Zagare. "Credibility, Uncertainty, and Deterrence." American Journal of Political Science 35, no. 2 (May 1991): 305-334. http://dx.doi.org/10.2307/2111365.

Kim, Jiye. "China's Wars and Strategies: Looking Back at the Korean War and the SinoIndian War." Strategic Analysis 42, no. 2 (2018): 119-33. https://doi.org/10.1080/09700161.2018.1439329.

Kim, Yongho. North Korean Foreign Policy: Security Dilemma and Succession. Lanham: Lexington Books, 2011.

Kitano, Mitsuru. "Opaque Nuclear Proliferation Revisited: Determinants, Dynamism, and Policy Implications.” The Nonproliferation Review 23, no. 3-4 (2016): 459-79. https://doi.org/10.1080/10736700.2017.1279792.

Kim, Sung Chull. North Korea under Kim Jong Il: From Consolidation to Systematic Dissonance. Albany: State University of New York Press, 2006.

Knopf, Jeffrey W. "The Fourth Wave in Deterrence Research." Contemporary Security Policy 31, no. 1 (2010): 1-33. http://dx.doi.org/10.1080/13523261003640819.

Koithara, Vergese. Managing India's Nuclear Forces. Washington, DC: Brookings Institution Press, 2012. 
Kohama, Shoko, and Kazuto Ohtsuki. "Political Institutions and Nuclear Deterrence." Presented at the 60th International Studies Association Annual Convention, Toronto, March 27-30, 2019. http://web.isanet.org/Web/Conferences/Toronto\%202019-s/Archive/9ed874b6e516-4f4e-bd0e-f51198181128.pdf.

Korbatov, Anna Bella, Erika Suzuki, and Bethany L. Goldblum. "The Fight against Nuclear Terrorism Needs Global Cooperation - and the IAEA." Bulletin of the Atomic Scientists 71, no. 5 (2015): 67-76. https://doi.org/10.1177/0096340215590795.

Krasner, Stephen D. "Toward Understanding in International Relations." International Studies Quarterly 29, no. 2 (June 1985): 137-144. https://dx.doi.org/10.2307/2600501.

Krippendorf, Klaus. Content Analysis: An Introduction to Its Methodology. London: SAGE Publications, 1980.

Kroenig, Matthew. "Nuclear Superiority and the Balance of Resolve: Explaining Nuclear Crisis Outcomes." International Organization 67, no. 1 (2013): 141-71. https://doi.org/10.1017/S0020818312000367.

Ladwig, Walter C. III. "A Cold Start for Hot Wars? The Indian Army's New Limited War Doctrine." International Security 32, no. 3 (Winter 2007): 158-90. https://doi.org/10.1162/isec.2008.32.3.158.

. "Indian Military Modernization and Conventional Deterrence in South Asia." Journal of Strategic Studies 38, no. 5 (2015): 729-72. https://doi.org/10.1080/01402390.2015.1014473.

Laron, Guy. "The Six Day War and the Nuclear Coup That Never Was." War on the Rocks, June 29, 2017. https://warontherocks.com/2017/06/the-six-day-war-andthe-nuclear-coup-that-never-was/.

Larson, Eric V., and Bogdan Savych. Misfortunes of War: Press and Public Reactions to Civilian Deaths in Wartime. Santa Monica: RAND Corporation, 2007. https://doi.org/10.7249/mg441af.

Lebow, Richard Ned, and Janice Gross Stein. "Rational Deterrence Theory: I Think, Therefore I Deter." World Politics 41, no. 2 (1989): 208-24. https://doi.org/10.2307/2010408.

Lee, Hanhee. "Analyzing the Political Survival Prospects of Kim Jong-Un's North Korean Regime through the Framework of Selectorate Theory." Japanese Journal of Political Science 19, no. 3 (September 2018): 474-88. https://doi.org/10.1017/S1468109918000130. 
Lektzian, David, and Mark Souva. "A Comparative Theory Test of Democratic Peace Arguments, 1946-2000." Journal of Peace Research 46, no. 1 (2009): 17-37. https://doi.org/10.1177/0022343308098402.

. "An Institutional Theory of Sanctions Onset and Success." Journal of Conflict Resolution 51, no. 6 (2007): 848-871. http://dx.doi.org/10.1177/0022002707306811.

Levite, Ariel E., and Emily B. Landau. "Arab Perceptions of Israel's Nuclear Posture, 1960-1967.” Israel Studies 1, no. 1 (1996): 3. https://doi.org/10.1353/is.2005.0036.

Levy, Jack S. "Case Studies: Types, Designs, and Logics of Inference." Conflict Management and Peace Science 25, no. 1 (2008): 1-18. https://doi.org/10.1080/07388940701860318.

Levy, Jack S., and William R. Thompson. Causes of War. Chichester: Wiley-Blackwell, 2010.

Lewis, Jeffrey G., and Scott D. Sagan. "The Nuclear Necessity Principle: Making U.S. Targeting Policy Conform with Ethics \& the Laws of War." Daedalus 145, no. 4 (2016): 62-74. https://doi.org/10.1162/DAED_a_00412.

Liberman, Peter. "The Rise and Fall of the South African Bomb." International Security 26, no. 2 (2001): 45-86. https://doi.org/10.1162/016228801753191132.

Lieber, Keir A., and Daryl G. Press. "The New Era of Counterforce: Technological Change and the Future of Nuclear Deterrence." International Security 41, no. 4 (2017): 9-49. https://doi.org/10.1162/ISEC_a_00273.

Litwak, Robert S. "Recalibrating Deterrence to Prevent Nuclear Terrorism." The Washington Quarterly 40, no. 1 (2017): 55-70. http://dx.doi.org/10.1080/0163660X.2017.1302739.

Lorenzo, David J. "Democratic Peace Theory, the Problems of Pluralism, and the Opposition to the Use of Military Force in the US." Democracy and Security 14, no. 4 (2018): 414-42. https://doi.org/10.1080/17419166.2018.1517335.

Lupton, Danielle L. "Reexamining Reputation for Resolve: Leaders, States, and the Onset of International Crises." Journal of Global Security Studies 3, no. 2 (2018): 198-216. https://dx.doi.org/10.1093/jogss/ogy004.

Malhotra, Aditi. "Assessing Indian Nuclear Attitudes: A Visiting Fellow Working Paper." Washington, DC: Stimson Centre, 2016. Accessed June 17, 2019. https://www.stimson.org/sites/default/files/fileattachments/Assessing\%20Indian\%20Nuclear\%20Attitudes\%20-\%20Final.pdf.

Malik, Priyanjali. India's Nuclear Debate: Exceptionalism and the Bomb. New Delhi: Routledge, 2010. 
Mann, Joseph. "Syria, Precipitator of the Six Day War." Middle Eastern Studies 49, no. 4 (2013): 547-62. https://doi.org/10.1080/00263206.2013.798306.

Ma'oz, Moshe. "From Conflict to Peace? Israel's Relations with Syria and the Palestinians." Middle East Journal 53, no. 3 (1999): 393-416. http://www.jstor.org/stable/4329353.

Maoz, Zeev. Defending the Holy Land: A Critical Analysis of Israel's Security and Foreign Policy. 2nd edition. Ann Arbor: University of Michigan Press, 2008. https://ebookcentral-proquest-com.proxy.library.carleton.ca/lib/oculcarletonebooks/detail.action?docID=3414489.

_ "The Mixed Blessing of Israel's Nuclear Policy." International Security 28, no. 2 (2003): 44-77. http://dx.doi.org/10.1162/016228803322761964.

Maoz, Zeev, and Bruce Russett. "Normative and Structural Causes of Democratic Peace, 1946-1986.” American Political Science Review 87, no. 3 (1993): 624-638. http://dx.doi.org/10.2307/2938740.

Mazarr, Michael J. “Understanding Deterrence.” Perspectives. RAND Corporation, 2018. https://www.rand.org/content/dam/rand/pubs/perspectives/PE200/PE295/RAND PE295.pdf.

McIntosh, Christopher, and Ian Storey. "Between Acquisition and Use: Assessing the Likelihood of Nuclear Terrorism." International Studies Quarterly 62, no. 2 (2018): 289-300. https://doi.org/10.1093/isq/sqx087.

McManus, Roseanne W. "Fighting Words: The Effectiveness of Statements of Resolve in International Conflict.” Journal of Peace Research 51, no. 6 (2014): 726-740. https://dx.doi.org/10.1177/0022343314539826.

Metcalf, Barbara D., and Thomas R. Metcalf. A Concise History of Modern India. Third Edition. Cambridge Concise Histories. New York: Cambridge University Press, 2012.

Miraglia, Sébastien. "Deadly or Impotent? Nuclear Command and Control in Pakistan." Journal of Strategic Studies 36, no. 6 (December 1, 2013): 841-66. https://doi.org/10.1080/01402390.2013.805126.

Morgan, T. Clifton, and Sally Howard Campbell. "Domestic Structure, Decisional Constraints, and War: So Why Kant Democracies Fight?” The Journal of Conflict Resolution 35, no. 2 (1991): 187-211. https://doi.org/10.1177/0022002791035002003.

Morgan, Patrick. Deterrence Now. Cambridge: Cambridge University Press, 2003.

Morris, Benny. The Birth of the Palestinian Refugee Problem Revisited. New York: Cambridge University Press, 2004. 
- Israel's Border Wars, 1949-1956: Arab Infiltration, Israeli Retaliation, and the Countdown to the Suez War. Oxford: Oxford University Press, 1993.

Morrow, Daniel, and Michael Carriere. "The Economic Impacts of the 1998 Sanctions on India and Pakistan." The Nonproliferation Review 6, no. 4 (1999): 1-16. https://doi.org/10.1080/10736709908436775.

Mueller, John E. War, Presidents, and Public Opinion. New York: Wiley, 1973.

Mukherjee, Kunal. “Ayub Khan's Basic Democracy and Political Continuity in Contemporary Pakistan.” India Quarterly 72, no. 3 (2016): 268-77. https://doi.org/10.1177/0974928416656498.

—. "Why Has Democracy Been Less Successful in Pakistan Than in India?" Asian Affairs 41, no. 1 (2010): 67-77. https://doi.org/10.1080/03068370903472132.

Naor, Moshe. “Israel's 1948 War of Independence as a Total War.” Journal of Contemporary History 43, no. 2 (2008): 241-57. https://doi.org/10.1177/0022009408089031.

Narang, Vipin. Nuclear Strategy in the Modern Era: Regional Powers and International Conflict. Princeton: Princeton University Press, 2014.

Narang, Vipin, and Paul Staniland. "Institutions and Worldviews in Indian Foreign Security Policy." India Review 11, no. 2 (2012): 76-94. https://doi.org/10.1080/14736489.2012.674818.

—. "Democratic Accountability and Foreign Security Policy: Theory and Evidence from India." Security Studies 27, no. 3 (2018): 410-47. https://doi.org/10.1080/09636412.2017.1416818.

Nasr, Vali. "Military Rule, Islamism and Democracy in Pakistan." The Middle East Journal 58, no. 2 (2004): 195-209. https://doi.org/10.3751/58.2.12.

Nephew, Richard. "How the Iran Deal Prevents a Covert Nuclear Weapons Program." Arms Control Today 45, no. 7 (2015): 8-15.

Noland, Marcus. "North Korea's Failed Currency Reform.” Peterson Institute for International Economics, March 2, 2016. https://www.piie.com/commentary/opeds/north-koreas-failed-currency-reform.

Norris, Robert S., William M. Arkin, and William Burr. "How Much Did Japan Know?" Bulletin of the Atomic Scientists 56, no. 1 (2000): 11-79. https://doi.org/10.1080/00963402.2000.11456913.

Norris, Robert S., William M. Arkin, Hans M. Kristensen, and Joshua Handler. "Israeli Nuclear Forces, 2002.” Bulletin of the Atomic Scientists 58, no. 5 (2002): 73-75. https://doi.org/10.1080/00963402.2002.11460610. 
Nye, Joseph S. "Deterrence and Dissuasion in Cyberspace." International Security 41, no. 3 (2017): 44-71. https://doi.org/10.1162/ISEC_a_00266.

Ochmanek, David, and Lowell H Schwartz. The Challenge of Nuclear-Armed Regional Adversaries. Santa Monica, CA: RAND Corporation, 2008. https://www.rand.org/pubs/monographs/MG671.html.

Odom, William E. The Collapse of the Soviet Military. New Haven, CT: Yale University Press, 1998.

Oren, Michael B. Six Days of War: June 1967 and the Making of the Modern Middle East. New York: RosettaBooks, 2004.

Palmer, Glenn, Vito D’Orazio, Michael R. Kenwick, and Roseanne W. McManus. "Updating the Militarized Interstate Dispute Data: A Response to Gibler, Miller, and Little." International Studies Quarterly 64, no. 2 (2020): 469-75. https://doi.org/10.1093/isq/sqz045.

Panda, Rajaram. "North Korea's Nuclear Policy: Domestic Determinants, Strategy and Future.” Journal of Comparative Asian Development 10, no. 2 (2011): 223-252. http://dx.doi.org/10.1080/15339114.2011.616705.

Park, Il-Song. "Chapter 18: Republic of Korea Army.” In The Ashgate Research Companion to the Korean War, edited by James Irving Matray and Donald W. Jr. Boose, eBook., 241-53. Farnham: Routledge, 2014.

http://search.ebscohost.com.proxy.library.carleton.ca/login.aspx?direct=true $\& \mathrm{db}=$ nlebk\&AN=754259\&site=ehost-live.

Partell, Peter J., and Glenn Palmer. "Audience Costs and Interstate Crises: An Empirical Assessment of Fearon's Model of Dispute Outcomes.” International Studies Quarterly 43, no. 2 (June 1999): 389-405. https://doi.org/10.1111/0020$\underline{8833.00125 .}$.

Paul, T.V. "Self-deterrence: Nuclear weapons and the enduring credibility challenge." International Journal 71, no. 1 (2016): 20-40. https://doi.org/10.1177/0020702015618682.

- The Warrior State: Pakistan in the Contemporary World. Oxford: Oxford University Press, 2014.

Paul, T. V., and Erik Underwood. "Theorizing India-US-China Strategic Triangle." India Review 18, no. 4 (2019): 348-67. https://doi.org/10.1080/14736489.2019.1662190.

Payne, Keith B. Deterrence in the Second Nuclear Age. Lexington: The University Press of Kentucky, 1996. 
Peceny, Mark, and Christopher K. Butler. "The Conflict Behavior of Authoritarian Regimes.” International Politics 41, no. 4 (2004): 565-81. https://doi.org/10.1057/palgrave.ip.8800093.

Peceny, Mark, Caroline C. Beer, and Shannon Sanchez-Terry. "Dictatorial Peace?" American Political Science Review 96, no. 1 (2002): 15-26. https://doi.org/10.1017/S0003055402004203.

Pinkus, Benjamin. "Atomic Power to Israel's Rescue: French-Israeli Nuclear Cooperation, 1949-1957.” Israel Studies 7, no. 1 (2002): 104-38. https://doi.org/10.1353/is.2002.0006.

Pollack, Jonathan D. No Exit: North Korea, Nuclear Weapons, and International Security. London: International Institute for Strategic Studies, 2011.

Pollack, Kenneth M. “Air Power in the Six-Day War.” Journal of Strategic Studies 28, no. 3 (2005): 471-503. https://doi.org/10.1080/01402390500137382.

Powell, Robert. "Nuclear Deterrence and the Strategy of Limited Retaliation." American Political Science Review 83, no. 2 (June 1989): 503-519. http://dx.doi.org/10.2307/1962402.

Press, Daryl G., Scott D. Sagan, and Benjamin A. Valentino. "Atomic Aversion: Experimental Evidence on Taboos, Traditions, and the Non-Use of Nuclear Weapons." The American Political Science Review 107, no. 1 (2013): 188-206. https://doi.org/10.1017/S0003055412000597.

Prins, Brandon C. "Institutional Instability and the Credibility of Audience Costs: Political Participation and Interstate Crisis Bargaining, 1816-1992.” Journal of Peace Research 40, no. 1 (2003): 67-84. https://doi.org/10.1177/0022343303040001206.

Quackenbush, Stephen L. "Deterrence Theory: Where Do We Stand?" Review of International Studies 37, no. 2 (2011): 741-62. http://dx.doi.org/10.1017/S0260210510000896.

Rabinowitz, Or. Bargaining on Nuclear Tests: Washington and Its Cold War Deals. Oxford: Oxford University Press, 2014.

Radchenko, Sergey. "The Soviet Union and the North Korean Seizure of the USS Pueblo: Evidence from Russian Archives." Cold War International History Project. Washington, DC: Woodrow Wilson International Center for Scholars, July 7, 2011. https://www.wilsoncenter.org/sites/default/files/CWIHP WP 47.pdf.

Raghavan, Srinath. "Chapter 11: A Bad Knock: The War with China, 1962." In $A$ Military History of India and South Asia: From the East India Company to the 
Nuclear Era, edited by Daniel P. Marston and Chandar S. Sundaram, 157-74. Bloomington: Indiana University Press, 2007.

—_ "Soldiers, Statesmen, and India's Security Policy." India Review 11, no. 2 (2012): 116-33. https://doi.org/10.1080/14736489.2012.674829.

Ragin, Charles C. The Comparative Method: Moving Beyond Qualitative and Quantitative Strategies. Berkeley: University of California Press, 2014. http://ebookcentral.proquest.com/lib/oculcarletonebooks/detail.action?docID=1698820.

Rauchhaus, Robert. "Evaluating the Nuclear Peace Hypothesis: A Quantitative Approach.” Journal of Conflict Resolution 53, no. 2 (2009): 258-277. http://dx.doi.org/10.1177/0022002708330387.

Ravlo, Hilde, Nils Petter Gleditsch, and Han Dorussen. "Colonial War and the Democratic Peace.” Journal of Conflict Resolution 47, no. 4 (2003): 520-48. https://doi.org/10.1177/0022002703254295.

Reiter, Dan, and Allan C. Stam. "Democracy, War Initiation, and Victory." The American Political Science Review 92, no. 2 (1998): 377-89. https://doi.org/10.2307/2585670.

Reiter, Dan, and Erik R. Tillman. "Public, Legislative, and Executive Constraints on the Democratic Initiation of Conflict." The Journal of Politics 64, no. 3 (2002): 81026. https://doi.org/10.1111/0022-3816.00147.

Rid, Thomas. "Deterrence beyond the State: The Israeli Experience.” Contemporary Security Policy 33, no. 1 (2012): 124-47. https://doi.org/10.1080/13523260.2012.659593.

Riedel, Bruce. Avoiding Armageddon: America, India, and Pakistan to the Brink and Back. Brookings Focus Books. Washington, DC: Brookings Institution Press, 2013.

Roehrig, Terence. "Chapter 3: The Role and Influence of the Military." In North Korea in Transition: Politics, Economy, and Society, edited by Kyung-Ae Park and Scott Snyder, 47-66. Lanham: Rowman and Littlefield, 2013.

Rolef, Susan Hattis. "The Domestic Fallout of the Yom Kippur War.” Israel Affairs 6, no. 1 (1999): 177-94. https://doi.org/10.1080/13537129908719551.

Rosato, Sebastian. "The Flawed Logic of Democratic Peace Theory." American Political Science Review 97, no. 4 (2003): 585-602. http://dx.doi.org/10.1017/S0003055403000893.

Ruys, Tom. "The Meaning of 'Force' and the Boundaries of the Jus Ad Bellum: Are 'Minimal' Uses of Force Excluded from UN Charter Article 2(4)?' American 
Journal of International Law 108, no. 2 (2014): 159-210.

https://doi.org/10.5305/amerjintelaw.108.2.0159.

Sadanandan, Anoop. "Bridling Central Tyranny in India: How Regional Parties Restrain the Federal Government." Asian Survey 52, no. 2 (2012): 247-69. https://doi.org/10.1525/as.2012.52.2.247.

Sagan, Scott D. "Why Do States Build Nuclear Weapons? Three Models in Search of a Bomb." International Security 21, no. 3 (1996): 54-86. http://dx.doi.org/10.1162/isec.21.3.54.

Sankaran, Jaganath. "Pakistan's Battlefield Nuclear Policy: A Risky Solution to an Exaggerated Threat." International Security 39, no. 3 (2014): 118-51. https://doi.org/10.1162/ISEC_a 00191.

Sasikumar, Karthika. "After Nuclear Midnight: The Impact of a Nuclear War on India and Pakistan." Bulletin of the Atomic Scientists 73, no. 4 (2017): 226-32. https://doi.org/10.1080/00963402.2017.1338009.

Sauer, Frank. Atomic Anxiety: Deterrence, Taboo and the Non-Use of U.S. Nuclear Weapons. Houndmills: Palgrave Macmillan, 2015.

Schaub, Gary, Jr. "Deterrence, Compellence, and Prospect Theory." Political Psychology 25, no. 3 (2004): 389-411. https://dx.doi.org/10.1111/j.1467-9221.2004.00377.x.

Schelling, Thomas C. Arms and Influence. New Haven and London: Yale University Press, 1966.

- The Strategy of Conflict. Cambridge: Harvard University, 1960.

Schofield, Julian. "Militarized Decision-Making for War in Pakistan: 1947-1971." Armed Forces \& Society 27, no. 1 (2000): 131-48. https://doi.org/10.1177/0095327X0002700108.

Schofield, Victoria. Kashmir in Conflict: India, Pakistan and the Unfinished War. London: I.B. Tauris, 2000.

Schultz, Kenneth A. "Domestic Opposition and Signaling in International Crises." The American Political Science Review 92, no. 4 (1998): 829-44. https://doi.org/10.2307/2586306.

Sechser, Todd S. "Militarized Compellent Threats, 1918-2001." Conflict Management and Peace Science 28, no. 4 (2011): 377-401. https://dx.doi.org/10.1177/0738894211413066.

_. "Reputations and Signaling in Coercive Bargaining." Journal of Conflict Resolution 62, no. 2 (2018): 318-345. https://dx.doi.org/10.1177/0022002716652687. 
Sechser, Todd S., and Matthew Fuhrmann. Nuclear Weapons and Coercive Diplomacy. New York: Cambridge University Press, 2017.

Shah, Aqil. "Constraining Consolidation: Military Politics and Democracy in Pakistan (2007-2013).” Democratization 21, no. 6 (September 19, 2014): 1007-33. https://doi.org/10.1080/13510347.2013.781586.

_. "Pakistan: Voting Under Military Tutelage." Journal of Democracy 30, no. 1 (January 9, 2019): 128-42. https://doi.org/10.1353/jod.2019.0010.

Sheffer, Gabriel. "From Crisis to Change: The Israeli Political Elites and the 1973 War." Israel Affairs 6, no. 1 (1999): 153-76. https://doi.org/10.1080/13537129908719550.

Shlaim, Avi. "The Protocol of Sevres, 1956: Anatomy of a War Plot." International Affairs 73, no. 3 (1997): 509-30. https://doi.org/10.2307/2624270.

Simon, Herbert A. Models of Bounded Rationality. Cambridge: MIT Press, 1982.

Singer, J. David. "International Conflict: Three Levels of Analysis." World Politics 12, no. 3 (1960): 453-61. https://doi.org/10.2307/2009401.

Singh, Mahendra Prasad. "The Decline of the Indian Parliament." India Review 14, no. 3 (2015): 352-76. https://doi.org/10.1080/14736489.2015.1066216.

Sirin, Cigdem V., and Michael T. Koch. "Dictators and Death: Casualty Sensitivity of Autocracies in Militarized Interstate Disputes." International Studies Quarterly 59, no. 4 (2015): 802-14. https://doi.org/10.1111/isqu.12207.

Sloan, Elinor C. Modern Military Strategy: An Introduction. New York: Routledge, 2017.

Snyder, Glenn H. "The Balance of Power and the Balance of Terror." In Balance of Power, edited by Paul Seabury, 184-201. San Francisco: Chandler Publishing Co, 1965. Quoted in Watterson, Christopher J. "Competing Interpretations of the Stability-Instability Paradox: The Case of the Kargil War." Nonproliferation Review 24, no. 1-2 (2017): 83-99. http://dx.doi.org/10.1080/10736700.2017.1366623.

Sobek, David, Dennis M. Foster, and Samuel B. Robison. "Conventional Wisdom? The Effect of Nuclear Proliferation on Armed Conflict, 1945-2001." International Studies Quarterly 56, no. 1 (2012): 149-62. https://doi.org/10.1111/j.14682478.2011.00707.x.

Solingen, Etel. Nuclear Logics: Contrasting Paths in East Asia \& The Middle East. Princeton: Princeton University Press, 2007.

Sperandei, Maria. "Bridging Deterrence and Compellence: An Alternative Approach to the Study of Coercive Diplomacy." International Studies Review 8, no. 2 (2006): 253-280. http://dx.doi.org/10.1111/j.1468-2486.2006.00573.x. 
Staniland, Paul, Adnan Naseemullah, and Ahsan Butt. "Pakistan's Military Elite." Journal of Strategic Studies (2018), 1-30. https://doi.org/10.1080/01402390.2018.1497487.

Stone, John. "Conventional Deterrence and the Challenge of Credibility." Contemporary Security Policy 33, no. 1 (2012): 108-123. http://dx.doi.org/13523260.2012.659591.

Sullivan, Patricia Lynne, and Scott Sigmund Gartner. "Disaggregating Peace: Domestic Politics and Dispute Outcomes." International Interactions 32, no. 1 (September 2006): 1-25. http://dx.doi.org/10.1080/03050620600574840.

Swami, Praveen. "Failed Threats and Flawed Fences: India's Military Responses to Pakistan's Proxy War.” India Review 3, no. 2 (2004): 147-70. https://doi.org/10.1080/14736480490465045.

Szalontai, Balazs, and Sergey Radchenko. "North Korea's Efforts to Acquire Nuclear Technology and Nuclear Weapons: Evidence from Russian and Hungarian Archives." Cold War International History Project. Washington, DC: Woodrow Wilson International Center for Scholars, July 7, 2011. https://www.wilsoncenter.org/sites/default/files/WP53 web final.pdf.

Talbot, Ian. Pakistan: A New History. London: Hurst \& Company, 2012.

Tannenwald, Nina. The Nuclear Taboo: The United States and the Non-Use of Nuclear Weapons Since 1945. Cambridge: Cambridge University Press, 2007.

Tarrow, Sidney. "Bridging the Quantitative-Qualitative Divide in Political Science." The American Political Science Review 89, no. 2 (1995): 471-74. https://doi.org/10.2307/2082444.

Tiargan-Orr, Roni, and Meytal Eran-Jona. "The Israeli Public's Perception of the IDF: Stability and Change." Armed Forces \& Society 42, no. 2 (2016): 324-43. https://doi.org/10.1177/0095327X15592214.

Tomz, Michael R., and Jessica L.P. Weeks. "Public Opinion and the Democratic Peace." The American Political Science Review 107, no. 4 (2013): 849-65. https://doi.org/10.1017/S0003055413000488.

Trager, Robert, Kyle Beardsley, Dan Reiter, Nina Tannenwald, and Todd S. Sechser. "Roundtable 11-15 on Nuclear Weapons and Coercive Diplomacy." H-Diplo | ISSF, April 6, 2020. https://issforum.org/roundtables/11-15-coercive.

Valentino, Benjamin A., Paul K. Huth, and Sarah E. Croco. "Bear Any Burden? How Democracies Minimize the Costs of War." The Journal of Politics 72, no. 2 (2010): 528-44. https://doi.org/10.1017/S0022381609990831. 
Vanaik, Achin, and Jamia Millia Islamia. "Making India Strong: The BJP-led Government's Foreign Policy Perspectives." South Asia: Journal of South Asian Studies 25, no. 3 (2002): 321-41. https://doi.org/10.1080/00856400208723505.

Von Hlatky, Stéfanie. 'Revisiting France's Nuclear Exception after Its 'Return' to NATO.” Journal of Transatlantic Studies 12, no. 4 (2014): 392-404. http://dx.doi.org/10.1080/14794012.2014.962785.

Waltz, Kenneth N. "More May Be Better." In The Spread of Nuclear Weapons: An Enduring Debate, edited by Scott D. Sagan and Kenneth N. Waltz, Third Edition., 3-40. New York: W.W. Norton \& Company, 2013.

Watterson, Christopher J. "Competing Interpretations of the Stability-Instability Paradox: The Case of the Kargil War." Nonproliferation Review 24, no. 1-2 (2017): 83-99. http://dx.doi.org/10.1080/10736700.2017.1366623.

Way, Christopher, and Jessica L. Weeks. "Making It Personal: Regime Type and Nuclear Proliferation.” American Journal of Political Science 58, no. 2 (2014): 705-719. http://dx.doi.org/10.1111/ajps.12080.

Weeks, Jessica L. "Autocratic Audience Costs: Regime Type and Signaling Resolve." International Organization 62, no. 1 (2008): 35-64. https://doi.org/10.1017/S0020818308080028.

—. "Strongmen and Straw Men: Authoritarian Regimes and the Initiation of International Conflict." American Political Science Review 106, no. 2 (2012): 326-47. https://doi.org/10.1017/S0003055412000111.

Weiss, Leonard. "The Lavon Affair: How a False-Flag Operation Led to War and the Israeli Bomb." Bulletin of the Atomic Scientists 69, no. 4 (2013): 58-68. https://doi.org/10.1177/0096340213493259.

Weiss, Leonard. “On Fear and Nuclear Terrorism.” Bulletin of the Atomic Scientists 71, no. 2 (2015): 75-87. https://doi.org/10.1177/0096340215571909.

Wenger, Andreas, and Alex Wilner. "Deterring Terrorism: Moving Forward." In Deterring Terrorism: Theory and Practice, edited by Andreas Wenger and Alex Wilner, 301-24. Stanford, CA: Stanford University Press, 2020.

Westcott, Stephen P. "Mao, Nehru and the Sino-Indian Border Dispute: A Poliheuristic Analysis." India Quarterly 75, no. 2 (2019): 155-71. https://doi.org/10.1177/0974928419841770.

Wojczewski, Thorsten. "Populism, Hindu Nationalism, and Foreign Policy in India: The Politics of Representing 'the People.'” International Studies Review, January 29, 2019. https://doi.org/10.1093/isr/viz007. 
Wilner, Alex S. "Deterring the Undeterrable: Coercion, Denial, and Delegitimization in Counterterrorism." The Journal of Strategic Studies 34, no. 1 (2011): 3-37. https://dx.doi.org/10.1080/01402390.2011.541760.

Wirtz, James J. "How Does Nuclear Deterrence Differ from Conventional Deterrence?" Strategic Studies Quarterly 12, no. 4 (Winter 2018): 58-75.

Woo, Jongseok. "Structural Impediments, Domestic Politics, and Nuclear Diplomacy in Post-Kim Il-Sung North Korea." Pacific Focus 30, no. 1 (April 2015): 59-77. http://dx.doi.org/10.1111/pafo.12041.

Zacher, Mark W. "The Territorial Integrity Norm: International Boundaries and the Use of Force." International Organization 55, no. 2 (2001): 215-50. https://doi.org/10.1162/00208180151140568.

Zeb, Rizwan. "Pakistan's Nuclear Weapons: How Safe Is Safe Enough? Transparency versus Opacity." Defense \& Security Analysis 30, no. 3 (July 3, 2014): 230-44. https://doi.org/10.1080/14751798.2014.925640.

\section{2: Datasets}

Brecher, Michael, Jonathan Wilkenfeld, Patrick James, and David Quinn. International Crisis Behavior Data Codebook, Version 12, 2017. http://sites.duke.edu/icbdata/data-collections/.

Center for Systemic Peace. "Polity IV Project Annual Time Series, 1800-2018." Center for Systemic Peace, July 27, 2019. http://www.systemicpeace.org/polityproject.html.

Center for Systemic Peace. "Polity 5 Annual Time-Series, 1946-2018." Center for Systemic Peace, April 23, 2020. http://www.systemicpeace.org/inscr/p5v2018.xls.

CSIS Beyond Parallel. "Database: North Korean Provocations." Center for Strategic and International Studies, April 16, 2020. https://beyondparallel.csis.org/databasenorth-korean-provocations/.

Economist Intelligence Unit. Democracy Index 2010: Democracy in Retreat. Economist Intelligence Unit Democracy Index. London: Economist Intelligence Unit, 2010. https://graphics.eiu.com/PDF/Democracy_Index_2010_web.pdf.

- Democracy Index 2011: Democracy under Stress. Economist Intelligence Unit Democracy Index. London: Economist Intelligence Unit, 2011. http://www.eiu.com/Handlers/WhitepaperHandler.ashx?fi=Democracy_Index_20 11 Updated.pdf\&mode=wp\&campaignid=DemocracyIndex2011.

- Democracy Index 2012: Democracy at a Standstill. Economist Intelligence Unit Democracy Index. London: Economist Intelligence Unit, 2013. 
http://www.eiu.com/Handlers/WhitepaperHandler.ashx?fi=Democracy-Index2012.pdf\&mode=wp\&campaignid=DemocracyIndex12.

- Democracy Index 2013: Democracy in Limbo. Economist Intelligence Unit Democracy Index. London: Economist Intelligence Unit, 2014. http://www.eiu.com/Handlers/WhitepaperHandler.ashx?fi=Democracy_Index_20 13 WEB-2.pdf\&mode=wp\&campaignid=Democracy0814.

- Democracy Index 2014: Democracy and Its Discontents. Economist Intelligence Unit Democracy Index. London: Economist Intelligence Unit, 2015. http://www.eiu.com/Handlers/WhitepaperHandler.ashx?fi=Democracy-index2014.pdf\&mode=wp\&campaignid=Democracy0115.

- Democracy Index 2015: Democracy in an Age of Anxiety. Economist Intelligence Unit Democracy Index. London: Economist Intelligence Unit, 2016. http://www.eiu.com/Handlers/WhitepaperHandler.ashx?fi=EIU-DemocracyIndex-2015.pdf\&mode=wp\&campaignid=DemocracyIndex2015.

- Democracy Index 2016: Revenge of the "Deplorables." Economist Intelligence Unit Democracy Index. London: Economist Intelligence Unit, 2017. http://www.eiu.com/Handlers/WhitepaperHandler.ashx.

- Democracy Index 2017: Free Speech under Attack. Economist Intelligence Unit Democracy Index. London: Economist Intelligence Unit, 2018. https://pages.eiu.com/rs/753-RIQ-438/images/Democracy_Index_2017.pdf.

- Democracy Index 2018: Me Too? Political Participation, Protest and Democracy. Economist Intelligence Unit Democracy Index. London: Economist Intelligence Unit, 2019.

http://www.eiu.com/public/thankyou_download.aspx?activity=download\&campai gnid=Democracy 2018 .

. The Economist Intelligence Unit's Index of Democracy 2008. Economist Intelligence Unit Democracy Index. London: Economist Intelligence Unit, 2009. https://graphics.eiu.com/PDF/Democracy\%20Index\%202008.pdf.

Freedom House. "Freedom in the World." Freedom House, 2020. https://freedomhouse.org/sites/default/files/202002/2020_Country_and_Territory_Ratings_and_Statuses_FIW1973-2020.xlsx.

_ . "Freedom in the World 2017: Israel," 2017. https://freedomhouse.org/country/israel/freedom-world/2017.

—_. "Freedom in the World 2020: Israel," 2020. https://freedomhouse.org/country/israel/freedom-world/2020.

—_. "Freedom in the World 2020: North Korea," 2020. https://freedomhouse.org/country/north-korea/freedom-world/2020. 
Graybow, Charles, Martin Edwin Andersen, Kristen Guida, Marshall Freeman Harris, Thomas R. Lansner, Arch Puddington, Leonard R. Sussman, and George Zarycky. Freedom in the World 1997-1998. Edited by Adrian Karatnycky and Roger Kaplan. New York: Freedom House, 1998. https://freedomhouse.org/sites/default/files/202002/Freedom in the World 1997-1998_complete book.pdf.

International Institute for Strategic Studies. “American Bilateral Treaty Powers.” The Military Balance 68, no. 1 (1968): 38-40. https://doi.org/10.1080/04597226808459770.

_. "Asia and Australasia." The Military Balance 71, no. 1 (1971): 40-52. https://doi.org/10.1080/04597227108459811.

_. "Asia and Australasia." The Military Balance 87, no. 1 (1987): 143-76. https://doi.org/10.1080/04597228708459988.

—_. "Central and South Asia.” The Military Balance 99, no. 1 (1999): 151-70. https://doi.org/10.1080/04597229908460132.

—. "Central Treaty Organization." The Military Balance 65, no. 1 (1965): 27-28. https://doi.org/10.1080/04597226508459729.

—. "Chapter Six: Asia." The Military Balance 118, no. 1 (2018): 219-314. https://doi.org/10.1080/04597222.2018.1416982.

. "East Asia and Australasia." The Military Balance 94, no. 1 (1994): 164-93. https://doi.org/10.1080/04597229408460070.

. "East Asia and Australasia." The Military Balance 106, no. 1 (2006): 247-302. https://doi.org/10.1080/04597220600782887.

. "The Middle East and the Mediterranean." The Military Balance 73, no. 1 (1973): 30-38. https://doi.org/10.1080/04597227308459831.

. "The Middle East and North Africa." The Military Balance 90, no. 1 (1990): 97 122. https://doi.org/10.1080/04597229008460020.

_ . "Other Communist Countries." The Military Balance 68, no. 1 (1968): 12-14. https://doi.org/10.1080/04597226808459765.

_. "Part III: Non-aligned Countries." The Military Balance 65, no. 1 (1965): 34-39. https://doi.org/10.1080/04597226508459732.

Kekic, Laza. The Economist Intelligence Unit's Index of Democracy. Economist Intelligence Unit Democracy Index. London: Economist Intelligence Unit, 2007. https://www.economist.com/media/pdf/DEMOCRACY_INDEX_2007_v3.pdf. 
Kristensen, Hans M., and Robert S. Norris. "Chinese Nuclear Forces, 2018." Bulletin of the Atomic Scientists 74, no. 4 (2018): 289-95. https://doi.org/10.1080/00963402.2018.1486620.

. "Israeli Nuclear Weapons, 2014." Bulletin of the Atomic Scientists 70, no. 6 (2014): 97-115. https://doi.org/10.1177/0096340214555409.

_. "Nuclear Arsenals of the World." Bulletin of the Atomic Scientists (blog), 2018. https://thebulletin.org/nuclear-notebook-multimedia/.

Kristensen, Hans M., Robert S. Norris, and Julia Diamond. "Pakistani Nuclear Forces, 2018." Bulletin of the Atomic Scientists 74, no. 5 (2018): 348-58. https://doi.org/10.1080/00963402.2018.1507796.

Kristensen, Hans M., and Matt Korda. "Indian Nuclear Forces, 2018." Bulletin of the Atomic Scientists 74, no. 6 (2018): 361-66. https://doi.org/10.1080/00963402.2018.1533162.

_. "United States Nuclear Forces, 2020." Bulletin of the Atomic Scientists 76, no. 1 (2020): 46-60. https://doi.org/10.1080/00963402.2019.1701286.

Maoz, Zeev, Paul L. Johnson, Jasper Kaplan, Fiona Ogunkoya, and Aaron P. Shreve. "The Dyadic Militarized Interstate Disputes (MIDs) Dataset Version 3.0: Logic, Characteristics, and Comparisons to Alternative Datasets." Journal of Conflict Resolution 63, no. 3 (2019): 811-35. https://doi.org/10.1177/0022002718784158.

Marshall, Monty G., Ted Robert Gurr, and Keith Jaggers. Polity IV Project Dataset Users' Manual. Vienna: Center for Systemic Peace, 2018. http://www.systemicpeace.org/inscr/p4manualv2017.pdf.

Marshall, Monty G, and Ted Robert Gurr. Polity 5 Political Regime Characteristics and Transitions, 1800-2018: Dataset Users' Manual. Vienna: Center for Systemic Peace, 2020. http://www.systemicpeace.org/inscr/p5manualv2018.pdf.

Medcalf, Rory. “India Poll 2013.” Lowy Institute, May 20, 2013. https://www.lowyinstitute.org/publications/india-poll-2013.

"North Korea's Nuclear Program, 2003.” Bulletin of the Atomic Scientists 59, no. 2 (2003): 74-77. https://doi.org/10.1080/00963402.2003.11460666.

Palmer, Glenn, Vito D’Orazio, Michael Kenwick, and Matthew Lane. "The MID4 Dataset, 2002-2010: Procedures, Coding Rules and Description." Conflict Management and Peace Science 32, no. 2 (2015): 222-42. https://doi.org/10.1177/0738894214559680.

Sarkees, Meredith Reid. "The COW Typology of War: Defining and Categorizing Wars (Version 4 of the Data)." Correlates of War Project, 2010. Accessed October 29, 2017. http://www.correlatesofwar.org/data-sets/COW-war/the-cow-typology-ofwar-defining-and-categorizing-wars/at_download/file. 
Stockholm International Peace Research Institute. "SIPRI Military Expenditure Database 2019.” SIPRI, 2019. Accessed February 20, 2019. https://sipri.org/databases/milex.

Uppsala University Department of Peace and Conflict. "UCDP - Uppsala Conflict Data Program," 2019. https://ucdp.uu.se/\#/.

\section{3: News Sources}

ABC News. “'This Week' Transcript: High Alert, North Korea.” ABC News, April 16, 2017. https://abcnews.go.com/Politics/week-transcript-high-alert-northkorea/story?id=46819310.

Abi-Habib, Maria. "After India Loses Dogfight to Pakistan, Questions Arise About Its 'Vintage' Military." New York Times, March 3, 2019. https://www.nytimes.com/2019/03/03/world/asia/india-military-united-stateschina.html.

Ahronheim, Anna. "IDF Military Censor Banned Nearly 300 Articles Last Year." The Jerusalem Post, July 12, 2018. https://www.jpost.com/International/IDF-MilitaryCensor-banned-nearly-300-articles-last-year-562318.

Anonymous. "A Major Modern General.” The Economist, January 18, 2020, 54-55. https://www.economist.com/asia/2020/01/18/indias-armed-forces-get-theirbiggest-shake-up-in-decades.

Bedi, Rahul. “Army Says India Must Hit Hard at Militants.” The Telegraph, December $18,2001$. https://www.telegraph.co.uk/news/worldnews/asia/india/1365671/Army-saysIndia-must-hit-hard-at-militants.html.

Bergman, Ronen, and David M. Halbfinger. "Israel Hack of Iran Port Is Latest Salvo in Exchange of Cyberattacks." New York Times, May 19, 2020. https://www.nytimes.com/2020/05/19/world/middleeast/israel-irancyberattacks.html.

Blenckner, Stephanie, and Alexandra Manolache. "Global Military Spending Remains High at \$1.7 Trillion | SIPRI." Stockholm International Peace Research Institute, May 2, 2018. https://www.sipri.org/media/press-release/2018/global-militaryspending-remains-high-17-trillion.

Burns, John F. "Confrontation in the Gulf; Iraqis Threaten to Attack Saudis and Israelis If Nation Is 'Strangled' by Embargo." New York Times, September 24, 1990. https://www.nytimes.com/1990/09/24/world/confrontation-gulf-iraqis-threatenattack-saudis-israelis-if-nation-strangled.html. 
Callender, Harold. "Paris Is Opposed to Atom Bomb Use." New York Times, December 1,1950 . http://timesmachine.nytimes.com/timesmachine/1950/12/01/91120174.html.

Chaudhry, Suparna. “Analysis: India's New Law May Leave Millions of Muslims without Citizenship." Washington Post, December 13, 2019. https://www.washingtonpost.com/politics/2019/12/13/indias-new-law-may-leavemillions-muslims-without-citizenship/.

Choe, Sang-hun. "Korean Crisis Is Different This Time." New York Times, August 3, 2009. https://www.nytimes.com/2009/08/04/world/asia/04iht-letter.html.

Coll, Steve. "U.S. Nuclear Diplomacy in South Asia Faces Obstacles." Washington Post, February 8, 1992. https://www.washingtonpost.com/archive/politics/1992/02/08/us-nucleardiplomacy-in-south-asia-faces-obstacles/a75cff43-ccb7-412d-9d9860b1abb070e6/.

"Cyber-Attack: US and UK Blame North Korea for WannaCry." BBC News, December 19, 2017. https://www.bbc.com/news/world-us-canada-42407488.

Doerner, William R. "Pakistan Knocking at the Nuclear Door." Time Magazine, March 30, 1987. http://content.time.com/time/magazine/article/0,9171,963894,00.html.

Dugger, Celia W. "Atmosphere Is Tense as India and Pakistan Agree to Talks." New York Times, June 1, 1999. https://www.nytimes.com/1999/06/01/world/atmosphere-is-tense-as-india-andpakistan-agree-to-talks.html.

Furukawa, Eiji. “'Hacker Armies' Linked to China and Russia Ramp up Cyberattacks.” Nikkei Asian Review, July 18, 2020. https://asia.nikkei.com/Politics/Internationalrelations/Hacker-armies-linked-to-China-and-Russia-ramp-up-cyberattacks.

Gady, Franz-Stefan. "North Korea Is Mobilizing for War." The Diplomat, August 21, 2015. https://thediplomat.com/2015/08/north-korea-is-mobilizing-for-war/.

Gopalakrishnan, Raju. "India Directs Anger at Politicians after Mumbai Attacks." Reuters, November 30, 2008. https://in.reuters.com/article/idINIndia$\underline{36786620081130 .}$.

Haidar, Suhasini, and Dinakar Peri. "India Bombs Jaish Camp in Pakistan's Balakot." The Hindu. February 26, 2019. https://www.thehindu.com/news/national/airstrikes-hit-balakot-in-pakistan-initial-assessment-100-hitsources/article26373318.ece.

Harel, Amos, Aluf Benn, and Ha'Ha'aretz Service. “Israel to U.S.: We Won’t Practice Restraint of Gulf War." Ha'aretz, October 8, 2002. https://www.haaretz.com/1.5025851. 
Heller, Jeffrey. "Netanyahu, in Apparent Stumble, Calls Israel 'Nuclear Power."” Reuters, January 5, 2020. https://www.reuters.com/article/us-israel-netanyahunuclear-idUSKBN1Z40CS.

Hirsh, Michael. "How Kim Jong Il Became the Most Successful Dictator in Modern History." The Atlantic, December 19, 2011. https://www.theatlantic.com/international/archive/2011/12/how-kim-jong-ilbecame-the-most-successful-dictator-in-modern-history/250194/.

Hoffman, Gil. "Knesset Rejects International Nuclear Oversight." The Jerusalem Post, July 4, 2018. https://www.jpost.com/Israel-News/Knesset-votes-against-nuclearmonitoring-for-Israel-561520.

Jewish Telegraphic Agency. "Knesset Openly Debates Nukes for First Time." Jewish Telegraphic Agency. February 2, 2000. Accessed November 7, 2019. http://www.jta.org/2000/02/02/default/knesset-openly-debates-nukes-for-firsttime.

_ "Syrian Chief of State Calls for 'liberation War' Against Israel." Jewish Telegraphic Agency Daily News Bulletin. November 4, 1966. Accessed October 8, 2019. https://www.jta.org/1966/11/04/archive/syrian-chief-of-state-calls-forliberation-war-against-israel.

KCNA. "Kim Jong Un Makes Report on Work of WPK Central Committee at Its 7th Congress." KCNA Watch, May 7, 2016. https://kcnawatch.org/newstream/1546587644-964527319/kim-jong-un-makesreport-on-work-of-wpk-central-committee-at-its-7th-congress/.

—. "Law on Consolidating Position of Nuclear Weapons State Adopted." KCNA Watch, April 1, 2013. https://kcnawatch.org/newstream/1451896124739013370/law-on-consolidating-position-of-nuclear-weapons-state-adopted/.

_. "Statement of DPRK Government on Its Withdrawal from NPT." KCNA Watch, January 11, 2003. https://kcnawatch.org/newstream/1452003631225477096/statement-of-dprk-government-on-its-withdrawal-from-npt/.

Kim, So Yeol. "Psychological Warfare Will Resume.” Daily NK, May 24, 2010. https://www.dailynk.com/english/psychological-warfare-will-resume/.

"President Vows to Take Self-Defense Measures." The Korea Herald, May 24, 2010. http://www.koreaherald.com/view.php?ud=20100524000371.

"Seoul to Bolster Security Apparatus." The Korea Herald, April 27, 2010. http://www.koreaherald.com/view.php?ud=20100427000670.

Laub, Zachary, and Kali Robinson. "What Is the Status of the Iran Nuclear Agreement?" Council on Foreign Relations, January 7, 2020. https://www.cfr.org/backgrounder/what-status-iran-nuclear-agreement. 
Magid, Jacob. “After 508-Day Crisis, Israel's New Government Finally Sworn in by Knesset." The Times of Israel, May 17, 2020.

https://www.timesofisrael.com/ending-political-crisis-new-government-sworn-inby-knesset/.

Mainichi Japan. "Interview: Ex-Pakistani Pres. Musharraf Mulled Using Nukes against India after 2001 Attack.” Mainichi Daily News, July 26, 2017. https://mainichi.jp/english/articles/20170726/p2a/00m/0na/018000c.

McCurry, Justin. "Senior Communist Falls Victim to North Korea's Currency Disaster." The Guardian, February 3, 2010. https://www.theguardian.com/world/2010/feb/03/north-korea-won-currencyrevaluation.

Morello, Carol. 'North Korea's Top Diplomat Says Strike against U.S. Mainland Is 'Inevitable." Washington Post, September 23, 2017. https://www.washingtonpost.com/world/national-security/north-koreas-topdiplomat-says-strike-against-us-mainland-is-inevitable/2017/09/23/c3bcb108dd8f-4761-b55f-92044348f179 story.html.

Narang, Vipin, and Ankit Panda. "Command and Control in North Korea: What a Nuclear Launch Might Look Like.” War on the Rocks, September 15, 2017. https://warontherocks.com/2017/09/command-and-control-in-north-korea-what-anuclear-launch-might-look-like/.

Naurath, Nicole, and Julie Ray. "Pakistanis Still Rate Military Tops Among National Institutions.” Gallup, July 29, 2011. https://news.gallup.com/poll/148709/Pakistanis-Rate-Military-Tops-AmongNational-Institutions.aspx.

Nayar, Kuldip. “We Have the A-Bomb, Says Pakistan's 'Dr Strangelove.” The Observer. March 1, 1987. http://search.proquest.com/hnpguardianobserver/docview/477071639/citation/6Co FA65F3D81F49FDPQ/1.

New York Times. "Israel Protests in U.N." New York Times, September 29, 1955. https://timesmachine.nytimes.com/timesmachine/1955/09/29/83375249.html?pag eNumber $=3$.

New York Times. "Schlesinger Vows Defense of Korea." The New York Times, September 2, 1975. https://www.nytimes.com/1975/09/02/archives/schlesingervows-defense-of-korea.html.

"Pakistan Forces Put on High Alert: Storming of Parliament." Dawn, December 15, 2001. http://beta.dawn.com/news/10821/pakistan-forces-put-on-high-alert-storming-ofparliament. 
Peri, Dinakar. "Budget 2019: Defence Allocation Disappoints Military." The Hindu. July 7, 2019. https://www.thehindu.com/news/national/defence-allocation-disappointsmilitary/article28313288.ece.

Perlez, Jane, and Salman Masood. "Pakistan Denies Any Role in Mumbai Attacks." The New York Times, November 29, 2008. https://www.nytimes.com/2008/11/30/world/asia/30pstan.html.

Richardson, Michael. "Q\&A / George Fernandes: India and Pakistan Are Not 'imprudent' on Nuclear Option." New York Times, June 3, 2002. https://www.nytimes.com/2002/06/03/news/qa-george-fernandes-india-andpakistan-are-not-imprudent-on-nuclear.html.

Ripley, Will. "North Korea Revives Guam Threat Ahead of US-South Korea Drills." CNN, October 15, 2017. https://www.cnn.com/2017/10/13/asia/north-koreaguam-threat/index.html.

Safi, Michael, Hannah Ellis-Petersen, and Helen Davidson. "Soldiers Fell to Their Deaths as India and China's Troops Fought with Rocks." The Guardian, June 17, 2020. https://www.theguardian.com/world/2020/jun/17/shock-and-anger-in-india-afterworst-attack-on-china-border-in-decades.

Sanger, David E., and Nicole Perlroth. "U.S. Accuses North Korea of Cyberattacks, a Sign That Deterrence Is Failing.” New York Times, April 15, 2020. https://www.nytimes.com/2020/04/15/world/asia/north-korea-cyber.html.

Samanta, Pranab Dhal. "26/11: How India Debated a War with Pakistan That November." Indian Express, November 26, 2010.

http://archive.indianexpress.com/news/2611-how-india-debated-a-war-withpakistan-that-november/716240/0.

Stephens, Robert, and Patrick Seale. "Nasser: We Want to Be Friends with Britain." The Observer. July 5, 1964. http://proxy.library.carleton.ca/login?url=https://searchproquest-com.proxy.library.carleton.ca/docview/475690650? accountid=9894.

The Sunday Times. "Revealed: The Secrets of Israel's Nuclear Arsenal." The Sunday Times. October 5, 1986. The Sunday Times Digital Archive. Accessed October 19, 2018. https://link-galecom.proxy.library.carleton.ca/apps/doc/FP1802397806/GDCS?u=ocul_carleton\& $\underline{\text { sid }=\text { GDCS\&xid=88a59057. }}$.

Thatcher, Jonathan. "North Korea Threatens Fight with South.” Reuters, May 25, 2010. https://www.reuters.com/article/us-korea-north-idUSTRE64N0F520100525.

Times of India. "Sovereignty surrendered." Times of India, July 1, 1965. Quoted in Chaudhuri, Rudra, “Just Another Border Incident': The Rann of Kutch and the 1965 India-Pakistan War." Journal of Strategic Studies 42, no. 5 (2019): 654-676. https://doi.org/10.1080/01402390.2019.1571996. 
Valentino, Benjamin A., and Scott D. Sagan. “Atomic Attraction." The Indian Express, June 3, 2016. https://indianexpress.com/article/opinion/columns/barack-obamahiroshima-speech-india-nuclear-weapon-terrorism-atomic-attraction-2831348/.

Wagner, John, and Jenna Johnson. "Trump Vows North Korea Will Be Met with 'Fire and Fury' If Threats Continue." The Washington Post, August 8, 2017. https://www.washingtonpost.com/news/post-politics/wp/2017/08/08/trump-vowsnorth-korea-will-be-met-with-fire-and-fury-if-threatscontinue/?utm term=.3f8742580061.

Ward, Alex. “The Rumors of Kim Jong Un's 'Grave' Illness, Explained.” Vox, April 23, 2020. https://www.vox.com/2020/4/23/21232665/north-korea-kim-jong-uncoronavirus-sick.

Watts, Jonathan. "How Clinton Came Close to Bombing." The Guardian, December 5, 2002. https://www.theguardian.com/world/2002/dec/05/northkorea.

Wootliff, Raoul. "With 'Paritetic' Proposal, Rivlin Looks to the Past for a Power-Sharing Model." The Times of Israel, September 26, 2019. https://www.timesofisrael.com/with-paritetic-proposal-rivlin-looks-to-the-pastfor-power-sharing-model/.

Yoo, Choonsik. "North Korea's Economy Tanks as Sanctions, Drought Bite: South Korea." Reuters, July 26, 2019. https://www.reuters.com/article/us-northkoreaeconomy-gdp-idUSKCN1UL08G.

\section{4: Government and International Organization Documents and Publications}

Azzam, Abdul Rahman Hassan. "Press Release S/745: Cablegram Dated 15 May 1948 Addressed to the Secretary-General by the Secretary-General of the League of Arab States.” United Nations Department of Public Information, May 15, 1948. https://unispal.un.org/DPA/DPR/unispal.nsf/0/A717E30BD2F6E5EC8525761E00 72E9B3.

Bank of Korea. "Gross Domestic Product Estimates for North Korea in 2018." Bank of Korea, July 26, 2019. https://www.bok.or.kr/eng/bbs/E0000634/view.do?nttId=10053001\&menuNo=40 $\underline{0069}$.

Ben-Gurion, David. "308. Letter from Prime Minister Ben Gurion to President Kennedy." United States Department of State, June 24, 1962. Foreign Relations of the United States, 1961-1963, Volume XVII, Near East, 1961-1962. United States Department of State - Office of the Historian. https://history.state.gov/historicaldocuments/frus1961-63v17/d308.

Bureau of Democracy, Human Rights, and Labour. "Country Reports on Human Rights Practices for 2011: Korea, Democratic People's Republic Of.” Bureau of 
Democracy, Human Rights and Labor Country Reports on Human Rights Practices for 2011. Washington, DC: United States Department of State, 2011. https://2009-2017.state.gov/documents/organization/186491.pdf.

Bush, George W. "Text of President Bush's 2002 State of the Union Address." Washington Post, January 29, 2002. https://www.washingtonpost.com/wpsrv/onpolitics/transcripts/sou012902.htm.

Central Intelligence Agency. "CIA/DIA/State Memorandum, 'Reactions to Certain US Actions,' January 28, 1968. Secret.," January 28, 1968. National Security Archive. https://nsarchive2.gwu.edu/NSAEBB/NSAEBB453/docs/doc06.pdf.

_. "National Intelligence Estimate, NIE 35-61, 'The Outlook for Israel." Central Intelligence Agency, October 5, 1961. CIA declassification release. Obtained by William Burr. History and Public Policy Program Digital Archive. https://digitalarchive.wilsoncenter.org/document/123846.

Chanlett-Avery, Emma, Caitlin Elizabeth Campbell, Mark E. Manyin, Wil Mackey, and Mary Beth D. Nikitin. "North Korea: U.S. Relations, Nuclear Diplomacy, and Internal Situation." Congressional Research Service Report. Washington, DC: United States Congressional Research Service, July 27, 2018. https://crsreports.congress.gov/product/pdf/R/R41259.

Chanlett-Avery, Emma, and Sharon Squassoni. "North Korea's Nuclear Test: Motivations, Implications, and U.S. Options." Congressional Research Service Report. Washington, DC: United States Congressional Research Service, October 24, 2006. https://fas.org/sgp/crs/nuke/RL33709.pdf.

Cronin, Patrick M., and Robert J. Art. The United States and Coercive Diplomacy. Washington, D.C: United States Institute of Peace Press, 2003.

Datcu, Ion, and William Tapley Bennett. "Telegram from New York to Bucharest, SECRET, Urgent, No. 060.387," August 20, 1976. Archives of the Romanian Ministry of Foreign Affairs, Matter 220 - Relations with the Democratic People's Republic of Korea, 1976.Obtained by Izador Urian and translated by Eliza Gheorghe. History and Public Policy Program Digital Archive. https://digitalarchive.wilsoncenter.org/document/114115.

David, Vaclav, A. M. Puzanov, and Kohousek. "Report on Political Development in the DPRK," April 18, 1961. State Central Archive in Prague. Translated by Adolf Kotlik. History and Public Policy Program Digital Archive. https://digitalarchive.wilsoncenter.org/document/116752.

Eshkol, Levi. "Statement to the Knesset by Prime Minister Eshkol - 18 May 1966." Israel Ministry of Foreign Affairs, May 18, 1966. https://mfa.gov.il/MFA/ForeignPolicy/MFADocuments/Yearbook1/Pages/20\%20 
Statement $\% 20$ to $\% 20$ the $\% 20$ Knesset $\% 20$ by $\% 20$ Prime $\% 20$ Minister $\% 20$ Eshk.aspx

Gandhi, Indira, and Zulfikar Ali Bhutto. "Agreement between the Government of India and the Government of the Islamic Republic of Pakistan on Bilateral Relations (Simla Agreement).” Ministry of External Affairs, Government of India, July 2, 1972. https://www.mea.gov.in/bilateraldocuments.htm?dt1/5541/Simla+Agreement.

Gavrilescu, Nicolae, Xiaohui Peng, and Zhan Yu. "Telegram from Beijing to Bucharest, SECRET, Urgent, No. 066.252," August 25, 1976. Archives of the Romanian Ministry of Foreign Affairs, Matter 220 - Relations with the Democratic People's Republic of Korea, 1976. Obtained by Izador Urian and translated by Eliza Gheorghe. History and Public Policy Program Digital Archive. https://digitalarchive.wilsoncenter.org/document/114117.

Gleason, S. Everett. "Memorandum of Discussion at a Special Meeting of the National Security Council on Tuesday, March 31, 1953," March 31, 1953. George Washington University National Security Archive. https://nsarchive2.gwu.edu//dc.html?doc=4316141-Document-03-Memorandumof-Discussion-at-a.

Gromyko, Andrei Andreevich, and Sin-pal Ri. "From the Journal of Gromyko, Record of a Conversation with Ambassador Ri Sin-Pal of the Democratic People's Republic of Korea," April 28, 1958. AVPRF fond 0102, opis 14, delo 4, p. Translated for NKIDP by Gary Goldberg. History and Public Policy Program Digital Archive. https://digitalarchive.wilsoncenter.org/document/116019.

Herrmann, J. “Informational Report by Ambassador Herrmann,” February 1, 1968. MfAA C 1023/73. Translated by Karen Riechert. History and Public Policy Program Digital Archive. https://digitalarchive.wilsoncenter.org/document/113741.

Holub, Miroslav. "Report from East German Ambassador to North Korea, 'Some Aspects of the Political Line of the Korean Workers' Party after the January Events," February 15, 1968. Archives of the Ministry of Foreign Affairs. Translated for NKIDP by Vojtech Mastny. History and Public Policy Program Digital Archive. https://digitalarchive.wilsoncenter.org/document/113196.

Hyland, William. "Letter from William Hyland to Brent Scowcroft." In After Detente: The Korean Peninsula, 1973-1976, edited by James Person, 695-99. Wilson Center, 1976. https://www.wilsoncenter.org/sites/default/files/2011_COHC_BB_Part_6_1976.p df.

Ignatiev, Aleksei, Terenti Shtykov, and Il Sung Kim. "The Political Situation in Korea during the Period of Military Operations," August 11, 1950. AVP RF f. 0102. op. 
6, p. 21, d. 47, pp. 29-40. Translated for NKIDP by Gary Goldberg. History and Public Policy Program Digital Archive.

https://digitalarchive.wilsoncenter.org/document/114916.

International Court of Justice. Legality of the Threat or Use of Nuclear Weapons:

Advisory Opinion of 8 July 1996. The Hague: International Court of Justice, 1996.

Israel Ministry of Foreign Affairs. "The Governments of Israel-Coalitions 1949 to the Present,” 2013. Accessed September 11, 2019.

https://mfa.gov.il $/ \mathrm{mfa} /$ aboutisrael $/$ state/government/pages/the $\% 20$ governments $\% 2$ 0of\%20israel.aspx.

Israeli Foreign Affairs and Defense Committee. "Protocol number 62 of the Israeli Foreign Affairs and Defense Committee, Friday, May 26, 1967 at 4 pm, in The Kirya, Tel Aviv," May 26, 1967. Israel State Archives. Obtained by Adam Raz. History and Public Policy Program Digital Archive. https://digitalarchive.wilsoncenter.org/document/145002.

Kargil Review Committee. From Surprise to Reckoning: The Kargil Committee Report. New Delhi: SAGE Publications, December 15, 1999.

Kaul, F. K., and Hanfu Zhang. "Meeting Minutes between Chinese Vice Foreign Minister Zhang Hanfu and Indian Commisioner T.N. Kaul," November 27, 1951. PRC FMA 105-00082-03, 10-14. Obtained by Dai Chaowu and translated by 7Brands. History and Public Policy Program Digital Archive. https://digitalarchive.wilsoncenter.org/document/114750.

Kerr, Paul K., and Mary Beth D. Nikitin. "Pakistan's Nuclear Weapons." Congressional Research Service Report. Washington, DC: United States Congressional Research Service, August 1, 2016. https://fas.org/sgp/crs/nuke/RL34248.pdf.

Kim, Jae-bong, and Jarck. "Memorandum of the Foreign Ministry of the DPRK for the Ambassadors and Acting Ambassadors of all Socialist Countries accredited to the DPRK," January 24, 1968. MfAA C 1023/73. Translated for NKIDP by Karen Riechert. History and Public Policy Program Digital Archive. https://digitalarchive.wilsoncenter.org/document/113715.

Kissinger, Henry A. "Memorandum from Henry Kissinger to President Nixon, 'Israeli Nuclear Program,' n.d., with Enclosures Dated 19 July 1969, Top Secret, Excised Copy.” Richard Nixon Presidential Library, July 19, 1969. National Security Archive. https://nsarchive2.gwu.edu/nukevault/ebb485/docs/Doc\%2010\%207-1969\%20circa.pdf.

The Knesset. "All Governments of Israel," 2020. Accessed July 14, 2020. https://main.knesset.gov.il:443/EN/mk/government/Pages/governments.aspx.

The Knesset. "Basic Law: The Government (2001)," 2001. https://knesset.gov.il/laws/special/eng/basic14_eng.htm. 
Malenkov, Georgii Maksimilianovich, Joseph Stalin, Il Sung Kim, Heon-yeong Pak, Dehuai Peng, and Enlai Zhou. "Record of a Conversation between Stalin, Kim Il Sung, Pak Heon-yeong, Zhou Enlai, and Peng Dehuai," September 4, 1952. APRF, f. 45, o. 1, d. 348, 11. 71-82. Also available in RGASPI, f. 558, op. 11, d. 348, 11. 0071-0082, as well as Library of Congress, Manuscript Division, Dmitrī Antonovich Volkogonov papers, 1887-1995, mm97083838. Translated by Gary Goldberg. History and Public Policy Program Digital Archive. https://digitalarchive.wilsoncenter.org/document/114936.

Meir, Golda. "26 Statement to the General Assembly by Foreign Minister Meir - 1 March 1957." Israel Ministry of Foreign Affairs, March 1, 1957. https://mfa.gov.il $/ \mathrm{mfa} /$ foreignpolicy/mfadocuments/yearbook $1 /$ pages $/ 26 \% 20$ state ment $\% 20$ to $\% 20$ the $\% 20$ general $\% 20$ assembly $\% 20$ by $\% 20$ foreign $\% 20$ mi.aspx.

Mikoyan, Anastas Ivanovich, and Il Sung Kim. "Telegram from A. Mikoyan to the CPSU Central Committee," September 23, 1956. GARF, Fond 5446, Opis 98c, Delo 718, Listy 3-6. Translated by Gary Goldberg. History and Public Policy Program Digital Archive. https://digitalarchive.wilsoncenter.org/document/120189.

Ministry of External Affairs. "The Cabinet Committee on Security Reviews Operationalization of India's Nuclear Doctrine." Government of India, January 3, 2003. https://www.mea.gov.in/pressreleases.htm?dtl/20131/The+Cabinet + Committee + on + Security + Reviews + peratio nalization + of + Indias + Nuclear+Doctrine.

Office of the Historian. "207. Telegram: The Chargé in India (Donovan) to the Secretary of State." United States Department of State, January 2, 1948. Foreign Relations of the United States, 1948, The Near East, South Asia, and Africa, Volume V, Part 1. United States Department of State - Office of the Historian. https://history.state.gov/historicaldocuments/frus1948v05p1/d207.

. "282. Minutes of Washington Special Actions Group Meeting, Washington, August 18, 1976, 3:47-4:43 p.m." United States Department of State, August 18, 1976. Foreign Relations of the United States, 1969-1976, Volume E-12, Documents on East and Southeast Asia, 1973-1976. United States Department of State - Office of the Historian.

https://history.state.gov/historicaldocuments/frus1969-76ve12/d282.

. "285. Minutes of Washington Special Actions Group Meeting, Washington, August 19, 1976, 8:12-9:15 a.m." United States Department of State, August 19, 1976. Foreign Relations of the United States, 1969-1976, Volume E-12, Documents on East and Southeast Asia, 1973-1976. United States Department of State - Office of the Historian. https://history.state.gov/historicaldocuments/frus1969-76ve12/d285. 
. "286. Minutes of Washington Special Actions Group Meeting, Washington, August 25, 1976, 10:30 a.m." United States Department of State, August 25, 1976. Foreign Relations of the United States, 1969-1976, Volume E-12, Documents on East and Southeast Asia, 1973-1876. United States Department of State - Office of the Historian. https://history.state.gov/historicaldocuments/frus1969-76ve12/d286.

. "January 24, 1968: Notes of the President's Meeting." In Foreign Relations of the United States, 1964-1968, Volume XXIX, Part 1, Korea, 29:492-95. Foreign Relations of the United States. Washington, DC: United States Department of State, 2018. https://history.state.gov/historicaldocuments/frus1964-68v29p1/d221.

"January 24, 1968: Summary Minutes of Pueblo Group." In Foreign Relations of the United States, 1964-1968, Volume XXIX, Part 1, Korea, 29:468-75. Foreign Relations of the United States. Washington, DC: United States Department of State, 2018. https://history.state.gov/historicaldocuments/frus1964-68v29p1/d217.

_. "Status of the Foreign Relations of the United States Series." United States Department of State. Accessed March 17, 2019. https://history.state.gov/historicaldocuments/status-of-the-series.

Park, In-kook. "Letter Dated 4 June 2010 from the Permanent Representative of the Republic of Korea to the United Nations Addressed to the President of the Security Council." United Nations Security Council, June 4, 2010. https://www.securitycouncilreport.org/atf/cf/\%7B65BFCF9B-6D27-4E9C-8CD3CF6E4FF96FF9\%7D/DPRK\%20S\%202010\%20281\%20SKorea\%20Letter\%20an d\%20Cheonan\%20Report.pdf.

Popa, N. "Telegram from Pyongyang to Bucharest, TOP SECRET, No. 76.012, Urgent," January 22, 1968. Political Affairs Fond, Telegrams from Pyongyang, TOP SECRET, 1968, Archive of the Romanian Ministry of Foreign Affairs. Obtained and translated for NKIDP by Eliza Gheorghe. History and Public Policy Program Digital Archive. https://digitalarchive.wilsoncenter.org/document/113939.

. "Telegram from Pyongyang to Bucharest, TOP SECRET, No. 76.017, Flash," January 25, 1968. Political Affairs Fond, Telegrams from Pyongyang, TOP SECRET, 1968, Archive of the Romanian Ministry of Foreign Affairs. Obtained and translated by Eliza Gheorghe. History and Public Policy Program Digital Archive. https://digitalarchive.wilsoncenter.org/document/113944.

Popa, N., and Jae-bong Kim. "Telegram from Pyongyang to Bucharest, TOP SECRET, No: 75.015, Flash,” January 24, 1968. Political Affairs Fond, Telegrams from Pyongyang, TOP SECRET, 1968, Archive of the Romanian Ministry of Foreign Affairs. Obtained and translated for NKIDP by Eliza Gheorghe. History and Public Policy Program Digital Archive. https://digitalarchive.wilsoncenter.org/document/113942. 
Richardson, Elliot L. "Memorandum for the Secretary of Defense. Subject: Stopping the Introduction of Nuclear Weapons into the Middle East." Department of State, March 29, 1969. United States National Archives. https://www.archives.gov/files/declassification/iscap/pdf/2009-076-doc1.pdf.

Shtykov, Terenti. "Report of the DPRK Ministry of Internal Affairs," June 25, 1950. Translated by Gary Goldberg. History and Public Policy Program Digital Archive. https://digitalarchive.wilsoncenter.org/document/114909.

"Telegram From the Commander in Chief, United Nations Command, and Commander of United States, Korea (Bonesteel) to the Commander in Chief, Pacific (Sharp)," January 23, 1968. Department of State, INR/IL Historical Files, Pueblo, 23 January 1968 to December 1968. Secret; Immediate; Noforn. History and Public Policy Program Digital Archive. https://digitalarchive.wilsoncenter.org/document/113368.

United Nations. "Charter of the United Nations." United Nations, April 15, 2016. http://www.un.org/en/sections/un-charter/un-charter-full-text/.

United Nations General Assembly. "United Nations General Assembly Resolution 195(III): The Problem of the Independence of Korea," December 12, 1948. United Nations Documents. https://undocs.org/en/A/RES/195(III).

United Nations Office for Disarmament Affairs. "Treaty on the Non-Proliferation of Nuclear Weapons," July 1, 1968. https://www.un.org/disarmament/wmd/nuclear/npt/text/.

United Nations Security Council. "Resolution 83: Complaint of aggression upon the Republic of Korea," S/1511 § (1950). http://unscr.com/en/resolutions/83.

US Congressional Budget Office. "Projected Costs of U.S. Nuclear Forces, 2019 to 2028." Congressional Budget Office, January 24, 2019. https://www.cbo.gov/system/files/2019-01/54914-NuclearForces.pdf.

United States Joint Chiefs of Staff. "Memorandum for the Chairman, Joint Chiefs of Staff, 'Possible Responses to North Korean Attack on the Republic of Korea,' May 14, 1968, Top Secret.” National Security Archive, May 14, 1968. United States National Archives. https://nsarchive2.gwu.edu/NSAEBB/NSAEBB453/docs/doc17.pdf.

Walsh, John P. "NSSM 40: Israeli Nuclear Weapons Program.” United States Department of State, May 30, 1969. National Security Archive. https://nsarchive2.gwu.edu/nukevault/ebb485/docs/Doc\%206\%205-3069\%20NSSM $\% 2040 \% 20$ report.pdf.

Warnke, Paul. "Memorandum of Conversation: Negotiations with Israel - F-4 and Advanced Weapons.” United States Department of Defense, November 12, 1968. 
National Security Archive.

https://nsarchive2.gwu.edu/NSAEBB/NSAEBB189/IN-03c.pdf.

Zhou, Enlai. "Letter from Prime Minister of China to the Prime Minister of India, 23 January 1959," January 23, 1959. Ministry of External Affairs, Government of India, Notes, Memoranda and Letters Exchanged and Agreements Signed between the Governments of India and China 1954-1959: White Paper I (New Delhi: External Publicity Division, Ministry of External Affairs, 1959), 52-54. History and Public Policy Program Digital Archive. https://digitalarchive.wilsoncenter.org/document/175951.

Zhou, Enlai, and Jawaharlal Nehru. "Record of Talks between P.M. [Jawaharlal Nehru] and Premier Chou En Lai [Zhou Enlai] Held on 22nd April, 1960 from 10 A.M. to 1.10 P.M.," April 22, 1960. Nehru Memorial Museum and Library, P.N. Haksar Papers (I-II Installment), Subject File \#24, 40-53. History and Public Policy Program Digital Archive. https://digitalarchive.wilsoncenter.org/document/175916.

- "Record of Talks between P.M. [Jawaharlal Nehru] and Premier Chou En Lai [Zhou Enlai] Held on 24th April, 1960, from 10.30 a.m. to 1.45 p.m.," April 24, 1960. Nehru Memorial Museum and Library, P.N. Haksar Papers (I-II Installment), Subject File \#24, 69-85. History and Public Policy Program Digital Archive. https://digitalarchive.wilsoncenter.org/document/121124.

\section{5: Additional Primary Sources}

Azaryahu, Arnan. Interview with Arnan "Sini" Azaryahu by Avner Cohen. Interview by Avner Cohen, January 2008. From the personal collection of Avner Cohen. History and Public Policy Program Digital Archive. https://digitalarchive.wilsoncenter.org/document/117848.

Geisler, Elie. "The Israeli Nuclear Drama of May 1967: A Personal Testimony.” The Nonproliferation Review 25, no. 5-6 (September 2, 2018): 399-404. https://doi.org/10.1080/10736700.2018.1607179.

Tzur, Tzvi. Interview with Tzvi Tzur at the Rabin Memorial Center, Tel Aviv. Interview by Boaz Lev Tov, August 16, 2001. Rabin Memorial Center. Obtained by Adam Raz. History and Public Policy Program Digital Archive. https://digitalarchive.wilsoncenter.org/document/134926.

Ya'akov, Yitzhak. Interview with Yitzhak "Ya'tza" Ya'akov by Avner Cohen. Interview by Avner Cohen, 1999. From the personal collection of Avner Cohen. History and Public Policy Program Digital Archive.

https://digitalarchive.wilsoncenter.org/document/145093. 